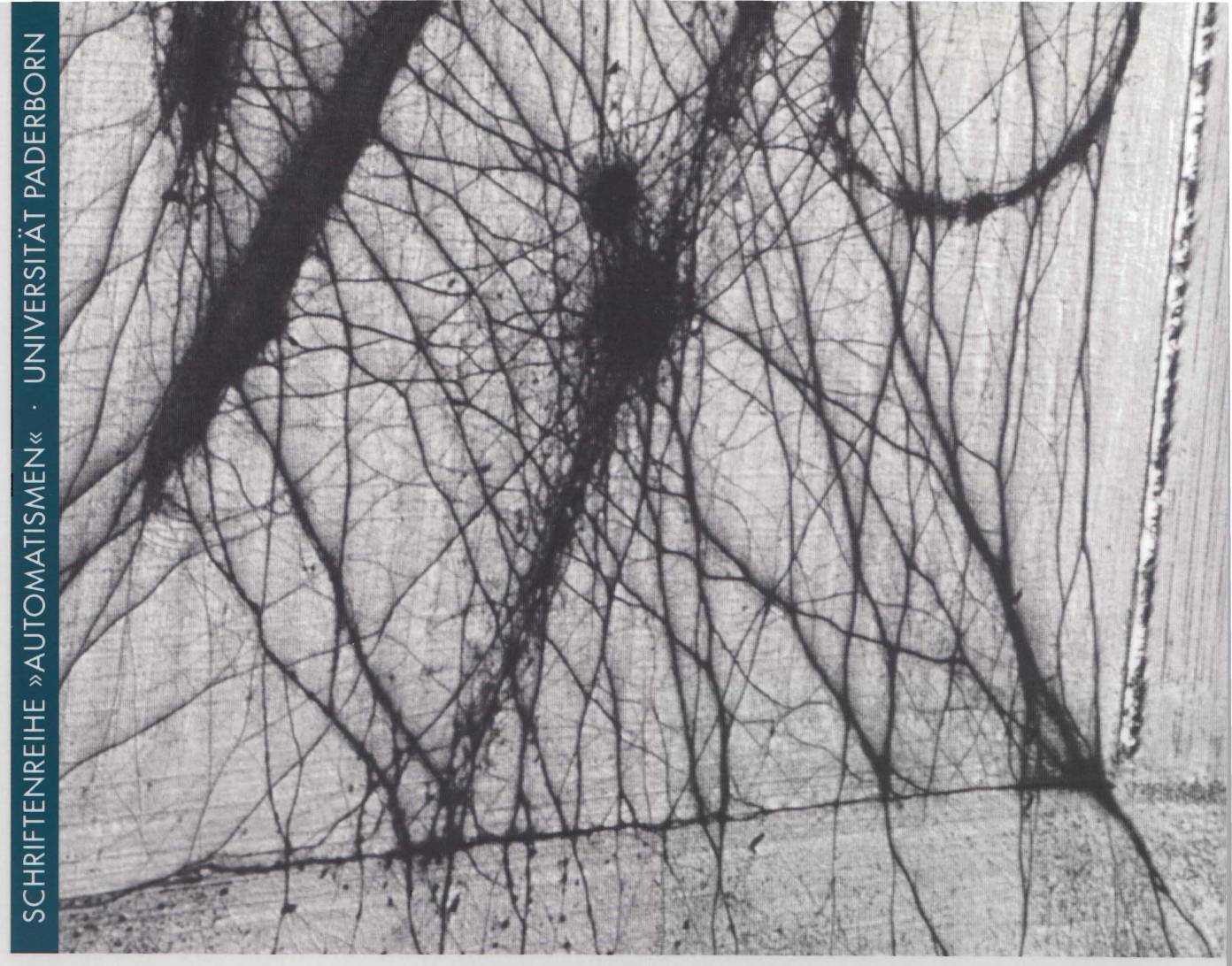

NORBERT OTTO EKE

ULRIKE HAB

IRINA KALDRACK $\cdot H G$.

\title{
BÜHNE: RAUMBILDENDE PROZESSE IM THEATER
}

$\begin{array}{lllllllllllllllllllllllllll}1 & 1 & 1 & 1 & 1 & 1 & 1 & 1 & 1 & 1 & 1 & 1 & 1 & 1 & 1 & 1 & 1 & 1 & 1 & 1 & 1 & 1 & 1 & 1 & 1 & 1\end{array}$

SCHRIFTENREIHE DES GRADUIERTENKOLLEGS »AUTOMATISMEN« 
Norbert Otto Eke, Ulrike Haß, Irina Kaldrack (Hg.)

BÜHNE: RAUMBILDENDE PROZESSE IM THEATER 
SCHRIFTENREIHE DES GRADUIERTENKOLLEGS

„AUTOMATISMEN““

Herausgegeben von

Hannelore Bublitz, Gisela Ecker, Norbert Otto Eke, Reinhard Keil

und Hartmut Winkler 
Norbert Otto Eke, Ulrike Haß, Irina Kaldrack (Hg.)

\section{BÜHNE: RAUMBILDENDE PROZESSE IM THEATER}

Wilhelm Fink 
Gedruckt mit Unterstützung der Deutschen Forschungsgemeinschaft

Umschlagabbildung:

Jürgen Gebhard (picturepress)

Online-Ausgabe: 2016

Bibliografische Information der Deutschen Nationalbibliothek

Die Deutsche Nationalbibliothek verzeichnet diese Publikation in der Deutschen

Nationalbibliografie; detaillierte bibliografische Daten sind im

Internet über http://dnb.d-nb.de abrufbar.

Gedruckt auf umweltfreundlichem, chlorfrei gebleichtem und alterungsbeständigem Papier.

Alle Rechte, auch die des auszugsweisen Nachdrucks, der fotomechanischen Wiedergabe und der Übersetzung, vorbehalten. Dies betrifft auch die Vervielfältigung und Übertragung einzelner Textabschnitte, Zeichnungen oder Bilder durch alle Verfahren wie Speicherung und Übertragung auf Papier, Transparente, Filme, Bänder, Platten und andere Medien, soweit es nicht

$\S \S 53$ und 54 UrhG ausdrücklich gestatten.

(C) 2014 Wilhelm Fink, Paderborn

(Wilhelm Fink GmbH \& Co. Verlags-KG, Jühenplatz 1, D-33098 Paderborn)

Internet: www.fink.de

Lektorat und Satz: Margret Westerwinter, Düsseldorf; www.lektorat-westerwinter.de

Einband: Evelyn Ziegler, München

Printed in Germany.

Herstellung: Ferdinand Schöningh GmbH \& Co. KG, Paderborn

ISBN 978-3-7705-5536-9 


\section{INHALT}

NORBERT OtTO EKE, ULRIKE HAß, IRINA KALDRACK

Bühne: Raumbildende Prozesse im Theater

Bernhard Waldenfels

Die Bühne als Brennpunkt des Geschehens

\section{GESTIMMTE RÄUME}

NORBERT OTTO EKE

Bühne als Wahrnehmungsraum. Stimme, Klang und Präsenz

MARITA TATARI IM GESPRÄCH MIT CLAUDIA BOSSE

Vom Entspringen des Raums vor dem Wort

Claudia Bosse

es gibt keine unschuldigen räume

63

\section{ENTFALTETE RÄUME}

\section{MARITA TATARI}

Bühne des Dramas.

Primäre Exposition und Raum ästhetischer Erfahrung

CHRISTOPH RODATZ

Der Schnitt durch den Raum als Wahrnehmungskonstellation

ANDRÉ EIERMANN

„Beyond the scope of human vision“ -

Bühnen für andere Blicke 


\section{ENTGRENZTE RÄUME}

\section{MARTINA LEEKER}

Performativierung des Raums.

Wissens- und technikgeschichtliche Aspekte

zeitgenössischer Bühnenräume

BIRGIT WIENS

Verkabelte Bühnen.

Szenographie im Spannungsfeld zwischen

Theater und anderen Medien

IRINA KALDRACK

Kinects Bühne: Selbstorganisierte Mimesis

\section{RÄUME ENDEN}

\section{SEBASTIAN KIRSCH}

Wie man einen Quantensprung tanzt, oder:

Bühne des Begehrens, Bühne des Triebs.

Versuch über Laurent Chétouanes Zürcher Publikumsbeschimpfung

NIKOLAUS MÜLLER-SCHÖLL

Raum-zeitliche Kippfiguren.

Endende Räume in Theater und Performance der Gegenwart

\section{GEORG DÖCKER}

Eine andere Grazie.

Zur Aktualisierung der Diagonale

in Laurent Chétouanes Tanzperformance horizon(s)

NICOLA SUTHOR

(Theater-)Graben:

Die untere Bildkante als grenzwertiger Spielraum des Betrachters

Mark Lammert

Raum als Dramaturgiemaschine 
RÄUME ÖFFNEN

JÖRN ETZOLD

Gegend ohne Könige.

Die Bühne von Hölderlins Empedokles

MEIKE HINNENBERG

Ausstreichungder Bühne.

Überlegungen zum Ort der Bühne im Anschluss an Derridas chōra

ULRIKE HAß

Von der Schau-Bühne zur Architektur und über das Theater hinaus.

Raumbildende Prozesse bei Sabbatini, Torelli, Pozzo und Appia 345

Hofmann\&Lindholm

Fremdenzimmer 371

ABBILDUNGSNACHWEISE 387

ÜBER DIE AUTORINNEN UND AUTOREN 389 



\title{
BÜHNE: RAUMBILDENDE PROZESSE IM THEATER
}

\author{
Bühne: Raumbildende Prozesse im Theater
}

Ausgangspunkt der hier versammelten Beiträge sind Fragen der performativen, also beweglichen und im Fluss befindlichen Raumpraktiken im Theater. Sie fragen nach Raumerfahrungen und der Entstehung von Räumen auf Bühnen im Wechselspiel von Akteuren und Zuschauern. Sie fragen nach der experimentellen Entgrenzung von Raum, nach seinen Enden und Öffnungen und nicht zuletzt auch nach dem Schwinden und der möglichen Neueröffnung von Räumen in der Gegenwart medialer Figurationen. Sie wurden zunächst vorgetragen im Rahmen einer Tagung, die vom 14. bis 16. Juli 2011 an der Universität Paderborn in Zusammenarbeit mit der Ruhr-Universität stattgefunden hat. Für den Druck wurden sie gründlich überarbeitet und erweitert.

Umgangssprachlich ist Bühne wohl eine der am häufigsten verwendeten Theatermetaphern. Meist wird damit etwas gekennzeichnet, das, in gewisser Weise verstärkt und mit einem besonderen Aufsehen verbunden, in Erscheinung tritt und somit geeignet ist, die Aufmerksamkeit der Umgebung auf sich zu ziehen. Von der Sache her fungiert hier die Bühne als Analogon zu einem Podest und meint eine Hervorhebung, einen Ausschnitt, eine Unterbrechung durch ein in besonderer Weise hergerichtetes Ereignis. Die Betonung liegt hier auf der Herrichtung oder Anrichtung, auf der intentionalen Hervorbringung von etwas, das zur Erscheinung kommen soll, und insofern ist Bühne in diesem Zusammenhang meist eng verknüpft mit der Intention und dem Auftritt von Personen. Umgangssprachlich betreten Staatsmänner die Bühne der Geschichte, gehen Schauspieler, Tänzer, Musiker auf die Bühne, um ihre Künste darzubieten, zeigen sich Jubilare oder Diven auf Bühnen, um sich feiern oder anschauen zu lassen. Aber auch Kaufhäuser, Marktstände, bestimmte Lokale können als Bühnen hergerichtet werden, auf denen die Waren, Angebote oder ein spezielles Szene- oder Lokalkolorit seinen Auftritt hat, durch Personen assistiert oder durch wechselndes Personal der jeweiligen Darstellung zugeführt. In diesen Belangen verschmilzt der Gebrauch des Wortes Bühne schon fast mit dem des Wortes Theater, das als Metapher einen ebenso weitreichenden und gleichzeitig stereotypen Einsatz in allen möglichen $\mathrm{Zu}$ sammenhängen kennt wie die Bühne. Vor diesem Hintergrund mutet es einigermaßen erstaunlich an, dass das Schlagwort „Bühne“ nicht unter den Lemmata der derzeit gebräuchlichen Lexika zur Theatertheorie zu finden ist.

Heute über einen möglichen Begriff der Bühne zu sprechen, geschieht unweigerlich vor dem Hintergrund der „räumlichen Wende“, die sich in den 
deutschsprachigen Kultur- und Geisteswissenschaften seit Ende der 1990er Jahre vollzogen hat. In diesen Debatten, die sich immer wieder auf frühere Schriften bezogen haben, so auf Henri Lefèbvres Die Revolution der Städte, Michel de Certeaus Kunst des Handelns oder Michel Foucaults Heterotopien, wurden allmählich die Konturen einer Überwindung der Containerraum-Vorstellung deutlich. In den Vordergrund rückten Fragen nach der gesellschaftlichen, politischen, medialen, imaginären, ästhetischen und lebensweltlichen Hervorbringung von Räumen. Theoretisch und methodologisch wurden antiessentialistische Sichtweisen der Topologie aufgegriffen, um raumbildende Prozesse zu beschreiben. Diese Raumdebatten sind nicht aufgrund ihrer vermeintlichen Originalität von Bedeutung. In vielen Punkten führen sie nur zusammen, was von Phänomenologen, Philosophen, Künstlern und Kunsttheoretikern im 20. Jahrhundert schon vielerorts gedacht worden ist. Es geht also nicht um eine „Wiederkehr des Raumes“ oder Ähnliches. Aber diese Raumdebatten fokussieren und bündeln unsere Aufmerksamkeit und fordern sie in produktiver Weise heraus. Erneut verlangen sie, die Einlassung Foucaults ernst zu nehmen, der „unsere Zeit“ charakterisierte als „Zeitalter des Raumes [...]; der Gleichzeitigkeit; des Aneinanderreihens, des Nahen und Fernen, des Nebeneinander und des Zerstreuten“. ${ }^{1}$

Nehmen wir also die Impulse der Raumdebatten zum Anlass, um uns einem möglichen Begriff der Bühne zuzuwenden. Die Theaterentwicklung der Moderne hat uns das Paradoxon eines optisch erschlossenen Raums hinterlassen. Bild oder Raum: Lange Zeit ist die Anomalie des Theaterraums unter Maßgabe dieser Dichotomie diskutiert worden und hat in Bezug auf die Bühne die standarisierte Rede von zweidimensionaler Bildwirkung und dreidimensionalen Körpern hervorgebracht. Sie geht zum einen auf Diderots Begriff der Szene als Tableau zurück und bezieht sich andererseits auf die Entdeckung des szenischen Raums durch die historischen Avantgarden im frühen 20. Jahrhundert. Mit wenigen Ausnahmen, unter die vor allem Adolphe Appia zählt, ist der szenische Raum dabei als ausgedehnte Fläche oder Kubus gedeutet worden, der durch die Bewegungen der menschlichen Figur definiert wird (Bauhaus). Dies scheint hauptsächlich der Schwierigkeit geschuldet, die mit der Eigenschaft des Theaterraums als einem fensterlosen, geschlossenen Kubus zusammenhängt. Entsprechend wurde der Theaterraum als optische Höhle zur Herstellung bildhafter Repräsentationen begriffen, und der von den Avantgarden stark gemachte szenische Raum fügte dem vor allem das Element der Bewegung hinzu. Doch auch das durch Bewegung allererst werdende Bild verhielt sich ungefragt in einem Raum der Bühne, für den weiterhin die Bezeichnungen Guckkasten oder Blackbox galten. Die räumliche Metaphorik verhielt sich gegenüber dem Theaterraum und der Bühne eindeutig. Sie unterstellte beide dem Stereotyp des Behälterraums oder des Containers. Infolge-

Michel Foucault, „Von anderen Räumen“, in ders., Schriften 4, Frankfurt/M., 2005, S. 931942: 931. 
dessen gingen die Bedingungen des Containers als unbedachte Voraussetzungen in die theoretischen und praktischen Auseinandersetzungen mit diesem Raum ein. Sie setzten ihn als Behälter voraus. Sie erkundeten seine inneren Einrichtungen und analysierten sie hinsichtlich ihrer ästhetischen, semiotischen oder visuellen Strategien. Aber alle diese Einsätze operierten in einem Raum, den sie als passive Gegebenheit behandeln. Die Frage des Raums, genauer: die Frage nach Räumen auf Bühnen, blieb infolgedessen verdeckt, wozu auch die lang anhaltende, einseitige Konzentration auf den Schauspieler, der auf der Bühne wie auf einem gleichsam natürlich wirkenden Podest agierte, beigetragen haben mag.

Dass die Raumdiskussion im Hinblick auf das Theater notwendigerweise auf verschiedenen Ebenen zu führen ist, liegt auf der Hand: auf einer ästhetischen (Kunstraum), auf einer erkenntnistheoretischen (Ort perzeptorischer Erfahrung, Wahrnehmungs- und Schauraum), auf einer medientheoretischen (Raum medialer und mediatisierter Bezüge), auf einer gesellschaftswissenschaftlichen (sozialer Raum) und selbstverständlich auch auf einer institutionellen bzw. institutionengeschichtlichen Ebene (Theater als Einrichtung und als Gebäude im öffentlichen Raum). Unter den Impulsen der Raumdebatten sind es aber vor allem die Versuche, Erkenntnisse der Topologie kulturtheoretisch zu wenden, die uns inspiriert haben. Sie ermöglichen, in vollem Umfang zu begreifen, warum strukturierte Räume keine diskreten Entitäten sind. Topologie umfasst die Beziehungen, das Prozessuale und das Zwischenräumliche, das zwischen Kognition, Wahrnehmung, Kommunikation, Körpern, konkreten Materialitäten und Techniken spielt. Aus diesem Grund haben wir hier den Begriff der Bühne mit dem Terminus „raumbildende Prozesse“ zusammengeführt. Zum einen setzt sich das Adjektiv passenderweise aus den Begriffen „Raum - Bild - Ende“ zusammen. Zum anderen wird durch das Substantiv „Prozesse“ der Plural von Bewegungen fokussiert, die sich als Phänomene der Erfahrungswelt und/oder der Wahrnehmung beschreiben lassen, die aisthetische Konstellationen eröffnen, aber auch die Bedingungen ihrer medialen Verfasstheit deutlich machen können.

In ihrer Vielzahl spielen Bewegungen zwischen Bühnenhaus, Licht, Körpern, räumlichen Fragmenten und bringen gleichsam spielend sich stetig verändernde Räume hervor. Es geht also weniger um den Raum, als vielmehr um Prozesse der Verräumlichung oder des Entspringens von Raum, die wir hier mit dem Begriff der Bühne engzuführen versuchen. Nicht zuletzt stellt sich damit die Frage auch hier nach der Rolle von Automatismen in diesem Geschehen. Betont wird das Netzwerk aus Bezugspunkten. Betont wird das Konglomerat aus Kapazitäten (der Speicherung oder des Verkehrsflusses im weitesten Sinn), der Kommunikation und der Macht, die sich noch immer und weiterhin im Theaterbau der Moderne materialisiert und dort sedimentiert hat. Dieser Umstand macht auch weiterhin, vor allem in den künstlerischen Auseinandersetzungen mit beweglichen Räumen und räumlichen Bewegungen auf oder als Bühnen, den Einsatz von Polemik unerlässlich. 
Wird in Bezug auf die Bühne eine ständige Gabelung der Wege, die Multiplizität der Perspektiven zwischen Nähe und Distanz, zwischen Konkretheit und Abstraktion, zwischen Zeitfluss und Arretierung des Augenblicks betont, dann kann der Körper nicht als Werkzeug der Orientierung gelten, das Ortungen in einem Raum ermöglicht. Offenbar wird vielmehr die unendliche Verflechtung von Lagerungen in einer dichten Textur von Subjekt und Welt. Ähnliches gilt auch für Texte, die nicht als Versprechen von Tiefe und Sinn, sondern als Oberflächen akzentuiert werden, auf denen sich Perspektiven (Blickwinkel) oder Stimmen (auditive Ereignisse) in kombinatorischer Unruhe kreuzen oder ineinander verwandeln. Zu fragen ist hiermit weniger danach, welcher Räume ein Text (im Sinne der Ausstattung) bedarf, als danach, wie die Sprache räumlich bewegt wird. Wird der Sprache in dieser Hinsicht zu ihrer Autonomie verholfen, kann überraschenderweise sogar das Drama als Eröffnung von unabsehbaren Handlungen im Plural gelesen werden.

Unter dem Aspekt von Topologie im angesprochenen Sinn vom Theaterraum zu handeln, macht noch eine letzte Vorbemerkung möglich. Michel Serres hat darauf hingewiesen, dass die Topologie entwicklungsgeschichtlich und systematisch der projektiven und euklidischen Geometrie vorausgeht. Die Topologie stelle sich gleichsam als eine „Geometrie“ dar, die von metrischen Fragen absieht, während die projektive und euklidische Geometrie dem ,Geo“ die ,metrie“ sozusagen erst hinzugesetzt oder hinzugefügt habe. Das Metrische, logisch Notwendige und Berechenbare kann nach Serres als Sonderfall des allgemeinen Falls unbestimmbarer Determinationsflüsse gelten. Topologisch gewendet kann daher der Containerraum, genauso wie das dialektischdialogische Modell der Kommunikation, als Spezialfall beschrieben werden, der genauso unwahrscheinlich wie ärmlich ist. Unter dem Aspekt der Topologie käme es also darauf an, den Spezialfall wieder in sein Stadium des allgemeinen Falls zu überführen. In den Fall, in dem Räume das Innere außerhalb von ihnen sind - auch dies wäre eine Umschreibung für den Begriff der Bühne. 


\section{BERNHARD WALDENFELS}

\section{Die BÜHNE ALs BRENNPUNKT DES GESCHEHENS}

An der erstaunlichen Tatsache, dass traditionelle Konzeptionen einer Theaterkunst, die sich doch selbst als Bühnenkunst bezeichnet, auf die Bühne nur beiläufig oder gar nicht zu sprechen kommen, ist die Philosophie nicht ganz schuldlos. In der heutigen Welt des Theaters hat sich daran offensichtlich vieles geändert, teilweise trifft dies auch auf die Sichtweise der Philosophie zu. Beginnen wir mit einem kurzen Rückblick, in dem einige Leitlinien skizziert werden und nach den Gründen für die so auffällige Missachtung der Bühne gefragt wird.

\section{Proömium: Die missachtete Bühne}

Unser Proömium beschränkt sich auf theaterphilosophische Aperçus, die sich in weitem Maße auf die aristotelische Poetik stützen. Diese grundlegende Schrift entstand in der zweiten Hälfte des 4. Jahrhunderts v. Chr., also etwa hundert Jahre nach der Blütezeit der griechischen Tragödie. Für den nicht überlieferten Teil, der dem Lächerlichen in der Komödie gewidmet war, hat Umberto Eco in seinem Roman Im Namen der Rose eine fiktive Rolle erdacht. Es bleibt der vorliegende Traktat über die Tragödie. Dort werden in Kapitel 6 die Kernbegriffe der aristotelischen Tragödienkonzeption aufgeführt. Aufseiten des Produzenten, des „Poeten“, wörtlich des „Machers“ finden wir die Mimesis, also die Nachahmung oder Darstellung, aufseiten der Zuschauer die Katharsis, also die Reinigung der Affekte oder von den Affekten. ${ }^{1}$ Der Aufbau der Tragödie enthält folgende Grundkomponenten: den Mythos (die Fabel, den Plot), der als eine konfigurierende Zusammenstellung von Begebenheiten verstanden wird; das Ethos, das den Charakter der Figuren ausmacht; die Dianoia als die Absicht und Einsicht der Beteiligten; die Lexis als Sprechweise, als Diktion; das Melos, dessen Musikalität sich zählbar im Versmaß, tänzerisch im Versfuß äußert - und last and least die Opsis, die das Sehen und wie in unserem Fall auch das Aussehen bedeutet. Erst an letzter Stelle kommt das Spektakuläre, die appearance, wie es bei dem englischen Übersetzer und Herausgeber Bywater heißt. All das also, was die Zuschauer vor Augen haben.

1 Die Behandlung der Frage ob der griechische Genitiv $\tau \dot{\omega} \nu \pi \alpha \theta \eta \mu \alpha ́ \alpha \omega \nu$ in einem objektiven oder einem separativen Sinne zu verstehen sei, füllt ganze Bibliotheken; vieles spricht für die erste Variante, die einen medizinischen Beiklang hat und keine moralische Triebbekämpfung anzeigt. 
Hierzu zählen Bühnenausstattung, Kostüme, Masken, Bühnenbilder und Ähnliches. $^{2}$

Entscheidend für diese Hintanstellung des Bühnenhaften ist die Art und Weise der Bewertung. Das Bühnenhafte trägt zwar psychagogisch zur Wirkung bei, indem es die Anteilnahme der Zuschauer weckt, wachhält und steigert, doch von allen erwähnten Komponenten entfernt es sich am stärksten von der maßgebenden Dichtkunst. Als das Kunstloseste (’̉ $\tau \varepsilon \chi v o ́ \tau \alpha \tau o v)$ fällt es in den Zuständigkeitsbereich des Bühnenbildners, der lediglich die Ausrüstung und das nötige Zubehör ( $\sigma \kappa \varepsilon v \hat{v}$ ) ) liefert. Die Wirkung der Tragödie ist auf solche Dinge nicht angewiesen, sie kommt auch ohne Wettkampf ohne den „Kampf der Wagen und Gesänge“ - und ohne Schauspieler zustande. Ähnlich äußert Aristoteles sich in Kapitel 14 (1453 b 1-11). Furcht und Mitleid entspringen in erster Linie und in vorzüglichem Maße dem Aufbau der Handlung selbst und nicht der optischen Bühnendarbietung. Die Wirkung, die der Ödipus-Mythos hervorbringt, stellt sich auch beim bloßen Hören ein, ohne dass wir das Gehörte zu sehen bekommen. Das Furchterregende ( unterscheidet sich darin vom Monströsen, Wunderlichen ( $\tau \varepsilon \rho \alpha \tau \omega \dot{\delta} \delta \varepsilon \varsigma)$, also

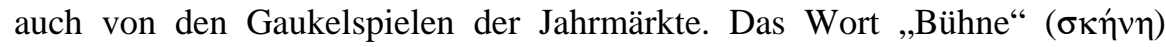
kommt gar nicht vor, außer in der beiläufigen Form der sophokleischen „Skenographie“ (1449 a 18). Ähnlich ergeht es dem Regisseur; er tritt ganz zurück hinter den Geldgeber, der pflichtgemäß für die Choregia, für die Ausstattung und den Unterhalt des Chores aufzukommen hatte. Diese beschränkte Sichtweise fügt sich in den allgemeinen Rahmen der Poetik als einer Wortkunst, die sich an die Tonkunst anlehnt und dem Bildnerischen nur in der Sprache Zugang gewährt. Die Bühnenkunst steht somit ganz und gar im Schatten der Wortkunst, die sich sorglich von jeglichem Spektakel und Bühnenzauber fernhält.

Machen wir einen Sprung in die Moderne, die in Hegels Ästhetik einen eigenen Höhepunkt erreicht. ${ }^{3}$ Den Rahmen bildet weiterhin die aristotelische Poetik, die nun als dramatische Poesie auftritt. Dabei wird unterschieden zwischen dem Drama als dem poetischen Kunstwerk, dessen innerer Geist sich mit dem poetischen Wort verbündet ${ }^{4}$, und der äußeren Exekution des dramatischen Kunstwerks. Das poetische Wort gilt als der „hervorstechende Mittelpunkt“ ${ }^{5}$ Daraus ergibt sich eine eindeutige Stufenfolge. An erster Stelle kommt das Lesen und Vorlesen des Dramas. An zweiter Stelle folgt die Schauspielkunst, die in der Verständlichkeit der Rede gipfelt. Sie ist das „Instrument, auf welchem der Autor spielt“, der „Schwamm, der alle Farben auf-

\footnotetext{
Die Behandlung des optischen Zubehörs (1450 b 16-20) nimmt nur knapp fünf Zeilen in Anspruch.

3 Georg Wilhelm Friedrich Hegel, Werke, Bd. 15, Vorlesungen über die Ästhetik III, Frankfurt/M., 1970.

Ebd., S. 490.

Ebd., S. 505.
} 
nimmt und unverändert wiedergibt“ “ ${ }^{6}$ Erst an letzter Stelle kommt die sich von der Herrschaft der Poesie emanzipierende theatralische Kunst, die mit den grellen Farben bloßer Verfallserscheinungen gezeichnet wird. ${ }^{7}$ Die Schauspielkunst überhebt sich, indem sie verlangt: „Die Dichter sollen für sie schreiben“. Sie gilt als ephemeres Geschäft; dass die Nachwelt dem Mimen „keine Kränze flicht“, steht schon im Wallenstein. Die Oper glänzt mit bloßen Accessoires, mit Dekoration und der Pflege der „sinnlichen Außenseite“. Das Ballett verfällt vollends dem bloß „Märchenhaften“ und „Wunderbaren“, das schon Aristoteles beiseite schiebt; die „Bravour und Geschicklichkeit der Beine“ endet beim „Extrem des Sinnlosen und der Geistesarmut“. Pure Virtuosität ist nicht Kunst. Die Bühne als Ort und Raum des Geschehens taucht auch hier nicht auf. Die Bühnengestaltung, die dem Regisseur obliegt, beschränkt sich auf bloße Zutaten. Der Leib, in dem sich das mimetische Geschehen verkörpert, tritt nur am Rande der großen Vernunft auf, nicht wie in Nietzsches Zarathustra als die „große Vernunft“ selbst. Doch ähnlich wie Husserl sich einer „Philosophie von unten“ befleißigt, die sich nicht in Konzepten, Konstrukten und Argumenten verfängt, könnte man ein „Theater von unten“ reklamieren, das nicht auf populäre Anbiederung aus ist, wohl aber auf Erfahrungsnähe.

Ein letztes Beispiel entnehmen wir dem Werk von Marcel Proust. In Im Schatten junger Mädchenblüten, dem zweiten Band seiner Recherche, führt der Autor uns den Übergang vom Lese- zum Sprechtheater als eine Art Bildungserlebnis, aber zugleich als ein Bildung sprengendes Erlebnis vor Augen. ${ }^{8}$ Er schildert, wie der Erzähler in jungen Jahren das leibhaftige Theater für sich entdeckt. Alles beginnt mit einer empfindlichen Enttäuschung. Der Erzähler ist bereits ein begeisterter Leser von Racines Tragödie Phädra, er kennt ganze Partien auswendig, als er in gespannter Erwartung das Theater betritt, um das Gelesene auf ungeahnte Weise aus dem Munde der berühmten Berma, alias Sarah Bernard, zu vernehmen. Doch das Vergnügen nimmt ein plötzliches Ende, als da eine Frau die Bühne betritt und das Gelesene in ein ,akustisches Medium“ eintaucht. „Ich hörte ihr zu, wie ich Phèdre gelesen hätte oder als ob Phädra selbst in diesem Augenblick die Dinge gesagt hätte, die ich hörte, ohne daß das Talent der Berma irgend etwas dem hinzuzufügen schien.“ Die Lage wendet sich, sobald im Zuschauerraum der Beifallssturm einsetzt: „Endlich brach in mir ein erstes Gefühl der Bewunderung durch: es wurde durch den frenetischen Beifall der Zuschauer geweckt“, als hätte die Menge ein besonderes Organ für die „Aura großer Ereignisse“. ${ }^{9}$ Verstärkt wird dieses Gefühl

\footnotetext{
Ebd., S. 513.

Vgl. ebd., S. 515-518.

8 À la recherche du temps perdu, hg. v. Jean-Yves Tadié, Bd. I, Paris, 1987, S. 440-442; deutsch: Auf der Suche nach der verlorenen Zeit, übers. v. Eva Rechel-Mertens, revidiert v. Luzius Keller, Bd. 2, Frankfurt/M., 1995, S. 32-35.

9 In Goethes Gesprächen mit Eckermann (Frankfurt/M., 1985, S. 530) findet sich unter dem Datum 27. März 1805 eine bestätigende Bemerkung: „Der gebildete Franzose sieht die klassi-
} 
durch die acht Tage später erscheinende Zeitungskritik. Ungeachtet des mondänen Einschlags, der dem Einfluss des Gesellschaftstheaters anhaftet, hat dieses Theatererlebnis etwas von einer Erweckung, deren Wirkung sich mit beträchtlicher Verzögerung einstellt. Wie wir sehen werden, bildet die Bühne nicht nur einen öffentlichen Ort, der sich deutlich von der einsamen Lesekammer unterscheidet, das Bühnengeschehen hat auch eine eigene Zeit, die alle Erwartungen sprengt.

Die folgende Revision geht aus von Gesichtspunkten und Motiven, die sich einer leiblich verankerten Phänomenologie des Ortes, des Raums und der Zeit entnehmen lassen. ${ }^{10}$ Wenn hierbei die neuerlich verkündete Wiederkehr des Raumes zum Zuge kommt, so bleibt zu fragen, welche Wiederkehr welchen Raumes einer Wiederkehr der Bühne entspricht. Bei der Annäherung an den speziellen Bühnenraum werde ich mich dementsprechend von einigen bühnennahen Raumideen leiten lassen.

\section{Theaterschwelle und Theaterrahmen}

Ich gehe ins Theater - als Zuschauer; jemand arbeitet am Theater - als Schauspieler, Regisseur, Dramaturg, Bühnenbildner, nicht zu vergessen die „Belegschaft“, eingedenk der Mahnung Brechts: „Caesar schlug die Gallier. Hatte er nicht wenigstes einen Koch bei sich?“ Das Theater, das wir betreten, ist ein Raum von Räumen mit seinen Verschiebungen, Verschachtelungen und Enklaven. In Zeiten des Gesellschaftstheaters, wie es uns in der Romanliteratur und in Bildszenen des 19. Jahrhunderts begegnet, war die Loge ein eigener Ort für Rendezvous. Doch auch wenn die Außenwelt bis in die Theaterwelt hineinreicht, betreten wir das Theater über eine Schwelle hinweg, die unsere gewöhnliche Alltagswelt von der Theaterwelt als einer Sonderwelt scheidet. Schwellen bilden generell „Grenzzonen“, wo Vertrautes in Fremdes übergeht, ähnlich wie es immer wieder beim alltäglichen und allnächtlichen Einschlafen und Aufwachen geschieht, das stets eine leichte, manchmal auch eine stärkere Verwirrung hinterläßt. ${ }^{11}$ Der Kleiderwechsel, wie freizügig auch immer er sich vollziehen mag, gehört ebenfalls dazu; er ist Ausdruck eines Szenenwechsels und mehr als ein gesellschaftliches Etikett.

schen Stücke seiner großen Dichter so oft, daß er sie auswendig weiß und für die Betonung jeder Silbe ein geübtes Ohr hat.“

10 Vgl. speziell Bernhard Waldenfels, Ortsverschiebungen, Zeitverschiebungen: Modi leibhaftiger Erfahrung, Frankfurt/M., 2009, S. 83-86; und ders., Sinne und Künste im Wechselspiel: Modi ästhetischer Erfahrung, Berlin, 2010, Kap. 9-10.

11 Vgl. dazu Walter Benjamins Bemerkung im Passagen-Werk, Frankfurt/M., 1983, Bd. I, S. 167 f. Von der Schwellenidee habe ich mich wiederholt leiten lassen. Vgl. zuletzt meinen Aufsatz „Schwellenerfahrungen“, in: Jochen Achilles/Roland Borgards/Brigitte Burrichter (Hg.), Liminale Anthropologien. Zwischenzeiten, Schwellenphänomene, Zeiträume in Literatur und Philosophie, Würzburg, 2012. 
Was den Theaterbau angeht, so bildet es einen Innenraum mit mehr oder weniger durchlässigen Außengrenzen. Das gilt selbst für das Freilufttheater, das sich wie schon das griechische Amphitheater auf eigene Weise vor seiner Umwelt abschirmt. Innerhalb des Theaterraums setzt sich die Bühne vom $\mathrm{Zu}$ schauerraum ab. Der Übergang ist markiert durch eine Bühnenschwelle, die Rampe. Schließlich hebt und senkt sich der Vorhang, indem er nicht nur räumliche, sondern auch zeitliche Zäsuren setzt. Besagte Grenzen können mehr oder weniger scharf gezogen werden; diese Grenzziehungen sind wie alle Grenzziehungen kontingent, sie könnten auch anders ausfallen. Daraus ergeben sich je nach Geschichtsepoche und je nach Kulturbereich verschiedene Bühnentypen, etwa auf dem Weg von der Guckkastenbühne zur beweglichen Raumbühne oder in der geteilten Bühne des japanischen Bunraku-Theaters. ${ }^{12}$

Das Theatergeschehen organisiert sich in einer besonderen Form von Rahmung, wie Erving Goffman in seiner Rahmenanalyse zeigt. ${ }^{13}$ Es bedarf spezifischer Transkriptionsmethoden, „um ein Stück wirklicher Vorgänge außerhalb der Bühne in ein Stück Bühnenwelt zu transformieren “. ${ }^{14}$ Dies erinnert an die Funktion des Bilderrahmens, der zu Zeiten Simmels als ästhetische Grenze besondere Beachtung fand, der aber inzwischen auf neuartige Weise in den Bildprozess einbezogen wird. Goffman schließt sich an Gregory Bateson an, indem er den Rahmen als einen Rahmungsprozess fasst, geleitet von einem wechselnden Organisationsprinzip, das verschiedene Ereignisse koordiniert und sie zu einem Erfahrungsfeld zusammenfügt. Die Schlüsselfrage „What is going on here?“, die immer wieder neu zu stellen ist, wenn Ungewöhnliches geschieht, ruft nach einer solchen Rahmung. Dabei unterscheidet Goffman zwischen einem primären Rahmen, der unsere normale Erfahrung organisiert, und einem speziellen Rahmen wie dem des Theaters. Die Rahmung kann sich auch spontan und informell vollziehen wie in den Kranichen des Ibykus: „Die Szene wird zum Tribunal“ unter den „geflügelten Schriftzeichen“ der Kraniche am Himmel, die zum Rechtsspruch auffordern, wo die menschliche Stimme versagt. ${ }^{15}$ Selbst politische Demonstrationen weisen Züge eines schwer zu kontrollierenden Straßentheaters auf.

12 Vgl. Waldenfels (2009), Ortsverschiebungen, S. 85; dazu Jens Roselt, Phänomenologie des Theaters, München, 2008, S. 61-112.

13 Erving Goffman, Rahmen-Analyse. Ein Versuch über die Organisation von Alltagserfahrungen, übers. v. H. Vetter, Frankfurt/M., 1980, Kap. 5.

14 Ebd., S. $158 \mathrm{f}$.

15 Zum Kranich-Motiv in der Literatur vgl. Ernst Robert Curtius, Europäische Literatur und europäisches Mittelalter, 4. Aufl., Bern, 1963, S. 349; der Kranichflug wurde auch als griechisches Lambda gedeutet. 


\section{Bühne als Spiel- und Schauplatz}

Die Rolle der Bühne hängt ganz entscheidend davon ab, wie der Theaterraum konzipiert ist. Das Wort „Theater“ hat die doppelte Bedeutung von Theaterspiel und Theatergebäude; ähnliches gilt für die „Szene“ als architektonisches Gerüst und als raumbildender Vorgang. Dieser Bedeutungsgehalt verkümmert, wenn der Raum entsprechend dem cartesianischen Raumschema als ein Behälter oder ein Gehäuse gefasst wird, also als etwas, das sich beliebig anfüllen oder leeren lässt. In einem solchen Raum gibt es zwar Abstände, aber keine Ferne und Nähe; ein jedes ist irgendwo an einer wechselnden Raumstelle, aber nichts ist an seinem eigenen Ort, am rechten oder am falschen Ort. Auf andere Weise gilt dies auch für den digitalen Raum. Strenggenommen gibt es keinen digitalen, sondern nur einen digitalisierten Raum; denn wird der Rückbezug auf die Raumerfahrung getilgt, so behalten wir nur physikalische Daten und Algorithmen zurück, die sich so wenig selbst verorten wie eine mathematische Gleichung. Die Bühne ist dagegen ein Ort, wo buchstäblich etwas stattfindet (vgl. avoir lieu, to take place). Etwas ereignet sich, tritt hervor, kommt zustande im Zuge einer eigentümlichen Orts- und Zeitbildung. Die Aufführung schafft sich selbst einen Standort, ein Umfeld, einen Boden, sie bahnt sich eigene Wege. Dieser Ort im Werden ist kein vorhandenes Etwas, er ist auch kein bloßes Konstrukt, sondern er fungiert in der Erfahrung als originäre Orientierungsinstanz. Er antwortet in elementarer Form auf die Frage „Wo?“. Wo ist Ödipus? Auf Kolonos. Die Wo-Frage ist eine Orientierungsfrage, die sich mit der Wann-Frage verbindet; denn es kann sein, dass die jeweilige Ortsangabe schon morgen hinfällig ist. Doch wer stellt die Frage, und von wo aus wird sie gestellt?

\section{Ort und Raum}

Entscheidend für eine genuine Phänomenologie des Raumes ist eine Verdoppelung des Wo in Ort und Raum. Unter Ort, griechisch topos, lateinisch locus, verstehe ich das Hier, wo jemand sich befindet, der ausdrücklich oder unausdrücklich „hier“ sagt, und dies im Gegensatz zum „dort“, wo man war, wo man möglicherweise sein wird oder wo man sein möchte. Das Hier fungiert, wie Husserl es nennt, als ein leibhaftiger Nullpunkt, der sich gleich dem Kreuzungspunkt der Koordinaten keiner Achse zurechnen lässt. Das Hier ist weder oben noch unten, weder rechts noch links, weder vorn noch hinten, weil im Hier die diversen Raumdifferenzen entspringen. Karl Bühler spricht in seiner Sprachtheorie ganz ähnlich vom „Hier-Jetzt-Ich“ als der Origo eines Zeigfeldes, die allerdings durch ein „Du“ oder „Ihr“ zu ergänzen wäre. Das Hier bildet den Ausgangspunkt für raumbildende Bewegungen, die vor und zurück, auf und ab, nach rechts oder nach links gehen. Dieser Ausgangspunkt zeigt sich, und er lässt sich zeigen mithilfe sogenannter indexicals, er lässt sich je- 
doch nicht durch eine definitive, kontextfreie Kennzeichnung ersetzen. Die Lexis, die bei Aristoteles zum Bestand des Dramas gehört, stößt in der Deixis auf eine innere Grenze. Im Sagen zeigt sich mehr, als wir sagen. Die Performativität der Sprache, die in der Phänomenologie der Sprache ebenso wie in der Sprachpragmatik Wittgensteins zum Zuge kommt, berührt sich mit der Performanz des Theaters.

Die Verklammerung von Sagen und Zeigen lässt sich bestens illustrieren, wenn wir das Incipit eines beliebigen Schauspiels in Betracht ziehen. ${ }^{16}$ Nehmen wir den Anfang von Sophokles’ Antigone: „Ismene, Schwester - teures Haupt, mir blutsverwandt! Weißt du ein Unheil, uns vererbt von Ödipus, das Zeus, schon seit wir leben, nicht an uns erfüllt?“ Die Protagonistin bezieht sich auf Theben als eine Unheilsstadt, auf der ein Geschlechterfluch liegt, und dies nicht nur wie eine Pest, sonder als eine Pest, die Albert Camus in den Titel seines Romans aufgenommen hat. Die Fortsetzung im Ödipus auf Kolonos beginnt dann so: „Antigone, Tochter eines alten blinden Manns, in welche Gegend nun, zu welcher Männer Stadt gelangten wir? ${ }^{\text {“17 }}$ Ein Einheimischer, der für den flüchtigen Fremden selbst ein Fremder ist, antwortet: „Kolonos“. Das Geschehen beginnt also an einem Fremdort der Verbannung. Oder nehmen wir Schillers Don Carlos: „Die schönen Tage in Aranjuez sind nun zu Ende. Eure königliche Hoheit verlassen es nicht heitrer." Hier beginnt alles an einem Abschiedsort. In beiden Fällen steht hinter dem Hier ein Fragezeichen, eine sichere Bleibe ist nicht in Sicht. Zusammen mit der place identity gerät jegliche Identität ins Wanken. Ein letztes Beispiel liefert uns Dantes Divina Commedia: „In der Mitte unsres Lebensweges fand ich mich wieder in einem dunklen Wald - Nel mezzo del cammin di nostra vita / mi ritrovai nel una selva oscura." Auch diese Wanderung durch Himmel und Hölle beginnt an einem Nicht-Ort.

Im Gegensatz zum Ort verstehe ich unter Raum, lateinisch spatium, einen Bereich, in den man sich, andere und alle Dinge einordnet. Handelt es sich also um zwei Arten von Raum, einen subjektiven und einen objektiven Raum, einen Raum in der ersten und einen in der dritten Person? Aristoteles unterscheidet in seiner Poetik zwischen dem Drama, in dem, wie etwa bei Sophokles, die dargestellten Figuren selbst als Handelnde dargestellt werden, und dem Epos, in dem, wie bei Homer, lediglich von Handelnden berichtet wird (Poetik, 3, 1148 a 19-24). Doch mit dieser rudimentären Unterscheidung ist es nicht getan. In der selbstbezüglichen Rede, die in der Anrede zugleich als fremdbezügliche Rede auftritt, kommt es zu einer Ortsverdoppelung. „Hier“, der wandelbare Ort des Aussagens, ist nicht identisch mit dem Ort der Aussage: „Auf Kolonos“. Für das „Jetzt“ gilt Ähnliches. Orts-und Zeitangaben

16 Ich habe an anderer Stelle auf die Anfangs- und Endproblematik zurückgegriffen, um das Unerzählbare im Erzählen zu problematisieren. Vgl. Bernhard Waldenfels, Phänomenologie der Aufmerksamkeit, Frankfurt/M., 2004, Kap. III.

17 Die Übersetzung der Zitate von Sophokles stammt von Roman Woerner: Sophokles, Tragödien, Leipzig, 1942. 
können falsch und mehr oder weniger genau sein, während „Hier“ und „Jetzt“ als leibhaftige Origo der Rede, diesseits von wahr und falsch fungieren. Den gespaltenen Raum, der sich daraus ergibt, bezeichne ich als Ortsraum. Diese Doppelheit entspricht dem Leibkörper, für den - frei nach Plessner - gilt: Ich bin am Ort und habe einen Raum. Damit nimmt der Eigenort Züge eines Fremdortes an; denn ich bin nie ganz und gar hier. Ich befinde mich hier und zugleich anderswo an einer anderen Stelle; ich bin nicht nur dort, wo ich selbst sein könnte, sondern zugleich dort, von wo aus mich etwas trifft, was ich mir nicht eigentätig und eigenhändig zurechnen kann. Schon mein Geburtsort ist nicht schlechthin mein eigener Ort. Damit wird die Bühne, auf der die Spieler sich verorten, doppelbödig wie unsere natürliche Erfahrung. Die Doppelbödigkeit verschwände, wenn die Stimme der Schauspieler ganz und gar entleiblicht und von der körperlichen Materialität abgelöst würde. Auch die vielfältige Anonymisierung der Stimme kann nur eine Stimme von irgendwo meinen; eine Stimme von nirgendwo wäre keine Stimme mehr, sondern ein bloßer flatus vocis, der von einem Windhauch nicht zu unterscheiden wäre. Die Leiblichkeit setzt der Technisierung Grenzen. Ohne den Bezug auf ein leibliches Hier und Jetzt würde das verleugnete Selbst in die allzu vertraute Rolle eines gottgleichen „Weltenbetrachters“ zurückkehren. Eine überdrehte Technologie hat weiterhin ihre „theologischen Mucken“.

\section{Raumdarstellung und Darstellungsraum}

Mit der Frage nach dem Wo des Bühnengeschehens begegnet uns erneut der Unterschied von Ort und Raum. Die Bühne ist offensichtlich ein exemplarischer Ort. Sie wird dadurch zur Bühne, dass jemand dort auftritt; der Rest ist Kulisse oder Lagerhalle, also nichts weiter als ein Raum, den man benutzt. Sie wird ferner dadurch zur Bühne, dass das aufgeführte Geschehen die Aufmerksamkeit auf sich zieht und Anwesende in Zuschauer verwandelt. Doch wo ist nun Fritz Kortner, wenn er den Shylock spielt, ist er in Venedig, wo das Stück spielt, oder in Berlin, wo das Schauspielhaus steht? Und wo liegt die Insel Kolonos, die der flüchtige Ödipus betritt? Allem Anschein nach zählt für den Zuschauer der dargestellte Ort, nicht der Ort der Darstellung. Doch vielleicht kennen wir diesen Ort schon von unseren Ferien- oder Bildungsreisen. Sicherlich wäre es abwegig zu erwarten, dass Theaterbesucher ihre Alltagserfahrungen zurücklassen wie ein lästiges Gepäck. Doch die Transformation von Erfahrung in Theatererfahrung müsste auch hier besagen, dass nichts unverändert wiederkehrt. Was sich auf der Bühne abspielt, hat nicht schon einen festen Standort. Venedig? Was wäre Venedig für den Erzähler aus Prousts Recherche ohne das Stolpern über die ungleichen Bodenplatten im Hof der Guermantes, das auf ungeahnte Weise Erinnerungen wachruft und Venedig auf gewisse Weise neu erschafft? Spielt der Kaufmann von Venedig also in 
Venedig, oder ist Venedig nicht umgekehrt dort, wo sich die Geschichte des Juden Shylock abspielt?

Die Bühne ist kein bloßer Teilraum, kein bloßer Ausschnitt unserer aktuellen Lebenswelt, sondern aristotelisch formuliert handelt es sich um einen mimetischen Raum, der erst im Zuge der theatralischen Mimesis entsteht. Jede Mimesis beruht auf einer mimetischen Differenz. Darstellungsort und dargestellter Ort, etwas das Wiener Burgtheater und das unheilvolle Theben, differieren. Die mimetische Differenz entspricht mutatis mutandis der ikonischen oder pikturalen Differenz, die Bildendes und Gebildetes, Materialität und Bildlichkeit voneinander absondert. Karl V. hängt nicht an der Wand der Münchner Alten Pinakothek, wenn sein von Tizian gemaltes Porträt dort hängt. Die innere Verschiebung, die den Prozess der Mimesis auszeichnet, entspringt einer Suspension der lebensweltlichen Verankerung; sie entspringt einer theatralischen Epoché; sie stellt eine Spezifizierung der phänomenologischen Epoché dar, mit der wir von der vorgegebenen Welt zum Wie ihrer Gegebenheit überwechseln. Der Boden, auf dem sich unser normales Leben abspielt, gerät mitsamt allen lebensweltlichen Überzeugungen ins Schwanken, er wird brüchig. Dieses Fraglichwerden des Ortes kommt in der theatralischen Darstellung selbst zum Ausdruck, wie wir gesehen haben.

Doch über dieses bruchartige Fraglichwerden hinaus bedarf es einer spezifischen Transkription und Transformation, „um ein Stück wirklicher Vorgänge außerhalb der Bühne in ein Stück Bühnenwelt zu transformieren“. ${ }^{18}$ Der Wiener Fritz Kortner, der als Schauspieler auftritt, verwandelt sich in den jüdischen Kaufmann Shylock, die Berliner Bühne verwandelt sich in das Venedig der Renaissance und so fort. Die Zuschauer machen eine entsprechende Wandlung durch. Das Gelächter über einen gelungenen Spaß unterscheidet sich vom Gelächter über den Schauspieler, der stecken bleibt oder sonst wie aus der Rolle fällt. „Im ersten Fall lacht man als Zuschauer, im zweiten als Theaterbesucher. “19 Die unerlässliche Transformation pendelt zwischen zwei Extremen. Unhaltbar ist einerseits eine Theatralisierung des Lebens nach dem Motto: „Alles ist Theater.“ Wenn für Artaud gilt: „Das Theater der Grausamkeit ist keine Repräsentation. Es ist das Leben selbst in dem, was an ihm nicht darstellbar ist - Le théâtre de la cruauté n'est pas une représentation. C'est la vie elle-même en ce qu'elle est irréprésentable ${ }^{\text {"20 }}$, so ist diese Darstellung des Nicht-Darstellbaren als ein Überschuss zu verstehen und keineswegs als unmittelbarer Ausdruck des Lebens selbst. Fragwürdig ist andererseits eine einseitige Ästhetisierung und Fiktionalisierung des Theaters, die so tut, als ginge es um ein spielerisches Als-ob, das jeden Ernst hinter sich lässt.

18 Goffman (1980), Rahmen-Analyse, S. $158 \mathrm{f}$.

19 Ebd., S. 150.

20 Vgl. Jacques Derrida, L'écriture et la différence, Paris, 1967, S. 343; deutsch: Die Schrift und die Differenz, übers. v. Rodolphe Gasché, Frankfurt/M., 1978, S. 353. 
Theatralische Darstellung, die ihrem eigenen Anspruch auf Lebensbefragung gerecht wird, erfordert eine Realisierung im Modus der Irrealisierung, die mit dem Spiel ernst macht, indem sie die leibhaftige Gegenwart verfremdet, sie in eine „leibhaftige Abwesenheit“ verwandelt.. ${ }^{21}$ Die Dauerfrage: „Wer und wo bin ich, wer und wo sind wir?“ entspricht der Kondition eines „nicht festgestellten Tieres“, das seinen Ort sucht und ihn nicht schon hat wie ein Tier, das seine Höhle oder sein Nest bewohnt.

\section{Hier und anderswo}

Wir drehen uns im Kreise, solange wir den Ort der Darstellung und den dargestellten Ort gegeneinander ausspielen. Ein Ausweg öffnet sich, wenn wir davon ausgehen, dass sich etwas auf der Bühne ereignet, das unsere Vorstellungen sprengt und die Horizonte der Vertrautheit durchbricht. Die Verdoppelung von Ort und Raum ruft eine zusätzlich verfremdende Wirkung hervor. Diese verstärkt sich, wenn das, was sich auf der Bühne abspielt, dem grundlegenden Zweiklang von Pathos und Response folgt. ${ }^{22}$ Redend und handelnd antworten wir auf etwas, das uns widerfährt, das uns affiziert, an uns appelliert. In diesem Sinne wäre jede Lexis und jede Praxis in einem radikalen Sinne responsiv. Die Frage, worauf das jeweilige Reden und Tun antwortet, ist dann ebenso grundlegend wie die übliche Frage, wie es zu verstehen ist und ob es wahr oder rechtens ist. Diese Annahme steht durchaus im Einklang mit dem Geschehen der antiken Tragödie, jedoch nicht unbedingt mit ihrer antiken Deutung. „Drama“ bedeutet wörtlich „Handlung“ beziehungsweise ein „Handlungsstück“. Zwar werden bei Aristoteles neben der tragenden Handlung ( $\pi \rho \alpha \xi_{\xi}(\varsigma)$ auch Umstände und Begebenheiten $(\pi \rho \alpha ́ \gamma \mu \alpha \tau \alpha)$ berücksichtigt, und als Unheil, Unglück und Gewalt gehört das Leiden ( $\pi$ ó $\theta$ os) zum Grundbestand der Tragödie und ihrer kathartischen Wirkung. Doch versteht man Passion und Passivität als eine Abschwächung von Aktion und Aktivität, wie es das aristotelische, aber mehr noch das moderne Denken nahelegt ${ }^{23}$, so wohnt das Pathos keineswegs im Herzen des eigenen Redens und Tuns als ein pathischer Impuls und als ein pathischer Untergrund, von dem alles ausgeht. Ödi-

21 Der Ausdruck absent en chair et en os, der Husserls „leibhafte Gegenwart“ in die Ferne rückt, ohne die Leibhaftigkeit preiszugeben, findet sich in Jean-Paul Sartre, Les mots, Paris, 1964, S. 73.

22 Diesen Gedanken, der meiner responsiven Phänomenologie zugrunde liegt, habe ich anderswo ausführlich dargelegt. Vgl. Bernhard Waldenfels, Antwortregister, Frankfurt/M., 1994; und zuletzt ders., Grundmotive einer Phänomenologie des Fremden, Frankfurt/M., 2006.

23 Aristoteles arbeitet mit einer Kontinuität von Dynamis und Energeia, während Descartes die Passion als diametralen Gegensatz zur Aktion behandelt (Leidenschaften der Seele, Art. 73). Teilweise auszunehmen ist allerdings das platonische Denken und Schreiben, das den erotischen Aufschwung der Seele als ein Pathos fasst und so auch der Fremdheit einen stärkeren Platz einräumt, so in den Gestalten von Sokrates oder Diotima. 
pus’ Bekenntnis: „Meine Taten sind ja mehr erlitten als getan“ 24 wäre dann kaum mehr als ein Eingeständnis eigener Schwäche, das durch Heldentaten der Vernunft zu überwinden ist.

Unterliegt unser Reden und Tun dagegen dem Zweiklang von Pathos und Response, so besagt dies, dass es im radikalen Sinne anderswo beginnt und dass etwas auf uns zukommt. Aus der griechischen Tragödie kennen wir dieses Pathos als etwas, das uns widerfährt und das uns in Form von Furcht und Mitleid in Mitleidenschaft zieht. Es lässt sich weder auf frei gestaltete Handlungen und Reden von Akteuren noch auf das willkürliche Interesse von $\mathrm{Zu}$ schauern reduzieren. Die Geschichte des Ödipus kann bei all ihrer Besonderheit paradigmatisch verstanden werden, wenn man unter Verhängnis ein radikales Widerfahrnis versteht, das eigene Antworten hervorruft, und nicht etwa eine fatalistische Außensteuerung, die den Menschen mundlos und zum Spielball der Götter oder des Schicksals macht. Bemerkenswert ist die Tatsache, dass der Schauspieler im Griechischen, anders als in den lateinisch geprägten Sprachen, nicht als „Handelnder“ (actor) auftritt, sondern als „Antwortender“, als Respondent (ijoкрıтńs). Schon die eigene Stimme hat eine echoartige Wirkung, indem sie fremde Stimmen durchtönen lässt. Die Stimme wird zur ganz normalen Stimme, wenn die fremden Untertöne überhört werden.

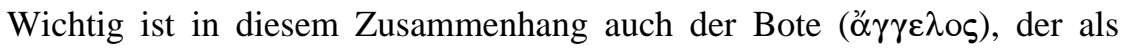
leibhaftiger Mediator auftritt und mit seiner aus der Ferne kommenden Botschaft, darunter die sprichwörtliche Hiobsbotschaft, Handlungen in Gang setzt. ${ }^{25}$ Den Hintergrund dafür bildet eine radikale Orts- und Zeitverschiebung, die jedes überraschende und überwältigende Ereignis nur über eine Kluft hinweg zu uns gelangen lässt. Das gesamte Ödipus-Drama, das für Freud eine besondere Quelle der Inspiration war, vollzieht sich, ähnlich wie die therapeutische Verarbeitung eines traumatischen Ereignisses, mit uneinholbarer Nachträglichkeit. Der Anfang ist da, aber als ein entrückter Anfang, der eben deshalb eigene Wirkungen entfaltet, die nur in einer rückwärtigen Deutung als Nachwirkung zu fassen sind. Dazu gehört auch die Instanz eines Dritten, der nur indirekt in das Geschehen eingreift. Dafür steht die Rolle des antiken Chores, der warnend, bezeugend, kommentierend oder auch beschwichtigend das Geschehen begleitet. Ähnlich wie die Malerei ihre Bilder ins Bild aufnimmt, gibt es auf der Bühne Ansätze zu einem gespielten Zuschauen. Handeln und Zuschauen greifen schon hier ineinander.

Der raumzeitliche Verzug, der jedes pathisch initiierte Geschehen prägt, ist der Grund dafür, dass in aller Darstellung etwas Undarstellbares aufleuchtet, etwas, das zur Darstellung drängt und zur Darstellung kommt, aber sich dem direkten Zugriff entzieht. Undarstellbar ist nicht etwas Jenseitiges, sondern das

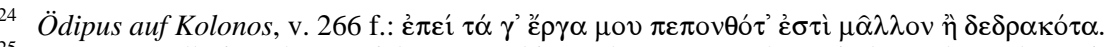

25 Zur Botenrolle im Theater siehe Hans-Thies Lehmann, „Prädramatische und postdramatische Theater-Stimmen“, in: Doris Kolesch/Jenny Schrödl (Hg.), Kunst-Stimmen, Berlin, 2004, S. 4956. (= Theater der Zeit. Recherchen 21.) 
Ereignis, das zur Darstellung kommt, so etwa das Leid des Ödipus und die gnadenlose Gerechtigkeit, die Shylock auf sich zieht. Ereignisse, die nicht schon einen Ort und eine Zeit haben, sondern auf der Suche nach Ort und Zeit sind, müssen nicht auf große Erzählstoffe zurückgreifen. Sie können sich in der Unalltäglichkeit des Alltäglichen einnisten, so wenn Stanislawski seinen Schauspielern aufträgt, die Floskel „sevodna vecerom - heute abend“ so auszusprechen, dass sie zum Kern einer Abendszene voller ungeahnter Effekte wird. ${ }^{26}$

Der Entzug des Undarstellbaren schließt einen Ortsentzug mit ein. Das berühmte Diktum von Rimbaud: „JE est un autre“ wäre entsprechend zu ergänzen durch ein: „JE est ailleurs.“ In Poetik 9 wertet Aristoteles die Poesie gegenüber der Historie auf, da sie nicht nur wiedergibt, wie es tatsächlich zuging, sondern berücksichtigt, wie es hätte zugehen können. Bringt nun also der pathische Charakter des Geschehens etwas ins Spiel, das unserer eigenen Initiative zuvorkommt, so hat es die Theaterkunst, und nicht nur sie, immer auch mit Un-möglichem zu tun. ${ }^{27}$

\section{Diesseits und jenseits der Rampe}

Kehren wir zurück zum Theater als einem Raum der Räume. Die Rampe trennt herkömmlicherweise Spielbühne und Zuschauerraum. Doch auch hier deuten sich Grenzen eines Repräsentationstheaters an. Wenn der Schauspieler im radikalen Sinne kein bloßer Akteur ist, sondern Patient und Respondent, so greift dies über auf die Beziehung zwischen Schauspieler und Zuschauer. Was sich über die Rampe hinweg abspielt, lässt sich nicht mehr auf gegensätzliche Instanzen wie Aktion und Passion, Produktion und Rezeption verteilen. Die Überraschung, die jeder starken Erfahrung innewohnt, beginnt mit der Selbstüberraschung der Schauspieler, die sich wie ein Buschfeuer auf die Zuschauer übertragen kann, wenn die Aufführung über bloße Routine hinausgeht. Wenn etwas im Zwischenfeld von Bühne und Auditorium zustande kommt, so geht es nicht aus einer Absprache hervor, die zu einem Konsens führt, sondern aus einer vorsprachlichen Ko-affektion, einer gemeinsamen Affektion, die in verschiedene Richtungen ausstrahlt und verschiedene Antworten zulässt. Dieses übergreifende Zwischengeschehen erfordert ein aktives Hören, das sich nicht auf den abschließenden Applaus beschränkt, sondern mehr oder weniger in das Geschehen eingreift.

Ein solches Zwischen hat auch Kleist im Auge, wenn er in seinem Essay Von der allmählichen Verfertigung der Gedanken in der Rede bemerkt: „Ein

26 Vgl. Konstantin S. Stanislawskij, Theater, Regie und Schauspieler, Hamburg, 1958, S. 37-58: Der Weg zum „körperlichen Leben der Rolle“.

27 Vgl. dazu meine Überlegungen in: Bernhard Waldenfels, Hyperphänomene. Modi hyperbolischer Erfahrung, Berlin, 2012, Kap. 3. 
Blick, der uns einen halbausgedrückten Gedanken schon als begriffen ankündigt, schenkt uns oft den Ausdruck für die ganze andere Hälfte desselben.“ Der Autor verlässt den intimen Bereich der Zwiesprache und betritt die öffentliche Bühne, wenn er uns im gleichen Essay eine Szene aus der Vorgeschichte der Französischen Revolution vor Augen führt: Es ist Mirabeau, den er wie einen „Donnerkeil“ dazwischenfahren lässt mit der Versicherung, „daß wir unsre Plätze anders nicht, als auf die Gewalt der Bajonette verlassen werden“. Hinzu kommen unscheinbare Gesten, die beträchtliche Wirkungen auslösen können: „Vielleicht, daß es auf diese Art zuletzt das Zucken einer Oberlippe war, oder ein zweideutiges Spiel an der Manschette, was in Frankreich den Umsturz der Ordnung der Dinge bewirkte.“ Diese historische Miniaturszene lässt den Leib mitspielen. So wie der Leib immer schon mehr ist als bloßer Körper, so ist das Theater immer schon mehr als bloßes Theater. Wer mag bei diesem theatralischen Staatsstreich Regie geführt haben?

Was auf der Bühne geschieht, geschieht bis zu einem gewissen Grad anonym. „Es spielt“ sollte man sagen, wie man auf Geheiß Lichtenbergs sagen sollte: „es denkt“ wie „es blitzt“. Wenn es über die Bühnenrampe hinweg zu einem Zusammenspiel kommt, so resultiert es nicht aus einem förmlichen Konsens. Schauspieler und Zuschauer antworten in vielfacher Hinsicht auf dasselbe, aber sie tun dies nicht auf dieselbe Weise. Dazu käme es nur, wenn wir es mit einem fait accompli zu tun hätten, bei dem nichts recht eigentlich auf dem Spiel stünde.

\section{Literatur}

Benjamin, Walter, Passagen-Werk, Frankfurt/M., 1983.

Curtius, Ernst Robert, Europäische Literatur und europäisches Mittelalter, 4. Aufl., Bern, 1963.

Derrida, Jacques, L'écriture et la différence, Paris, 1967. (Deutsch: Die Schrift und die Differenz, übers. v. Rodolphe Gasché, Frankfurt/M., 1978.)

Goethe, Johann Wolfgang von, Gespräche mit Eckermann, Frankfurt/M., 1985.

Goffman, Erving, Rahmen-Analyse. Ein Versuch über die Organisation von Alltagserfahrungen, übers. v. H. Vetter, Frankfurt/M., 1980.

Hegel, Georg Wilhelm Friedrich, Werke, Bd. 15, Vorlesungen über die Ästhetik III, Frankfurt/M., 1970.

Lehmann, Hans-Thies, „Prädramatische und postdramatische Theater-Stimmen“, in: Doris Kolesch/Jenny Schrödl (Hg.), Kunst-Stimmen, Berlin, 2004, S. 49-56. (= Theater der Zeit. Recherchen 21.)

Proust, Marcel, À la recherche du temps perdu, hg. v. Jean-Yves Tadié, Bd. I, Paris, 1987. (Deutsch: Auf der Suche nach der verlorenen Zeit, übers. v. Eva RechelMertens, revidiert v. Luzius Keller, Bd. 2, Frankfurt/M., 1995.)

Roselt, Jens, Phänomenologie des Theaters, München, 2008. 
Sartre, Jean-Paul, Les mots, Paris, 1964.

Sophokles, Tragödien, Leipzig, 1942.

Stanislawskij, Konstantin S., Theater, Regie und Schauspieler, Hamburg, 1958.

Waldenfels, Bernhard, Antwortregister, Frankfurt/M., 1994.

Ders., Phänomenologie der Aufmerksamkeit, Frankfurt/M., 2004.

Ders., Grundmotive einer Phänomenologie des Fremden, Frankfurt/M., 2006.

Ders., Ortsverschiebungen, Zeitverschiebungen: Modi leibhaftiger Erfahrung, Frankfurt/M., 2009.

Ders., Sinne und Künste im Wechselspiel: Modi ästhetischer Erfahrung, Berlin, 2010.

Ders., Hyperphänomene. Modi hyperbolischer Erfahrung, Berlin, 2012.

Ders., „Schwellenerfahrungen“, in: Jochen Achilles/Roland Borgards/Brigitte Burrichter (Hg.), Liminale Anthropologien. Zwischenzeiten, Schwellenphänomene, Zeiträume in Literatur und Philosophie, Würzburg, 2012. 
GESTIMMTE RÄUME 



\section{NORBERT OTTO EKE}

\section{BÜHNE ALS WAHRNEHMUNGSRAUM. STIMME, KLANG UND PRÄSENZ}

Die kathartische Affektion des Zuschauers vor Augen, bringt Aristoteles im 14. Abschnitt seiner Poetik en passant eine Vorstellung auditiver Reizstimulation ins Spiel. Es könne „das Schauderhafte und Jammervolle“, heißt es hier, „durch die Inszenierung“ bedingt sein; es könne sich aber auch „durch die Zusammenfügung der Geschehnisse“ ergeben, was „das Bessere“ sei „und den besseren Dichter“ zeige. Eine Handlung müsse nämlich solcherart beschaffen sein, „daß jemand, der nur hört und nicht auch sieht, wie die Geschehnisse sich vollziehen, bei den Vorfällen Schaudern und Jammern“ empfinde - so wie es bei der Geschichte von Ödipus der Fall sei. ${ }^{1}$

Vor dem Hintergrund dieser Textpassage irritiert die innerhalb der TheaterMediengeschichte lange Zeit zu beobachtende Konzentration auf das Theater als Schauraum, die noch Derrick de Kerckhoves überaus anregende Überlegungen zum Theater als medientechnologischem Labor der Perzeptionsschulung an der Schwelle zwischen oraler Kultur und alphabetisierter Schriftkultur (La civilisation vidéo-chrêtienne, 1990; dt.: Schriftgeburten, 1995) in ganz entscheidender Weise bestimmt hat. Im attischen Theater, so de Kerckhove, hätten die Zuschauer zugleich mit der Unterscheidung zwischen realer und symbolischer Handlung (die im Ritus noch vereint seien) und der Einübung eines zentralisierten Blicks (nämlich auf den klar definierten und vom $\mathrm{Zu}-$ schauerraum abgetrennten Bühnenraum, der keine kollektive Teilnahme mehr erlaubte) die neuen Wahrnehmungsstrategien der Schriftkultur eingeübt. Während die kultische und rituelle Theaterhandlung noch eine multisensorische Teilnahme ermöglicht hätte, sei das Spiel regelrecht nun zum Schauspiel geworden, das eine dezidiert visuelle Perzeption erfordert habe. Dabei habe das theatron durch einen Vorgang der Übertragung zum Ort der Einübung eines neuen Sehens werden können. Der Zuschauer sollte hier

den sinnlichen Reichtum der Aufführung auf geistiger Ebene in eine abstrakte Ordnung übertragen. Er sollte seine Sinne gegen den Sinn (Bedeutung) eintauschen, was der umgekehrten Operation im Vergleich zur Lektüre entspricht. Dafür erhielt er als Gegenleistung vom Theater anhand von Beispielen eine Unterweisung in Methoden, wie er seine Wahrnehmungen nach kognitiven Kriterien, die von der Sequenz der Erzählung bestimmt wurden, auswählen und organisieren konnte. Er lernte, ähnlich wie der Leseanfänger, eine lineare und kau-

Aristoteles, Poetik, Gr./Dt., übers. u. hg. v. Manfred Fuhrmann, Stuttgart, 1994, S. 41-43.

[Herv. N. O. E.] 
sale Ordnung in einem verinnerlichten Sehfeld anzubringen, das allerdings (für den Leser wie für den Zuschauer) von einer andauernden äußeren Simulation gestützt wurde. [...] Konsequenz dieser Modifikation des Zugangs zum kognitiven Feld war, daß sich ein neuer Typus des Sehens für die Art, wie das Subjekt die Wahrnehmung seiner Beziehungen zur Umwelt organisierte, entwickelte. ${ }^{2}$

Mit dem Interesse für die Prozessualität kulturspezifischer Phänomene und die Bedeutung performativer Praktiken hinsichtlich der Aushandlung symbolischer und sozialer Ordnungen, mentaler Dispositionen, nicht zuletzt auch ästhetischer Formen, haben mittlerweile auch die nicht-visuellen Aspekte des Theaters, insbesondere akustische Phänomene, an Aufmerksamkeit gewonnen - und dies gleichermaßen unter medientechnischen, kommunikationstheoretischen, kognitionstheoretischen, aisthetischen und ethischen Fragestellungen. ${ }^{3}$ Ausführlich beforscht worden ist insbesondere dabei die Stimme, die als performatives Phänomen schlechthin gilt, wofür Doris Kolesch und Sybille Krämer im Wesentlichen fünf Aspekte verantwortlich gemacht haben: ihre Ereignishaftigkeit, ihren Aufführungs- und Verkörperungscharakter, ihr Subversions- und Transgressionspotenzial sowie ihre Intersubjektivität. ${ }^{4}$ Dabei ist keineswegs ausgemacht, welche - phänomenologisch betrachtet - Bewandtnis es mit der Stimme nicht zuletzt im Verhältnis zum Raum auf sich hat. Ist sie als eher atopisches Phänomen begreifbar, dessen Qualität in der Unentschiedenheit besteht, oder mehr ein Hybrid, das durch die Vermischung der Register (,Sinn und Sinnlichkeit, Soma und Sema, Index und Symbol“5) charakterisiert ist? Und in welchem Verhältnis genau stehen produktive (die klanglich oder stimmlich erzeugte Herstellung/Bereitstellung von Wahrnehmungsräumen) und rezeptive (Stimme als Erfahrung der Anwesenheit von Gegenständen, Räumen, Menschen im Raum) Anteile bei der Bestimmung des Phä-

2 Derrick de Kerckhove, Schriftgeburten. Vom Alphabet zum Computer, aus dem Frz. v. Martina Leeker, München, 1995, S. 83.

3 Zur Aufmerksamkeit, die akustische Phänomene und insbesondere die Stimme in den zurückliegenden Jahren in der Forschung gefunden haben, vgl. Karl-Heinz Göttert, Geschichte der Stimme, München, 1998; Reinhart Meyer-Kalkus, Stimme und Sprechkünste im 20. Jahrhundert, Berlin, 2001; Friedrich Kittler/Thomas Macho/Sigrid Weigel (Hg.), Zwischen Rauschen und Offenbarung. Zur Kultur- und Mediengeschichte der Stimme, Berlin, 2002; Cornelia EppingJäger/Erika Linz (Hg.), Medien/Stimmen, Köln, 2003; Brigitte Felderer (Hg.), Phonorama. Eine Kulturgeschichte der Stimme als Medium, Berlin, 2004; Doris Kolesch/Jenny Schrödl (Hg.), Kunst-Stimmen, Berlin, 2004; Doris Kolesch/Sybille Krämer (Hg.), Stimme. Annäherung an ein Phänomen, Frankfurt/M., 2006; Doris Kolesch/Vito Pinto/Jenny Schrödl (Hg.), Stimm-Welten. Philosophische, medientheoretische und ästhetische Perspektiven, Bielefeld, 2009; Bernhard Waldenfels, Sinne und Künste im Wechselspiel. Modi ästhetischer Erfahrung, Berlin, 2010; Vito Pinto, Stimmen auf der Spur. Zur technischen Realisierung der Stimme in Theater, Hörspiel und Film, Bielefeld, 2012.

4 Vgl. Doris Kolesch/Sybille Krämer, „Stimmen im Konzert der Disziplinen. Zur Einführung in diesen Band“, in: dies. (Hg.), Stimme. Annäherung an ein Phänomen, Frankfurt/M., 2006, S. 715: 11 .

5 Vgl. Sybille Krämer, „Die ,Rehabilitierung der Stimme‘. Über die Oralität hinaus“, in: Doris Kolesch/Sybille Krämer (Hg.), Stimme. Annäherung an ein Phänomen, Frankfurt/M., 2006, S. 269-295: 289-291. 
nomens ,Stimme‘? Diese in der Forschung diskutierten Fragen bilden die Hintergrundfolie für die folgenden Überlegungen zur raumpoietischen Bedeutung von Klanglichkeit und Stimmlichkeit im Theater. Abschließend beantwortet werden können sie nicht.

\section{Räume hören}

Als performative Phänomene treten Stimme und Klang ereignishaft in die Erscheinung, als „etwas, das geschieht“6. Hören als der Lautgebung komplementäres Phänomen wiederum ist seinerseits als Einbruch eines Anderen in den subjektiven Erfahrungsraum instantan, unmittelbar und dem Augenblick geschuldet. „Unser Hören beginnt damit“, so hat Bernhard Waldenfels diesen Wahrnehmungsvorgang beschrieben, „daß sich etwas zu Gehör bringt, sich einschleicht, uns anrührt, aufschreckt, verführt, stört und im äußersten Fall einen Hörschock oder einen Hörsturz herbeiführt. “7 Beides verweist auf die zeitliche Dimension von Klang/Stimme und seiner/ihrer Wahrnehmung. So wie die Stimme im Hier in die Präsenz tritt, so findet das Hören als sinnliche Perzeption statt im Jetzt, d. h. in der Gegenwart des Wahrnehmungsgeschehens. ${ }^{8}$

Der zeitlichen Dimension von Klang und Stimme wiederum entspricht eine räumliche. Klang und Stimme überschreiten die eng gesetzte Grenze ihres Ausgangs- und Ursprungsortes und breiten sich als Schall bis zu den Grenzen der Hörbarkeit im Raum aus, während das Hören den Wahrnehmenden innerhalb dieses Klangraums verortet. Die Lautgebung schafft mithin einen verklingenden, an den Rändern zudem ausfransenden Wahrnehmungs- oder HörRaum, dessen ontologischer Status letztlich allerdings unbestimmt bleibt, da seine Zuschreibung zu den „Objekten oder Umgebungen“, von denen Klang und Stimme jeweils ausgehen, oder eben den Subjekten, „die sie erfahren“, unsicher ist. ${ }^{9}$ Der Hör-Raum ist m. a. W. relationaler Raum; er entsteht performativ zwischen Objekt(en) und Subjekt(en) in der Aufhebung unterscheidender Grenzziehungen zwischen Innen und Außen, Wahrnehmendem und Wahrgenommenem.

Von dieser Seite ihrer Wirkung her sind Stimmlichkeit und Lautlichkeit durchaus geeint. Im Gegensatz zu Lautlichkeit allerdings ist Stimmlichkeit an

Waldenfels (2010), Sinne und Künste im Wechselspiel, S. 189.

Ebd., S. 164.

8 Vgl. dazu Vito Pinto, „Mediale Sphären. Zur Einführung in das Kapitel [Mediale Sphären. Phonografie - Hörspiel - Medienkunst]“, in: Doris Kolesch/Vito Pinto/Jenny Schrödl (Hg.), Stimm-Welten. Philosophische, medientheoretische und ästhetische Perspektiven, Bielefeld, 2009, S. 87-98: 87.

9 Ich greife hier auf Überlegungen Gernot Böhmes zur Atmosphäre zurück. Vgl. Gernot Böhme, „Atmosphäre als Grundbegriff einer neuen Ästhetik“, in: ders., Atmosphäre. Essays zur neuen Ästhetik, 7. Aufl., Berlin, 2013, S. 21-48: 22. 
den Körper gebunden, geht aus ihm hervor, berührt einen anderen Körper, dringt in ihn ein. In der Verlautbarung verlängert sich der räumlich situierte Stimm-Körper in den Raum; als Entäußerung des Körpers ist Stimme aber nicht nur gegenwärtig, sie hat auch ein taktiles Moment in der Eröffnung eines leibhaftigen (körperlichen) Kontaktes. ${ }^{10}$ Umgekehrt ist das Hören kein einfacher Vorgang des Empfangens, sondern etwas, in das der Körper des Aufnehmenden einbezogen ist, was Gernot Böhme vom Hören als „leibliche[r] Anwesenheit im Raum“11 hat sprechen lassen, die der Stimme als der Artikulation einer leiblicher Anwesenheit korrespondiere. ${ }^{12}$ In dieser Körperlichkeit begründet liegt das, was Dieter Mersch die Ethizität der Stimme genannt hat. ${ }^{13}$ Sie „eröffnet den Moment des Sagens“, was als solches einen performativen Akt bezeichnet, dessen Zeitlichkeit „im Augenblick“ beruht. ${ }^{14}$ Vor allem aber wird in diesem performativen Akt „der Bogen [gespannt] zwischen der Leiblichkeit des Sprechenden und der Beziehung zum Anderen“ “. ${ }^{15}$

John Cage hat diese Leiblichkeit auditiver Wahrnehmungsvorgänge in seinem 1952 in New York uraufgeführten „Silent Piece“ 4“33“ - ein gern zitiertes, in der Tat aber auch überaus treffendes Beispiel akustischer Raumgenerierung - erfahrbar gemacht, indem er beim Gegenüber des Lauts und seiner Wahrnehmung, der Stille als der Voraussetzung des Hörens (das Nichthörbare/die Stille umgrenzt das Hörbare) angesetzt hat. Cage hatte mit diesem ,Stück' bekanntlich kein musikalisches Werk im traditionellen Verständnis zur Aufführung gebracht, vielmehr einen Hörraum in Szene gesetzt, an dem der auftretende Pianist David Tudor lediglich mit den Geräuschen, die er beim Betreten der Bühne und beim dreimaligen Öffnen und Schließen des Klavierdeckels machte, beteiligt war. Das Publikum hörte nicht Musik im Sinne tonaler Fügungen, sondern den Raum einer gemeinsamen Anwesenheit, der als solcher nicht das Produkt einer geplanten Herbeiführung war, sondern vielmehr als emergentes Ergebnis eines ungeplanten, d. h. nicht gerichteten Prozesses in die Erscheinung trat: als Aistheton (Wahrnehmbares), an dem die Geräusche des ausführenden Künstlers, des Publikums und der Außenwelt gleichermaßen Anteil hatten.

${ }^{10}$ Vgl. zu dieser Taktilität Dieter Mersch, „Präsenz und Ethizität der Stimme“, in: Doris Kolesch/ Sybille Krämer (Hg.), Stimme. Annäherung an ein Phänomen, Frankfurt/M., 2006, S. 211236: 211 f. Siehe auch Erika Fischer-Lichte, Ästhetik des Performativen, Frankfurt/M., 2004, S. $226 \mathrm{f}$.

11 Gernot Böhme, „Die Stimme im leiblichen Raum“, in: Doris Kolesch/Vito Pinto/Jenny Schrödl (Hg.), Stimm-Welten. Philosophische, medientheoretische und ästhetische Perspektiven, Bielefeld, 2009, S. 23-32: 24.

12 Diese Spur des Körpers bleibt auch in der technisch reproduzierten Stimme erhalten, wie Vito Pinto mit seiner Kritik an der Vorstellung der Körperlosigkeit der Stimmen in der radiophonen Kunst deutlich gemacht hat. Pinto (2012), Stimmen auf der Spur, S. 163.

13 Mersch (2006), Präsenz und Ethizität der Stimme.

14 Ebd., S. 211.

15 Ebd., S. 213. 
Das Beispiel von Cages seinerzeit das Publikum skandalisierender Inszenierung macht über das Gesagte hinaus ein Weiteres deutlich: die Notwendigkeit der Unterscheidung zwischen Stimme als akustischem Phänomen und Stimme als Medium von Mitteilung. Angesprochen ist damit das schwierige Verhältnis zwischen Stimme (im Sinne des Vollzugs des Sprechens) und Sprache (hier im Sinne ihres lexikalischen Bestandes), die Derrida in seiner Grammatologie mit der Konzeptualisierung der Verlautbarung als Explikation von Zeichen und Stimme als Übertragungsmedium noch recht umstandslos zusammengedacht hatte. Unter anderem hatte Derrida hier von einem „Logozentrismus“ gesprochen, „der zugleich ein Phonozentrismus“ sei: „absolute Nähe der Stimme zum Sein, der Stimme zum Sinn des Seins, der Stimme zur Idealität des Sinns“. ${ }^{16} \mathrm{Zu}$ Recht hat Dieter Mersch den Automatismus solcher Zuordnungen von phóné und logós als unzureichende Verkürzung kritisiert. Sie erfasse lediglich einen Aspekt des Stimmlichen, nämlich denjenigen, „der die Bewegung eines ,Zu-jemandem-Sprechens‘, und sei es ein ,Zu-mir-selbst-Sprechen', in jedem Fall aber ein Sprechen, ein Sagen impliziert“"17, während sie die Nichtzeichenhaftigkeit der Stimme, kurz: ihre Fähigkeit, Intensität jenseits des Gesagten in die Erscheinung treten zu lassen, nicht hinreichend in die Überlegung einschließt. Stimme aber kann sowohl sprachliche Gestalt als auch Materialcharakter haben, Klangmaterial sein. Insbesondere die Performance- und Installationskünste haben immer wieder so die Stimme aus dem Korsett der Semantik befreit und die raumkonstituierende Bedeutung von Tonmaterial erprobt. ${ }^{18}$ Umgekehrt haben Komponisten wie Heiner Goebbels - um hier nur ein Beispiel zu nennen - Texte in ihrem Materialcharakter bei der Herstellung akustischer Collagen zu nutzen gewusst, sie fragmentiert, (re-)kombiniert und in neue mediale Erfahrenskontexte gestellt. ${ }^{19}$

\section{Bühne: architektonischer Raum - Raum der Anwesenheit}

Theater als durch Architektur umschlossener Raum definiert den Ort des Spielens, das eine von der Realität geschiedene „Welt der Andersheit“20, einen Raum (und eine Zeit) zweiter Ordnung in den Rahmen des architektonischen Raums hineinstellt und sich solcherart als eine Differenzoperation bestimmen lässt. ${ }^{21}$ Wie jede Raumwahrnehmung als solche „eine konstitutive Leistung“

16 Jacques Derrida, Grammatologie, übers. v. Hans-Jörg Rheinberger und Hanns Zischler, Frankfurt/M., 1983, S. 25.

17 Mersch (2006), Präsenz und Ethizität der Stimme, S. 218.

18 Vgl. dazu die Beiträge und Diskussionsrunden in Christoph Metzger (Hg.), Musik und Architektur, Saarbrücken, 2003.

19 Vgl. Anna Souksengphet-Dachlauer, Text als Klangmaterial. Heiner Müllers Texte in Heiner Goebbels’ Hörstücken, Bielefeld, 2010.

20 Waldenfels (2010), Sinne und Künste im Wechselspiel, S. 245.

21 Zur raumbildenden Bedeutung der Stimme vgl. weiterführend Jenny Schrödl, „Stimm(t)räume. Zu Audioinstallationen von Laurie Anderson und Janet Cardiff“", in: Doris Kolesch/Jenny 
ist, die sich - ich folge hier der Komponistin und Musiktheoretikerin Isabel Mundry - „zu einem gegebenen Ort“ verhält und gebunden ist „an einen Blickwinkel und einen Moment in seiner besonderen Beschaffenheit, also an die Leiblichkeit dessen, der sich zu einem Raum so oder so verhält‘‘22, so rechnet die Differenzoperation des Spiels (der Stimme, der Bewegung von Spielern/Sängern/Tänzern) auf der Bühne mit dem Raumkörper, in dem es/sie in die Erscheinung tritt. Im Unterschied zum architektonischen Raum des Theaters, im Unterschied aber auch zum gestalteten (möblierten) Spielplatz ,Bühne', die jeweils einen objektiven Charakter haben, hat diese raumzeitliche Anordnung des Spiels keine überzeitliche Identität, sondern erweist sich als epiphane und als solche zugleich ephemere Entität. Sie gewinnt Evidenz im Zusammenhang von Zeigen/Sehen und Klang (Stimme)/Hören.

Dieser (Zeit-)Raum des Spiel(en)s ist einerseits das Ergebnis einer inszenatorischen Anstrengung bzw. intentionalen Handlung, andererseits eines atmosphärischen Geschehens, an dessen Konstituierung Stimme und Klang einen nicht unmaßgeblichen Anteil haben, was nicht heißt, dass der architektonische Raum wie ein leerer Container einfach mit Stimmen/Klängen gefüllt würde, sondern vielmehr, dass Sprechen/Stimme bzw. Klang/Ton die epiphane und ephemere Raum-Entität ,Theater` als Erfahrungsraum durch ihre Anwesenheit erst herstellen. In diesem Sinne kann Waldenfels dann davon sprechen, dass sich der Laut der Stimme „seinen Zeit-Raum“ schaffe. ${ }^{23}$ Klänge (Stimme und Ton) schaffen Räume, d.h.: Wir hören Räume „und nicht bloß etwas im Raum“. ${ }^{24}$ Stimm- und Klangwelten umgeben uns, sie ,hüllen uns ein', lassen den Wahrnehmenden regelrecht „inmitten des Hörfeldes“ schweben ${ }^{25}$, das sich in ganz eigentümlicher Weise als ein atmosphärischer Zwischenraum - ich schließe hier an Gernot Böhmes ästhetisches Atmosphären-Konzept an - einstellt, der sich öffnet, wenn die Stimme erklingt, und der einer ist, in dem alles möglich ist (aber nicht alles, was möglich ist, auch geschehen muss): Der Bühnenraum ist ein anderer in dem Moment, in dem die Stimme erklingt; in dem Moment verwandelt er sich vom Schau-Raum (theatron) in einen HörRaum. Stimme, so Böhme, ist „die atmosphärische Präsenz von etwas oder jemandem. Sie ist eine der Dimensionen, in denen etwas oder jemand aus sich

Schrödl (Hg.), Kunst-Stimmen, Berlin, 2004, S. 143-161; Doris Kolesch, „Labyrinthe: Resonanzräume der Stimme“, in: Christa Brüstle/Albrecht Riethmüller (Hg.), Klang und Bewegung. Beiträge zu einer Grundkonstellation, Aachen, 2004, S. 117-125.

22 Isabel Mundry, „Choreographie des musikalischen Raumes“, in: Christoph Metzger (Hg.), Musik und Architektur, Saarbrücken, 2003, S. 62-67: 62.

23 Waldenfels (2010), Sinne und Künste im Wechselspiel, S. 192.

24 Ebd., S. 168.

25 Doris Kolesch, „Zwischenzonen. Zur Einführung in das Kapitel [Zwischenzonen. Leiblichkeit - Räumlichkeit - Aisthesis]“, in: dies./Vito Pinto/Jenny Schrödl (Hg.), Stimm-Welten. Philosophische, medientheoretische und ästhetische Perspektiven, Bielefeld, 2009, S. 1322: 19. 
heraus tritt und die Atmosphäre in der Umgebung wesentlich emotional tönt."26

Der entscheidende Punkt an diesem Gedanken ist nicht die Individualität stimmlich-verbaler Äußerungsformen und der durch sie bestimmten Atmosphäre(n), sondern vielmehr dass diese Atmosphäre(n) in der Wechselseitigkeit zwischen Wahrnehmendem und Wahrgenommenem entstehen:

Die Atmosphäre ist die gemeinsame Wirklichkeit des Wahrnehmenden und des Wahrgenommenen. Sie ist die Wirklichkeit des Wahrgenommenen als Sphäre seiner Anwesenheit und die Wirklichkeit des Wahrnehmenden, insofern er, die Atmosphäre spürend, in bestimmter Weise leiblich anwesend ist. ${ }^{27}$

„Jetzt“ hat der Dramatiker, Erzähler, Filmemacher und Regisseur Werner Fritsch diesen atmosphärischen Raum, den Schauspieler/Sänger/Tänzer und Zuschauer sich teilen, genannt. Dessen Bedeutung wiederum ergibt sich für ihn gerade daraus, dass er nicht allein die raumzeitliche Anordnung der gespielten Wirklichkeit repräsentiert, sondern ein Raum der Begegnung und Kommunikation ist, der aus den Präsenzeffekten der gleichermaßen leibhaftig im Raum anwesenden Schauspieler und Zuschauer heraus ,emergiert ‘ - eine Vorstellung, die in der Idee gründet, dass Sprechen und Hören als korrespondierende Ereignisse Gegenwärtigkeit im Sinne von Präsenz/Anwesenheit induzieren. $^{28}$

In der Bestimmung des Hörraums als Sonosphäre, wie sie in der Hörspieltheorie diskutiert wird, kommen diese Aspekte zusammen. Der Begriff der Sonosphäre zielt auf den durch akustische Phänomene bestimmten Teil atmosphärischer Wahrnehmung. Als Sonosphäre lässt sich mit Pinto so allgemein ein durch Klänge und Stimmen generierter Wahrnehmungsraum bezeichnen, der ,-- wie eine bewegliche Hülle (in etwa in der Form einer Blase oder akustischen Glocke) - das Schallereignis und dessen Rezipienten umgibt. “29 Sie ist im Theater ein Raum, der performativ durch Verlautbarung/Sprechen und Hören unter Überwindung der räumlichen Trennung von Sprecher und Zuhörer entsteht (bei der Rezeption radiophoner Kunst ist sie aufgrund der zeitlichen Differenz zwischen Produktion und Rezeption ein Zwischen- und Vermittlungsraum zwischen dem Raum des radiophonen Kunststücks und dem Raum der Rezeption). ${ }^{30}$

In beispielgebender Weise hat Beckett diese raumbildende Wirkung der Stimme in seinen späten Theaterexperimenten (Not I, Krapp's Last Tape, Rockaby, Solo, Eh Joe!, Ohio Impromptu) erprobt und die Stimme - Helga Finter hat dies eingehend dargestellt - als poietisches Medium erkundet: als

\footnotetext{
Böhme (2009), Die Stimme im leiblichen Raum, S. 30.

27 Böhme (2013), Atmosphäre als Grundbegriff einer neuen Ästhetik, S. 34.

28 Zur Induzierung von Gegenwärtigkeit als einer aus der Materialität der Stimme entspringenden Erfahrung vgl. Mersch (2006), Präsenz und Ethizität der Stimme, S. 212.

29 Pinto (2009), Mediale Sphären, S. 87.

30 Vgl. Pinto (2012), Stimmen auf der Spur, S. 190 f.
} 
Phänomen, „das letztlich das Theater und die Theatralität generiert, das heißt die Person, den Raum, die Zeit und die Handlung.“" ${ }^{\text {"31 }}$ In ihrer Konsequenz letztlich unübertroffen, haben Becketts Erkundungen an den Grenzen der Gattung und über diese hinaus gerade im deutschen Theater eine produktive Aufnahme gefunden. Dass etwa Peter Stein in seiner legendären Orestie-Inszenierung (Schaubühne Berlin, 1980) zu Beginn menschliche Stimmen aus dem Dunkel erklingen lässt, mag solcherart als Beckett-Reminiszenz verstanden werden. Das Erklingen der Stimme(n) markiert nicht nur den Beginn der Aufführung, es öffnet auch, noch bevor das Spiel sichtbar in die Erscheinung tritt, den (einen) imaginären Raum - und dies unabhängig davon, dass diese das Anfangen markierenden Stimmen zunächst keine sprachlichen Laute hörbar werden lassen: noch bevor das Theater zum Schau-Raum wird, ist es bereits atmosphärischer Hör-Raum: Sonosphäre.

Heiner Müller wiederum - ein zweites Beispiel - hat etwa zeitgleich, von anderer Seite her kommend, den Faden von Becketts Versuchen aufgenommen, „allein durch das Sprechen des Textes den Bühnenort in einen theatralen Raum“ zu verwandeln, „den jeder Zuschauer für sich mental zu konkretisie-

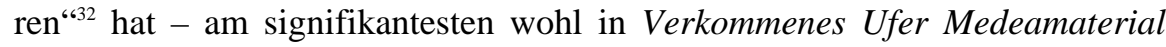
Landschaft mit Argonauten (UA 1983, Bochum) und Bildbeschreibung (UA 1985, Graz), zwei Stücken, die jeweils für sich die Bedeutung des Sprechens als raumpoietisches Element des Theaters in selbstreflexiver Weise zum Gegenstand des Spiels machen. Während Bildbeschreibung so einen Bildraum ,stimmt' (Ausgangspunkt und Ort der Stimme des Textes sind nicht markiert, die Artikulation der Stimme ist dramaturgisch entfunktionalisiert, d. h. sie dient nicht der Verkörperung einer Figur), den es im Akt des Sprechens erst evoziert, ist Verkommenes Ufer Medeamaterial Landschaft mit Argonauten gleich als mehrteilige Anordnung von Echoräumen angelegt. In ihnen füllen jeweils Einzelstimmen den Raum der Stille, erklingen und finden im folgenden Teilstück gleichsam ein Echo in geringerer Tonstärke, wobei die sukzessive Reduzierung der Abschnittstitel (,Verkommenes Ufer Medeamaterial Landschaft mit Argonauten“ - „Medeamaterial Landschaft mit Argonauten“ „Landschaft mit Argonauten“) das allmähliche Verklingen der Stimmen (und damit auch das Schwinden des gestimmten Raums) selbst thematisiert. Wird zu Beginn noch ein Ganzes hörbar, ein vielstimmiger Raum, dem der Text an seinem Ende mit der Bildevokation einer Pietá-Szene eine Grenze setzt („Auf dem Grund aber Medea den zerstückten / Bruder im Arm Die Kennerin / Der

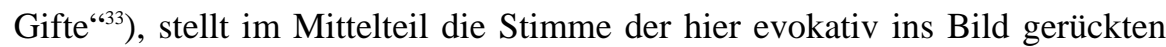
Medea ihre Geschichte buchstäblich wieder still (,Jetzt ist alles still / Die

31 Helga Finter, „Unmögliche Räume. Die Stimme als Objekt in Becketts (spätem) Theater“, in: Franziska Sick (Hg.), Raum und Objekt im Werk von Samuel Beckett, Bielefeld, 2011, S. 5565: 56.

32 Ebd.

33 Heiner Müller, „Verkommenes Ufer Medeamaterial Landschaft mit Argonauten“, in: Werke 5: Die Stücke 3, hg. v. Frank Hörnigk, Frankfurt/M., 2002, S. 71-83: 74. 
Schreie von Kolchis auch verstummt Und nichts mehr'(34), die sie zuvor in einem distanzierten Modus der Selbstpräsentation in Anwesenheit eines Publikums, ihrer Amme, vor Zeugen gleichsam damit, regelrecht vorgestellt (imaginiert) und gerade nicht gespielt hat (was wie ein Rückgriff auf die eingangs zitierte Überlegung Aristoteles' zur Wirkung auditiver Wahrnehmung anmutet). Im dritten Teil des Stückes schließlich erreicht die Absenkung der Echoschwelle in der buchstäblichen Entkörperlichung, dem Ausbluten ${ }^{35}$, einer das Wort zur Selbstexplikation (,Soll ich von mir reden Ich wer / Von wem ist die Rede wenn / Von mir die Rede geht ${ }^{* 36}$ ) ergreifenden Stimme, möglicherweise diejenige Jasons, möglicherweise diejenige einer Autor-Persona, den finalen Schlusspunkt wieder einsetzender Stille. Die (Spiel-)Räume werden solcherart schrittweise enger und vor dem Verstummen der Stimme bleibt allein noch die Frage „Wer hat bessre Zähne / Das Blut oder der Stein““ ${ }^{37}$

Ich möchte das Gesagte zur raumpoietischen Dimension von Klang und Stimme im Folgenden am Beispiel der Theatertheorie des eingangs bereits schon einmal erwähnten Autors und Regisseurs Werner Fritsch abschließend noch etwas zu konkretisieren versuchen, zumal die Vorstellungskonzepte von atmosphärischer Präsenz/Gegenwärtigkeit und Körperlichkeit/Anwesenheit gerade bei diesem Autor eine grundlegende Rolle spielen. Ich setze dabei an bei den ersten Versen des Prologs von Fritschs 2004 in Bielefeld uraufgeführtem Stück Heilig Heilig Heilig. Das Theater des Jetzt, das Überlegungen des Autors zum Theater, zur Kunst und Ästhetik unmittelbar in den Theatertext hineinträgt. $^{38}$

\section{Performative Raum- und Zeitpraxis bei Werner Fritsch}

\section{$\mathrm{ICH}$}

HEILIG HEILIG HEILIG Allen

Ist ein Theater gegen alles

Theater Allen

Es macht den Raum hier

Zu einer Oase der Stille

Die Zuschauer sitzen im Aug

34 Ebd., S. 80.

35 Vgl. zu dieser Metaphorik die schließende Todesvision des Textes: „Und Schüsse knallten in meine torkelnde Flucht / Ich spürte MEIN Blut aus MEINEN Adern treten / Und MEINEN Leib verwandeln in die Landschaft / MEINES Todes“ (ebd., S. 83).

36 Ebd., S. 80.

37 Ebd., S. 83.

38 Ich greife hier Überlegungen auf, die ich ausführlich entfaltet habe in meinem Aufsatz „Werner Fritsch: ,Theater gegen alles Theater'“, in: Alo Allkemper/Norbert Otto Eke/Hartmut Steinecke (Hg.), Poetologisch-poetische Interventionen: Gegenwartsliteratur schreiben, München, 2012, S. 371-387. 
Des Tornados Tod

Der rings um uns tobt ${ }^{39}$

Bereits diese eröffnenden Verse aus dem im Echoraum von Allen Ginsbergs Poem Howl (1955) geschriebenen Stück Heilig Heilig Heilig enthalten im Kern die theater- und medienästhetischen Grundvorstellungen, die Werner Fritsch in den zurückliegenden Jahren in programmatischen Manifesten wie Jenseits dieses Jahrtausends (1999), Hieroglyphen des Jetzt (2000), Natalität versus Fatalität (2005) und zuletzt in den Paderborner und Frankfurter Poetikvorlesungen Mnemosyne: Mutter Sprache (2007/08) und Die Alchemie der Utopie (2008/09) zum Programm einer Theorie ästhetischer Präsenz ausgearbeitet hat. ${ }^{40}$ Heilig Heilig Heilig ist angelegt als Selbstexplikation des AutorIchs in der imaginierten Anwesenheit eines Adressaten, des Dichters „Allen“ (Ginsberg), der wie alle anderen im Stück in Erscheinung tretenden Stimmen (einschließlich der im Personenverzeichnis als „Ich“ ausgewiesenen) ,persona' im Sinne der Ursprungsbedeutung des Begriffs im antiken Theater ist: Maske, durch die Sprache/das Gesprochene als Stimme ,hindurchtönt‘. Die in den Untertitel des Stückes gesetzte Metapher vom „Theater des Jetzt“, mit welcher der Prolog programmatisch überschrieben ist, hat im Rahmen dieser Selbstentäußerung der tönenden Autor-Stimme neben ihrer ästhetischen (Theater als Kunstraum) und medientheoretischen (Theater als Raum medialer Kreuzungen) vor allem eine erkenntnistheoretische (Theater als Ort perzeptorischer Erfahrung, als Wahrnehmungs- und Schauraum) und kommunikationstheoretische (Theater als Kommunikationsraum) Dimension, die am fluiden, ephemeren Charakter des Spiels als uneinholbarem Ereignis ansetzt und - wie alle Aussagen zu Zeit und Raum - Theorie und Praxis der Wahrnehmung betrifft. ,Theater ' wird angesprochen mit den zitierten Versen des Prologs so auch nicht als empirische Entität, sondern in der Fluchtlinie von Überlegungen Kants zur Konstituierung des Raums als eine Erkenntnis und Wahrnehmung ermöglichende Größe (Kant selbst spricht in der Kritik der reinen Vernunft vom Raum in dieser Hinsicht als „Bedingung der Möglichkeit aller Erfahrung ${ }^{\text {“41 }}$ ). Fritsch entwirft Theater so performativ, als den „Raum hier“; dieser „Andersraum“ im Sinne Waldenfels’ entsteht aus dem Gesagten, aus Sprache, entlang einer Grenzziehung gegenüber dem gesellschaftlich Alltäglichen, das als der „rings um uns“ tobende „Tornado Tod“ firmiert: als ,gestimmter“ Raum reiner Gegenwärtigkeit („Jetzt“). Der raumpoietischen Dimension des

39 Werner Fritsch, Heilig Heilig Heilig. Das Theater des Jetzt, Suhrkamp Theatertext (Bühnenmanuskript), Frankfurt/M., 2004, S. 2.

40 Die Paderborner Vorlesungen hat Fritsch nicht veröffentlicht; wesentliche Teile dieser Vorlesungen aber fanden Eingang in die Frankfurter Vorlesungen, die 2009 unter dem Titel Die Alchemie der Utopie. Frankfurter Poetikvorlesungen 2009 im Suhrkamp Verlag (Frankfurt/M.) erschienen sind.

41 Immanuel Kant, „Kritik der reinen Vernunft, zweite Auflage 1787“, in: ders., Gesammelte Schriften, hg. v. der Preußischen Akademie der Wissenschaften, Bd. III, Erste Abtheilung: Werke. Dritter Band, Berlin, 1911, S. 56. 
Spiels tritt in Fritschs Überlegungen damit zugleich ein zeitpoietisches Moment an die Seite. Das „Theater des Jetzt“ ist mit anderen Worten performative Raumpraxis in zeitlicher Perspektive, ist Gegen-Raum und Gegen-Zeit, die sich gleichermaßen aus den Präsenzeffekten von Spielenden (Schauspielern) und Zuschauenden/Zuhörenden (Publikum), d. h. aus den zwischen ihnen stattfindenden Kommunikationen konstituieren. An einer Stelle seiner Poetikvorlesungen spricht Fritsch entsprechend vom „lebendigen Augenblick[]“ eines „magische[n] Jetzt“, das „Gegenwart stiftet und Zukunft zeugt.“42 Hier ansetzend hat Fritsch Theater wiederholt als eine Kunstform beschrieben, die ihre Bestimmung in der Vereinigung von allen am Theater Beteiligten „im Namen einer künstlerischen Vision“*43 findet - womit er sich gleichermaßen gegen die Praktiken der Entortung und Entzeitlichung von Kunst durch Techniken der Reproduzierung und Multiplizierung wendet wie gegen ihre ,Naturalisierung ' durch ein Übermaß an Repräsentationen, die Evidenz und Authentizität beanspruchen. Theater, so Fritsch in der im Dezember 2000 in der Zeitschrift Theater der Zeit veröffentlichten Programmschrift Hieroglyphen des Jetzt, ,ist, seit der Gottesdienst an Bedeutung verloren hat und an Wahrhaftigkeit, in unserer Gesellschaft der letzte Ort für Metaphysik - durch das Fleisch und Blut der Menschen und die Materialität der Requisiten beglaubigt““. ${ }^{44}$

Zwar entwirft Fritsch seinen Begriff vom Theater hier im Rückgriff auf Vorstellungsbilder aus dem Bereich der symbolischen Form Religion. Die dahinter stehende Leitidee allerdings ist weniger eine sakrale als vielmehr eine kunstphilosophische: die Verwandlung der Bühne von einem Medium der Repräsentation (von Wirklichkeit) zu einem der Produktion (von Präsenz). Energisch hat Fritsch das Theater von hier aus als eine Kunst ernst zu nehmen gefordert, die Wirklichkeit nicht verdoppelt, sondern Möglichkeiten zur Erfahrung für Anderes jenseits des Gewohnten schafft. Bereits in der Vorbemerkung zu seinem 1998 am Staatstheater Darmstadt uraufgeführten Traumspiel Wondreber Totentanz hat er im Rückgriff auf antike Tragödienkonzepte in dieser Hinsicht Vorstellungen zur Öffnung von Erfahrungsräumen durch die Stimulation anderen Sehens und Hörens (oder einfach des Anderssehens und Andershörens) ausgesprochen. „Das Geschehen“, heißt es hier, „findet - wie in der antiken Tragödie - zumeist in der Sprache, also im Kopf des Zuschauers, statt. Denn ich glaube, daß im Zeitalter des Alleszeigens in Film und Fernsehen, dies dem Theater gut ansteht. “45 In seinen Frankfurter Poetikvorle-

${ }^{42}$ Fritsch (2009), Die Alchemie der Utopie, S. 67.

43 Jörg Lukas Matthaei, ,,,Das Theater ist der letzte Ort für Metaphysik‘. Gespräch mit Werner Fritsch über sein Schreiben fürs Theater und die beiden Lustspiele ,Die lustigen Weiber von Wiesau' und ,Es gibt keine Sünde im Süden des Herzens'“, in: Werner Fritsch, Die Lustigen Weiber von Wiesau. Stück und Materialien, Frankfurt/M., 2000, S. 166-182: 173.

44 Werner Fritsch, „Hieroglyphen des Jetzt -Theater. Sprache. Hörspiel. Film“, in: Hans-Jürgen Drescher/Bert Scharpenberg (Hg.), Werner Fritsch. Hieroglyphen des Jetzt. Materialien und Werkstattberichte, Frankfurt/M., 2002, S. 227-235: 229.

45 Werner Fritsch, „Wondreber Totentanz. Traumspiel“, in: ders., Es gibt keine Sünde im Süden des Herzens. Stücke, Frankfurt/M., 1999, S. 139-213: 141. 
sungen hat Fritsch diesen Gedanken aufgenommen. Fritsch spricht hier vom „Kinematograph[en] Kopf““46, von der ,inneren Bühne“ der Imagination, die Theater zum kulturellen Möglichkeitsraum werden lässt. Ein Text müsse „so gut sein, daß, wenn ein guter Schauspieler den Mund aufmacht, die Bühne voll ist. Dann wird die Bühne transzendiert zu einem Ort, der sich im Bewußtsein des Zuschauers lokalisiert. “47

Die Herstellung dieses im Verständnis des Autors transzendierten Raums zweiter Ordnung bleibt in Fritschs Vorstellung - die zitierten Stellen verweisen darauf - eng an die Sprache als „Katalysator für Phantasie“ ${ }^{648}$ und ihre Verlautbarung durch die leibhaftige (siehe oben) Stimme gebunden. Angesichts einer technologischen Entwicklung, die nicht nur die Voraussetzung bietet für multimediale (Verbindung von Text, Grafik, Ton, Fest- und Bewegtbild, Animation etc.) Informationsstrukturen, sondern zugleich auch die „Wahrheit“ und „Beweiskraft“ der visuellen Speichermedien als solche wieder infrage gestellt und das Bild als kulturelles Leitmedium in die Krise getrieben hat, gewinnt die gesprochene, stimmlich verkörperte Sprache, so Fritschs Überlegung, wieder Bedeutung als Vorstellungs-Medium im buchstäblichen Sinn, das den theatralen Raum der Präsenz generiert. „Das Theater des Jetzt“, schreibt er in dem Essay Natalität versus Fatalität,

ist ein Raum, in dem nicht das Theater ein weiteres Mal stattfindet, das wir uns und anderen ohnehin vorspielen. [...] Das Theater des Jetzt besteht gerade darin, dass Wahrhaftigkeit als Phantasma im Raum ist: als Denken, das sich im Raum, der als solcher durchlässig sein muss, damit alles in der Vorstellung Gesagte auch sich in der Vorstellung der Anwesenden kristallisieren kann [!].

Aus wenigen Phonemen erstehen Welten in der Vorstellung des Zuschauers. ${ }^{49}$

Im theatralen Monolog und seiner Realisierung als radiophonem StimmenSpiel (u. a. Jenseits, Nico. Sphinx aus Eis, Enigma Emmy Göring, Bach, Magma, Faust Song of the Sun etc.) hat Fritsch in den zurückliegenden Jahren zunehmend eine Möglichkeit der praktischen Umsetzung dieser Theorie ästhetischer Präsenz sehen wollen. Fritschs vielfach, zuletzt mit dem Prix Marulić (2013 für Faust Song of the Sun), ausgezeichnete Radioarbeiten sind einerseits dramaturgisch offene „Spiel[e] mit Hörbarem“50, geben andererseits das Ziel einer Poetisierung (oder auch: Transzendierung) der Wirklichkeit nicht auf.

46 Fritsch (2009), Die Alchemie der Utopie, S. 7.

47 Ebd., S. 123. [Herv. N. O. E.]

48 Fritsch (2002), Hieroglyphen des Jetzt, S. 230.

49 Werner Fritsch, „Natalität versus Fatalität. Einige Gedanken zum THEATER DES JETZT im Kontext der Inszenierung von DAS RAD DES GLÜCKS“, in: Programmheft zur Uraufführung von „Das Rad des Glücks“ am Bayerischen Staatsschauspiel München, 12.5.2005, Programmheft Nr. 64, hg. v. Bayerischen Staatsschauspiel München, Redaktion: Werner Fritsch und Georg Holzer, München, 2005, S. 8-15: 12.

50 Ich verwende hier eine Formulierung Helmut Heißenbüttels aus der Diskussion um das Neue Hörspiel aus den 1960er Jahren („Horoskop des Hörspiels“, in: Deutsche Akademie der darstellenden Künste in Verbindung mit dem hessischen Rundfunk: Internationale Hörspieltagung vom 21. bis 27. März 1968 in Frankfurt/Main, S. 19-40: 19). 
Die Monologe sind Grenzgänge zwischen den Medien (Literatur/Drama, Film, Installation), die nicht allein der Stimme bzw. der Körperlichkeit der Stimme in besonderer Weise Geltung verschaffen, sondern der Stimmlichkeit als solcher auch aufgrund ihrer spezifischen Ortlosigkeit ein besonderes Gewicht bei der Herstellung der Gegenwärtigkeit/Präsenz (Theater des Jetzt) zusprechen. Der Monolog schafft Räume der Anwesenheit für die und durch die Stimme.

Am stringentesten hat Fritsch dies in dem sowohl theatral aufgeführten (UA 2001, Staatstheater Darmstadt) als auch radiophon (HR und SWR, 2003) realisierten Monolog Nico. Sphinx aus Eis umgesetzt, in dem eine gleichsam spektrale Stimme von der Grenze zwischen Leben und Tod her das Wort ergreift. Mit Nico. Sphinx aus Eis geht Fritsch dahin, wo die Geschichte aufhört und die Mythen beginnen; er verschmilzt dabei biografische Elemente (die Geschichte der Christa Päffgen, die als Nico die Enge ihres Elternhauses hinter sich gelassen, zunächst als Model und Schauspielerin, dann als Sängerin Karriere gemacht und sich durch ihren exzessiven Drogenkonsum selbst zerstört hat), die Revolten der rebellischen Söhne und Töchter in der Aufbruchszeit der sechziger Jahre, die Erinnerung an - deutsche - Geschichte. Es ist der Sog der ortlosen Stimme einer Sterbenden, der persona Nico, die den Zuschauer/ Zuhörer berührt und hineinzieht in einen atmosphärischen bzw. sonosphärischen Raum der Erinnerung, in dem der Mythos der orphischen Hadesfahrt als Traum einer Versöhnung von Leben und Tod durch die Macht der Kunst nachklingt. In ihm findet die Vorstellung Ausdruck, dass die Kunst die Toten zurückzuholen, ,Geschichte` damit gleichsam zu ,heilen' in der Lage ist: Nicos Gesang ist - in Umkehrung der alten Rollenverteilung - Versuch, so den toten Geliebten (die Vergangenheit) aus dem Totenreich zu befreien, ihn erinnernd zu verlebendigen und damit gegenwärtig zu machen. Der Monolog Nico ist zum anderen und darüber hinausgehend auf einer übergeordneten Ebene Probe aufs Exempel eben der poetischen Kommunion, die Fritschs Theaterästhetik zum Ziel hat. Denn die Stimme, die hier mit den Toten spricht und zugleich den Zuhörer/Zuschauer anspricht, ist letztlich selbst Kunstwerk: Bild/Ikon („Nico“ ist ein Anagramm von „Icon“, was wiederum auf das grie-

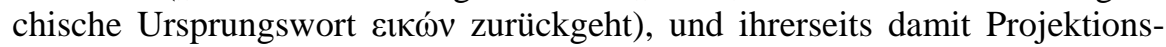
fläche für die Freiheitsoperationen des „Theaters des Jetzt“. Die durch das Sprechen/Spiel verleiblichte Stimme schafft den Raum der Anwesenheit, in dem sich Wahrnehmungsobjekt und Wahrnehmende begegnen und so die

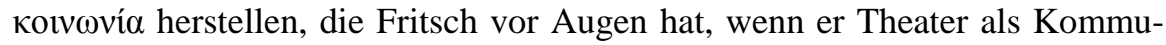
nion zu begreifen und zu realisieren verlangt. 


\section{Raum und/der Aura}

Dieser Seitenblick auf Werner Fritschs performative Raum- und Zeit-Praxis zeigt vor allem eines: die anhaltende Wirkung von Aura-Konzepten in raumpoietischen Entwürfen. ${ }^{51}$ Fritsch zumindest macht durchaus kein Hehl aus der Affinität seiner Theorie ästhetischer Präsenz zu insbesondere Benjamins AuraKonzept. So schreibt er in seinen Frankfurter Poetikvorlesungen:

Indem im Theater des Jetzt Dinge, die nicht oder so, wie sie NICHT in den Medien an- und ausgesprochen werden, an- und ausgesprochen werden, legitimiert Theater sich selber aus sich selbst heraus, neu.

Durch die Zeugenschaft und Zeitgenossenschaft, durch das Hier und Jetzt aller in einem Raum Anwesenden.

Nicht weitere Meinungen sollen im Theater des Jetzt vorgeführt werden, sondern es soll ein Raum geschaffen werden, in dem sich, nicht im Sinn der Esoterik, sondern im Sinn Benjamins, Aura einstellen darf, und der Zuschauer selbst, sofern überhaupt noch Hoffnung ist, in feinere Bereiche der Wahrnehmung vorstößt.

Nicht das Gezeigte ist das Entscheidende, sondern das, was sich im Zuschauer über das Gezeigte hinaus einzustellen vermag. ${ }^{52}$

Fritsch hat den hier eher en passant erfolgten Rückbezug auf den Aura-Begriff Walter Benjamins an späterer Stelle seiner Poetikvorlesungen ein Stück weit präzisiert. Er zitiert zunächst eine Notiz aus Benjamins selbstexperimentellen Drogen- und Rauschaufzeichnungen ${ }^{53}$ und vermerkt dann dazu:

Erweitert man Benjamins Ding zum Wesen, im Sinn von Lebewesen, hin, so entsteht die Aura für mich zum einen aus der Sprache der Figur, die eine eigene Welt, die der Figur, und stellvertretend auch die unsere, weil wir im Spiel, durch die Sprache der Figur auch die Welt der Figur erschaffen, erschafft, zum anderen entsteht Aura für mich durch den Raum, in dem die Figur sich aufhält und in dem das Wort fällt ...54.

51 Nicht von ungefähr hat auch Böhme seinen Ausführungen zur „Atmosphäre als Grundbegriff einer neuen Ästhetik“ eine längere Diskussion zur Aura eingefügt. Vgl. Böhme (2013), Atmosphäre als Grundbegriff einer neuen Ästhetik, S. 25-28.

52 Fritsch (2009), Die Alchemie der Utopie, S. 113.

53 Vgl. ebd., S. 121 f.: „Walter Benjamin skizziert die Aura mit wenigen Strichen: Erstens erscheint Aura an allen Dingen. Zweitens ändert sich Aura durchaus und von Grund auf mit jeder Bewegung, die das Ding macht, dessen Aura sie ist. Drittens kann die echte Aura auf keine Weise als der geleckte spiritualistische Strahlenzauber gedacht werden, als den die vulgären mystischen Bücher sie abbilden und beschreiben. Vielmehr ist das Auszeichnende der echten Aura: das Ornament, eine ornamentale Umzirkung, in der das Ding oder Wesen fest wie in einem Futteral eingesenkt liegt. Nichts gibt vielleicht von der echten Aura einen so richtigen Begriff wie die späten Bilder van Goghs, wo an allen Dingen - so könnte man diese Bilder beschreiben - die Aura mitgemalt ist.“ - Vgl. dazu Walter Benjamin, „Protokolle zu Drogenversuchen $<\mathrm{V}>$ : Haschisch Anfang März 1930“, in: ders., Gesammelte Schriften, unter Mitwirkung von Theodor W. Adorno und Gershom Scholem, Bd. VI, hg. v. Rolf Tiedemann und Hermann Schweppenhäuser, Frankfurt/M., 1985, S. 587-591: 588.

54 Fritsch (2009), Die Alchemie der Utopie, S. 122. 
Fritsch bestimmt „Aura“ damit hier in erster Linie als ein performatives Phänomen, das Autorität aus Einmaligkeit und Unnahbarkeit (Ferne) bezieht. Das schließt an Vorstellungen über eine den Dingen zukommende originale (echte) Aura an, wie Benjamin sie in seiner Kleine[n] Geschichte der Photographie von 1931 entfaltet; Benjamin spricht hier von der Aura als einem „sonderbaren“ „Gespinst von Raum und Zeit: einmalige Erscheinung einer Ferne, so nah sie sein mag ${ }^{\star 655}$, deren Verfall dem auf die Entwicklung neuer Reproduktionstechniken zurückzuführenden Traditionsbruch des 19. Jahrhunderts geschuldet sei.

Die Konturen dieser Referenzbildung schärfen sich von der „übergreifenden Theorie der Erfahrung ${ }^{\text {(56 }}$ her, zu der Benjamin 1939 in dem Aufsatz Über einige Motive bei Baudelaire nach Josef Fürnkäs Beobachtung die rezeptionsästhetische Wahrnehmungstheorie der Aura mit ihrer geschichtsphilosophischen und kunstpolitischen Perspektive zusammengebracht hat. Benjamin führt hier den Gedanken ein, Aura sei nichts dem Gegenstand (der Kunst, aber auch jedem anderen Objekt) Eigentümliches, sondern entstehe erst zwischen Objekt und Subjekt und ermögliche so immer neue Erfahrungen. In diesem Zusammenhang fällt die berühmte Formulierung vom „Belehnen“ einer Erscheinung mit dem Vermögen der Blicköffnung:

Dem Blick wohnt aber die Erwartung inne, von dem erwidert zu werden, dem er sich schenkt. Wo diese Erwartung erwidert wird (die ebensowohl, im Denken, an einen intentionalen Blick der Aufmerksamkeit sich heften kann wie an einen Blick im schlichten Wortsinn), da fällt ihm die Erfahrung der Aura in ihrer Fülle zu. [...] Die Erfahrung der Aura beruht also auf der Übertragung einer in der menschlichen Gesellschaft geläufigen Reaktionsform auf das Verhältnis des Unbelebten oder der Natur zum Menschen. Der Angesehene oder angesehen sich Glaubende schlägt den Blick auf. Die Aura einer Erscheinung erfahren, heißt, sie mit dem Vermögen belehnen, den Blick aufzuschlagen. ${ }^{57}$

Der Zusammenhang zwischen Benjamins dialektischem Aura-Begriff des Baudelaire-Aufsatzes als einem Erfahrung erst ermöglichenden Phänomen mit Fritschs Konzeptualisierung des Theaters als mentalem Raum perzeptionsästhetischer Erweiterungen wird auf schlagende Weise evident, liest man die zitierte Passage zusammen mit Osamu Nomuras Erläuterungen zum „paradoxen Zugleich“ von Aktivität und Passivität in Benjamins Modell. „Wenn wir imstande sein können, unbefangen und intensiv etwas anzusehen“, so Nomura,

55 Walter Benjamin, „Kleine Geschichte der Photographie“, in: ders., Gesammelte Schriften, Bd. II, 1, hg. v. Rolf Tiedemann und Hermann Schweppenhäuser, Frankfurt/M., 1977, S. 368385: 378.

56 Josef Fürnkäs, „Aura“, in: Michael Opitz/ErdmutWizisla (Hg.), Benjamins Begriffe, Bd. 1, Frankfurt/M., 2000, S. 95-146: 142.

57 Walter Benjamin, „Über einige Motive bei Baudelaire“, in: ders., Gesammelte Schriften, Bd. I, 2, hg. v. Rolf Tiedemann und Hermann Schweppenhäuser, Frankfurt/M., 1974, S. 605653: $646 \mathrm{f}$. 
schlägt das Angesehene den Blick auf. Wir werden angesehen (passiv), indem wir ansehen (aktiv). Erst in diesem paradoxen Zugleich ist es möglich, einen Gegenstand frisch und in seiner Aktualität zu erfahren. Wenn wir die Sätze so deuten dürfen, können wir sagen, daß die Erkenntnis, von der Benjamin hier spricht, dieselbe ist, in der in Schlaf, in Traum abgesunkene Sachen zur ,Jetztzeit‘ erwachen. ${ }^{58}$

Über die Stimme und das Hören und den in der leiblichen Anwesenheit von Spielenden und Publikum entstehenden Raum ist damit erst einmal nichts gesagt. Angesichts der Hysterie des Realen in unserer durch ein Übermaß an Medien-Bilder umstellten Wirklichkeit lässt sich das hier Gesagte mit gutem Grund, wie ich meine, allerdings auch auf die raumpoietische Kraft des Theaters übertragen; dann nämlich, wenn das Spiel als Differenzoperation Selbstverständlichkeiten und Evidenzen aus dem Weg schafft und sich solcherart anschickt, Räume der Anwesenheit zu öffnen.

\section{Literatur}

Aristoteles, Poetik, Gr./Dt., übers. u. hg. v. Manfred Fuhrmann, Stuttgart, 1994.

Benjamin, Walter, „Über einige Motive bei Baudelaire“, in: ders., Gesammelte Schriften, Bd. I, 2, hg. v. Rolf Tiedemann und Hermann Schweppenhäuser, Frankfurt/M., 1974, S. 605-653.

Ders., „Kleine Geschichte der Photographie“, in: ders., Gesammelte Schriften, Bd. II, 1, hg. v. Rolf Tiedemann und Hermann Schweppenhäuser, Frankfurt/M., 1977, S. 368-385.

Ders., „Protokolle zu Drogenversuchen <V>: Haschisch Anfang März 1930“, in: ders., Gesammelte Schriften, unter Mitwirkung von Theodor W. Adorno und Gershom Scholem, Bd. VI, hg. v. Rolf Tiedemann und Hermann Schweppenhäuser, Frankfurt/M., 1985, S. 587-591.

Böhme, Gernot, „Die Stimme im leiblichen Raum“, in: Doris Kolesch/Vito Pinto/Jenny Schrödl (Hg.), Stimm-Welten. Philosophische, medientheoretische und ästhetische Perspektiven, Bielefeld, 2009, S. 23-32.

Ders., „Atmosphäre als Grundbegriff einer neuen Ästhetik“, in: ders., Atmosphäre. Essays zur neuen Ästhetik, 7. Aufl., Berlin, 2013, S. 21-48.

Derrida, Jacques, Grammatologie, übers. v. Hans-Jörg Rheinberger und Hanns Zischler, Frankfurt/M., 1983.

Eke, Norbert Otto, „Werner Fritsch: ,Theater gegen alles Theater““, in: Alo Allkemper/Norbert Otto Eke/Hartmut Steinecke (Hg.), Poetologisch-poetische Interventionen: Gegenwartsliteratur schreiben, München, 2012, S. 371-387.

Epping-Jäger, Cornelia/Linz, Erika (Hg.), Medien/Stimmen, Köln, 2003.

58 Osamu Nomura, „Der Begriff der Aura bei Benjamin und bei Adorno“, in: Klaus Garber/Ludger Rehm (Hg.), global benjamin. Internationaler-Walter-Benjamin-Kongreß 1992, München, 1999, S. 391-408: 399. 
Felderer, Brigitte (Hg.), Phonorama. Eine Kulturgeschichte der Stimme als Medium, Berlin, 2004.

Finter, Helga, „Unmögliche Räume. Die Stimme als Objekt in Becketts (spätem) Theater“, in: Franziska Sick (Hg.), Raum und Objekt im Werk von Samuel Beckett, Bielefeld, 2011, S. 55-65.

Fischer-Lichte, Erika, Ästhetik des Performativen, Frankfurt/M., 2004.

Fritsch, Werner, „Wondreber Totentanz. Traumspiel“, in: ders., Es gibt keine Sünde im Süden des Herzens. Stücke, Frankfurt/M., 1999, S. 139-213.

Ders., „Hieroglyphen des Jetzt - Theater. Sprache. Hörspiel. Film“, in: Hans-Jürgen Drescher/Bert Scharpenberg (Hg.), Werner Fritsch. Hieroglyphen des Jetzt. Materialien und Werkstattberichte, Frankfurt/M., 2002, S. 227-235.

Ders., Heilig Heilig Heilig. Das Theater des Jetzt, Suhrkamp Theatertext (Bühnenmanuskript), Frankfurt/M., 2004.

Ders., Nico. Sphinx aus Eis. Monolog, Frankfurt/M., 2004.

Ders., „Natalität versus Fatalität. Einige Gedanken zum THEATER DES JETZT im Kontext der Inszenierung von DAS RAD DES GLÜCKS“, in: Programmheft zur Uraufführung von „Das Rad des Glücks“ am Bayerischen Staatsschauspiel München, 12.5.2005, Programmheft Nr. 64, hg. v. Bayerischen Staatsschauspiel München, Redaktion: Werner Fritsch und Georg Holzer, München, 2005, S. 8-15.

Ders., Die Alchemie der Utopie. Frankfurter Poetikvorlesungen 2009, Frankfurt/M., 2009.

Fürnkäs, Josef, „Aura“, in: Michael Opitz/ErdmutWizisla (Hg.), Benjamins Begriffe, Bd. 1, Frankfurt/M., 2000, S. 95-146.

Göttert, Karl-Heinz, Geschichte der Stimme, München, 1998.

Heißenbüttel, Helmut, „Horoskop des Hörspiels“, in: Deutsche Akademie der darstellenden Künste in Verbindung mit dem hessischen Rundfunk: Internationale Hörspieltagung vom 21. bis 27. März 1968 in Frankfurt/Main, S. 19-40.

Kant, Immanuel, „Kritik der reinen Vernunft, zweite Auflage 1787“, in: ders., Gesammelte Schriften, hg. v. der Preußischen Akademie der Wissenschaften, Bd. III, Erste Abtheilung: Werke. Dritter Band, Berlin, 1911, S. 56.

Kerckhove, Derrick de, Schriftgeburten. Vom Alphabet zum Computer, aus dem Frz. v. Martina Leeker, München, 1995.

Kittler, Friedrich/Macho, Thomas/Weigel, Sigrid (Hg.), Zwischen Rauschen und Offenbarung. Zur Kultur- und Mediengeschichte der Stimme, Berlin, 2002.

Kolesch, Doris, „Die Spur der Stimme. Überlegungen zu einer performativen Ästhetik“, in: Cornelia Epping-Jäger/Erika Linz (Hg.), Medien/Stimmen, Köln, 2003, S. 267-281.

Dies., „Labyrinthe: Resonanzräume der Stimme“, in: Christa Brüstle/Albrecht Riethmüller (Hg.), Klang und Bewegung. Beiträge zu einer Grundkonstellation, Aachen, 2004, S. 117-125.

Dies., „Zwischenzonen. Zur Einführung in das Kapitel [Zwischenzonen. Leiblichkeit Räumlichkeit - Aisthesis]“, in: dies./Vito Pinto/Jenny Schrödl (Hg.), Stimm-Welten. Philosophische, medientheoretische und ästhetische Perspektiven, Bielefeld, 2009, S. 13-22.

Dies./Schrödl, Jenny (Hg.), Kunst-Stimmen, Berlin, 2004.

Dies./Krämer, Sybille (Hg.), Stimme. Annäherung an ein Phänomen, Frankfurt/M., 2006.

Dies./Pinto, Vito/Schrödl, Jenny (Hg.), Stimm-Welten. Philosophische, medientheoretische und ästhetische Perspektiven, Bielefeld, 2009. 
Dies./Krämer, Sybille , „Stimmen im Konzert der Disziplinen. Zur Einführung in diesen Band“, in: dies. (Hg.), Stimme. Annäherung an ein Phänomen, Frankfurt/M., 2006, S. 7-15.

Krämer, Sybille, „Die ,Rehabilitierung der Stimme‘. Über die Oralität hinaus“, in: Doris Kolesch/Sybille Krämer (Hg.), Stimme. Annäherung an ein Phänomen, Frankfurt/M., 2006, S. 269-295.

Matthaei, Jörg Lukas, „,Das Theater ist der letzte Ort für Metaphysik‘. Gespräch mit Werner Fritsch über sein Schreiben fürs Theater und die beiden Lustspiele ,Die lustigen Weiber von Wiesau' und ,Es gibt keine Sünde im Süden des Herzens،“", in: Werner Fritsch, Die Lustigen Weiber von Wiesau. Stück und Materialien, Frankfurt/M., 2000, S. 166-182.

Mersch, Dieter, „Präsenz und Ethizität der Stimme“, in: Doris Kolesch/Sybille Krämer (Hg.), Stimme. Annäherung an ein Phänomen, Frankfurt/M., 2006, S. 211-236.

Metzger, Christoph (Hg.), Musik und Architektur, Saarbrücken, 2003.

Meyer-Kalkus, Reinhart, Stimme und Sprechkünste im 20. Jahrhundert, Berlin, 2001.

Müller, Heiner, „Bildbeschreibung“, in: Werke 2: Die Prosa, hg. v. Frank Hörnigk, Frankfurt/M., 1999, S. 112-119.

Ders., „Verkommenes Ufer Medeamaterial Landschaft mit Argonauten“, in: Werke 5: Die Stücke 3, hg. v. Frank Hörnigk, Frankfurt/M., 2002, S. 71-83.

Mundry, Isabel, „Choreographie des musikalischen Raumes“, in: Christoph Metzger (Hg.), Musik und Architektur, Saarbrücken, 2003, S. 62-67.

Nomura, Osamu, „Der Begriff der Aura bei Benjamin und bei Adorno“, in: Klaus Garber/Ludger Rehm (Hg.), global benjamin. Internationaler-Walter-Benjamin-Kongreß 1992, München, 1999, S. 391-408.

Pinto, Vito, „Mediale Sphären. Zur Einführung in das Kapitel [Mediale Sphären. Phonografie - Hörspiel - Medienkunst]“, in: Doris Kolesch/Vito Pinto/Jenny Schrödl (Hg.), Stimm-Welten. Philosophische, medientheoretische und ästhetische Perspektiven, Bielefeld, 2009, S. 87-98.

Ders., Stimmen auf der Spur. Zur technischen Realisierung der Stimme in Theater, Hörspiel und Film, Bielefeld, 2012.

Schrödl, Jenny, „Stimm(t)räume. Zu Audioinstallationen von Laurie Anderson und Janet Cardiff“, in: Doris Kolesch/Jenny Schrödl (Hg.), Kunst-Stimmen, Berlin, 2004, S. 143-161.

Souksengphet-Dachlauer, Anna, Text als Klangmaterial. Heiner Müllers Texte in Heiner Goebbels’ Hörstücken, Bielefeld, 2010.

Waldenfels, Bernhard, Sinne und Künste im Wechselspiel. Modi ästhetischer Erfahrung, Berlin, 2010. 


\section{VOM ENTSPRINGEN DES RAUMS VOR DEM WORT}

MT: Das Sprechen ist besonders beeindruckend in Deiner Arbeit. Es verliert seine Selbstverständlichkeit als Mittel für die Übertragung von Bedeutungen und Emotionen. Man hat den Eindruck, dass es eine Verdopplung gibt: Ein Sprechen, das sich hört, das sich auf sich bezieht. Und dass diese Verdopplung das Sprechen als Tun erfahrbar macht: nicht als Bestand, sondern als die Aktivität seiner Entfaltung im Außen. Das Sprechen in seiner Entfaltung, ein Sprechen, das sich im Außen aufrichtet. Ein Sprechen, das, indem es sich in dieser Verdopplung, d. h. als Bezug auf sich und Bezug auf Andere, erfahrbar macht, Räume öffnet. Es öffnet die Räume, die diese Bezüge sind. Es schließt sich jedoch in diesen Räumen nicht, sondern formt sie mit jeder neuen Skandierung um. Ein Sprechen, das sich zuvorderst sich selbst gegenüber und folglich im Raum immer wieder als Ansprache aufrichtet und die vorhandenen Räume flüssig macht.

Wie arbeitest Du konkret mit dem Sprechen? Was berücksichtigst Du? Wie entsteht sein Rhythmus? Und wie verhält sich dieses Sprechen dem gesprochenen Text gegenüber? Wie gehst Du mit Texten um, die aus einer historischen Ferne kommen?

CB: Der Ausgang jedes Sprechens ist für mich ein Bewusstsein des Körpers des Sprechers über den Ort, an dem er sich befindet, über den Ort seines Körpers und über das Verhältnis dieses Körpers zum anderen Körper oder Ort, der ihn hört, nennen wir es Adressat. Dieses Verhältnis von sich zum Anderen ist zunächst wie eine Vermessung zu sich und zum Anderen. Diese Verortung des eigenen Körpers, auch die geistige Verortung des Körpers, ist die Voraussetzung dafür, dass man das Wort richten oder formulieren kann. Seit zwei Jahren versuche ich, dass es, egal welche Bewegungen, Rhythmen, Spannungen man mit dem Körper oder der Außenmuskulatur vollführt, einen Innenraum gibt: Die Verbindung der Atmung, die eine Stabilität im Zentrum benötigt, also eine Bewahrung des Innenraums braucht.

\section{MT: Welches Zentrum?}

CB: Das konkrete körperliche Zentrum, das ich mit dem Bauchnabel stütze, wo ich die Luftsäule oder das Innere meines Körpers zu stabilisieren und offen zu halten versuche. Es handelt sich um eine sehr fragile Achse in mir, die immer wieder zugleich bewahrt und hergestellt werden muss. Sie ist nicht einfach da, sie ist kein Zustand, sondern ein ständiger, dynamischer Prozess, der 
sich mit jeder Atmung wiederherstellt. Das ist die Voraussetzung des Körpers, um überhaupt entscheiden zu können, wie du das Wort anfasst, in den Raum richtest und formulierst.

MT: Ist es das Entspringen des Wortes, das Du meinst, das Wort, das nicht vorhanden ist, sondern immer wieder neu hergestellt werden muss?

CB: Ich glaube nicht, dass es das Entspringen des Wortes ist, sondern ein Vordem-Wort. Es geht an dieser Stelle überhaupt um die Möglichkeit und die Bereitschaft des Körpers zu sprechen und die Weisen des Sprechens abwägen zu können, und eben nicht im Affekt dem Wort oder durch die Aktion einer bestimmten Dynamik oder Intensität unterworfen zu sein. Es geht darum, immer wieder einen Nullpunkt, wie einen Ausgangspunkt, im Körper zu schaffen (mit sich zu sich), von dem aus man das Wort entscheiden und gleichzeitig lassen und wieder weiterspinnen kann im Satz, in einer Formulierung. Ich glaube, es braucht diesen Ort als Konzentration oder als Lockerheit oder als Verortung, konkret an einer Stelle in einem Raum, damit ich der Sprache oder dem Sprechen in mir einen Raum gebe und ihr dadurch auch einen Raum im Anderen ermögliche.

\section{MT: Also das Entspringen des Raums vor dem Wort.}

CB: Genau. Das Entspringen des Raums im eigenen Körper im Verhältnis zum Raum, zum Anderen; im eigenen Körper, der eigentlich erst den Raum oder den Luftraum, den Innenraum gibt, aus dem das Wort in den Außenraum treten kann. Der Luftraum, die Kontrolle der Luft und das Entscheiden der Luftdynamik, haben viel mit dem möglichen Wortkörper zu tun. Viele Leute können die Luft nicht kontrollieren. Dann platzt die Stimme heraus oder die Stimme rutscht aufgrund einer Anstrengung des Hörens, zum Beispiel auf jemanden, der weiter entfernt ist, in die Kopfstimme, weil das der Ort ist, an dem ich höre. Es handelt sich um einen permanent zu erneuernden Vorgang, dass ich den Ort meiner Stimme wieder ins Verhältnis setze zu dem Wort, das ich spreche, und zu dem, das ich gehört habe. Es handelt sich um kurze Präparationen, um mir immer wieder den Ausgangspunkt zu schaffen, so dass ich im Moment dort bin, wo ich bin und im Moment dort bin, bei den Worten, die ich zu jemandem sage. Das ist grundlegend für diese Reaktualisierung des Sprechens im Vorgang des Sprechens. Ich spreche jetzt, in einer bestimmten Rhythmizität. Aber Körper oder Geist müssen sich gegenüber dem Rhythmus, den ich produzieren möchte, frei verhalten.

Es gibt immer zwei Rhythmen. Derjenige, den man im eigenen Körper als Verfasstheit in sich oder als Emotionalität spürt und als ein Ausgangspunkt aufsucht, indem man sich als wahrnehmenden und zugleich produzierenden Körper aktiviert. Dann jener Rhythmus im Verhältnis zu einem Rhythmus, den ich produzieren möchte. 
CB: Rhythmus ist für mich die Skandierung, die Schnelligkeit von Abfolgen von Impulsen. So wie wenn du schnell sein willst, dann musst du innerlich langsam sein. Du darfst nie versuchen, dich mit dem Vorgang, den du tust, zu identifizieren, so dass du jedes Mal das, was du herstellst, wieder in ein Verhältnis zu dir bringen kannst und nicht gefangen bist in der Absicht einer Handlung. Dann stürzt man in eine Handlung und verliert diese Ruhe, Konzentration oder Verortung, von der aus man im Moment der Produktion das Produzierte verfertigen kann. Nur wenn ich diesen Ausgangspunkt habe, kann ich mit mir etwas tun. Das geht nicht vorsätzlich, und deshalb brauchst es immer diese zwei Rhythmen, den Herzschlag, die Atmung und die Manipulation dieses Körpers. Aus diesem Grund verwende ich Yoga, weil es da die Koordination der Bewegung mit der Atmung gibt, und es um eine Führung der Atmung geht, die ich dann in ein anderes Verhältnis bringe zu dem, wie oder was ich in welcher Intensität als Sprache in den Raum stelle.

MT: Aber so, wie Du das beschreibst, stellst Du nicht etwas in den Raum, sondern es geht jeweils um ein Auftauchen von Raum.

CB: Es geht rudimentär um eine Position von zwei Körpern mit einer bestimmten Entfernung und Ausrichtung, die einen Raum bilden, der eine bestimmte Materialität, einen bestimmten Boden, Klang, eine Höhe, Frequenz hat. Er klingt in einer bestimmten Weise. Es geht darum, wie man dieses Verhältnis zueinander erzeugen kann und wie man in diesem Verhältnis dann auch vielleicht Sprache erzeugen kann, die Raum schafft, erzeugt, beschreibt oder vermisst. Es gibt immer die körperliche Versicherung eines Körpers im Verhältnis zum anderen Körpern und zu diesem Raum und seinen Entfaltungen in einem sehr konkreten Sinn, der besagt, dass ich mir immer wieder erneut einen Ausgangspunkt suche, um daran Mittel zu messen oder Proportionen zu gewinnen für mein Tun. Es ist immer schon was da. Wie gelingt es, das, was da ist, wahrzunehmen und als Information ernst zu nehmen und ins Verhältnis zu dem zu setzen, was man selbst an Bewegung, Sprache oder Handlung vollführt. Es gibt immer Rhythmen, Klänge, Spannungen, die schon da sind, ein Ensemble von vorhandenen Informationen, egal wo ich bin. Eine Verortung verlangt also, sich im Ensemble vorhandener Informationen zu entscheiden, Parameter auszuwählen und somit einen Ort herzustellen, um dort Relationen oder Proportionen herzustellen, die ich aber in einen schon informierten Raum hineingebe.

\section{MT: Das ist aber keine rationale Entscheidung, oder?}

CB: Es ist nicht rational, nicht wie ein Schritt nach vorn, sondern erst einmal zurück. Man merkt oft bei Darstellern, dass sie nicht beginnen, sondern in 
etwas springen. Wo ist der Ort einer Konzentration und Wahrnehmung, von dem sich zuallererst etwas beginnen lässt? Es geht um diesen Ort davor, um dann in das Ensemble all dieser Informationen eine andere Qualität hineinsetzen zu können.

MT: Also dorthin gelangen, wo man schon ist.

CB: Genau. Im körperlich-geistigen Wissen dorthin zu gelangen, wo man eigentlich schon ist. Denn oft ist man nicht da, wo man ist. Wie oft sitzt du im Theater und bist eigentlich nicht dort, deine Gedanken sind woanders. Wie lange brauchst du, dich so zu konzentrieren, dass alle deine Sinne mit dem Körper, mit dem Ort, an dem du bist, einhergehen. Das ist grundlegend, diese Art der Präsenz, Raum für seine eigene Präsenz zu schaffen. Es ist die Voraussetzung, um handeln zu können.

Das nächste Moment ist das Etwas-zusammen-Tun. Das Klischee vom Zusammen im Theater ist oft, dass sich Energien, Gesten, Rhythmen, die Weisen etwas zu tun angleichen. Die Frage aber ist, wie ist es möglich, dass ich bei mir und mit den Anderen zugleich bin. Wie bleibt dieses Verhältnis offen, so dass ich mich nicht im Anderen verliere, sondern ihm begegnen kann.

MT: Aber wenn dieses Bei-sich-Bleiben, wie Du das beschreibst, ein Zu-demPunkt-wo-man-schon-ist-Gelangen ist, heißt das eben, zu einem Bezug auf etwas zu gelangen. Weil der Raum kein Container oder vorhandenes Ding ist, wo man drinnen ist, geht es nicht um ein ,sich“ und ein Anderes als zwei vorhandene Sachen, sondern dieses $\mathrm{Zu}$-sich-Gelangen ist eine nicht-rationale Entscheidung als Gelangen zu dem Punkt, wovon aus man Raum ist, weil man eigentlich Raum ist.

CB: Man ist Raum für sich oder in sich, nicht für einen Anderen. Hinzu kommt jedoch, dass man nicht selbst derjenige ist, der Raum erst herstellt. Es sind stets mehrere, Du oder ich stellen Raum her, in dem wir uns befinden.

MT: Oder ich gelange zu dem Punkt, von wo aus es Raum gibt, von wo aus ich Raum bin als Bezug auf: Eins ist schon zwei.

CB: Es gibt geografische, naturwissenschaftliche, gesellschaftliche Räume. Es gibt Koordinaten für einen Ort. Aber Raum existiert nie ohne mich. Denn ich - jetzt ich exemplarisch - bin derjenige, der Raum erst herstellt. Ich bin immer Produzent dieses Raums, weil er sich in meiner Vorstellung als Raum zusammensetzt. Und außerhalb von mir ist er nicht einfach da, sondern benötigt mich, indem ich ihn als Raum herstelle.

MT: Dieses „sich“, wenn es um Raum geht, ist nicht allein. Raum ist „Bezug auf“. 
CB: Es bedarf jedoch das Moment einer Entscheidung. Weil du immer schon in derart vielen Bezugssystemen bist und aus diesen viel zu vielen etwas nimmst, bedarf es einer Konzentration auf etwas, auf einen Moment. Erst über diese Entscheidung auf oder für etwas, kann dir selbst klar werden, dass da ein Raum wird. Sonst gäbe es ja zu viel und alles Mögliche, in dem du ständig verbleibst.

MT: Genau, weil es sonst alles und nichts ist, deswegen gelangt man zur Öffnung eines Raums, zu einem Raumwerden, nur von der Stelle aus, wo du schon bist.

CB: Ja, eine nicht-rationale Orientierung als Öffnung ermöglicht erst dieses Werden.

MT: Diese Öffnung ist das Nicht-Vorhandene, das Dorthin-Gelangen, wo du schon bist: Dass es Raum gibt.

CB: Im Theater frage mich jedoch oft, sehr konkret, da sind Körper auf einer Bodenfläche, du bist auch dort und hast den Eindruck, dass dieser Körper plötzlich Verhältnisse zu allem anderen aufnimmt, was da ist. Aber es gibt auch Momente, wo ein Körper dort ist und keine Öffnung der Haut, der Muskeln oder der Sinnes im Sinn einer räumlichen Präsenz hat. Wie lässt sich das beschreiben, wenn ich von einem konkreten Tun ausgehe? Wenn ich jemanden beobachte und diese Person oder diesen Körper als eine im Raum präsente Gestalt wahrnehme? Was geschieht da? Entscheide ich oder entscheidet diese Person mit? Lässt sich da was verbinden? Gibt es eine Öffnung?

MT: Eine Öffnung wird erfahrbar, auch wenn die Person, der Körper sich nicht bewegt, sich einfach ruhig verhält.

CB: Meistens sogar viel mehr.

MT: Und dann fängt Theater an.

CB: Genau. Wir sprechen von Raum, aber im Theater siehst du oft nur Ausrichtungsflächen, keine Öffnung der Körper, sondern ihre Ausrichtung im Blickregime. Der Körper unterstellt sich ihm fast reflexartig. Quasi automatisch richtet er sich nach den Blicken aus, die ihn betrachten. Das negiert den Raum, der hinter den Blicken liegt, macht ihn zum Bild.

MT: Um zum Sprechen zurückzukommen: Wie funktioniert in diesem Dispositiv ein Sprechen, das Raum erfahrbar macht? Diese Verdopplung, als ob das Sprechen sich auf sich bezieht und zugleich auf anderes, das sich nicht als Bestand, sondern in seiner Entfaltung erfahrbar macht? 
CB: Ich glaube, der Ort dieses Sprechens ist absolut wesentlich. Ebenso das Verhältnis zum Raum, in dem es statthat, denn es ist immer von konkreten physikalischen Bedingungen abhängig, aus und mit denen es sich erzeugt. Das ist wesentlich und wird meist ignoriert. In den letzten zwei, drei Jahren interessiert mich immer mehr, dass das Wort eine Bewegung der Luft ist, eine Schallwelle, die Luft in Bewegung versetzt. Der Zustand der Luft wird durch das Sprechen in andere Schwingungen versetzt. Jemand sagt etwas, und es trifft einen körperlich. Es ist ein körperliches Hören, man wird berührt und angefasst von Worten. Das hat mit dem Körperraum des Sprechenden zu tun, wenn man ihn nicht verengt. Es gibt jedoch auch Sprache, die den ganzen Körper verneint und Körper, die sich schließen. Die ganze Resonanz des Wortklangs ist dann die der eigenen Knochen. Diese Körper können nur räsonieren, wenn sie Raum haben. Oder sie verkrampfen sich. Das verändert sofort den Stimmkorpus und damit auch den Raum, aus dem das Sprechen erzeugt wird, vielleicht auch als geistigen Raum. Ich finde die Möglichkeit, dies zu kontrollieren immer wichtiger. Ich kann ein geöffnetes Sprechen herstellen, aber es ist nötig, dass ich die Möglichkeit habe, darüber zu entscheiden.

\section{MT: Du sprichst sehr viel von Entscheidung.}

CB: Ja, ich glaube nicht, dass „es“ spricht oder es „aus einem“ spricht. Vielmehr denke ich, dass das Jetzt des Wortes und das Sich-selbst-Hören-undtrotzdem-Geben nur möglich ist, wenn gelingt, dass eine Mischung aus Bewusstsein, Fallenlassen, Sich-gehen-Lassen im Spiel gehalten wird. D. h., ein Wort transportiert sich räumlich nur, wenn es im Wort einen Ort gibt, wo ich das Wort loslasse. Es gibt eine Kontrolle über die Spannung und Entspannung im Wort.

MT: Spannung ist mit Druck verbunden, der einen Raum nur durchqueren kann, wenn es Entspannung gibt, die besagt: Ich behalte es nicht, ich lasse los.

CB: Das gelingt oder es misslingt, aber ich habe ein Bewusstsein davon. $\mathrm{Zu}$ diesem Wort setze ich das nächste, in einem permanenten Spiel mit dir, dem Sprechenden, Wort für Wort, die sukzessive Sätze bilden. Es geht nicht um die Vorstellung eines ganzen Satzes. Die gibt es natürlich auch, im Zug einer Atmung oder über größere Entfernungen hinweg. Dann geht es erst einmal um eine Grundverbindung, die hergestellt werden muss, ein Anker, den ich in dem Raum werfe, auf dem sich dann die Sprache ablegen lässt. Stets geht es um eine Verbindung, die ich versuche körperlich zu schaffen. Auf dieser Verbindung kann ich loslassen und zugleich gucken, wie ich mit dem Loslassen oder Nicht-Loslassen spiele. Wie verändert sich der Sinn, wie die Aussage? Ein Satz, wenn er gesprochen wird, ist nicht vorprogrammiert, sondern hat einen Fluss, eine Dynamik, bleibt aber ein Tasten in jedem Moment. 
MT: Dabei muss man immer wieder an einem Punkt gelangen, von dem aus sich der freie Gang als Impetus gibt. Welche Rolle spielt dabei der Rhythmus?

CB: Der Rhythmus ist das Metrum, auf das ich die Verhältnisse der Worte setze. Wenn ich jedoch auf dem Rhythmus sprechen würde, wäre das Sprechen tot. Der Rhythmus ist wie eine andere Grundlage, ein Takt, der unter mir liegt. Er gibt auch den Pausen ein bestimmtes Referenzsystem - wie eine unsichtbare Kette, die die kurzen, schnellen Einstiege in die Worte untereinander allererst erkennbar macht, hält oder verbindet. Rhythmus ist stets die Unterlage für die Verhältnisse von Wort-Ein- und Ausstiegen. Ich habe einen Wortkörper mit Silben. Ich kann unterschiedlich in das Wort einsteigen und daraus den Wortsinn weiter treiben oder, noch im Wort, mit den Silben spielen.

MT: Ich frage mich, ob der Rhythmus nicht eher mit diesem Alternieren zwischen Entscheidung und Entspannung zu tun hat.

CB: Entspannung benötigt eine Kontrolle, und das Loslassen verlangt eine schwierigere Kontrolle des Körpers als das Nicht-Loslassen. Demgegenüber ist der Rhythmus wie der Takt meiner Präsenz. Er ist eine Verfremdung, jedoch mir selbst gegenüber. Er verhilft mir, dorthin zu gelangen, wo mir Sachen bewusst werden. Das ist der Rhythmus.

MT: Genau, Rhythmus nicht in der Sprache als Dispositiv. Wie ist es dann, wenn man mit Texten arbeitet?

CB: An Texten, die man für das Sprechen überprüft, fasziniert mich, den Körper des Texts herauszufinden, auch die Grammatik der jeweiligen Konstruktion, die sehr unterschiedliche Weisen oder gedankliche Anwesenheiten produziert. Brecht baut immer Wort nach Wort auf, ich muss nicht vor-zurückdenken, sondern immer noch weiterdenken. Wenn man mit einer Müller'schen Aischylos-Übersetzung arbeitet, hat man ständig Vor-zurück-Sprünge von Wortbezügen, permanent verschiedene Verweise und ganz andere Hierarchien von Worten in einem Satz, die man nachvollziehen muss, um überhaupt Bezugsebenen herzustellen. Das Wichtigste ist für mich, den Körper zu verstehen im Verhältnis von konkreter Wortabfolge, der Struktur, inwieweit die Struktur noch einmal andere mögliche Sinne in dieser Abfolge der Worte nahelegt, welche Körperlichkeiten die Texte produzieren mittels und als Interpunktion. Hat das einen kurzen oder langen Atem? Darüber entsteht ein Gefühl vom Rhythmus eines Texts. Wie funktionieren Metaphern? Wie werden sie zusammengesetzt? Welche Assoziationen hat ein Wort zum anderen? Was macht es, wenn man sie zusammensetzt? Wie hört man die Zusammensetzung einer Metapher und nicht das Endbild einer Metapher?

MT: Es geht grundsätzlich darum, gegen das Endbild des Texts zu arbeiten? 
CB: Immer, bzw. wenn man von Bild redet, möchte ich immer den Vorgang dieser Bildkonstruktion hören. Die Konstruktion fasse ich als ein aktives Tun auf, auch als ein Spezifikum eines bestimmten Texts gegenüber einem anderen Text. Wenn du also einen Satz beginnst und die Ökonomie dieses Satzes kennst, geht es darum, sich nicht ins Antizipieren zu stürzen, sondern den Satz wirklich im Geben und im weiteren Verlauf zu öffnen. Wenn das geschieht, empfinde ich das als einen unglaublichen Genuss. Ich bin dann in der Lage, die Gedanken im Raum noch mal denken zu dürfen als jemand, der sie hört. Das ist etwas ganz anderes, als das Abbild eines fertigen Gedankens zu begutachten.

MT: Alles, was Du sagst, hat sehr grundsätzlich mit der Entfaltung von Räumen zu tun.

CB: Vollkommen. Es geht darum, den Klang konkret herzustellen. Ich möchte nicht die Oberfläche einer Fremdheit des Texts kommentieren. Es gibt eine kulturelle Oberfläche, den Kommentar, eine kulturelle Melodie, die den Klang verstellt. Einen Heiner Müller-Text zum Beispiel spricht man neutral und monoton. Aber das ist ein Klischee, ein Missverständnis. Man stellt nicht den Vorgang her, über den der Klang entsteht. Wie ist es möglich, nicht von den Oberflächen bestimmter Klanglichkeiten her zu lesen, sondern immer wieder den Klang, mit den konkreten Materialien dieser Worte in genau dieser Abfolge, herzustellen? Gegen irgendwelche Ohrwürmer der Konventionen anzugehen? Mein Lieblingsbeispiel ist Racine, seine minimalistische Sprache. Wenn du mit den Akzenten operierst, hast du ein und dasselbe Wort, das, je nachdem, wo es im Satz steht, anders betont werden muss. Wendest du im Satz ein Wort gegen seinen üblichen Klang, verschiebst du ihn leicht. Es gibt Emotionalitäten erzeugende Sätze, für die du eine Disziplin des Atems halten musst und immer wieder versuchen musst, die Endungen in ihre Doppelreimkonstruktion zu führen, diese dabei aber entstehen zu lassen und nicht einfach zu bedienen. Diesen Moment herzustellen und nicht in der Antizipation eines Klanges oder einer Logik oder Emphase aufzulösen, benötigt ein hohes Bewusstsein und eine Transparenz des Denkens, des Übersetzens in die Muskeln des Körpers, der Übersetzung in den Raum.

MT: Einerseits geht es um den Rhythmus, den der Text hat, und andererseits um den Rhythmus, der körperlich hervorgebracht wird im Raum. Wie verhält sich das zueinander?

CB: Ich kann den Rhythmus des Texts nur im Dialog mit dem Rhythmus meines Körpers erfahren. Den Rhythmus des Texts muss ich erst hervorholen, er ist nicht per se gegeben. Es erscheint etwas und das muss ich mit dem Rhythmus meines Denkens und meines Körpers abgleichen. Daraus entstehen Konflikte, der Versuch auszuweichen. Wie kann ich diesen Dialog offen halten? 
Es gibt für mich die Forderung, dieses Aufeinandertreffen, dieses Zerren und Ziehen, diesen Zwischenraum offen zu halten als dasjenige, was den Rhythmus des gesprochenen Texts erzeugt. Die Forderung, dass sich nicht das Eine dem Anderen beugt oder umgekehrt, im wachen Dialog mit dem Denken und dem Körper.

MT: Wenn der Rhythmus dieses Nicht-selbstverständlich-Werden der Präsenz, diese Skandierung ist, dann wäre er ebenso Raum, der sich jeweils aus diesem Nicht-selbstverständlich-Werden erfahrbar macht ...

CB: Das ist ein Raum, aber der Sprachraum ist ein anderer Raum. Die Präsenz ist der Rhythmus der Anwesenheiten aller - der Darstellenden und der Zuschauer. Die Situation dieses Gemeinsam-anwesend-Seins erzeugt in irgendeiner Weise eine durchlässige Präsenz. Das ist die Grundlage. Von der aus geschehen dann Bewegungen, Formulierungen, Sprache usw. und erzeugen einen anderen Raum. Die Räume überschreiben sich, bilden Schichten. Im Moment der Sprache kommt ein Satz und ich bin in diesem Satz, der einen anderen Raum kreiert. Wenn der Satz zu Ende ist, bleibt der Raum des Satzes dort und ich gelange wieder an diese Präsenz. Das ist die Möglichkeit, dass ich den nächsten Satz formulieren kann.

\section{MT: Wie sind diese beiden Ebenen aber miteinander verbunden?}

CB: Von der Spielerdynamik her ist es wichtig, dass die beiden Ebenen als zwei differente verstanden werden. Sie sind verbunden, weil sie in einer zeitlichen Abfolge stehen. Das Wort entsteht immer nach dem Wort. Wenn ich das Wort sage, entsteht es erst viel später bei dir. Das Wort existiert im Theater nie in dem Moment, in dem es entsteht, sondern immer nachträglich. Wenn ich einen fremden Text spreche, versuche ich, ihn in diesen gegenwärtigen Anwesenheiten zu erzeugen. In ihnen erinnere ich mich an einen Text, schicke ihn durch meinen Körper. Damit erzeuge ich einen Moment und erst in der Vergangenheit hörst du mich. Du hörst mich erst in meiner Vergangenheit. Und trotzdem ist der Darsteller permanent in dieser Präsenz.

MT: Du hörst dich aber auch in deiner Vergangenheit.

CB: Ich höre mich aber eher als du, weil ich näher an meiner Frequenz bin. Je weiter du weg bist, desto später hörst du mich. Ich muss jedoch das Wort so lange vertreten, bis du mich hörst. Je größer die Distanz ist, die der Schall übertragen werden muss, desto größer ist die zeitliche Verschiebung.

MT: Gibt es aber diese Verschiebung nicht schon sich selbst gegenüber? Wenn das Wort nicht als Vorhandenes gemeint ist, muss es doch erst dahin gelangen, wo es ist. Für Dich, die das ausspricht, ist es schon verschoben. 
CB: Absolut. Das andere ist, dass wenn ich einen Satz sage, jedes Wort immer wieder bei mir beginnt, während sich der Satz bei dir zusammensetzt. Ich zeige den Satz nicht als das Nacheinander von verschiedenen Worten, als vermeintliche Satzmelodie. Die melodische Zeichnung eines Satzes stellt nur eine scheinbare Verbindung zwischen uns her. Ich tue dann so, als ob ich mit dem Satz einen Raum vermessen würde. Demgegenüber muss ich das Ankommen der Worte bei dir, beim Zuschauer komponieren, weil der Satz erst dort entsteht. Er entsteht immer außerhalb von mir. Ich lasse ihn entstehen, aber er wird erst im Gegenüber ein Satz. Wenn ich den Satz spreche, will ich ihn dir geben. Ich bin ein Quasi-in-Dir-außer-mir, weil ich ermessen muss, wie in dir der Satz entsteht. In dem Verhältnis höre ich mich und bestimme ich mich. Als wir Die Perser in einem Tunnel von 700 Meter Länge gemacht haben, bedurfte es einer Artikulation, die am Ort ihres Erzeugens völlig aberwitzig war, unproportional und mit unendlichen Pausen, die aber notwendig waren, um dort einen Satz entstehen zu lassen. Der Satz kann nicht verkörpert werden, sondern wird in einem Raum mit seinem Raum erzeugt, so dass der Satz im Anderen entstehen kann.

\section{MT: Und die Verschiebung sich selbst gegenüber?}

CB: Wenn ich mich nicht öffne zu dem, zu dem ich spreche, habe ich nur die Zeitlichkeit meines Ortes. Aber wenn ich die Worte in einen Raum schicke und Du diese Worte in einem bestimmten Verhältnis zusammensetzt, ist meine Zeitlichkeit in diesem Zwischenraum, den die Worte durchdringen, in einem Verhältnis. Dadurch entsteht für mich wiederum eine Fremdheit zu meinem eigenen Sprechen, weil sich Verschiebungen ergeben. Du bist da, aber die Zeiterfahrung mit und in der Sprache ist eine völlig aufgespreizte, fragmentierte, auch wenn sie immer im Moment, in diesem Rhythmus bleibt. Das macht die Sprache dem, der sie erzeugt, wieder fremd und ermöglicht so, mit ihr im Satz zu dialogisieren, damit sie den Anderen erreicht.

MT: Du machst einen Unterschied zwischen dem Inneren des Satzes und dem Satz. Der ganze Satz ist fragmentiert, aber innerhalb des Fragments ...

CB: Genau. Wenn ich einen Satz spreche, habe ich das Bewusstsein einer Kontinuität. Aber die Teile, die diesen Satz bilden, sind aus ihrem üblichen Fluss gerissen.

MT: Und der andere Fluss, zu dem sie gelangen?

CB: Das ist der Raum.

MT: Wie verbinden sich die beiden Sachen? Wie verhält sich der Rhythmus des Texts zu diesem anderen Fluss? 
CB: Ob ich den Rhythmus des Texts in einem Freiraum, in einem WC oder in einem Tunnel anwende, verändert die Kondition des Rhythmus des Texts durch den anderen Raum und verändert auch den Text. Es bleibt nach wie vor der Rhythmus des Texts. Aber die Übertragung von mir und dem Rhythmus des Texts wird neu gerahmt über die konkreten Anordnungen oder Konditionen des Raums.

MT: Was sich ändert, ist das, was die konstitutive Öffnung des Texts erlaubt. Wenn der Text kein Block ist, sondern ein immer wieder neu Auftauchendes, dann sind diese Skandierungen die konstitutive Öffnung des Texts ...

CB: Ja, aber in der Differenz zu sich an einem konkreten Ort im Verhältnis zu. Es gibt Verhältnisse in einem Text von Wort zu Wort als Rhythmus. Aber der Rahmen, in dem du den Rhythmus jetzt öffnest, ist ebenfalls konstitutiv dafür, was du am Text öffnest, weil die Bedingungen der Verräumlichung dieser Sprache deinen Körper verändern: als Präsenz, als Kraft, als Atem, als Stimmlage, als Sprachcouleur, als möglichen Rhythmus. Wenn ich in einem Raum spreche, der zwölf Sekunden Resonanz hat, ergibt das eine ganz andere Art von Öffnung, als wenn ich in einem Raum spreche, der schalltot ist. Das Echo zu sich zurück ist die Mischung zwischen dem Raum zu sich und dem Raum zum Anderen und dem Raum zum Text. Das Wort, das ich initiiere, wird vom Raum als Resonanzkörper getragen. Der Raum trägt und er trägt unterschiedlich. Aber diese Zeit des Raums muss mein Raum werden als Raum zum Text. Erst dann ist dieser Raum der Raum nach außen jenes Gedankens, den ich mit diesem Text verfertige, veräußere oder verräumliche. Der Rhythmus des Texts bleibt als Raster, aber unter gegebenen, konkreten Bedingungen verändert sich der Text sehr. Die Erfahrung der Differenzen, die das bedeuten kann, ist extrem.

MT: Es ist interessant, was Du über den Rhythmus des Raums und des Texts sagst und wie diese zusammenkommen ...

CB: Im Theater, das eine vermeintlich klare akustische Rahmung hat, ist dieser Aspekt oft nicht reflektiert. Ich arbeite aber mit Theater auch in anderen Räumen. Wenn ich einen Satz in einer Halle von zweitausend Quadratmetern spreche, egal wie ich ihn denke, stellt der Raum an mich, was das Verhältnis zum Text und das Verhältnis des Körpers zu meinen Gedanken betrifft, völlig andere Bedingungen. Der Raum wird zum Anordnungsrahmen für das Auftreffen zwischen Körper und Text, abhängig von der Anordnung der Zuhörer und der Hörbarkeit, die ich erzeugen will.

In Räumen mit unheimlicher Resonanz habe ich ein Zeitloch. Wenn es zwölf Sekunden dauert, bis das Wort bei dir ankommt, gibt es eine Lücke, die ich bearbeiten muss. Ganz anders ist zum Beispiel die Anordnung in dominant powers, wo man sich in einer Nähe und permanent ändernden Kleinteiligkeit befindet, die eine ganz andere zeitliche Ferne zum Fluss des Gesagten und 
zum Text erzeugt. Es ist interessant, wie viel Zeit man je nach Text braucht zwischen den Worten in bestimmten Räumen. Es ist interessant, dass man genau dieses Schaffen, diese Archäologie der Sprache hören kann als den Vorgang, den sie eigentlich beschreibt und wie sich der gleiche Text, sowohl von der Sprache als auch von den räumlichen Bedingungen her, verändert.

MT: Deine Arbeit dominant powers ging von den politischen Revolten der letzten Jahre in den arabischen Ländern und anderswo aus und stellte, wie auch Deine Arbeit Vampires of the 21st century die Frage „Was also tun?“. Es ging jedoch, scheint mir, nicht darum, eine Antwort auf diese Frage zu finden. Vielmehr zeichnete sich der ästhetische Vorgang durch einen vehementen, dringlichen Gestus aus. Die immanenten Formen der Einrichtung (Einrichtung auf allen ihren, miteinander zusammenhängenden Ebenen - der ausgestalteten Bedeutung, der gesellschaftlichen Aufteilung, der medialen Anweisung, der räumlichen Einrichtung) wurden erschüttert. Würde also die Frage selbst den ästhetischen Vorgang dieser Theaterform betreffen? Ich meine, indem dieser, gegen ein gegebenes Tun, einen gegebenen Raum, eine gegebene Rollenaufteilung usw. revoltiert? Ginge es also nicht darum, zu einem anderen Tun oder zu einer neuen Gegebenheit zu gelangen, sondern innerhalb der jeweiligen Immanenz oder Gegebenheit, die Kraft ihrer Formierung ausbrechen zu lassen? Ein Tun, das, indem es zu sich als Frage gelangt (Was also tun?), die Kraft seiner Formierung gegen ein gestaltetes, gegebenes Tun freisetzt? Die Kraft des Werdens, eines flüssigen Raumwerdens mit allen seinen Folgen (das Sprechen als Werden, Tun bzw. Ansprache gegen Bedeutungsbestand, der Raum als Formierung von Räumen, und in dominant powers auch explizit die Position des Zuschauers als nicht gegeben, indem der Zuschauer unter parallelen Vorgängen eine Strecke suchen musste usw.)?

CB: Diese Frage, was also tun, ist keine Frage, die ich stellvertretend stelle. Diese Frage versucht, immer wieder die Handlungsspielräume innerhalb der gesellschaftlichen Zusammenhänge, in denen wir uns bewegen, herauszufinden. Ich habe den Eindruck, dass wir uns in einer unendlich konsensuellen Kultur befinden, innerhalb der wir Kultur, egal wie avanciert bestimmte Konzepte sind, immer in einer repräsentativen Vorbildfunktion betrachten, wo harmonische Symbiosen hergestellt werden. Was mich am Theater prinzipiell interessiert, ist die Weise der Begegnung in einer raumzeitlichen Anordnung, die nicht als harmonische Begegnung stattfindet, sondern Energien entfacht, gebunden an die Konstitution bestimmter Situationen, die in ihrem Tun innerhalb eines Spiels so etwas wie eine Wirklichkeit in diesem Spiel entwickeln. Diese hängen für mich mit dem Wechseln sehr unterschiedlicher energetischer Anrufungen zusammen, die etwas konkret entfachen in diesem Moment, als elementare Möglichkeit. Weil ich den Eindruck habe, dass sämtliche Bedenken oder andere Energien in diesem konsensuellen Europa privatisiert sind und sich über Drogen, Depressionen oder über andere Sachen abspielen. Es 
geht um die Frage, wo, auf welcher Ebene es Handlungsoptionen gibt und was die Handlungsoption des Theaters ist. Und wo ist der Ort, wo eine räumliche, geistige Transformation stattfindet, die sich in dem Moment mit den dort Anwesenden auflädt, entlädt und verändert. Die Befriedung der Verhältnisse, in denen man lebt, ist oft, dass man Optionen nicht wahrnimmt, Konditioniertheiten übernimmt und im Rahmen dieser Konditionierung in bestimmten Variationen agiert. Dieser Rahmen muss immer wieder befragt werden. Ein Weg aus diesem Konsum von Bedingungen heraus ist, die konstituierenden Elemente als solche zu befragen, um sie entweder zu akzeptieren oder nicht. Aber die Konditionen müssen beweglich sein und bleiben. Ein Ringen darum, dass überhaupt wieder gedacht wird. Ich habe keine Antwort. Es gibt keine Antwort. Ich kann nur versuchen, die Elemente gegeneinander zu mobilisieren und zu sehen, ob die Mobilisierung Potenzialitäten erscheinen lässt.

MT: In dem, was Du sagst, wird erstens die Handlung zur Frage. Und zweitens geht es grundsätzlich um einen Dissens. Es geht nicht darum, einen Vorschlag für einen anderen Konsens zu machen, zu einer anderen Immanenz zu gelangen, sondern darum, dass die Kraft der Formbarkeit der Immanenz aufbricht und im Werden gehalten wird, dass sie irgendwie freigesetzt wird und zwar im räumlichen Sinn, mit allem, was das mit sich bringt und was Du mit dem Sprechen beschrieben hast. Was Du Handlungsoptionen nennst, setzt voraus, dass die Handlung nicht gegeben ist, zur Frage wird.

CB: Es geht in keiner Weise um die Aufrufung einer Lösung, denn die gibt es nicht, sondern um das Befragen als Produktivkraft, die das Denken jedes Einzelnen in diesen Optionen öffnet und ermöglicht.

MT: Das geht in jeder Hinsicht weit: der Raum - Medialraum, Bedeutungsraum usw. - gelangt zur Kraft seiner Formbarkeit, als Tun, als Werden. Das geht ästhetisch sehr weit, so dass schließlich weder eine Position noch eine Negation vermittelt wird, sondern die Dringlichkeit und die Vehemenz dieser Kraft, die die Kraft der Formierung selbst ist, die Formen hervorbringen kann.

CB: Ich benutze die Texte oder die Elemente nicht mehr aus der Versicherung ihres Zusammenhangs heraus, nicht in der Autorität ihres Verweises, sondern als das, was sie als Teil, als Materialität, einem anderen Teil, einer anderen Materialität, antun. Elemente der Darsteller in ihrer Anwesenheit und ihrem Handeln, gepaart mit Objekten oder Dokumenten im Raum, re-informieren sich miteinander ständig und verändern sich dadurch. In ihrer Veränderung konstituieren sie immer temporäre Bedeutungen, die aufgrund des Zusammentreffens entstehen und dann wieder gerinnen und zerfallen und plötzlich auf einem anderen Bedeutungszusammenhang hinweisen. Es geht darum, Felder zu konstruieren, nicht nur mit differenter, sondern auch mit ideologisch nicht 
einwandfreier Materialität. Es wird nichts zusammengefasst. In einem zeitlichen und in diesem Sinne theatralen Ablauf differenter Überlagerungen werden bestimmte Bedeutungen produziert und lösen sich wieder auf. Obwohl die Elemente oft da bleiben und nur noch etwas dazu kommt, wird der Raum ein anderer Raum.

MT: Ein anderer Raum: Trotz der Auflösung, wie Du sagst, bleibt man nicht bei dem Verlust. Das meinte ich mit Vehemenz und Dringlichkeit. Dieses Werden, das in seinem Tun behalten wird, $d$. h. immer wieder freien Lauf nimmt, ist auch das, was Du mit dem Sprechen skizziert hast: Immer wieder zu diesem Punkt zu gelangen, wo die Präsenz ihre Selbstverständlichkeit verliert.

CB: In dominant powers wird innerhalb eines theatralen Ablaufs eine Gewissheit erzeugt, die wieder entzogen wird, ein qualitativer und konstellativer Wechsel. Die Grammatik der Zusammenhänge wird infrage gestellt und wieder anders konstruiert. Sonst orientieren und organisieren wir uns in inhaltlich verbürgten ästhetischen Oberflächen, die wie fixe Bausteine von Wirklichkeitskonstruktionen sind. In einer Ästhetik des Auftretens werden die Spielelemente oft als Ganzheiten begriffen. Das ästhetische Spiel sollte diese Relativität und auch die ideologische Abhängigkeit bestimmter Ästhetiken jedoch immer auf dieses mögliche Spiel zurückführen. Denn viele ästhetische Überlieferungen sind ideologische Raster. Wie kriege ich diesen Raum wieder geweitet? Wie mache ich erfahrbar, dass das Auftreten ein anderes sein könnte, dass die Ästhetik von bestimmten Elementen eine mögliche ist und nicht nur so möglich ist. Wenn ich diesen Zwischenraum wieder öffnen kann, wird das Erscheinen von bestimmten Dingen relativ und gestärkt wahrnehmbar, kritisierbar. Und es gibt einen operativen Zwischenraum für einen selbst.

MT: Interessant erscheint mir, dass es nicht einfach um Relationen innerhalb eines Dispositivs geht. Es geht nicht bloß um eine Montage. Es knüpft sich eher an eine Skandierung, die das Substantivierte erschüttert. Es geht um Verräumlichung, nicht um den Raum als Vorhandenes, sondern um das, was erfahrbar wird, wenn mein Dasein nicht mehr selbstverständlich ist: Dann wir das Auftauchen von Raum, der ich schon bin, erfahrbar. Was geschieht, wenn man zu diesem Schon-da-Sein gelangt und von dort aus ...

CB: Es ist der Ort, den jeder Theatermacher anders beschreibt und von dem aus alles möglich scheint. Aber alles hat immer das Bewusstsein seiner temporären Formung. Dieses Bewusstsein ist so klar vorhanden, dass es als Formbarkeit selbst erfahrbar wird. Diese konzentrierte Offenheit, die einen Darsteller, Akteur, Spieler in die Möglichkeit versetzt, als ein bündelndes und nicht begrenzendes Bewusstsein etwas zu bündeln und wieder abzugeben. Ein permanenter Prozess, der ständig in Gefahr ist, zu verstopfen, sich zu verschlie- 
ßen, anzuhalten. Es geht um eine körperliche Formulierung, die nie zur Grenze der Möglichkeit werden darf.

MT: Die nicht etwas Gegebenes werden darf.

CB: Genau. Die Bedingung der Möglichkeit als solche ist, dass das, was gerade eine Definition erfährt, ständig unterbrochen werden kann. Das meinte ich anfangs mit den zwei Rhythmen. Einerseits ist die Konstitution dieser Präsenz, dieses Bündeln und Aufnehmen von Dingen, ihrer Formbarkeit, die Möglichkeit die Dinge umzuformieren, ohne in der Umformatierung zu enden. Der zweite Rhythmus ist der Rhythmus der konkreten Handlung, die ich vorführe. Aber ich brauche den ersten und die Möglichkeit, den Rhythmus der Handlung jederzeit wieder zu verlassen. Damit ich nicht im Nichts herumstochere, sondern wieder an diesem Ort bin, mit mir und dieser Bündelung dessen, was da ist und dem, was ich formuliert habe.

MT: Sonst wärst du identisch mit dem, was du tust. Das wäre die Illusion. Nur über das Fremdbleiben in der Handlung ist es möglich ...

CB: Es ist möglich, im Rahmen des Theaters etwas zu erzeugen, das über die Rahmung hinausweist, weil du ihn wieder verlassen kannst. Dieser Abstand des Aufnehmens und Wieder-Einschreibens ist eine ständige Bewegung - zusammen mit dem, was dich umgibt und dem, was dir möglich wird in dem, was dich umgibt. Dies verhält sich völlig konträr zu einem sklavischen Identitätskonzept der Verkörperung im Handeln und im Bewusstsein, das diese Wahl, diese Möglichkeit ausschließt, weil es an einen organischen Fluss glaubt.

MT: Der Ausgangspunkt war, inwiefern die Frage - Was also tun? - den ästhetischen Vorgang beschreibt, in dem das Tun, aus seiner Gegebenheit gelöst, zur Frage wird und zur Kraft seiner Formbarkeit gelangt, im Werden gehalten wird. Und dass diese Frage selbst den ästhetischen Vorgang Deiner Arbeit beschreibt. Sie ist grundsätzlich auch die Frage des Dramas. Dran (im Gegensatz zu prattein und poiein), bezeichnet das Moment, wo die praxis nicht mehr gegeben, sondern zur Frage wird. Drama bezeichnet die Einmaligkeit des Vorgangs des Verbs, nicht das substantivierte Ergebnis dieses Tuns. „,Was tun?" setzt eine Verdopplung des Tuns voraus, ein Tun, das sich selbst zur Frage wird.

CB: Ein Beispiel, wo sich plötzlich ein Raum formiert, der in seiner Erscheinungsform nicht vorhersehbar, sondern wirklich Handeln ist: Es gab einen Moment, wo ich Nora, eine der Darstellerinnen, zugeschaut habe, und es einerseits die Struktur, das Gerüst ihrer Handlung gab, andererseits aber sich die Frage ihres Handelns innerhalb des vorhandenen Rahmens nicht auf ein vor- 
handenes Handeln stützen konnte, so dass es plötzlich bar aller Kriterien war, was für Nora einen unglaublichen Schock darstellte. Mich hat es unglaublich berührt, wie sie dann im Spiel mit den Gegebenheiten agiert hat. Ihr Handeln wurde immer unwahrscheinlicher. Aber immer wieder hat sie versucht, mit dem Vorgefundenen ihr nächstes Tun zu informieren. Sie hat die Suche so ernst genommen und nicht versucht, über irgendwelche Repräsentationen oder Verhärtungen zu flüchten, dass sie fast in ein Verschwinden geriet. Diese Qualität des Tuns ist nicht geschützt. Sie wird nicht geschützt und sie kann auch verschwinden. Denn sie ist sämtlichen Verständnissen von Anwesenheit ausgeliefert. Das finde ich in diesem Zusammentreffen von Theater und Raum so unglaublich risikoreich oder interessant. Sich selbst berühren lassen, aber nicht in Betroffenheit verfallen. Es ist ein bedrohter Ort, der sich nicht wehrt, sondern versucht, diese Art von Formierung weiterzutreiben. Dieses Handeln oder Werden ist auch auf den Zuschauer anzuwenden, der in unterschiedlicher Weise, bewusst oder unbewusst, agiert. 


\section{Claudia Bosse}

\section{ES GIBT KEINE UNSCHULDIGEN RÄUME}

jeder raum ist teil eines territorialen geopolitischen gefüges oder aber jeder raum ist teil eines bestimmten ideologischen einverständnisses oder systems, oder gegenstand einer ideologischen aushandlung raum ist ideologie es gibt keine unschuldigen räume

einige gedanken, fragen, beschreibungen

imagination, synthese, fragment

raum wird hergestellt durch imagination, durch den konstruktiven vorgang des subjekts; dies geschieht an einem ort, und dieser ort ist teil eines systems von konflikten und übereinkünften. imagination ist geprägt durch politische, gesellschaftliche, kulturelle und individuell biografische raster, erfahrungen und erinnerungen. die frage, die sich dabei stellt, ist die: nach welchen mustern werden welche imaginativen folgerungen erzeugt? wie ist die grammatik der erinnerungen, die ein konstruieren von raum bedingt? wie werden diese parameter gesellschaftlich mitbestimmt und herausgebildet? welches wissen oder welche annahmen, oder bedrohungen werden wie und durch wen oder was erzeugt, und wie gelangen diese voraussetzungen $\mathrm{zu}$ mir, dem in diesem fall exemplarischen subjekt, in meine werte, erinnerungen und vorstellungen, die dann von mir abgewägt werden? oder aber, wie werden wissen, annahmen, erinnerungen bestimmbar, analysierbar, in ihren kombinatorischen einflüssen nachvollziehbar, wenn ein wesentlicher teil der raumbildungsprozesse an diesen berechenbar unberechenbaren partner, die imagination, im einzelnen subjekt abgegeben wird, an dieses subjekt, das den raum in seiner vorstellung erst herstellt?

die imagination, als konstruktives zusammensetzen von informationen, ist ein komplettierungsvorgang, der bestimmte informationen zu einem bestimmten kompletten „etwas“ zusammensetzt. die imagination ist teil des herstellungsprozesses von raum, die die materiellen informationen an einem ort aufnimmt und ideologisches, religiöses, politisches, wissenschaftliches wissen in bestimmter weise sortiert und „sinnvoll“ zusammenfügt, raum herstellt.

ein gedanke wurde durch die frage ausgelöst, warum

etwas, das baulich nicht abgeschlossen ist, wie der sicherungsschutzwall in israel, genau diesen sicherungszaun gedanklich erst erzeugt, und dabei die 
idee dieses materiell angedeuteten gegenstandes in einer bestimmten weise im bewusstsein einer gemeinschaft viel manifester herstellt (z. b. der gemeinschaft der bürger israels), als wenn dieses objekt als geschlossenes haptisches konstrukt dastehen würde, als manifestation einer abgeschlossenen und zugleich problematischen idee. die bauliche manifestation hätte dann die möglichkeit, auch vergangenheit werden zu können und nicht immer wieder gegenwart zu werden, in der komplettierenden vorstellung der teilnehmer dieser gemeinschaft. warum ist das so?

warum wird das teil-materialisierte als bedrohte und nicht abgeschlossene idee existenter und gegenwärtiger im bewusstsein vieler?

meine antwort ist, dass der konflikt, der diesen bau als ideologische und zugleich haptische grenze hervorgerufen hat, somit immer wieder aufs neue erzeugt wird und aufgerufen wird, genau aufgrund der absenz des kompletten logischen und haptisch funktionalen gefüges. das heißt, die imagination des einzelnen ist immer teil der verfertigung dieser idee, und die konsequenz dieser angedeuteten idee ist, dass der riss, den die angedeutete bauliche verkörperung hervorruft, immer wieder aufbricht, die möglichkeit eines anderen ausgangs immer wieder offen ist, gerade aufgrund der quasi-offenheit des ausgangs dieses unabgeschlossenen vorhabens; dadurch werden der, den sicherungsschutzwall erzeugende konflikt und die daran gebundenen zweifel und fragwürdigkeiten immer wieder aufs neue in der imagination des einzelnen aufgerufen - die imagination des einzelnen, die geordnet ist durch unterschiedliche überzeugung, anschauung, emotionen des eben diesen schutzwall re- oder besser produzierenden einzelnen. der eigentliche kampfort dieses konfliktes wird die vorstellungskraft des einzelnen, das kollektive imaginäre, da der konflikt, der diesen bau erforderlich gemacht haben soll, immer wieder aufs neue abgerufen wird, erzeugt wird und dieser durch die notwendige wiederholung im bewusstsein sich manifestiert, durch eben die unklare, offene, aber zugleich angedeutete aufteilung des raumes, die angedeutete territorialisierung des politisch religiösen raumes, durch ein-/ausschluss, trennung und eine geografie der angst.

die choreografien der imagination, die initiierung der bewegungen in der vorstellung von nationen, gruppierungen, gemeinschaften, die auch über politische mechanismen ausgelöst und bestimmt werden, sind ein wesentlicher ort der aushandlung raumbildender prozesse. diese raumbildenden prozesse setzen eine bestimmte ethik über wertende relationen, grenzen, ein- und ausschluss voraus und vergegenwärtigen dadurch die ränder des seh-, wahrnehmungs- und/oder vorstellungsbildes.

die zuordnungen, vergleiche und unterscheidungen sind selbstverständlicher und konstituierender teil eines jeden raumbildungsprozesses.

was ist die unterschiedlichkeit der imagination, die aufgerufene informationen in bestimmter weise komplettiert und austrägt, in einem prozess der konstruie- 
renden synthese, in dem verschiedene informationen zusammengefasst und verknüpft werden?

ist die imagination die voraussetzung der synthese oder handelt es sich um parallele und deutlich verschiedene zugriffe?

ist die synthese auch die analyse verschiedener zusammenhänge? und ist die imagination der eher unbewusste sozial, kulturell, politisch, biografisch geprägte apparat der komplettierung bestimmter informationen zu einem informations,,bild“? ist die imagination die geschmierte produktion einer einheit verschiedener teile oder aber der gedankliche rahmen, das spannungsfeld eines gestimmten konfliktes, in dem unvereinbare informationen zusammengefasst werden?

wie hängen beide prozesse mit der raumbildung zusammen?

wenn die imagination die nachahmung einer vorstellung ist, woher generiert sich das wissen um die komponenten dieser vorstellung, die diese nach-ahmung ermöglicht?

jede vorstellung ist also erinnerung. und raum ist immer vorstellung, eine bildung in der vorstellung, in der synthese, durch das zusammenfügen bestimmter informationen, die in meiner vorstellung ein „bild“, einer in mir bereits zugeordneten information, oder mehrerer informationen abrufen.

„um aber irgend etwas im raume zu erkennen, z. b. eine linie, muss ich sie ziehen, und also eine bestimmte verbindung des gegebenen mannigfaltigen synthetisch zustande bringen, so, dass [...] dadurch allererst ein objekt (ein bestimmter raum) erkannt wird.“ (krv b 137-138) kant

der vorgang der analyse endet in der erkenntnis über das wesen einer erscheinung und dessen inneren zusammenhängen. die synthese kehrt diesen vorgang um und versucht, aus den elementen, welche durch die analyse gefunden wurden, ein neues ganzes zusammenzusetzen. dialektisch erhebt die synthese das einzelne auf die stufe des allgemeinen, das konkrete auf die des abstrakten, sie fasst das mannigfaltige zu einer einheit zusammen. dadurch gelangt man mit elementareren zu komplexeren begriffen.

ein raum mit offenen grenzen

das verhandeln des raumes

wie verpflichtet und bindet die offenheit komplettierungs- und synthese-prozesse? was ist ein ort?

was macht einen ort zu einem ort?

wie ist die wahrnehmung eines ortes?

wodurch wird ein ort, ein geografisch bestimmbarer punkt zu einem raum? 
mit welchem wissen, welcher kulturellen, sozialen, politischen und individuellen erfahrung nehme ich die grenze z. b. zwischen israel und den besetzten gebieten wahr? diese grenze ist ein teil von israel und teil auch von dem nicht oder doch existierenden palästinensischen staat (je nachdem, ob man an die gleichberechtigte einstaatenlösung oder aber an die zweistaatenlösung glaubt, ändert es z. b. die lektüre dieser angedeuteten unterscheidung).

die vorstellung des raumes und seiner flüssigen ausgreifungen, seiner zweidimensionalen repräsentationen wie z. b. auf karten etc., bestimmen die vorstellung einer nation über ihr land. die zweidimensionale darstellung ist eine abstrakte skizze, die man in einen sinnvollen zusammenhang übersetzt, und die bewusstsein schafft über ihre grenze.

diese abstraktion teilt, sektioniert und bestimmt einen gedanklichen rahmen, wie z.b. die bedrohte grenze eines ideologischen gefüges; innerhalb und außerhalb dieses rahmens wird der ideologische raum der an diesem raumkonflikt PARTIZIPIERENDEN UND MIT-KONSTRUIERENDEN ERZEUGT (z. b. die bürger dieser landstriche, wie auch die so oder so sympathisierende weltöffentlichkeit). die so oder so repräsentierte abstraktion ist der rahmen einer ideologischen szene, die sich zum teil über praktiken im räumlichen gebrauch und verfahren überträgt, aber auch in der gewichtung des ideologischen feldes bemerkbar macht, über die herstellung des raumes in der gedanklichen konstruktion, oder aber dem akzeptieren oder widersprechen dieser oder jener implizierten kategorien innerhalb und/oder außerhalb dieser bedrohten grenzen und daraus folgenden unterscheidungen.

imaginäre räume

ideologische räume

welche ideologien ordnen die imagination

das aushandeln von räumen und raumregimen

das imaginäre und konkrete aushandeln von raumregimen

es gibt keine unschuldigen räume

ideologie, grammatik, öffentlichkeit

wenn ideologie die grammatik von ideen und vorstellungen einer bestimmten interessengruppe und von machtverhältnissen ist, gibt es dann un-ideologische vorstellungen? und wo sollte es un-ideologische räume geben, wenn die vorstellung immer teil der raumproduktion ist, und meine vorstellung oder teile meiner imagination immer das produkt oder die assoziative zusammenkunft bestimmter unnachgiebiger und z. t. unbewusster ideologien darstellt? 
öffentlicher raum

welcher öffentliche raum ist öffentlich oder vielmehr, vielleicht genauer, eher ort einer bestimmten öffentlichkeit. einer öffentlichkeit, die ihre gemeinsamen zusammentreffen als allgemein wesentliche öffentliche äußerung ansieht, herstellt. öffentlichkeit.

ist der öffentliche raum vielmehr ein emotionaler raum einer gewissen individuell sozialen selbstvergewisserung? je nach teilnahmemöglichkeiten an einer bestimmten öffentlichkeit und eher das gleiten in ein bestimmtes umfeld? wenn es einen rahmen der öffentlichen äußerungsmöglichkeit erhält, ein „aufgehoben sein“ in einem geteilten mentalen zusammenhang der gewisse übereinkünfte, aushandlungs- und raumpraxen nach sich zieht? wo ist der öffentliche raum derer, denen die teilnahme aus unterschiedlichen gründen verweigert wird? derer, die ausgeschlossen werden aus der gemeinschaft der teilhabenden? wo ist ihr raum, ihr öffentlicher raum, auf welche grundlagen, erfahrungen und übereinkünften organisiert sich ihre imagination?

„jeder will teil sein einer erfolgreichen bewegung“ sagte ein interviewter aktivist nach dem anfänglichen scheitern der zeltbewegung in jerusalem, konfrontiert mit dem „erfolg“ der gleichen bewegung in tel aviv. in der folge verändertete sich die situation und der erfolg stellte sich ein in jerusalem. aber was ist erfolg im hinblick auf raum und politische bewegung? wirksamkeit und massenwirksamkeit und die macht, eine bestimmte vorstellung wirksam durchzusetzen und auszubreiten im bewusstsein vieler?

was bedeutet erfolg im hinblick auf raumpraxis und das aushandeln politischer anliegen? erfolgreich ist die vorstellung, die sich möglichst breit durchsetzt, einschreibt in viele vorstellungen. erfolg von vorstellung.

was sind die referenzsysteme und perspektiven in situationen, in denen konflikte politisch ausagiert werden? was sind die mechanismen der aushandlung? wo ist der ort der aushandlung?

perspektive, position und abstraktion

was ist meine perspektive auf etwas und was meine position in situationen? wie funktioniert die grammatik meiner vorstellungen und die lektüre von situationen, die die herstellung von raum und die zuordnung der informationen gemäß meiner perspektive (blick) und position (ort/haltung) bedingt?

warum spreche ich repräsentierend über das unrecht anderer, das mich empört? weil ich nicht in so einer gesellschaft leben will? warum tue ich das und verkehre so meine perspektive im politischen feld und nehme die position anderer ein?

ist das laute formulieren meiner privatisierten ängste in der öffentlichkeit ein akt, der den politischen raum verändern kann? 
ist das sprechen über politische zusammenhänge als andere narrative und ideologische umordnung teil einer veränderung bestimmter raumbildungsprozesse? weil dieser vorgang die konsensualen grammatiken der zusammenfügung bestimmter informationen und annahmen umdefiniert?

was, wenn ich in dem erklären meiner mich betreffenden missstände, ängste und ungerechtigkeiten, dann weit deutlicher betroffene dieser gesellschaft nicht einschliessen kann, weil ich aus meiner position spreche?

was ist meine konkret ökonomische, gesellschaftliche position, aus der ich beginne einen ort zu bestimmen, im raum der gesellschaftlichen aushandlungen? was ist das interesse meiner territorialen allianzen oder abgrenzungen im raum meiner betätigungen? (d. h. im umfeld der kunst oder aber im feld der wissenschaft.)

muss jeder aus seiner perspektive, von seinem ort raum bestimmen, ihn besprechen, ihn herstellen? (was ist mit denen „ohne“ stimme, mit denen, die sich nicht artikulieren wollen, oder können, oder nicht gehört oder verstanden werden. von welchem raum sprechen wir dann?) wo ist ein ort, der raum werden kann?

wenn raum häufig durch die ideologischen gewichtungen materialisiert wird, die z. t. auch durch zweidimensionale abstraktionen, durch karten oder schrift oder moralische zuordnungen in meinem bewusstsein hergestellt werden?

was ist der raum, den ich herstellen kann, im verhältnis zu dem raum den medien herstellen? der mediale raum, der zweidimensionale, visuelle und akustische informationen versammelt und andere imaginationen von mir erwartet. was sind die trigger dieser informationen? wie ordnen die medialisierten informationen meine vorstellung? wie ordnen diese informationen zugleich meine vorstellung über das medium, seine grammatik und abstraktion und als strukturelle ideologie?

aber dennoch sind territorial gedankliche gewichtungen gesellschaftlicher sphären, die an orten ausgetragen werden, prinzipiell anderes, als projizierte und konsensual ausgehandelte annahmen.

was ist raum?

eine dynamische sphäre in der einzelne abstraktionen in gewissheiten übersetzt werden? 
präsenz / stimme / raum - imagination

der raum in der überlagerung von stimmen. stimmen, die orte erhalten, stimmen, die untereinander, übereinander sprechen. die verlagerungen, überlagerungen schaffen wertigkeiten.

stimmen aus einer anderen zeit. stimmen, die schon gesprochenes in diesem moment sprechen, erzeugen etc.

wenn ich ein dokument einer aufgenommenen stimme in einem raum abspiele, existiert diese stimme in diesem moment in diesem raum. weil die schallinformationen der aufnahme durch die lautsprecher, mit entsprechenden einstellungen, ort etc. diese stimme in diesem konkreten raum auftreten lassen. und die stimme und der raum und meine anwesenheit sich vermengen zu so etwas wie gegenwärtiger präsenz. wenn ich eine stimme, die stimme eines bereits gestorbenen menschen in einem raum abspiele, steht mit der stimme diese person für diesen moment des abspielens wieder auf. ist da in der gegenwart. wenn stimmen verschiedener zeiten sich in einem raum begegnen zur gleichen zeit und diese in konstellationen treten, die sie historisch und situativ nie hätten eingehen können, geschieht etwas wie eine rekonfiguration von geschichte und ihren wahrscheinlichkeiten anhand dieser sich treffenden, auftreffenden, sich informierenden stimmen und aussagen. geschichtsschnitte, die in der gegenwart, im moment dieses auftreffens und meines hörens stattfinden.

jede stimme transportiert einen körper und zugleich seine vergänglichkeit, weil der atem den worten in diesem raum dieses körpers über den klang den körper wieder hörbar macht und wiederauferstehen lässt. warum?

die sprache, die auf dem papier steht, ist sprache, die von einem körper erzeugt wurde. sehe ich nur den körper des erzeugers, wenn ich in der handschrift, dem zug des stiftes oder der tinte auf einem papier die zeit und die energie seines schreibers lesen kann. welchen körper hat eine gedruckte schrift?

meine imagination komplettiert die stimme, die aus einem gerät, in einer bestimmten weise klingt, zu einem körper und liest die aufnahme als dokument einer situation in einem raum und zugleich als ein dokument von aufnahmetechniken. die aufgenommene stimme wird zum dokument des sie erzeugenden körpers, des biologischen körpers des erzeugers ihres klanges, ihres alters, ihrer emotionen, ihres verhältnisses zum gesagten und vielleicht dem verhältnis zu den adressaten.

zugleich tritt die stimme über den lautsprecher in diesem raum wieder auf, weil sie sich wieder ausbreitet in dem raum, in dem ich die stimme höre. weil, wenn ich eine stimme höre, höre ich immer auch den raum, in dem sie erklingt. also wird die aufgezeichnete stimme, wenn sie erklingt, gegenwart und entwickelt eine gegenwärtige präsenz, anders als es ein bewegtes bild eines toten erzeugen kann, weil das bild immer auch das bild eines anderen raumes bleibt. 
gegenwart, raum

was ist die gegenwart von raum? die gegenwart des raumes ist die gegenwart des rezipienten als teil des raumes und den informationen, die ihn erzeugen lassen. die gegenwart dessen, der durch vergleiche seiner persönlichen und der kulturellen vergangenheit dinge wahrnimmt, aufnimmt, zusammenfügt und wertet, und sie mit den jeweils zugeteilten informationen in seiner vorstellung zusammensetzt, synthetisiert und raum herstellt. ihn produziert. ein wesentlicher part dieser synthese ist die imaginationskraft des „raumherstellers“, des rezipienten von informationen. seine imagination ordnet, wertet und stellt den entsprechenden raum in seiner vorstellung her. der zeitpunkt dieser abgleichprozesse ist die gegenwart, die zeitliche abfolge, in der informationen gesammelt werden an einem ort. die verarbeitung dieser informationen ist der abgleich mit einer bereits gemachten erfahrung, einem gespeicherten wissen, einer bekannten narration zu oder über diesen raum. voraussetzungen, die die verwertung der gegenwart ordnet, systematisiert. aus diesem vorgang entsteht der zukünftige raum, der raum in der imagination des betrachters, mit dem die wiederum stattfindende gegenwart abgeglichen wird und wieder eine folgende zukunft erzeugt, die vergangenheit wird in der gegenwart.

über licht sehe ich die informationen im raum. d. h., das licht lässt die dinge erscheinen, sichtbar werden. wie ist mein verhältnis zum raum, zum licht, zum himmel, in dem ich sonne, mond und sterne sehe? was sehe ich, wenn ich in den nächtlichen himmel schaue? was sehe ich und welches wissen mischt sich mit dem sehen? ich sehe sterne, oder genauer das licht auf materie, das eigentlich vergangenheit ist, wenn es als licht bei mir ankommt, der stern, der an dem ort, von dem ich in den himmel schaue, sichtbar wird, ist vergangenheit. lichtjahre. kann ich mir die zeit und die entfernung noch vorstellen? vorstellung.

und warum wurde dem zusammenhang bestimmter sternkonstellationen tierbilder zugeordnet, die eigentlich nicht erkennbar sind, wenn ich diese sterne sehe. abstraktion und imagination. woher entstanden? bestimmte leuchtende punkte im himmel wurden, nach längerer beobachtung, für zueinander zugehörig erklärt, weil sie sich zueinander nicht verändern. wie wurden und werden diese zueinanderstehenden leuchtenden punkte ein sternbild? was für ein unglaublicher vorgang! ein sternbild fügt bestimmte lichtpunkte zusammen zu einem system und benutzt ein bild zur übersetzung dieses systems. dieses bild wird zusammengeführt mit einem anderen abbild eines gegenstandes, einem tier, einem gott. aber was für ein unglaublicher abstraktionsvorgang zwischen den für zusammengehörig beobachteten punkten am himmel und der übertragung in ein (tier)zeichen. welche vorstellungen haben diese übertragung und diese abstraktion möglich gemacht? und warum setzt sie sich durch und gelangt in mein wissen? 
territorium, perforation, imagination

bühne und staat, als der zusammenhang von politischer praxis und praxis im theater.

„[...] die mauer ist das emblem und die ikone der trennung. der trennung zwischen bürgern und nicht bürgern, zwischen gaza und westbank. jede dieser territorialen einheiten hat seine eigenen regeln, um das territorium zu kontrollieren. die mauer ist die ikone einen ganzen systems von abgrenzungen. jede grenze schafft spannungen, und ist nicht nur vorhanden zur abtrennung, sie dient der trennung und der kontrolle darüber wie spannungen und kontakte entstehen. sowie der umstand, dass die mauer nicht fertiggestellt wurde. die mauer wird nicht fertiggestellt werden, die mauer ist nicht fertiggestellt worden. das ist ein teil der logik von abgrenzung, das macht die trennung zu einer dynamik und schafft möglichkeiten für interventionen. die mauer ist das barbarischste und destruktivste element in dieser logik. es ist ein monster. wir nennen die mauer den schwanz des monsters, weil das monster das regime ist. die mauer ist der schwanz des monsters. [...]“

das ist ein auszug aus einem gespräch vom 21. mai 2012 mit dem philosophen adi ophir in tel aviv zu der frage, wie er den sicherungsschutzwall um/in israel sieht. der geplante mehr als 110 km lange sicherungswall wurde 2002 zur abwehr palästinensischer selbstmordattentäter zu bauen begonnen und wurde nicht als grenze definiert. ein weiteres system existiert zwischen westjordanland und israel mit geplanten $759 \mathrm{~km}$, dieser bau begann 2003. palästinenser in den sperrgebieten sind rechtlos.

im weiteren gespräch sagte adi ophir, dass als der bau der mauer in israel 2002 begonnen wurde, ihre fertigstellung bis 2005 geplant war. er habe damals nicht geglaubt, dass die mauer fertiggestellt wird. jetzt ist 2012 und die mauer existiert nur zum teil, $60 \%$ bis $2 / 3$ wurden umgesetzt, die mauer existiert mit lücken, mit auslassungen und er ist überzeugt, dass dieser sicherungsschutzwall durch seine lücken viel effizienter ist.

der gedanke hat mich verwirrt und beim genaueren nachdenken sind mir andere erzählungen eingefallen: die landkarten in der schule von israel habe keine klaren grenzen. die karten in der schule zeigen ein gebiet im mittleren osten, ohne klare begrenzung. so denken zunächst alle schulkinder, das israel endlos sei, wie julie khromchenko bei einem interview in jerusalem erzählte. und erst später lernen sie in der schule die geschichte der besetzen gebiete.

das bedeutet vielleicht, wenn grenzen angedeutet und nicht ausgeführt sind, sind diese grenzen kein klares gegenüber, an dem man sich orientieren könnte. zu dem man sich verhalten könnte. sondern ein markiertes, angedeutetes, das sich erst im imaginären des einzelnen zusammensetzen muss und so zwischen dem verschwinden und herstellen mitgeschaffen wird im kopf und bewusst- 
sein jedes einzelnen bürgers. die bedrohung dieser markierung und die mögliche aufhebung dieser markierung, die ideologische bedrohung um diese trennung kreiert umso mehr diese grenze als sortierung eines innen und außen. als einschluss und ausschluss eines territorialen und zugleich nationalen und immer auch ideologischen gefüges.

was hat das alles mit theater zu tun?

theater entsteht im kopf. in der andeutung von handlungen, die sich in der kommunikation von etwas mit etwas im bewusstsein der einzelnen gemeinsamen aushandeln und individuell als emotion, vergleich und sinn zusammensetzen.

die bedrohung eines zustandes oder einer situation macht diese als existierende situation erst deutlich und lässt sie manifester entstehen, die perforation einer kontinuität lässt die not der komplettierung erst entstehen und bindet mich als erzeuger dieser komplettierung an die ideologische szenerie dieser andeutung. die „freiheit“ der vorstellung ist vielmehr die aufforderung einer komplettierung und teil eines bestimmten gedanklichen rahmens.

der ideologische rahmen eines feindes, einer bedrohung, eines anderen, einer anderen ästhetik lässt dieses andere erst existieren. weil die zusammensetzung von „etwas“ immer über den vergleich mit etwas „anderem“ entsteht, wenn wir im binären system denken, in dialektischen konstellationen. die auszeichnung von etwas, deren herausstellung geschieht qua der differenz zu etwas anderem. das sind vielleicht grundregeln ästhetischer entscheidungen, unterscheidungen. grundregeln ethischer entscheidungen, grundregeln politischer entscheidungen.

wo entstehen die räume und wie die entscheidungen?

in der imagination des einzelnen.

wie wird diese imagination konstruiert oder beeinflusst?

oder ist die imagination etwas komplett individuelles?

aber wenn imagination z. t. immer erinnern ist

an etwas schon gewusstes, erfahrenes, dagewesenes?

wie setzten sich diese elemente meiner vergleiche zu einem mehr oder weniger sinnvollen bild eines politischen, oder kulturellen ereignisses zusammen?

was ist da?

was nehme ich wahr?

was setzte ich wie zusammen?

was setzte ich voraus?

was sind die mechanismen und spannungsfelder, die territorien der unterscheidung zeichnen? umzeichnen, abgrenzen und sie zugleich bestimmen? 
relationen, möglichkeiten, lektüre

raum ist ein relationales gefüge von materiellen anordnungen und raumbildenden prozessen, die an diesem ort stattfinden. martina löw bezeichnet dies als raumkonstitutierende prozesse, die diesen raum herstellen, den raum, den der rezipient synthetisiert. also sind vorgänge in einem raum teil eines raumes und die informationen über die bedeutung von elementen, von szenarien der bedrohung oder des zerfalls schreiben sich sofort in die analyse oder wahrnehmung von vorgängen ein, und somit verändern sie den raum, weil er eben kein objekt, oder in diesem sinne kein sich nicht veränderndes gegenüber ist, sondern durch mich, den rezipienten, den produzenten, mein wissen, glauben, emotionen, denken, wahrnehmen erst hergestellt wird.

oder anders:

welchen wert hat etwas? der wert oder die bedeutung erschließt sich erst immer in dem verhältnis zu etwas anderem, im verhältnis des materials, der oberfläche, der information, des status, der lautstärke, der begehrlichkeit, die etwas auslöst etc. es gibt immer einen rahmen, der diese verhältnisse umgrenzt und die maßstäbe liefert, durch das verhältnis der elemente zueinander und meiner perspektive wertigkeiten schafft. die perspektive der betrachtung, die informiertheit des betrachtenden, die wertende einordnung, die psychische verfasstheit des betrachtenden in genau diesem moment.

das heißt, objekte und informationen informieren sich immer gegenseitig und zueinander und werden in den emotionalen und erinnerungsregistern des betrachters eingeordnet. er bestimmt, wenn er bestimmen will, den wert und die wichtigkeit von sich ihm bietenden dingen und wird zugleich mitbestimmt von werten und wissen seiner ihn umgebenden ,kultur“.

oder anders

am beispiel einer raumlektüre:

auf einer insel sagt bei der begrüßung unser vermieter, dass der mann der nachbarin schwer krank ist und im krankenhaus liegt. es sei unsicher, ob er lebend wieder nach hause komme. seitdem observierte ich die vorgänge in dem haus anders. nach einigen tagen des leerstands kam die ehefrau des kranken mit wahrscheinlich ihrem bruder, ich interpretiere ihren gang und versuche an dem gang den krankheitszustand ihres mannes abzulesen. am gleichen tag gab es eine versammlung. die älteren des dorfes standen vor dem haus, diskutieren, warten, telefonieren. meine vermutung, dass der mann gestorben ist und der leichnam nach hause gebracht wird zur aufbahrung. ich lese den raum aufgrund meiner information. wir fahren weg. aber jedes indiz der vorgänge um dieses haus geschah mit dem wissen um den todkranken mann. das leitet mein lesen oder einordnen jeglicher vorgänge um dieses haus. es leitet meine lektüre des raumes und der vorgänge innerhalb dieses raumabschnittes. die information um den kranken verändert meine lektüre von vorgängen, handlungen, bewegungsrhythmen und vom aufenthalt von menschen um dieses haus. die versammlung war die gemeinsame reparatur einer defekten wasserpumpe. ah 
ja. ganz anders. tage später ist wieder jemand in dem haus. im eingang hängt zum auslüften ein schwarzes sakko und ein weisses hemd ...etc. etc.

was sind raumbildende prozesse, welcher teil der raumbildung ist bewusst, welcher gegenwärtig, welcher „real“? welcher teil der raumbildung wird geleitet durch bestimmte informationen, wissen, szenarien? welcher teil der raumbildung ist ein aufgreifen von emotionen oder erfahrungen meiner vergangenheit, von mir als teil eines kulturellen, gesellschaftlichen und politischen gefüges. welche prozesse beziehen sich auf kulturelles oder naturwissenschaftliches wissen, das mir bekannt oder vertraut ist und die koordinaten meiner subjektiv gesellschaftlichen raumbildungsprozesse sind? was ist imagination?

gibt es freiheit in der vorstellung? 


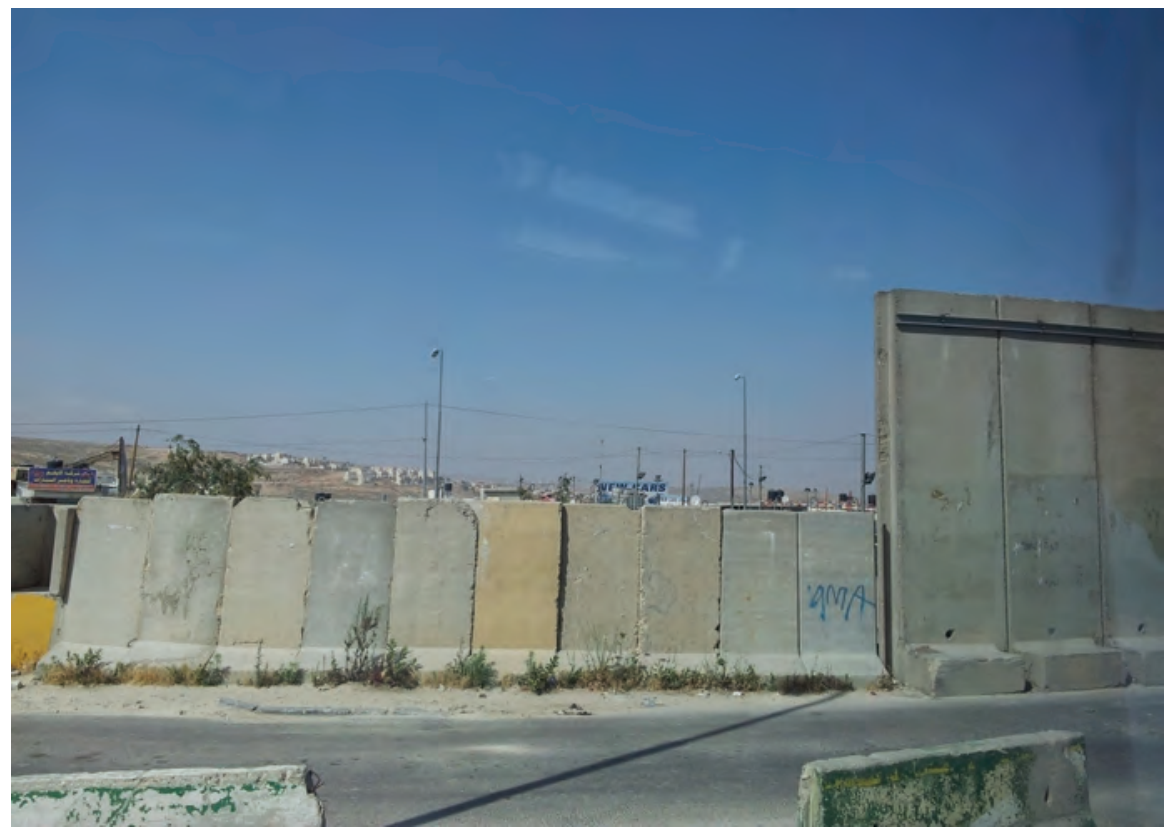

1 - Der israelische „Schutzwall“ aufgenommen im Mai 2012, auf dem Weg von Jerusalem (IL) nach Ramallah (PS) 


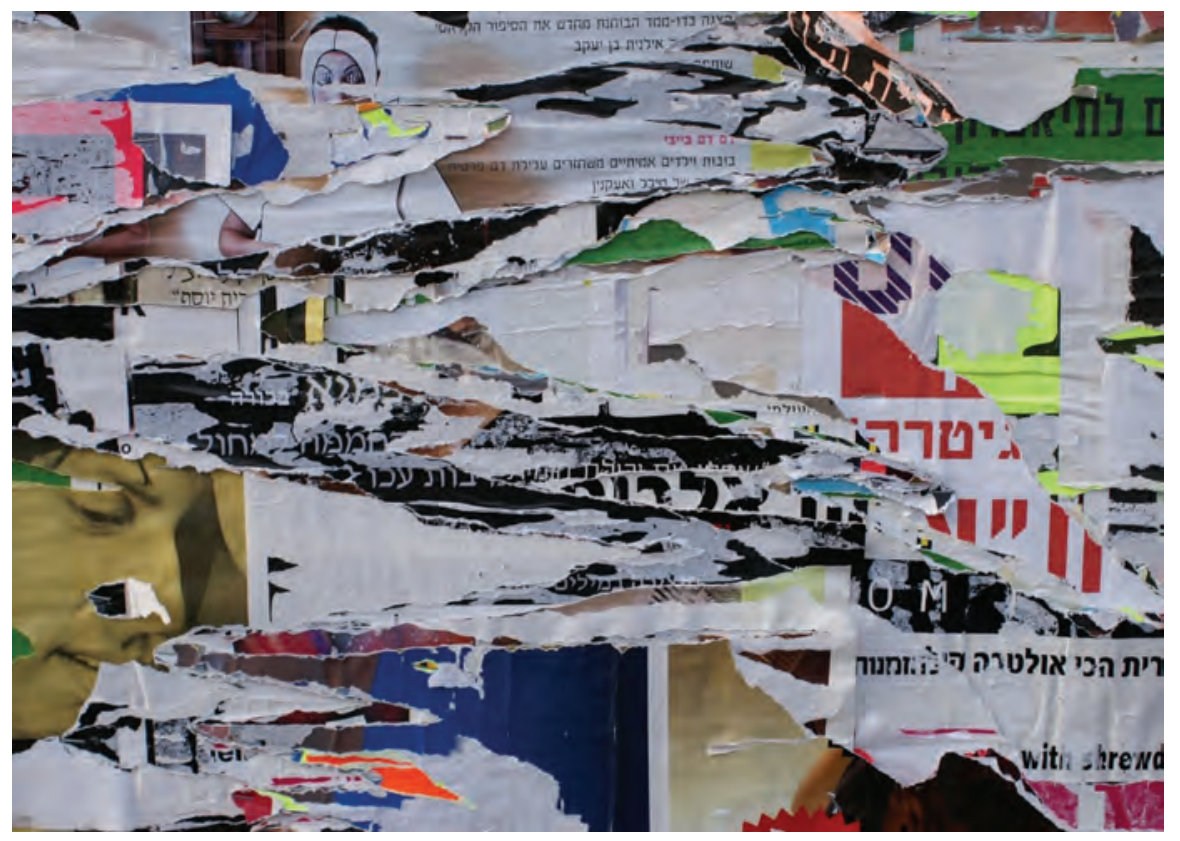

2 - Mai 2012, Tel Aviv (IL) 


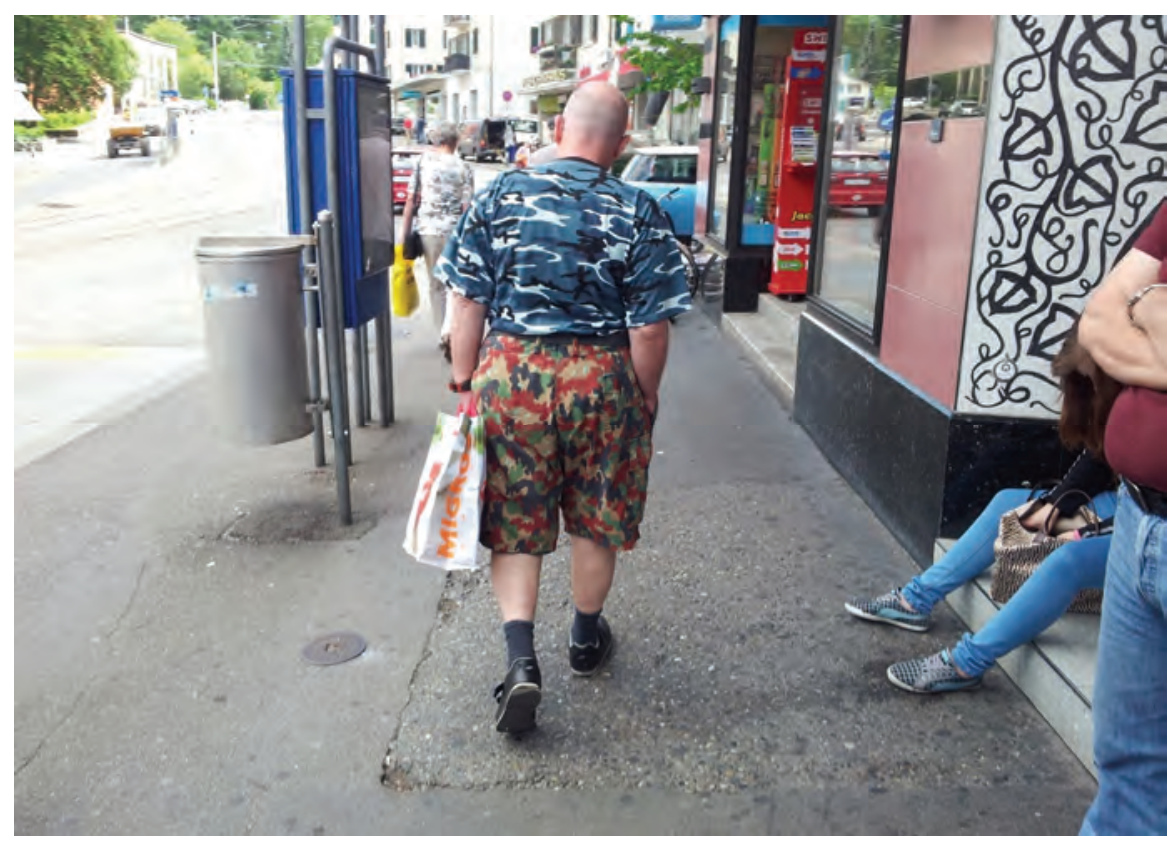

3 - Straßenszene, Juni 2012 in Zürich (CH) 


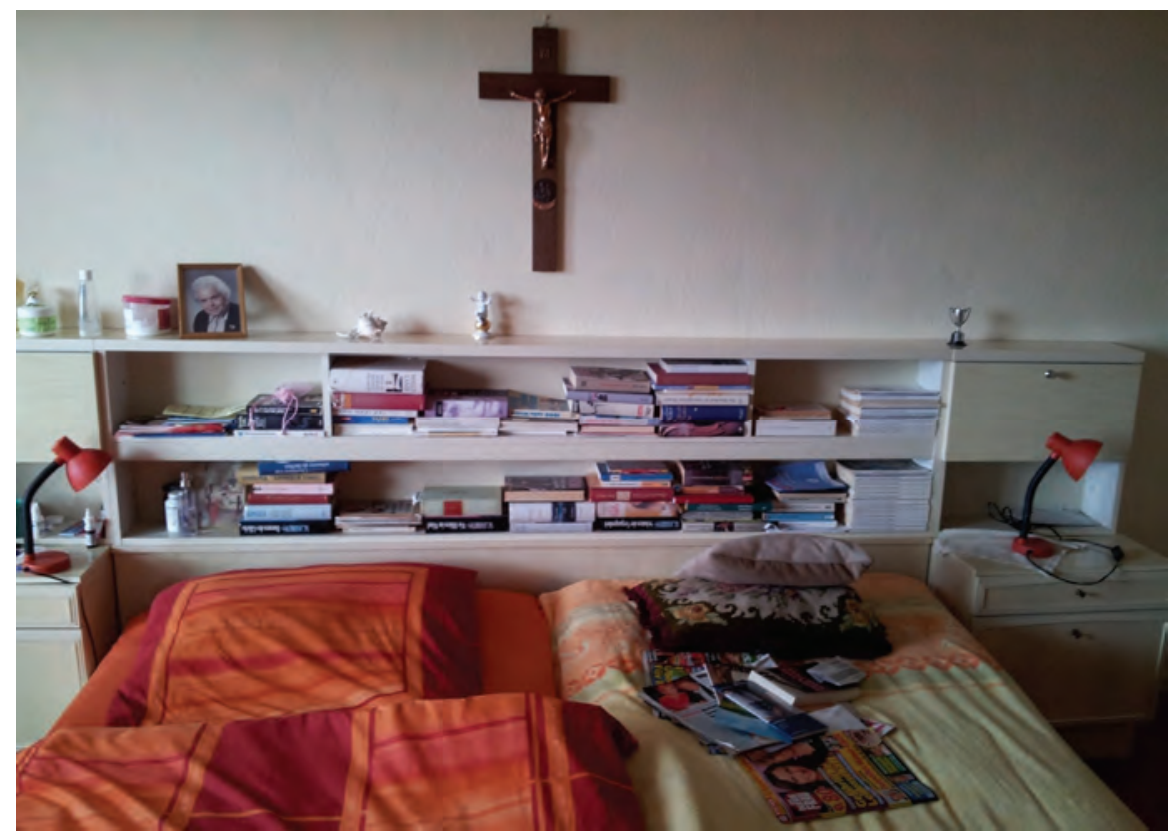

4 - Bett meiner Großmutter, April 2012 in Salzgitter (D) 


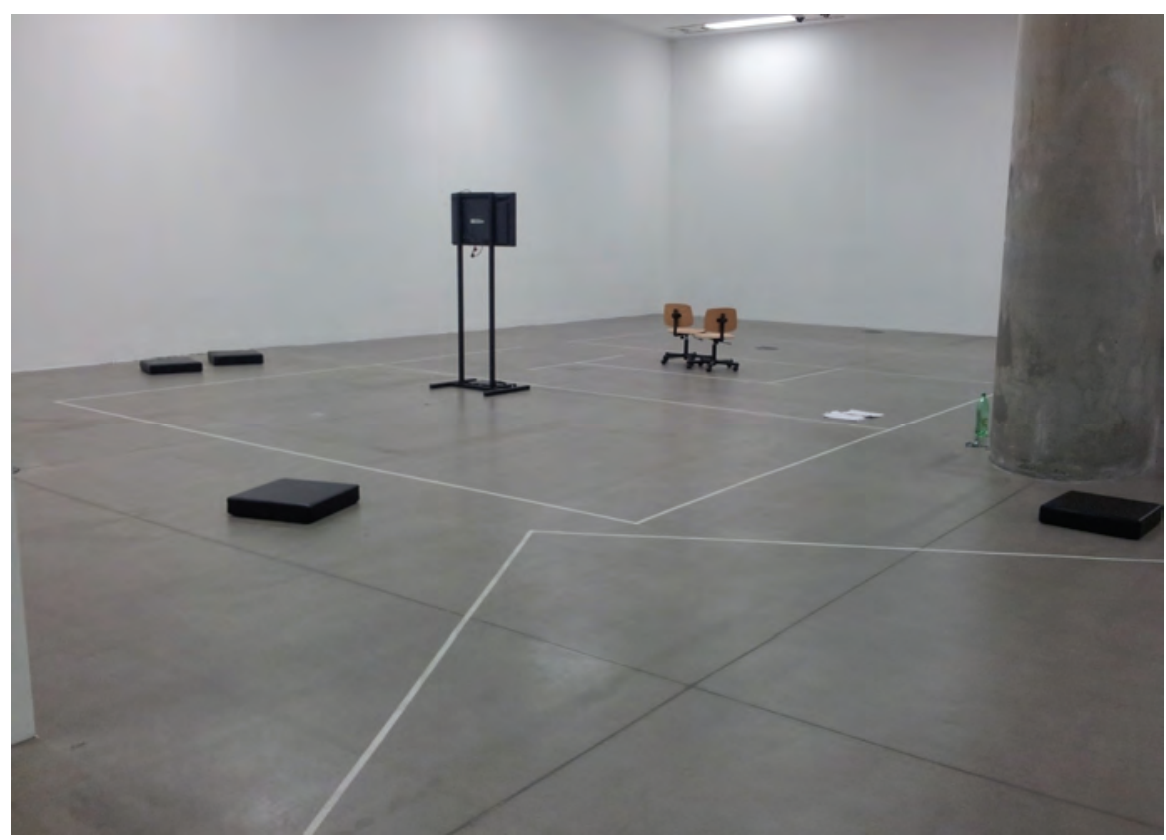

5 - Raumfragmente meiner Installation „Biografical Landscapes of New Zagreb“, Juni 2012 im Museum of Contemporary Art/MSU Zagreb (HR) 


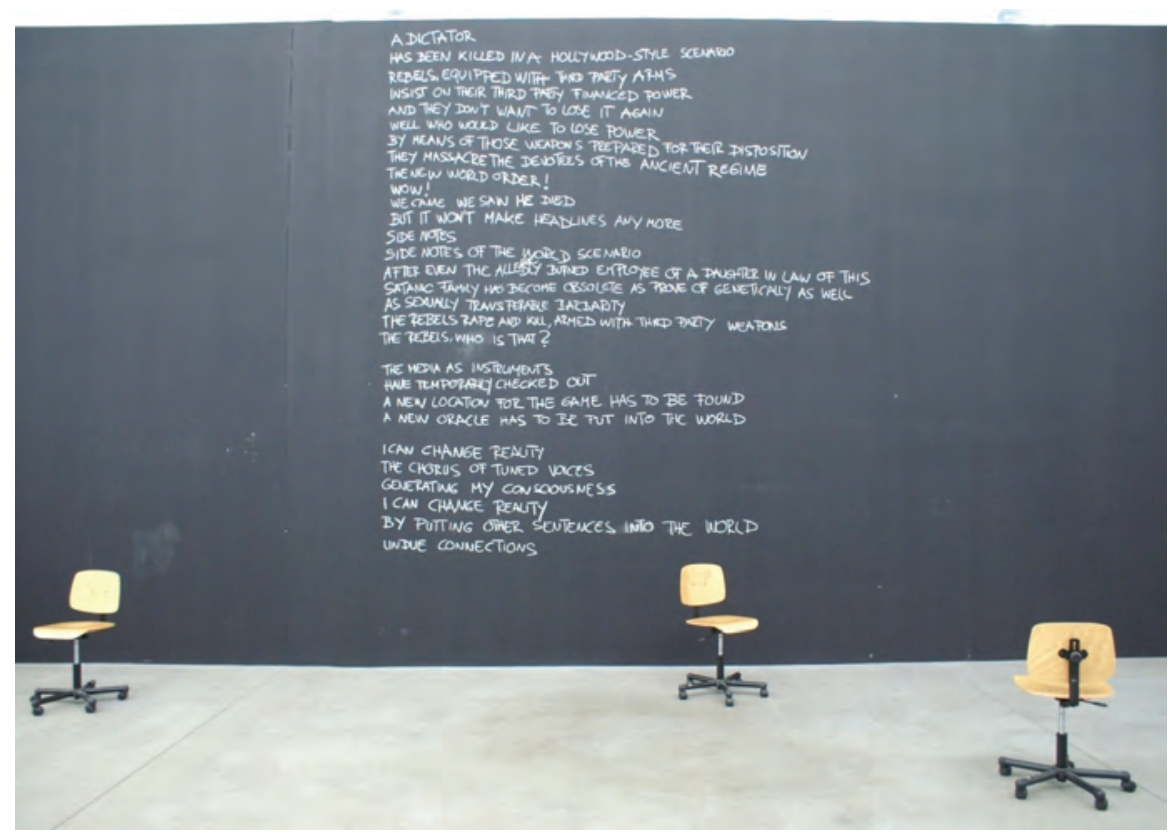

6 - Raumfragmente meiner Installation „Biografical Landscapes of New Zagreb“, Juni 2012 im Museum of Contemporary Art/MSU Zagreb (HR) 


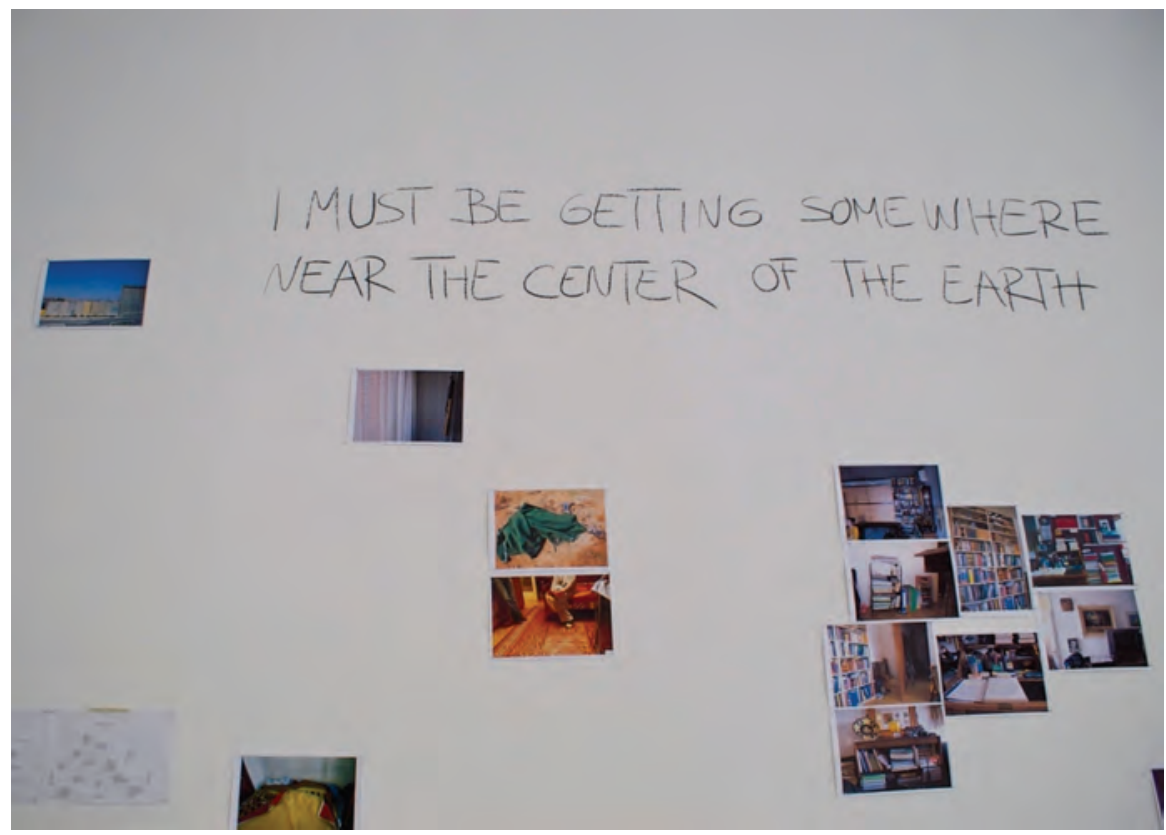

7 - Raumfragmente meiner Installation „Biografical Landscapes of New Zagreb“, Juni 2012 im Museum of Contemporary Art/MSU Zagreb (HR) 

ENTFALTETE RÄUME 



\section{BÜHNE DES DRAMAS. PRIMÄRE EXPOSITION UND RAUM ÄSTHETISCHER ERFAHRUNG}

Mit der Infragestellung oder der Sprengung der Repräsentation in gegenwärtigen Theaterpraktiken tritt die Erfahrung der Raumzeit als sich ereignender hervor. Die Bühne wird dabei nicht mehr als Bedingung für die Darstellung einer in sich geschlossenen Welt bzw. einer Raumzeit verstanden, die sich einem zuschauenden Subjekt darbietet. So setzen sich heutige Praktiken von der Guckkastenbühne ab, welche vermeintlich die in ihr sich darstellende Welt zum Gegenstand eines zuschauenden Subjekts machte.

Gegen die Vorstellung, dass die Guckkastenbühne dem Zuschauer Raum und Zeit als Bestand zur Verfügung stellt, möchte ich hier die Nicht-Gegebenheit, Nicht-Gegenständlichkeit der in der Guckkastenbühne sich darstellenden Welt oder Raumzeit aufweisen. Das Feld meiner Befragung ist der Zusammenhang zwischen Guckkastenbühne und Drama.

Für die deutschsprachige Theaterwissenschaft bleibt Peter Szondis kurze Beschreibung der formalen, ästhetischen Merkmale des neuzeitlichen Dramas ein Kapitel von sechs Seiten in seinem schmalen Band Theorie des modernen Dramas - bis heute grundlegend. Szondi behauptet dort einen unwidersprechlich notwendigen Zusammenhang zwischen Guckkastenbühne und Drama: „Dem Drama einzig adäquat ist die Guckkastenbühne“, schreibt er ${ }^{1}$, worunter er das in der Renaissance entstandene „Drama der Neuzeit“ versteht. ${ }^{2}$ Es gibt also für Szondi eine ästhetische Notwendigkeit, welche Guckkastenbühne und Drama verbindet, die darauf begründet ist, was „Drama der Neuzeit“ ist. Dieser Zusammenhang wird von Szondi abstrakt und allgemein behandelt. Ohne Bezug auf konkrete Dramen reflektiert er das Drama der Neuzeit mit Hegel philosophisch, bzw. er leitet die formalen, ästhetischen Merkmale des neuen Dramas aus einer philosophischen, von Hegel stammenden Reflexion dessen her, was das neue Drama ist.

Das Interessante daran ist, dass der Zusammenhang zwischen Guckkastenbühne und Drama, so wie Szondi ihn behauptet, nicht die Repräsentation einer gegebenen, dem Zuschauer zur Verfügung gestellten Raumzeit ist. Bühne und

Peter Szondi, Theorie des Modernen Dramas, Frankfurt/M., 1959, S. 16.

Ebd., S. 14. 
Drama bieten sich nicht der Vorstellung eines zuschauenden Subjekts an, sondern Bühne und Drama sind das Stattfinden einer Subjektivität.

Was hier mit Subjektivität gemeint ist und welche - im Ausgang von Szondi - Verbindung zwischen Drama, Bühne und Subjekt genau besteht, werde ich zuerst herausarbeiten. Es geht mir in diesem Schritt darum, zu zeigen, dass im Stattfinden der dramatischen Subjektivität, und das heißt eben schon in der Guckkastenbühne, die Erfahrung der Nicht-Gegebenheit und Nicht-Gegenständlichkeit der im Drama sich entfaltenden Raumzeit auftritt. Dieser Hypothese nach setzen sich also die neueren Verwandlungen der Bühne in nichtdramatischen Theaterformen - Verwandlungen der Bühne, die raumgreifende Prozesse erfahrbar machen - nicht von der Guckkastenbühne ab, sondern radikalisieren lediglich das, was schon Szondi als neuzeitliche Bedingung des Dramas gedacht hat: Sie lassen eine Erfahrung der Raumzeit in den Vordergrund treten, die schon in der Guckkastenbühne, nämlich hinter einer Fassade der Gegenständlichkeit, enthalten ist.

Die raumzeitliche Dimension dieser sich im Drama ereignenden Subjektivität werde ich anschließend am Beispiel einer vermeintlich nicht dramatischen Aufführung, Goschs/Schütz'/Schimmelpfennigs Idomeneus, zu veranschaulichen versuchen.

Das neuzeitliche Drama versteht Peter Szondi im Ausgang von zwei Grundzügen, die, wie er sagt, Hegels ästhetischen Ausführungen entnommen sind: Das neuzeitliche Drama ist, erstens, der Akt des Sich-Entschließens des Menschen zur Mitwelt, weder das Diesseits noch das Jenseits dieses Aktes, und, zweitens, dieser Akt als absoluter, d. h. als reiner Bezug. Das Drama kennt, wie Szondi schreibt, nichts außer sich. ${ }^{3}$ Diese Absolutheit macht aus dem im Drama sich entfaltenden zwischenmenschlichen Bezug einen Selbstbezug. So ist die im Drama entstehende Subjektivität das Zu-sich-Kommen des sich entfaltenden zwischenmenschlichen Bezugs. Die Objektivität oder die Gegenständlichkeit dessen, was im Drama verläuft, bzw. der zwischenmenschliche Bezug, wird selbst zu einer Art von Subjekt. Subjekt heißt hier: Bezug auf sich, Auftritt des „sich selbst“ von Etwas, zu sich kommen.

Die Guckkastenbühne ist Bedingung für die Entfaltung dieser Subjektivität, für den Auftritt oder das Stattfinden dieser Absolutheit:

3 „Der Mensch ging ins Drama gleichsam nur als Mitmensch ein. [...] Der ,Ort‘, an dem er zu dramatischer Verwirklichung gelangte, war der Akt des Sich-Entschließens. Indem er sich zur Mitwelt entschloß, wurde sein Inneres offenbar und dramatische Gegenwart. Die Mitwelt aber wurde durch seinen Entschluß zur Tat auf ihn bezogen und gelangte dadurch allererst zu dramatischer Realisation. Alles was diesseits oder jenseits dieses Aktes war, mußte dem Drama fremd bleiben: das Unausdrückbare sowohl wie der Ausdruck, die verschlossene Seele wie die dem Subjekt bereits entfremdete Idee.“ Ebd., S. 14. Und „Das Drama ist absolut. Um reiner Bezug, das heißt: dramatisch sein zu können, muß es von allem ihm Äußerlichen abgelöst sein. Es kennt nichts außer sich.“ Ebd., S. 15. 
Die Bühnenform, die sich das Drama der Renaissance und der Klassik schuf, die vielgeschmähte ,Guckkastenbühne‘, ist der Absolutheit des Dramas als einzige adäquat und zeugt von ihr in jedem ihrer Züge. Sie kennt Übergang (etwa Treppen) zum Zuschauerraum sowenig wie das Drama vom Zuschauer sich stufenweise abhebt. Sie wird ihm erst bei Beginn des Spiels, ja, oft erst nachdem das erste Wort gefallen, sichtbar, also existent: dadurch erscheint sie als vom Spiel selbst erschaffen. Bei Aktschluß, wenn der Vorhang fällt, entzieht sie sich wieder dem Blick des Zuschauers, wird gleichsam vom Spiel zurückgenommen und als zu ihm Gehörendes bestätigt. Die Rampe, die sie beleuchtet, bezweckt den Anschein, als spende das dramatische Spiel auf der Bühne sich selber das Licht. ${ }^{4}$

Statt von vornherein die Auflösung der dramatischen Bühne in neueren Theaterformen zu verfolgen und sie als mit einer totalisierenden Identität verknüpft zu bekämpfen, sollte erst einmal hinterfragt werden, wie diese Totalität, Subjektivität oder Absolutheit gemeint ist. Was geht in ihr auf? Denn das, was Hegel als das Absolute im Drama gedacht hat, ist nicht die Gegebenheit einer in sich geschlossenen Welt. Die absolute Subjektivität des Dramas ist nicht die Aufhebung der zwischenmenschlichen Dialektik in die Gestalt der dramatischen Welt, die sich dem aneignenden Zuschauerblick bietet; sie gibt nicht das Modell für den vorbildlichen Subjekt-Bürger. Das Absolute im Drama ist vielmehr eine Form des $\mathrm{Zu}$-sich-Kommens des sich entfaltenden dramatischen, zwischenmenschlichen Bezugs, eine Form, die das erfährt, was ihr darin unendlich entgeht.

Hegels Geschichtsphilosophie der Kunst zufolge steht das Absolute im Drama für die Erfahrung der Nicht-Gegebenheit des Sinns oder der Zweckmäßigkeit des Menschen (des „Geistes“). In Hegels Geschichtsphilosophie sind die Gestalten der griechischen Skulptur dem Drama vorgängig. Jene Gestalten waren schön, d. h. für Hegel absolut als sinnliche, unmittelbare Erscheinungen des Göttlichen, d. h. des höchsten Sinns, des Endzwecks des Menschen, so wie dieser in diesem Moment der Geschichte erfahrbar werden konnte. Jedoch vermochten die Skulpturen absolut bzw. schön zu sein nur, indem sie der Welt enthoben waren und sich miteinander nicht in Bezug setzten. Dagegen stand das antike Drama für den Eintritt des Göttlichen (sozusagen des Sinns) in die endliche Welt, in die Praxis: Es stand für das Moment, den Akt des sich Entschließens zur Mitwelt. Mit der dramatischen Handlung traten die schönen Gestalten in die Welt hinein, setzten sich miteinander in Bezug und kollidierten, weil der absolute Anspruch jeder Gestalt die anderen ausschloss.

Das antike Drama sah Hegel als die Auflösung der Einseitigkeit dieser kollidierenden Mächte im Erkennen der Notwendigkeit des Untergangs jener Auffassung des Sinns (des „Geistes“), welche die griechische Skulptur (die „Kunstreligion“) haben konnte. Das Absolute im Drama ist keine unmittelbare Erscheinung des Göttlichen. Es ist keine Erscheinung des Geistes als eines

4 Ebd., S. 16. 
Gegebenen, Unmittelbaren, sondern als eines Sich-Gebenden: als der Akt des Sich-auf-sich-Beziehens, und in diesem Sinn als Subjekt.

Weil aber das Element der Kunst das Sinnliche ist, kann sie für Hegel den Geist nur unmittelbar zur Anschauung und Empfindung bringen. Deswegen ist die Erfahrung der Notwendigkeit des Untergangs der Kunstreligion im antiken Drama sogleich das Auftreten der Einschränkung des sinnlichen Absoluten, d. h. der Kunst. Zwar bleibt die Kunst auch nach dem Ende der Kunstreligion eine Form des Absoluten. Dieses Absolute hat jedoch innerhalb der Gesellschaft eine andere Funktion als die Kunstreligion: Es weiß, dass die neue geschichtliche Form von Subjektivität, die neue Form von Geist- oder Sinnerfahrung, es übersteigt. Es ist ein Absolutes, das in sich das erfahrbar macht, was es übersteigt; eine Subjektivität, die sich auf das hin öffnet, was ihr entgeht; oder - noch - eine Form, die das formt, was ihr entkommt.

Das neuzeitliche Drama entsteht zusammen mit dem Ästhetischen allererst auf der Grundlage dieser Erkenntnis. Das neuzeitliche Drama geht aus der Kunst nach dem Ende der antiken Kunstreligion hervor und steht für die Aufhebung der dramatischen Kollision in die Reflexivität des Ästhetischen. Es ist nicht tragisch, denn sein Anspruch ist nicht der der Kunstreligion, die im antiken Drama zu ihrem notwendigen Niedergang kommt. Es kennt seine eigene ästhetische Grenze.

Gleichwohl ist es in einem neuen Sinn absolut. Es ist die Entfaltung der dramatischen Handlung als reiner Bezug zu sich selbst, ein Prozess, der schon im antiken Drama hervortritt: die Einheit von Produkt und Produzieren, das ästhetische Werk als Tun und Tätigkeit, nicht als gegeben, sondern als sich gebend. Das neuzeitliche Drama reflektiert sein eigenes ästhetisches Tun. Es stellt auf ästhetischer Ebene einen Prozess der Subjektivierung dar. So bildet die sinnliche Entfaltung der dramatischen Kollision eine ästhetische Totalität.

Szondi, Hegel interpretierend, übersetzt einerseits die Absolutheit des Dramas und andererseits den Akt, dessen Entfaltung das Drama ist, mit einigen formalen, ästhetischen Merkmalen, von denen eines die Guckkastenbühne ist. Hegel aber schränkt den absoluten Charakter des Dramas ganz und gar nicht auf das neue Drama ein und leitet aus seiner Absolutheit nicht diese formalen Merkmale ab. Er redet nirgendwo von Guckkastenbühne oder von Rampe.

Szondi lesend, gewinnt man fast den Eindruck, das neue Drama wäre in Hegels Sinn vollständiger als das antike, denn in ihm erst (durch Ausschaltung des umgebenden Raums usw.) gelangt der zwischenmenschliche Akt vollständig zu sich und wird vollständig absolut. Das stimmt aber für Hegel keineswegs. So entsteht der Eindruck, dass, mit Hegel gedacht, das neue Drama vollständig dem neuen Absoluten bzw. dem Subjekt entspricht. Das aber ist mit Hegel völlig unmöglich zu behaupten, denn das neue Drama entspricht zwar der neuen geschichtlichen Form des Absoluten, dem Subjekt, kennt aber gleichwohl seine eigene Einschränkung als Kunst und öffnet sich auf das, was ihm entkommt. 
Der Eindruck, der bei einer ersten Lektüre von Szondi entstehen kann, dass die Guckkastenbühne deshalb dem neuen Drama adäquat ist, weil sie die Bedingung für die Darstellung einer geschlossenen Welt ist, erweist sich demnach als falsch. Sie ist falsch, weil diese Bühne Bedingung für ein Absolutes ist, das gleichwohl Endliches genannt werden kann.

Die Guckkastenbühne beruht auf diesem Sinn des erst in der Neuzeit gebildeten ästhetischen Absoluten. Sie stellt eine raum-zeitliche Abgeschiedenheit aus, die die Darlegung einer Situation und einer Zeit, welche aus sich selbst erwuchs, erlaubt. Erst dank dieser Abgeschiedenheit wird die Selbst-Übernahme, d. h. die ästhetische Reflexivität der dargestellten Handlung möglich. Die Guckkastenbühne ist also nicht bloß die Bedingung für die Entfaltung einer anderen Raumzeit. Vielmehr erlaubt sie die Entfaltung einer absoluten Raumzeit, einer Raumzeit, die nicht vorgegeben ist und in Bezug zu nichts außer sich steht. Die Trennung vom Zuschauerraum und der Entzug aus der umfassenden Raumzeit ist die Bedingung der Möglichkeit für die Entfaltung und Erfahrung der dargestellten Raumzeit als absoluter.

Das Drama gelangt zu dieser Totalität erst in der Neuzeit, wenn es die ästhetische Grenze seines Absoluten erkennt und in und aus diesem heraus sich selbst, also „total“ erkennt. Wenn Szondis Beschreibung des neuzeitlichen Dramas von Hegel stammt, dann setzt sie eine Auslegung des Status voraus, den Hegel dem neuzeitlichen Drama beimisst und der so explizit nicht bei Hegel formuliert wird.

Das Absolute des neuzeitlichen Dramas ist, indem es Kunst ist, eine der höchsten Formen der Freiheit. Es ist diese aber nur, indem es seine eigene Negativität kennt. Es kennt seine Negativität nicht als notwendiger Untergang der Kunstreligion (wie die antike Tragödie), sondern als Form eines Absoluten, das sich gleichzeitig schon als begrenzt kennt. Es kann diese höchste Form der Freiheit nur sein, indem es sich als endliche Form, d. h. als nur ästhetisch kennt. So ist das neuzeitliche Drama das Auftauchen eines Absoluten, das auf seine eigene Überwindung, Aufhebung oder Destruktion verweist.

So stößt die Frage nach der Bedeutung des Absoluten im neuzeitlichen Drama auf die Frage nach der Bedeutung der Kunst nach dem Ende der Kunstreligion bei Hegel, die unterschiedlich interpretiert wurde und interpretiert werden kann. Eine Weise, die Bedeutung, die Hegel dem neuzeitlichen Drama beimisst, zu interpretieren, ist, sie als sekundär, dienend oder komplementär für außerhalb der Kunst sich bildende Bereiche auszulegen. ${ }^{5}$ Es ist möglich, die Negativität, die mit der Schranke der Kunst auftritt, in Bezug auf ihren

\footnotetext{
Bspw. sieht Annemarie Gethmann-Siefert in Schillers Drama bzw. im Drama nach der Kunstreligion „eine Orientierung im Handeln durch eine Vorbereitung des Handelns in der Reflexion“. Dies., „Hegel über das Hässliche in der Kunst“, in: Andreas Arndt/Karol Bal/Henning Ottmann (Hg.), Hegel-Jahrbuch 2000, Die Kunst der Politik - Die Politik der Kunst, Berlin, 2000, S. 21-41: 38.
} 
Beitrag zu dem, was sie selbst nicht erfüllen kann, zu untersuchen: Ihren Beitrag zur Bildung eines guten Bürgers, den sie selbst nicht bilden kann.

Weit entfernt davon, die vollständige Gestalt einer Subjektivität im neuzeitlichen Drama zu sehen, setzt Szondis Beschreibung ihrerseits auch eine Auslegung der Art und der Bedeutung des Absoluten des neuzeitlichen Dramas implizit voraus. Mir scheint, dass Szondi das sozusagen endliche, ästhetische Absolute im neuzeitlichen Drama als antinomisch versteht: Als Absolutheit der Form, die inm Widerspruch zum Inhalt gerät, einen Widerspruch, der die Auflösung der Form des neuzeitlichen Dramas vorantreibt, ihre Entwicklung in anderen Formen, die er in seinem Buch analysiert. ${ }^{6}$

Ich werde hier nicht die Folgen untersuchen, die diese Interpretation des dramatischen Absoluten als eines nur formalen bzw. des Dramas als eines antinomischen für die räumliche Dimension der Theateraufführung und der Bühne hat. Ich möchte zwar mit Szondi feststellen, dass das dramatische Absolute ein endliches ist: dass es darin nicht um die Aufhebung der zwischenmenschlichen Dialektik in die Gestalt der dramatischen Welt und ihrer zeiträumlichen Dimension geht. Gegen Szondi jedoch möchte ich dieses endliche Absolute nicht als ein nur formales interpretieren.

Ich möchte den absoluten Charakter des Ästhetischen im neuzeitlichen Drama ernst nehmen, d. h. das Paradox jenes endlichen Absoluten reflektieren, ohne seine Absolutheit zu nivellieren. Als Absolutes ist das neuzeitliche Drama kein Mittel für einen außer ihm liegenden Zweck. Dafür muss seine ästhetische Schranke als unendlich reflektiert werden. Das Paradox dieser unendlichen Endlichkeit kann auch so verstanden werden: Es lässt in seiner Gestalt die Vergänglichkeit des Aktes seiner Gestaltung erscheinen. Es lässt die Plastizität dieser Gestaltung erscheinen, als Verräumlichung dessen, was es von vornherein als Entgangenes kennt. So gesehen, bringt die Negativität der Kunst im neuzeitlichen Drama nicht die Einsicht in das notwendige Scheitern seiner Zweckmäßigkeit hervor, sondern sie bringt die Plastizität seines Auftauchens zur Anschauung und Empfindung. Sie macht die Gestalten als reine Gestaltungen erfahrbar, als die Entfaltung der Formen. ${ }^{7}$ So begriffen, wird das neuzeit-

6 „Eine eigentliche Form-Semantik läßt sich auf diesem Wege entwickeln, und die Form-Inhalt-Dialektik erscheint nun als Dialektik zwischen formaler und inhaltlicher Aussage. Damit ist jedoch schon die Möglichkeit gesetzt, daß die inhaltliche Aussage zur formalen in Widerspruch gerät. Bewegt sich im Falle der Entsprechung von Form und Inhalt die inhaltliche Thematik gleichsam im Rahmen der formalen Aussage als eine Problematik innerhalb etwas Unproblematischem, so entsteht der Widerspruch, indem die fraglos-feststehende Aussage der Form vom Inhalt her in Frage gestellt wird. Diese innere Antinomie ist es aber, die eine Dichtungsform geschichtlich problematisch werden läßt, und das hier Vorgelegte ist der Versuch, die verschiedenen Formen neuerer Dramatik aus der Auflösung solcher Widersprüche zu erklären.“ Ebd., S. 11.

7 In diese Richtung wird Hegel u. a. von Jean-Luc Nancy gelesen (Jean-Luc Nancy, Die Unruhe des Negativen, Zürich, 2011). Vgl. auch Catherine Malabou, L'avenir de Hegel. Plasticité, temporalité, dialectique, Paris; 1996 und Susanna Lindberg, Heidegger contre Hegel, Paris, 2010. 
liche Drama in ein neues Licht gestellt und eine Kontinuität zu heutigen Theaterformen erkannt. In diese Perspektive möchte ich im Folgenden die Auffassung der Bühne als Container rücken.

Die Guckkastenbühne wird als Bedingung für die Entfaltung einer anderen Raumzeit aufgefasst. Die Abgeschiedenheit vom gegebenen Zeitraum, die Trennung von den Zuschauern wird als Bedingung für ihre Identifikation mit der ausgestellten Welt verstanden, die, dank dieser Abgeschiedenheit, total erscheinen darf. Aber was heißt hier total? Es heißt erstens, dass das Gezeigte sich auf sich selbst bezieht; dass seine Entfaltung, d. i. seine „Handlung“, der sich entfaltende zwischenmenschliche Bezug, dieser Selbstbezug ist. Es wird nicht etwas gezeigt, sondern etwas so entfaltet, dass es zu sich kommt, dass es innerhalb seiner Kontingenz die Notwendigkeit (bspw. den Ablauf der Handlung als aus der dramatischen Situation notwendig hervorgehend) dartut und so frei wird.

In die Perspektive der Bedeutung des neuzeitlichen Dramas gestellt, öffnet sich das Zu-sich-Kommen, das sich in dieser Form formt, auf das, was ihm in ihm entgeht. So ist diese Form ihr eigenes Entspringen, ihre eigene Formierung. Sie ist ein Absolutes, das seiner Endlichkeit als der Plastizität seines Stattfindens zustimmt. Vor diesem Hintergrund, und über Hegel hinausgehend, ist die Abgeschiedenheit der Bühne Bedingung für die Entfaltung dieser Handlung als Entspringen aus der Abgeschiedenheit: Nicht eine andere gezeigte Welt, sondern die Emergenz selbst der Welt, die sich jeweils verräumlicht oder zeitigt.

So gesehen sind die Worte, Gesten und Bewegungen auf der dramatischen Bühne keine in sich geschlossene Welt, sondern das Auftauchen einer Welt, die ihre eigene Errichtung im Außen ist (man sollte bspw. die dramatischen Figuren nicht als Charaktere denken, sondern vor allem als Orte eines Aussprechens, das Bezüge schafft, je nachdem, wie etwas ausgesprochen wird). Diese Funktion der Bühne gibt die sogenannte Achse der binnendramatischen Bedeutung durchweg als Theatron-Achse zu denken: die Bedeutung, der $\mathrm{Zu}$ sammenhang, die Figuren, die Zeit und der Raum der Fiktion, kurz das Innere (des Werkes) werden weder als gegeben, noch als nichtig erfahren. Das angeblich „Innere“ des Werkes ist nie gegeben, sondern nur sich gebend, als ausgestellte Äußerlichkeit, die, indem sie Außen ist, indem sie sich dem Blick, dem Gehör, der Begegnung gibt, einen Raum zeitigt.

„Die Schauspieler bei Aufführung eines Dramas sprechen nicht nur untereinander, sondern mit uns, und nach beiden Seiten hin sollen sie verständlich sein. Und so ist jedes Kunstwerk ein Zwiegespräch mit jedem, welcher davorsteht ${ }^{\text {, }}$, schreibt Hegel. Dieses Zwiegespräch, aus dem hier entworfenen Hin-

8 Georg Wilhelm Friedrich Hegel, Vorlesungen über die Ästhetik, Werke 13-15, auf der Grundlage der Werke 1832-1845 neu edierte Ausgabe, Redaktion Eva Moldenhauer u. Karl Markus Michel, Frankfurt/M., 1986. S. 341. 
tergrund heraus verstanden, zeitigt den Raum der ästhetischen Erfahrung. Die ästhetische Erfahrung ist nicht die Wahrnehmung des Gesagten, Gehandelten der dramatischen Welt. Sondern die ästhetische Erfahrung ist die Welt, die sich jeweils, in jeder Aussage, jeder Geste erschafft, ohne in einer Gestalt zu gerinnen. Wir nehmen als Zuschauer nicht ein Etwas wahr, sondern wir gelangen mit jedem Wort, jedem Blick und jedem Gestus jeweils anders zu einem anderen „wir“, zu einem anderen „ich“, zu einer anderen Welt.

Das ist kein performatives Ereignis, denn es geht nicht um etwas, das hervorgebracht wird und die Zuschauer verwandelt. Es ist vielmehr ein Entzug, der aus der dramatischen Totalität bewirkt wird: die Entleerung jeder Gestalt, nicht nur des Werkes, sondern auch der Zuschauer. Die dramatische Totalität ist im Grunde genommen ein sich aus dem Entzug, aus dem Ausschnitt heraus Begreifen/Erfahren/zur Anschauung und Empfindung Kommen und noch mehr, sie ist das Sich-Begreifen als dieses Entspringen selbst: „Sich“ als das in den jeweils entspringenden, errichtenden, raumgreifenden Bezügen Aufgehende.

Der Entzug jeder gegebenen Raumzeit ist die Bedingung für die Erfahrung der Emergenz selbst der Zeit, die sich zu keiner vorhandenen Zeit umdrehen lässt, und die Emergenz selbst einer Äußerlichkeit, die Raum greift.

So verstanden, stellt die dramatische Bühne nicht bloß etwas dar, sondern stellt jenes Etwas als seine Darstellung dar. Sie exponiert nicht etwas, sondern macht in jenem Etwas seine Exposition erfahrbar und macht sogar jenes Etwas als sein Exponieren, als sein Nach-außen-Stellen erfahrbar.

Wenn die neuzeitliche dramatische Bühne die Bedingung für die Aufhebung der dramatischen Kollision im ästhetischen Absoluten ist, d. h. wenn die neuzeitliche dramatische Bühne die Entfaltung der dramatischen Handlung als einen reinen Bezug zu sich selbst erlaubt, dann höhlt sie gleichzeitig jenen „reinen Bezug“ aus. Weil das neuzeitliche dramatische Absolute seine Endlichkeit kennt und seine Destruktion verlangt, macht es sich als seine eigene Plastizität erfahrbar. Deshalb ermöglicht die dramatische Bühne jenen reinen Bezug zu sich selbst - das vermeintlich ästhetisch gebildete „Selbst“ des Dramas - als reinen Bezug zum Anderen zu erfahren: Als das sich dem Blick, dem Gehör, den Sinnen, dem Denken Gebende, bzw. dem Anderen Gebende, der selbst entleert von einer vorhandenen Raum-Zeit, jener errichteten Äußerlichkeit entgegenkommt.

Ich möchte diese Funktion der Bühne am Beispiel der Bühne von Johannes Schütz für Schimmelpfennigs Idomeneus in der Regie von Jürgen Gosch untersuchen, ein Stück, das 2009 am Deutschen Theater Berlin uraufgeführt wurde. Es ist kein Drama im herkömmlichen Sinn, jedoch verstricken sich Text, Regie und Bühne dicht miteinander, indem sie, meiner Meinung nach, die Grundbedingung des neuzeitlichen Dramas offen auftreten lassen. Um die ästhetische Funktion dieser Bühne zu präzisieren, möchte ich kurz den dramatischen Hintergrund skizzieren. 
Das Thema stammt aus dem trojanischen Mythenkomplex. Idomeneus, König von Kreta, gerät auf der Heimfahrt nach zehnjährigem Krieg in ein mörderisches Unwetter und verspricht, um sein Leben zu retten, das erste Wesen, das ihm auf Kreta begegnet, zu opfern. Das wird Idamantes sein, sein Sohn. Von da an werden nacheinander verschiedene mögliche Variationen der Abwicklung des Mythos erzählt: Dass er seinen Sohn tötet und dann selbst von seinen Männern umgebracht wird; dass er seinen Sohn nicht töten will, aber schließlich doch tötet und deswegen vom Volk verbannt wird; dass er seinen Sohn nicht tötet und daraufhin vom Volk verbannt wird usw.

Von der Geschichte des Krieges ausgehend, handeln alle Variationen des Mythos von der (tragischen) Kollision bzw. der Vernichtung des Anderen, die das Übermaß des Einen, welcher seine Endlichkeit nicht kennt, mit sich bringt und von der Notwendigkeit seines Untergangs bzw. von der Erkenntnis der Schuld seines Übermaßes. Also das tragische Thema schlechthin: Die Auflösung der Einseitigkeit der Mächte, die Erkenntnis, dass die Mitwelt diese Mächte notwendig in den Untergang führt, d. i. die Erkenntnis einer unüberwindbaren Endlichkeit, aus der das Subjekt und die Freiheit entspringen können. Gleichzeitig verstricken sich mit diesem Thema komische Elemente. Indem bspw. mögliche Versionen der Abwicklung des Mythos diskutiert werden und so die Figuren sich selbst verhandeln, zeigen sie sich, mit Hegel formuliert, als sich an ihnen selbst unmittelbar auflösend.

Trotz des tragischen und komischen Erkennens ist dieser Idomeneus weder tragisch noch komisch. Tragisches und Komisches „stumpfen sich“ hier „wechselseitig ab“, um es mit Hegels Beschreibung des neuzeitlichen Dramas zu formulieren. Das Erkennen der Endlichkeit, das gleichzeitig das Entspringen der Freiheit ist, wird immer wieder vorgeführt, immer wieder erfahren, ohne zu einer neuen, vermeintlich freien Zeit, einer Zeit nach dem Aberglauben, wie es in Schimmelpfennigs Text heißt, zu gelangen. Das Erkennen der Endlichkeit wird immer wieder vorgeführt, immer wieder im Wissen, dass es unmöglich ist, zu einer solchen anderen Zeit zu gelangen.

Kennzeichnend aber für das ästhetische Ganze scheint mir der gegen Ende vielmals wiederholte Ausspruch: „Ich hänge am Leben“. Mir scheint, dass es ästhetisch grundsätzlich um das Bestehen eines conatus geht, der aus der Erfahrung der Endlichkeit entspringt und das Leben bejaht, ohne die Endlichkeit zu übersteigen: Dass es um die Plastizität des Lebens selbst geht, das keine gegebene Form hat, sondern das Entspringen von Formen selbst ist.

Denn das, was in der Aufführung ästhetisch vorgeführt wird, ist das Beharren in diesem „Dazwischen“: Weder eine absolute Gestalt, noch ihr Niedergang, sondern aus der Erfahrung der Notwendigkeit jenes Niedergangs, d. h. aus der Erfahrung ihrer unüberwindbaren Endlichkeit, das Auftauchen selbst des Subjekts, das aber keine Figur ist oder sein kann, sondern die Welt, die sein Auftauchen verräumlicht, die Welt, die dieses Entspringen jeweils ist.

So bietet Schütz’ Bühne keinen Rahmen, in dem die Figuren sich bewegen; sie umrahmt nicht das Nach- und Nebeneinander einer Welt. Die Bühne ist 
hier eine blendend weiße Wand, eine Oberfläche ohne Tiefe, stark beleuchtet, dicht an der Rampe vor den Zuschauern errichtet, mit einer genauso weißen Bank, auf der elf Schauspieler sitzen, stehen, sich drängen. Die Schauspieler sind Orte des Aussprechens, das zwischen ihnen hin und herspringt, sich verteilt, ein Chor in immer anderen Konstellationen. Gleichzeitig wird das Ausgesprochene mit einer beeindruckenden körperlichen Intensität lebendig bzw. gespielt. Die Todesangst, die Leichtigkeit oder die Schwere, das Jung- oder Altsein werden mal von einem, mal von mehreren Schauspielern gleichzeitig gespielt. Jedoch wird dieses Spiel nie zu einer in sich geschlossenen Welt mit ihrer eigenen Raumzeit.

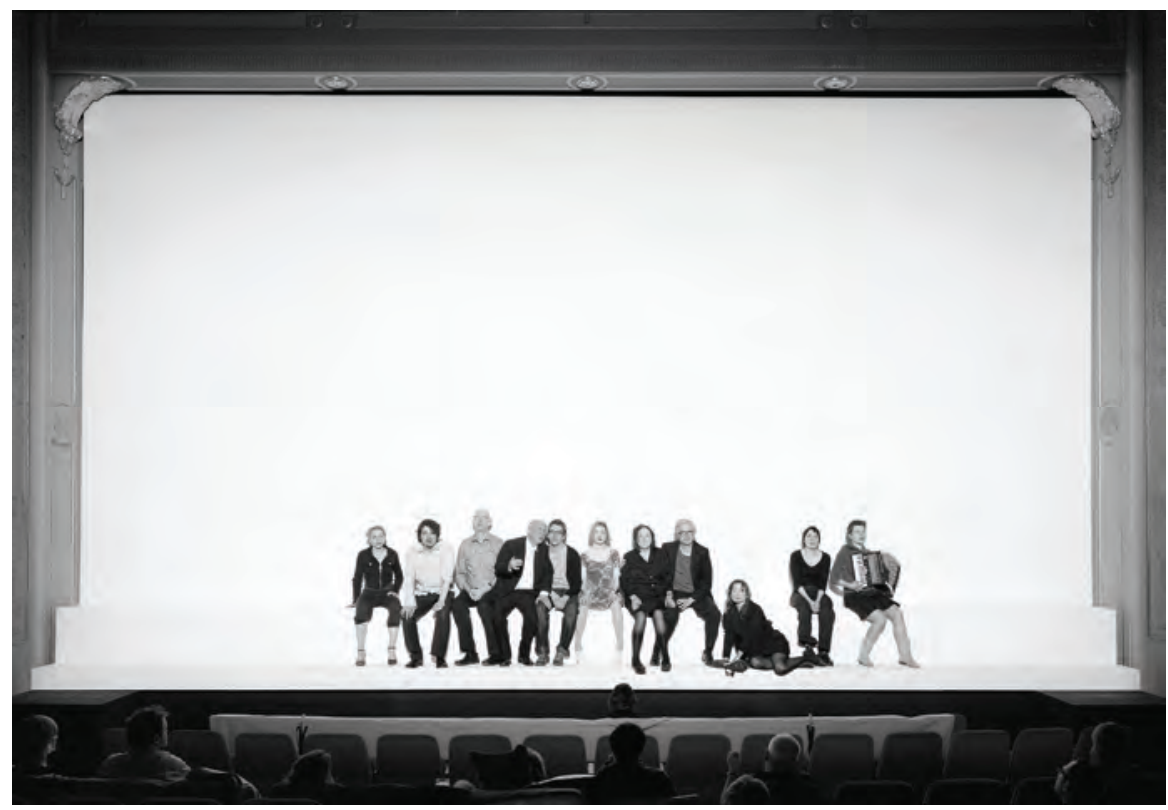

1 - Idomeneus, von Roland Schimmelpfennig, Regie: Jürgen Gosch, Bühne: Johannes Schütz, Deutsches Theater Berlin, 2009

Die Bühne wird nicht erst zu Beginn des Spiels als vom Spiel selbst erschaffen sichtbar, sondern bleibt ständig sichtbar. Die Grundbedingung des Spiels wird offengelegt: die Bühne, die das Spiel, als seine eigene Errichtung im Außen, ist.

So bleibt der Blick der Schauspieler durchgängig nach vorn gerichtet, hin zum Ende des Saals, der selbst durchgängig nicht im Dunkeln versinkt. Ihr Blick bleibt nach vorne gerichtet, auch wenn sie sich zueinander wenden. So wird das Im-Außen-errichtet-Sein ihres Spiels spürbar bzw. es wird als nicht in festen Bezügen gebunden, als ungebunden von der Gestalt einer Welt mit verkörperten Rollen spürbar, und trotzdem oder deshalb immer wieder andere 
Bezüge schaffend in der gespielten Geschichte, andere Zusammenhänge in der ständig sich wandelnden Konstellation, andere Dispositionen der auftretenden Intensitäten.

Diese sich wandelnden Dispositionen sind die Handlung, um die es geht. Der Chor selbst tritt als diese Handlung auf: Als der Akt des Eintritts in die Praxis, d. h. in die Mitwelt. Wie Szondi schrieb: Weder das Diesseits noch das Jenseits dieses Aktes, weder eine Koexistenz gegebener Substanzen noch eine Handlung individueller Gestalten, sondern die unbändige Emergenz von Welten als Miterscheinung immer anderer Intensitäten.

Diese auf nichts, auf kein Dekor, keinen Rahmen, auf keine Perspektive hinter der flachen Bühne zurückgreifende Körperlichkeit, die sich auf und um die enge Bank zwischen Rampe und Wand drängt, sowie die Dringlichkeit bzw. die körperliche Intensität, mit der - vor der stark beleuchteten weißen Wand - das Gesagte und Gespielte hervortritt, machen das jeweils Gesprochene und Gespielte in dem schwebenden Moment, in dem es sich errichtet, in dem es im Außen stattfindet, ergreifbar.

Einmal wird ein Fenster mit einem Kopf, Idomeneus' Sohn, mit Kohle auf die weiße Wand gemalt. Einmal streut einer der Schauspieler den anderen weißes Puder auf den Kopf, während sie gerade das Altsein spielen. Selbst dieses minimale Dekor wird als Geste vorgeführt und in seiner vergänglichen Entfaltung sichtbar. Die jeweils sich schaffende Welt wird in ihrer Entstehung erfahrbar und in der Schwebe gehalten, synkopiert von der Endlichkeit, aus der immer wieder andere Zusammenhänge entspringen und andere Bezüge verhandelt werden. Es geht nicht um die hergestellten Bezüge zwischen auf der Bühne verkörperten Rollen und vor der Bühne sitzenden Zuschauern, sondern um das Sich-im-Außen-Errichten, das als solches gerichtet ist.

Diese Bühne, die das Auftreten der sinnlichen Intensitäten erfahrbar macht und alles von der Endlichkeit dieses Auftretens durchdringen lässt, die gleichzeitig aushöhlt und belebt, veranschaulicht die Grundbedingung des neuzeitlichen Dramas. Eine radikal endliche, punktuell, lokal, horizontal auftretende Eröffnung der Freiheit: Eröffnung von Orten, die keine gegebenen Orte sind oder werden können, absolute, d. h. auch inäquivalente Orte als pulsierende Eröffnungen von Raumzeiten, die keine Epiphanien sind und keinen geschichtlichen Wandel ankündigen, sondern die nicht-außerordentliche Raumzeit, die jeweils ein immer anderes „Wir“ ist, adressieren. 


\section{Literatur}

Gethmann-Siefert, Annemarie, „Hegel über das Hässliche in der Kunst“, in: Andreas Arndt/Karol Bal/Henning Ottmann (Hg.), Hegel-Jahrbuch 2000. Die Kunst der Politik - Die Politik der Kunst, Berlin, 2000, S. 21-41.

Hegel, Georg Wilhelm Friedrich, Vorlesungen über die Ästhetik, Werke 13-15, auf der Grundlage der Werke 1832-1845 neu edierte Ausgabe, Redaktion Eva Moldenhauer u. Karl Markus Michel, Frankfurt/M., 1986.

Lindberg, Susanna, Heidegger contre Hegel, Paris, 2010.

Malabou, Catherine, L'avenir de Hegel. Plasticité, temporalité, dialectique, Paris, 1996.

Nancy, Jean-Luc, Die Unruhe des Negativen, Zürich, 2011.

Szondi, Peter, Theorie des Modernen Dramas, Frankfurt/M., 1959. 


\section{DER SCHNITT DURCH DEN RAUM ALS WAHRNEHMUNGSKONSTELLATION}

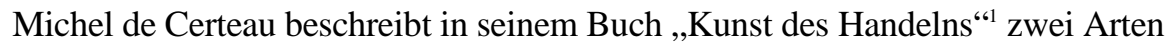
von Raumwahrnehmung. Am Beispiel New Yorks schildert er einerseits den Blick vom World Trade Center herunter auf die Straßen und die direkte Anwesenheit im Stadtraum andererseits. Gottgleich, aus sicherer Distanz erhält man von oben einen machtvollen Überblick auf die Ordnungen und Strukturen; dagegen lässt die Anwesenheit in den Straßen New Yorks keinerlei Distanzierung zu. Das unmittelbare Spüren der eigenen Befindlichkeit rückt hier ins Zentrum. ${ }^{2}$ Dieses Beispiel zweier Raumwahrnehmungen von New York soll mir als Leitfaden dienen, den Schnitt durch den Raum einzuführen.

Gegenwärtig verlassen viele Inszenierungsprojekte den Theaterbau und suchen den öffentlichen Raum als Aufführungsort. Dies bringt für alle Beteiligten Herausforderungen mit sich, die ein erweitertes Denken in Bezug auf Raum und Raumwahrnehmung erfordern und sich vor allem in der Darstellung, in den Inhalten und der Frage nach dem erschaffenen Gefüge widerspiegeln. Theater und theatrale sowie performative Ereignisse finden unter den neuen Anforderungen in gänzlich anderen Wahrnehmungskonstellationen statt als innerhalb des Theaterbaus.

Im Folgenden schlage ich vor, die theatrale Situation mittels des Atmosphärenbegriffs von Gernot Böhme als Schnitt durch den Raum leiblicher Anwesenheit zu charakterisieren. Die These ist, dass mit dem Theaterbau seit jeher versucht wurde, den verschiedenen Schnitten durch den Raum leiblicher Anwesenheit, denen wir auch in unserem Alltag begegnen, eine materielle Basis zu verleihen. Der Theaterbau schafft es so, dem Schnitt durch den Raum Dauer zu verleihen, ihn kontrollierbar zu machen und so einen Raum des Theaters bereitzustellen, in dem Wirklichkeit erschafft werden kann.

Ich will den Schnitt durch den Raum entlang der von Michel de Certeau eingeführten zwei Perspektiven vorstellen. Zum einen geht es um eine abgerückte Betrachtung von Raum und im Speziellen den klassischen Theaterbau. Dabei stehen Eigenschaften von Raum und dessen Ordnung im Vordergrund, aber auch wie ein Schnitt Raum verändert und strukturiert. Zum anderen aber lässt sich der Schnitt durch den Raum auch als Teil leiblicher Wahrnehmung charakterisieren; beschreibbar wird er dann als Phänomen in der Wahrnehmung.

Michel de Certeau, Kunst des Handelns, Berlin, 1988.

Vgl. ebd., S. 179-181. 


\section{Materielle Schnitte durch den Raum}

Der klassische Theaterbau kann als Apparatur der Trennung verstanden werden, die einerseits den Alltag auszugrenzen versucht, andererseits einen Raum des Theaters schafft, der eine Anordnung bereitstellt, die den Publikumsraum vom Aufführungsraum abtrennt. Ein Aspekt dieser durch materielle Mittel und Konventionen erzeugten Trennung und der damit anvisierten Trennschärfe ist, Theaterereignisse kalkulierbar und kontrollierbar gegenüber Unvorhersehbarkeiten und ungewollten Störungen $\mathrm{zu}$ machen. Gleichzeitig bildet sie aber auch die Basis für eine bewusste Manipulation von Raum, Wahrnehmung und Handlungen sowie die Erzeugung von Ereignissen und Inszenierungen. Der Schnitt wird so als Mittel der Stabilisierung von theatralen und performativen Ereignissen eingeführt. Ebenso lassen sich aber auch Spielarten von Schnitten im Prozess des Erzeugens solcher Ereignisse ausmachen. Der kreative Prozess des Inszenierens und Erschaffens findet als eine Art Zusammenschnitt von Kompetenzen, Ideen, Professionalisierungen und Formen statt.

Vom Schnitt durch den Raum zu sprechen, bedeutet - so vermutlich die erste Assoziation Vieler - von der Trennung auszugehen. Ein sehr einfaches Bild davon bietet das Zerschneiden eines Blatts Papier. Der Schnitt erzeugt eine Trennung, die nicht ohne Weiteres rückgängig gemacht werden kann.

Bei einem Stück Papier haben wir es mit einem Ding zu tun. Stellt sich die Frage, was geschieht, wenn man sich in den Raum begibt? Im Raum kann der flächige Schnitt als Mischform zwischen Raum und Objekt beschrieben werden, der von Gemälden, Bildschirmen oder einer Kinoleinwand erzeugt wird. Ein Bildraum trennt sich vom Raum der Anwesenheit ab. Ähnlich ist es bei mobilen Räumen, wie dem Auto, der Eisenbahn oder auch Flugzeugen. Hier von Schnitten durch den Raum zu sprechen geht insofern auf, weil man sich mit ihnen innerhalb eines autonomen Innenraums durch einen abgetrennten Außenraum bewegt. Der Außenraum wird durch Fenster und Öffnungen in den Außenflächen aus dem Innenraum heraus erfahren. Das Reiseideal sieht vor, dass zwischen Innen- und Außenraum eine so große Differenz entsteht, dass der Außenraum als Raum eigener Anwesenheit verschwindet. Das Außen wird zur bildlichen Projektion eines von der eigenen Befindlichkeit abgetrennten Raumes. ${ }^{3}$

Ganz anders ist es nun, wenn man den Raum durchschneidet, in dem man sich befindet. Man kann Mauern hochziehen oder Gräben ausheben, aber die dadurch entstandenen angrenzenden Räume lassen sich in der Regel nicht voneinander ablösen. Der Graben schafft Entfernung zwischen zwei Bereichen und trennt sie physisch voneinander ab. Aber je nach Breite gibt es eine akustische oder visuelle Anbindung. Auch wenn eine Mauer eine akustische und visuelle Anbindung minimiert, die Nähe des Raums dahinter ist immer präsent. Vor

\footnotetext{
Vgl. Joachim Paech, Literatur und Film, Stuttgart, 1988, S. 73; Wolfgang Schivelbusch, Geschichte der Eisenbahnreise, München, 1977, S. 51-53.
} 
allem aber können Mauern und Gräben überwunden werden. Nicht zuletzt liegt es immer auch im Interesse der Erbauer, dass es Durchgänge und Brücken gibt, die den Grad an Durchlässigkeit regulieren. Die Schnitte weisen eine gewisse Trennschärfe auf, welche aber niemals absolut sein kann.

Betrachtet man die Funktion der Schnitte, so lässt sich weiter differenzieren: Mauern und Wände bilden nicht nur einen ausgrenzenden Schnitt, sondern es besteht ja auch die Möglichkeit die Umgebung, also das Wetter, die Kälte oder den Alltag auszugrenzen. Dieser Schnitt sieht vor, dass der Mensch ihn überwindet, in manchen Fällen wird ein Eindringen sogar schmackhaft gemacht. Dafür werden Übergangsräume bzw. Schleusen konzipiert, die zum einen ein Hineinfinden erleichtern, aber auch den Übergang explizit spürbar machen. Das trifft besonders auf Kaufhäuser oder Einkaufspassagen zu, deren Ziel es ja ist, die Kunden möglichst lange bei sich zu halten. Die neue ThierGalerie in Dortmund wirbt in einem Videospot mit dem Slogan „Abschalten, Wohlfühlen, Leben““4. Das Shoppingcenter wird zum Ort erhoben, an dem man den Alltag abstreift und sich gerne aufhält. Ganz gleich, ob sich dieser Werbeslogan auch tatsächlich einlöst, der Übergang von Außen ins Innere eines Gebäudes soll als Raumwechsel erlebt werden, der mit mir etwas macht. Die Materialität des Gebäudes hilft dabei, allein schon weil Wind und Wetter draußen bleiben, vielleicht auch weil ich mich darin wohl fühle oder - ganz profan -, weil ich etwas kaufen möchte. Die hier suggerierte Trennschärfe wird materiell erzeugt und dient dazu, ein besonderes Wahrnehmungsgefüge zu schaffen: Ich soll mich wohlfühlen.

Mit dieser Perspektive bekommt der Schnitt durch den Raum eine neue Ausrichtung. Denn die Trennung, um die es ja immer wieder geht, wird erzeugt, um eigene Wirklichkeiten zu schaffen; dafür werden Umgebungen und Zustände sowohl ausgeschlossen als auch bewusst hergestellt. Wobei wirklich hier als das verstanden wird, was einem gegenwärtig und spürbar ist und real das, „was dinglich dahinter stehen mag“. ${ }^{5}$ Genau hierauf sind das Theater, vor allem der tradierte Theaterbau im Besonderen spezialisiert. So etabliert der Theaterbau sehr unterschiedliche Raumschnitte, die ebenso mit Trennung und der Überwindung von Trennung sowie sehr unterschiedlichen Ausformungen von Trennschärfe versehen sind. Die Bereiche wie das Foyer und alles, was sich daran anschließt, sind Übergangsräume. Sie dienen dazu, den Gast in den Raum des Theaters - den Raum, in dem Bühnen- und Publikumsraum aufeinandertreffen - zu überführen. Bei diesem theaterbaulichen Schnitt geht es darum, den Außenraum auf ganz unterschiedlichen Ebenen auszuschließen. Das betrifft neben Wind und Wetter auch den Alltag der Gäste, damit sie sich ganz auf eine Aufführung einlassen können.

Vgl. www.thiergalerie.de/das-center/ueber-uns, zuletzt abgerufen am 31.03.2012.

Gernot Böhme, Aisthetik. Vorlesung über Ästhetik als allgemeine Wahrnehmungslehre, München, 2001, S. 57. 
Aber auch im Raum des Theaters wird durch materielle Mittel Trennung erzeugt. Diese sind aus gutem Grund nicht so massiv und trennscharf, wie die bisher beschriebenen. Vielmehr haben wir es mit materiellen und von Konventionen bestimmten Andeutungen zu tun, die aufgrund ihrer Durchlässigkeit auch eine gewisse Labilität mit sich bringen. Das wohl anschaulichste Beispiel für einen objekthaft symbolischen und auf Konventionen aufbauenden Schnitt findet sich im Raum des Theaters eines tradierten Theaterbaus. Das fängt mit dem Portal und der Rampe an, betrifft die Anordnung und Ausrichtung der Bestuhlung für die Theatergäste, den Vorhang als eigenständigen Akteur ${ }^{6}$, aber auch den Orchestergraben der Oper. All dies sind Elemente, die ihren Beitrag dafür leisten, dass der Bühnenraum klar vom Publikumsraum abgetrennt ist. Damit aber Theater überhaupt stattfinden kann, müssen letztlich beide Räume zueinander durchlässig sein. Der Schnitt kann auf der materiellen Ebene nur symbolisch und entlang gewachsener Konventionen hergestellt werden, was immer bedeutet, dass er eben anfällig und labil ist. Ein naheliegendes Beispiel: Die Schauspieler können in den Publikumsraum eindringen und umgekehrt.

Die räumliche Trennung, so notwendig sie zu sein scheint, hat aber auch Folgen für die Wahrnehmung im Raum des Theaters. Denn die Mittel, um die architektonisch erzeugte Trennung zwischen Bühnen- und Publikumsraum zu überwinden, sind in erster Linie die Fernsinne des Menschen. Der Theaterbau konzentriert die Anwesenheit des Gasts im Raum darauf, im Sehen und Hören sowie in seiner Gegenwärtigkeit im anderen Raum anwesend zu sein. Ebenso nimmt der so zum Zuhörer und Zuschauer gewordene Gast im Raum des Theaters jene Position ein, die ihn im übertragenen Sinne auf die Spitze des World Trade Centers setzt: Er ist körperlich vom Geschehen abgekoppelt, mit optimiertem Überblick auf das Bühnengeschehen.

Somit ist ein Problem des Theaters in Bezug auf den materiellen Schnitt durch den Raum beschrieben. Es geht darum, das richtige Maß an Trennschärfe zu erzeugen und die Trennung zwischen Bühne und Publikum überwindbar zu gestalten, ohne dabei die Trennung aufzugeben. Auf der einen Seite soll sich das Publikum involviert fühlen, auf der anderen Seite soll Theater aber auch stattfinden können. Anders ausgedrückt geht es dem tradierten Theaterbau darum, ein umfassendes Wahrnehmungsgefüge zu schaffen, in dem eine Wirklichkeit erzeugt werden kann, die die Realität wenn nicht gänzlich ausschließt, so doch kontrolliert und intendiert zum Verschwinden bringt. Gleichzeitig geht es aber auch darum ein Gefüge zu schaffen, das es aushält, wenn die Realität in die Wirklichkeit einbricht. Das zeitgenössische Theater testet immer wieder aus, welche Grenzüberschreitungen möglich und zulässig sind und führt gerne das Gefüge zwischen Publikums- und Bühnenraum an seine Grenzen. Gemeint sind Brüche mit einer Illusion oder auch Stimmung, ebenso

6 Vgl. Gabriele Brandstetter, „Lever de Rideau - die Szene des Vorhangs“, in: dies./Sibylle Peters (Hg.), Lever de Rideau - Die Schnittflächen der Künste, Freiburg i. Br., 2008, S. 19-44. 
die Situationen und inszenatorischen Mittel, die Erika Fischer-Lichte als ästhetische Erfahrung im Sinne einer „Schwellenerfahrung“" beschreibt. Und da der Schnitt vorwiegend symbolisch und von Konventionen erzeugt wird, sind die Variationen dieser Brüche vielfältig.

Die Erzeugung einer spezifischen Wirklichkeit führt, genau genommen, weg vom materiellen Schnitt und vom Schnitt durch den Raum. Dennoch hat der Ausdruck Schnitt hier eine nicht zu unterschätzende Präsenz. Die bisherigen Ausführungen waren stark an Dinge und eine geometrisch ausgerichtete Raumvorstellung gebunden. Damit verbunden ist die Beschreibung und Vorstellung eines Schnitts, der Trennung und Distanzierung erzeugt. Gleichzeitig wurde aber auch deutlich, dass gerade im Theater die Frage nach der Überwindung der Distanz und der Trennung ganz grundlegend ist. Die daraus resultierende These ist, dass wirklichkeitserzeugende Prozesse eine wichtige Rolle spielen und dass sich diese sogar in Anlehnung an den Ausdruck Schnitt beschreiben lassen.

Schaut man auf den sprachlichen Gebrauch von Schnitt, zeigt sich, dass es nicht nur um das Zertrennen geht, sondern auch um die Erzeugung von neuen Zusammenhängen. Ein Beispiel aus der Mathematik: Man bildet eine Schnittmenge, indem man Elemente mit gemeinsamen Eigenschaften aus zwei oder mehreren Mengen zusammenführt. Dabei geht es nicht nur um das Selektieren im Sinne eines Zertrennens, sondern auch um den Prozess des Wiederzusammenführens, mit dem etwas Neues und Einheitliches erschaffen wird.

Auch im Kreativbereich taucht der Schnitt in Zusammenhang mit dem Erzeugen von etwas Neuem und dem Vereinheitlichten auf: Neben dem Scherenschnitt auch der Filmschnitt. Beim Filmschnitt wird zusätzlich der widersinnige Ausdruck des Zusammenscheidens verwendet, den ich - da man im Theaterbereich keine begriffliche Analogie zu dem des Schnitts findet - für meine Betrachtungen aufgreifen will. Hier entsteht durch den Prozess des Zerschneidens und Zusammenfügens ein in sich stimmiges Werk, das den Schnitt als solchen zum Verschwinden bringt. Diese Art des Zerschneidens und Zusammenschneidens ist Teil eines jeden kreativen Prozesses, sei es in der Malerei, im Design, in der Werbung oder im Theater. Es finden Prozesse der Selektion, Professionalisierung, Reduktion oder auch Komprimierung statt. So ist auch jede Erarbeitung eines theatralen oder performativen Ereignisses das Produkt sehr unterschiedlicher Arbeitsprozesse, in die alle Beteiligten in ihrer Weise Kompetenzen und Entscheidungen einbringen, die im Prozess zusammengeführt werden. Das, was am Ende im klassischen Sinne als Werk aufgeführt wird oder sich ereignet, ist das Produkt eines in sich heterogenen Prozesses von Einzelelementen, die zusammengefügt werden. Dies sind Prozesse, die zum Beispiel als Inszenierung beschrieben werden und eine eigene Wirklichkeit schaffen, die sich von der Realität abhebt.

Erika Fischer-Lichte, Ästhetische Erfahrung. Das Semiotische und das Performative, Basel, 2001, S. 347-349. 
Der Schnitt mit diesen Vorgaben entfaltet sich in zweifacher Weise. Zum einen räumlich als Schnitt, der Dinge, Personen und Gefüge in ein Verhältnis zueinander setzt. Zum anderen aber auch als Prozess des Konstruierens, Erzeugens und Inszenierens. Die Konsequenz dieser beiden Aspekte ist, dass als Problem des Schnitts die Diskrepanz beschrieben werden kann, Getrenntes wieder zusammenführen zu müssen. Aufgrund der räumlichen Trennung müssen Wege und Mittel gefunden werden, die das Inszenierte und Erzeugte an das Subjekt heranführen, damit sie als Wirklichkeit erfahrbar werden.

Die wesentliche Voraussetzung für Theater und theatrale sowie performative Ereignisse ist, dass zwei tatsächliche Räume aufeinander treffen und im Hier und Jetzt in Beziehung zueinander treten. Sowohl der Publikumsraum als auch der Bühnenraum sind physikalisch, handlungs- und wahrnehmungsorientiert betrachtet, natürliche Räume, in denen jegliche Haltung, Handlung und Wahrnehmungsweise eingenommen werden kann. Dennoch unterscheiden sich beide Räume maßgeblich voneinander; sie erzeugen je eine eigene Weise von Anwesenheit, Handlung und Wahrnehmung. Anders als bei technischen Medien können diese in Beziehung stehenden Räume des Theaters jederzeit aufgelöst werden, weshalb sie hochgradig labil und anfällig für Störungen sind. Umso weniger erstaunlich ist es, dass sich in den letzten Jahrhunderten der Theaterbau zu der Form entwickelt hat, wie wir ihn heute kennen: Als architektonische Anordnung, die das Verhältnis von Publikum zu Bühne stark reguliert, äußere und innere Störungen einschränkt und dabei immer einen Umgang mit der so erzeugten Trennung zu finden versucht. Und so ist der Widerstreit zwischen Trennung und Zusammenführen, zwischen Distanz schaffen und Involvieren, aber auch der Umgang mit Störungen für Theater grundlegend. Denn in keiner anderen Kunstform oder bei keinem anderen Medium lassen sich die Übergänge zwischen Inszenierung und Alltag, zwischen Wirklichkeit und Realität so leicht auflösen. Theatrale und performative Ereignisse bedürfen keiner Apparatur, keines Mediums, sie können sich immer und überall einfach ereignen. Gerade deshalb aber greift das Theater in seiner Form und für seinen Inhalt auf Medien zurück und schafft sich mit dem Theaterbau eine Apparatur oder dem Drama Mittel, mit denen Ereignisse als vom Alltag abgehobene Hervorhebungen, Inszenierungen oder auch Erzeugnisse erfahren werden. Es braucht den Zusammenschnitt, damit erfahrbar wird, dass der andere Raum ein fiktiver und inszenierter ist, dessen Realität weder existenziell wird noch ein Eingreifen erfordert.

Das ist eine Erklärung, warum der klassische Theaterbau und daran geknüpft die Vorstellung von Theater, die architektonisch physische Trennung zwischen Publikums- und Bühnenraum so deutlich vorgibt. Die mit ihr anvisierte Trennschärfe dient der Kalkulierbarkeit und Kontrolle von Unvorhersehbarkeiten und ungewollten Störungen. Sie dient aber auch der bewussten Manipulation von Raum, Wahrnehmung sowie Handlungen und der Erzeugung von Ereignissen und Inszenierungen. Nicht zuletzt schafft aber diese Trennung auch eine Distanzierung und drängt den Gast im Raum des Theaters 
in die von de Certeau auch als „Fiktion des Wissens“8 ${ }^{\text {“8 }}$ beschriebene Position, ein Lesender zu sein, der eine Inszenierung als Text zu begreifen versucht. Der Raum der Anwesenheit als gemeinsamer Handlungs-, Stimmungs- und Wahrnehmungsraum wird durch die materiellen Eingriffe stark strukturiert und in Bezug auf theatrale und performative Möglichkeiten eingegrenzt. Der Theaterbau wird verlassen, um sich von diesen Zwängen zu befreien.

\section{Der Schnitt durch den Raum leiblicher Anwesenheit}

Theatrale und performative Ereignisse mit dem Fokus auf den Schnitt durch den Raum zu betrachten, hat zur Folge, dass Inszenierungen als Gefüge vorgestellt werden. In diesem erfährt ein Subjekt durch einen Schnitt einen anderen Raum als eigenständige Wirklichkeit. In den bisherigen Betrachtungen wurde beschrieben, wie dieses Gefüge als räumliches zustande kommt und sich im Theaterbau materiell niederschlägt. Dabei diente als Leitfaden, der von de Certeau geschilderte abgehobene und überblickende Standpunkt. Da wir es aber eben mit einem räumlichen Gefüge zu tun haben, drängt es sich förmlich auf, das obere Stockwerk des World Trade Center zu verlassen und sich in das städtische Getümmel hineinzubegeben, also von der Anwesenheit im Raum des Theaters auszugehen. Als theoretische Grundlage dafür dient Gernot Böhmes Auseinandersetzung mit Atmosphäre, anhand derer ich den von mir eingeführten Schnitt durch den Raum als Wahrnehmungsschnitt vorstellen werde. Die Perspektive verschiebt sich somit auf Wahrnehmung und Leiblichkeit.

Bislang kam die eigene Anwesenheit im Raum zu kurz und damit eine spezifische Eigenschaft dieser: die Befindlichkeit. Im Deutschen verbindet sich mit Befindlichkeit eine vielsagende doppelte Bedeutung, auf die Gernot Böhme aufmerksam macht: nämlich in einem Raum befindlich, anwesend sein und die eigene Befindlichkeit im Sinne einer Stimmung. ${ }^{9}$ Beides gehört zusammen, weil in meiner Anwesenheit hier, ich so und so gestimmt bin. Für die Befindlichkeit spielt meine Position oder auch Lage zu anderen Personen und Dingen eine nur untergeordnete Rolle. Dafür aber ist der Raum meiner Befindlichkeit erst einmal schnittfrei.

Daher soll es im Folgenden darum gehen, sich den Schnitt durch den Raum als einen Schnitt vorzustellen, der weniger eine Trennung, sondern vielmehr eine Ausdifferenzierung erzeugt. Nicht der geometrische Raum bildet die Grundlage, sondern die leibliche Anwesenheit im Raum und die darin sich vollziehenden Ausdifferenzierungen meines Seins innerhalb eines Handlungs-, Stimmungs- und Wahrnehmungsraums. Es wird sich zeigen, dass sich der Theaterbau und das Theater als Kunstform in vielerlei Hinsicht an dieser Aus-

Michel de Certeau (1988), Kunst des Handelns, S. 180.

9 Vgl. Gernot Böhme, „Leibliche Anwesenheit im Raum, in: Egon Schirmbeck (Hg.), RAUMstationen: Metamorphosen des Raums im 20. Jahrhundert, Ludwigsburg, 2001, S. 92-98: 96. 
differenzierung orientieren und gerade durch den materiellen und durch Konventionen herbeigeführten Schnitt versuchen, dieser eine Dauer und Verlässlichkeit zu verleihen. Zum besseren Verständnis soll Gernot Böhmes Auffassung vom Raum leiblicher Anwesenheit und der Atmosphäre als erster Wahrnehmungswirklichkeit vorgestellt werden. Anschließend soll der Schnitt durch den Raum leiblicher Anwesenheit mit dem Fokus auf den Schnitt durch den Handlungs-, Stimmungs- und Wahrnehmungsraum eingeführt werden.

\section{Atmosphäre und der Raum leiblicher Anwesenheit}

„Wir haben in ausgelassener Atmosphäre gefeiert“. „Die Atmosphäre unter den Kollegen war angespannt“. „Bei der Nachtwanderung herrschte eine gruselige Atmosphäre“. Das sind Beispiele dafür, wie der Ausdruck Atmosphäre in der Alltagssprache gebraucht wird. Er wird eingesetzt, um etwas Unbestimmtem, nicht Greifbarem und nicht Sagbarem einen Ausdruck zu verleihen: Einer Stimmung, einem spürbaren Zustand oder auch Emotionen.

Auch wenn Atmosphären als Phänomen unbestimmt sind, können wir sie so Böhme in seinem Atmosphären-Aufsatz von $1995^{10}$ - doch bestimmen, indem wir sie charakterisieren. Eine Atmosphäre ist eben ausgelassen, angespannt oder gruselig. Dagegen fällt es sehr viel schwerer, ihren „ontologischen Status“111, das was an ihr unbestimmt ist, zu benennen. „Man weiß nicht recht, soll man sie den Objekten oder Umgebungen, von denen sie ausgehen, zuschreiben oder den Subjekten, die sie erfahren. Man weiß auch nicht so recht, wo sie sind. “12

Eine Atmosphäre scheint irgendwie als Gefühlsmacht gegenwärtig zu sein und meine Gegenwärtigkeit zu beeinflussen. Sie ist in den Raum meiner Anwesenheit eingelassen und betrifft mich. Das heißt, ich bin es, der sie erfährt und sie wird erst durch mich wirklich. Dieser letzte Aspekt stellt sich als Schwierigkeit in der Auseinandersetzung um den Begriff Atmosphäre heraus. Atmosphären werden gerne als „Projektion der Stimmung des Subjekts" ${ }^{\text {“13 }}$ beschrieben und damit ganz dem Subjekt und seiner Wahrnehmung zugeschrieben. Böhmes Ziel war es von Anfang an, diese einseitige Sichtweise zu durchbrechen und einen umfassenderen Begriff der Atmosphäre zu entwickeln. Dabei orientiert er sich an Hermann Schmitz' Leibphilosophie. ${ }^{14}$ In der Beschreibung von Hermann Schmitz sind Atmosphären immer räumlich „rand-

10 Gernot Böhme, Atmosphäre. Essays zur neuen Ästhetik, Frankfurt/M., 1995.

11 Ebd., S. 22.

12 Ebd.

13 Gernot Böhme, „Brief an einen japanischen Freund über das Zwischen“, in: Tadashi Ogawa/ Michael Lazarin/Guido Rappe (Hg.), Interkulturelle Philosophie und Phänomenologie in Japan. Beiträge zum Gespräch über Grenzen hinweg, München, 1998, S. 233-239: 235.

14 Vgl. Böhme (1995), Atmosphäre, S. 28. 
los, ergossen, dabei ortlos, d. h. nicht lokalisierbar“15 und wie Böhme es weiter zusammenfasst: „Sie sind ergreifende Gefühlsmächte, räumliche Träger von Stimmungen“. ${ }^{16}$ Eine Atmosphäre ist ohne den Menschen als Wahrnehmenden und im Raum Anwesenden nicht denkbar.

Warum es sich dennoch nicht nur um eine „Projektion der Stimmung des Subjekts“ handeln kann, verdeutlicht Böhme sowohl an der sogenannten Ingressions-, als auch der Diskrepanzerfahrung. ${ }^{17}$ Einer Atmosphäre wird man insbesondere dann gewahr, wenn man in sie hineingerät. Betrete ich einen Saal, in dem eine Feier stattfindet, komme ich selbst aus einer ganz anderen Atmosphäre und erfahre deshalb die im Saal vorherrschende Atmosphäre auf besondere Weise. Letztlich kommt es zu einer Störung zum Beispiel in Bezug auf meine Stimmung oder auch Wahrnehmung. Genau diese Störung trägt nun dazu bei, dass sich die für mich andere Atmosphäre als quasi Gegenstand ausmachen lässt. Genau das beschreibt der Ausdruck Ingressionserfahrung.

Im besonderen Maße tritt nun der Charakter einer Atmosphäre hervor, wenn die Atmosphäre in der ich befindlich war, im starken Kontrast zu der steht, in die ich hineingerate. Wenn ich heiter gestimmt in eine angespannte Atmosphäre gerate, wird sie mir im besonderen Maße gewahr, weil sie sich grundlegend von meiner unterscheidet. Und weil ich mich nur ungern auf diese dort vorherrschende Atmosphäre einlassen werde, bleibt sie für mich als Diskrepanzerfahrung bestehen.

Böhme verdeutlicht mit der Beschreibung dieser beiden Erfahrungen, dass eine Atmosphäre nicht ausschließlich eine Projektion meiner Stimmung sein kann, weil sie auch nicht nur eine Projektion des Wahrnehmenden ist. Vielmehr erfahre ich sie als eigenständige Qualität, die erst einmal nichts mit mir zu tun hat. Atmosphäre ist als Zwischenphänomen immer Teil der Umgebungen, Dinge und Personen sowie Teil meiner selbst. Somit wird sie einerseits von Umgebungen, Dingen und Personen erzeugt und ich bin in ihr anwesend, wie auch ich an ihrer Erzeugung teilhabe und die Umgebungen, Dinge und Personen mit mir rechnen müssen.

Das heißt, um die Einführung in den Begriff der Atmosphäre abzuschließen, wir haben es mit einem Zwischenphänomen zu tun: Atmosphäre „ist weder etwas Objektives noch etwas Subjektives und sie ist doch quasi objektiv und quasi subjektiv““. ${ }^{18}$ Auch wenn sie nicht greifbar und nur schwer bestimmbar ist, ist sie doch räumlich gegenwärtig und wird von mir als wahrnehmendem Subjekt als quasi objektiv erfahren. Atmosphäre ist somit ein im klassisch sinnesphysiologischen Kontext nicht ausmachbarer Gegenstand, weshalb er im herkömmlichen Sinne abwesend anwesend ist. Abwesend, weil Atmosphären weder riech- noch hörbar, weder sichtbar noch sensorisch spürbar

\footnotetext{
Zit. n. ebd., S. 29.

Ebd.

Vgl. Böhme (2001), Aisthetik, S. 46-48.

18 Böhme (1998), Brief an einen japanischen Freund, S. 235.
} 
usw. sind. Anwesend, weil sie eben doch quasi objektiv im Raum vorliegen und quasi subjektiv erfahren werden.

Böhme geht es demnach nicht um die Frage nach der Objektivierbarkeit von Atmosphären, ihm geht es vielmehr darum, dass wir es mit einem Phänomen zu tun haben, das im Raum immer und umfassend befindlich ist und von der Kunst, letztlich aber auch von Politikern, der Werbung, Designern und Anderen genutzt wird und explizit erzeugt werden kann. Er spricht dabei von ästhetischen Arbeitern ${ }^{19}$, deren Arbeit nicht allein Kunstinstitutionen und Kunstschaffenden vorbehalten ist, sondern genauso im Alltagsleben getätigt wird.

Zusammenfassend ist Atmosphäre im Sinne von Böhme der Raum meiner leiblichen Anwesenheit. ${ }^{20}$ Dieser Raum ist aber ganz anders organisiert als der geometrische Raum. Hier bin ich im doppelten Sinne befindlich, ich bin anwesend und gleichzeitig fühle ich mich so und so gestimmt. ${ }^{21}$ Es geht nicht um Lage oder Position, sondern um meine Befindlichkeit.

\section{Der Schnitt durch den Raum leiblicher Anwesenheit}

„Der Raum meiner leiblichen Anwesenheit ist in meiner ersten Wahrnehmungswirklichkeit zunächst nichts weiter als die spürbare unbestimmte Weite, aus der sich durch Artikulation Räume unterschiedlichen Charakters bilden

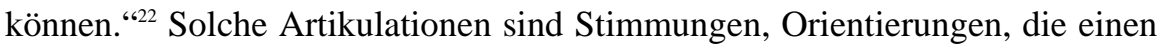
Raum bilden, mich als Subjekt ausrichten oder Konzentrationen schaffen. Diese Artikulationen setzen keinen gegenständlichen Raum voraus, werden also nicht zwangsläufig von Körpern und Dingen gebildet. Sie benötigen ein Subjekt, das sich als im Raum leiblich anwesend diesen Atmosphären aussetzt und sie erfährt. ${ }^{23}$

Der Raum leiblicher Anwesenheit kann somit nicht rein abstrakt erfahren werden. Es ist zwar möglich, über ihn zu reden, aber dafür muss ich leiblich anwesend gewesen sein, um genau das auch tun zu können. Mit dem Reden über Atmosphären stellt sich aber ein Problem: Ich als leiblich Anwesender kann aus der Unbestimmtheit abrücken und zwischen mir und der Atmosphäre als Gegenstand differenzieren, wenn es darum geht, über das Erfahrene zu reden. Doch führt das aus der leiblichen Anwesenheit heraus und rückt mich in die Position eines außenstehenden Betrachters. Reden über Atmosphäre spielt sich daher im Ideal im Zwischenfeld zwischen der unbestimmten Atmo-

19 Vgl. Böhme (1995), Atmosphäre, S. 35.

20 Vgl. Böhme (2001), Leibliche Anwesenheit im Raum, S. 96.

21 Ebd.

22 Gernot Böhme, „Atmosphäre als Gegenstand der Architektur“, in: Philip Ursprung (Hg.), Herzog \& de Meuron: Naturgeschichte, Ausstellungskatalog Canadian Centre for Architecture, Montréal, Baden, 2002, S. 410-417.

23 Vgl. ebd. 
sphäre als erster Wahrnehmungswirklichkeit und einem Abrücken von dieser Wahrnehmungswirklichkeit ab. Der Schnitt durch den Raum der Atmosphäre, etabliert sich nun in diesem Zwischenfeld.

Böhme unterscheidet drei Weisen, auf die man mit dem Raum leiblicher Anwesenheit involviert ist: als handelnder, wahrnehmender und atmosphärisch spürender Mensch. ${ }^{24}$ Dabei ist „der leibliche Raum die Weise, in der ich selbst da bin bzw. mir anderes gegenwärtig ist“ ${ }^{25}$

Für die Wahrnehmung im Raum leiblicher Anwesenheit beschreibt Böhme ein Zwischen, das aber nicht trennend auf den Raum oder die Wahrnehmung wirkt, sondern im Gegenteil Wahrnehmung als eine gesamträumliche Erfahrung beschreibt, in der letztlich alles mit allem einen gemeinsamen Erfahrungsraum schafft. Betrete ich einen Raum, in dem eine angespannte Stimmung herrscht, so treffe ich mit meinen Handlungen, meiner Stimmung und Wahrnehmung auf ein Gefüge aus Menschen und Dingen, die ebenfalls handelnd, wahrnehmend und gestimmt dort anwesend sind. Mit meinen Handlungen, meiner Stimmung und Wahrnehmung wirke ich auf diesen anderen Raum ein, und ich selbst eröffne dort einen eigenen Handlungs-, Stimmungs- und Wahrnehmungsraum. Gleiches geschieht nun auch von Seiten des Gefüges, in das ich trete. Auch dieses greift in meinen Raum durch Handlung, Stimmung und Wahrnehmung ein. Ebenso hat das Gefüge und jeder und jedes darin einen Handlungs-, Stimmungs-, und Wahrnehmungsraum.

Alles zusammen beschreibt Böhme als ein Zwischen, das als erste Wahrnehmungswirklichkeit mein Sein im Raum leiblicher Anwesenheit bestimmt und erst einmal schnittfrei ist. Ein Schnitt fügt sich in diese Wahrnehmung ein, sobald ich eine so genannte Ingressions- oder Diskrepanzerfahrung mache, in dem der Raum meiner leiblichen Anwesenheit als anderer erfahren wird und ich das Gefüge, in dem ich anwesend bin, als Übergangsraum erfahre. Dieser Schnitt verläuft durch den Raum meiner leiblichen Anwesenheit und dort innerhalb des Handlungs-, Stimmungs- und Wahrnehmungsraums.

\section{Der Schnitt durch den Handlungsraum}

Als Handlungsraum beschreibt Böhme den „Spielraum meiner Handlungsmöglichkeiten und Bewegungsmöglichkeiten“26, der sich auf zweierlei Weise entfaltet. Zum einen wird der physische Raum insoweit zum Raum meiner leiblichen Anwesenheit, als dass mit meinem Eingreifen gerechnet werden muss. Zum anderen zählt auch zum Raum meiner leiblichen Anwesenheit,

24 Gernot Böhme, „Der Raum leiblicher Anwesenheit und der Raum als Medium von Darstellung“, in: Sibylle Krämer (Hg.), Performativität und Medialität, München, 2004, S. 129140: 135.

25 Ebd., S. 134.

26 Ebd. 
„was immer sich in unmittelbarer Erreichbarkeit befindet. Dieser Raum ist also für mich als Handelnden die Sphäre meines unmittelbaren Handelns. “27

Ein Schnitt durch den Handlungsraum wird erzeugt, wenn ich in eine handlungsentlastende Position gerate, d.h. zum (zufälligen) Zuschauer werde. Handlungsentlastung verstehe ich in diesem Zusammenhang wortwörtlich und wieder polar. Ich bin also handlungsentlastet, wenn ich nicht handeln muss und Andere ebenso in Bezug auf mich nicht handeln müssen. Denn nur dann können die Anderen ihren Handlungen nachgehen, während ich mich ihnen widme und so zum Zuschauer werde.

Die Handlungsentlastung ist eine ganz wesentliche Voraussetzung für ein spezifisches Erleben nicht nur theatraler und performativer Ereignisse. Sie ist Voraussetzung für eine Grundkonzentration und Fokussiertheit auf Ereignisse im Raum leiblicher Anwesenheit. Ganz gleich, ob es um ein inszeniertes Ereignis geht, um einen Sonnenuntergang als Naturereignis oder darum, ob ich in der Innenstadt spontaner Zuschauer einer zufälligen Alltagsszene wie einem Ehestreit werde: Die Handlungsentlastung betrifft ausschließlich die Personen, die als Gast, Betrachter, Zuschauer oder Publikum an einem Geschehen teilhaben.

Der Schnitt durch den Handlungsraum ist, wie alle Schnitte durch den Raum leiblicher Anwesenheit, sehr labil und anfällig für Störungen. Löst er sich auf, löst sich auch die Differenz zwischen dem Raum meiner Anwesenheit und dem durch den Schnitt erzeugten anderen Raum auf.

Bezogen auf den Theaterbau und den darin befindlichen Raum des Theaters, ist die Handlungsentlastung eine seiner entscheidenden Funktionen. Der Theaterbau grenzt äußere Handlungsanlässe ebenso aus wie innere. Der Alltag und das Wetter sind solche Handlungsanlässe, die man beim Betreten hinter sich lassen soll. Aber auch die Anordnung des Raums des Theaters, die Bestuhlung, die Verdunklung und die Distanzierung zum Geschehen, bringen mich als Zuschauer in eine Situation, in der ich einerseits handlungsentlastet bin, andererseits aber auch jederzeit eingreifen könnte. Mit mir ist zu rechnen. All das ist eine von außen gesetzte Festschreibung auf meine Handlungsentlastung. Das Bühnengeschehen stellt dem Zuschauer und Zuhörer einen Raum gegenüber, in dem sich Handlung ereignet, ohne dass er selbst Handelnder wird. Seine Handlungsentlastung basiert auf der dosierten und kulturellen Vereinbarung, dass alles das, was auf der Bühne geschieht, inszeniert ist. Bedrohliche Bühnengeschehen sind für ihn selbst deshalb nie bedrohlich. Zwar muss er damit rechnen, Handelnder zu werden, aber in der Regel beschränkt sich sein Handeln auf wenige Vereinbarungen: Er darf lachen, schweigen, klatschen oder vielleicht husten. Doch klappt das nicht immer, manchmal überschreiten Akteure oder Gäste den Schnitt durch den Handlungsraum, der sich dann für die Betroffenen auflöst. Der Schnitt durch den Handlungsraum ist im

27 Ebd. 
Rahmen des hier vorgestellten Ansatzes der wichtigste und grundlegendste Schnitt durch den Raum des Theaters.

\section{Der Schnitt durch den Stimmungsraum}

Auch beim Stimmungsraum beschreibt Böhme eine Bipolarität vom Raum als gestimmtem Raum und meiner Anteilnahme am gestimmten Raum: „Der Stimmungsraum ist einerseits der gestimmte Raum, d.h. eine bestimmte Atmosphäre oder Tönung, die über der jeweiligen Umgebung liegt, wie auch die räumlich ergossene Atmosphäre, an der ich mit meiner Stimmung partizipiere. ${ }^{\text {“28 }}$ Der Schnitt durch den Stimmungsraum etabliert sich, sobald wir Ingressions- und Diskrepanzerfahrungen machen. Bewege ich mich durch die Stadt und begegne einem Ehepaar, das sich gerade streitet, so gerate ich ungewollt in deren Stimmungsraum. Ihren Streit erfahre ich als zu meiner Stimmung diskrepant.

Genau diese Diskrepanz erzeugt einen anderen Raum, auf dessen Schwelle ich mich befinde. Neben der anderen Stimmung spielt hier aber auch der Aspekt der Erzeugung einer Stimmung eine wichtige Rolle. Weil das Ehepaar Verhaltensmuster an den Tag legt, die einer Inszenierung gleichen - die Art, wie sich beide gebärden, verwendete Formulierungen und Reaktionen und ihr mögliches Bewusstsein öffentlich wahrgenommen zu werden - schaffen sie einen hervorgehobenen Stimmungsraum.

Der Schnitt durch den Stimmungsraum ist ein wesentliches Merkmal von Alltagsinszenierungen. Durch Ingressions- und Diskrepanzerfahrungen werden andere Räume erfahrbar, in die ich mich hineinbegebe, wenn ich auch und das ist essenziell - an ihrer Schwelle verharre. Es sind Störungen meines Alltags, Hervorhebungen oder Aufmerksamkeiten, die mich als Passanten dazu bringen, mich in eine handlungsentlastete Position zu begeben, um vielleicht nur für wenige Sekunden Zuschauer zu werden. Die Dauer meiner Anwesenheit hängt vor allem davon ab, wie stabil der andere Raum, meine Handlungsentlastung und mein Sein auf der Schwelle sind. Vielleicht ist der Streit zu Ende und der andere Raum löst sich auf. Vielleicht habe ich einen Termin und muss weiter oder ich greife ein und überschreite so die Schwelle. Das heißt, es ist ein Leichtes, bewusst oder unbewusst das Geschehen zu stören und den Schnitt aufzulösen, weil ich an der Erzeugung des anderen Stimmungsraumes ebenso beteiligt bin.

Der Mensch zeichnet als Erzeuger solcher anderen Räume verantwortlich. Das unterscheidet eine Inszenierung vom Sonnenuntergang. Der Sonnenuntergang ist als anderer Stimmungsraum erst einmal vorhanden. Weder wurde er inszeniert noch hat es einen Einfluss auf ihn, was ich mit ihm mache und wie ich ihn erfahre. Stimmungsräume sind somit Teil unseres Alltags, sie umgeben

28 Ebd. 
uns und wir sind darin leiblich anwesend. Nur selten werden wir uns ihrer bewusst, weil wir immer schon in sie eingelassen sind. Erfahren wir sie in einer Ingressions- oder Diskrepanzerfahrung, eilen wir in der Regel weiter, weil wir unserem gesteckten Ziel nachgehen. Der Schnitt durch den Stimmungsraum ist hochgradig labil, selbst dann, wenn ich mich auf ihn einlasse.

Das Theater und der Theaterbau suchen einen Umgang mit der Labilität, indem sie eine materielle Ordnung schaffen, die den Schnitt durch den Stimmungsraum stabilisiert. Die Anordnung, der abgedunkelte Raum oder die ausgerichteten Sitzplätze schaffen nicht nur Handlungsentlastung, sondern stabilisieren den Zustand auf der Schwelle zum anderen Raum, in dem man dennoch leiblich anwesend sein kann. Und weil der Theaterbau die Handlungsentlastung und den Schnitt durch den Stimmungsraum stabilisiert, wird im modernen Theater ein Spiel mit Störungen und dem bewussten Erzeugen von Ingressions- und Diskrepanzerfahrungen möglich. Gerne wird damit gespielt, den Schnitt durch den Stimmungsraum beständig zu erzeugen und zum Verschwinden zu bringen. Das Ideal eines illusionistischen Theaters hingegen strebt nach seinem Verschwinden, das Publikum soll ganz in den von der Inszenierung erzeugten Stimmungsraum eindringen.

\section{Der Schnitt durch den Wahrnehmungsraum}

Den Wahrnehmungsraum beschreibt Böhme auch wieder als einen, der vom Subjekt aufgespannt wird und gleichzeitig vom atmosphärischen Raum selbst ausgeht: „Der Wahrnehmungsraum ist mein Sein bei den Dingen, d. h. die Weise, in der ich wahrnehmend außer mir bin. [...] Umgekehrt wird der Raum leiblicher Anwesenheit durch die Reichweite unserer Wahrnehmung aufgespannt. ${ }^{29}$ Als Beispiel führt Böhme das Sehen und Hören an. Man ist sehend und hörend, um wieder auf das eingeführte Beispiel zurückzukommen, bei dem streitenden Ehepaar anwesend. Neben meinem Sein bei den Dingen, spannt meine Wahrnehmung den Raum meiner leiblichen Anwesenheit auf. Alles jenseits meiner Wahrnehmungsmöglichkeit ist auch jenseits meines Wahrnehmungsraums.

Es ist hilfreich, die eingeführte Differenz von Wirklichkeit und Realität im Folgenden noch einmal genauer vorzustellen. Wirklichkeit macht Böhme zum zentralen Begriff einer als Aisthetik verstandenen Wahrnehmung und stellt sie dem sonst in der Ästhetik üblichen Begriff des Erscheinens entgegen. Wirklich ist „primär das Gegenwärtige, die spürbare Anwesenheit““. ${ }^{30}$ Das Wirkliche ist im Verständnis von Böhme von einem dinglichen Gegenstand abgelöst und erfüllt freischwebend den Raum. Es ist eine Atmosphäre, in die ich involviert bin und die ich spüre. Dagegen ist real das ,was dinglich dahinter

29 Ebd., S. 135.

30 Böhme (2001), Aisthetik, S. 56. 
stehen mag“311 . Hierbei kann es um ein einzelnes Bild gehen, das eine spezifische Wirklichkeit erzeugt, einen Darsteller mit seiner als Wirklichkeit erfahrenen Ausstrahlung, aber auch einen alltäglichen Streit, der erst einmal als eine Stimmung erfahren wird. Gleichermaßen kann es um ein Gesamtsetting gehen, eine Szene, deren Wirklichkeit eine spezifische Stimmung erzeugt.

Der Schnitt durch diesen vermeintlich schnittfreien Wahrnehmungsraum basiert auf eben jener Differenz von Wirklichkeit und Realität. Auch ihr begegnen wir in unserem Alltag, insbesondere in Inszenierungen von Stadt, Produkten, Oberflächen oder bei der Selbstinszenierung von Personen und ihrer gesellschaftlichen und sozialen Zugehörigkeit.

Bezieht man sich wieder auf Theater so zeigt sich, dass der Schnitt durch den Wahrnehmungsraum als Inszenierungsweise beschrieben werden kann, Wirklichkeit zu erzeugen. Und da der Theaterbau Handlungsentlastung schafft und den Schnitt durch den Stimmungsraum stabilisiert, sind Voraussetzungen geschaffen, Wirklichkeiten durch Inszenierung zu schaffen. Dabei gilt, gerade für tradierte Kunstauffassungen: Die Differenz von Wirklichkeit und Realität gelangt erst zur Perfektion, wenn die Realität vollständig verschwindet. Es geht um Illusion. Der perfekte illusionistische Moment ist der, in dem die Realität gänzlich ausgeblendet wird und mir als Zuschauer oder Betrachter nur die Wirklichkeit anmutet. Ich erfahre die Figur des Hamlet als eigenständige Wirklichkeit, ohne dass ich über die Ursprünge oder die Verursacher dieser Wirklichkeit ein Verständnis brauche. Das Wirkliche ist von einem dinglichen Gegenstand abgelöst und erfüllt freischwebend den Raum. Es ist die Atmosphäre, in die ich involviert bin und die ich spüre. Doch nicht allein diese tradierte Auffassung von Illusion ist nötig, sondern letztlich, wie es Nikolaus Müller-Schöll beschreibt: „Etwas, woran geglaubt wird, obwohl man weiß oder zu wissen glaubt, daß es der Wirklichkeit [in der hier verwendeten Terminologie Realität; Anm. C.R.] nicht entspricht, ein spontaner Glaube an Unglaubliches. ${ }^{\text {“32 }}$

Wenn ich als Wahrnehmender im Raum meiner leiblichen Anwesenheit bei dem, was ich wahrnehme, sein kann, wird die in der Atmosphäre von der Realität abgekoppelte Wirklichkeit zu meiner Erfahrung. Doch auch dieser Zustand ist äußerst instabil und löst sich schnell und leicht auf. In zeitgenössischen Inszenierungen und Performances wird mit der Differenz von Wirklichkeit und Realität gespielt. Die Körper der Akteure, die realen Orte oder Wind und Wetter werden Teil der Inszenierung. Ein Spiel mit Störungen, Ingressions- und Diskrepanzerfahrungen und dem Bewusstmachen, dass die Handlungsentlastung instabil ist und man mit Realität rechnen muss, sind Mittel und Effekte, die zum Einsatz kommen. Daher ist es essenziell zu wissen, man hat mit Theater zu tun. Handlungsentlastung wird erst im sicheren

31 Ebd., S. 57.

32 Nikolaus Müller-Schöll, „,(Un-)Glauben. Das Spiel mit der Illusion“, in: Forum Modernes Theater, Bd. 22/2, S. 141-151: 141. 
Wissen um die Realität des inszenierten Ereignisses möglich. Nur dann weiß ich, was Spiel und Ernst, was Inszenierung und Alltag ist. Genau das leistet der materielle Schnitt des Theaterbaus, er schließt das Außen aus, trennt die Bühne vom Publikumsraum ab, regelt durch Konventionen die Durchlässigkeit zwischen beiden und schafft im Bühnenraum eine Wirklichkeit.

\section{Abschluss}

Der Schnitt durch den Raum wurde auf zwei sehr unterschiedliche Weisen eingeführt. Im ersten Teil ging es um ein eher dingliches Erfassen und Beschreiben eines Schnitts, der Trennungen und Distanzierung verursacht und einen Raum ordnet und gliedert. Im zweiten Teil wurde von der direkten Involviertheit im Raum ausgegangen und der Schnitt als Schnitt durch den Raum leiblicher Anwesenheit vorgestellt. Es wurde dabei zwischen dem Schnitt durch den Handlungsraum, den Stimmungsraum und den Wahrnehmungsraum unterschieden. In der Vorstellung der sehr unterschiedlichen Charaktere der jeweiligen Schnitte wurde immer wieder hervorgehoben, dass der Schnitt durch den Raum nicht theaterspezifisch und schon gar nicht nur dem Theaterbau vorbehalten, sondern Teil unserer Alltagswahrnehmung ist.

Als Ergebnis der Betrachtung lässt sich sagen, der Schnitt durch den Raum leiblicher Anwesenheit ist alläglich und extrem labil. Für die Erzeugung theatraler und performativer Ereignisse ist er aber essenziell. Damit sich so etwas wie ein Zuschauer herausbilden kann, braucht es Bedingungen, die eine Handlungsentlastung zulassen und eine Hervorhebung oder Störung, auf die sich die Aufmerksamkeit lenkt. Damit sich so etwas wie eine Bühne etablieren kann, braucht es eine inszenierte Wirklichkeit und einen Stimmungsraum, der den potenziellen Zuschauer einerseits integriert, dennoch immer auf der äußeren Schwelle belässt. All das sind Voraussetzungen dafür, dass sich ein Zwischen zwischen Zuschauer und Bühne herausbildet, das nicht nur materiell oder symbolisch ist, sondern in der Wahrnehmung gegeben ist.

Der Theaterbau hat über die Jahrhunderte hinweg dem Schnitt durch den Raum leiblicher Anwesenheit einen spezifischen Ort gegeben. Mit materiellen und symbolischen Mitteln hat er Voraussetzungen geschaffen, die dem labilen Schnitt zur Dauer verhelfen. Und weil das nicht immer gut geht und gut gehen kann, wenn das, was in der Wahrnehmung gegeben ist, durch materielle und symbolische Mittel artfremd fixiert wird, wurde die Kritik am tradierten Theaterbau spätestens Anfang des 20. Jahrhunderts laut.

Die zwei hier beschriebenen Weisen über Raum zu sprechen und Raum zu reflektieren, sind kaum vereinbar. Entweder, um abschließend noch einmal de Certeau heranzuziehen, stehe ich auf dem World Trade Center oder ich befinde mich in den Straßen. Der Versuch beides zu vereinen, erzeugt immer nur einen Kompromiss. Ob und wie gut dieser Kompromiss funktioniert, hängt glücklicherweise nicht allein von der Materialität zum Beispiel eines Theater- 
baus ab, sondern auch von der Art und Weise, wie dort Wirklichkeiten erzeugt werden und die Gäste im Raum des Theaters auf der Schwelle im Bühnenraum anwesend sein können. Dennoch ist der Weg aus dem Theaterbau in einer Zeit, in der jede und jeder sich selbst inszeniert und der Schnitt durch den Raum nicht mehr allein durch zufällige Begegnungen zustande kommt, sondern Teil unserer medialisierten Welt geworden ist, ebenso nachvollziehbar wie konsequent. Die Ästhetisierung spielt sich nicht mehr allein in den Bauten der Hochkultur ab, sondern ist längst im Alltag angekommen.

\section{Literatur}

Böhme, Gernot, Atmosphäre. Essays zur neuen Ästhetik, Frankfurt/M., 1995.

Ders., „Brief an einen japanischen Freund über das Zwischen“, in: Tadashi Ogawa/Michael Lazarin/Guido Rappe (Hg.), Interkulturelle Philosophie und Phänomenologie in Japan. Beiträge zum Gespräch über Grenzen hinweg, München, 1998, S. 233239.

Ders., Aisthetik. Vorlesung über Ästhetik als allgemeine Wahrnehmungslehre, München, 2001.

Ders., „Leibliche Anwesenheit im Raum, in: Egon Schirmbeck (Hg.), RAUMstationen: Metamorphosen des Raums im 20. Jahrhundert, Ludwigsburg, 2001, S. 92-98.

Ders., „Atmosphäre als Gegenstand der Architektur“, in: Philip Ursprung (Hg.), Herzog \& de Meuron: Naturgeschichte, Ausstellungskatalog Canadian Centre for Architecture, Montréal, Baden, 2002, S. 410-417.

Ders., „Der Raum leiblicher Anwesenheit und der Raum als Medium von Darstellung“, in: Sibylle Krämer (Hg.), Performativität und Medialität, München, 2004, S. 129-140.

Brandstetter, Gabriele, „Lever de Rideau - die Szene des Vorhangs“, in: dies./Sibylle Peters (Hg.), Lever de Rideau - Die Schnittflächen der Künste, Freiburg i. Br., 2008, S. 19-44.

de Certeau, Michel, Kunst des Handelns, Berlin, 1988.

Fischer-Lichte, Erika, Ästhetische Erfahrung. Das Semiotische und das Performative, Basel, 2001.

Müller-Schöll, Nikolaus, „(Un-)Glauben. Das Spiel mit der Illusion“, in: Forum Modernes Theater, Bd. 22/2, Tübingen, 2007, S. 141-151.

Paech, Joachim, Literatur und Film, Stuttgart, 1988.

Schivelbusch, Wolfgang, Geschichte der Eisenbahnreise, München, 1977.

\section{Internetquellen}

www.thiergalerie.de/das-center/ueber-uns 



\section{„BEYOND THE SCOPE OF HUMAN VISION“- BÜHNEN FÜR ANDERE BLICKE}

Desert Walker, so lautet der Titel eines Projekts, das die Künstlergruppe Motherboard 2008 auf einer - wie es im entsprechenden Informationstext heißt „stage that stretches beyond the scope of human vision “1 realisierte, indem sie die Choreographie von Samuel Becketts Fernsehspiel Quad in die Salzwüste von Utah und Nevada übertrug. Und The Plastic Bag ist der Titel eines anderen Projekts, mit dem die Gruppe International Festival 2005 ganz Europa - wenn nicht sogar den gesamten Globus - zur Bühne machte, indem sie 25000 weiße, mit ihrem pinken Logo bedruckte Plastiktüten über 25 europäische Spielstätten in Umlauf brachte und jede mögliche Verwendung dieser Plastiktüten - wo und durch wen auch immer - als Teil einer Choreographie deklarierte. Um diese Beispiele wird es im Folgenden gehen (im Zusammenhang mit Desert Walker wird dabei auch näher auf Becketts Quad eingegangen). Und im Mittelpunkt wird dabei die Frage stehen, an welche Blicke sich die beiden Arbeiten richten wobei der Titel des vorliegenden Aufsatzes ja schon darauf hinweist, dass es sich bei diesen Blicken um andere als nur um diejenigen menschlicher Zuschauer handelt, denn schließlich spielen beide Arbeiten auf Bühnen, die sich vom herkömmlichen Standpunkt eines solchen Zuschauers aus gar nicht mehr vollständig überblicken lassen.

Im Hinblick auf den Begriff der Bühne bzw. hinsichtlich Fragen zu Realität, Geschichte und Aktualität raumbildender Prozesse ist an Desert Walker und The Plastic Bag zunächst von Interesse, dass diese Arbeiten durch eine ganz konkrete, räumliche Ausdehnung ihrer Bühnen zeigen, wie dehnbar auch der Begriff der Bühne ist. Oder anders formuliert: Beide Arbeiten öffnen den Begriff der Bühne auf jenen des Raums, wie ihn z. B. Jens Roselt im theaterwissenschaftlichen Sinne verstanden wissen will. Denn unter „Raum“, so Roselt, „muss nicht nur ein Gebäude oder ausschließlich die Bühne als Ort der Szene verstanden werden, sondern der R[aum] kann ein Versammlungsort, ein offener oder eingegrenzter Platz sein oder allgemein der Ort, an dem sich Theater ereignet. “2

Insbesondere ist jedoch von Interesse, dass Desert Walker und The Plastic Bag nicht nur über einen engen, an bestimmte Architekturen gebundenen Bühnenbegriff hinausgehen, sondern auch über den Horizont horizontal-zwischen-

\footnotetext{
http://www.liveart.org/desertwalker/index.html, zuletzt aufgerufen am 02. November 2012.

2 Jens Roselt, „Raum“, in: Erika Fischer-Lichte/Doris Kolesch/Matthias Warstat (Hg.), Metzler Lexikon Theatertheorie, Stuttgart, Weimar, 2005, S. 260-267: 260.
} 
menschlicher Blickverhältnisse - und damit über eben jenen Horizont, in welchem das Nachdenken über raumbildende Prozesse im aktuellen theaterwissenschaftlichen Diskurs oftmals verbleibt. Denn als weitgehend unhinterfragte Prämisse herrscht in diesem Diskurs immer noch die Annahme vor, Theater oder allgemeiner: jede Art von Aufführung - könne sich nur unter der Voraussetzung einer gemeinsamen Anwesenheit und gegenseitigen Wahrnehmbarkeit von Akteuren und Zuschauern ereignen. Und obgleich es gerade im zeitgenössischen Theater zahlreiche Beispiele für Aufführungen gibt, die diese Annahme widerlegen, wird auf die Frage, welchen Blickverhältnissen Bühnen Raum geben, in diesem Zusammenhang meist geantwortet, dass es sich bei diesen Blickverhältnissen um solche eines zwischenmenschlich-reziproken Sehens und Gesehenwerdens leiblich kopräsenter Akteure und Zuschauer im Hier und Jetzt des Theater- bzw. Aufführungsereignisses handelt. ${ }^{3}$ Das Nachdenken über die Begriffe der Bühne und des Raums verbleibt so in den meisten Fällen im Rahmen eines herkömmlichen Aufführungsbegriffs. Und dies ist nicht allein deshalb problematisch, weil dieser Begriff die Aufführung auf Situationen einer Kopräsenz von Akteuren und Zuschauern einschränkt, sondern auch, weil er die Beschreibung der Alterität der Aufführung - d. h. der Erfahrung von Andersheit in Aufführungen - auf diejenige einer unmittelbaren, dualen Beziehung reduziert. ${ }^{4}$

Desert Walker und The Plastic Bag geben nun auf besondere Weise Anlass dazu, dieser Sicht der Dinge zu widersprechen. Und dies haben sie mit jenen Arbeiten der zeitgenössischen szenischen Kunst gemeinsam, welche ich an anderer Stelle als Beispiele eines postspektakulären Theaters beschrieben habe, d. h. als Beispiele eines Theaters, welches vor dem Hintergrund veränderter Bedingungen jener von Guy Debord zuerst 1967 beschriebenen „Gesellschaft des Spektakels“5 das kritische Potenzial der Aufführung nicht mehr in der Betonung von Unmittelbarkeit sucht, sondern es vielmehr in einer Reflexion der prinzipiellen Mittelbarkeit jeglicher Erfahrung findet. ${ }^{6}$ Genauer gesagt: Postspektakuläres Theater reflektiert die Alterität der Aufführung als mittelbares Dreierverhältnis, als Verhältnis, in dem immer schon eine vermittelnde dritte Instanz interveniert, eine Instanz, die sich mit Jacques Lacan als diejenige des Symbolischen beschreiben lässt. Oder um es mit Bernhard Waldenfels zu sagen: Aufführungen des postspektakulären Theaters weisen darauf hin, dass

3 Vgl. z. B. Adam Czirak, Partizipation der Blicke. Szenerien des Sehens und Gesehenwerdens in Theater und Performance, Bielefeld, 2012.

4 Diesen problematischen Aufführungsbegriff vertritt insbes. Erika Fischer-Lichte. Vgl. z. B. dies., Ästhetik des Performativen, Frankfurt/M., 2004; sowie dies., Performativität. Eine Einführung, Bielefeld, 2012.

5 Vgl. Guy Debord, Die Gesellschaft des Spektakels, Berlin, 1996. [Frz. OA 1967.]

6 Vgl. hierzu ausführlich André Eiermann, Postspektakuläres Theater - Die Alterität der Aufführung und die Entgrenzung der Künste, Bielefeld, 2009. 
„[d]er Dritte [...] immer im Spiel [ist], nur eben oft als geheimer Souffleur, der mit dem Akteur nahezu verschmilzt." ${ }^{\text {"7 }}$

Dass der Dritte immer im Spiel ist und mit dem Akteur eben nur nahezu, nie jedoch vollständig verschmelzen kann, wird nun beispielsweise dann besonders deutlich, wenn in Aufführungen auf die Anwesenheit von Akteuren verzichtet wird (was gleichzeitig den herkömmlichen Aufführungsbegriff infrage stellt). Denn in solchen Fällen bleibt der Dritte - jener ,geheime Souffleur` - gewissermaßen übrig. Seine Einflüsterungen werden auf der leeren Bühne sozusagen hörbar, d. h. sie machen sich bemerkbar in Form der Erwartungen, welche die Zuschauer aufgrund der ihnen geläufigen Konventionen an die Aufführung richten, sowie in Form der Vorstellungen, die sie aufgrund dieser Erwartungen in die Leere der Bühne hineinprojizieren. Anders formuliert: Insbesondere dann, wenn sich auf einer Bühne kein Akteur findet bzw. einfindet, mit dem jener „geheime Souffleur“ nahezu verschmelzen könnte, eröffnet sich den Zuschauern die Möglichkeit der Erfahrung, dass sie sich schon bevor sie sich auf ein anwesendes Gegenüber beziehen - auf die dritte Instanz des Symbolischen beziehen.

Umgekehrt - und darum soll es im Folgenden gehen - kann sich dieser Dritte aber auch bemerkbar machen, indem Aufführungen die Anwesenheit von Zuschauern als Bedingung ihres Zustandekommens in Frage stellen und sich z. B. der Sicht menschlicher Zuschauer entziehen, wie es im Fall von Desert Walker und The Plastic Bag geschieht. Denn auf diese Weise wird deutlich, dass die Akteure - auch ohne vom Auge eines anwesenden Zuschauers gesehen zu werden - von einem anderen Blick getroffen sind, bzw. dass sie immer schon - mit Lacan gesagt - „im Schauspiel der Welt angeschaute Wesen sind." ${ }^{* 8}$

Eingeführt ist damit auch schon jene begriffliche Unterscheidung, welche den folgenden Überlegungen zu den von Desert Walker und The Plastic Bag eröffneten Bühnen für andere Blicke zugrunde liegt, nämlich Lacans Unterscheidung zwischen Auge und Blick. Und treffen sich diese Überlegungen einerseits mit der Betonung der Relevanz dieser Unterscheidung für das Nachdenken über Bühnenformen, wie sie insbesondere Ulrike Haß in ihrer Schrift Das Drama des Sehens verdeutlicht hat ${ }^{9}$, so treffen sie sich andererseits auch mit einem von Nikolaus Müller-Schöll in seinem Aufsatz „Das undarstellbare Publikum“ formulierten Hinweis, welcher lautet:

Nicht zuletzt ist es das Problem des heutigen Diskurses über den Zuschauer, dass darin die Frage ausgeblendet wird, ob es überhaupt eines menschlichen Zuschauers bedarf, damit Theater stattfinden kann. Damit ist nicht nur danach gefragt, ob Theater auch vor einem Gott, einem Tier, einer Pflanze, einem Stein oder einem

7 Bernhard Waldenfels, Bruchlinien der Erfahrung. Phänomenologie - Psychoanalyse Phänomenotechnik, Frankfurt/M., 2002, S. 257.

8 Jacques Lacan, Die vier Grundbegriffe der Psychoanalyse. Das Seminar Buch XI (1964), Weinheim, Berlin, 1996, S. 81.

9 Ulrike Haß, Das Drama des Sehens. Auge, Blick und Bühnenform, München, 2005. 
Spiegel gespielt werden kann, sondern darüber hinaus auch nach dessen medialer Grundlage. Wenn es keinerlei menschliche Äußerung gibt, die nicht aufgrund ihrer sprachlichen Verfasstheit immer schon eine Art von Theater impliziert, Theater herstellt - in dem Sinne, dass man in einer szenisch oder medial zu nennenden Konstellation steht, dann wirkt die Frage nach dem Zuschauer unerheblich, weil sie die Frage der Alteritätserfahrung durch das Medium positivistisch und empirisch verkürzt und deshalb verkennt. Denn nicht der empirische $\mathrm{Zu}$ schauer, auch nicht das Ich, das behauptet, Zuschauer zu sein, ist unter dem Begriff des Publikums zu bedenken, sondern die Tatsache, der Ordnung des Anderen aufgrund der unhintergehbaren medialen Grundlage jeder menschlichen Äußerung ausgesetzt zu sein. ${ }^{10}$

Angesprochen ist damit eben jene prinzipielle Mittelbarkeit jeglicher Erfahrung, welche im postspektakulären Theater und, wie im Folgenden gezeigt werden soll, auch in Desert Walker und The Plastic Bag reflektiert wird. Denn die Frage, ob es überhaupt eines menschlichen Zuschauers bedarf, damit Theater stattfinden kann, wird von diesen beiden Arbeiten nicht ausgeblendet, sondern vielmehr gerade gestellt - und in Form ihrer Verneinung auch beantwortet. Und wenn dabei im Titel des vorliegenden Textes von anderen Blicken die Rede ist, dann ist an dieser Stelle zu präzisieren, dass mit diesen anderen Blicken der Blick des Anderen gemeint ist, d. h. der Blick jenes „großen Anderen“, welcher bei Lacan für die symbolische Ordnung steht und auf welchen im zitierten Argument Müller-Schölls die Rede von einer Ordnung des Anderen als unhintergehbarer medialer Grundlage menschlicher Äußerungen verweist. Die von Desert Walker und The Plastic Bag eröffneten Bühnen für andere Blicke sind also - weil beide Arbeiten von der Prämisse Abstand nehmen, Theater bedürfe eines anwesenden menschlichen Zuschauers, um stattfinden zu können - Bühnen für den Blick des großen Anderen. Oder anders formuliert: Sie sind Bühnen, auf denen dieser Blick, der immer im Spiel ist, ausgespielt und die Erfahrung von Alterität nicht auf diejenige der Andersheit eines menschlichen Gegenübers reduziert wird.

Dieser Blick des großen Anderen - das ist zunächst noch vorauszuschicken, bevor konkret auf die Beispiele eingegangen wird - ist nun aber im Sinne Lacans nicht etwa der Blick irgendeines allsehenden Agenten. Zwar steht er mit der „Phantasie eines absoluten Wesens, dem die Eigenschaft des Allsehenden übertragen ist ${ }^{\text {“11 }}$, in Verbindung. Doch diese Verbindung besteht gerade darin, dass die „Annahme der Existenz eines universalen Sehenden“ nur die Art und Weise darstellt, auf welche ein „Sehen [...], das sich selbst genügt, indem es sich als Bewußtsein imaginiert“12, den Blick verkennt. Denn der Blick ist Lacan zufolge gerade das, was unserem Sehen entgeht und uns eben deshalb -

10 Nikolaus Müller-Schöll, „Das undarstellbare Publikum. Vorläufige Anmerkungen für ein kommendes Theater“, in: Sigrid Gareis/Krassimira Kruschkova (Hg.), Ungerufen. Tanz und Performance der Zukunft, Berlin, 2009, S. 82-90: 84. [Herv. i. O.]

11 Lacan (1996), Die vier Grundbegriffe der Psychoanalyse, S. 81.

12 Ebd., S. 80. 
im Sinne einer Verunsicherung unseres Bewusstseins bzw. Selbst-Bewusstseins - angeht. Der Blick ist - wie Lacan sich ausdrückt - ein Fleck im Sehfeld, genauer gesagt ein blinder Fleck - oder auch: ein Unsichtbares im Sichtbaren (um nicht zu sagen: ein Unbewusstes im Bewussten). Er steht für die Unvollständigkeit unserer Wahrnehmung, die unserer vermeintlichen Gewissheit einer selbstsicheren und selbstbestätigenden Sicht auf die Dinge einen Riss zufügt. ${ }^{13}$ Und er steht somit gleichsam für die Inkonsistenz der symbolischen Ordnung, d. h. für die Unmöglichkeit, das Reale symbolisch einzuholen. Der Blick ist im Sehfeld jenes sich stets entziehende „Objekt klein a“ der Lacan'schen Theorie, jener Mangel also, der das Subjekt als begehrendes Subjekt ins Spiel bringt und der gleichsam das Reale des Symbolischen ist - im Gegensatz zu dessen Imaginärem, das in der Vorstellung seiner Konsistenz besteht. Die Phantasie eines allsehenden Wesens entspricht eben dieser Vorstellung. Sie dient gerade dazu, den Mangel bzw. die Inkonsistenz der symbolischen Ordnung zu verschleiern und den ihr inhärenten Riss imaginär zu kitten, um die Verunsicherung eines bewussten Sehens bzw. (selbst-)bewussten Seins abzuwehren. Kurz gesagt: Die Funktion der Annahme eines allsehenden Wesens besteht gerade darin, den Blick, so Lacan, zu eskamotieren, also zum Verschwinden zu bringen.

In Desert Walker und The Plastic Bag geschieht nun das genaue Gegenteil: Der Blick wird nicht zum Verschwinden gebracht, sondern vielmehr zum Auftauchen. Und dies geschieht eben gerade in Form einer Auseinandersetzung mit jener Phantasie eines allsehenden Wesens, genauer gesagt als Auseinandersetzung mit jenen Bühnenformen, Technologien und Dispositiven, in denen sich diese Phantasie manifestiert bzw. ihre (post-)panoptische Ausprägung findet. $^{14}$

Im Fall von Desert Walker ist allein schon der Bezug auf Becketts Quad ein Indiz dafür. Denn bereits für sich genommen (und deshalb möchte ich zunächst etwas ausführlicher auf diese Arbeit eingehen) stellt dieses Fernsehspiel, das Beckett 1981 in zwei Versionen - Quadrat I + II - für den Süddeutschen Rundfunk realisierte, eine Auseinandersetzung mit der Phantasie eines absoluten Sehens dar, genauer gesagt eine Auseinandersetzung mit dem Prinzip der Zentralperspektive, das ja aufs Engste mit dieser Phantasie verbunden ist.

13 Vgl. z. B. Georg Christoph Tholen, Die Zäsur der Medien. Kulturphilosophische Konturen, Frankfurt/M., 2002.

14 Zum Begriff des Panopticons bzw. Panoptikums vgl. Michel Foucault, Überwachen und Strafen. Die Geburt des Gefängnisses, in: ders., Die Hauptwerke, Frankfurt/M., 2008 [frz. OA 1975], S. 701-1019: 900-934, insbes. 905-916. Zum darauf basierenden Begriff des Postpanoptikums vgl. Zygmunt Bauman, Flüchtige Moderne, Frankfurt/M., 2003. [Engl. OA 2000.] 


\section{Quad}

Vier PerformerInnen in Djellabas (das sind traditionelle marokkanische Kapuzengewänder) laufen in Quad, einem strikten Muster folgend, die Seiten und Diagonalen einer hellen quadratischen Fläche ab, die sich in einem dunklen Umraum befindet. ${ }^{15}$ Sie treten in versetzter Reihenfolge und aus unterschiedlichen Richtungen auf, laufen ihre Parcours und verschwinden wieder, wobei immer mindestens eine PerformerIn zugegen ist. ${ }^{16}$ Gezeigt wird diese Szenerie aus der Perspektive einer zentral platzierten, schräg von oben filmenden Kamera, deren Bildausschnitt die quadratische Fläche relativ eng umrahmt. In der Mitte des Quadrats befindet sich ein kleiner dunkler Punkt, dem die PerformerInnen auf ihren Wegen über die Diagonalen stets mit einem kleinen Ausfallschritt nach links ausweichen. Dieser Mittelpunkt des Quadrats liegt auch exakt in der Mitte des gefilmten Bildes - als unverkennbarer Verweis auf einen zentralperspektivischen Fluchtpunkt, obwohl er hier gerade nicht als solcher funktioniert.

Noch unverkennbarer aber - wenn es sich hier nicht bloß um eine sehr passende Koinzidenz handelt - verweist schon allein der Titel des Fernsehspiels auf die Geschichte der zentralperspektivischen Bühne. Denn in Quad klingt recht deutlich der Begriff des quadro an, der für jene berühmte, von Andrea Pozzo um 1700 konzipierte Bühnenform von zentraler Bedeutung ist $-\mathrm{d}$. h. für jene Bühnenform, in welcher, so Ulrike Haß, „das perspektivische Schema vollständige Autonomie [erlangt] “17 und „die alles, was auf ihr zur Darstellung gebracht wird, in ein Verhältnis zur Bildlichkeit zwingt.“18 Der Begriff des quadro steht dabei für die als Bildfläche gedachte Grenze zwischen Bühne und Zuschauerraum, d. h. das quadro wird als ein Bereich definiert, bei dem es sich, so Haß, „um eine optische Fläche und nicht um einen Raum [han-

15 Die beiden Versionen Quadrat I und Quadrat II unterscheiden sich dabei in folgenden Punkten: Quadrat I wurde in Farbe aufgezeichnet, während Quadrat II schwarz-weiß gefilmt wurde. Verbunden ist mit diesem Unterschied, dass die PerformerInnen in Quadrat I verschiedenfarbige Djellabas tragen (weiß, blau, rot und gelb), während diese in Quadrat II einheitlich in weiß-grau gehalten sind. Weiterhin wird das Gehen der PerformerInnen in Quadrat I jeweils von einem spezifischen Percussion-Pattern begleitet, während in Quadrat II nur die schlurfenden Schritte der PerformerInnen zu hören sind. Auch gehen diese in Quadrat I schneller als in Quadrat II. Dennoch dauert Quadrat I länger, da hier mehrere Durchläufe der Choreographie stattfinden, in denen unterschiedliche Reihenfolgen des Auf- und Abtritts der verschiedenfarbig gekleideten PerformerInnen durchgespielt werden. In Quadrat II hingegen wird nur ein Durchlauf gezeigt, da hier keine Variationen hinsichtlich der Farbkombinationen möglich sind.

16 Als Fernsehspiel beginnen die beiden Versionen von Quad so auch nicht etwa mit dem Bild einer zunächst leeren Bühne. Stattdessen wird jeweils in die bereits laufende Ausführung der Choreographie eingeblendet. Entsprechend wird auch das Ende beider Versionen nicht szenisch, sondern filmisch markiert, nämlich durch ein Ausblenden aus der noch laufenden Ausführung der Choreographie. Suggeriert wird auf diese Weise eine Wiederholung der Choreographie in Endlosschleife.

17 Haß (2005), Das Drama des Sehens, S. 369.

18 Ebd. S. 10 u. S. 381. 
delt]“19 bzw. um eine „Eintragungsfläche innerhalb eines optisch erschlossenen Systemraums. “20 Und was den Blick betrifft, so schreibt Haß über diese ,Architektur des Sehens': „Es fehlt das Subjekt, es fehlt der Blick, und es fehlt das Subjekt, das den Blick begehrt. “21

Was nun Becketts Auseinandersetzung mit dieser den Blick verdrängenden Architektur des Sehens betrifft, so ist es sehr wahrscheinlich kein Zufall, dass er an anderer Stelle und bereits zu einem viel früheren Zeitpunkt - nämlich in Warten auf Godot - ausgerechnet eine Figur namens Pozzo erblinden lässt. Und im Hinblick auf das, was Haß weiterhin über die Bühnenkonzeption des gleichnamigen Barockmalers und -architekten schreibt, lässt sich insbesondere die Beziehung dieser Beckett'schen Figur zu ihrem Diener Lucky geradezu als Allegorie auf jenes Verhältnis lesen, in welchem Haß zufolge Pozzos Architektur des Sehens zum Theater der Schauspieler steht, das Mitte des achtzehnten Jahrhunderts in die zentralperspektivisch gestalteten Bühnenräume Einzug hält. ${ }^{22}$

Denn wie Becketts Pozzo seinen Diener dazu zwingt, Kunststückchen aufzuführen (schließlich sogar das Kunststück, laut zu denken), so zwingt auch die Architektur Andrea Pozzos die Schauspieler in ein Verhältnis zur Bildlichkeit bzw. dazu, ihre „Kunststückchen“ im Korsett einer Architektur des Sehens aufzuführen - allerdings, wie Haß ausführt, auf eine ganz besondere Weise:

In einer paradoxen Entwicklung, die den modernen Schauspieler im Zuge einer Domestizierung seiner Gesten als ,natürliche Gestalt‘ erfindet, wird nun der schauspielerischen Darstellung aufgelastet, was der optischen Architektur als solcher fehlt: der Blick, der Gesichtspunkt, die Seele, das Subjekt, sein Begehren. $^{23}$

Hier liegt natürlich die Versuchung nahe, in jenem Gepäck, welches Lucky in Warten auf Godot von Pozzo aufgelastet wird, ein Motiv zu sehen, das auf diese paradoxe Entwicklung anspielt. Und ebenso bietet es sich an, jenen Strick, an welchem Lucky von Pozzo geführt wird, als Bild jener Verstrickung des Schauspielers in die zentralperspektivische Architektur des Sehens zu lesen, welche Haß wie folgt beschreibt:

19 Ebd., S. 378: „Sucht man nach einem Bildtypus, mit dem sich dieses quadro vergleichen läßt, so wäre dies am ehesten das Fotonegativ als ein Bildträger, der durch den perspektivischen Apparat ,von hinten` belichtet und ,von vorne' gelesen werden kann und sich durch seine Durchsichtigkeit auszeichnet. [...] Es handelt sich um eine optische Fläche und nicht um einen Raum. Die räumliche Beziehung zwischen dem Zuschauerraum und der Bühne ist zerschnitten. Das was sie verbindet, ist dieser Schnitt.“

20 Ebd., S. 10.

21 Ebd., S. 381. Als „Architektur des Sehens“ bezeichnet Haß die Bühnenkonzeption Andrea Pozzos in der Überschrift des entsprechenden Abschnitts (vgl. ebd., S. 366).

22 Vgl. ebd., S. 10 u. 382.

23 Ebd., S. 382. Mit dem Begriff der „natürlichen Gestalt“ bezieht sich Haß hier auf Günther Heeg, Das Phantasma der natürlichen Gestalt. Körper, Sprache und Bild im Theater des 18. Jahrhunderts, Frankfurt/M., 2000. 
Der Schauspieler hingegen, der von seiner Geschichte her mit den visuellen Bedingungen dieser neuen Systemräume nichts zu tun hat, verstrickt sich in einen unaufhörlichen Kampf gegen seine bedingungslose Sichtbarkeit und sein Gesehenwerden, das im System dieses Raumes verankert ist und gleich einem ,toten Auge“ auf seinen Gebärden lastet. ${ }^{24}$

Fast scheint es so, als habe Beckett eben dieses „tote Auge“ im Sinn, wenn er Pozzo im zweiten Akt von Warten auf Godot als Blinden zurückkehren lässt. Und ebenso naheliegend ist es, die Tatsache, dass Lucky unter diesem auf ihm lastenden „toten Auge“ stumm geworden ist, als Bild für eine Schauspielkunst zu verstehen, die aufgrund ihrer Domestizierung durch die Architektur des Sehens zu einer nichtssagenden geworden ist. Aber wie auch immer, auf jeden Fall stellt Beckett - insofern das Verhältnis von Pozzo und Lucky tatsächlich als Allegorie der Domestizierung des Schauspielers durch die Architektur des Sehens gelesen werden kann - sowohl die barocke Bühne, die „das quadro als reine Einschreibungsfläche innerhalb eines optisch erschlossenen Systemraums [definiert]“, als auch den sich ein halbes Jahrhundert nach (Andrea) Pozzo auf dieser Bühne einstellenden „menschliche[n] Darsteller einer Figur und ihrer Theaterbilder“, d. h. „[b]eide Elemente oder Seiten dieser Struktur, die im bürgerlichen Theater zur modellstiftenden Wirkung gelangen“ “25, als solche dar, die ziemlich am Ende sind - schließlich bricht das Gespann aus blindem Pozzo und stummem Lucky immer wieder zusammen. ${ }^{26}$

Artikuliert sich also in diesem Sinne in Warten auf Godot eine Kritik des bürgerlichen Theaters, die gleichermaßen an den beiden Elementen der diesem zugrunde liegenden Struktur sowie an deren Zusammenhang ansetzt, so nimmt sich Quad als konsequente Fortsetzung dieser Kritik aus. Konsequent ist diese Fortsetzung schon allein (aber keineswegs nur) deshalb, weil es sich bei ihr um eine solche mit anderen Mitteln handelt, bzw. - um „Mittel“ ganz buchstäblich zu verstehen - um eine Fortsetzung in einem anderen Medium. Denn dass Beckett für Quad, wie es in einem Informationstext zu Desert Walker heißt, die Technologie des Theaters gegen die des Filmstudios eintauscht ${ }^{27}$, bringt geradezu jene technische Ersetzbarkeit der beiden Strukturelemente des bürgerlichen Theaters auf den Punkt, welche Haß wie folgt beschreibt:

Beide Elemente [...] lassen sich technisch ersetzen. Dies geschieht mit den bewegten Bildern des Films von jenem Moment an, da das Kameraauge den

24 Haß (2005), Das Drama des Sehens, S. 382.

25 Ebd., S. 10.

26 Mit Bezug auf Haß ließe sich das Bild dieses Gespanns auch als das eines an die Kandare der zentralperspektivischen Bühnenform genommenen „Harlekin-Prinzips“ beschreiben, insofern Haß über dieses Prinzip schreibt: „Harlekin, so läßt sich zugespitzt formulieren, ist der Blick, oder umgekehrt, der Blick ist das Harlekin-Prinzip - jenes andere Prinzip des Theaters, das unabhängig von Theaterhäusern, Gebäuden, Wänden oder Bildwänden existiert, und ebenfalls dasjenige Prinzip, das von den Architekturen, den Wänden und Bildwänden des Theaters schließlich verdrängt werden wird“ (Haß (2005), Das Drama des Sehens, S. 160).

27 Vgl. http://lostlab.wordpress.com/desert-walker/it-is-winter-i-switch-on/, zuletzt aufgerufen am 02. November 2012. 
Sprung über die Rampe unternahm. In systematischer Hinsicht setzten sich damit das Kameraauge und die filmische Kadrage an die Stelle des quadro, während die Ablichtungen des Darstellers an die Stelle der Körper traten. Wieder gibt es eine doppelte Struktur, die ein bewegtes Bild erzeugt, das zudem transportabel, kopierbar und wiederholbar ist. ${ }^{28}$

Exakt diese technische Ersetzbarkeit sowohl des quadro einerseits als auch der Darstellerkörper andererseits wird in Quad in die Tat umgesetzt. Und wie im Fall von Warten auf Godot, setzt Becketts Kritik am Modell des bürgerlichen Theaters auch hier sowohl an beiden Elementen als solchen als auch an deren Zusammenhang an.

Was dabei zunächst das Element des quadro betrifft, so stimmt Becketts Operation haargenau mit dem überein, was Haß über dessen Ersetzbarkeit schreibt - oder genauer gesagt: Becketts Operation stellt diese Ersetzbarkeit geradezu aus. Denn sie setzt nicht nur (wie jeder herkömmliche Film) das Kameraauge und die filmische Kadrage an die Stelle des quadro, sondern sie stellt förmlich ein Bild dieser Ersetzung her - ein Sinnbild dieser Ersetzung sozusagen bzw. ein Meta-Bild -, indem sie das Kameraauge im Verhältnis zu der von ihm abgelichteten Szenerie auf deutlichste Weise im Zentrum platziert und darüber hinaus die filmische Kadrage den Rahmen jener quadratischen Fläche bilden lässt, welche diese Szenerie bestimmt. Ein in die Horizontale verlegtes und somit begehbar gemachtes quadro sozusagen. Und wenn Beckett - wie oben schon gesagt - die technische Ersetzbarkeit des quadro damit auf den Punkt bringt, so ist dies ganz buchstäblich zu verstehen. Denn in der Tat ist es insbesondere jener Punkt in der Mitte sowohl der quadratischen Fläche als auch des filmisch kadrierten Bildes, der dem beschriebenen Sinnbild das I-Tüpfelchen aufsetzt und besonders deutlich auf die Eigenschaft des quadro verweist, alles in ihm zur Darstellung kommende in ein Verhältnis zur Bildlichkeit zu zwingen, „pinnt“ er doch gewissermaßen den abgebildeten Raum mit der Fläche des Bildes zusammen bzw. das abgebildete (horizontale) Quadrat mit der dieses abbildenden (vertikalen) filmischen Kadrage - und hier drängt sich nicht von ungefähr eine Assoziation mit Lacans Begriff des „Steppunkts“ auf. ${ }^{29}$

${ }^{28} \mathrm{Ha}$ (2005), Das Drama des Sehens, S. 10.

29 „Die wörtliche Bedeutung von Steppunkt ist ein Polsterknopf, der da gesetzt wird, wo ,der Polsterer mit seiner Nadel hart gearbeitet hat, damit sich die formlose Masse der Füllung nicht zu leicht bewegt' (nach: Malcolm Bowie, Lacan, Harvard, MA, 1991, S. 74), folglich sind die Steppunkte eben diejenigen Punkte, an denen ,Signifikat und Signifikant zusammengeknüpft sind' (Se 3, 303)“ (Dylan Evans, Wörterbuch der Lacanschen Psychoanalyse, Wien, 2002, S. 286). Der Punkt in Quad verknüpft in diesem Sinne also das Filmbild mit dem abgebildeten Raum, d. h. er macht das Bild zu einem Signifikanten und den Raum zu jenem Signifikat, welches an diesen Signifikanten geknüpft wird. Vor dem Hintergrund dessen, was oben im Zusammenhang mit der Erläuterung der Lacan’schen Konzeption des Blicks gesagt wurde, ist hier zu erwähnen, dass Steppunkte im Sinne Lacans gerade das sind, was dem Symbolischen - indem sie diesem eine Ordnung geben bzw. eine symbolische Ordnung herstellen scheinbare Konsistenz verleiht bzw. „die notwendige Illusion einer festgelegten Bedeutung produziert“ (ebd., S. 287). Gerade dieser Aspekt ist nun aber ebenfalls Gegenstand der kritischen Operation Becketts, denn wie noch gezeigt werden soll, wird mit diesem „Steppunkt“ 
Aber damit nicht genug. Denn dieser Punkt ist nicht nur das I-Tüpfelchen auf dem Sinnbild für die technische Ersetzbarkeit des quadro, sondern auch derjenige, in welchem die ganze Konsequenz der Beckett'schen Operation einer Fortsetzung der Kritik des bürgerlichen Theaters mit anderen Mitteln kulminiert. Er ist nämlich auch im Hinblick auf die Kritik des zweiten Strukturelements dieses Theatermodells von Bedeutung, d. h. im Hinblick auf die zur „natürlichen Gestalt“ domestizierten Darstellerkörper und deren technische Ersetzbarkeit. Und er stellt somit auch gleichzeitig den Zusammenhang beider Strukturelemente her. Will heißen: „Versteppt“ werden durch den Punkt nicht nur gefilmter Raum und Filmbild, sondern auch die Elemente des quadro bzw. der filmischen Kadrage einerseits und der Darstellerkörper bzw. ihrer filmischen Ablichtungen andererseits - genauer gesagt: der kritische Bezug auf beide.

Der Punkt ist im wahrsten Sinne des Wortes das, worum es in Quad geht denn er ist schließlich die Stelle, um welche die PerformerInnen auf ihren Wegen über die Diagonalen des Quadrats stets herumgehen. Und als solche Stelle ist er gleichzeitig diejenige, an welcher die PerformerInnen einander buchstäblich aus dem Weg gehen, wenn sie sich zu mehreren auf dem Quadrat bewegen und sich auf den Diagonalen entgegenkommen. Er ist der Ort einer aufgrund ausweichender Bewegung ausbleibenden Begegnung. Und hinsichtlich der Frage, inwiefern sich darin eine Kritik an der Erfindung des modernen Schauspielers bzw. an der Domestizierung seiner Gesten und seines Körpers zur „natürlichen Gestalt“ artikuliert, lohnt sich erneut ein Blick auf das, was Haß zu diesem Thema weiterhin schreibt. Denn jenes Körperbild einer „natürlichen Gestalt“, welches aus der Domestizierung des Darstellerkörpers durch die Architektur des Sehens resultiert, ist ihr zufolge u. a. dadurch gekennzeichnet, dass „es als Ertrag aus einer bestimmten dialogischen, interpersonalen dramatischen Struktur hervorgegangen ist und mit dieser Struktur - auf welcher trivialen oder banalen Stufe und in welchem Medium auch immer verknüpft bleibt. “"30 Und weiter schreibt sie in diesem Zusammenhang:

Bekanntlich ist die dialogische Face-to-Face-Situation zum grundlegenden Interaktionstypus überhaupt erklärt worden. Insofern man davon ausgegangen ist, daß innerhalb dieser Form Subjekt und Objekt, das Ich und der andere, Du und Ich sich wechselseitig konstituieren, wird diese Form bis heute als Ur-Modell des identitätsstiftenden, kommunikativen Handelns gedeutet. In der aufklärerischen Aufbruchsstimmung, aber auch in der Not, nach dem Zerfall des mittelalterlichen Weltbildes keine andere Form der Zusammengehörigkeit mehr zu haben als das abstrakte Zwischen (den einzelnen), ist die interpersonale Struktur darüber hinaus emphatisch zur Begegnung umgedeutet worden. ${ }^{31}$

in Quad auf eine Weise umgegangen - bzw. wird er auf eine Weise umgangen - die ihn zu einem Verweis auf die prinzipielle Inkonsistenz der symbolischen Ordnung werden lässt.

30 Haß (2005), Das Drama des Sehens, S. 385.

31 Ebd. 
Eben diese emphatische Deutung der dialogischen Face-to-Face-Situation als Begegnung - an der auch und gerade die ÄsthetikerInnen des Performativen mit ihrem Theorem der leiblichen Kopräsenz von Akteuren und Zuschauern als Bedingung der Aufführung partizipieren (und hier lässt sich durchaus sagen, dass sie darin dem Modell des bürgerlich-dramatischen Theaters eher verhaftet bleiben, als von ihm Abstand zu nehmen ${ }^{32}$ ) -, eben diese Deutung wird in Quad zurückgewiesen. Oder anders formuliert: Quad wendet sich kritisch gegen diese Deutung, indem sich die PerformerInnen von einer Begegnung von Angesicht zu Angesicht abwenden bzw. dieser Begegnung ausweichen.

Quad stellt somit einerseits die Architektur des Sehens in ihrer technischen Ersetzbarkeit aus und verweigert andererseits gerade das, worauf die Domestizierung des Darstellerkörpers durch diese Architektur im bürgerlichen Theater hinausläuft, nämlich sowohl den Auftritt „natürlicher Gestalten“ - bzw. deren Ablichtung - als auch deren Face-to-Face-Begegnung. D. h. zum einen werden die Körper der auftretenden PerformerInnen nicht als „natürliche Gestalten“ abgelichtet, sondern verbergen sich vielmehr vor einer solchen Ablichtung unter ihren - nicht umsonst herkömmlicherweise zum Schutz vor Sonnenlicht getragenen - Djellabas, die weder Gesicht noch Hände (also weder Mimik noch Gestik) zu sehen geben und auch das jeweilige Geschlecht der PerformerInnen im Dunkeln lassen. Und zum anderen steht in Quad das Ausbleiben einer Face-to-Face-Begegnung dieser verhüllten Gestalten im wahrsten Sinne des Wortes im Mittelpunkt, sprich: Der Mittelpunkt sowohl des abgebildeten Quadrats als auch der abbildenden Kadrage ist das, was in Quad die Weichen für die Verweigerung einer Face-to-Face-Begegnung „,natürlicher Gestalten“ stellt bzw. den Ort markiert, um den herum einer solchen Begegnung ausgewichen wird.

Die Einschätzung Chris Ackerleys, Quad sei eine „metaphor of coincidence, or meeting in time and space, and hence the ,danger zone' where this might happen “333, trifft deshalb nicht wirklich ins Schwarze - es sei denn, mit der von Beckett für das Zentrum des Quadrats geprägten Bezeichnung „danger zone“ wäre hier auf die „Gefahr“ hingewiesen, die prinzipielle Mittelbarkeit jeglicher Erfahrung im Fall einer Face-to-Face-Begegnung zugunsten des Glaubens an eine besondere Unmittelbarkeit dieser Begegnung zu verkennen.

32 Hier lässt sich sogar sagen, dass diese ÄsthetikerInnen die Emphase jener Deutung geradezu intensivierend weiterführen, insofern sie die Face-to-Face-Begegnung nicht mehr ,nur' innerszenisch von Akteuren dargestellt, sondern vielmehr zwischen Akteuren und Zuschauern tatsächlich vollzogen bzw. die dialogische Struktur des Dramas sozusagen auf diese übertragen sehen wollen.

33 Chris Ackerley, „Samuel Beckett and Mathematics“, als PDF verfügbar auf http://www.uca.edu.ar/uca/common/grupo17/files/mathem.pdf (zuletzt aufgerufen am 02. November 2012), zuerst veröffentlicht in: Cuadernos de literatura Inglesa y Norteamericana (Buenos Aires) 3.1-2 (May-Nov 1998), S. 77-102. Die entsprechende Stelle findet sich in der PDF-Version auf S. 18. Diese wird auch in einem Informationstext zu Desert Walker leicht verändert wiedergegeben, vgl. http://lostlab.wordpress.com/desert-walker/part-2-squaringthe-circle/, zuletzt aufgerufen am 02. November 2012. 
Doch Ackerleys Bezug auf Becketts Bezeichnung meint wohl eher eine Gefahr, die gerade auf Grundlage der Vorstellung einer besonderen Unmittelbarkeit von Face-to-Face-Begegnungen gedacht wird, d. h. die Gefahr eines direkten, ungeschützten Kontakts - wobei die Behauptung einer solchen Gefahr insofern an der von $\mathrm{Ha}$ beschriebenen Emphase partizipiert, als sie der Begegnung eine besondere Qualität zuschreibt.

Aber ob nun gefährlich oder ungefährlich - um ein direktes Zusammentreffen bzw. eine unmittelbare Begegnung geht es in Quad gerade nicht. Es geht, wie gesagt, um das genaue Gegenteil, nämlich um das Potenzial gerade des Ausbleibens einer Begegnung - nicht umsonst ist die Choreographie von Quad so konzipiert, dass sie auf ein eben solches Ausbleiben im wahrsten Sinne des Wortes hinausläuft. Näher als Ackerley kommt der Sache deshalb Martin Esslin, wenn er über Quad schreibt:

[T]he hooded shapes hurrying along their pre-ordained paths in Quadrat $1+2$ are clearly engaged in a quest for an Other. [...] And the center that the hooded wanderers have so fearfully to avoid is obviously the point at which real communication, a real ,encounter', would be potentially possible but inevitably proves - by the very nature of existence itself - impossible. ${ }^{34}$

Diese auf den ersten Blick paradox anmutende Beschreibung der Möglichkeit einer realen Begegnung, die sich als Unmöglichkeit erweist, lässt sich nun in der Tat im Sinne des bisher Gesagten lesen. Zwar schwingt in der Rede von einer , angstvollen Vermeidung' durchaus die Vorstellung einer Gefahr im Sinne Ackerleys mit. Doch letztlich spricht Esslin mit seiner Feststellung der Unmöglichkeit einer realen Begegnung vielmehr die prinzipielle Mittelbarkeit jeglicher Erfahrung an. Oder genauer gesagt: Indem er die Unmöglichkeit betont, dem Anderen im Realen zu begegnen bzw. unmittelbar mit ihm zu kommunizieren, weist er die Annahme einer realen Begegnung bzw. unmittelbaren Kommunikation implizit als Phantasie aus, welche die Intervention der symbolischen Ordnung verkennt. D. h. seine Beschreibung verweist darauf, dass eine Begegnung immer den Umweg über die symbolische Ordnung als vermittelnde dritte Instanz voraussetzt und Kommunikation nur über diesen Umweg stattfinden kann. Dass er in diesem Zusammenhang jenen Anderen, den die verhüllten Gestalten seines Erachtens suchen, großschreibt, ist hier bezeichnend, ist es doch der große Andere, der somit auf den Plan tritt - gerade weil Quad der vermeintlich unmittelbaren Begegnung mit einem „kleinen anderen“ im Sinne Lacans, d. h. mit einem Gegenüber, in dem man sich spiegeln bzw. wiedererkennen bzw. selbstbestätigen kann, ausweicht. Anders formuliert: Was jene von Esslin beschriebene „Suche nach dem Anderen“ nicht findet, ist die vermeintlich unmittelbare Begegnung mit einem kleinen anderen. Auf was

34 Martin Esslin, „Patterns of Rejection. Sex and Love in Beckett’s Universe“, in: Linda BenZvi (Hg.), Women in Beckett. Performance and Critical Perspectives, Urbana, Chicago, IL, 1992, S. 61-67: $66 \mathrm{f}$. 
sie aber gerade deshalb trifft, ist die vermittelnde dritte Instanz des großen Anderen.

Als „Metapher eines Zusammentreffens“ und einer „Begegnung in Raum und Zeit“, wie Ackerley schreibt, ist Quad in diesem Sinne also allenfalls insofern zu verstehen, als diese Metapher die Mittelbarkeit jeglicher Begegnung reflektiert. Oder mit Slavoj Žižek gesagt: Quad ist weniger die Metapher einer Begegnung als vielmehr eine Metapher dafür, dass „der andere, dem wir begegnen, nicht nur der imaginäre semblant [der kleine andere, Anm. A. E.] ist, sondern auch der ungreifbare Andere des realen Dings, mit dem kein reziproker Austausch möglich ist“, weshalb aber gerade -,,[u]m unserer Koexistenz mit dem Ding ein Mindestmaß an Erträglichkeit zu verschaffen“ - der große Andere bzw. „die symbolische Ordnung qua Drittes, qua befriedender Vermittler intervenieren [muß] ${ }^{* 35}$, ohne dass diese Vermittlung jedoch jemals vollständig aufgehen könnte (eben hierin liegt die prinzipielle Inkonsistenz jeder symbolischen Ordnung begründet).

Quad bricht also mit jener dialogischen, interpersonalen dramatischen Struktur, auf der die Körperbilder des bürgerlichen Theaters beruhen, und somit auch mit der Überzeugung, es handle sich bei der dialogischen Face-toFace-Situation um den grundlegenden Interaktionstypus überhaupt. Statt in dieser Situation die Chance eines direkten Zugangs zum Anderen zu vermuten, verweist Quad darauf, dass der Andere nie nur der kleine andere ist, sondern immer auch „der Andere als das Reale, das unmögliche Ding, der ,unmenschliche Partner', der Andere, mit dem kein symmetrischer Dialog, vermittelt durch die symbolische Ordnung, möglich ist“36 - der aber gerade deshalb diese Vermittlung bzw. die Intervention des großen Anderen notwendig macht. Denn, wie Žižek ausführt:

Die Domestizierung des Anderen-Dinges zu einem ,normalen Mitmenschen kann nicht durch direkte Interaktion geschehen, sondern setzt das dritte Agens voraus, dem wir beide uns unterwerfen - ohne die impersonale symbolische Ordnung gibt es keine Intersubjektivität (keine symmetrische, gemeinsam ,gelebte‘ Beziehung zwischen Menschen). ${ }^{37}$

Übertragen auf die Domestizierung des Schauspielerkörpers durch die Architektur des Sehens heißt das: Der Andere ist nie nur die ,natürliche Gestalt‘, sondern immer auch das reale, gestaltlose Ding. D. h. die „,natürliche Gestalt“ ist nicht natürlich, sondern lediglich eine imaginäre Oberfläche, deren Zustandekommen sich der vermittelnden Intervention der symbolischen Ordnung verdankt - wobei sich das Ding zwar ein Stück weit, nie jedoch restlos domestizieren lässt.

Quad konfrontiert in diesem Sinne die Architektur des Sehens mit ihrem Realen, d. h. mit der Tatsache, dass sich die Phantasie eines vollständigen Se-

\footnotetext{
35 Slavoj Žižek, Die politische Suspension des Ethischen, Frankfurt/M., 2005, S. 24.

36 Ebd., S. 23.

37 Ebd., S. 24. [Herv. i. O.]
} 
hens bzw. einer kompletten Übersicht über die Dinge - und entsprechend auch die Phantasie einer vollständigen Sichtbarkeit des Anderen bzw. einer unmittelbaren Begegnung mit diesem - einer Verkennung sowohl des „AnderenDinges“ als auch der Intervention des großen Anderen verdankt. Und wenn sich mit Haß sagen lässt, dass die Architektur des Sehens zwar den Schauspielerkörpern auflastet, was ihr fehlt - nämlich den Blick -, diese Last aber letztlich in den von ihr domestizierten, einander begegnenden Körperbildern nicht mehr zum Tragen kommen lässt - sprich: den Blick verdrängt -, dann lässt sich über Quad sagen, dass hier der Blick in die als solche ausgestellte Architektur des Sehens eingetragen, sozusagen von den verhüllten PerformerInnen, die sich gerade nicht als „natürliche Gestalten“ begegnen, geradezu in diese Architektur hineingetragen wird. Mit ihnen tritt etwas auf, das der zentralperspektivischen Sicht der Kamera entgeht - ihre verhüllten, unsichtbaren Körper -, so wie diese Körper einander buchstäblich ent- bzw. aus dem Weg gehen. Mit ihnen zieht etwas in die Architektur des Sehens ein, das sich dem Sehen entzieht - sowohl dem Sehen des Kameraauges bzw. der Ablichtung durch dieses als auch dem gegenseitigen Sehen und Gesehenwerden von Angesicht zu Angesicht. Oder - um es mit Žižek zu sagen: Quad bringt den Anderen als solchen ins Spiel, in dem „immer ein fremder traumatischer Kern verbleibt“ und der „eine träge, undurchschaubare, rätselhafte Präsenz [bleibt]“ - wobei „[d]er Kern dieser Präsenz [...] natürlich das Begehren des Anderen [ist], ein Rätsel nicht nur für uns, sondern auch für den Anderen selbst. ${ }^{\text {“38 }} \mathrm{D}$. h. das, was der Architektur des Sehens Haß zufolge fehlt - oder vielmehr, was diese Architektur verdrängt und was auch die Schauspielerkörper, denen sie dieses Verdrängte auflastet, aufgrund ihrer Domestizierung zur „natürlichen Gestalt“ nicht in ihr zum Tragen bringen können - kehrt in Quad, in Gestalt der verhüllten Gestalten, ins quadro zurück, nämlich das Subjekt, der Blick, und das Subjekt, das den Blick begehrt. Kurz gesagt: Quad lässt den Blick im quadro auftauchen.

\section{Desert Walker}

Wie bezieht sich nun aber Desert Walker auf Quad, d. h. wie wird hier der Blick zum Auftauchen gebracht? Oder genauer gefragt: Wie setzt Desert Walker Becketts kritische Auseinandersetzung mit der Architektur des Sehens bzw. mit der damit verbundenen Phantasie eines allsehenden Überblicks fort? Eine erste Antwort ist: Wenn Quad das quadro ins Visier nimmt und in diesem den Blick auftauchen lässt, so konzentriert sich der kritische Ansatz von Desert Walker auf zeitgenössische Technologien des Sehens, in denen die Phantasie einer vollständigen Übersicht ihre (post-)panoptische Ausprägung findet. Gemeint sind hier Technologien, die im Dienst einer möglichst voll-

38 Ebd., S. 20. 
ständigen Übersicht aus der Vertikalen stehen, wie z. B. Luftbild- und insbesondere Satellitenfotografie, aber auch Visualisierungstechnologien auf Grundlage von GPS-, Mobilfunk- oder Netzwerkdaten. Und in diesem Zusammenhang steht auch die Tatsache, dass sich Desert Walker neben Quad auch noch auf ein anderes künstlerisches Projekt bezieht, bei dem es sich um eines der wohl berühmtesten Land-Art-Projekte handelt, nämlich die Spiral Jetty von Robert Smithson, eine riesige, aus Geröll bestehende, spiralförmige Landzunge mit einer Länge von etwa 460 Metern und einer Breite von etwa 46 Metern, die 1970 im großen Salzsee von Utah in der Nähe des Ölfelds Rozel Point aufgeschüttet wurde - und einem breiteren Publikum vor allem durch eine filmische Dokumentation bekannt geworden ist, die zu einem großen Teil aus der Luft aufgenommen wurde.

Desert Walker - von Motherboard im Rahmen einer Künstlerresidenz am Center for Land Use Interpretation in Wendover (einer von der Grenze zwischen Utah und Nevada geteilten, sehr kleinen Kleinstadt) entwickelt - lässt sich nun in einem ersten Schritt gewissermaßen als Synthese von Quad und Spiral Jetty beschreiben. ${ }^{39}$ Denn was im Rahmen von Desert Walker passierte, war Folgendes:Wie eingangs beschrieben, wurde die Choreographie von Quad in die Salzwüste von Utah und Nevada übertragen - in jene Landschaft also, in welcher sich auch die Spiral Jetty befindet - und damit auf eine ,Bühne', die sich weiter erstreckt, als das sprichwörtliche Auge reicht. Ausgedehnt wurde die Bühne dabei aber nicht nur in Form einer Öffnung der filmischen Kadrage bzw. anhand der Ersetzung des filmischen „Offs“ durch die offene Landschaft der Salzwüste. Darüber hinaus wurde auch - in Anlehnung an die Ausmaße der Spiral Jetty - das abzulaufende Quadrat als solches beträchtlich ausgedehnt, so dass seine Seitenlängen je etwa 250 Meter und die Länge seiner Diagonalen je etwa 360 Meter betrugen ${ }^{40}$ (was sich auch auf die zum Ablaufen des Quadrats benötigte Zeit auswirkte, die bei etwa acht Stunden lag). ${ }^{41}$

Schon allein das Quadrat wurde also derart vergrößert, dass es sich vom herkömmlichen Standpunkt eines menschlichen Zuschauers aus kaum noch vollständig überschauen ließ. Vollständig überschauen ließ es sich nur aus der

39 Dabei ist auch zu erwähnen, dass zwischen den beiden Arbeiten als solchen bereits Bezüge bestehen (wenn auch nur indirekte). Amanda Steggell - Mitglied von Motherboard - betont hier insbesondere das Motiv einer Bewegung gegen den Uhrzeigersinn, dass sich sowohl in der Choreographie von Quad als auch in dem - vom Ufer aus gesehenen - Verlauf der Spiral Jetty findet. Dass dies einen Bezug zwischen den Arbeiten Smithsons und Becketts darstellt, betont sie dabei mit Verweis darauf, dass sich Smithson im Zusammenhang seiner Arbeit an der Spiral Jetty mit Becketts Roman The Unnameable von 1953 beschäftigt hat. Vgl. hierzu ausführlich die Ausführungen Steggells auf http://lostlab.wordpress.com/desert-walker/it-iswinter-i-switch-on/, zuletzt aufgerufen am 02. November 2012.

40 Vgl. die GPS-basierte Visualisierung der abgelaufenen Strecke auf http://www.gpsies. com/map.do?fileId=rcgqjlvrcuhiytox bzw. die Auswahl von Ansichten auf http://lostlab. wordpress.com/desert-walker/part-2-squaring-the-circle/, beide zuletzt aufgerufen am 02. November 2012.

41 Quadrat I dauert nur ca. neun Minuten, Quadrat II lediglich ca. vier Minuten. 
Luft - womit der oben bereits erwähnte Bezug auf die Spiral Jetty wieder angesprochen wäre, ein Bezug, der hinsichtlich jener Auseinandersetzung mit Technologien eines vertikalen Sehens von besonderem Interesse ist. Denn wie Smithson im Fall seiner Dokumentation der Spiral Jetty, so setzte auch Motherboard im Rahmen der Dokumentation von Desert Walker Kameras ein, die von oben filmten - womit die bereits in Quad vorliegende Elevation der Kamera auf einen erhöhten Punkt sozusagen konsequent weitergeführt wurde. Gefilmt wurde dabei sowohl aus einem Sportflugzeug als auch mit Kameras, die an Wetterballons befestigt waren - und darüber hinaus wurde die Dokumentation des Projekts auch durch den Einsatz von GPS-Tracking ergänzt, so dass zusätzlich zu den Vogelperspektiven der Luftbildkameras auch noch eine Satellitenperspektive adressiert wurde, deren Sicht sich als online verfügbare Visualisierung einsehen lässt. ${ }^{42}$

Im Fall von Desert Walker - anders als im Fall von Quad - kam also nicht nur eine Kamera zum Einsatz. Und hinzuzufügen ist, dass auch nicht allein aus der Vertikalen, sondern durchaus auch aus der Horizontalen gefilmt wurde. Denn neben den von oben filmenden Kameras wurde die Performance auch mithilfe solcher dokumentiert, welche die PerformerInnen auf dem Kopf trugen. Darüber hinaus wurde auch mit einer auf einem Stativ montierten, schwenkbaren Kamera gefilmt, die sich exakt auf jenem besonderen Punkt befand, für welchen Beckett die Bezeichnung „danger zone“ geprägt hat, d. h. auf dem Mittelpunkt des Quadrats.

Wie lässt nun aber Desert Walker - wie oben behauptet - den Blick in dieser Vielfalt sowohl vertikaler als auch horizontaler Perspektiven auftauchen? Wie wendet sich die Arbeit an andere Blicke als diejenigen menschlicher $\mathrm{Zu}$ schauer bzw. an den Blick des großen Anderen? Und wie ist dies überhaupt möglich, wenn gerade jener Punkt, welcher in Quad für das Auftauchen dieses Blicks innerhalb des quadro bzw. der Architektur des Sehens von entscheidender Bedeutung ist, keine Leerstelle mehr ist, sondern selbst von einer Apparatur des Sehens besetzt wird, die - als horizontal filmendes Kameraauge - den herkömmlichen Standpunkt eines menschlichen Zuschauers gewissermaßen vertritt?

In der Tat kann es auf den ersten Blick so scheinen, als ob es bei dem Einsatz jener Technologien des Sehens bzw. Visualisierens in Desert Walker weniger um das Auftauchen des Blicks geht als darum, eine Performance möglichst umfangreich für das Sehen menschlicher Zuschauer zu dokumentieren insbesondere angesichts folgender Formulierung aus dem Konzeptpapier: „As there are not many people in Wendover to witness the performance, documentation is important. “43 Denn hier wird die visuelle Dokumentation offenbar we-

42 Vgl. http://www.gpsies.com/map.do?fileId=rcgqjlvrcuhiytox und http://lostlab.wordpress. com/desert-walker/part-2-squaring-the-circle/, beide zuletzt aufgerufen am 02. November 2012.

43 http://www.liveart.org/desertwalker/DW_eng.pdf, S. 2, zuletzt aufgerufen am 02. November 2012. 
niger als Teil des Konzepts präsentiert, sondern vielmehr pragmatisch aus der Notwendigkeit begründet, die Performance für menschliche Zuschauer aufzuzeichnen bzw. in Form einer möglichst umfangreichen Aufzeichnung zu überliefern. Die Frage, ob sich Desert Walker an andere Blicke als diejenigen menschlicher Zuschauer wendet, ließe sich vor diesem Hintergrund also insofern verneinen, als die Antwort lauten könnte: Desert Walker richtet sich zwar nicht an die Augen anwesender Zuschauer - aber bei jenen anderen Augen, an welche sich die Performance richtet, handelt es sich lediglich um stellvertretende Kamera- bzw. Satellitenaugen, deren Aufgabe es ist, menschlichen Zuschauern einen Eindruck von der Performance zu vermitteln.

Vergleicht man die scheinbar pragmatische Begründung der Dokumentation nun aber mit anderen Formulierungen aus den Paratexten zu Desert Walker - wie z. B. mit der bereits zitierten Rede von einer „stage that stretches beyond the scope of human vision" -, dann nimmt sie schnell einen eher augenzwinkernden Charakter an. D. h. es wird deutlich, dass der Einsatz visueller Dokumentationstechniken keineswegs allein pragmatisch gedacht ist, sondern insbesondere in Bezug auf die Arbeiten Smithsons und Becketts durchaus einen entscheidenden konzeptuellen Aspekt des Projekts darstellt - einen Aspekt, der über die bloße Dokumentation der Performance hinaus gerade in der kritischen Auseinandersetzung mit der Phantasie einer vollständigen Übersicht besteht. Will heißen: Die Dokumentationstechniken werden nicht einfach eingesetzt, um die Performance möglichst umfangreich und übersichtlich zu dokumentieren. Vielmehr hat ihr (im Fall von Desert Walker fast exzessiver) Einsatz den Effekt, jene Phantasie einer vollständigen Übersicht sowohl zu evozieren als auch kritisch zu konfrontieren - nämlich mit dem Blick, wie noch zu zeigen sein wird. Es geht hier also nicht nur um die sozusagen sekundäre Dokumentation der Performance. Vielmehr ist die Dokumentation als solche konzeptueller Bestandteil der Auseinandersetzung mit einer Phantasie der Übersicht - einer Phantasie, die sich zwar in jenen Technologien des Sehens, welche in Desert Walker zum Einsatz kommen, auf besondere Weise manifestiert, jedoch keineswegs erst mit diesen Technologien und auch nicht erst mit der Erfindung der Zentralperspektive entstanden ist.

Auch darauf weist die Konzeption von Desert Walker als solche bereits hin. Denn wie die Spiral Jetty, so erinnert ja auch das riesige, von Motherboard in der Salzwüste abgesteckte bzw. abgelaufene Quadrat an viel frühere künstlerische Arbeiten, die über den Bereich der menschlichen Sicht hinausgehen, d. h. an Arbeiten aus einer Zeit, in der es die Möglichkeit einer filmischen Dokumentation noch gar nicht gab - geschweige denn aus der Luft oder gar aus dem Orbit. Ein Beispiel sind hier die riesigen Bodenzeichnungen der NazcaEbene in Peru, die erst in den 1920er Jahren aus der Luft entdeckt wurden, teilweise aber schon über 2500 Jahre alt sind - und in deren Fall es ziemlich eindeutig ist, dass sie nicht für menschliche Augen (oder gar für Kameraaugen) gemacht sind. Vielmehr ist es der Blick des großen Anderen, der von diesen Zeichnungen adressiert wird. Oder anders formuliert: Wenn man nicht mit 
Ufologen wie Erich von Däniken davon ausgehen möchte, dass es sich bei den Nazca-Zeichnungen um Landemarkierungen für die Augen irgendwelcher Aliens handelt - die in all ihrer erdenklichen Monstrosität doch immer irgendwie menschenähnliche kleine andere bleiben -, dann kann man sich stattdessen auch hier auf Žižek beziehen, der u. a. in Bezug auf die Nazca-Zeichnungen eine „elementarste Theatralizität der Condition humaine“ beschreibt, und zwar so:

Unser fundamentaler Drang ist nicht der Drang zu beobachten, sondern der, Teil einer Inszenierung zu sein, sich einem Blick zu zeigen - allerdings nicht dem Blick einer bestimmten Person in der Realität, sondern dem nichtexistenten reinen Blick des großen Anderen. Dies ist der Blick, für den die jedem menschlichen Auge unsichtbaren Details oben auf den Reliefs der antiken römischen Viadukte gemeißelt wurden; der Blick, für den die gigantischen steinernen Zeichnungen der alten Inkas bestimmt waren, deren Umrisse nur aus großer Höhe, aus der Luft erfasst werden konnten [.... ${ }^{44}$

Und um in diesem Zusammenhang eine weitere Parallele zur Antike - diesmal allerdings zur griechischen - herzustellen, lässt sich in Bezug auf Hans-Thies Lehmanns Überlegungen zur attischen Tragödie sagen, dass dieser Blick des großen Anderen auch derjenige ist, vor dem sich der Diskurs dieser Tragödie artikuliert. Denn unterscheidet Lehmann in seiner Schrift Theater und Mythos diesen Diskurs als prädramatischen von demjenigen des Dramas, so macht er diese Unterscheidung insbesondere daran fest, dass es im tragischen Diskurs „kaum einen Dialog auf der Szene zwischen den Akteuren geben kann, ohne daß eine dritte Instanz anwesend ist." ${ }^{\text {"45 }}$ Im Gegensatz zum sozusagen dualen System des dramatischen Diskurses werde auf diese Weise, so Lehmann weiter, ,jeder Verinnerlichung Widerstand geboten. [...] Es wird jeder Dialog von einem dritten Punkt aus wahrgenommen. [...] Jeder spricht seine Wahrheit, seine Welt, seine Perspektive polemisch, agonal aus, doch nicht der andere ist der eigentliche Adressat, sondern die Götter“446 - wobei hier allerdings auch schon der folgende Hinweis Žižeks den Blick des großen Anderen betreffend zu erwähnen ist: „Diesen Blick als ,göttlichen` zu bestimmen heißt schon, seinen Status zu domestizieren, ihm sein ,Akusmatisches` zu nehmen, die Tatsache zu ignorieren, daß er niemandes Blick ist, ein Blick, der frei, ohne Träger, umherschweift.“ ${ }^{47}$ Aber dazu später mehr ${ }^{48}$, um zunächst erst einmal die Parallelen zwischen dem postspektakulären Diskurs, wie er sich in Desert Walker

\footnotetext{
44 Žižek (2005), Die politische Suspension des Ethischen, S. 91. [Herv. i. O.]

45 Hans-Thies Lehmann, Theater und Mythos. Die Konstitution des Subjekts im Diskurs der antiken Tragödie, Stuttgart, 1991, S. 49. Im Hinblick auf den postspektakulären Diskurs lässt sich in diesem Zusammenhang sagen, dass dieser die Intervention einer dritten Instanz nicht auf der Ebene des „Dialogs auf der Szene zwischen Akteuren“ reflektiert, sondern auf der Ebene des Dialogs im Theaterraum zwischen Akteuren und Zuschauern.

Ebd.

47 Žižek (2005), Die politische Suspension des Ethischen, S. $91 \mathrm{f}$.

48 Vgl. Fußnote 68 des vorliegenden Textes.
} 
artikuliert, und dem prädramatischen Diskurs der attischen Tragödie weiterzuverfolgen.

Diese Parallelen zeigen sich insbesondere dort, wo Lehmann auf die Bühnenform eingeht, die mit dem prädramatischen Diskurs der attischen Tragödie und dessen Adressierung einer dritten Instanz der Götter verbunden ist. So schreibt er:

Das athenische Theater [...] ,sagt' als Raum [...], daß im Diskurs dieses Theaters die umfassenden Fragen zwischen Menschen- und Göttermacht verhandelt werden. [...] Wie mit der Polis, so steht das Theater im engsten Zusammenhang mit der als von göttlichen Mächten durchwaltet vorgestellten Naturlandschaft ringsumher. ${ }^{49}$

Auch über Desert Walker lässt sich nun sagen, dass das Projekt umfassende Fragen verhandelt, die das Verhältnis menschlicher Macht zu anderen Mächten betreffen. Und obgleich es sich dabei nicht um Göttermächte handelt, so doch durchaus um solche, welche menschliche Mächte übersteigen. Denn Desert Walker bezieht sich nicht nur auf Smithsons Spiral Jetty und Becketts Quad, sondern ganz konkret auch auf die Charakteristika der Landschaft, in der das Projekt realisiert wurde. Und als sozusagen übermenschliche Mächte, zu denen sich die „Menschenmacht“ der PerformerInnen dabei ins Verhältnis setzt bzw. denen sie sich aussetzt, sind zunächst allein schon die extremen geologischen und meteorologischen Bedingungen dieser Landschaft zu nennen, die auch explizit im Konzeptpapier als gewählte Herausforderungen erwähnt werden. Darüber hinaus - und auch darauf weist das Konzeptpapier hin - ist hier aber auch und insbesondere die Tatsache zu nennen, dass es sich bei dieser Landschaft um ein Gebiet handelt, das von exzessiver industrieller und militärischer Nutzung geprägt ist - wobei vor allem letztere keine unerhebliche Rolle im Hinblick auf die weltpolitische Vormachtstellung der USA spielt. Denn nicht nur war diese Landschaft - und ist es teilweise noch heute ein militärisches Testgebiet, in dem insbesondere zwischen 1940 und 1950 chemische und nukleare Kampfstoffe getestet wurden. Darüber hinaus befindet sich das Center for Land Use Interpretation - also die Institution, an der Motherboard residierte - auf dem Areal eines ehemaligen Luftwaffenstützpunkts, wo u. a. die Besatzung der Enola Gay, deren Hangar dort noch zu finden ist, ausgebildet wurde. Und zu finden sind in der Landschaft von und um Wendover auch alle möglichen anderen Überbleibsel ihrer militärischen Nutzung - sowohl sichtbare als auch unsichtbare..$^{50}$ Bei der Bühne, auf der Desert

49 Lehmann (1991), Theater und Mythos, S. 30 f.

50 Auf diesen Aspekt einer militärischen Nutzung der Landschaft beziehen sich auch die Kostüme der PerformerInnen, bei denen es sich - anstelle von Djellabas - um sogenannte BushRag-Tarnanzüge für Scharfschützen handelt, d. h. um fransige Kutten mit Kapuzen aus einer Art Tarnnetz-Textilie. Wenn die traditionelle Lichtschutz-Funktion der Djellabas im Kontext von Quad metaphorisch als ein Schutz vor der Ablichtung der PerformerInnen durch das Kameraauge bzw. vor ihrem Gesehenwerden gelesen werden kann, so lässt sich dies auf die 
Walker stattfand, handelt es sich also um eine Landschaft, die von Spuren zwar nicht göttlicher, sondern menschengemachter, aber in ihrer Zerstörungskraft die „Menschenmacht“ weit übersteigender Macht durchzogen ist. Und insofern diese Macht - insbesondere in ihrer nuklearen Form - eng mit der politischen Macht des Staates verbunden ist, der sie in dieser Landschaft „ausgetestet" und auf die Probe gestellt bzw. auf diese Landschaft losgelassen hat, lässt sich die oben zitierte Beschreibung Lehmanns in Bezug auf Desert Walker folgendermaßen variieren: Die ,Bühne' von Desert Walker ,sagt' als Raum, dass im Diskurs dieses Projekts die umfassenden Fragen zwischen Menschenund Weltmacht - „Weltmacht“ im doppelten Sinne - verhandelt werden. Wie mit dem Staat, so steht das Projekt im engsten Zusammenhang mit der als nicht nur von geologischen und meteorologischen Mächten, sondern auch von nuklearen und chemischen bzw. militärisch-politischen Mächten durchwalteten Naturlandschaft ringsumher.

Eine weitere Parallele dieser Art lässt sich auch in Bezug auf Lehmanns Betonung jener Bedeutung ziehen, welche dem Blick aufs Meer für die Opsis des attischen Theaters zukommt. Hier schreibt er (vor dem Hintergrund eines Bezugs auf Siegfried Melchinger):

Für das Theater stellt das Meer, wie überhaupt die landschaftlichen Gegebenheiten, ein wesentliches Element der ,Opsis' dar: über die Theateranlage hinaus Hain, Landschaft und am Horizont das Meer [...]: Realmetapher der ausgreifenden Weltmacht, der Ort von Erkundung, Eroberung, freilich auch der Gefahr. ${ }^{51}$

Übertragen auf Desert Walker könnte diese Beschreibung lauten: Für die Performance stellt die Salzwüste als landschaftliche Gegebenheit das wesentliche Element der Opsis dar: Über das Quadrat hinaus Salzwüste, ein paar Berge, und am Horizont immer noch Salzwüste - Realmetapher einer ausgreifenden Weltmacht, der Ort militärischer Erprobung und Ausbildung, der Sicherung weltpolitischer Vormachtstellung, freilich auch der Gefahr.

Assoziationen zu Desert Walker weckt auch Lehmanns Rede von dem auf der attischen Bühne „exponierten, isolierten und vor dem Hintergrund des Naturpanoramas verschwindend kleinen, verlorenen Menschenkörper und der bis zum Horizont sich erstreckenden quasi-theatralen Raumkulisse [...]. ${ }^{\text {(52 }}$ Und von besonderem Interesse hinsichtlich der These, dass Desert Walker den Blick des großen Anderen auftauchen lässt, indem sich das Projekt mit der Phantasie einer vollständigen Übersicht auseinandersetzt, sind schließlich Lehmanns Überlegungen zur Auseinandersetzung des tragischen Diskurses mit der Machtordnung seiner Zeit. Denn „Macht begegnet dem Athener des klassischen Zeitalters“, so Lehmann, „,in Gestalt der Götter, auch in der Person einflußreicher Aristokraten, im Tyrannen des 6. Jahrhunderts, im Gegensatz

Bush-Rag-Tarnanzüge insofern übertragen, als es sich auch bei diesen um eine Kleidung handelt, deren Funktion darin besteht, nicht gesehen zu werden.

51 Lehmann (1991), Theater und Mythos, S. 31.

52 Ebd. 
von Arm und Reich, in Krieg und sozialen Kämpfen. ${ }^{\text {ㄷ3 }}$ Im Gegensatz jedoch zum epischen Diskurs der Antike, der aus Lehmanns Sicht einer Affirmation dieser Machtordnungen verpflichtet blieb, zeugt für ihn der tragische Diskurs von einem Bewusstsein, das diese Machtordnungen zunehmend als Gegenstand einer Beunruhigung erfährt und entsprechend problematisiert bzw. infrage stellt $t^{54}$ - wobei dem Spiel unter freiem Himmel eine besondere Bedeutung zukommt, denn, so Lehmann, „[d]urch das Spiel unter freiem Himmel werden Spieler (wie Zuschauer) Blickobjekt jener Mächte, die in Gestalt der Götter angebetet und zugleich in Frage gestellt werden. ${ }^{\text {“55 }}$

Etwas ganz Ähnliches geschieht nun in Bezug auf heutige Formen der Macht in Desert Walker - oder allgemein im postspektakulären Diskurs. Genauer gesagt: Was dieser Diskurs problematisiert und infrage stellt, ist eine Machtordnung, in der uns Macht nicht mehr in erster Linie in Form zentraler Disziplinierungsorgane begegnet, sondern vielmehr als permanente Aufforderung zur vermeintlich freien Selbstverwirklichung - eine Aufforderung, die sich allerdings gleichzeitig mit der Zunahme (post-)panoptischer Überwachungstechnologien und der Durchsetzung jener von Deleuze beschriebenen Kontrollformen mit freiheitlichem Aussehen verbindet. ${ }^{56}$

In jenem Spiel unter freiem Himmel, welches Desert Walker inszeniert,wird die Begegnung mit dieser Machtordnung nun als Begegnung mit der besonderen Machtordnung eines Staates thematisiert, in welcher (insbesondere seit 2001) die Begriffe von Freiheit und Kontrolle aufs Engste verkoppelt sind und die sich gerade hinsichtlich dieser Verkopplung weiterhin hegemonial durchzusetzen versucht. (Für die von Lehmann aufgezählten, oben zitierten Erscheinungsformen der Macht im Athen des klassischen Zeitalters lassen sich dabei nur allzu leicht zeitgenössische Entsprechungen finden, wobei die drei letzten Punkte - d. h. der Gegensatz von Arm und Reich, Krieg und soziale Kämpfe - sogar direkt übernommen werden können.) Ansatzpunkt dieser Thematisierung ist dabei der Bezug auf jene Formen militärtechnischer Übermacht bzw. Überwachungsmacht, die diese Ordnung stützen ${ }^{57}$ - auch und nicht zuletzt deshalb, weil sie es sind, aus denen sich auch die zivilen Überwachungstechnologien in der Regel entwickeln. Und um in diesem Zusammenhang nochmals auf die Parallelen zum prädramatischen Diskurs hinzuweisen: Wie Lehmann zufolge in diesem und insbesondere in Sophokles' König Ödipus immer wieder eindringlich das „Bild einer Überwachung aus dem Hin-

Ebd., S. 69.

Vgl. ebd., S. 70-73.

55 Ebd., S. 131.

56 Vgl. Gilles Deleuze, „Postskriptum über die Kontrollgesellschaften“, in: Christoph Menke/Juliane Rebentisch (Hg.), Kreation und Depression. Freiheit im gegenwärtigen Kapitalismus, Berlin, 2010, S. 11-17 (zuerst erschienen in: L'autre journal 1, 1990, in deutscher Übersetzung in Gilles Deleuze, Unterhandlungen. 1972-1990, Frankfurt/M., 1993).

57 Die Verbindung von Bush-Rag-Tarnanzügen und Satellitenbildern lässt so z. B. an militärische Operationen denken, die in einer punktgenauen Erfassung und ,chirurgischen` Eliminierung feindlicher Ziele bestehen. 
terhalt ${ }^{\star 58}$ erscheint, so lässt auch Desert Walker dieses Bild anhand des Bezugs auf die postpanoptischen Überwachungstechnologien erscheinen. D. h. im Bezug auf diese Überwachungstechniken findet jene Vorstellung eines allsehenden und allwissenden Gottes, welche sich, wie Lehmann zeigt, neben König Ödipus beispielsweise auch in der Aias-Tragödie oder in Hesiods Werke und Tage artikuliert ${ }^{59}$, ihre postpanoptische Entsprechung. Die zahlreichen Kameraperspektiven, von denen die Inszenierung „durchwaltet“ ist wie die „Naturlandschaft ringsumher“ von Mächten, die der „Athener des klassischen Zeitalters“ sich wohl als „göttliche“ vorgestellt hätte, wecken dabei nicht nur Assoziationen zu der Art und Weise, wie die öffentliche Sphäre unter postpanoptischen Bedingungen von den Perspektiven unzähliger Überwachungskameras bestimmt ist. Sie stellen darüber hinaus auch die postpanoptische Entsprechung jenes Motivs dar, welches Lehmann zufolge oft mit der „Vorstellung eines allwissenden Gottes in der Mythologie der verschiedenen Kontinente einher[geht]“, nämlich das „Motiv göttlicher Späher und Spione, die die Beobachtungen des alles-sehenden Gottes ergänzen. ${ }^{“ 60}$ Und erwähnt z. B. Hesiod in Werke und Tage neben dem „Blick des Zeus [...] auch 30000 (d. h. unendlich viele) Spione - vermutlich auf die Sterne zu beziehen, die man als Augen betrachtete" ${ }^{\text {“61 }}$, dann ist es in Desert Walker insbesondere die Satellitenperspektive, in der sich dieses Motiv einer spionierenden, alles-sehenden Sicht aus dem All in ihrer postpanoptischen Version wiederfindet.

Jene Machtordnung, welche auf diese Weise thematisiert wird, wird nun auch gleichermaßen als solche problematisiert - sowie kritisch infrage gestellt, wie gleich noch gezeigt werden soll. Doch zuvor sei vor diesem Hintergrund noch etwas über das Verhältnis zwischen postspektakulärem Diskurs und jenem Diskurs gesagt, welcher die Paradigmen der zeitgenössischen szenischen Kunst in den transgressiv-emanzipatorischen Experimenten der 1960er und 1970er Jahre sieht und die wesentliche Bedingung der Aufführung in einer von jenen Experimenten betonten - Kopräsenz von Akteuren und Zuschauern gegeben wissen will. Denn für letzteren kann Ähnliches gelten wie das, was Lehmann über den Diskurs der antiken Epik sagt. D. h. auch hier kann davon gesprochen werden, dass dieser Diskurs die permissiven Machtordnungen affirmiert, weil er nach wie vor an die - wie Deleuze sagen würde - zunächst markierten neuen Freiheiten glaubt, die jedoch längst Bestandteile neuer Kontrollmechanismen geworden sind.$^{62}$ Und hier lässt sich mitunter sogar die These wagen, dass die viel beschworene ,Befreiung' des Publikums aus seiner

58 Lehmann (1991), Theater und Mythos, S. 131.

59 Vgl. ebd.

60 Ebd.

61 Ebd.

62 Vgl. in diesem Zusammenhang auch Žižek (2005), Die politische Suspension des Ethischen; Juliane Rebentisch, „Spektakel“, in: Texte zur Kunst, Kurzführer/Shortguide, 17. Jg., Heft 66/1 (2007), S. 120-122 sowie Eiermann (2009), Postspektakuläres Theater, insbes. den Abschnitt „,spektakulär - (anti-)spektakulär - postspektakulär“, S. 15-18. 
Passivität im dunklen Zuschauerraum vielleicht in Wahrheit einer effektiveren Kontrolle des Publikums entgegenkommt, die eine gewisse Verwandtschaft mit dem von Foucault beschriebenen Übergang von der Unsichtbarkeit des Gefangenen im dunklen Kerker zu seiner Sichtbarkeit im hellen Panoptikum ${ }^{63}$ (und erst recht im gleichermaßen permissiv wie kontrolltechnisch ausgeleuchteten Postpanoptikum) aufweist.

Affirmiert der auf die leibliche Kopräsenz von Akteuren und Zuschauern abhebende Theaterdiskurs in diesem Sinne also die aktuellen Machtordnungen, so legt es demgegenüber das postspektakuläre Theater, wie gesagt, gerade auf eine kritische Auseinandersetzung mit ihnen an. Dies bedeutet nun auch, dass es sich kritisch mit jenem Diskurs zum postdramatischen Theater auseinandersetzt, welcher im Rahmen der Prämisse einer leiblich-unmittelbaren Kopräsenz von Akteuren und Zuschauern verbleibt. Genauer gesagt: Im postspektakulären Theater entfaltet sich auf besondere Weise eine von Lehmann selbst aufgezeigte Parallele zwischen prädramatischem und postdramatischem Diskurs - eine Parallele, die jedoch in seiner eigenen Beschreibung des letzteren nicht sehr stark betont wird und insbesondere in der Rezeption dieser Beschreibung weitgehend von den Einflüssen des Kopräsenz-Diskurses verdeckt bleibt. Deutlich betont findet sich diese Parallele aber in einem Text zum Verhältnis zwischen prädramatischen und postdramatischen Theaterstimmen, in dem Lehmann den Bezug auf die Figur einer dritten Instanz aus Theater und Mythos wieder aufgreift, wenn er auf Grundlage Lacan'scher Begrifflichkeit über eine postdramatische Stimmästhetik und das seines Erachtens durch diese brisant werdende Thema der Zeugenschaft schreibt:„,Das Thema der Zeugenschaft [...] ist auf den Begriff des Anderen mit großem A zu beziehen. ${ }^{\text {} 64}$ Und: „Eine dritte Instanz neben den beteiligten Partnern muss dafür existieren, und das ist eben die Sprache selbst, groß A [...]." ${ }^{“ 65}$ Weist Lehmann hier also über einen auf die Prämisse der Kopräsenz eingeschränkten Diskurs zum postdramatischen Theater hinaus, so ist es auf besondere Weise das postspektakuläre Theater, in dem diese dritte Instanz ins Spiel kommt. Und wie Lehmann zufolge der prädramatische bzw. tragische Diskurs jene Machtordnung infrage stellt, welche für den epischen Diskurs noch in Ordnung ist ${ }^{66}$ und in der epischen Erzählinstanz - verkörpert durch die Stimme des Rhapsoden - ihr „ordnendes Zentrum “ findet ${ }^{67}$, so problematisiert das postspektakuläre Ins-SpielBringen der dritten Instanz bzw. des großen Anderen die zeitgenössischen, permissiv-postpanoptischen Machtordnungen auch und gerade in Form einer Auseinandersetzung mit der Frage nach der Macht dieses großen Anderen -

63 Vgl. Foucault (2008), Überwachen und Strafen, S. 905-916.

${ }^{64}$ Hans-Thies Lehmann, „Prädramatische und postdramatische Theaterstimmen. Zur Erfahrung der Stimme in der Live-Performance“, in: Doris Kolesch/Jenny Schrödl (Hg.), Kunst-Stimmen, Berlin, 2004, S. 40-66: 59.

65 Ebd., S. 60.

66 Vgl. ebd., S. 71.

67 Vgl. ebd., S. 34. 
genauer gesagt: als Infragestellung eines vermeintlich allmächtigen, allsehenden großen Anderen. ${ }^{68}$

Im Fall von Desert Walker - um nun darauf zurückzukommen - geschieht dies, indem die Vorstellung eines allsehenden Überblicks einerseits evoziert wird, diese Vorstellung jedoch andererseits gleichzeitig unterlaufen bzw. umgangen wird. Und wenn in Bezug auf Quad von einer kritischen Auseinandersetzung mit dem Prinzip der Zentralperspektive gesprochen werden kann, so

${ }^{68}$ In diesem Zusammenhang ist nun auch darauf hinzuweisen, dass Lehmanns Rede von einer dritten Instanz als göttlicher Instanz nur bedingt jener Domestizierung entspricht, welche Žižek dort am Werk sieht, wo der Blick des großen Anderen als ,göttlicher` Blick bestimmt wird (vgl. Žižek (2005), Die politische Suspension des Ethischen, S. 91 f.). Denn Lehmanns Beschreibung zeigt, dass diese dritte Instanz im tragischen bzw. prädramatischen Diskurs bereits auf eine andere Weise als im epischen Diskurs ins Spiel kommt, nämlich auf eine solche, welche die vermeintliche Konsistenz dieser Instanz gerade hinterfragt. Die „Formulierung radikaler Abhängigkeit des Helden von der göttlichen Ordnung“ (Lehmann (1991), Theater und Mythos, S. 135, [Herv. i. O.]) steht dabei für ihn in deutlicher Korrespondenz mit der Abhängigkeit des Subjekts von der Sprache, wie Lacan diese denkt (vgl. ebd., S. 133-136). Entsprechend betont er im Rahmen seiner Überlegungen zur postdramatischen Stimmästhetik, dass „der Andere mit großem A bei Lacan zugleich die unkontrollierbare Sprache selbst bedeutet, in der das Subjekt immer schwindet“ (ders. (2004), Prädramatische und postdramatische Theaterstimmen, S. 60) sowie dass Lacan zufolge die Stimme - und dies hat sie in dessen Theorie mit dem Blick gemein - nicht aufseiten des Subjekts sondern des Objekts zu verorten ist, d. h. ein „Objekt klein a“ darstellt, welches sich dem symbolischen Zugriff stets entzieht (vgl. ebd., S. 59) und somit für die Inkonsistenz der symbolischen Ordnung steht bzw. diese ausmacht. In Theater und Mythos findet sich ein entsprechender Hinweis auf S. $133 \mathrm{f} .:$, Wer ich bin, bestimmt der Andere. In der attischen Tragödie nehmen die Götter den Platz ein, den die moderne philosophische Thematisierung des Selbstbewußtseins dem anderen Subjekt bzw. dem Feld der Sprache zuschreibt. Das Subjekt ist abhängig von dem, als was die anderen es bestimmen, erkennen und ,anerkennen'. In diesem Verhältnis ist unabweisbar eine fundamentale Lücke, eine Dunkelstelle des Bewußtseins eingeschrieben, kann doch über fremdes Bewußtsein niemals verfügt werden. Es ist nicht direkt zugänglich, der Weg zu ihm führt über das Zeichen, besser: den Signifikanten, dessen Wahrheitsgehalt niemals feststeht. Wie die Götter, so kann der Andere täuschen, denn menschliche Sprache als Ort der Vermittlung zwischen Subjekten beginnt, wo die Lüge möglich ist.“ Findet sich dieser Aspekt des prädramatischen Diskurses Lehmann zufolge nun in gewissermaßen säkularisierter Form im postdramatischen Diskurs wieder, so bringt der postspektakuläre Diskurs diesen Aspekt auf besondere Weise - und entgegen der ihn im Diskurs zum postdramatischen Theater oft verdeckenden Unmittelbarkeitsemphase - zum Tragen, wobei er sich gerade auch von jenem Aspekt des prädramatischen Diskurses besonders deutlich abhebt, der trotz der von Lehmann aufgezeigten Korrespondenzen zur Lacan'schen Theorie in Žižeks Sinne noch als domestizierend beschrieben werden kann, nämlich jener, dass eben im prädramatischen Diskurs die Götter wie Lehmann schreibt - noch den Platz des großen Anderen einnehmen - und trotz aller Infragestellung ihrer Macht letztlich als übermächtig imaginiert werden (darauf gehe ich unten näher ein). Doch abgesehen davon: Jenes fremde, unverfügbare Bewusstsein lässt sich jedenfalls mit Lacan - wie auch Lehmann zeigt (vgl. ebd., S. 134 f.) - als Unbewusstes des Subjekts selbst explizieren. Und ist mit diesem Unbewussten gleichsam der Aspekt der Mittelbarkeit wie derjenige der Lüge bzw. der Täuschung verbunden, so verwundert es nicht, dass sich die für das postspektakuläre Theater charakteristische Reflexion einer prinzipiellen Mittelbarkeit jeglicher Erfahrung auch in Form eines verstärkten Spiels mit Täuschungen und verwandten Aspekten - z. B. solchen der Illusion - beobachten lässt (diese Beobachtung war der thematische Ausgangspunkt der Tagung TO DO AS IF - Realitäten der Illusion im zeitgenössischen Theater, die ich am 6. und 7. Juli 2012 in Gießen veranstaltet habe). 
lässt sich die Fortsetzung dieser Auseinandersetzung durch Desert Walker auch als solche beschreiben, die das Postpanoptikum im Sinne Baumans als Weiterentwicklung des Panopticons im Foucault'schen Sinne kritisch ins Visier nimmt - das ja seinerseits bereits, wie Foucault zeigt, die Zentralperspektive des Souveräns weniger ablöst als sie vielmehr in eine hinsichtlich ihrer Machtwirkung effizientere Anordnung von „Körpern, Oberflächen, Lichtern und Blicken“69 weiterentwickelt, indem es „die Macht automatisiert und entindividualisiert“70 bzw. von einer zentralen Person auf eine Apparatur überträgt. Will heißen: Wie Quad das Prinzip der Zentralperspektive bzw. die Architektur des Sehens sowohl in Szene setzt als auch die damit verbundene Phantasie einer vollständigen Übersicht kritisch in den Blick nimmt - d. h. sozusagen in den Blick des großen Anderen, der genau an dem Punkt auftaucht, welcher auf den zentralperspektivischen Augenpunkt verweist -, so setzt sich Desert Walker mit den Beobachtungsmechanismen des Panoptikums und deren zeitgenössischen bzw. postpanoptischen Ausprägungen auseinander, indem die Phantasie einer vollständigen Übersicht durch den Einsatz der vielen verschiedenen Kameraperspektiven sowohl evoziert als auch gleichzeitig fragmentiert wird. Oder anders formuliert: Wenn Quad das quadro gewissermaßen von der Vertikalen in die Horizontale verlegt und sozusagen die Einschreibefläche, auf der sich von Angesicht zu Angesicht begegnende „natürliche Gestalten“ den Zuschauenden zur Identifikation anbieten, in eine Einschreitefläche verhüllter Gestalten verwandelt, die sowohl einander als auch der Identifikation der Zuschauenden mit ihnen aus dem Weg gehen - und so den Blick des großen Anderen als das ins Spiel bringen, was dem Sehen stets entzogen bleibt -, dann bringt Desert Walker diesen Blick ins Spiel, indem es ihn zwischen den kaleidoskopierten, fragmentarischen Ansichten, welche die zahlreichen Kameraperspektiven liefern, als das auftreten lässt, was zwischen oder auch in diesen Ansichten - so zahlreich sie auch sein mögen - stets fehlt. Die Phantasie einer (post-)panoptischen Übersicht verliert so gewissermaßen ihre scheinbare Konsistenz, ihr vermeintliches (und auch unter den Bedingungen des dezentrierten Postpanoptikums noch phantasmatisch virulentes) Zentrum - und dies nun auch und gerade, weil auch das Zentrum des Quadrats von einer Kamera besetzt ist. Gerade diese zentrale Kamera nämlich gibt eine eindeutig unvollständige Sicht wieder. Sie präsentiert ein Bild, dem auf besondere Weise seine Unvollständigkeit eingeschrieben ist, da aufgrund des Schwenkens der Kamera deutlich wird, dass immer etwas hinter ihr stattfindet, das ihrem Sehen entzogen ist. Ihr kommt sozusagen nie nur Sichtbares entgegen, sondern sie wird immer auch von Unsichtbarem umgangen, wie sich an einer Videosequenz verdeutlichen lässt, die Folgendes zeigt:

Eine Performerin, die zunächst nur als kleiner dunkler Punkt am Horizont zu sehen ist, nähert sich der Kamera. Kurz bevor sie sie erreicht, weicht sie

69 Foucault (2008), Überwachen und Strafen, S. 907.

70 Ebd. 
(von ihr aus gesehen) nach links aus und macht einen Bogen um die Kamera. Diese folgt ihr anhand eines Schwenks. Doch dieser endet nicht, wenn die Performerin sich wieder - der Diagonale des Quadrats folgend - von der Kamera entfernt. Stattdessen schwenkt die Kamera weiter, verliert die Performerin aus ihrem Sichtfeld, trifft dann aber auf eine zweite Person, die sich ebenfalls schon von ihr entfernt, und bleibt auf diese ausgerichtet. ${ }^{71}$

In dem Moment, in dem eine zweite Person im Sichtfeld der Kamera erscheint, wird plötzlich deutlich, dass der gefilmte Raum nicht der gesamte Raum der Performance ist, und dass die zunächst gefilmte Person nicht die einzige ist, die zum Zeitpunkt der Aufnahme performt. D. h. der Kameraschwenk zeigt, dass der Sicht der Kamera stets ein Großteil der Performance und des Raums, in dem diese stattfindet, entgeht. Und auf diese Weise bringt schon allein die einzelne, im Zentrum platzierte Kamera den Blick als „Fleck“ im Sichtbaren - und zwar als ziemlich großen Fleck - ins Spiel.

Erst recht aber wird dieser Blick durch die Kombination der unterschiedlichen Kameraperspektiven ins Spiel gebracht. D. h. er taucht zwischen diesen Perspektiven auf. Genauer gesagt: Weder in einer einzelnen Perspektive etwa einer Vogelperspektive - noch in der Gesamtheit der Perspektiven kommt er zum Tragen. Vielmehr macht er sich zwischen ihnen bemerkbar als ortloser, impersonaler und umherschweifender Blick, der weder von einem Subjekt noch von einer Kamera eingenommen werden kann, sondern sich wie Lacan sagt - auf der Seite des Objekts befindet.

Hierin besteht nun aber auch der entscheidende Unterschied zum tragischen bzw. prädramatischen Diskurs und zu der Art und Weise, wie die dritte Instanz von diesem ins Spiel gebracht wird. Denn wenn Lehmann betont, dass dieser Diskurs die Machtordnungen seiner Zeit problematisiert, so zeigt er auch, dass dies vor allem im Hinblick auf die Unterworfenheit des Subjekts geschieht - und zwar vor allem in Form der Darstellung des Leidens des Subjekts an dieser Unterworfenheit. D. h. in dieser Hinsicht bleibt die dritte Instanz letztlich noch mit der Vorstellung eines allsehenden Wesens verbunden, und der Blick des großen Anderen wird eigentlich als das Sehen unbarmherziger, strafender Götter oder als An- bzw. Eingriff anderer Mächte imaginiert, denen das Subjekt ausgeliefert ist. Mit Lehmann gesagt: „[N]icht in seiner Freiheit, [sondern] in seiner Ohnmacht artikuliert sich zum erstenmal auf der tragischen Bühne das Subjekt.“72

Im Diskurs des postspektakulären Theaters hingegen artikuliert sich das Subjekt gerade nicht in seiner Ohnmacht, sondern in seiner Freiheit - und zwar in seiner Freiheit als Subjekt bzw. Unterworfenes. D. h. es handelt sich hier nicht etwa um eine Freiheit in jenem Sinne, in welchem Kant sie in der Kritik der Urteilskraft im Zusammenhang seiner Bestimmung des Erhabenen

\footnotetext{
${ }^{71}$ Ich danke Per Platou von Motherboard, der mir unterschiedliche Videoaufzeichnungen, darunter die beschriebene, zur Verfügung gestellt hat.

72 Lehmann (1991), Theater und Mythos, S. 85. [Herv. i. O.]
} 
denkt - also nicht um jene Konzeption von Freiheit, die, wie Lehmann betont, „[i]mmer wieder [...] auf die Fläche der attischen Tragödie projiziert worden [ist] und [...] das Bild der Passivität, welches vom tragischen Diskurs gezeichnet wird, übermalt [hat].“”3 Statt einer Freiheit im Kant’schen Sinne, die darin besteht, dass der Mensch im Angesicht des Erhabenen zwar seine physische Ohnmacht erfährt, dabei aber gleichzeitig „als Vernunftwesen [...] der Naturmacht überlegen [bleibt]“, artikuliert sich Freiheit im postspektakulären Diskurs als diejenige eines Subjekts, das - ganz wie Lehmann zufolge das im tragischen Diskurs aufdämmernde Subjekt - „weder personale Identität noch das Substrat des logischen Bewußtseins und seiner Synthesis, noch auch moralisches Freiheits- und/oder Verantwortungsbewußtsein [ist]“, sondern sich vielmehr als ,untrennbar [...] von einer Beziehung auf die Instanz eines ,Anderen ““74 erfährt - und zwar auf die Instanz des großen Anderen. Im Unterschied zum tragischen bzw. prädramatischen Diskurs wird diese Beziehung im postspektakulären Diskurs jedoch nicht „als Objektsein, Opfersein, Abhängigkeit und Angewiesenheit auf diese andere Instanz ${ }^{\text {"75 }}$ verhandelt. D. h. es geht hier nicht um eine Ohnmacht des Subjekts in Bezug auf einen als übermächtig gedachten großen Anderen. Vielmehr geht es um eine Freiheit, die dem Subjekt gerade deshalb - und gerade in seiner Unterworfenheit - zukommt, weil der große Andere inkonsistent ist. Anders formuliert: Im postspektakulären Diskurs artikuliert sich das Subjekt insofern in seiner Freiheit, als der große Andere als impersonale, inkonsistente Instanz ins Spiel gebracht wird. Und mit Žižek gesagt: Der tragische Diskurs verbleibt letztlich noch im Rahmen der prinzipiell psychotischen Erfahrung, einem „alles sehenden Blick des Anderen ausgesetzt zu sein [...].“76 Bei der Erfahrung hingegen, die sich im postspektakulären Diskurs artikuliert, handelt es sich um diejenige, dass „nichts nach uns blickt, weil es ,keinen großen Anderen gibt‘ ${ }^{\star}$, weil der Andere selbst inkonsistent, mangel-haft ist“".77

Hier schließt sich nun auch der Bogen zu dem bereits zitierten Hinweis Žižeks, dass jener Blick, für welchen ihm zufolge u. a. die Nazca-Zeichnungen gemacht sind (auch wenn davon auszugehen ist, dass deren Herstellung durchaus von der Phantasie eines allsehenden göttlichen Wesens motiviert war), nicht als „göttlicher“ Blick, sondern als „akusmatischer“, impersoneller, frei umherschweifender Blick zu verstehen ist. Und was Žižek im Zusammenhang dieses Hinweises weiterhin schreibt, eignet sich gut als Übergang zur gleich an- und diesen Text auch abschließenden Beschreibung des Projekts The Plastic Bag:

\footnotetext{
Ebd., S. 129. [Herv. i. O.]

Ebd.

Ebd.

76 Žižek (2005), Die politische Suspension des Ethischen, S. 95.

Ebd.
} 
Die beiden korrelativen Positionen des Schauspielers auf der Bühne und des Zuschauers sind nicht ontologisch gleichwertig oder gleichzeitig: Wir sind ursprünglich nicht Beobachter der Schaubühne der Realität, sondern Teil des Tableaus, das für die Leere eines nichtexistenten Blicks inszeniert wird, und erst nachträglich können wir die Position derer einnehmen, die den Blick auf die Bühne richten. Die unerträgliche, ,unmögliche‘ Position ist nicht die des Schauspielers, sondern die des Zuschauers, des Publikums. ${ }^{78}$

The Plastic Bag ist nämlich ein Projekt, das in einem ganz buchstäblichen Sinne eine Inszenierung für die Leere eines nichtexistenten Blicks in die Tat umsetzt und die Unmöglichkeit einer beobachtend-überschauenden Zuschauerposition auf besondere Weise ausspielt. Denn es geht über das Register des Sichtbaren hinaus und verlässt dieses sogar.

\section{The Plastic Bag}

Das Projekt ist schnell beschrieben: 2005 brachte die Gruppe International Festival, wie eingangs erwähnt, 25000 weiße Plastiktüten in Umlauf, die mit dem pinkfarbenen Logo der Gruppe bedruckt waren bzw. sind. Genauer gesagt wurden jeweils 1000 Tüten an 25 Spielstätten in Europa verteilt - mit der Bitte, jeweils 500 davon an eine weitere Spielstätte weiterzugeben und die andere Hälfte für den täglichen Gebrauch zu verwenden. Die Plastiktüte wurde dabei verstanden als ein „open script for a potential choreography of 25.000 performers, a kind of inter European dance performed through our everyday movements. “79 Der zugrunde liegende Gedanke war also, die Plastiktüte als verbindendes und rahmendes Element einer Performance, die aus den alltäglichen Formen der Nutzung dieses Utensils resultieren sollte, europa- oder sogar weltweit zu verbreiten - wobei mit dieser räumlichen Ausdehnung der ,Bühne' (wie im Fall von Desert Walker, nur weitaus extremer) auch eine enorme zeitliche Ausdehnung verbunden war bzw. ist, denn die Choreographie dauert so lange, bis sich die letzte Plastiktüte zersetzt hat, was ja bekanntlich nicht allzu schnell geht.

Im Unterschied zu Desert Walker ist das Projekt somit so konzipiert, dass eine auch nur annähernd vollständige Dokumentation der Performance ein Ding der Unmöglichkeit darstellt. Und die Vorstellung einer vollständigen Übersicht wird hier tatsächlich nur als reine Vorstellung evoziert. D. h. anstelle der Verwendung von Technologien, in denen sich die panoptische Phantasie zumindest noch ein Stück weit manifestiert, um dann durch die Fragmentierung einer zentrierten Übersicht unterlaufen zu werden, wurde die Vorstellung eines solchen Überblicks im Fall von The Plastic Bag von vornherein als völlig haltlose Vorstellung inszeniert. Denn zum einen evoziert die Ankündi-

\footnotetext{
78 Ebd., S. 92.

79 http://international-festival.org/node/56, zuletzt aufgerufen am 02. November 2012.
} 
gung einer europa- oder sogar weltweiten Plastiktüten-Performance ja durchaus das Bild eines Blicks, der versucht, diese Performance in Gänze zu erfassen - und dieses Vorstellungsbild ähnelt mitunter sehr stark den uns mittlerweise sehr geläufigen Satellitenbildern. Doch sobald diese Vorstellung aufkommt, entlarvt sie sich auch schon wieder selbst als völlig illusorische, absurde Vorstellung, die keinerlei tatsächliche Umsetzung finden kann - selbst dann nicht, wenn jede Plastiktüte mit einem GPS-Sender ausgestattet wäre.

Zwar ist es im Fall von The Plastic Bag durchaus so, dass Teile der Performance für menschliche Zuschauer sichtbar sind, die gesamte Performance ist jedoch von keinem menschlichen Zuschauer auch nur annähernd überschaubar. D. h. über den Horizont menschlichen Sehens hinaus, ist The Plastic Bag auch und gerade eine Inszenierung für die Leere des nichtexistenten Blicks des großen Anderen. Und weit davon entfernt, von der prinzipiell psychotisch-paranoiden Annahme der Existenz eines - wie Žižek mit Lacan sagt - „Anderen des Anderen“ auszugehen, d. h. von der Existenz irgendeines „verborgenen Subjekts, das die Fäden des großen Anderen (der symbolischen Ordnung) zieht“"80, spielt The Plastic Bag vielmehr mit dem, wovor die Annahme eines konsistenten großen Anderen Žižek zufolge flüchtet, nämlich „mit blindem, kontingentem Automatismus, der konstitutiven Blödigkeit der symbolischen Ordnung." ${ }^{\text {81 }}$

Sowohl Desert Walker als auch The Plastic Bag - so lässt sich nun abschließend sagen - setzen nicht etwa eine Ohnmacht des Subjekts in seiner Unterworfenheit unter das panoptisch-kontrollierende Auge eines als konsistent imaginierten großen Anderen in Szene. Vielmehr inszenieren sie, indem sie den großen Anderen als Inkonsistenten ins Spiel bringen, insofern die Freiheit des Subjekts, als diese Freiheit - so Žižek - „die Kluft oder Spalte im großen Anderen [...] [ist]“ und ,[d]er erste Schritt zur ideologisch-kritischen Entlarvung des großen Anderen [darin] besteht [...], seine inhärente Dummheit

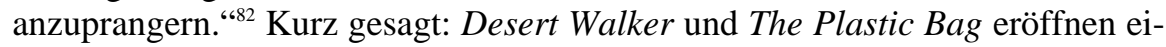
nen anderen Blick auf den Blick des großen Anderen - und damit auch auf den Begriff der Bühne. Jene Bühnen für andere Blicke, auf welchen die beiden Projekte stattfinden, sind Bühnen für den impersonalen Blick des inkonsistenten großen Anderen. Und damit sind sie ihrerseits „,andere“ Bühnen, d. h. andere Bühnen als jene, für welche der Begriff der Bühne dort steht, wo er im Horizont der Vorstellung verbleibt, eine Bühne sei ein Raum, der das in ihm präsentierte vollständig zu sehen gibt bzw. unmittelbar erfahrbar macht. Statt die Bühne als einen Raum der vollständigen Übersicht bzw. unmittelbaren Begegnung zu begreifen, stellen Desert Walker und The Plastic Bag gerade einen solchen Begriff der Bühne infrage - und zwar über den Blick, den sie auf ih-

${ }^{80}$ Slavoj Žižek, Mehr-Genießen. Lacan in der Populärkultur, Wien, 1997, S. 36.

81 Ebd.

82 Slavoj Žižek, Körperlose Organe. Bausteine für eine Begegnung zwischen Deleuze und Lacan, Frankfurt/M., 2005, S. 138. [Herv. i. O.] 
ren anderen Bühnen ins Spiel bringen. Weder reduzierbar auf die Vorstellung einer panoptischen Übersicht noch auf diejenige eines zwischenmenschlich-reziproken Sehens und Gesehenwerdens, verweist dieser Blick darauf, dass der Begriff der Bühne über den Horizont vermeintlicher Überschaubarkeit und Unmittelbarkeit hinaus zu denken ist - als Raum einer Darstellung, die immer schon ihren Abgrund und ihre Unmöglichkeit in sich trägt, d. h. als Raum der Inkonsistenz des Symbolischen bzw. großen Anderen. Und vielleicht ist „Bühne“ im Grunde tatsächlich nichts anderes als eben dies: Eine inkonsistente symbolische Struktur, die zwar immer wieder imaginär zu schließen versucht wird - durch das quadro Pozzos ebenso wie durch die praktischen und theoretischen Betonungen einer vermeintlich aufführungsspezifischen Kopräsenz von Akteuren und Zuschauern -, die aber letztlich, wie Desert Walker und The Plastic Bag zeigen, immer offen bleibt - um nicht zu sagen: ihr eigenes „Off“.

\section{Literatur}

Ackerley, Chris, „Samuel Beckett and Mathematics“, online unter: http://www.uca.edu. ar/uca/common/grupo17/files/mathem.pdf, zuletzt aufgerufen am 02.11.2012 [1998].

Bauman, Zygmunt, Flüchtige Moderne, Frankfurt/M., 2003. [Engl. OA 2000.]

Czirak, Adam, Partizipation der Blicke. Szenerien des Sehens und Gesehenwerdens in Theater und Performance, Bielefeld, 2012.

Debord, Guy, Die Gesellschaft des Spektakels, Berlin, 1996. [Frz. OA 1967.]

Deleuze, Gilles, „Postskriptum über die Kontrollgesellschaften“, in: Christoph Menke/ Juliane Rebentisch (Hg.), Kreation und Depression. Freiheit im gegenwärtigen Kapitalismus, Berlin, 2010, S. 11-17. [Frz. OA 1990.]

Eiermann, André, Postspektakuläres Theater - Die Alterität der Aufführung und die Entgrenzung der Künste, Bielefeld, 2009.

Esslin, Martin, „Patterns of Rejection. Sex and Love in Beckett’s Universe“, in: Linda Ben-Zvi (Hg.), Women in Beckett. Performance and Critical Perspectives, Urbana, Chicago, IL, 1992, S. 61-67.

Evans, Dylan, Wörterbuch der Lacanschen Psychoanalyse, Wien, 2002.

Fischer-Lichte, Erika, Ästhetik des Performativen, Frankfurt/M., 2004.

Dies., Performativität. Eine Einführung, Bielefeld, 2012.

Foucault, Michel, Überwachen und Strafen. Die Geburt des Gefängnisses, in: ders., Die Hauptwerke, Frankfurt/M., 2008, S. 701-1019. [Frz. OA 1975.]

Haß, Ulrike, Das Drama des Sehens. Auge Blick und Bühnenform, München, 2005.

Heeg, Günther, Das Phantasma der natürlichen Gestalt. Körper, Sprache und Bild im Theater des 18. Jahrhunderts, Frankfurt/M., 2000.

Lacan, Jacques, Die vier Grundbegriffe der Psychoanalyse. Das Seminar Buch XI (1964), Weinheim, Berlin, 1996. [Frz. OA 1973.]

Lehmann, Hans-Thies, Theater und Mythos. Die Konstitution des Subjekts im Diskurs der antiken Tragödie, Stuttgart, 1991. 
Ders., „Prädramatische und postdramatische Theaterstimmen. Zur Erfahrung der Stimme in der Live-Performance“, in: Doris Kolesch/Jenny Schrödl (Hg.), Kunst-Stimmen, Berlin, 2004, S. 40-66.

Müller-Schöll, Nikolaus, „Das undarstellbare Publikum. Vorläufige Anmerkungen für ein kommendes Theater“, in: Sigrid Gareis/Krassimira Kruschkova (Hg.), Ungerufen. Tanz und Performance der Zukunft, Berlin, 2009, S. 82-90.

Rebentisch, Juliane, „Spektakel“, in: Texte zur Kunst, Kurzführer/Shortguide, 17. Jahrgang, Heft 66/1 (2007), S. 120-122.

Roselt, Jens, „Raum“, in: Erika Fischer-Lichte/Doris Kolesch/Matthias Warstat (Hg.), Metzler Lexikon Theatertheorie, Stuttgart, Weimar, 2005, S. 260-267.

Tholen, Georg Christoph, Die Zäsur der Medien. Kulturphilosophische Konturen, Frankfurt/M., 2002.

Waldenfels, Bernhard, Bruchlinien der Erfahrung. Phänomenologie - Psychoanalyse - Phänomenotechnik, Frankfurt/M., 2002.

Žižek, Slavoj, Mehr-Genießen. Lacan in der Populärkultur, Wien, 1997.

Ders., Die politische Suspension des Ethischen, Frankfurt/M., 2005.

Ders., Körperlose Organe. Bausteine für eine Begegnung zwischen Deleuze und Lacan, Frankfurt/M., 2005. [Engl. OA 2003.]

\section{Internetquellen}

http://international-festival.org/node/56

http://lostlab.wordpress.com/desert-walker/it-is-winter-i-switch-on/

http://lostlab.wordpress.com/desert-walker/part-2-squaring-the-circle/

http://www.gpsies.com/map.do?fileId=rcgqjlvrcuhiytox

http://www.liveart.org/desertwalker/DW_eng.pdf

http://www.liveart.org/desertwalker/index.html 

ENTGRENZTE RÄUME 



\title{
PERFORMATIVIERUNG DES RAUMS. WISSENS- UND TECHNIKGESCHICHTLICHE ASPEKTE ZEITGENÖSSISCHER BÜHNENRÄUME
}

\begin{abstract}
Es gibt etwas, worüber der mensch noch nicht herr geworden ist, von dessen gegenwart er sich nichts träumen liess und das noch darauf wartete, dass er sich ihm liebevoll näherte; etwas unsichtbares und doch stets gegenwärtiges; etwas von überwältigendem zauber, schnell bereit sich zurückzuziehen, und nur in der erwartung verharrend, dass sich die rechten menschen nähern, um mit ihnen sich emporzuschwingen über die erde hinaus durch alle sphären - die bewegung. Edward Gordon Craig ${ }^{1}$
\end{abstract}

Performance does not happen in time, it creates its own time; it does not happen in space, it creates its own space. Daniel Charles ${ }^{2}$

And since all content is created in real-time by the performers, it shows us the fascination but also the limitations of our unescapable existence in the here and now.

Klaus Obermaier $^{3}$

\section{Performativierung des Raums als Dispositiv}

Der zeitgenössische Bühnenraum entsteht, so könnte es zugespitzt werden, aus einer „Performativierung des Raums“, die sowohl Theater seit 1900 kennzeichnet als auch den theoretischen Hintergrund zur Beschreibung von Raum seit den 1980er Jahren bildet. Im spatial turn ${ }^{4}$ sowie im performative turn ${ }^{5}$, die

Edward Gordon Craig, Über die kunst des theaters, Berlin, 1969, S. 45.

2 Zit. nach: The concept of ... (here and now), Medien-Tanzstück von Klaus Obermaier, 2010, online unter: http://www.exile.at/concept/project.html, zuletzt aufgerufen am 01.02.2012.

3 Ebd.

4 Zum „spatial turn“ vgl. Jörg Döring/Tristan Thielmann, Spatial Turn: Das Raumparadigma in den Kultur- und Sozialwissenschaften, Bielefeld 2008; sowie Stephan Günzel (Hg.), Topologie. Zur Raumbeschreibung in den Kultur- und Medienwissenschaften, Bielefeld, 2007.

5 Zum „performative turn“ vgl. Erika Fischer-Lichte, „Auf dem Wege zu einer performativen Kultur“, in: dies./Doris Kolesch (Hg.), Kulturen des Performativen, Paragrana 7, 1 (1998), 
den zeitgenössischen Diskurs der theoretischen Beschreibung von Raum konfigurieren, meint die „Performativierung des Raums“ eine Auflösung seiner materiellen Bedingungen in Handlungen und Verhaltensweisen seiner Bewohner $^{6}$, durch die Raum erst entsteht. Auch im Theater seit 1900 soll der Bühnenraum erst im Vollzug von Handlungen erzeugt werden und unterläuft auf Grund von deren Fragilität und Transistorik die Vorstellung, dass es eine vorgängige Räumlichkeit und Wirklichkeit gäbe. Vor allem im Theater wird zudem dem Raum selbst eine eigene Performativität zugestanden, wodurch sich Vorstellungen von Performance auflösen, die diese auf die mehr oder weniger intentionalen Handlungen ${ }^{7}$ menschlicher Akteure beziehen. An die Stelle dieser Vorstellung tritt nun ein Verständnis von Performance und Performativität als Performanz des Vollzugs von Operationen.

Im Folgenden wird eine technik- und wissensgeschichtlich ${ }^{8}$ orientierte Rekonstruktion von Diskurs und Praxis dieser Performativierung des Raums vorgeschlagen. Ausgangspunkt sind dabei zwei Beobachtungen. Mit der Performativierung des Raums gerät erstens im spatial wie im performative turn die Aufmerksamkeit für Dispositive ${ }^{9}$, d. h. für die materiellen Umgebungen, die Wahrnehmung und Subjekte konfigurieren - paradigmatisch ist Foucaults Panopticum ${ }^{10}$ - tendenziell ins Hintertreffen. Wo Raum nicht unabhängig existiert, sondern überhaupt erst im Verhalten und Handeln der Menschen entsteht, kann er auch nicht a priori deren Konstitution konfigurieren. Ich werde dagegen im Folgenden argumentieren, dass der in der Performativierung entstehende Topos des „performative Raums“ ${ }^{\text {“11 }}$ ein Dispositiv ist. ${ }^{12}$ Dieses weist,

S. 13-29; Erika Fischer-Lichte/Christoph Wulf (Hg.), Theorien des Performativen, Paragrana 10, 1 (2001); sowie Erika Fischer-Lichte, Ästhetik des Performativen, Frankfurt/M., 2004.

6 Vgl. dazu paradigmatisch Michel de Certeau, „Pratiques d'espace“, in: ders., L'invention du quotidien. Paris, 1990, S. 139-191.

7 Vgl. einführend zum Begriff der Handlung in der soziologischen Handlungstheorie Hans-Joachim Schubert, „Analyse und Kritik aus Sicht soziologischer Handlungstheorie“, in: Analyse \& Kritik - Zeitschrift für Sozialtheorie, 30 (2008), S. 627-646, online unter: http://www.ana lyse-und-kritik.net/2008-2/AK_Schubert_2008.pdf, zuletzt aufgerufen am 01.02.2012.

8 Der Begriff „wissensgeschichtlich“ bezieht sich hier auf die Ordnungen des Wissens, die zu einer historischen Phase auftauchen und nicht auf eine Wissenschaftsgeschichte. Eine Wissensgeschichte wäre Letzterer vorgängig.

9 Grundlegende und richtungsweisende Ausnahmen bilden: Jörg Dünne/Sabine Friedrich/Kirsten Kramer (Hg.), Theatralität und Räumlichkeit: Raumordnungen und Raumpraktiken im theatralen Mediendispositiv, Würzburg, 2009; Hans-Christian von Herrmann, Das Archiv der Bühne. Eine Archäologie des Theaters und seiner Wissenschaft, München, 2005; sowie Jörg Dünne, Die kartographische Imagination. Erinnern, Erzählen und Fingieren in der Frühen Neuzeit, München, 2011.

10 Vgl. Michel Foucault, Überwachen und Strafen. Die Geburt des Gefängnisses, Frankfurt/M., 1994.

11 Der „performative Raum“ ist aus systematischer Sicht als Produkt der Performativierung anzusehen, da er sich etwa durch Transformation, Handlungsmacht sowie dadurch auszeichnet, dass er den Handlungen seiner Bewohner nicht vorgängig ist. Welche Gestalt diese systematische Kategorie bzw. diese Perspektivierung des Raums annimmt, ist eine andere Sache.

12 Vgl. zur Unterscheidung von räumlicher Materialität und Dynamisierung des Raums: Jörg Dünne, „Geschichten im Raum und Raumgeschichte, Topologie und Topographie“, online 
so die These, erstens sehr materielle Grundlagen auf, nämlich - zumindest in den hier verhandelten Beispielen - die Erzeugung eines elektromagnetischen sowie eines symbolverarbeitenden Raums. Auch wenn diese imaginär sind, werden sie doch in der Inszenierung als reale, wirksame generiert. In diesen Räumen kommt es gemäß der Wirkungsweisen von Dispositiven zum anderen zu einer Hervorbringung von Subjekten, die sich aufgrund der Performativierung technischer Dinge in der Verbindung von Mensch und Technik zu symmetrischen Handlungsnetzen formieren. Die Performativierung des Raums ist zweitens in der theatralen Praxis sowie in der theoretischen Diskussion zudem äußerst positiv besetzt, da sie u. a. Raum sowie Subjekt seit der Renaissance von variierenden dispositiven Anordnungen befreie, mit denen Raum in mathematisch grundierte, illusionäre Konstruktionen gefesselt und das Subjekt aus ihnen verdrängt und zum Bild entkörpert wurde. ${ }^{13}$ Verklärt wird in dieser positiven Sicht der turns allerdings, dass die Nobilitierung des performativen Raums ein Diskurs ist, mit dem die Virtualisierung der Akteure in technisch performativierten Räumen und damit ihr Kontrollverlust über Technik ausgeblendet wird. Die Rekonstruktion der Performativierung des Raums wird entsprechend zeigen, dass es sich bei dieser im Theater sowie in der Raumdebatte seit den 1980er Jahren um in Ersterem entwickelte und erprobte Maschinendiskurse handelt. Die Ausblendung der Materialität von Dispositiven sowie der Diskursivität der Nobilitierung von Performativität könnten dazu führen, dass der technisch-materielle Status des performativen Raums sowie der performativen Raumtheorie verschleiert wird.

Ich möchte nun anhand von unterschiedlichen Weisen der Performativierung des Raums im Theater um 1900, 1960 und 2000 exemplarisch zeigen, dass sie sich aus einer Faszination an sich entfesselnden technischen Dingen und Apparaten konstituiert, die es vor allem ermöglicht, menschliche Akteure in diese selbstbezüglichen Welten zu vermitteln und dabei deren Virtualisierung und Steuerung auszublenden. Dies erschließt sich aus der Wissens- und Technikgeschichte der Performativierung von Raum im Theater. Da zentrale Theoreme zeitgenössischer Raumtheorien im Theater seit 1900 vorgedacht wurden, schlage ich deren Analyse zugleich als Grundlage für eine Reflexion aktueller Bühnenräume sowie zeitgenössischer Raumtheorien vor.

\section{Formale Logik und Elektromagnetismus auf der Bühne}

Die technik- und wissensgeschichtliche Genese der zeitgenössischen Performativierung des Bühnenraums lässt sich um 1900 verorten. Zu diesem Zeit-

unter: http://www.uni-potsdam.de/romanistik/ette/buschmann/dynraum/pdfs/dynamisierte_raeume komplett.pdf, zuletzt aufgerufen am 26.01.2012.

13 Vgl. die grundlegende und wegweisende Studie von Ulrike Haß, Das Drama des Sehens. Auge, Blick und Bühnenform, München, 2005. 
punkt wird Theater u. a. durch Edward Gordon Craig $^{14}$ und Loïe Fuller ${ }^{15}$ als Raumkunst $^{16}$ entdeckt und damit theatrale Bestandteile wie Bewegung, Klang, Körper, Kostüm und Raum als Gestaltungsmittel jenseits des Textes freigesetzt. Diese Wendung entspricht zum einen insofern einer Performativierung des Raums, als er erst aus den flüchtigen Handlungen der Akteure entsteht und mit diesen wieder vergehen soll. Zum anderen werden Raum und Dinge, die sich in ihm befinden, zu Partnern der Akteure, mithin zur Performance mit eigenen ästhetischen Qualitäten entfesselt.

\section{Craigs Symbolismus. Theater logischer Formalisierungen}

Diese Performativierung des Raums kommt prägnant in der Theaterarbeit von Edward Gordon Craig zum Tragen. In deren Zentrum steht, so kann es gelesen werden, ein von Craig um 1900 entwickelter universeller Symbolismus theatraler Zeichen. „Symbolismus ist in wirklichkeit etwas sehr einfaches, etwas ganz normales, klar geordnetes und universal verwendbares. [...] Denn symbolismus gehört nicht nur zu den grundlagen der kunst, sondern zu den grundlagen des lebens überhaupt [...].“17 Invariante Symbole sollten die Qualität von Inbegriffen haben und aus ihnen sollte alles Mögliche werden können, „dass der maler durch bestimmte zeichen und formen den eindruck eines esels entstehen lässt; und wenn er ein grosser künstler ist, dann wird er den eindruck der ganzen gattung esel wiedergeben, die geistige essenz der sache. ${ }^{\text {18 }}{ }^{18}$ Dies zu erreichen, verbannte Craig menschliche Akteure und Szenographien aus Pappmaché aus dem Bühnengeschehen. Der theatrale Raum konstituierte sich nun vielmehr aus Animationen von überdimensionalen Figuren, Craig nannte sie Übermarionetten, sowie der „Scene“, die aus in Boden und Decke heb- und senkbaren Bühnenelementen sowie aus beweglichen Leinwänden, Screens bestand. Christopher Innes schreibt zur „Scene“:

He also believed that this mechanisme could be developed to the point at which a director could work it from a console at the rear of the auditorium during a performance, so responding directly to the emotional moods of the audience. [...] Craig believed he had found such an instrument in Scene, in which the human voice and figure could be replaced by ,light - shadow - motion through impersonal mediums - and silence ${ }^{19 ،} \cdot{ }^{20}$

14 Craig (1969), Über die kunst des theaters.

15 Loïe Fuller, Fifteen Years of a Dancer's Life, Boston, 1913, reprint: New York, NY, 1977.

16 Vgl. Max Herrmann, „Das theatralische Raumerlebnis“ (1931), in: Jörg Dünne/Stephan Günzel (Hg.), Raumtheorie. Grundlagentexte aus Philosophie und Kulturwissenschaften, Frankfurt/M., 2006, S. 501-514.

17 Craig (1969), Über die kunst des theaters, S. 189.

18 Ebd., S. 55.

19 Zitat v. Craig nach Christopher Innes, Edward Gordon Craig - A Vision of Theater, London, New York, NY, 1998, S. 179.

20 Ebd., S. $178 \mathrm{f}$. 
Es sollten also, so ließe es sich zusammenfassen, künstliche Welten entstehen, die den Menschen nicht mehr zwingend als Vorbild brauchen. Sie folgen vielmehr einer eigenen Logik, die die Zuschauer als visuelle Präsenz und Zeichen höherer, heiliger Ordnungen bannen sollten.

Relevanz und Wirkung der Performativierung des Raums in Craigs Theaterarbeit sowie sein Symbolismus erschließen sich aus einer bisher noch wenig rezipierten wissensgeschichtlichen Kontextualisierung. ${ }^{21}$ Craigs Vorliebe für das Symbolische kann nämlich, wie Alexander Firyn herausgearbeitet hat ${ }^{22}$, aus dem Dunstkreis der Denkfiguren und Episteme der seit den 1850er Jahren entwickelten Formalen Logik rekonstruiert werden. Aus dieser Sicht geht es dann um die Idee, universelle Symbole zu kreieren und Materielles oder lebendige Performer wegen ihrer formalen Unzulänglichkeit abzuschaffen. Kerngedanke der Formalen Logik in Sprachwissenschaft, Philosophie wie Mathematik ist nämlich, dass eine künstliche Ordnung invarianter universeller Symbole denkbar ist, die als selbstbezügliches und operatives System funktioniert. ${ }^{23}$ In diesem werden Wahrheit und Falschheit von Aussagen und Schlussfolgerungen auf der Grundlage einiger, widerspruchfreier (so die Hoffnung) Axiome generiert und geprüft. In der Mathematik wird ab 1850/um 1900 derart nicht mehr einfach nur gerechnet. Vielmehr wird Mathematik mit George Boole (1850) und David Hilbert (1900/1920), wenn auch auf sehr verschiedene Weise, operativ, d. h. sie wird selbsttätig. Denn Mathematik wird als Kalkül entworfen und zum widerspruchsfreien Schlussfolgern, das aus Axiomen, Definitionen und Beweisregeln besteht, welche die nötigen Operationen festlegen. Der Bezug zur Wirklichkeit fällt aus, wie Hilbert ausführt: „Es wird nichts darüber gesagt, was die Dinge sind. Wir haben die Freiheit uns darunter vorzustellen, was wir wollen - wenn es nur mit den Aussagen der dieser Erklärung folgenden Axiome verträglich ist.“24 Aus dem universellen Code kann, ähnlich wie bei Craig, alles Mögliche werden. Aus „x“ oder „y“ kann ein Satz werden, eine mathematische Formel oder ein Theaterstück. In diesen künstlichen Welten zählt, dass sie in sich schlüssig sind.

Wie eine axiomatisch geregelte und gereinigte „Kunstsprache“ aussieht, beschreibt Craig an einem Bühnenbild zu einer Shakespeare-Inszenierung. Aus Elementen wie Rechtecke und Farben wird eine Szenerie erstellt, die sich von einem Gebirge zu einem Innenraum in einem Schloss wandeln kann. Diese Wandlungen sind möglich aufgrund der logischen Folge, dass Wände aus Ge-

${ }^{21}$ Craig Symbolismus wird zumeist auf einen platonisch inspirierten Dualismus von Körper und Geist, Idee und Materie zurückgeführt. Vgl. dazu exemplarisch: Joachim Fiebach, Von Craig bis Brecht. Studien von Künstlertheorien des 20. Jahrhunderts, Berlin, 1975.

22 Alexander Firyn, Theaterpoesie und Mathematik, unveröffentlichte Magisterarbeit, FU Berlin, Institut für Theaterwissenschaft, o.J.

23 Vgl. dazu bezogen auf die wissensgeschichtlichen Aspekte einführend: Erich Hörl, Die heiligen Kanäle. Über die archaische Illusion der Kommunikation, Zürich, Berlin, 2005.

24 David Hilbert, Grundlagen der Geometrie, Leipzig, 1899, hier zit. n.: Bert Gaard, Die Rätsel der Welt. Gedanken zur Situation der Zeit, (1996/2007), online unter: http://www.tu-harburg. de/rzt/rzt/it/sofie/welt.pdf, S. 15, zuletzt aufgerufen am 09.07.2013. 
stein sind, das wiederum aus dem Gebirge kommt, und Möbel aus Holz, das aus dem Wald an Gebirgen stammt. Also kann das graue, überdimensionierte Rechteck ebenso Berg wie Innenraum eines Schlosses sein und eine grünbraune Komposition Wald und Möbelstück. Das heißt, es geht um Reduktionen sowie um logische Schlussfolgerungen und Klassifizierungen. Craig spricht vom Gesetz der Notwendigkeit sowie von der Prämisse, dass die Dinge am richtigen Platz sein müssen:

Die linien und die proportionen haben das stoffliche der felsenartigen substanz angedeutet; die farbe (eine farbe) und ihre verschiedenen abtönungen haben das ätherische der nebelhaften leere hinzugeben; [...]. Ich weiss, irgendwo bei Ihnen spukt die erinnerung, dass ein wenig später im stück sogenannte ,interieurs' vorkommen. Aber meine güte, machen sie sich darum keine sorgen. Bedenken sie, dass das innere der burg aus dem material ist, das aus den steinbrüchen der berge stammt. Sie brauchen dafür also genau dieselbe farbe wie für den felsen. [...] Sie haben nur variationen über dasselbe thema zu geben: felsen - braun, nebel grau. Und auf diese weise werden sie wunderbarerweise eine echte künstlerische einheit erzielen. ${ }^{25}$

Craig stößt ausgehend von einer typisch theatralen Problemstellung auf diese der formalen Logik vergleichbare Darstellungspraxis. Ausschlaggebend ist die Frage, wie Geistererscheinungen in Shakespeare-Stücken auf der Bühne so dargestellt werden könnten, dass sie nicht lächerlich wirken, mithin solche Dinge, die man nur ahnen oder fühlen könne und die unsichtbar bleiben sollten. Die Undarstellbarkeit im Materiellen bringt Craig zu einer Kritik an theatralen Zeichen und zur Lösung, über-natürliche, invariante Super-Zeichen zu nutzen. Jedes reale, vor allem lebendige Material, wäre dafür aufgrund seiner Morbidität und Fehleranfälligkeit ungeeignet. Invariante Symbole aber und die Logik ihrer Ordnungen seien ewig und unabhängig von ihrer Existenz in einem konkreten Material wahr. Logik wird regelrecht zum Medium des Metaphysischen und der Geistererschienung, wenn Craig schreibt:

Richtet der regisseur seine aufmerksamkeit und die des publikums nur auf die sichtbaren dinge, die der zeitlichkeit unterworfen sind, so raubt er einem solchen drama fast alle majestät und seine ganze bedeutung. Geht er aber, ohne es grotesk zu verzerren, vom element des übernatürlichen aus; steigert er die handlung von ihrem stofflichen inhalt zu einem seelischen gehalt und lässt er - wenn nicht dem leiblichen ohr, so doch dem gehör der seele -, das feierliche und unablässige flüstern vom menschen und seinem schicksal` hörbar werden; zeigt er die ,unsicheren und leidvollen schritte der kreatur, wie sie der wahrheit, der schönheit oder ihrem gott sich nähert oder entzieht', dann offenbart er in den tiefsten schichten des König Lear, Macbeth, Hamlet das raunen der ewigkeit am horizont $[\ldots] .^{26}$

Es geht also nicht einfach um einen möglichst optimalen Trick für die Darstellung von Geistern, sondern vielmehr um eine metaphysische Erkenntnis. In ihr

${ }^{25}$ Craig (1969), Über die kunst des theaters, S. 31.

26 Ebd., S. 173. 
wird der Tod, verkörpert in den überdimensionierten Dingen und Räumen, zum Ausblick auf einen Nullpunkt logischer Reinheit. Craig führt aus:

Ich strebe vielmehr danach, die schönheiten einer imaginären welt zu beschwören, einen fernen schimmer jenes geistes zu erhaschen, den wir tod nennen. [...] schatten und geister erscheinen mir schöner und lebensvoller als die männer und frauen von denen unsere städte voll sind, [...] - all dies geht freilich über blosse tatsächlichkeit weit hinaus. [...] Aus dieser idealen welt können wir eine so mächtige inspiration gewinnen, dass ich ihr ohne zögern frohlockend entgegenlaufe. $^{27}$

Theater von und nach Craig entspricht, so ließe es sich zusammenfassen, einem Bewegen in menschenleeren Kunstwelten, die sich selbst organisieren. Performance ist nicht länger die mit Intentionen versehene Handlung von Menschen, sondern vielmehr der logisch reine Vollzug von Bewegungen. Das heißt, es geht um eine schiere Performanz, die von Dingen und Apparaten auf der Bühne ausgeführt wird und dabei eine Ahnung an geistige Essenzen des Seins entfesseln soll. Mit diesem Versprechen wird die Performativierung des Raums zur Grundlage einer Faszinationsgeschichte, in der die Auflösung tradierter Vorstellungen des Menschen als autonomes Subjekt sowie des Theaters als anthropologischer Raum Voraussetzung für die Möglichkeit höherer Erkenntnis ist. An die Stelle der Materialität des Raums treten Bewegung, Transformation und symbolische (In-)Varianzen als Dispositiv, die den Zuschauer in ein Reich der Ahnung höherer Ordnungen mitnehmen sollen. In der Transzendierung des theatralen Raums ins Reich der Inbegriffe verspricht also die Auflösung materieller Dinge in Theater wie in der Formalisierung in Mathematik, Physik und Sprachwissenschaft eine höhere Erkenntnis. ${ }^{28}$

\section{Loïe Fullers ätherische Tuchtänze}

Auch Loïe Fullers Tanz kann so angesehen werden, dass sie um 1900 eine Performativierung des Raums vornimmt, d. h. seine Entfesselung hin zu einem eigentätigen, animierten System. Diese Entfesselung oder dieser Animismus zeigen sich darin, dass die Tänzerin überdimensionale Tücher im Raum schwingt, auf denen das Licht von bunten Scheinwerfern gefangen wird, das

27 Ebd., S. 61.

28 Die sprachkritische Wende bildet zugleich die Vorgeschichte des Computers als logische, nach Wahrheitstabellen und deren Transformation in Signale operierende Maschine. Das heißt, die Wende ist insofern Voraussetzung des Computers, als sie ein axiomatisches System aus invarianten Symbolen denkbar macht, das aus sich heraus operieren kann, weil es über richtige und falsche Schlüsse informiert ist. Zudem kann aus dem universellen Code in der Mathematik wie im Computer alles Mögliche werden. Aus „X“ oder „y“ kann ein Satz werden, eine mathematische Formel oder ein Theaterstück. In diesen künstlichen Welten zählt, dass sie in sich schlüssig sind. Vgl. auch Bettina Heintz, Die Herrschaft der Regel. Zur Grundlagengeschichte des Computers, Frankfurt/M., 1993. Das heißt, in weiterer Forschung wäre zu prüfen, ob Craigs Initialzündung für eine Performativierung des Raums im Kontext dieser wissensgeschichtlichen Rekonstruktion in der Vor-Geschichte des Computers siedelt. 
die Tücher in immer neue Farben taucht. Es entsteht ein Licht-Farben-Raum, in dem die Gestalt der Tänzerin sich in einem Zusammenspiel von Erscheinen und Verschwinden gleichsam entmaterialisiert. Sie ist nicht mehr Darstellerin, sondern Operatorin, die sich nach dem Fließen und Schwingen der Lichtstrahlen ausrichtet. Dieser Raum soll, so zeigt eine wissens- und technikgeschichtlich orientierte Rekonstruktion dieses Tanzens, den Äther als alles Mögliche übertragende Substanz in dem Moment evident machen, in dem die Physik des Elektromagnetismus ihn aufzulösen beginnt. ${ }^{29}$

Die ätherische Seite der Tänze der Fuller zeigt sich anschaulich im Radium Dance mit von selbst leuchtenden Seidenstoffen, der 1904 in den Folies Bergère in Paris aufgeführt wurde. Die Tänzerin verstand ihn ausdrücklich als eine Parteinahme für die Existenz von sphärischen, übernatürlich-materiellen matter forces. Das geheimnisvolle farbige Leuchten und Strahlen auf ihren radioaktiven Tüchern erklärt sie nämlich dezidiert unter Bezugnahme auf den von dem britischen Physiker und Spiritisten William Crooke vermeintlich entdeckten vierten, „strahlende[n] Zustand der Materie“, der für diesen wie für Loïe Fuller als Nachweis des Äthers galt. ${ }^{30}$ Diese Sicht auf Radioaktivität setzt die Fuller in einer Abhandlung in ihrem Arbeitstagebuch explizit gegen die unter anderem durch die Entdeckung des Radiums durch die Curies aufkommende Physik der nicht mehr greifbaren Elektronen und zerfallenden Atome und der damit verbundenen Auflösung des Äthers. ${ }^{31}$ In ihrer Show soll dagegen, so kann es gelesen werden, die ubiquitäre Präsenz des Äthers sichtbar gemacht werden, wenn er sich vermeintlich im Strahlen der Tücher materialisiert. Es scheint so, dass die Welt aus sich heraus glüht und leuchtet, weil der Äther da ist und Licht durch ihn zu verschiedenen Farben wird.

Im Festhalten des verschwindenden Äthers tritt auch bei Loïe Fuller, wie schon bei Crookes, eine spiritistische Deutungstradition der ätherischen Experimente auf den Plan. ${ }^{32}$ Denn in Crookes Ätherphysik entsprach die strahlende

${ }^{29}$ Vgl. zu dieser Perspektivierung zu Loïe Fuller: Martina Leeker, „Weibliche Medien um 1900. Über okkulte Herkünfte der Medienwissenschaft“, in: Hedwig Wagner (Hg.), GenderMedia Studies. Zum Denken einer neuen Disziplin, Weimar, 2008, S. 117-140.

30 Vgl. Wolfgang Hagen, „Loïe Fuller. The Shock of Electricity and the Technological History of Modern Dance or the Overwhelmingness of Technology and the Possibilities of Art“, in: Söke Dinkla/Martina Leeker (Hg.), Tanz und Technologie. Auf dem Weg zu medialen Inszenierungen, Berlin, 2002, S. 118-131; zum Zusammenhang von Crookes Physik der vierten Materie und Kunst vgl.: Wolfgang Hagen, Der Okkultismus der Avantgarde um 1900, 1997, online unter: http://www.whagen.de/vortraege/OccultismAvantgarde/Okkavang.htm, zuletzt aufgerufen am 01.02.2012.

31 Siehe die 1907 bis 1911 entstandene, handschriftliche Abhandlung von Loïe Fuller mit dem Titel Lectures on Radium, online unter http://digitalgallery.nypl.org/nypldigital/dgkeysearch detail.cfm?strucID=773 359\&imageID=FUL001_001B, hier S. 21-23, zuletzt aufgerufen am 01.02.2012.

32 Vgl. zur Verbindung von Performance, Elektrizität, Medien und Spiritismus auch: Marcus Hahn/Erhard Schüttpelz (Hg.), Trancemedien und Neue Medien um 1900. Ein anderer Blick auf die Moderne, Bielefeld, 2009; vgl. auch Petra Bahr, Lö̈e Fuller. Grenzgängerin des Tanz- 
Materie, mithin elektromagnetische Wellen, der Überträgersubstanz für übernatürliche Erscheinungen wie Geister und Gedanken. ${ }^{33}$ Loïe Fuller avisiert und erprobt dieser Denkfigur folgend eine durch Licht und Farbe ausgelöste psychedelisch-hypnotische Beeinflussung ihres Publikums. Das Publikum sollte mit den Materialisierungen des Äthers in Farben nämlich, so ist zu folgern, in eine psychedelische Resonanz mit den heilenden und harmonisierenden Schwingungen von Licht- und Farbfrequenzen versetzt werden. ${ }^{34}$

Die Performativierung des Raums bei Loïe Fuller impliziert also dessen Aufladung mit Äthervorstellungen sowie mit okkulten, zumindest aber mit psychedelisch-esoterischen Phantasmen und macht den performativen, in Bewegung, Übertragung und Transformation entfesselten Raum in diesem Sinne geradezu zu einem mediumistischen Medium.

\section{Akteur-Agenten in elektro-kybernetisch entfesselten technischen Umwelten}

In der Performancereihe 9 Evenings, Theatre and Engineering ${ }^{35}$, die 1966 im New Yorker Armory, einer riesigen Militärhalle, zur Aufführung kamen, wurden - so die hier vorgeschlagene Lesart - die eben skizzierten formallogischen und die okkulten Szenarien in der Performativierung des Raums aufgerufen und zusammengeführt. Es entstand ein psychedelischer elektro-kybernetischer Raum, in dem die Akteure auf der Grundlage von elektrischen Signalen und elektronmagnetischen Vibrationen in kybernetische Automatismen und Steuerungen eingebunden werden sollten. ${ }^{36}$

ästhetischen, 1999, online unter: http://www.theomag.de/02/pb1.htm, zuletzt aufgerufen am 31.01.2012.

33 Vgl. Wolfgang Hagen, Die entwendete Elektrizität. Zur medialen Genealogie des ,modernen Spiritismus‘, 2002, http://www.whagen.de/publications/EntwendeteElektrizitaet/26Hagen.htm, zuletzt aufgerufen am 01.02.2012.

34 Um die Wirkungen von Farben zu erforschen, experimentierte die Fuller zusammen mit dem Spiritisten Camille Flammarion mit Blinden und mit Pflanzen zu deren Auswirkungen auf die menschliche Psyche bzw. auf das Wachstum von Pflanzen. Die elektromagnetischen, über den Äther übertragenen Wellen von Farben haben, so die Überlegung aus den Forschungen der beiden, spezifische Wellenlängen, die sich in Resonanz zum Körper befinden und Physis und Psyche in (dis-) harmonische Zustände versetzen können. Vgl. William Everett Leonhard, Loïe Fuller's Contributions to Stage Light, University of Texas, 1964, S. 71-73, online unter: http://etd.lib.ttu.edu/theses/ available/etd-06082009- 31295001113470/unrestricted/31295001113470.pdf, zuletzt aufgerufen am 31.01.2012; sowie Fuller (1913/1977), Fifteen Years of a Dancer's Life.

35 Vgl. zu den 9 Evenings die Dokumentation der „Foundation Langlois“: 9 Evenings. Theatre and -Engineering fonds: http://www.fondation-langlois.org/html/e/page.php?NumPage=294; sowie Clarisse Bardiot, 9 Evenings. Theatre and Engineering: http://www.fondation-langlois. $\mathrm{org} / \mathrm{html} / \mathrm{e} /$ page.php?NumPage=572, beide zuletzt aufgerufen am 01.02.2012.

36 Vgl. auch Martina Leeker, „Camouflagen des Computers. McLuhan und die Neo-Avantgarden der 1960er Jahre“, in: Derrick de Kerckhove/dies./Kerstin Schmidt (Hg.), McLuhan neu lesen. Kritische Analysen zu Medien und Kultur im 21. Jahrhundert, Bielefeld, 2008, S. 345375. 


\section{Raum als elektromagnetisches Leitsystem}

In den Performances ${ }^{37}$ von u. a. John Cage, David Tudor, Robert Rauschenberg, Yvonne Rainer und Alex Hay wurden über elektromagnetische Wellen im Raum elektrische Signale geleitet, die in Apparaten wie in den Akteuren mediale Effekte auslösten. Derart wurde in diesem imaginären Raum Elektrizität zum kleinsten gemeinsamen Nenner unterschiedlicher Erscheinungen und Entitäten wie Scheinwerfer, Lautsprecher, Video, Fernsteuerung und schließlich Menschen. So ließ etwa Alex Hay in Grass Field Gehirnwellen abnehmen, diese in elektrische Signale umwandeln und verstärken und zu Geräten weiterleiten, so dass sie Ton oder Licht an- und ausschalteten oder deren Intensitäten steuerten..$^{38}$ Auch John Cage arbeitete in Variations VII ${ }^{39}$ mit der Abnahme von Signalen des Gehirns, die Scheinwerfer regelten oder akustisch verstärkt wurden. Zu den Klängen des Gehirns gesellten sich solche von elektrischen Mixern, Schildkrötenbassins sowie Sendungen, die gerade zufällig im Radio liefen. So wurde der Anschein einer All-Übersetzbarkeit in einem elektromagnetisch gefüllten Raum erzeugt und inszeniert. Sie wird möglich durch ein Konzept von Raum in den 9 Evenings, das besagt, der Raum sei ein Medium des Transfers von elektrischen Signalen auf der Grundlage von elektromagnetischen Wellen. Auch hier ist Raum also nicht mehr als stabile Entität gedacht. Er löst sich vielmehr von einer festen Form und wird zu einem Übertragungs-Raum, in dem sich Performances der Steuerung sowie der elektroanalogen Transformation ereignen; eine Raumordnung, die gleichwohl ein Dispositiv ist, wie nun zu zeigen sein wird.

David Tudors Bandoneon! (a combine). Performances technischer Dinge und medialer Räume

Diese Art der Performativierung des Raums sowie deren Bedeutung werden besonders deutlich in Tudors Performance Bandoneon! (a combine $)^{40}$, wie sich aus einer wissens- und technikgeschichtlichen Kontextualisierung darlegen lässt.

37 Vgl. zu den Performances: http://www.fondation-langlois.org/html/e/selection.php?Selection =9EVO, zuletzt aufgerufen am 01.02.2012.

38 Vgl. zur Performance von Alex Hay: http://www.fondation-langlois.org/html/e/page.php? NumPage=662; sowie http://www.fondation-langlois.org/flash/e/index.php?NumPage=571, beide zuletzt aufgerufen am 01.02.2012.

39 Vgl. zur Performance von John Cage: http://www.fondation-langlois.org/html/e/page.php? NumPage=611; sowie http://www.fondation-langlois.org/flash/e/index.php?NumPage=571, beide zuletzt aufgerufen am 01.02.2012.

40 Vgl. zu Tudors Performance Bandoneon! (a combine): http://www.fondation-langlois.org/ html/e/page.php?NumPage=583; sowie http://www.fondation-langlois.org/flash/e/index.php? NumPage=571, beide zuletzt aufgerufen am 01.02.2012. 
Ihr Ausgangspunkt ist, dass in Bandoneon entfesselte technische Dinge sowie der Raum selbst zum Klingen gebracht werden; sie performen. ${ }^{41}$ Tudor zelebrierte seine Selbstkomposition der Geräte und Instrumente mithilfe des extra dafür präparierten Bandoneons. Es produzierte nämlich keine Töne, sondern elektrische Steuersignale, die in den Fluss von Elektronen oder elektromagnetischen Wellen eingriffen und darüber den Geräten bzw. gar dem Raum selbst vermeintlich zur Kreation verhalfen. Erzeugt wurde diese als Komposition inszenierte Steuerung und Resonanz der Geräte dadurch, dass die Signale zu kleinen Wagen, Carts, gesendet wurden, mit denen die auf ihnen befindlichen Lautsprecher und Klangskulpturen durch den Raum transportiert wurden. Kamen sie an fix im Raum installierten Lautsprechern vorbei, dann generierte diese Zusammenkunft in einer nicht vorhersehbaren und sich selbst aufschaukelnden Weise eine akustische, positive Rückkopplung. Es entstand eine Selbsterregung des Systems als resonantes Schwingen. Immer wieder unterbrach Tudor die Bewegungen des Bandoneons, um den Nachhall des Armory selbst klingen zu lassen, gerade so, als kämen nun in den erregten Schwingungen die höherer Sphären des Raums zum Vorschein.

Mit Tudors selbsterregter Frequenzen-Schwingungswelt wird in den 9 Evenings zugleich die Denkwelt von Loïe Fuller wieder lebendig, denn spiritistische Denkfiguren des 19. Jahrhunderts tauchen auf. Wenn Tudor, der nachweislich Leser von Rudolf Steiner und seit 1957 Mitglied der anthroposophischen Gesellschaft ist, seine Installation ausschaltet, um den sphärischen Klang des Armory zu Gehör zu bringen, dann geht es ihm um das Ertönen von Steiners Klangäther, in den die Aura-Existenz des Menschen integriert ist. ${ }^{42}$ Tudor geht allerdings da über Steiners Kosmologie hinaus, wo er dieser mit dem Eigenklang der elektrischen Geräte das Ertönen eines Techno-Äthers hinzufügt. Damit wird der Performativierung des Raums die der Geräte in besonderer Weise hinzugefügt. Auch Technik ist Teil des Äthers, seine Ordnung kommt in ihr zum Tragen.

Tudors selbsterregte Frequenzen-Schwingwelt lässt sich also vor allem vor dem Hintergrund einer spiritistischen, ätherischen Mediengeschichte verste-

41 Ob die Genese von „Agententheorien“ dort im Kontext der Performativierung des Raums stehen könnte, wo in Anlehnung an Bruno Latours „Laborstudien“ Raum selbst mit Handlungsmacht ausgestattet wird, mithin als Agent und Agentur erzeugt wird, wäre zu klären. Vgl. Bruno Latour/Steve Woolgar, Laboratory Life: The Social Construction of Scientific Facts, Beverly Hills, 1979; sowie Bruno Latour, Science in Action. How to Follow Scientists and Engineers through Society, Cambridge, 1987.

42 Ein weiterer Nachweis für Tudors Interesse an der Existenz einer höheren Ordnung sowie am Körper als Medium des Empfänglichwerdens für übersinnliche Erfahrungen ist eine Begegnung, die sein Kollege Lowell Cross (Videokünstler, bei Bandoneon verantwortlich für die Visuals: http://www.lowellcross.com/home/) beschreibt. Bei einem Besuch in Tudors Haus verweigert dieser Cross den Zutritt zu seinem Zimmer und Cross vermutet, dass er Schriften von Madame Blavatsky, 1875 Begründerin der Theosophischen Gesellschaft, vor ihm verbergen will. Vgl. Lowell Cross, Remembering David Tudor: A $75^{\text {th }}$ Anniversary Memoir, 2001, online unter: http://www.fzmw.de/2001/2001T1.pdf, beide zuletzt aufgerufen am 01.02.2012. 
hen. In Bandoneon erklingen elektromagnetische Wellen als Nachweis einer höheren, integrierenden Ordnung, an der Mensch und Technik gleichermaßen partizipieren.

\section{Subjekte als Akteur-Agenten}

Der Künstler reflektiert auch über das Subjekt, das in diesem performativierten Raum erzeugt wird, in dem die Ausführung von Handlungen selbst eine iterative, transformierende und kreative Kraft hat. Wie der menschliche Performer in dieser Unvorhersehbarkeit und Unbestimmtheit bestehen kann, beschreibt David Tudor: „If you put yourself in a situation of unpredictability and then find that it's completely possible to accept it, then you become an observer. “43 Dass dieser Beobachter aber zugleich Versatzstücke eines intentional handelnden Subjektes aufweist, zeigt sich, wenn Tudor bemerkt: „And that's when it occurs to me, it's I who have done that [...]. I have given life to this configuration. ${ }^{“ 44}$ Es entsteht also, so lässt sich interpretieren, ein Subjekt in der Funktion eines Beobachters zweiter Ordnung, der sich als integraler Bestandteil des Feedback-Systems von Steuerung und Kontrolle selbst beim Handeln zuschaut. ${ }^{45}$ Es kommt derart zu einer prekären Konstitution, in der das Subjekt Handlungsmacht hat und doch nur beobachten kann. Das Subjekt wird, so ließe sich zuspitzen, im performativen Übertragungs- und Steuerungsraum ein Agent der technischen Dinge, der in fremdem Auftrag handelt und doch zugleich diese Dinge erst der Eigenkomposition zuführt.

Um die entfesselte technische Welt zu bewältigen, aus der der menschliche Agent sich auf Grund der elektrischen Verkopplung nicht zurückziehen kann, wird Performativität zum bloßen Aus- und Aufführen von Dingen umgedeutet und erhält darin selbst Handlungsmacht. Performativität ist mithin nichts anderes als die Operativität eines entfesselten Netzwerkes von unterschiedlichen Agenten, eine Entfesselung von Performativität im bloßen Agieren und Operieren. Es kommt zu einer technischen Sinnverschiebung: Existenz selbst wird zur Performance eines medienökologischen Seins.

43 Teddy Hultberg, „I smile when the sound is singing through the space“. An Interview with David Tudor by Teddy Hultberg in Dusseldorf, May 17/18 1988, online unter: http://david tudor.org/Articles/hultberg.html, zuletzt aufgerufen am 06.08.2013.

44 Ebd.

45 Vgl. zur Bedeutung von Kontrolle und Subjektivität bei Tudor auch: Julia Kursell, „Immanenzebene: Zur elektronischen Musik von David Tudor“, in: Daniel Gethmann (Hg.), Klangmaschinen zwischen Experiment und Medientechnik, Bielefeld, 2010, S. 231-248. 
2000.

Klaus Obermaiers virtuelle Bühnen mit menschlichen Versatzstücken

Klaus Obermaier ${ }^{46}$ soll abschließend als Beispiel herangezogen werden für einen vom Computer generierten und auf die Bühne projizierten Bühnenraum, in dem die Visionen von Craig, nämlich die Erzeugung künstlicher Welten aus invarianten Symbolen nach den Maßgaben einer formalen Logik, eine Erfüllung erlangen. Obermaier löst das ein, was Craig einst vorschwebte, technisch aber nicht umsetzbar war. Bei Obermaier werden allerdings, anders als bei Craig, die Körper der Akteure in den virtuellen, mit symbolischen Operationen erzeugten Raum integriert. Denn Obermaier setzt diese in unterschiedlicher Weise für Projektionen ein, die ungeahnte, virtuelle Variationen des menschlichen Körpers entstehen lassen, statt ihn von der Bühne zu verbannen.

Die Verwendung von Körper und Raum als Bestandteile und Medien der Projektion kann z. B. wie in Apparition (2004) ${ }^{47}$ aus der Interaktion mit ihr bestehen. Eine radikalere Version der Beziehung entsteht, wenn die datentechnisch erzeugten Bilder direkt auf die Körper der Performer projiziert werden, sie diese gleichsam mit ihren Körpern animieren und dabei untrennbar mit ihnen verschmelzen. Das Eine könnte ohne das Andere nicht sein. Während in D.A.V.E (1999) ${ }^{48}$ die Körper der Tänzer immer als Projektionsoberfläche sichtbar sind, durch diese aber erweitert werden, verschwimmen in Vivisector $(2000)^{49}$ Körper und Projektion, so dass sie nicht mehr unterscheidbar sind.

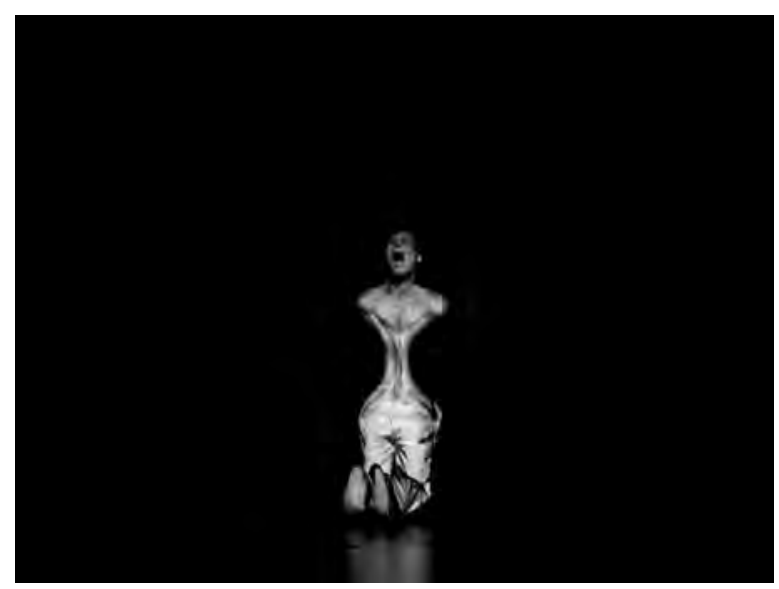

1 - Klaus Obermaier, D.A.V.E., 1998

\footnotetext{
46 Vgl. http://www.exile.at/ko/, zuletzt aufgerufen am 02.02.2012.

47 Vgl. http://www.exile.at/apparition/, zuletzt aufgerufen am 02.02.2012.

48 Vgl. http://www.exile.at/dave/, zuletzt aufgerufen am 02.02.2012.

49 Vgl. http://www.exile.at/vivisector/, zuletzt aufgerufen am 02.02.2012.
} 


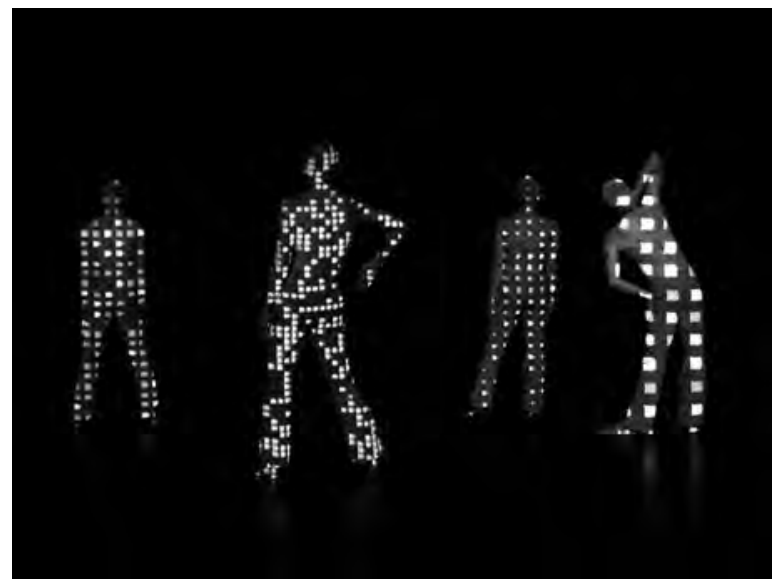

2 - Klaus Obermaier, Vivisector, 2000

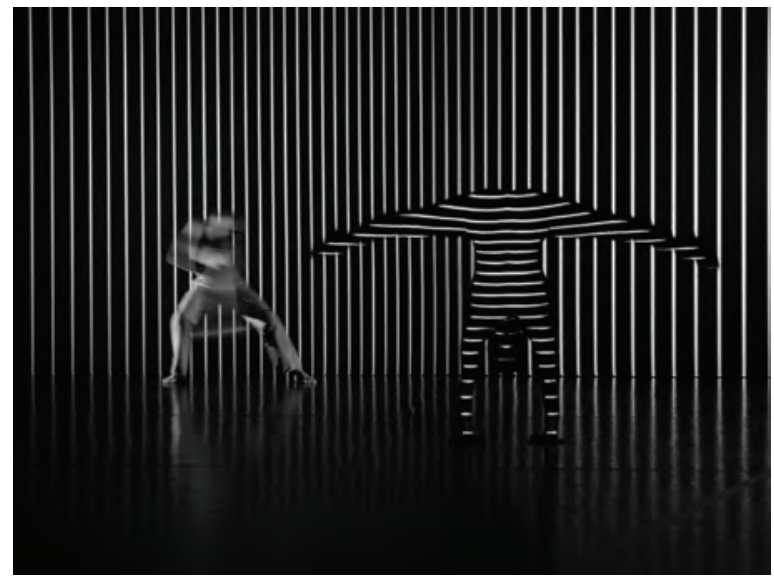

3 - Klaus Obermaier, Apparation, 2004

\section{Sacre du Printemps}

Während in den genannten Projekten der virtuelle Raum in den physikalischen übersetzt wird und mit diesem verschmilzt, entsteht in der Produktion Sacre du Printemps (2006) $)^{50}$ ein anderes Format der Projektion sowie der Bezugnahme von Körper und Technik. In Sacre wird nicht mehr auf den Körper projiziert, sondern vielmehr der Körper der Tänzerin in virtueller Form in die Projektion integriert. Zugleich bleibt der Körper der Tänzerin ohne technische Überformung ausgestellt, denn sie agiert auf einer kleinen Bühne, während die

50 Vgl. http://www.exile.at/sacre/, zuletzt aufgerufen am 01.02.2012. 
Integration der Tänzerin auf einer überdimensionalen Projektionsfläche in Gestalt eines Datenkörpers sichtbar wird. Es entsteht also eine zweifache Räumlichkeit, bestehend aus einem Daten- und einem physikalischen Raum. Datenkörper und errechnete Welt können nun nach Belieben gestaltet werden, wie Irene Judmayer beschreibt:

Blutrote Farbschlieren beginnen einen rasenden Tanz. Umschlingen eine Frau, deren Gliedmaßen seltsam verzerrt wirken. Wie Spinnenarme greift es über unsere Häupter hinweg. Wie im Spiegelkabinett multiplizieren sich Beine und Arme. Bälle aus Körpern schießen durch den Raum. Lichtpunkte explodieren. Wie ein elastisches Drahtgeflecht wölbt sich ein Raster ins Publikum. ${ }^{51}$

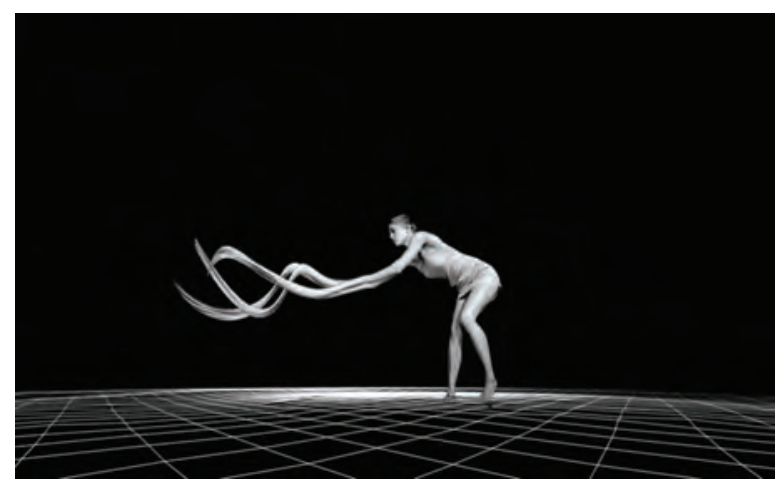

4 - Klaus Obermaier, Sacre du Printemps, 2006

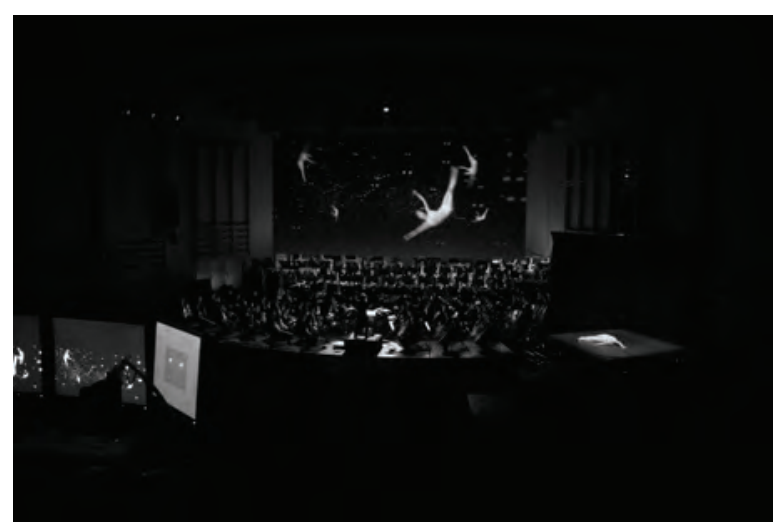

5 - Klaus Obermaier, Sacre du Printemps, 2006

51 Irene Judmayer, „Jubelstürme im Brucknerhaus“, in: Oberösterreichische Nachrichten vom 12.09.2006, online unter: http://www.exile.at/sacre/reviews_de.html, zuletzt aufgerufen am 01.02.2012. 
Klaus Obermaier formuliert, worum es ihm geht:

Heute, [...] stellt sich die Frage nach Authentizität des Erlebens aufgrund stetig fortschreitender Virtualisierung unserer Lebensräume. Es ist die Auflösung unserer sinnlichen Wahrnehmung, des Raum-Zeit-Kontinuums, die sich verwischende Trennlinie zwischen real und virtuell, Fakt und Fake, die uns an die Grenzen unserer Existenz führt. ${ }^{52}$

Im Setting von Sacre wird, so ließe sich Obermaiers Überlegung deuten, die Funktion des menschlichen Akteurs in virtuellen Räumen und virtueller Existenz entworfen. Die Tänzerin wird dabei exemplarisch zur Datengeberin der Projektion, die im Computer errechnet wird. Zugleich aber wird sie als leibliche Existenz ausgeschlossen und tendenziell irrelevant. Denn der Bezugsrahmen der Steuerung, und das ist die entscheidende Modifikation dieser Performance im Vergleich zu anderen interaktiven Bühnensettings, wird da aus dem physikalischen Raum in den Virtuellen verlegt, wo die Tänzerin ihr Bild im virtuellen Raum steuert und nicht mehr auf ihren Tanz konzentriert ist. Tanz ist damit deutlich sichtbar Grundlage der Verrechnung in Bilder oder Sound und wird nicht mehr, wie bisher, als Interaktion von Performance und Computer inszeniert. In Sacre werden der tanzende Leib und der physikalische Raum somit zum Anhängsel, auf die die Zuschauer wenig achten und die sie ob der 3-D-Brillen, die sie tragen, um Datenkörper und Datenraum in der Projektion in der dreidimensionalen Illusion sehen zu können, kaum erkennen können. Es kommt derart zu einer Performativierung des Raums, in der der Datenraum die Performance hervorbringt und kontrolliert. Anders als bei Craig wird der menschliche Akteur so nicht vertrieben, sondern - radikaler noch - zum Anhängsel der Präsentationen. Im theatral-kinematografischen Modell von Körper und Raum wird in Sacre das Modell Mensch mithin von den computergenerierten Welten vereinnahmt. Theater und Bühnenraum sind in Animationen, d. h. in eine operativ-performative Räumlichkeit aufgelöst. Klaus Obermaier beschreibt die spirituelle Dimension dieses Animationstheaters:

Das Eintauchen der ,Auserwählten` in Virtualität, ihre Verschmelzung mit Musik und Raum, als zeitgemäßes ,Opfer‘ für das ungewisse Neue, als Metapher der Erlösung und Vorwegnahme des ewigen Glücks, das uns neue Technologien und alte Religionen versprechen. Oder zumindest als neue Dimension der Wahrnehmung. 53

Um 2000 wird Existenz also als virtueller Raum inszeniert, in dem der menschliche Akteur unter dem Versprechen einer Erweiterung von Wahrnehmung und Erkenntnis zum Anhängsel an computergenerierte Welten wird.

\footnotetext{
52 Klaus Obermaier and Ars Electronica Futurelab, „Le Sacre du Printemps. Igor Stravinsky“, online unter: http://www.exile.at/sacre/project_de.html, zuletzt aufgerufen am 01.02.2012.

53 Ebd.
} 
Resümee. Beiträge zur Theoriedebatte um den spatial turn

\section{Performative Räume als Dispositiv}

Die Untersuchungen zur Konstitution des Bühnenraums in den angeführten Beispielen sollen abschließend im Hinblick auf ihren Beitrag zur theoretischen Erfassung von Raum ausgewertet werden. Mit dem spatial turn ist seit den 1980er/1990er Jahren Raum als performativ gemachter in den Fokus gerückt und der Vorstellung, Raum sei eine fixe Materialität, sehr zu Recht eine Absage erteilt worden. ${ }^{54}$ Gleichwohl ist die Materialität des Raums nicht schlicht verschwunden, wie in manchen Ausprägungen der aktuellen Raumtheorie nahegelegt wird, und in der theoretischen Erfassung zu vernachlässigen. Eine Vernachlässigung wäre vielmehr problematisch, da sich mit der Materialität des Raums Macht einschreibt und die Berücksichtigung des Gebauten deshalb Grundlage der Analytik von Herrschaft ist. ${ }^{55}$

Auf den Bühnen und in den Bühnenräumen (als Ensemble von Bühnenund Zuschauerraum zur Blick- und Subjekterzeugung), die hier behandelt wurden, entsteht vielmehr durchaus eine materielle Räumlichkeit. So wird bei Edward Gordon Craig Raum zu einer Ordnung von sich beständig in Bewegung befindenden Symbolträgern, die seiner dispositiven Operativität entspricht. Der Betrachter sieht sich in dieser einem beständigen Wandel ausgesetzt sowie zu einer logischen Lektüre aufgefordert, die ihm eine Verortung erlauben und diese zugleich in ein Diktum der beständigen Transformation auflösen. Der Bühnenraum ist mithin Medium in dem Sinne, dass er Wahrnehmung und Subjektivität konfiguriert.

Dass Raum sich zugleich aus Medialität konstituiert, Medium Raum wird, zeigt sich bei Klaus Obermaiers Sacre. Hier wurde der Aufführungsraum in unterschiedliche Räumlichkeiten und Orte aufgeteilt, etwa in den Raum des Orchesters, die Projektionsfläche der errechneten virtuellen Welt, die kleine Bühne der Tänzerin sowie die Sitzreihen der Zuschauer. Das heißt, Raum wird zum einem Relationsgefüge, das Wahrnehmung durch sein Setting sowie durch die in ihm stattfindenden, Aufmerksamkeit regulierenden Aktionen lenkt. Zugleich aber ist dieser Raum mit einer Wahrnehmungshilfe zu betrachten, denn die dreidimensionale Illusion der Projektionen stellt sich nur durch das Tragen einer entsprechenden Brille ein. Diese doppelte Konstitution des

54 Vgl. zur Diskussion um die Materialität des Raums: Jörg Dünne, Forschungsüberblick „Raumtheorie“, 2004, online unter: http://www.raumtheorie.Imu.de/Forschungsbericht4.pdf, zuletzt aufgerufen am 01.02.2012; Jörg Döring/Tristan Thielmann, „Einleitung: Was lesen wir im Raume? Der Spatial Turn und das geheime Wissen der Geographen“, in: dies. (Hg.), Spatial Turn: Das Raumparadigma in den Kultur- und Sozialwissenschaften, Bielefeld, 2008. S. 7-47.

55 Raum in seiner Materialität zu beachten heißt allerdings zugleich nicht, dass nicht berücksichtigt würde, dass und wie Raum erst im Umgang mit einem Gegebenen sowie auf der Grundlage einer sich mit medientechnischen und wissensgeschichtlichen Bedingungen verändernden Wahrnehmung entsteht. 
Raums, bestehend aus räumlichem Arrangement und Betrachtungsgestell, ist für die theoretische Erfassung von Raum nun von besonderem Interesse. Denn Raum ist hier in seiner physikalischen Materialität anwesend und zugleich ist er nur durch eine mediale Vermittlung, die medial gestützte oder aber historisch gebildete Wahrnehmung der Zuschauer. Mit dieser Konstitution des Raums in der medial gestützten Wahrnehmung in Sacre treten realer und virtueller Raum nicht länger in Konkurrenz oder lösen einander $a b .{ }^{56}$ Sie stehen vielmehr als Möglichkeiten nebeneinander. Diese Positionierung entsteht durch den Körper der Tänzerin, der nur bedingt verrechnet werden kann und somit als Bezugsfolie für Grenzen und Überschreitungen zwischen Realem und Virtuellem steht. Der Beitrag von Sacre zu Raumdiskussion ist, dass der historisch gewordene und medial gestützte Zustand der Wahrnehmung zur Bedingung der Möglichkeiten von Raum wird.

In den 9 Evenings zeigte sich schließlich, dass Raum vor allem ein Imaginäres ist. Denn in das Armory, die riesige Militärhalle als Aufführungsort, in dem Positionen für Zuschauer und Akteure erst erzeugt werden mussten und die für jede Performance unterschiedlich waren, wurde eine imaginäre Welt hineingezaubert. Der signalleitende Raum wurde dabei zum Zeichen einer höheren Ordnung und mit Metaphern überschrieben, die zugleich körperlichen Erfahrungen entsprachen, etwa der psychedelische Nachhall sowie die Qualität der Klänge in Tudors Bandoneon. Effekt der Überschreibung war die Erzeugung eines imaginären, elektromagnetisch gefüllten Raums, in dem unterschiedliche Akteure gemeinsam schwingen und ineinander übersetzbar sein sollten. Derart entstand ein imaginärer Raum durch die Performances seiner menschlichen und technischen Bewohner, der gleichwohl materiell wurde und auf Körper und Subjektbildung wirkte. Dieses Imaginäre wurde allerdings nur erkannt durch eine wissens- und technikgeschichtliche Rekonstruktion. Daraus folgt als systematisches Merkmal für eine theoretische Erfassung von Raum zum einen, dass der imaginäre Raum abhängig ist von der Historizität von Wissen sowie von Wahrnehmung. Zum anderen wird deutlich, dass Dispositive imaginär sind, was auch gelten dürfte, wenn anders als in Bandoneon z. B. eine physische Konstruktion etwa von Sichtbarkeit und Blickerzwingung vorliegt.

Die Beiträge des Theaters zur Raumtheorie seien zusammengefasst. Es wird erstens deutlich, dass Raum, auch wenn er erst in kulturellen Handlungen und Vollzügen entsteht, gleichwohl in seiner Materialität, und sei es eine imaginäre, inszenatorisch erzeugte, ein Dispositiv ist. Es zeigte sich zweitens, dass die Materialität von Medialität überlagert, flankiert oder transformiert werden kann. Raum ist immer eine Vielheit von Möglichkeiten, die untrennbar mit den medialen Bedingungen der Möglichkeiten verbunden sind.

56 Vgl. zum gängigen Dualismus von Real Virtuality und Virtual Reality: Döring/Thielmann (2008), Einleitung, S. 28-32. 


\section{Performativierung des Raums als Faszinationsgeschichte}

Schließlich sollte anhand der Beispiele deutlich geworden sein, dass eine positive Bewertung des spatial turn, der ein performative turn ist, als Befreiung der Existenz in Bewegtheit und Bewegung, nicht unbesehen vorgenommen werden sollte. Denn die wissens- und technikgeschichtliche Rekonstruktion zeigte, dass die Performativierung in einer Faszinationsgeschichte der Vermittlung mit entfesselten technischen Welten situiert ist, die die Unvermittelbarkeit ausblendet und schließlich in einer Vision geteilter Agentenschaft auffängt.

Theater könnte also bezogen auf Diskurs und Praxis der Performativierung des Raums als eine kulturelle Instanz rekonstruiert werden, mit entfesselter Technik umzugehen, indem Raum performativiert und der menschliche Agent in ein Netzwerk mit ihm verwoben oder - wie bei Obermaier - von diesem vereinnahmt und als Datengeber neu erfunden wird. Es geht damit bei der Performativierung des Raums zugleich um das Ende eines instrumentellen, kommunikativen und interaktiven Modells von Mensch und Technik. An dessen Stelle tritt nun zum einen eine mediale Existenz in einem elektrischen Animismus, wie sie in den Tuchtänzen von Loïe Fuller oder den 9 Evenings entworfen wird. Auf der anderen Seite kommt es zur Generierung künstlicher Welten, die den Menschen nicht mehr zwingend als Vorbild oder als Steuerelement brauchen, sondern vielmehr einer eigenen Logik folgen.

Die zeitgenössische Performativierung des Raums wissens- und technikgeschichtlich als Faszinationsgeschichte einer unmöglichen Vermittlung zu rekonstruieren, heißt zugleich, ihr auf die Schliche zu kommen. Ihre Fluchtlinie ist nämlich seit 1900 eine Verabschiedung des menschlichen Akteurs von der Bühne und die Übernahme von dessen Position durch universelle symbolische Operationen. Aus dieser Sicht ist zeitgenössisches Theater mit computergenerierten Räumen nur eine folgerichtige, aber wissensgeschichtlich betrachtet keine neuartige Entwicklung. Die Besinnung von Theater auf Raum als seine Performativierung entspricht somit dem Abschied vom menschlichen Akteur. An seine Stelle treten sich selbst organisierende künstliche Welten. In der Faszinationsgeschichte entfesselter technischer Dinge wird derart nobilitiert und teilweise maskiert, dass der Mensch als handlungsmächtiges Subjekt in den Ding-Welten technisch und epistemologisch nur noch einen virtuellen, oder auch gar keinen Platz mehr einnehmen kann und muss. Denn, so ließe es sich zuspitzen, bei der Performativierung des Raums handelt es sich um einen Maschinendiskurs, der auf der Abschaffung des Menschen aus dem Bühnenraum und seine Besetzung mit Geistern und invarianten Symbolen gründet und diese in Performances gutheißt. Vor diesem Hintergrund erhält die Verabschiedung der Materialität des Dispositivs im aktuellen Raumdiskurs eine pointierte Relevanz. Sie scheint der Durchsetzung künstlicher, selbst organisierter Welten noch Vorschub zu leisten. 
Wird diese Faszinationsgeschichte nicht beachtet, dann kann eine Anthropologie entwickelt werden, die ihre Konstitution in Maschinendiskursen oder unbewussten Bindungen an Technik nicht erkennt und sich in diesen unreflektiert verliert. Dieses Ergebnis gründet nicht auf der Idee, es gäbe ein unwandelbares Anthropologisches. „Mensch“ ist Teil seiner technischen Umwelt, in der er sich allerdings nicht allein aus Technik, sondern ebenso aus diskursiven und dispositiven Selbstbeschreibungen konstituiert. Es ist wichtig, in diese Einblick zu erhalten, deren Genese und Wirkungen zu erkennen und sie gerade im Übergang zu einer medienökonomischen Existenz ${ }^{57}$ mit entfesselten technischen Dingen und Räumen diskurskritisch zu betrachten. ${ }^{58}$

\section{Literatur}

Bahr, Petra, Loïe Fuller. Grenzgängerin des Tanzästhetischen, 1999, online unter: http://www.theomag.de/02/pb1.htm, zuletzt aufgerufen am 31.01.2012.

Bardiot, Clarisse, 9 Evenings. Theatre and Engineering, online unter: http://www.fonda tion-langlois.org/html/e/page.php?NumPage=572, zuletzt aufgerufen am 01.02.2012.

de Certeau, Michel, „Pratiques d’espace“, in: ders., L'invention du quotidien, Paris, 1990, S. 139-191.

Craig, Edward Gordon, Über die kunst des theaters, Berlin, 1969.

Cross, Lowell, Remembering David Tudor: A $75^{\text {th }}$ Anniversary Memoir, 2001, online unter: http://www.fzmw.de/2001/2001T1.pdf, zuletzt aufgerufen am 01.02.2012.

Döring, Jörg/Thielmann, Tristan (Hg.), Spatial Turn: Das Raumparadigma in den Kultur- und Sozialwissenschaften, Bielefeld, 2008.

Dies., „Einleitung: Was lesen wir im Raume? Der Spatial Turn und das geheime Wissen der Geographen“, in: dies. (Hg.), Spatial Turn: Das Raumparadigma in den Kultur- und Sozialwissenschaften, Bielefeld, 2008. S. 7-47.

Dünne, Jörg, Die kartographische Imagination. Erinnern, Erzählen und Fingieren in der Frühen Neuzeit, München, 2011.

Ders., Forschungsüberblick „Raumtheorie“, 2004, online unter: http://www.raumtheo rie.lmu.de/Forschungsbericht4.pdf, zuletzt aufgerufen am 01.02.2012.

Ders., „Geschichten im Raum und Raumgeschichte, Topologie und Topographie“, online unter: http://www.uni-potsdam.de/romanistik/ette/buschmann/dynraum/pdfs/dy namisierte_raeume_komplett.pdf, zuletzt aufgerufen am 26.01.2012.

Ders./Friedrich, Sabine/Kramer, Kirsten (Hg.), Theatralität und Räumlichkeit: Raumordnungen und Raumpraktiken im theatralen Mediendispositiv, Würzburg, 2009.

57 Siehe zur medienökonomischen Existenz: Erich Hörl, „Die technologische Bedingung. Zur Einführung“, in: ders. (Hg.), Die technologische Bedingung - Beiträge zur Beschreibung der technischen Welt, Frankfurt/M., 2011, S. 7-53.

58 Vgl. zur Lage des Subjektes im Diskurs entfesselter technischer Dinge: Alexander Firyn/ Alexander Klüppel/Martina Leeker/Joachim Schlömer - mit Festspielhaus St. Pölten (Hg.), Entfesselte technische Objekte. Mensch - Kunst - Technik 2010, online unter: http://entfes selt.kaleidoskopien.de/, zuletzt aufgerufen am 01.02.2012. 
Fiebach, Joachim, Von Craig bis Brecht. Studien von Künstlertheorien des 20. Jahrhunderts, Berlin, 1975.

Firyn, Alexander, Theaterpoesie und Mathematik, unveröffentlichte Magisterarbeit, FU Berlin, Institut für Theaterwissenschaft, o.J.

Ders./Klüppel, Alexander/Leeker, Martina/Schlömer, Joachim - mit Festspielhaus St. Pölten (Hg.), Entfesselte technische Objekte. Mensch - Kunst - Technik 2010, online unter: http://entfesselt.kaleidoskopien.de/, zuletzt aufgerufen am 01.02.2012.

Fischer-Lichte, Erika, Ästhetik des Performativen, Frankfurt/M., 2004.

Dies., „Auf dem Wege zu einer performativen Kultur“, in: dies./Doris Kolesch (Hg.), Kulturen des Performativen, Paragrana 7, 1 (1998), S. 13-29.

Dies./Wulf, Christoph, (Hg.), Theorien des Performativen, Paragrana 10, 1 (2001).

Foucault, Michel, Überwachen und Strafen. Die Geburt des Gefängnisses, Frankfurt/M., 1994.

Fuller, Loïe, Fifteen Years of a Dancer's Life, Boston, 1913, reprint: New York, NY, 1977.

Dies., Lectures on Radium, online unter: http://digitalgallery.nypl.org/nypldigital/dg keysearchdetail.cfm?strucID=773 359\&imageID=FUL001_001B, hier S. 21-23, zuletzt aufgerufen am 01.02.2012.

Günzel, Stephan, (Hg.), Topologie. Zur Raumbeschreibung in den Kultur- und Medienwissenschaften, Bielefeld, 2007.

Hagen, Wolfgang, Die entwendete Elektrizität. Zur medialen Genealogie des ,modernen Spiritismus', 2002, online unter: http://www.whagen.de/publications/Entwende teElektrizitaet/26Hagen.htm, zuletzt aufgerufen am 01.02.2012.

Hagen, Wolfgang, „Loïe Fuller. The Shock of Electricity and the Technological History of Modern Dance or the Overwhelmingness of Technology and the Possibilities of Art“, in: Söke Dinkla/Martina Leeker (Hg.), Tanz und Technologie. Auf dem Weg zu medialen Inszenierungen, Berlin, 2002, S. 118-131.

Ders., „Der Okkultismus der Avantgarde um 1900“, 1997, online unter: http://www. whagen.de/vortraege/OccultismAvantgarde/Okkavang.htm, zuletzt aufgerufen am 01.02.2012.

Ders./Schüttpelz, Erhard (Hg.), Trancemedien und Neue Medien um 1900. Ein anderer Blick auf die Moderne, Bielefeld, 2009.

Haß, Ulrike, Das Drama des Sehens. Auge, Blick und Bühnenform, München, 2005.

Heintz, Bettina, Die Herrschaft der Regel. Zur Grundlagengeschichte des Computers, Frankfurt/M., 1993.

Herrmann, Hans-Christian von, Das Archiv der Bühne. Eine Archäologie des Theaters und seiner Wissenschaft, München, 2005.

Herrmann, Max, „Das theatralische Raumerlebnis“ (1931), in: Jörg Dünne/Stephan Günzel (Hg.), Raumtheorie. Grundlagentexte aus Philosophie und Kulturwissenschaften, Frankfurt/M., 2006, S. 501-514.

Hilbert, David, Grundlagen der Geometrie, Leipzig, 1899, hier zit. n.: Bert Gaard, Die Rätsel der Welt. Gedanken zur Situation der Zeit, (1996/2007), online unter: http:// www.tu-harburg.de/rzt/rzt/it/sofie/welt.pdf, S. 15, zuletzt aufgerufen am 09.07.2013.

Hörl, Erich, Die heiligen Kanäle. Über die archaische Illusion der Kommunikation, Zürich, Berlin, 2005.

Ders., „Die technologische Bedingung. Zur Einführung“, in: ders. (Hg.), Die technologische Bedingung - Beiträge zur Beschreibung der technischen Welt, Frankfurt/M., 2011, S. 7-53.

Hultberg, Teddy, „I smile when the sound is singing through the space“. An Interview with David Tudor by Teddy Hultberg in Dusseldorf, May 17/18 1988, online unter: http://davidtudor.org/Articles/hultberg.html, zuletzt aufgerufen am 06.08.2013. 
Innes, Christopher, Edward Gordon Craig - A Vision of Theater, London, New York, NY, 1998.

Judmayer, Irene, „Jubelstürme im Brucknerhaus“, in: Oberösterreichische Nachrichten vom 12.09.2006, online unter: http://www.exile.at/sacre/reviews_de.html, zuletzt aufgerufen am 01.02.2012.

Kursell, Julia, „Immanenzebene: Zur elektronischen Musik von David Tudor“, in: Daniel Gethmann (Hg.), Klangmaschinen zwischen Experiment und Medientechnik, Bielefeld, 2010, S. 231-248.

Latour, Bruno, Science in Action. How to Follow Scientists and Engineers through Society, Cambridge, 1987.

Ders./Woolgar, Steve, Laboratory Life: The Social Construction of Scientific Facts, Beverly Hills, CA, 1979.

Leeker, Martina, „Camouflagen des Computers. McLuhan und die Neo-Avantgarden der 1960er Jahre“, in: Derrick de Kerckhove/dies./Kerstin Schmidt (Hg.), McLuhan neu lesen. Kritische Analysen zu Medien und Kultur im 21. Jahrhundert, Bielefeld, 2008, S. 345-375.

Dies., „Weibliche Medien um 1900. Über okkulte Herkünfte der Medienwissenschaft“, in: Hedwig Wagner (Hg.), GenderMedia Studies. Zum Denken einer neuen Disziplin, Weimar, 2008, S. 117-140.

Leonhard, William Everett, Loïe Fuller's Contributions to Stage Light, University of Texas, 1964, S. 71-73, online unter: http://etd.lib.ttu.edu/theses/available/etd06082009- 31295001113470/unrestricted/31295001113470.pdf, zuletzt aufgerufen am 31.01.2012.

Obermaier, Klaus and Ars Electronica Futurelab, „Le Sacre du Printemps. Igor Stravinsky“, online unter: http://www.exile.at/sacre/project_de.html, zuletzt aufgerufen am 01.02.2012.

Schubert, Hans-Joachim, „Analyse und Kritik aus Sicht soziologischer Handlungstheorie“, in: Analyse \& Kritik - Zeitschrift für Sozialtheorie, 30 (2008), S. 627-646, online unter: http://www.analyse-und-kritik.net/2008-2/AK_Schubert_2008.pdf, zuletzt aufgerufen am 01.02.2012.

\section{Internetquellen}

http://www.exile.at/apparition/

http://www.exile.at/concept/project.html

http://www.exile.at/dave/

http://www.exile.at/ko/

http://www.exile.at/sacre/

http://www.exile.at/vivisector/

http://www.fondation-langlois.org/flash/e/index.php?NumPage=571

http://www.fondation-langlois.org/html/e/page.php?NumPage $=572$

http://www.fondation-langlois.org/html/e/page.php?NumPage=294

http://www.fondation-langlois.org/html/e/page.php?NumPage=583

http://www.fondation-langlois.org/html/e/page.php?NumPage=611

http://www.fondation-langlois.org/html/e/page.php?NumPage $=662$

http://www.fondation-langlois.org/html/e/selection.php?Selection=9EVO

http://www.lowellcross.com/home/ 


\section{VERKABELTE BÜHNEN. SZENOGRAPHIE IM SPANNUNGSFELD ZWISCHEN THEATER UND ANDEREN MEDIEN}

\section{Raumbildungsprozesse im medialen Wandel. Einleitung}

Schon in den 1980er Jahren sagte der Medienphilosoph Vilém Flusser voraus, dass die Erfahrung des sogenannten zweiten „Medienumbruchs“ (der Wechsel von den Analog- zu den Digitalmedien sowie die globale Verbreitung von elektronischer Telekommunikation und Internet) das Denken und Wahrnehmen des Raums merklich verändern würden. Fortan sei der Mensch in einer anderen Welt zu Hause, denn ein „heiles Haus“, eine Heimstatt (im Sinne eines überschaubaren Raums leiblicher Bezugnahme) gebe es nur noch im Märchen: „Materielle und immaterielle Kabel haben es wie einen Emmentaler Käse durchlöchert: auf dem Dach die Antenne, durch die Mauer der Telefondraht, statt Fenster das Fernsehen [...]. Das heile Haus wird zur Ruine, durch deren Risse der Wind der Kommunikation bläst“ ${ }^{1}$ Um die Jahrtausendwende sind jene Veränderungen des Raumdenkens und der Raumwahrnehmungen, die Flusser vorausahnte und, noch etwas vage, als „Zeichen eines neuen Unbehaustseins“' ${ }^{\text {2 }}$ beschrieb, zum Bestandteil alltäglich-lebensweltlicher Erfahrungen geworden, die das „In-der-Welt-Sein“ des Menschen spürbar (und in noch zu wenig verstandener Weise) verändert haben. Auf die Beobachtung des medialen Wandels, mit dem eine „Raum-Wende“ einhergeht, hat die kulturwissenschaftliche Theoriebildung in den vergangenen Jahren intensiv reagiert ${ }^{3}$, aber auch die Künste - namentlich raumbildende Disziplinen wie etwa Architektur oder Installationskunst ${ }^{4}$ - erkennen darin eine Herausforderung.

Auch das Theater erkundet seit einiger Zeit Räume, die ihm eigentlich fremd sind. Im Spannungsfeld zwischen Theater und anderen Medien entwickeln Künstler experimentelle Verfahren, mit denen sie - intermedial - neue

1 Vilém Flusser, Medienkultur, 5. Aufl., Frankfurt/M., 2008 [1993], „Häuser bauen“ [1989], S. 160-163: 162.

2 Ebd.

3 Die Raumfrage hat in den Kulturwissenschaften seit einiger Zeit Konjunktur; vgl. wegweisend Mike Crang/NigelThrift (Hg.), Thinking Space, New York, NY, London, 2000; für eine Einführung in diese inzwischen inter-bzw. transdisziplinär geführte Debatte vgl. Doris Bachmann-Medick, Cultural Turns. Neuorientierungen in den Kulturwissenschaften, Reinbek b. Hamburg, 2009, darin das Kap. „Spatial Turn“, S. 284-328.

4 Vgl. dazu Topos RAUM. Die Aktualität des Raumes in den Künsten der Gegenwart, hg. v. Akademie der Künste Berlin, zusammengestellt v. Angela Lammert, Nürnberg, 2004. 
räumliche Relationen erforschen: sei es im kaleidoskopischen Zusammenspiel des Theaters mit Live-Video, TV und Film oder verschaltet mit den OnlineZonen und globalen Netzwerken des Internets. Dass Theater die Kapazität hat, andere Medien zu thematisieren bzw. gar in sich aufzunehmen: Dies ist inzwischen eine allseits akzeptierte Annahme der theaterwissenschaftlichen Intermedialitätsdiskussion. ${ }^{5}$ Darüber hinaus ist die Ausgangsbeobachtung des vorliegenden Beitrags, dass hierbei die Raumfrage - zum einen als Frage nach dem In-Erscheinung-Treten von Räumen (also nach ihrer ästhetischen Dimension) wie auch als Frage nach der sich im Horizont der neueren Medien verändernden Raumwahrnehmung (Aesthesis) - seit einiger Zeit besondere Aufmerksamkeit erfährt: Wie im Folgenden anhand eines Projekts der Künstlergruppe Rimini Protokoll gezeigt werden soll, wird sie im gegenwärtigen Theater in geradezu paradigmatischer Weise verhandelt. Eine Schlüsselfunktion kommt hierbei, wie zu zeigen sein wird, nicht nur der Regie und Dramaturgie, sondern vor allem der Szenographie zu. Welcher Erkenntnisgewinn sich ergeben kann, wenn Theater - unter den skizzierten Vorzeichen - anderen Medien eine Bühne bereitet: Dies soll anhand des Projektbeispiels diskutiert werden. Ausgegangen wird hierbei vom gegenwärtigen Stand der Intermedialitätsdebatte. Demnach ist es das Hauptmerkmal der intermedialen Bühne, dass sie vermag, andere Medien ästhetisch zu rahmen und das Publikum zu kritischer Medienreflexion anzuregen. ${ }^{6}$ Die Auseinandersetzung mit der Rimini-Protokoll-Produktion Breaking News wird darüber hinaus allerdings zeigen, dass die Erkenntnis bringende Sprengkraft und Relevanz intermedialer Konfigurationen keineswegs allein darin besteht, andere Medien in ihre bekannten, vom Publikum gewohnten Bühnenformen zu inkorporieren und zur Aufführung zu bringen. Vielmehr stellen intermediale Konfigurationen, aufgrund ihrer räumlichen Komplexität, das Theater als kulturell gewachsene Formation immer auch selbst ein Stück weit infrage. Dies geschieht beispielsweise dann, wenn man - wie im Fall des Rimini-Protokoll-Projekts - eine Theaterbühne live und „,in Echtzeit“ mit den virtuellen Räumen von Telekommunikation und Internet verschaltet: Solche Konfigurationen, die den ästhetischen Raum der Bühne medial hybrid werden lassen und gleichsam aufsprengen, ihn als Erfahrungsraum durchlöchern wie einen „Emmentaler Käse“ (Flusser), sind immer auch radikale Befragungen jener Parameter, die nach gängiger Auffassung das Medium Theater als solches konstituieren.

\footnotetext{
Vgl. v. a. Christopher Balme, „Theater zwischen den Medien: Perspektiven theaterwissenschaftlicher Intermedialitätsforschung“, in: ders./Markus Moninger (Hg.), Crossing Media. Theater - Film - Fotographie - Neue Medien, München, 2004, S. 13-31; sowie die Beiträge der Forschungsgruppe „Intermediality“ (FIRT/IFTR), v. a. den inzwischen in dritter Auflage erschienen Band Intermediality in Theatre and Performance, hg. v. Freda Chapple/Chiel Kattenbelt, Amsterdam, New York, NY, 2008, bes. die Einleitung.

6 Vgl. in diesem Sinne Kattenbelts Interpretation des Theaters als ,Bühne der Intermedialität‘: ders., „Theatre as the Stage of Intermediality“, in: Freda Chapple/ders. (Hg.), Intermediality in Theatre and Performance, Amsterdam, New York, NY, 2008, S. 29-40: 37 f.
} 
Die Frage nach dem Raum im Theater und in seiner Wissenschaft hat bekanntlich eine gewisse Tradition. Als sich die Theaterwissenschaft vor etwa hundert Jahren begründete, war es eine ihrer ersten theoretischen Setzungen, dass Theater auch und zu allererst als „Raumkunst“ zu begreifen sei. ${ }^{7}$ Als Parameter dieser „Raumkunst“ wurden differenziert: (1) die Architektur bzw. architektonische Gelegenheit, in der eine Aufführung statt hat, sowie die gewählte Bühnenform (,theatraler Raum“), (2) deren aufführungsbezogene Gestaltung (,szenischer Raum“), (3) der topologische (meist urbane) Kontext dieser Konfiguration („ortsspezifischer Raum“) und (4) der fiktive, gegebenenfalls durch ein Drama bzw. Stück thematisierte Raumentwurf („dramatischer Raum“), der sich realisiert im Spiel der Schauspieler bzw. Akteure; ; diskutiert wird zudem (5) die Erfahrungs- und Wahrnehmungsdimension des Raums, also der theatertypische Umstand, dass ästhetische Räume immer erst im Spannungsfeld zwischen dem Tun der Akteure und den Wahrnehmungsleistungen des Publikums hervortreten ${ }^{9}$ : Entlang dieser Parameter, die für die Dauer der Aufführung alle Beteiligten in einer aufeinander bezogenen, kommunikativen „Hier und Jetzt“-Konstellation verankern, definiert man heute die „spezifische Medialität“ des Theaters. ${ }^{10}$

Wie der vorliegende Beitrag zeigen will, leisten intermediale Konfigurationen demgegenüber spielerische Befragungen der genannten Parameter: Indem sie die Theaterbühne mit anderen medialen Dispositiven konfrontieren und ihre gewohnte Wahrnehmung als Präsenzfeld durchkreuzen, öffnen sie den theatralen Raum, wie man ihn bisher kannte, einer Auseinandersetzung mit experimentellen Raumbildungsprozessen. Inwiefern - so soll nun im Folgenden anhand des angekündigten Fallbeispiels überlegt werden - geht es hier um eine Revision der „Raumkunst“ Theater (oder vielleicht sogar um einen Paradigmenwechsel)? Mit anderen Worten: Inwiefern lassen sich solche Experimente als Versuch deuten, jener sich gegenwärtig abzeichnenden „Raum-Wende“,

7 „Bühnenkunst ist Raumkunst“, so die bekannte Formel, die Max Herrmann in seinem Aufsatz, „Das theatralische Raumerlebnis“ (1931) wegweisend formulierte, zit. n.: Jörg Dünne/ Stephan Günzel (Hg.), Raumtheorie. Grundlagentexte aus Philosophie und Kulturwissenschaften, Frankfurt/M., 2006, S. 501-513: 501.

8 Vgl. Christopher Balme, Einführung in die Theaterwissenschaft, Berlin, 2008, Kap. „Raum“, S. 141-153: 142.

9 Der Raum des Theaters, wie Jens Roselt betont hat, ist insofern immer „sowohl Voraussetzung für Aufführungen als auch Produkt theatraler Vorgänge“. Ders., „Raum“, in: Erika Fischer-Lichte/Doris Kolesch/Matthias Warstat (Hg.), Metzler Lexikon Theatertheorie, Stuttgart, Weimar, 2005, S. 260-267: 260.

10 Bezüglich dieser Formel besteht heute im Fach ein weitgehender, wenn auch nicht vollständiger Konsens, vgl. „Vom Nutzen und Nachteil des Medienbegriffs für das Theater und die Theaterwissenschaft“ (Podiumsdiskussion im Rahmen des 8. Kongresses der Gesellschaft für Theaterwissenschaft; Teilnehmer: Christopher Balme, Ulrike Haß, Chiel Kattenbelt u. a.), in: Henri Schoenmakers/Stefan Bläske/Kay Kirchmann/Jens Ruchatz (Hg.), Theater und Medien / Theatre and the Media. Grundlagen - Analysen - Perspektiven. Eine Bestandsaufnahme, Bielefeld, 2008, S. 545-560. 
die Flusser fast visionär als condition humaine einer „neuen Unbehaustheit“ beschrieb, künstlerisch Rechnung zu tragen ${ }^{11}$

\section{Der zersprungene Raum.}

Theaterbühnen im Horizont anderer Medien - am Beispiel des Rimini Protokoll-Projekts „Breaking News - Ein Tagesschauspiel“

Im Jahr 2008 produzierten die beiden Rimini Protokoll-Künstler Daniel Wetzel und Helgard Haug ein Stück, das sich die Nachrichtenberichterstattung im Fernsehen und verwandten Medien zum Gegenstand machte..$^{12}$ Das Projekt, so der Ankündigungstext, war darauf angelegt, die Theaterbühne - genauer: den Theaterguckkasten, die altbekannte „schäbige Illusionskiste“ - vorübergehend in eine Art „Lochkamera“ zu verwandeln ${ }^{13}$ : Zielsetzung war es, von der Bühne aus live die Mechanismen, Verflechtungen und auch Widersprüchlichkeiten des mit technischen Mitteln heute global vernetzten Nachrichtengeschehens zu erkunden. Um dieses Konzept zu realisieren, waren erkennbare Eingriffe in den Theaterraum nötig: Im Vorfeld der Aufführung installierte man auf dem Dach des Theaters vier große Satellitenschüsseln, Unmengen von Kabeln wurden verlegt und am Abend flimmerten unzählige Monitore auf der Bühne. Auf einmal gab es im Theater Fernsehsendungen aus aller Welt zu sehen: LiveNachrichten von BBC, CNN oder Al Jazeera, des Pentagon-Channel, des indischen Senders Rayat TV oder des südamerikanischen TeleSUR. Übertragungen von etwa zweitausend TV-Stationen konnten empfangen werden, und auf der Bühne hatte ein Team von insgesamt acht Akteuren (wie bei Rimini Protokoll üblich waren es keine Schauspieler, sondern für die Produktion eigens ausgewählte „Experten“) die Aufgabe übernommen, aus der Flut der eingehenden Nachrichten - live und jeden Abend anders - eine Auswahl zu treffen und für das Publikum aufzubereiten. Die vier Journalisten, darunter der ehemalige ARD-Afrika-Korrespondent Hans Hübner und der Medienkritiker Walter van Rossum, zudem drei Dolmetscher sowie eine Cutterin agierten gleichsam als Selbstdarsteller und Vertreter ihrer jeweiligen Profession: Ausgestattet mit Headsets, übersetzten, moderierten und kommentierten sie die auf

11 Experimentelle Raumbildungsprozesse, wie sie sich vermehrt etwa seit der Jahrtausendwende im Spannungsfeld zwischen dem Theater und anderen Medien (digitale audiovisuelle Medien, Telekommunikation, Internet) abzeichnen, sind auch der Gegenstand des DFG-geförderten Forschungsprojekts „Intermediale Szenographie. Raumästhetiken des Theaters am Beginn des 21. Jahrhunderts“ (Konzeption und Durchführung: Birgit Wiens), das seit 2010 am Institut für Theaterwissenschaft der Universität München realisiert wird; der vorliegende Beitrag gibt einen Einblick in die Fragestellungen des Projekts und seinen Forschungsansatz (Publikation der Studie voraussichtlich 2013).

12 Die folgende Projektbeschreibung bezieht sich auf einen Aufführungsbesuch am Berliner Hebbel-Theater (HAU 2).

13 Zit. n.: Programmflyer zur Aufführung; s. a. den Pressetext zum Projekt unter www.riminiprotokoll.de. 
den Monitoren eingespielten Nachrichten. Provisorisch könnte man sagen, dass die Theaterbühne, für die Dauer der jeweiligen Aufführung, auf diese Weise zu einer Art Knotenpunkt des internationalen, über die globalen Netze distribuierten Nachrichtengeschehens wurde: Ein virtuelles Geschehen, das man auf der Bühne in seiner Vielstimmigkeit aufscheinen ließ. Mit künstlerischen Mitteln, so die erklärte Absicht, sollte dieses (sich in seiner Virtualität und Komplexität jeder Darstellung eigentlich entziehende) Geschehen gleichsam gerahmt und in einigen Aspekten ausgestellt werden, um - im Sinne eines Perspektivwechsels -das Publikum zu einer kritischen Betrachtung des alltäglichen „Tagesschauspiels“ zu animieren.
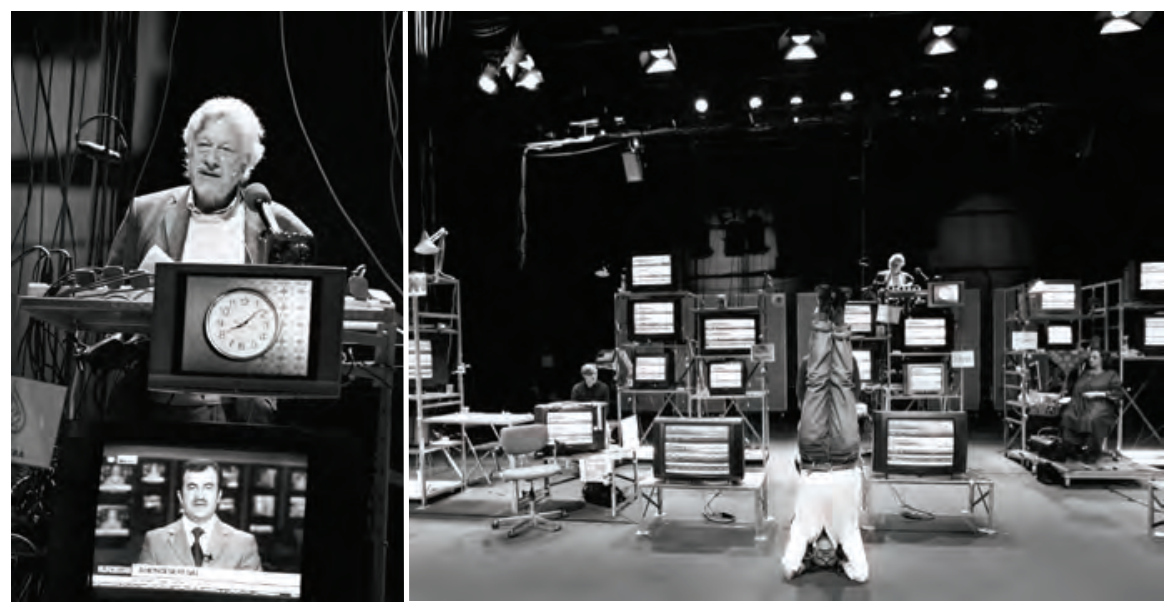

1 und 2 - Szenen aus Rimini Protokoll: Breaking News (2008) mit Hans Hübner (links) und Walter van Rossum

Wie gut dies gelang - darüber gingen die Meinungen übrigens auseinander. Eine Kritik, die in Aufführungsbesprechungen mehrfach zu lesen war, gab zu bedenken, ob der hohe technische Aufwand denn auch tatsächlich in angemessener Relation zum künstlerischen Ergebnis stünde. ${ }^{14}$ Die großen Satellitenschüsseln, die einen ungewohnten Eingriff in die Architektur des Theaters darstellten, signalisierten dem Publikum jedenfalls schon vor dem Betreten des Theatergebäudes, dass man es gleich mit einem Theatervorgang zu tun bekommen würde, der sich von konventionellen Aufführungen unterscheidet. Die Gestaltung der Bühne, im Innern des Gebäudes, bezog sich dann - zumindest auf den ersten Blick - auf Mittel, die man bereits seit einiger Zeit aus einer dem Experiment verpflichteten szenographischen Praxis her kennt: Gearbeitet wurde mit dem Prinzip der multiplen Monitore und pluralen Rahmun-

14 Vgl. z. B. Peter Hans Göpfert, „Unser tägliches Leben mit der Tagesschau“, in: Berliner Morgenpost vom 07.01.2008. 
gen, also mit jener „Windows-Ästhetik“, die seit den 1980er Jahren zu einem der Hauptmerkmale des postdramatischen Theaters avancierte. Im Sinne einer (in vergleichbarer Weise im Theater freilich schon oft geübten) Kritik an den elektronischen Medien, ihren Spektakeln und Simulationen, riefen die flimmernden Monitore - frontal auf das Publikum ausgerichtet und doch unübersichtlich - Irritationen hervor und forderten auf zu kritischer Wahrnehmung und Distanznahme.

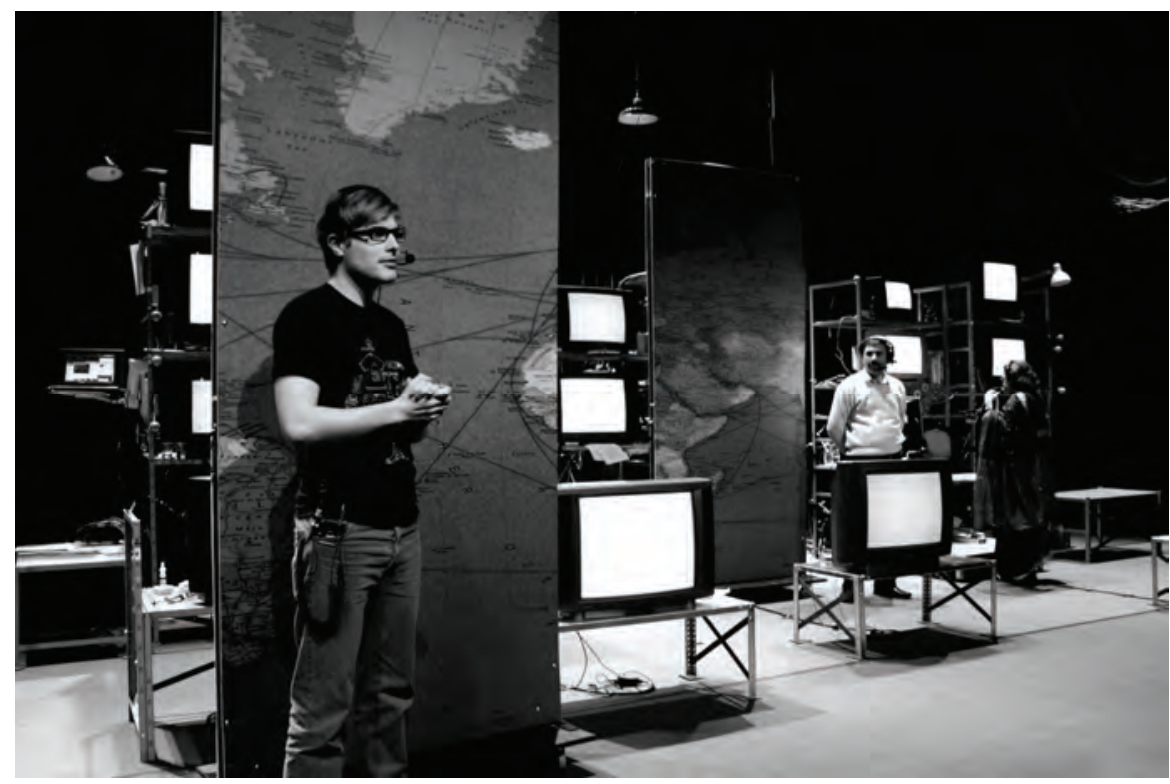

3 - Szene aus Breaking News, mit Simon Birgisson

Über jene bekannten Distanzierungsgesten gegenüber den Medienbildern hinaus ließ Rimini Protokolls „Tagesschauspiel“ aber auch noch etwas anderes gewahr werden. Indem den ganzen Abend geradezu notorisch gefragt wurde, welche Nachricht von wo aus und von wem gesendet wird, was eigentlich gezeigt oder aber nicht gezeigt wird („Afrika kommt nicht vor ...!“) und worin sich die Darstellungen unterscheiden, interessierte sich das Projekt nicht nur für die Virtualität medialer Räume, um sie als Oberflächensimulation auszustellen. Vielmehr ließ der hier in Gang gesetzte raumbildende Prozess etwas anderes aufscheinen: Nämlich eine Ahnung von der Multilokalität, der räumlichen Ausdehnung und akuten Simultanität der anderorts stattfindenden, um den Globus verteilten und vermittels der diversen medialen Schnittstellen auf dieser Bühne „telepräsent“ aufscheinenden (doch in ihrer Mehrzahl unsichtbar und unüberschaubar bleibenden) Ereignisse. Flüchtig, momenthaft wurde man sich als Zuschauer der globalen Dimension der elektronischen Medien und ih- 
rer Netzwerke bewusst, der Differenz der Kulturkreise und Sprachen sowie der Komplexität der Kommunikationsprozesse im medialen Äther. Eine solche Zersplitterung des erlebten Raumes in ein „Hier“ und ein fernes, aber gleichzeitiges „Anderswo“, das Gewahrwerden dessen, dass „der aktuelle Raum, mein Leib, mein Ich oder meine Kultur“ sich mit einmal nur mehr als „eine Möglichkeit unter anderen“ erweist, wäre in Anschluss an Waldenfels als Erfahrung des „zersprungenen Raums“ zu beschreiben, die der aktuelle Medienumbruch paradigmatisch bedingt. ${ }^{15}$ Rimini Protokolls Projekt Breaking News verhandelte diese Erfahrung auf seiner intermedialen Bühne; in der skizzierten Weise ließ es einen relationalen, hochkomplexen Raum entstehen, dessen Prozessualität und ästhetische Qualität im theaterüblichen Vorgang des Darstellens, Zeigens und Sichtbarmachens freilich nicht mehr aufging.

\section{Die intermediale Bühne:}

\section{Experimentierfeld einer veränderten „,communicatio“?}

Auf der Bühne der Breaking News wurden verschiedene Kommunikationsmodelle in ein Spannungsverhältnis gebracht: Die En-face-Kommunikation des Theaters sowie die mediatisierte Kommunikation und Vernetzung des Satellitenfernsehens traten dort in Verschränkung. Bei dem Raumgebilde, das das Projekt in dieser Weise entstehen ließ, handelte es sich somit in einen äußerst komplexen, medial hybriden Kommunikationsraum: Wie dargelegt, ging es darum, die virtuellen Räume globalisierter Telekommunikation und technisch mediatisierter Übertragung auf der Bühne zum Thema zu machen und ausgewählte Nachrichtenausschnitte zu reflektieren. Dabei wurden die Medienbilder nicht nur interpretiert, sondern auch ihrer Herkunft nach auf der Weltkarte zurückverfolgt, also gewissermaßen topologisch „rückverortet“ (vgl. Abb. 3). Wie auf einer imaginären Karte wurde so die Komplexität, Dynamik und auch geografische Ausdehnung jenes vernetzten Kommunikationsraums immerhin annähernd kenntlich: Bewusst gemacht wurden so die räumlichen Distanzen, die bei der kommunikativen Übermittlung von Nachrichten zwischen dem „Hier“ und einem „Dort“ überbrückt werden müssen, ebenso wie die solchen Prozessen inhärenten Transformationen der übermittelten Inhalte und stets auch auftretenden Übersetzungsprobleme. Durchgängig wurde der Spielvorgang zudem noch um einen medienarchäologischen Hinweis ergänzt: Mehrfach - wie in einem Zwischenspiel - wurde aus Aischylos' Tragödie Die Perser zitiert (dies war der Part Hans Hübners), namentlich aus dem Kriegsbericht jenes mit „guter oder schlimmer Nachricht“ erwarteten Boten ${ }^{16}$, der in

15 Bernhard Waldenfels, „Ortsverschiebungen“, in: Tom Fecht/Dietmar Kamper (Hg.), Umzug ins Offene. Vier Versuche über den Raum, Wien, New York, NY, 2000, S. 148-155: 150 f.

16 Aischylos, „Die Perser“ (472 AC), in: ders., Die Perser/Sieben gegen Theben, übers. u. hg. v. Emil Staiger, Stuttgart, 2007, S. 7-48: 16, VZ 248. 
einer der Schlüsselszenen des Stücks aus Griechenland zurückkehrt und den entsetzten Persern von der Niederlage ihres Heeres berichtet. Mithilfe dieses wiederkehrenden Zwischenspiels (vgl. Abb. 1) haben Wetzel und Haug ihre Versuchsanordnung um das mediatisierte Nachrichtengeschehen heutiger Prägung somit mit dem antiken Botenmotiv verschränkt und auf der Bühne der Breaking News - metatheoretisch - eine Befragung dessen nahegelegt, was Medien (sowohl neue als auch alte) grundsätzlich leisten.

Kommunikation - sei es in der En-face-Kommunikation, als Telekommunikation oder auch in Form der Nachrichtenübertragung aus der Ferne - generiert Räume. Bedingt durch die experimentelle Verknüpfung unterschiedlicher Medien traten auf der Bühne von Breaking News verschiedene kommunikative Formen und auch medial unterschiedliche Raumqualitäten in ein spannungsreiches Wechselspiel. ${ }^{17}$ Diese Bühne, die quer zu theaterüblichen Erwartungen offenkundig nicht als „Präsenzfeld“ fungierte, also kein Ereignis darbot, das der Zuschauer im Bild der Bühne hätte überblicken und „lesen“ können, lässt sich eher als eine Art Schwellenraum beschreiben: Eine Schwelle, auf der sich unterschiedliche mediale Performanzen ereignen, in Erscheinung treten, verschwinden oder sich lediglich andeuten und so stets zwischen Sichtbarem und Nicht-Sichtbarem, mithin nur Erahnbarem oszillieren.

Das Zusammenspiel, das eine solche Versuchsanordnung zwischen unterschiedlichen Medien in Gang setzt, gilt es zu analysieren und theoretisch zu erfassen; hierzu ist es zunächst notwendig, den verwendeten Medienbegriff zu präzisieren. ${ }^{18}$ Herangezogen kann dazu ein konzeptioneller Ansatz, der unlängst von der Berliner Medienwissenschaftlerin Sybille Krämer ausgearbeitet wurde. Ausgehend von der Grundfrage, was ein Medium überhaupt ist, proklamierte Krämer in ihrer 2008 publizierten Studie einen Medienbegriff, der insbesondere in Abgrenzung zu den weit verbreiteten technizistischen Ansätzen - nicht allein dem Technischen verpflichtet ist, sondern erlaubt, unterschiedliche Medienphänomene in den Blick zu nehmen; hierzu bezieht sie sich auf die Figur des Boten. ${ }^{19}$ Auf den ersten Blick mag diese Wahl überraschen. Boten, Läufer über weite Strecken, Überbringer von Nachrichten - sei es

17 Solche Verknüpfungen unterschiedlicher kommunikativer Formen ließen sich u. a. in Anschluss an Flusser ,kommunikologisch“ interpretieren; vgl. ders., Kommunikologie, hg. v. Stefan Bollmann/Edith Flusser, 4. Aufl., Frankfurt/M., 2007; ders., „Räume“ (1991), in: Jörg Dünne/Stephan Günzel (Hg.), Raumtheorie. Grundlagentexte aus Philosophie und Kulturwissenschaften, Frankfurt/M., 2006, S. 274-285; ein solcher Ansatz ist in der theaterwissenschaftlichen Intermedialitätsforschung bislang ein Desiderat.

18 Zum Umstand, dass auch der Begriff ,Medium“ (ähnlich wie der Theaterbegriff) definitorisch nicht feststeht, sondern in der Forschung kontrovers diskutiert wird, vgl. das Vorwort zum „Kursbuch Medienkultur“, deren Verfasser die These vertreten, dass „es keine Medien gibt, keine Medien jedenfalls in einem substanziellen und historisch stabilen Sinne“; Claus Pias et al. (Hg.), Kursbuch Medienkultur. Die maßgeblichen Theorien von Brecht bis Baudrillard, 5. Aufl., Stuttgart, 2004 [1999], S. 8-12: 10; s. a. Stefan Münker/Alexander Roesler (Hg.), Was ist ein Medium?, Frankfurt/M., 2008.

19 Vgl. Sybille Krämer, Medium, Bote, Übertragung. Kleine Metaphysik der Medialität, Frankfurt/M., 2008. 
mündlich oder in Briefform - wirken von heute aus gesehen wie ein geradezu archaisches Relikt aus jener Zeit, in der es (wie Krämer selbst vermerkt) „noch keine technische Unterstützung der Fernkommunikation gab“. ${ }^{20}$ Für das, was Medien - gleich in welcher Form - grundsätzlich leisten, bilde der Botengang jedoch eine Art „Urszene“: „Der Bote steht zwischen verschiedenartigen Welten und bringt Kraft seiner Position in deren Mitte und als Mittler einen Austausch in Gang “. ${ }^{21}$ Nicht Nähe, sondern (ein nicht nur räumliches, sondern auch existenzielles) Entferntsein sei Bedingung bzw. sogar Auslöser jedweden Kommunizierens, und in den unterschiedlichen Versuchen des Menschen, dieses Entferntsein zu überbrücken, fungieren Medien, so Krämer, dabei als „Mittler“, „Vermittler“.

Krämers Modell, bei dem es sich in erster Linie um ein kommunikationstheoretisches Modell handelt, hat mehrere Aspekte, die erlauben, die Rolle bzw. Funktion von Medien genauer in den Blick zu nehmen: Die Botenperspektive macht erkennbar, (1) dass Medien immer in einem Zwischenraum, in einem „Dazwischen“ agieren (Krämer bezeichnet dies als „abständige Kommunikation“), und dass (2) im „Dazwischen“ kommunikativer Vorgänge Medien auf unterschiedliche Weise bemerkbar werden, also hervortreten können oder aber zurücktreten, verlöschen (nach Krämer ist ein Medium nie transparent, aber auch nie die Nachricht selbst, es ergibt sich also eine Spannung zwischen „Medientransparenz“ vs. „Teilhabe“). (3) Drittens akzentuiere die Botenperspektive, in diesem Sinne, die Mittler-Funktion der Medien (,Drittheit"): Der Bote agiert somit auf einer Schwelle zwischen An- und Abwesenheit, und im Raum der Präsenz markiert die Figur des Boten, auch im Sinne Derridas, einen „Riss“. ${ }^{22}$ Ein weiterer Punkt in Krämers an so unterschiedlichen Theoretikern wie Walter Benjamin, Regis Debray, Michel Serres, Jacques Derrida, Jean-Luc Nancy und John Durham Peters anknüpfendem Modell ist schließlich eine Neubewertung der En-face-Kommunikation: Indem sie eine Aufwertung des „postalischen Prinzips“ gegenüber dem „dialogischen Prinzip“ des (vermeintlich unmittelbaren) En-face-Kommunizierens vornimmt, werden auch mediatisierte Kommunikations- und Übertragungsvorgänge (wie etwa die Übermittlung eines Videobildes, z. B. via Skype) gegenüber dem „unmittelbaren“ Gespräch als prinzipiell gleichwertig, oder - in Krämers Worten - als „kulturstiftende Tätigkeit“ verstanden ${ }^{23}$; in diesem Sinne sind sie stets „welterschließend“, aber auch „welterschaffend“.

20 Ebd., S. 10.

21 Ebd., S. 109; s. a. Sybille Krämer, „Medien, Boten, Spuren“, in: Stefan Münker/Alexander Roesler (Hg.), Was ist ein Medium?, Frankfurt/M., 2008, S. 65-90: 69.

22 Sybille Krämer, „Das Botenmodell“, in: dies. (2008), Medium, Bote, Übertragung, S. 103121.

23 S. a. Sybille Krämer, „Erfüllen Medien eine Konstitutionsleistung? Thesen über die Rolle medientheoretischer Erwägungen beim Philosophieren“, in: Stefan Münker/Alexander Roesler/ Mike Sandbote (Hg.), Medienphilosophie. Beiträge zur Klärung eines Begriffs, Frankfurt/M., 2003, S. 78-90. 
Welche Implikationen hat Krämers Botenmodell nun aber für die Auseinandersetzung mit Theater, mit dessen Medialität bzw. Intermedialität? Medien übermitteln Botschaften, sprachliche Inhalte, Informationen, Geschichten und lassen mithin ganze Welten hervortreten: Dies tut - im Zusammenspiel seiner Mittel und Medien - auch das Theater. Mit Blick also auf die dem Kunstmedium Theater inhärente Eigenschaft, mithilfe unterschiedlicher Medien ästhetisch komplexe, räumlich vielschichtige Szenarien hervorzubringen, ergeben sich für die Analyse folgende Konsequenzen: In Revision bisher vorliegender theaterwissenschaftlicher Ansätze, die vor allem die Semiotik und die Performativität des Theaters untersucht haben, wird damit möglich, die Mittelbarkeit (Multi-/Intermedialität) theatraler Konfigurationen in den Blick zu nehmen. Mit Krämers Botenmodell wäre also zu folgern:

1. Was theatrale Kommunikation auf einer Szene zur Aufführung bringt, ist so niemals tatsächlich präsent. Theater - gleich ob es seine Mittel verfremdet (etwa im Brecht'schen Sinne Distanz zu erzeugen) oder ob es als Medium „transparent“ wird (und seine Medialität gleichsam verbirgt) - ist immer vermittelte Kommunikation, die auf eigentlich Abwesendes verweist: Theater wäre somit prinzipiell kein Medium der Präsenz, sondern eines der Absenz. ${ }^{24}$ Auch ist auf der Szene niemals alles zu sehen, vielmehr treten dort reale und performative sowie fiktive und virtuelle Welten in Austausch, also in ein mehr oder weniger komplexes Spannungsverhältnis. ${ }^{25}$

2. Die Elemente der theatralen Kommunikation (und damit die Medialität des Theaters selbst) sind durch eine grundständige Multi- bzw. Plurimedialität gekennzeichnet. Das heißt, auf der Szene (die vorstellbar wird als Schwellenraum) treten verschiedene Medien auf, ab bzw. zueinander in Konfiguration und bringen, prozessual, heterogene Räumlichkeiten hervor, und auch die Schauspieler sind, ohne dass ihnen eine Sonderstellung zukäme, als Medien (,Mittler“) anzusehen. ${ }^{26}$

${ }^{24}$ Siehe auch die von Gerald Siegmund (aus tanzwissenschaftlicher Sicht) vorgelegte Dekonstruktion des Präsenzbegriffs: ders., Abwesenheit. Eine performative Ästhetik des Tanzes, Bielefeld, 2006.

25 Im Sinne bisher vorliegender theaterwissenschaftlicher Ansätze ist es für die Analyse solcher Prozesse ein erster Anhaltspunkt, Theater als ein realräumlich an einem bestimmten ,Platz ‘ verankertes Heterotop zu denken, dessen Medialität sich über die besondere Aufeinanderbezogenheit von Akteuren und Zuschauern definiert (vgl. Hans-Christian von Herrmann, „Medialität“, in: Erika Fischer-Lichte/Doris Kolesch/Matthias Warstat (Hg.), Metzler Lexikon Theatertheorie, Stuttgart, Weimar, 2005, S. 196-199; über Konzepte, die Theater hierbei, etwa im Sinne Fischer-Lichtes als „Feier leiblicher Anwesenheit“ interpretieren (vgl. dies., Ästhetik des Performativen, Frankfurt/M., 2004, S. 126) weicht der vorliegend projektierte Analyseansatz pluri- und intermedialer Konfigurationen allerdings notwendigerweise ab.

26 Wenn etwa Einar Schleef, in Anlehnung an Heiner Müller, vermerkte, dass Schauspieler „die Texte von Toten“ sprechen, so verweist dies auf die dem Theatervorgang prinzipiell inhärente ,Abständigkeit“. Einar Schleef, „Zehn Punkte für Schauspieler“, in: Theaterschrift 3 (Grenzverletzungen: Über Risiko, Gewalt und innere Notwendigkeit), Berlin u. a., 1993, S. 172181: 180; im Übrigen ist diese auch dann gegeben, wenn sich Laienspieler bzw. sog. ,Spezialisten` wie bei Rimini Protokoll, vermeintlich authentisch, im ästhetischen Rahmen der Bühne 
3. Das Gefüge der Bühne - sofern man mit Krämer das „dialogische“ und das „postalische“ Prinzip als prinzipiell gleichrangig anerkennt - verändert sich: Telekommunikation und mediatisierte Liveübertragung wären somit von der präsentischen Kommunikation auf der Bühne nicht mehr notwendig diametral (oder dieser gar nachgeordnet) unterschieden; vielmehr wird die Bühne, so verstanden, zum Auftrittsort und Erfahrungsfeld unterschiedlicher (,,unmittelbarer“ oder vermittels technischer Medien hervorgebrachter) Phänomene von Liveness. ${ }^{27}$ Der letzte Punkt betrifft die „Drittheit“ der Medien. Wie die Erfahrung zeigt - und dies ist zugleich eine zentrale Prämisse der Intermedialitätsforschung - tritt sie immer dann besonders hervor, wenn ein Medium neu bzw. in einem bestimmten Kontext „fremd“ ist ${ }^{28}$; im Theater wird die „Drittheit“" immer dann besonders erkennbar, wenn ein Medium auftritt, das weder bereits in das raumbildnerische Repertoire noch in die Wahrnehmungsgewohnheiten des Theaterpublikums eingegangen ist („Intermedialitätseffekt“). Insgesamt erlaubt Krämers Modell - das, wie der vorliegende Beitrag vorschlägt, auch für die theaterwissenschaftliche Analyse einen brauchbaren Ansatz bietet - den Blick zu schärfen für die Diversität von Räumen, die durch unterschiedliche Medien generiert werden. Seien es „Wortkulissen“, filmische Räume, oder - wie im Fall des Rimini-Protokoll-Projekts Breaking News - die global verzweigten Netzwerke heutiger Telekommunikation, die in ihrer Komplexität auf der Theaterbühne freilich nicht darstellbar sind, sondern dort, wie beschrieben, lediglich diskursiviert werden können bzw. ästhetisch allenfalls aufscheinen. Eine Analyse, die raumbildnerische Prozesse im Spannungsfeld zwischen dem Theater und anderen Medien untersucht, hätte insbesondere zu fragen, welche ästhetischen Relationen es zwischen den unterschiedlichen Räumen gibt, in welches Wechselspiel sie im Ablauf einer Aufführung treten und wie der Austausch zwischen ihnen vonstattengeht.

Krämer hat solche Prozesse, die sich zwischen unterschiedlichen Medien vollziehen, auch als eine Art Tanz beschrieben: als ein Tanz der Medien und Zeichen „mit nur vorübergehender Berührung“. ${ }^{29}$ Das, was Medien leisten, sei insofern nicht allein in Kategorien des Sich-Verständigens zu fassen, sondern eher in solchen des Wahrnehmbar-Machens und Erscheinen-Lassens. Hierbei, so Krämer, erfährt die Rolle des Rezipienten eine Aufwertung: Angesichts der Komplexität dieser Struktur kommt dem Rezipienten eine gesteigerte Verantwortung dafür zu, dass das Übermittelte „auf fruchtbaren Boden fällt““ ${ }^{30}$ Insbe-

exponieren: Im Sinne Krämers könnte man sagen, sie werden zu Boten ihrer eigenen Geschichte.)

27 Es ist das Verdienst Philip Auslanders, das Phänomen der Liveness im Spannungsfeld zwischen technischen und nicht-technischen Medien erstmals einschlägig problematisiert zu haben, vgl. ders., Liveness. Performance in a Mediatized Culture, London, New York, NY, 2008. [1999]

28 Vgl. dazu Balme (2004), Theater zwischen den Medien.

29 Krämer (2008), Das Botenmodell, S. 107.

30 Ebd. 
sondere die intermediale Bühne- wie am angeführten Projektbeispiel deutlich wurde - gibt Theaterereignisse nicht einfach zu sehen; vielmehr lässt sie zwar in physischen Raum verankerte, jedoch relational in unterschiedliche mediale Räume hineinspielende ästhetische Gefüge entstehen, die man auch als experimentelle „Verhaltens- und Verständigungslandschaften“ bezeichnen könnte: eine Art neu konfigurierte „communicatio“, die auch die Wahrnehmung und Reflexion des Publikums (Aisthesis) in besonderer Weise fordert. Vielleicht wäre ein solches Theater, in Anschluss an Bernhard Waldenfels, als „Raumkunst neuen Typs“ zu definieren; die besondere Vorgehensweise einer solchen Raumkunst bestünde demnach - unter besonderer Berücksichtigung der Raumfrage - darin,

dass die Räumlichkeit von ihr eigens modelliert, befragt, bearbeitet wird, ähnlich wie Malerei, Musik und Sprachkunst sich mit der Sichtbarkeit, der Hörbarkeit und Sagbarkeit als solcher befassen. Dabei werden gewohnte Formen gestört, verfremdet, gesteigert, überboten, bis hin zu einem Unsichtbaren, Unhörbaren, Unsagbaren $\left[\ldots . . .^{31}\right.$

\section{Reflexion und Analyse von Raumbildungsprozessen als ästhetischer Diskurs: Szenographie als Dispositiv}

Die Entscheidung darüber, was und vor allem wie kommuniziert wird - und im Falle intermedialer Versuchsanordnungen die Frage, auf welche Weise verschiedene Medien im Ablauf einer Aufführung zusammenspielen und im Schwellenraum der Bühne zum Auftritt kommen -, ist im Theater nicht allein Angelegenheit der Regie, auch nicht vornehmlich der Dramaturgie, sondern vor allem eine der Szenographie. Um die gestalterische und auch diskursive Funktion genauer beschreiben zu können, die Theaterszenographie - vielfach auch und gerade in Auseinandersetzung mit anderen Medien - im Theater der Gegenwart übernimmt, sei an dieser Stelle eine Präzisierung des Szenographie-Begriffs unternommen.

Szenographien - gemäß der hier vorgeschlagenen Arbeitsdefinition - sind temporär realisierte, künstlerische Raumentwürfe, die sich von dauerhafteren und eher dem Nicht-Künstlerischen zugerechneten Raumgestaltungen (Architektur, Stadtplanung, Design) in Gebrauch und Rezeption ästhetisch abheben; in der Weise, wie sie für besondere Ereignisse (beispielsweise für Ausstellungen oder für Theateraufführungen und Performances) gestaltet werden, werden Szenographien, im Rahmen dieser Ereignisse, zu „Objekte[n] eines anderen Erscheinens“ ${ }^{32}$ Theaterszenographien - also Raumgestaltungen im bzw.

31 Bernhard Waldenfels, Sinnesschwellen. Studien zur Phänomenologie des Fremden 3, Frankfurt/M., 1999, darin das Kap. „Raumnutzung als Überfluss“, S. 212-215: 215.

32 In Anschluss an Martin Seel könnte man sagen, Szenographie lässt Räume entstehen, die ästhetisch ,auffällig' werden, vgl. ders., Ästhetik des Erscheinens, Frankfurt/M., 2003, S. 172. [Herv. i. O.] 
für das Theater - werden mithilfe geeigneter Materialien, Objekte und technischer Apparaturen entworfen, um anlässlich von Aufführungen von Akteuren und Publikum bespielt und wahrgenommen zu werden. Obwohl anderen Gattungen vor allem der bildenden Kunst (etwa der Installation) verwandt, stehen Bühnenbilder bzw. Szenographien somit nicht für sich allein, sondern werden konzipiert, um in Theaterprozessen zu einem „Mitspieler“ zu werden; somit sind Szenographien keine freien künstlerischen Äußerungen, sondern immer auch mit allen anderen Arbeitsfeldern des Theaters verbunden. Dennoch - und dieses Forschungsfeld hat die Theaterwissenschaft bisher erstaunlich wenig berücksichtigt - bildet die Szenographie im Kontext des Theaters, seinen Institutionen, diversen Ausprägungen und seiner Geschichte einen eigenen Diskurs, mit dem Fragen des Gestaltens und Wahrnehmens von Räumen behandelt werden. Entwurf und Realisierung einer spezifischen Szenographie sind insofern immer in einem größeren diskursiven Zusammenhang zu sehen: Sie erzählen etwas über das Raumdenken und -wahrnehmen in einer Kultur sowie auch über raumbildende Medien und die Art ihres Gebrauchs. Somit wäre Szenographie nicht allein als angewandte Kunst zu verstehen, sondern, wie Patrice Pavis betont hat, als ästhetischer Diskurs und (im Foucault'schen Sinne) als Dispositiv, das teilhat an der Geschichte der Denksysteme. ${ }^{33}$

Betrachtet man den Wandel ihrer Formen und künstlerischen Verfahren, so zeigt sich, dass Szenographie in der Tat immer wieder auf ein sich veränderndes kulturelles Wissen über den Raum reagiert hat. Etymologisch gesehen ist der Begriff Szenographie allerdings so alt wie das europäische Theater selbst ${ }^{34}$ : In seiner ältesten Bedeutung stand das Kompositum Szenographie (gr. skene, Bühnenhintergrund, Front des Bühnenhauses, und graphein, schreiben) für das Malen, Bemalen und Ausgestalten der „Skene“ im antiken griechischen Theater; als Hintergrund der orchestra (dem Aktionsraum von Protagonisten und Chor) und integriert in die Gesamtanlage der Spielstätte (theatron) bildete die skene, zusammen mit den Kostümen und Masken, das wichtigste visuelle Gestaltungselement des Theatervorgangs. Später bezeichnete man als Szenographie die bildnerisch gestalteten Elemente der Bühne: Seitdem um 1600 die ersten geschlossenen Theateranlagen entstanden, mit denen der Spielort in einen (perspektivisch organisierten) Bildraum und einen gegenüber situierten Bildraum getrennt wurde, bezog sich der Begriff auf die gemalte Kulisse und meinte von nun an eine mathematisch berechnete und auf Illusionswirkung ausgerichtete Raumdarstellung. ${ }^{35}$ Der Anfang des 20. Jahrhunderts markierte eine weitere Zäsur: Sze-

33 Vgl. Patrice Pavis, „Scénographie“, in: ders., Dictionnaire du Théâtre, Paris, 1996, S. 314317: 315; ders., „Szenographie“, in: Manfred Brauneck/Gérard Schneilin (Hg.), Theaterlexikon 1: Begriffe und Epochen, Bühnen und Ensembles, 5. überarb. Aufl., Reinbek b. Hamburg, 2007, S. 969-971.

34 Erstmals findet er sich bei Aristoteles, vgl. ders., Poetik, hg. v. Manfred Fuhrmann, Stuttgart, 2003, S. 14.

35 So namentlich in den Architekturtraktaten Sebastiano Serlios, vgl. Ulrike Haß, Das Drama des Sehens. Auge, Blick und Bühnenform, München, 2005, S. 172 f. 
nographie, bis dahin ein Bilddiskurs, wurde zum Raumdiskurs. Den Auftakt dazu markierten die Reformen Adolphe Appias, die damals einem Ikonoklasmus der (seit der Renaissance gängig gewordenen) Bühnenform der Perspektivbühne und ihrer Kulissenbilder gleichkam. ${ }^{36}$ Seither bezeichnet man als Szenographie in Abgrenzung zum eher traditionellen Bühnenbild - die ganze Bandbreite raumbildender Verfahren, die mit verschiedenen experimentellen Strategien darauf abzielen, den Theaterguckkasten neu zu interpretieren bzw. aufzubrechen und zugunsten offener, variabler Konfigurationen zu revidieren. ${ }^{37}$ Dass ihr dabei inhärent ist, dass sie immer auch technologische Innovationen (vom elektrischen Licht über den Film bis hin zu den elektronischen Medien) in sich aufgenommen bzw. künstlerisch reflektiert und bearbeitet hat, gilt als weiteres Merkmal neuerer Szenographie. ${ }^{38}$

Die heute übliche Verwendung des Begriffs hat verschiedene, teilweise divergierende Facetten. Bedingt durch die Vielfalt ihrer gegenwärtigen Erscheinungsformen zeichnen sich zudem unterschiedliche Zugriffe auf die Szenographie als Forschungsgegenstand ab: Nach seinem gattungsübergreifenden Verständnis umfasst der Szenographie-Begriff Raumgestaltungen in verschiedenen disziplinären Kontexten (Museum, Eventkultur, Film, Computerspiel-Design) ${ }^{39}$ oder aber - theaterbezogen - experimentelle Gestaltungen von Bühnen bzw. temporären Spielorten im öffentlichen Raum. ${ }^{40}$ Wie erwähnt, wurzelt der Begriff zwar historisch in den Anfängen der Theatergeschichte, als künstlerische Disziplin agiert Szenographie aber spätestens seit der Moderne erkennbar inter- bzw. transdisziplinär und hat, in ihrer Eigenschaft als „Dispositiv“, mit ihren Konzepten und Verfahren bereits mehrfach auf ein sich veränderndes kulturelles Wissen über den Raum reagiert. ${ }^{41}$ Auch die eingangs erwähnte „Raum-Wende“-Diskussion, die durch den aktuellen Medienumbruch und die seit einiger Zeit virulenten Vernetzungs- und Globalisierungsprozesse in Gang kam, findet darin inzwischen ihren Niederschlag und stellt für den gegenwär-

${ }^{36}$ Vgl. Gabriele Brandstetter/Birgit Wiens (Hg.), Theater ohne Fluchtpunkt. Das Erbe Adolphe Appias, Berlin, 2010, bes. die Einleitung, S. 7-36.

37 Zu dieser Beobachtung vgl. auch Thea Brejzek/Gesa Mueller von der Haegen/Lawrence Wallen, „Szenografie“, in: Stephan Günzel (Hg.), Raumwissenschaften, Frankfurt/M., 2009, S. 370-385.

38 Siehe dazu auch Christopher Baugh, Theatre, Performance and Technology: The Development of Scenography in the Twentieth Century, Houndmills/Hampshire, New York, NY, 2005.

39 Vgl. Brejzek/Mueller von der Haegen/Wallen (2009), Szenografie, S. 370 f.

40 Ebd., S. 373; s. a. den theaterspezifischen Definitionsansatz von Christopher Balme: ders., „Szenographie“, in: Erika Fischer-Lichte/Doris Kolesch/Matthias Warstat (Hg.), Metzler Lexikon Theatertheorie, Stuttgart, Weimar, 2005, S. 322-325.

41 Aufgabe einer eigenen Untersuchung wäre es darzulegen, wie die Szenographie jeweils auf den kulturellen Wandel von Raumparadigmen reagiert hat; nach Bernhard Waldenfels wurden, historisch betrachtet, als Paradigmen bisher in Anschlag gebracht: 1. die aristotelische Topos-Lehre, 2. der neuzeitliche Raum der mathematisch berechenbaren Abstände und Ausdehnungen (,Spatium') sowie 3. seit Beginn des vergangenen Jahrhunderts das phänomenologische Konzept der ,Lebenswelt‘ (vgl. ders. (2000), Ortsverschiebungen, darin der Abschnitt „Drei historische Paradigmen“, S. 148 f.). 
tigen Szenographie-Diskurs eine neue Herausforderung dar. Mit künstlerischen Mitteln zu leisten gilt es hierbei: 1. eine grundsätzliche Neubetrachtung geltender Raumbegriffe (d. h. eine Auseinandersetzung mit der ihrerseits disziplinübergreifend geführten „Spatial Turn“-Diskussion), 2. eine Prüfung und Revision bisher gängiger raumbildender Verfahren und Kulturtechniken (im Sinne der „Topographical Turn“-Debatte) sowie 3. eine Neubewertung des (sich bisher im physischen Raum verankernden) Ortsbegriffs, im Spannungsfeld zwischen Lokalem und Globalem, zwischen Nähe und Ferne und zwischen Realem und Virtuellem („Topological Turn“). ${ }^{42}$ Die intermediale Bühne hat - wie mit dem angeführten Fallbeispiel gezeigt wurde - prinzipiell das Potenzial, solch vielschichtige Raumreflexionen zu leisten; hierbei tritt sie, wie Thea Brejzek beobachtet, in vielfältigen Formen auf:

Der szenographische Diskurs des 20. und beginnenden 21. Jahrhunderts verortet sich, theaterspezifisch, von der klassischen Portalbühne hin zu offenen Raumkonfigurationen, in der Verhandlung des Verhältnisses zwischen dem Raum der Aktion und dem Raum der Rezeption. Mit der Verwendung (interaktiver) Technologien im Installationskontext wie auf der Bühne wird die Auseinandersetzung zwischen räumlichen Konfigurationen des Darstellen und Zeigens einerseits und des Wahrnehmens andererseits zunehmend zu einem Diskurs über liveness und Mediatisierung [...]. ${ }^{43}$

\section{Szenographie als „Metaszenographie“? Vorläufige Schlussbemerkungen}

Am Beispiel des Rimini-Protokoll-Projekts Breaking News wurden im vorliegenden Beitrag die Merkmale der intermedialen Bühne diskutiert. In Auseinandersetzung mit den aktuellen Medienumbrüchen (Digitalmedien, elektronische Echtzeitkommunikation, mediale Vernetzung in globaler Reichweite) erhält, auch aus der Sicht des Theaters, die Frage nach den Räumen anderer Medien vermehrte Relevanz. Die intermediale Bühne, deren Spielarten vielfältig sind, nimmt - dies ist ihr Hauptmerkmal - Bezug auf andere Medien (im Fall des angeführten Beispiels auf das Digitalfernsehen) und wird zum Instrument bzw. zu einer Plattform ihrer reflektierenden Erfahrung.

Indem sich Theater anderen Medien öffnet, sich mit ihnen in actu verschaltet, wird aber auch der Raum des Theaters selbst befragt und als solcher neu reflektiert: In geradezu paradigmatischer Weise bricht im Besonderen die „verkabelte Bühne“ mit den überkommenen Raumvorstellungen vom „heilen Haus“ oder „Behälter“. Stattdessen machen solche Experimente den Raum als

\footnotetext{
42 Zu den Aufgabenfeldern der aktuellen ,Raum-Wende‘-Diskussion vgl. Stephan Günzel, „Spatial Turn - Topographical Turn - Topological Turn. Über die Unterschiede zwischen Raumparadigmen “, in: Jörg Döring/Tristan Thielmann (Hg.), Spatial Turn. Das Raumparadigma in den Kultur- und Sozialwissenschaften, Bielefeld, 2008, S. 219-237.

43 Brejzek/Mueller von der Haegen/Wallen (2009), Szenografie, S. 373.
} 
ästhetisches, kommunikatives und insofern durch Medien bedingtes Phänomen erkennbar. Demnach ist Raum nichts „Gegebenes“, sondern tritt - im Spannungsfeld zwischen den jeweils herrschenden Raumkonzepten und dem menschlichem Raumerleben, das wiederum geprägt ist durch erlernte, sich aber ebenfalls verändernde Wahrnehmungskonventionen - stets erst hervor. Die Bühne der Breaking News (abweichend von Interpretationen der Theaterbühne als „Präsenzfeld“) wurde - in Anschluss an Sybille Krämers „Botenmodell“ - als Schwelle beschrieben, auf der die Aufführung (inter-)mediale Austauschprozesse in Gang setzte zwischen dem im Realräumlichen verankerten, ästhetischen Raum des Theaters, der mit Pavis als „,szenographischer Raum“ („éspace scénographique“) zu bezeichnen wäre ${ }^{44}$ sowie dem virtuellen, allenfalls der Phantasie und einer gewissen Erfahrbarkeit zugänglichen Raum der telekommunikativen Vernetzung und Übertragung („éspace télématique“).

Der hier vorgestellte künstlerische Raumdiskurs kann auch als intermediale Szenographie bezeichnet werden. Sie entwirft die Bedingungen dafür, wie die Akteure im Spannungsfeld der unterschiedlichen Räume und Medien in den Spielvorgang eintreten können. Im Ablauf des Spiels wird die intermediale Bühne, wie dargelegt, zu einem Feld ästhetischer Erfahrung und vor allem zu einem Diskursfeld, das nicht nur die Akteure, sondern auch das Publikum in neuer Weise einbezieht, indem sie deren kollaborative Kreativität, kognitiven Fähigkeiten und intellektuelle Reflexion dezidiert anspricht; eine Szenographie, die so verfährt, trägt die Merkmale dessen, was die Kunstwissenschaft neuerdings auch als „Metaszenographie“ definiert. ${ }^{45} \mathrm{Ob}$ das Theater, in seiner Eigenschaft als „Raumkunst“, in Auseinandersetzung mit der im Alltag längst nahezu alle Lebensbereiche durchziehenden medialen Vernetzung selbst einen signifikanten Umbruch durchmachen wird, muss an dieser Stelle offen bleiben. Wahrscheinlicher aber ist es - die Prognose sei erlaubt -, dass das Theater (wie dies angesichts der diversen in den vergangenen Jahren bzw. Jahrzehnten ausgerufenen Paradigmenwechsel und „Wenden ${ }^{\text {‘46 }}$ bereits der Fall war) das kritische Potenzial der Intermedialitätsperspektive und auch der „Spatial Turn“-Diskussion für die eigenen Zwecke spielerisch nutzen und, unter Beibehaltung seiner gewohnten medialen Grundkonfiguration, seinen inzwischen außerordentlich vielfältig gewordenen Formenreichtum noch weiter auffächern wird. In dem Maß aber, in

44 Vgl. Pavis’ Eintrag: „Espace (au Théâtre)“, in: ders. (1996), Dictionnaire du Théâtre, S. 146.

45 Vgl. hierzu Pamela C. Scorzin: „Contemporary metascenography testifies to a remarkable new role of the audience a sactive, complicit participants and so-called ,prosumers' (a blending of ,consumers' and ,producers'), who contribute to the completion of performances as open artworks [...]. In this context, metareference can be understood as a significant symptom and an essential part of the general appreciation and celebration of the recipiants' creativity; moreover it bespeaks the concept of shared, or multiple authorship in contemporary culture“". Dies., „Metascenography. On the Metareferential Turn in Scenography“, in: Werner Wolf (Hg.), The Metareferential Turn in Contemporary Art an Media. Form, Functions, Attempts at Explanation, Amsterdam, New York, NY, 2011, S. 259-277: 259.

46 Für eine Zusammenstellung der diversen ,Wenden` vgl. Bachmann-Medick (2009), Cultural Turns. 
dem das Theater mit seiner Szenographie auf andere Medien und Diskurse Bezug nimmt, trägt es andererseits selbst immer weiter bei zu seiner eigenen Hybridisierung und agiert zudem in der Tat metareferenziell. Was wiederum bedeutet dies für die Theoriebildung? Die Theaterwissenschaft kommt, wie es sich zeigt, in Auseinandersetzung mit solchen Experimenten ihrerseits kaum ohne inter- bzw. transdisziplinäre Bezugnahmen aus; in diesem Sinne tut sich hier für das Fach (verbunden mit einer gewissen Selbstreflexion) die sicherlich reizvolle Herausforderung auf, die sich abzeichnenden Tendenzen intermedialer, metareferenzieller Spielanordnungen diskursiv zu begleiten und auf seinen eigenen „Bühnen“ zu reflektieren.

\section{Literatur}

Aischylos, „Die Perser“, in: Die Perser/Sieben gegen Theben, übers. und hg. v. Emil Staiger, Stuttgart, 2007, S. 7-48. [Gr. OA 472 AC.]

Akademie der Künste Berlin, Topos RAUM. Die Aktualität des Raumes in den Künsten der Gegenwart, zusammengestellt v. Angela Lammert, Nürnberg, 2004.

Aristoteles, Poetik [Griechisch/Deutsch], hg. v. Manfred Fuhrmann, Stuttgart, 2003. [OA um 335 AC.]

Auslander, Philip, Liveness. Performance in a Mediatized Culture, London, New York, NY, 2008. [1999]

Bachmann-Medick, „Spatial Turn“, in: dies., Cultural Turns. Neuorientierungen in den Kulturwissenschaften, Reinbek b. Hamburg, 2009, S. 284-328.

Balme, Christopher, Einführung in die Theaterwissenschaft, 4. durchges. Aufl., Berlin, 2008. [1999]

Ders., „,Theater zwischen den Medien: Perspektiven theaterwissenschaftlicher Intermedialitätsforschung“, in: ders./Markus Moninger (Hg.), Crossing Media. Theater Film - Fotografie - Neue Medien, München, 2004, S. 13-31.

Ders., „Szenographie“, in: Erika Fischer-Lichte/Doris Kolesch/Matthias Warstat (Hg.), Metzler Lexikon Theatertheorie, Stuttgart, Weimar, 2005, S. 322-325.

Ders. et al., „Vom Nutzen und Nachteil des Medienbegriffs für das Theater und die Theaterwissenschaft“ (Podiumsdiskussion im Rahmen des 8. Kongresses der Gesellschaft für Theaterwissenschaft), in: Henri Schoenmakers et al. (Hg.), Theater und Medien/Theatre and the Media. Grundlagen-Analysen-Perspektiven. Eine Bestandsaufnahme, Bielefeld, 2008, S. 545-560.

Baugh, Christopher, Theatre, Performance and Technology: The Development of Scenography in theTwentieth Century. Houndmills/Hampshire, New York, NY, 2005.

Brandstetter, Gabriele/Birgit Wiens (Hg.), Theater ohne Fluchtpunkt. Das Erbe Adolphe Appias. Szenographie und Choreographie im zeitgenössischen Theater, Berlin, 2010.

Brejzek, Thea/Gesa Mueller von der Haegen/Lawrence Wallen, „Szenografie“, in: Stephan Günzel (Hg.), Raumwissenschaften, Frankfurt/M., 2009, S. 370-385. 
Chapple, Freda/Chiel Kattenbelt (Hg.), Intermediality in Theatre and Performance, Amsterdam, New York, NY, 2008. [2006]

Crang, Mike/Nigel Thrift (Hg.), Thinking Space, New York, NY, London, 2000.

Fischer-Lichte, Erika, Ästhetik des Performativen, Frankfurt/M., 2004.

Flusser, Vilém, „Räume“ (1991), in: Jörg Dünne/Stephan Günzel (Hg.), Raumtheorie. Grundlagentexte aus Philosophie und Kulturwissenschaften, Frankfurt/M., 2006, S. 274-285.

Ders., Kommunikologie, hg. von Stefan Bollmann und Edith Flusser, 4. Aufl., Frankfurt/ M., 2007. [1996]

Ders., Medienkultur, Frankfurt/M., 2008. [1993]

Göpfert, Peter Hans, „Unser tägliches Leben mit der Tagesschau“, in: Berliner Morgenpost vom 07.01.2008.

Günzel, Stephan, „Spatial Turn - Topographical Turn - Topological Turn. Über die Unterschiede zwischen Raumparadigmen“, in: Jörg Döring/Tristan Thielmann (Hg.), Spatial Turn. Das Raumparadigma in den Kultur- und Sozialwissenschaften, Bielefeld, 2008, S. 219-237.

Haß, Ulrike, Das Drama des Sehens. Auge, Blick und Bühnenform, München, 2005.

Herrmann, Hans-Christian von, „Medialität“, in: Erika Fischer-Lichte/Doris Kolesch/ Matthias Warstat (Hg.), Metzler Lexikon Theatertheorie, Stuttgart, Weimar, 2005, S. 196-199.

Herrmann, Max, „Das theatralische Raumerlebnis“ (1931), in: Jörg Dünne/Stephan Günzel (Hg.), Raumtheorie. Grundlagentexte aus Philosophie und Kulturwissenschaften, Frankfurt/M., 2006, S. 501-513.

Kattenbelt, Chiel, „Theatre as the Stage of Intermediality“, in: Freda Chapple/ders. (Hg.), Intermediality in Theatre and Performance, Amsterdam, New York, NY, 2008, S. 29-40.

Krämer, Sybille, „Erfüllen Medien eine Konstitutionsleistung?“, in: Stefan Münker/ Alexander Roesler/Mike Sandbote (Hg.), Medienphilosophie. Beiträge zur Klärung eines Begriffs, Frankfurt/M., 2003, S. 78-90.

Dies., „Medien, Boten, Spuren. Wenig mehr als ein Literaturbericht“, in: Stefan Münker/ Alexander Roesler (Hg.), Was ist ein Medium?, Frankfurt/M., 2008, S. 65-90.

Dies., Medium, Bote, Übertragung. Kleine Metaphysik der Medialität, Frankfurt/M., 2008.

Münker, Stefan/Roesler, Alexander (Hg.), Was ist ein Medium?, Frankfurt/M., 2008.

Pias, Claus et al. (Hg.), Kursbuch Medienkultur. Die maßgeblichen Theorien von Brecht bis Baudrillard, Stuttgart, 2004. [1999]

Pavis, Patrice, „Scénographie“, in ders., Dictionnaire du Théâtre, Paris, 1996, S. 314317.

Ders., „Szenographie“, in: Manfred Brauneck/Gérard Schneilin (Hg.), Theaterlexikon 1: Begriffe und Epochen, Bühnen und Ensembles, 5. überarb. Aufl., Reinbek b. Hamburg, 2007, S. 969-971.

Roselt, Jens, „Raum“, in: Erika Fischer-Lichte/Doris Kolesch/Matthias Warstat (Hg.), Metzler Lexikon Theatertheorie, Stuttgart, Weimar, 2005, S. 260-267.

Schleef, Einar, „Zehn Punkte für Schauspieler“, in: Theaterschrift 3 (Grenzverletzungen: Über Risiko, Gewalt und innere Notwendigkeit), Berlin u. a., 1993, S. 172-181.

Scorzin, Pamela C., „Metascenography. On the Metareferential Turn in Scenography“, in: Werner Wolf (Hg.), The Metareferential Turn in Contemporary Art an Media. Form, Functions, Attempts at Explanation, Amsterdam, New York, NY, 2011, S. 259-277.

Seel, Martin, Ästhetik des Erscheinens, Frankfurt/M., 2003. 
Siegmund, Gerald, Abwesenheit. Eine performative Ästhetik des Tanzes, Bielefeld, 2006.

Waldenfels, Bernhard, Sinnesschwellen. Studien zur Phänomenologie des Fremden 3, Frankfurt/M., 1999.

Ders., „Ortsverschiebungen“, in: Tom Fecht/Dietmar Kamper, Umzug ins Offene. Vier Versuche über den Raum, Wien, New York, NY, 2000, S. 148-156.

\section{Internetquellen}

www.rimini-protokoll.de 



\section{KINECTS BÜHNE: SELBSTORGANISIERTE MIMESIS}

Zwei Menschen stehen im Zimmer vor einem Monitor, sie springen und ducken sich, beugen sich nach links und nach rechts, rennen auf der Stelle, boxen und treten in die Luft, fuchteln vor ihrem Körper oder machen Dehnübungen - die Blicke immer auf einen Screen gerichtet. Dort sind Animationen von Autorennen oder Hürdenlauf zu sehen, Figuren auf einer Floßfahrt mit Hindernissen oder Tanz- und Sporttrainer, die dazu auffordern, Bewegungsabläufe nachzuahmen. Nicht zu sehen ist ein Steuerungsgerät, sei es Tastatur, Gamepad, Joystick oder Ähnliches; nur ein schmaler schwarzer Kasten auf dem Monitor ist zu sehen - Microsofts Xbox Kinect. Dieses Kamerainterface ermöglicht zwei Spielern gleichzeitig, Spielfiguren durch ihre Körperbewegung zu steuern.

Diese erste Annäherung an die Spielsituation legt nahe, dass sich der Prozess des Spielens von einer Ausführungssituation in Richtung einer Aufführungssituation verlagert. Patrick Crogan hat diese Verschiebung schon für die Nutzung der Spielkonsole Wii von Nintendo konstatiert und mit Samuel Webers Theatralitätsbegriff beschrieben. Insbesondere betont er auch die Situation des gemeinsamen Spielens und damit des Spielens, während jemand anderes zuschaut. ${ }^{1}$ Auch bei Kinect erscheint die körperliche Bewegung zur Steuerung von Spielfiguren als rudimentäre Darstellungsform. Von dieser Beobachtung ausgehend, befrage ich im Folgenden die Spielsituation, die Kinect etabliert, im Hinblick auf einen prozessualen, Praktiken basierten Bühnenbegriff.

In einer basalen Annäherung an einen Bühnenbegriff lässt sich sagen, dass „Bühne“ der Bereich im Theaterraum ist, welcher der Darstellung zugehörig ist. Im Begriff der Bühnenform ${ }^{2}$ ist die Bühne an die Raumorganisation von Theaterformen gebunden und lässt sich als Schauanlage bzw. Wahrnehmungsanordnung begreifen, die organisiert und strukturiert wie etwas in Erscheinung tritt und zur Darstellung gelangt. Als Darstellungsraum ist Bühne gleichzeitig Handlungs- oder Aktionsraum. Bezogen auf einen Praktiken orientierten Bühnenbegriff lässt sich daran anschließend fragen, was die prozessualen Logiken des Erscheinens sind, wie sie Darstellung und Wahrnehmung genau verbinden und welche Praktiken dafür bestimmend sind. Dabei liegt auf der Hand, dass hier gleichermaßen Praktiken der Bühnenkonstruktion und Szenographie wie

1 Siehe Patrick Crogan, „The Nintendo Wii, Virtualisation and Gestural Analogics“, in: Culture Machine 11 (2010), online unter: http://www.culturemachine.net/index.php/cm/article/view/ 374/397, zuletzt aufgerufen am 06. 08. 2013, S. 82-101: $91 \mathrm{ff}$.

2 Ulrike Haß, Das Drama des Sehens. Auge, Blick und Bühnenform, München, 2005. 
auch des Schauspiels bzw. der körperlichen Bewegungen und Handlungsvollzüge relevant werden.

Dieser vorläufige Bühnenbegriff bildet nun den Zugang meiner folgenden Kinect-Analyse: Untersucht wird, wie eine - genauer zu bestimmende - technisch-mediale Logik der Darstellung mit einer körperlichen Bewegungslogik von Verkörperung und Verräumlichung zusammenwirkt. Damit lässt sich bestimmen, welche Form von Aus- bzw. Aufführung darin entsteht und die Frage der Bühne präzisieren.

\section{Kinects Praktiken}

Mit der Bewegungssteuerung Kinect für Microsofts Spielekonsole Xbox 360 ist es möglich, Xbox Spiele zu spielen, ohne ein Eingabegerät manuell zu bedienen. Der schmale schwarze Kasten enthält neben einer normalen RGB-Kamera und Mikrofonen zur Spracheingabe eine Tiefenkamera und Erkennungssoftware. Diese unterscheidet zwei Spieler im aufgenommenen Raum voneinander, berechnet deren Körpermodelle und Bewegungen und steuert darauf aufbauend Spielfiguren. Dabei umfassen die Spiele für Kinect eine Reihe von Sport-, Geschicklichkeits- und Kampfspielen sowie von Tanz- und Fitnessangeboten.

Betrachtet man die verschiedenen Spielegenres, so lässt sich in erster Annäherung feststellen, dass sie Bewegung und ihre mediale Darstellung auf drei unterschiedliche Weisen ins Verhältnis setzen: als Auslösen, Vorahmen oder Nachahmen. So gibt es explizit festgelegte, gewissermaßen ikonische Gesten, die in der Menüsteuerung gebraucht werden oder Spielereignisse auslösen. Neben dem bekannten „Wischen“ zum Auswählen von Menüpunkten steuern pantomimische Lenkbewegungen beispielsweise Autos. Laufen auf der Stelle bringt Figuren zum Rennen, deren Geschwindigkeit wiederum wird dadurch geregelt, wie hoch die eigenen Knie gezogen werden. Die Logik folgt der klassischen Steuerung: festgelegte und zu wiederholende Gesten lösen Ereignisse aus; bestimmte Eigenschaften der tatsächlichen Bewegung modifizieren die medialen Ereignisse und Effekte. Andere Spiele erzeugen eine Logik von Abbildung oder Vorahmung der Bewegung. So zeigen Sportspiele die Spielfiguren in spezifischen Situationen und fordern die Spieler auf, sich entsprechend zu bewegen: Wenn sie in die Luft boxen, mit dem Bein schießen oder mit der Hand Tischtennis spielen, bewegen sich die dargestellten Figuren analog. Allerdings stellt sich beim längeren Spielen heraus, dass man mehr Punkte nicht unbedingt durch exakte Bewegungen erhält. Großflächiges, schnelles Armfuchteln vor dem eigenen Körper kann beispielsweise zu mehr Box-Treffern führen als „korrekt“ ausgeführte Box-Schläge. Gerade Fitnessanwendungen zielen auf Nachahmung von Bewegung und deren Vermessung, wenn eine Tänzer- oder Trainerfigur einen Bewegungsablauf vorführt, den der Spieler wiederholen soll. Je nach Exaktheit der Nachahmung steigt die Punktzahl, wo- 
bei die Ähnlichkeit der Bewegung vor allem eine Ähnlichkeit der Körperhaltung ist.

Diese erste Annäherung soll deutlich machen, dass mit Kinect eine Art Aufführungssituation entsteht, in der körperliche Bewegung die im Bewegtbild dargestellte Situation verräumlicht und zwar im Modus von Auslösen, Vorahmen und Nachahmen. Dabei zielt Kinect auf die Wiederholung und Verbesserung von Bewegung, deren Richtigkeit sich in ihrer Wirkung zeigt.

Um körperliche Bewegung genauer als Aufführung beschreiben zu können, unterscheide ich im Folgenden entlang des vorläufigen Bühnenbegriffs zwischen einer technisch-medialen Ebene ihres Erscheinens und einer Ebene des Körpers und seiner Erfahrung.

\section{Kinects Techniken}

Die Bewegungserkennung von Kinect basiert auf der Berechnung eines Körpermodells der Spieler und dem daraus abgeleiteten Skelett oder Strichmännchen. Dabei nutzt die Tiefenkamera Infrarotlaser und -sensor, um zu jedem aufgenommenen Bildpunkt den Abstand zur Kamera zu berechnen. Die Körpersilhouette wird in jeder Aufnahme von der Umgebung getrennt, so dass für jedes Einzelbild eine 3-D-Darstellung der aktuellen Haltung des Spielerkörpers berechnet wird. Einige Spiele - beispielsweise in Ubisofts „Your Shape Fitness Evolved“ - nutzen diese dreidimensionale Silhouette, um daran zu vermessen, ob der Spieler eine korrekte Haltung eingenommen hat, andere Spiele greifen auf das daraus abgeleitete Skelett zu. Kinect unterteilt jede 3-D-Silhouette in Körperteile und definiert die Grenzen zwischen diesen als Gelenkpunkte, um aus deren Positionen und Abständen ein Strichmännchen als Repräsentation des Spieler zu berechnen. Dieses Verfahren basiert darauf, für jedes aufgenommene Pixel der Körpersilhouette zu entscheiden, zu welchem Körperteil es wahrscheinlich gehört - wobei die Entwickler von Kinect die Körperteile entlang typischer biometrischer Unterteilungen festgelegt haben. Dazu wird zunächst die geometrische Umgebung jedes einzelnen Pixels betrachtet und mittels Entscheidungsbäumen die Wahrscheinlichkeit bestimmt, dass es zu einem spezifischen Körperteil gehört. Eine weitere Wahrscheinlichkeitsfunktion vergleicht die Pixel der Körpersilhouette, unterteilt darauf aufbauend die Silhouette in Teile und berechnet das Skelett und seine Pose oder Haltung. Für die Posenbestimmung wurde der Algorithmus mittels einer Datenbank trainiert, in der Bilder und Datensätze von Motion-Capturing-Aufnahmen von typischen Kinect-Steuerungsbewegungen gespeichert sind. Anschließend daran unterscheidet das System Haltungen von aufgenommenen 3-D-Körpersilhouetten, wobei verschiedene Kriterien festgelegt sind, wann Körperposen als un- 
terschiedlich gelten ${ }^{3}$. Diese Posen werden dann auf die Spielfiguren abgebildet oder als Steuerbefehle genutzt. Gerade für die Steuerung medialer Effekte oder Ereignisse werden die Haltungsparameter weiterverrechnet und transformiert. Im oben genannten Beispiel der Laufsteuerung wird z. B. die Höhe der Knie zur Schnelligkeit der laufenden Figur umgerechnet - bei anderen Anwendungen wird die Stärke des dargestellten Schritts oder Schlags dadurch bestimmt, wie schnell die körperliche Bewegung ausgeführt wird, oder auch dadurch, wie ausladend sie vollzogen wird.

Das heißt: Auf einer algorithmisch-technischen Ebene ist die körperliche Bewegung als Ausführung einer Steuerungslogik durch die Kategorien von Vermessung, Abbildung von Körperposen und Transformation in mediale Effekte charakterisiert. Die Abbildung der Bewegung in den Animationen der Spiele lässt sich als stroboskopischer Effekt des schnellen Aufeinanderfolgens unterschiedlicher Posen beschreiben. Das Verhältnis zwischen körperlicher Bewegung und deren bewegtbildlicher Darstellung basiert insofern auf Ähnlichkeit, als dass die Körperbewegung in der Darstellung zu einer Abfolge ausreichend gut zu unterscheidender Positionen wird. Die Ähnlichkeit und Unterschiedlichkeit von Positionen sind mathematisch-algorithmisch durch eine Metrik bestimmt, während die Körperposen entlang biometrischer Modelle bestimmt werden. Die Wirkung der körperlichen Bewegung in den medialen Effekten wiederum basiert auf mathematischen Transformationen, die physikalisch und biometrisch plausibel erscheinen. In der technisch-medialen Logik der Darstellung von Bewegung verbinden sich also kinematografische, biometrische und statistische Prinzipien, um die Überlagerung von Transformation, Abbildung und Vermessung zu organisieren, die sich in der Nutzung als eine Mischung von Auslösen, Vorahmen und Nachahmung realisiert. Dabei spielt die Beziehung von Bewegung und Darstellung auf der technischen Ebene komplett auf einem bildlichen Register. Das ändert sich, wenn es um die Betrachtung der konkreten Praktiken und den darin angelegten Erfahrungen geht.

\section{Kinect'sche Erfahrungen}

Kinect selbst bewirbt das Verhältnis zwischen Körperbewegung und deren Darstellung in der konkreten medialen Anordnung mit den Slogans „Du bist der Controller. Keine Gadgets, kein Firlefanz, nur du! “ und „Du bist Teil des Spiels“. Die Erfahrung des Spielens wird in der Werbung als Mischung aus Steuerung und Immersion beschrieben, die auf der Unmittelbarkeit der Bewegung-als-Steuerung basiert. Betrachtet man die Bewegungspraktiken (Aus-

Siehe Jamie Shotton et al., „Real-Time Human Pose Recognition in Parts from Single Depth Images“ (June 2011), online unter: https://research.microsoft.com/pubs/145347/BodyPartRecognition.pdf, zuletzt aufgerufen am 30.06.2013. 
lösen, Vorahmen, Nachahmen), wie sie sich im Hinblick auf Erfahrung der NutzerInnen konkretisieren, ergibt sich ein abweichender Befund. So vollzieht sich die Steuerung durch Bewegung erstens als ein Betonen und Ausarbeiten bestimmter Eigenschaften oder Aspekte von Bewegung, wenn die Schnelligkeit einer laufenden Figur durch das besonders schnelle und hohe Hochziehen von Knien bestimmt ist. Zweitens muss die Bewegung effektiv im Hinblick auf den Punktestand sein. Darüber hinaus sollte sie situativ angemessen sein bezogen auf das dargestellte Szenario, auf das zuschauende „Publikum“ des realen Bewegungsvollzugs und auf die Schnappschüsse, die Kinect mit der integrierten RGB-Kamera machen kann. Drittens zielt Kinect auf die Exaktheit der Bewegung.

Ich möchte bezogen auf die Ebene von Erfahrung körperliche Bewegung entlang der Kategorien Qualität, Angemessenheit und Exaktheit beschreiben, die nicht deckungsgleich sind mit der technischen Ordnung von Steuerung, Abbildung und Vermessung und auch etwas verschoben zu den Kategorien von Auslösen, Vorahmen und Nachahmung. So sind Vorahmung und Nachahmung im Hinblick auf die Erfahrung des Kinect-Spielens nicht als Imagination und Ausführung im Sinne von Darstellung und Verkörperung idealer Bewegungsabläufe zu denken. Eher geht es um schnelle Verräumlichung der Szene in adäquate Körperbewegungen, die effizient sein müssen.

Daran anknüpfend lässt sich die Form von Bewegung auf der Ebene von Erfahrung genauer bestimmen. Das, was in der Selbstbeschreibung als Immersionserfahrung aufgrund der Unmittelbarkeit von Bewegung-als-Steuerung erscheint, lässt sich präziser fassen als eine Verräumlichung der dargestellten Situation in wirksame Bewegung. Dabei lässt sich Bewegung als eine Art vorahmende Mimesis in einem kinematografisch gedachten Reiz-Reaktions-Schema beschreiben, wobei die Wirksamkeit in der technisch-medialen Anordnung als Qualität, Angemessenheit oder Exaktheit erfahren und im Punktestand dargestellt wird.

Bewegung als Aufführung ist in dieser Perspektive so zu fassen, dass die körperliche Bewegung die verschiedenen Bewegungsordnungen der technischen Ebene, der Nutzungs- und der Erfahrungsebene ineinander überführt. Wenn steuern, abbilden und vermessen als Qualität, Angemessenheit und Exaktheit von Bewegung erfahren werden und als Auslösen, Vorahmen und Nachahmen praktiziert und semantisiert werden, „bin ich Teil des Spiels“, wird Bewegung zum Mittel einer erfolgreichen Immersion und zur Handlung im Spiel einerseits und zur Verräumlichung des Szenarios andererseits.

Für die skizzierte Annäherung an einen Aufführungs- und Bühnenbegriff von Kinect ist zentral, wie sich die technisch-formalistisch gefasste Körperbewegung - als stroboskopischer Effekt der schnellen Abfolge unterschiedlicher Posen - und die durch Erfahrung vermittelte Bewegungs-Auffassung - als Verräumlichung durch vorahmende Mimesis im Modus von Reiz-Reaktion miteinander verbinden oder ineinander überblendet werden. Im Folgenden möchte ich darstellen, an welche historischen Traditionen diese Überblendung 
anknüpft und welche Aufführungs- und Bühnenbegriffe darin aufgerufen werden. Dadurch lässt sich der Bühnenbegriff Kinects präzisieren.

\section{Historische Genealogien}

Folgt man der skizzierten Analyse, so sind vier technik-historische Konstellationen zu befragen, um zu bestimmen, wie sich technisch-mediale Logik und Körperlogik miteinander verkreuzen. Zunächst prägt die Entwicklung von Bewegtbild-Apparaten im 19. Jahrhundert das Verhältnis zwischen (Körper-)Bewegung, (Bewegt-)Bild und Wahrnehmung. Die Verbindung von Kinematografie und Biometrie zur physiologischen und arbeitswissenschaftlichen Erforschung von Bewegung, ihrer Vermessung und Berechnung, etabliert ihrerseits eine spezifische Relation zwischen Bewegung und Bewegtbild. Dabei gehen statistische Methoden in unterschiedlicher Weise in die Verfahren ein, als Bestimmung von Mittelwerten, Ähnlichkeiten, Abweichungen und ab dem frühen 20. Jahrhundert im Hinblick auf Optimierung und Verbesserung. Darüber hinaus wird „um 1900“ die Frage von Nachahmung und Mimesis in unterschiedlichen Disziplinen entlang des „neuen“ Mediums Film diskutiert, wobei auch und gerade die Frage der körperlichen Bewegung im Zentrum steht. In diesen vielfältigen Auseinandersetzung überkreuzen sich Wissensfiguren der Bewegungsvermessung und (versuchten) -berechnung mit der Möglichkeit, Bewegung vom Körper abzulösen und mit Vorstellungen der medialen Fernwirkung und Suggestionskraft von Film auf die Betrachter. Eine weitere genealogisch relevante Konstellation lässt sich in der Kybernetik und ihren Forschungen zu Steuerung und Bewegungswissen ausmachen.

Die diskursive und imaginäre Überkreuzung von technisch-medialer Logik und Körperlogik für das Verhältnis von Bewegung, Bild und Wahrnehmung wird im Folgenden schlaglichtartig an ausgewählten historischen Konstellationen beleuchtet. Gefragt wird, wie darin die Verkreuzung der Bewegungsordnungen diskurshistorisch plausibel wird und welche Aufführungsformen damit erscheinen.

Der Beginn der Erforschung und der Erzeugung von Bewegungsillusion setzt mit der Untersuchung des Zaunphänomens ein.

Im Januar 1821 wies der Buchhändler John Murray im von ihm selber verlegten Quarterly Journal of Science (praktisch ein Publikationsorgan der Royal Society) auf eine seltsame Erscheinung hin: Beobachtet man das Speichenrad eines fahrenden Wagens durch ein feststehendes Gitter, so sieht man ein mit dem Rad verbundenes, aber nicht rollendes strauchartiges Gebilde krummer Streifen. Am 9. und 16. Dezember 1824 hielt Peter Mark Roget, einer der Sekretäre der Royal Society, vor eben dieser einen Vortrag über das Zaunphänomen, und im November 1828 veröffentlichte Joseph Antoine Ferdinand Plateau in Quetelets Correspondance 
mathématique et physique einen Beitrag, in dem er das Zaunphänomen mit dem Sinneseindruck in Verbindung brachte, den gegenläufige Zahnräder machen. ${ }^{4}$

Der britische Physiker und Chemiker Michael Faraday untersucht genau solche Wahrnehmungsphänomene - Täuschungen, die durch sich drehende Zahnund Wagenräder erzeugt werden. ${ }^{5}$ Grund dafür ist die ,visuelle Überlagerung“ rotierender Räder, welche von Faraday mit dem Nachbildeffekt im Auge verbunden, als Impulsserie von Lichtereignissen erklärt, aber in den Kontext von Frequenzereignissen und Magnetismus gestellt wird. ${ }^{6}$ In dem Artikel beschreibt Faraday auch ein Experiment, das den später sogenannten Stroboskopeffekt erfahrbar macht. Dabei schaut ein Betrachter von hinten zwischen den schnell rotierenden langen „Zähnen“ eines Zahnrades in einen Spiegel und sieht in der Reflexion ein stehendes Zahnrad. Die „stroboskopischen Scheiben“, etwa zeitgleich von Joseph Plateau und Simon von Stampfer erfunden, nutzen diesen Effekt.

Der Aufsatz, in dem Plateau das Phenakistiskop vorstellt, ist auf den 20. Januar 1833 datiert, aber bereits in Quetelets Correspondance 1832 abgedruckt. Darin bezieht er sich explizit auf ein Experiment Faradays. Er beschreibt zunächst, wie eine Scheibe mit 16 Feldern und 16 Schlitzen dem Auge als bewegungslos erscheinen könne: ,comme l'a montré M. Faraday, à qui l'on doit cette éxperience [...]: vous y distinguerez les seize fentes, ainsi que les seize lignes qui séparent les secteurs, dans un état de fixité absolue`. Als nächsten Schritt setzt Plateau seine Apparatur ein, um ein bewegtes Bild vorzuführen.?

In dieser Entwicklung löst sich die Bewegung vom Körper und wandert in die Apparate. Es existiert keine Darstellung von Bewegung, sondern nur deren Illusion in der Wahrnehmung, die mittels eines Kraftfelds (dem Stroboskopeffekt in der Faraday'schen Lesart) zwischen Auge (Nachbild) und dem Momentbild entsteht. Etwa zeitgleich veröffentlichen die Brüder Weber mit der „Mechanik der menschlichen Gehwerkzeuge ${ }^{\text {“8 }}$ eine Berechnung des menschlichen Gangs. Sie zielen darauf, die Wahrheit über das Gehen, unabhängig von Willkür, Individualität und Untergrund des Gehenden zu fassen. Aufbauend auf Vermessungen von Leichen und dem Gang lebender Soldaten und deren statistischen Auswertungen im Hinblick auf einen „normalen“ Gang, berechnen sie den Doppelschritt eines Menschen mittels Differenzialgleichungen und

4 Bernhard Siegert, „Spectres. Faradays Experimente 1830-31“, in: Apparaturen bewegter Bilder, hg. v. Christoph B. Schulz und Daniel Gethmann, Münster, 2006, S. 36-50: 37.

5 Michael Faraday, „On a Peculiar Class of Optical Deceptions“, in: Experimental Researches in Chemistry an Physics, London, 1859 [engl. OA 1831], S. 291-311.

6 Vgl. Siegert (2006), Spectres; Irina Kaldrack, Imaginierte Wirksamkeit. Zwischen Performance und Bewegungserkennung, Berlin, 2011, S. 177 ff.

7 Joseph Wachelder, „Bewegte Bilder? Bewegte Scheiben! Die Wunderscheiben Joseph Plateaus und Simon Stampfers und ihre Rezeption“, in: Apparaturen bewegter Bilder, hg. v. Christoph B. Schulz und Daniel Gethmann, Münster, 2006. S. 96-122: 102.

8 Wilhelm Weber und Eduard Weber, Mechanik der menschlichen Gehwerkzeuge. Eine anatomischphysiologische Untersuchung, Göttingen, 1836. 
stellen Phasenbilder dieser Berechnungen her ${ }^{9}$. Bewegung wird dabei als Veränderung von Lage und Form des Körpers verstanden, die durch Pendelgleichungen berechenbar ist, und sich in Form der Phasenbilder an einen zu überzeugenden Betrachter richtet.

Während die Brüder Weber noch beobachten und die Zeit des Gehens stoppen müssen, nutzt (und entwickelt) der Mediziner und Physiologe ÉtienneJules Marey die Chronofotografie ${ }^{10}$. Mittels einer drehbaren Schlitzscheibe vor dem Objektiv der Kamera nimmt diese mehrere Momentaufnahmen eines Bewegungsablaufs in Form von Mehrfachbelichtungen auf eine fotografische Platte auf. Entscheidend ist, dass Marey die Bewegung visuell von den Körperbildern ablöst: Er stattet die Modelle mit schwarzer Kleidung aus, auf die weiße Punkte und Striche gemalt sind. Es entstehen Folgen wellenartig angeordneter Geraden und Punkte, die eine Bewegungsabfolge darstellen, z. B. Laufen oder Springen. Bewegung ist also nicht mehr Veränderung von Lage und Form eines Körpers, sondern Veränderung der relativen Lage von Punkten und Strichen zueinander. Damit löst sich die Bewegung nun in der Selbstabbildung vom Körper und zeigt gerade in ihrer Abstraktion und Schematisierung ihre Wahrheit - insofern die geometrischen Linienfolgen als Kurvengrafen physiologisch ausgewertet werden. Abstraktion und Berechnung machen die Wahrheit über Bewegung zugänglich, während sie sich mittels Bewegung der Apparate richtig abbildet (Chronofotografie) und als Kraft in die Wahrnehmung überträgt, so dass der richtige Bewegungseindruck entsteht.

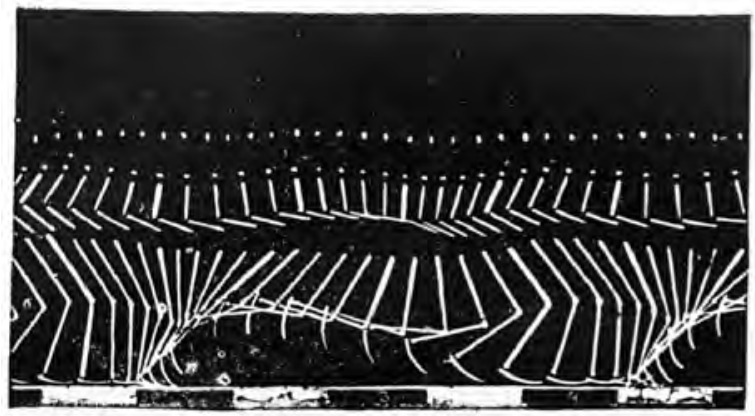

1 - Kurvengraph eines Läufers, Chronofotografie von Étienne-Jules Marey

In den 1910er Jahren löst Frank Bunker Gilbreth die Erforschung von Bewegung vom biomechanischen Modell ab, zugunsten eines Effizienz- und

9 Siehe ebd.; Hans-Christian von Herrmann, Das Archiv der Bühne, München,, 2005, S. 160 ff.; Friedrich Kittler, „Der Mensch, ein betrunkener Dorfmusikant“, in: Bühnen des Wissens. Interferenzen zwischen Wissenschaft und Kunst, hg.v. Helmar Schramm, Berlin, 2003, S. 300-318.

10 Siehe Étienne-Jules Marey, Die Chronophotographie (Kinematograph Nr. 2), aus dem Französischen übersetzt von A. von Heydebreck, Frankfurt/M., 1985. [Frz. OA 1893.] 
Trainingsgedankens. Er lässt die zerhackte Bewegung der Chronofotografie als Lichtspur erscheinen und baut diese als Drahtmodell nach. ${ }^{11}$

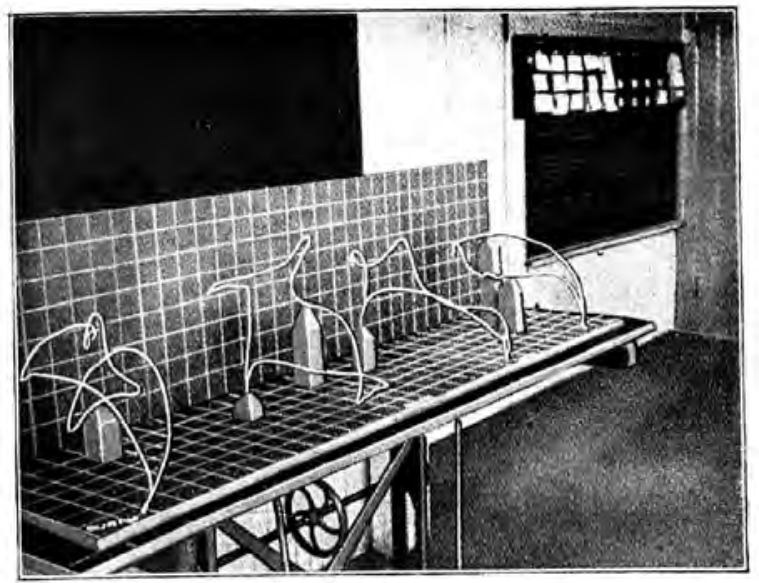

2 - Handbewegungen bei der Bedienung einer Bohrmaschine, Drahtmodelle von Frank Gilbreth und Lillian Moller Gilbreth

Entscheidend ist, dass die Arbeitswissenschaft in der Tradition von Taylors Scientific Management Bewegung in elementare Bewegungen zerlegt. Gilbreths Bewegungsstudien haben das Ziel, elementare Arbeitsbewegungen zu identifizieren und zu verbessern, indem unnütze Bewegungen eliminiert werden. Gilbreth entwickelt unterschiedliche Messinstrumente und -routinen (weiter), um auf Basis der Messung von Bewegung diese zu verbessern. So stattet er die Hände der Arbeitenden sowie die Werkzeuge und Maschinen mit Glühlampen aus und nimmt die Arbeitsbewegungen mit stereoskopischen Kameras auf. Die Bewegung erscheint als Lichtspur auf der Fotografie. Um genaue Informationen über die Zeitspannen zu enthalten, erlöschen die Glühlampen in kurzen Abständen. Auf Basis dieses Verfahrens werden die Arbeitsbewegungen verschiedener Arbeiter vermessen und nach Schnelligkeit, Wirksamkeit/Effizienz und geringstmöglicher Ermüdung beurteilt. Daraufhin wird eine ideale Bewegung als Norm bestimmt und diese als Drahtmodell verräumlicht. Es geht also bei Gilbreth nicht mehr um die Berechnung von Bewegung, sondern um ihre Optimierung. Sein Verfahren zielt auf die Extraktion von (typischen) Bewegungsmustern, welche in eine Norm überführt werden und als eine Art Spur vergegenständlicht werden. Zugespitzt formuliert, muss dieses Modell von den Arbeitenden aufgeführt werden. Es geht hier vordergründig

11 Zu Gilbreths Studien siehe Claus Pias, Computer Spiel Welten (2000), online unter: http://e-pub.uniweimar.de/volltexte/2004/37/pdf/Pias.pdf, zuletzt aufgerufen am 05.03.2013, S. 26 ff. und von Herrmann (2005), Das Archiv der Bühne, S. 167 ff. 
nicht um Rhythmen und Kräfte im Zusammenspiel mit Maschinen, sondern um eine Bewegung der Wiederverkörperung und Verzeitlichung der Form.

Im Rücken der hier skizzierten Entwicklung einer positivistischen Bewegungsauffassung bildet sich ein Verständnis heraus, das Bewegung der Intuition und dem Gefühl, dem Nicht-Rationalen und Metaphysischem zuschlägt und mit den Suggestionsvorstellungen des neuen Mediums Film kurzgeschlossen wird. Diese Vorstellung heftet sich an das physiologische Wissen der Bewegung an und wertet es um. Dabei schließt diese Bewegungsvorstellung auch an zeitgenössische Praktiken von Mesmerismus und Hypnose an.

Für diese Vorstellung ist die Popularisierung von Nietzsches Geburt der Tragödie und seine Unterscheidung zwischen Appolinischem und Dionysischem zentral. Das Appolinische der Kunst ist bei Nietzsche dem Traum, dem Visuellen und dem Bildnerischen zugehörig, während das Dionysische zum Rausch und der Musik gehört. Diese beiden wesenshaften Seiten der Kunst sind damit an den Leib gebunden, der dadurch „zur vorsprachlichen und vortheoretischen Quelle der Kunst ${ }^{\text {“12 }}$ wird. Auf Seiten der Kunst ist das Dionysische der Musik zugehörig, auf Seiten des Leibes der Bewegung, genauer dem Tanz. Musik, Tanz und Rausch haben dabei das Potenzial, durch Sympathie oder Erregung von einem auf andere Körper überzugreifen, und diese zu verwandeln. Das heißt, hier wird Tanz und Bewegung als etwas entworfen, das unbewusst und unsprachlich, rauschhaft und für den sich Bewegenden nicht (vollständig) kontrollierbar ist. Dabei kann Bewegung Zugang zum vorsprachlichen und vortheoretischen Wesen der Kunst verschaffen und sich von Leib zu Leib übertragen. Zeitgenössische Experimente und Vorstellungen hypnotisierter Frauen führen vor, dass und wie die Musik als unsichtbare Kraft auf die nicht-bewussten Körper wirkt und diese in Bewegung versetzt. Auch der „Freie Tanz“ und seine Protagonistinnen und Protagonisten knüpfen an dieses Bewegungswissen an: So kann tänzerische Bewegung den Zugang zum ursächlich Lebendigen bieten und dieses auf Zuschauer übertragen.

Gleichermaßen verbindet sich das neue Medium Film mit der Frage der Wahrnehmung und der Übertragung von Bewegung. Dabei wird Film als Objektivierung (und Steuerung) psychologischer Wahrnehmungsstrukturen - von Aufmerksamkeit, Gedächtnis und Phantasie - beschrieben ${ }^{13}$ und in diesem Sinne als Optisch-Unbewusstes konzeptionalisiert ${ }^{14}$. Gleichermaßen wird Film im Hinblick auf seine Wirkung befragt und auf Nervenreizungen sowie Erregungszustände der Zuschauer bezogen. Insbesondere schließen frühe Kinotheorien an tradierte Vorstellungen der Massenpsychologie an und deren Denkfiguren von Übertragung und Hypnose..$^{15}$ In dieser Gemengelage er-

12 Ebd., S. 184.

13 Hugo Münsterberg, The Photoplay. A Psychological Study, Appleton, 1916.

14 Walter Benjamin, Das Kunstwerk im Zeitalter seiner technischen Reproduzierbarkeit. Drei Studien zur Kunstsoziologie, Frankfurt/M., 1996. [OA 1955; frz. OA 1936.]

15 Siehe Michael Gamper, „Charisma, Hypnose, Nachahmung. Massenpsychologie und Medientheorie“, in: Trancemedien und neue Medien um 1900: ein anderer Blick auf die Moderne (Schriften- 
scheint Film als etwas, das geeignet ist, „Erfahrungen technisch von einem Individuum aufs nächste zu übertragen. ${ }^{\text {"16 }}$

Bewegung löst sich vom Körper und wirkt qua Film auf Bewegung, so ließe sich sehr verkürzt die für Kinect relevante Tradition benennen, die in dieser Zeit ihren medial-epistemischen Ausgang nimmt. Die Wirksamkeit ist nicht an Beobachtung und Interpretation gebunden, sondern passiert im Modus der „taktilen Gewöhnung“. Dabei fungiert Kinematografie als Test- und Trainingsumgebung, die Bewegung als Oberflächenphänomen vermisst und im Hinblick auf Verhalten testet. ${ }^{17}$

Die filmische Übertragung im Modus der taktilen Gewöhnung entspricht auf Seiten der Zuschauer Nachahmung und Mimesis. So stellt Marcel Mauss in seiner Begründung des Begriffs und Forschungsfelds der Körpertechniken heraus, wie „die amerikanische Gangart durch das Kino bei uns verbreitet zu werden “ ${ }^{18}$ begann und charakterisiert, dass Körpertechniken technische und physische Handlungen sind, die Wirksamkeit haben und durch Nachahmung erworben werden..$^{19}$ Mit dieser Verbindung von Wirksamkeit und Nachahmung - die Mauss insbesondere aus magisch-ritualen Praktiken ableitet - sind Körpertechniken der Mimesis nahe, die ihrerseits Praktiken der Magie verbunden ist. Wulf schlägt anknüpfend daran folgende Lesart vor:

Mimesis wäre dann die Kraft, die durch Angleichung an die ,urhebende natura naturans' Einfluß über diese gewinnt. In der Mimesis gäbe es nicht wie in der Wissenschaft die Subjekt-Objekt-Spaltung und den Versuch eines Subjekts, die zum Objekt gemachte Welt zu erkennen und zu beherrschen. Sondern durch Angleichung und Annäherung des in enger Beziehung zur Natur stehenden Menschen soll die Natur im Sinne des Menschen beeinflußt werden. Der Umwelt wird das nahegelegt, was man von ihr als Mensch erwartet. ${ }^{20}$

Während also Bewegung durch die Apparate in die Wahrnehmung übertragen wird und darin gewissermaßen unterhalb der Bewusstseinsschwelle als Verhalten auftritt, gleicht sich der Rezipient in eigener Bewegung körpertechnisch daran an. Als Aufführung gefasst, verbinden sich Übertragung qua Medientechnologie, eine Art Kraftfeld der Mimesis sowie ein Training zur verkörpernden Bewegung.

Die tatsächlich erfahrbare Wirksamkeit der eigenen Bewegung in Hinblick auf medientechnologische Darstellungen (und nicht im magischen Verhältnis

reihe Medienumbrüche 39), hg. v. Markus Hahn und Erhard Schüttpelz, Bielefeld, 2009, S. 351373.

16 Ute Holl, Kino, Trance \& Kybernetik, Berlin, 2002, S. 24.

17 Vgl. Benjamin (1996), Das Kunstwerk im Zeitalter seiner technischen Reproduzierbarkeit, S. 23 ff. und S. $40 \mathrm{ff}$.

18 Marcel Mauss, Die Techniken des Körpers, in: Soziologie und Anthropologie. Band 2, Frankfurt/ M., 1989 [frz. OA 1935], S. 199-220: 202.

19 Siehe ebd., S. 205.

20 Christoph Wulf, „Mimesis“, in: Vom Menschen, hg. v. Christoph Wulf, Weinheim, Basel, 1997. S. 1015-102: 1024. 
zur Umwelt) wird in der Kybernetik zentral. In der kybernetischen Auseinandersetzung und den begleitenden Experimenten wird am Beispiel der Bewegung die Frage des Verhältnisses von Regel und Freiheit diskutiert, die zentral für die Frage der Selbstorganisation war. Dabei wird auf der einen Seite überhaupt die Steuerung durch Bewegung in die informatorische Realität überführt und mit arbeitswissenschaftlichen Methoden untersucht. ${ }^{21}$ Auf der anderen Seite wird erforscht, welchen impliziten Regeln gerade auch willkürliche Bewegungen folgen. Angelehnt an Riegers Rekonstruktionen ${ }^{22}$ der Experimente zeichnet sich Bewegung durch implizite Selbstoptimierung in Hinblick auf ihr Ziel aus, welches sie während des Tuns immer wieder selbst entwirft. Dieses Wissen der Bewegung ist allerdings nur im Fremdverhältnis möglich - es zeigt sich in experimentellen Anordnung und ist immer nur nachträglich lesbar.

Kinect, so lässt sich in Anschluss an diese schlaglichtartige Rekonstruktion sagen, verschränkt die Praktiken der Test- und Beobachtungsumgebungen, das Imaginäre einer Bewegungswahrnehmung im Modus von taktiler Gewöhnung und Mimesis mit ihrem Suggestions- oder Steuerungspotenzial mit den Vorstellungen einer adaptiven selbstoptimierenden Bewegungspraxis zwischen Freiheit und Regel. Dabei realisiert sich Mimesis als vorahmende Bezugnahme auf die dargestellten Situationen. In der Überblendung von körperlicher Bewegungslogik und technisch-medialer Logik nähert sie sich auch an Letztere an, geht aber nicht komplett darin auf.

\section{Kinect als Bühne}

Kinect etabliert eine Aufführungssituation, insofern es auf die Verkörperung einer Situation zielt; diese Verkörperung lässt sich präziser als Bezugnahme auf das Dargestellte - das Bewegtbild und sein Imaginäres - beschreiben. Die Bezugnahme basiert wiederum auf einer Art Selbstoptimierung von Bewegung, die gleichsam die Synchronisation von technisch-medialer Logik und körperlicher Bewegungslogik in den Nutzungspraktiken ermöglicht. Dabei sind zwei epistemische Traditionen für diese Synchronisation entscheidend: Die technisch-mediale Logik Kinects knüpft an ein (prä-kinematografisches) Imaginäres an. Darin löst sich Bewegung vom Körper, wandert in die Apparate und wirkt auf die körperliche Bewegung der Nutzer. Auf Seiten der Wahrnehmung und der sich Bewegenden wiederum entspricht die Selbstoptimierung der Vorstellung von Mimesis als einer Kraft der Angleichung, welche das Bewegtbild und seine Darstellungen beeinflusst. In den Nutzungspraktiken erscheint die Synchronisation oder Überblendung der Logiken als Bezugnah-

\footnotetext{
21 Siehe Pias (2000), Computer Spiel Welten, S. 25 ff. und S. $66 \mathrm{ff}$.

22 Stefan Rieger, Kybernetische Anthropologie. Eine Geschichte der Virtualität, Frankfurt/M., 2003, S. 348-422.
} 
me auf das Bewegtbild, als Auslösen, Vorahmen und Nachahmen, die Technologie und Körperlogik verknüpfen und die Sematisierung der Bewegung zu Verkörperung, Aktion und Handlung ermöglichen.

Die Raumordnung, die Kinect etabliert, ist relational - man könnte von einer Schichtung unterschiedlicher Relationsgefüge sprechen. In der hier vorgeschlagenen Perspektivierung lässt sich eine Ebene der materiellen Räumlichkeit konstatieren, die die räumliche Anordnung umfasst, die Wirkungsrelationen zwischen körperlicher Bewegung und medialen Effekten (Vermessung, Abbildung, Transformation) sowie den Aufforderungscharakter, den die Darstellungsform mit ihren sozialen Konventionen und die Regelhaftigkeit der Wirkungen etabliert. Auf der Ebene der Erfahrung realisieren sich die Relationen zwischen Körper und Darstellungen als mimetische Bewegungsformen, die durch Schnelligkeit und Rhythmen, Ähnlichkeiten, Effizienz und Handhabbarkeit organisiert sind. In der Ausbildung von Bewegungsgefühlen als Qualität, Angemessenheit oder Exaktheit verdichten sich die Relationen und ermöglichen die Semantisierung von Bewegung als Bezugnahme. Damit wiederum geht die Verkörperung und Verräumlichung der dargestellten Situation einher. In Hinblick auf den Raum lässt sich daraus schließen, dass dieser erst aus der Bewegung und ihrer Erfahrung entsteht, als ein Körperraum, der sich in Bezug zum Bewegtbild setzt. Das hieße, der Kinect'sche Raum entsteht in der Zirkulation zwischen materieller Räumlichkeit, durch Erfahrung konkretisiertem Körperraum und den Darstellungen, wobei die Möglichkeit der Zirkulation selbst auf historisch tradierten Epistemen der Übertragung und Mimesis fußt. Die Frage der Bühne verschiebt sich damit auf die Frage, mittels welcher Praktiken und innerhalb welcher Diskurse materiell-technologische Anlage und erfahrungsgeprägter Körperraum ins Verhältnis gesetzt werden und welche Raumform in diesen Relationen entsteht.

\section{Literatur}

Benjamin, Walter, Das Kunstwerk im Zeitalter seiner technischen Reproduzierbarkeit. Drei Studien zur Kunstsoziologie, Frankfurt/M., 1996. [OA 1955; frz. OA 1936.]

Crogan, Patrick, „The Nintendo Wii, Virtualisation and Gestural Analogics“, In: Culture Machine 11 (2010), online unter: http://www.culturemachine.net/index.php/ cm/article/view/374/397, S. 82-101, zuletzt aufgerufen am 06.08.2013.

Faraday, Michael, „On a Peculiar Class of Optical Deceptions“, in: Experimental Researches in Chemistry an Physics, London, 1859 [engl. OA 1831], S. 291-311.

Gamper, Michael, „Charisma, Hypnose, Nachahmung. Massenpsychologie und Medientheorie“, in: Trancemedien und neue Medien um 1900: ein anderer Blick auf die Moderne (Schriftenreihe Medienumbrüche 39), hg. v. Markus Hahn und Erhard Schüttpelz, Bielefeld, 2009, S. 351-373. 
Gilbreth, Frank B./Gilbreth, Lillian Moller, Angewandte Bewegungsstudien. Neun Vorträge aus der wissenschaftlichen Betriebsführung, Berlin, 1920.

Haß, Ulrike, Das Drama des Sehens. Auge, Blick und Bühnenform, München, 2005.

Holl, Ute, Kino, Trance \& Kybernetik, Berlin, 2002.

Kaldrack, Irina, Imaginierte Wirksamkeit. Zwischen Performance und Bewegungserkennung, Berlin, 2011.

Kittler, Friedrich, „Der Mensch, ein betrunkener Dorfmusikant“, in: Bühnen des Wissens. Interferenzen zwischen Wissenschaft und Kunst, hg.v. Helmar Schramm, Berlin, 2003, S. 300-318.

Marey, Étienne-Jules, Die Chronophotographie (Kinematograph Nr. 2), aus dem Französischen übersetzt von A. von Heydebreck, Frankfurt/M., 1985. [Frz. OA 1893.]

Mauss, Marcel, Die Techniken des Körpers, in: Soziologie und Anthropologie. Band 2, Frankfurt/M., 1989 [frz. OA 1935], S. 199-220.

Münsterberg, Hugo, The Photoplay. A Psychological Study, Appleton, 1916.

Pias, Claus, Computer Spiel Welten (2000), online unter: http://e-pub.uni-weimar.de/ volltexte/2004/37/pdf/Pias.pdf, zuletzt aufgerufen am 05.03.2013.

Rieger, Stefan, Kybernetische Anthropologie. Eine Geschichte der Virtualität, Frankfurt/M., 2003.

Shotton, Jamie et al., „Real-Time Human Pose Recognition in Parts from Single Depth Images“ (June 2011), online unter: https://research.microsoft.com/pubs/145347/ BodyPartRecognition.pdf, zuletzt aufgerufen am 30.06.2013.

Siegert, Bernhard, „Spectres. Faradays Experimente 1830-31“, in: Apparaturen bewegter Bilder, hg. v. Christoph B. Schulz und Daniel Gethmann, Münster, 2006, S. 36-50.

von Herrmann, Hans-Christian, Das Archiv der Bühne, München, 2005.

Wachelder, Joseph, „Bewegte Bilder? Bewegte Scheiben! Die Wunderscheiben Joseph Plateaus und Simon Stampfers und ihre Rezeption“, in: Apparaturen bewegter Bilder, hg. v. Christoph B. Schulz und Daniel Gethmann, Münster, 2006. S. 96-122.

Weber, Wilhelm/Weber, Eduard, Mechanik der menschlichen Gehwerkzeuge. Eine anatomisch-physiologische Untersuchung, Göttingen, 1836.

Wulf, Christoph, „Mimesis“, in: Vom Menschen, hg. v. Christoph Wulf, Weinheim, Basel, 1997. S. 1015-1029. 


\section{RÄUME ENDEN}





\section{WIE MAN EINEN QUANTENSPRUNG TANZT, ODER: BÜHNE DES BEGEHRENS, BÜHNE DES TRIEBS. VERSUCH ÜBER LAURENT CHÉTOUANES ZÜRCHER PUBLIKUMSBESCHIMPFUNG}

„Verbringen wir unsere Zeit damit zu dekonstruieren, was schon dekonstruiert ist? Oder wagen wir einen Quantensprung?“ Mit diesen Worten hat Laurent Chétouane einmal seine neueren choreographischen Arbeiten kommentiert ${ }^{1}$, und in der Tat: Wer die Conditio sine qua non des zeitgenössischen Tanzes in der Kritik oder eben Dekonstruktion choreographischer Traditionen sieht, insofern diese der langen Geschichte der „Ideologie des Ästhetischen“ (Paul de Man) $)^{2}$ verhaftet sind, der muss von Chétouanes künstlerischer Entwicklung spätestens seit Tanzstück \#4: leben wollen (zusammen) (2009) irritiert sein. Denn die bewährten Strategien der Auseinandersetzung mit einer solchen Ideologie scheinen hier in durchaus skandalöser Weise suspendiert: Die Arbeiten sind augenscheinlich kaum von „negativen“ Entzugsbewegungen und Stillstellungen getragen, keine Exponierung von „Abwesenheit“ ist hier zu entdecken, kein „Tanz, der nicht tanzt“ nachzuvollziehen. Stattdessen sehen sich die Zuschauer eigentümlich weichen und fließenden Choreographien gegenüber, harmonischer, klassisch wirkender Musik, und einem nachgerade anmutigen Miteinander der tanzenden Körper. Und, besonders irritierend vor dem Hintergrund eines Tanzdiskurses, der speziell mit der Erbschaft und dem Formenkanon des Balletts hadert: Immer wieder zitieren die Stücke Ballettfiguren. „Schön war's“ - lapidar hat die Tanzkritikerin Astrid Peterle zu Beginn eines Artikels über Chétouanes horizon(s) (2011) eine Ratlosigkeit auf den Punkt gebracht, die diese Arbeiten in den letzten Jahren häufig ausgelöst haben. ${ }^{3}$

Nun geht es Chétouane sicher nicht um eine Rücknahme kritischer Einsichten über „schöne“ Ästhetiken, über ihre naturalisierenden Effekte und ihre daraus folgende ideologische Besetzbarkeit etwa, oder überhaupt über ihren zwanghaften Charakter, der daraus resultiert, dass ihnen für gewöhnlich ein

1 „Im Konzept-Schutzgebiet. Laurent Chétouanes Hommage an das Zaudern“, in: F.A.Z. vom 17.12.2011, S. 38.

2 Vgl. Paul de Man, Die Ideologie des Ästhetischen, Frankfurt/M., 1993.

3 Astrid Peterle, „Die Zukunft des Tanzes? Laurent Chétouane mit ,Horizon(s)“ im Tanzquartier Wien“, in: Corpus - Internetmagazin für Tanz Choreographie Performance vom 24.04.2011, online unter: http://www.corpusweb.net/die-zukunft-des-tanzes.html, zuletzt aufgerufen am 12.08.2013. 
Set unausgesprochen wirkender Regeln zugrunde liegt. Und dennoch scheint sich in diesen Tanzstücken der Impuls zu artikulieren, ein mögliches Jenseits solcher Erkenntnisse zu erkunden. Dabei legt die Rede vom Quantensprung nahe, dass hier nicht mehr, aber auch nicht weniger auf dem Spiel steht als ein minimaler Wechsel der Perspektive, eine leichte Verschiebung, mit der sich dennoch alles zu ändern scheint. Doch wie lässt sich dieser Wechsel genauer fassen?

Ich möchte in diesem Essay zwei miteinander verknüpften Überlegungen oder auch thematischen Zentren nachgehen: Zum einen scheint mir Chétouanes „Quantensprung“ in genuiner und genauer zu beschreibender Weise mit der Erforschung raum-zeitlicher Potenziale der Bühne zusammenzuhängen und grundsätzlich auf einen Prozess der Verräumlichung zu zielen. Dabei geht es allerdings weder um einen simplen Auszug aus der neuzeitlichen Bildbühne, wie sie sich, in sehr unterschiedlichen Varianten, im 17. Jahrhundert eingerichtet hat, noch um eine weitere Offenlegung und Durchleuchtung ihrer Ideologieanfälligkeit. Eher lässt sich vielleicht sagen, dass Chétouane in ein und derselben Geste die repräsentativen Momente dieser Bühne durchstreicht und sie auf das verzweigte historische Material hin öffnet, das sich in ihr angesammelt hat. Am besten scheint mir die fragliche Bewegung daher als eine Umfaltung charakterisierbar zu sein, mit der die Formelemente der Bühne keineswegs „verabschiedet“ werden, mit der aber nichtsdestotrotz ein signifikanter Statuswechsel verbunden ist.

Zum anderen, und das wäre die zweite Überlegung, scheint mir in Chétouanes künstlerischer Suchbewegung eine theoretische Frage widerzuhallen, die heute vielfach und in widersprüchlicher, oft genug polemischer Weise diskutiert wird. Sie betrifft das Problem, ob es möglich ist, sich grundsätzlich in einem Jenseits oder Außerhalb der Repräsentation zu bewegen oder nicht. Dabei kann man in der Diskussion, trotz all ihrer Schattierungen und im Bewusstsein um die Holzschnittartigkeit solcher Zusammenfassungen, zunächst zwei widerstreitende Pole ausmachen: Auf der einen Seite eben „dekonstruktive“ Perspektiven, die sich einer radikalen Repräsentationskritik verpflichtet fühlen, zugleich aber darauf beharren, dass ein Jenseits der Repräsentation ein präsenzmetaphysischer Traum bleiben muss. Und auf der anderen Seite Ansätze, die sich auf Deleuze/Guattaris Immanenzdenken, beispielsweise ihre Begriffe des „reinen Werdensflusses“ oder des „ein Leben“ berufen - Begriffe also, die eine Ebene unterhalb jeder Repräsentation zu bezeichnen suchen und aus deren Perspektive speziell die für die Dekonstruktion so wichtige Figur eines „einbrechenden Anderen“ als ein, vielleicht überkommenes, in jedem Fall zu überwindendes monotheistisches Erbe erscheinen muss. ${ }^{4}$

4 Jean-Luc Nancy hat die Spannung zwischen der Dekonstruktion und dem deleuzianischen Immanenzdenken auf den Begriff der „Parallelen Differenzen“ gebracht (in: ders./René Schérer, Ouvertüren. Texte zu Gilles Deleuze, Zürich, Berlin, 2008, S. 31-50). In ähnlichem Kontext sieht auch der Bochumer Medienwissenschaftler Erich Hörl heute Figuren des „QuasiTranszendentalismus“ und der „reinen Immanenz“ um die Auslegung der „sinngeschichtli- 
Ich möchte mich der Spannung, die damit angesprochen ist, nun allerdings von einer anderen, dritten Referenz her nähern, die für Chétouanes Arbeiten eine nicht minder große Rolle spielt als die Dekonstruktion oder das Denken von Deleuze, die zu diesen beiden Bewegungen aber wiederum eine verschobene Stellung einnimmt: von der Psychoanalyse Jacques Lacans (die unter anderem im Programmheft zu horizon(s) als theoretische Referenz angeführt wird). Das mag auf den ersten Blick überraschen, scheint doch gerade Lacans „Lehre“ die Frage nach einem Jenseits der Repräsentation bzw. einem Jenseits der „symbolischen Ordnung“ erst gar nicht zu stellen, sondern ihr Reich zu zementieren, was sich etwa in vielzitierten Formeln wie „Ein Signifikant repräsentiert das Subjekt für einen anderen Signifikanten“ oder „Das Unbewusste ist strukturiert wie eine Sprache“ anzeigt. Doch meine These ist, dass sich von Lacans Spätwerk her ein differenzierteres Bild ergibt. Denn ab einem nicht genau zu bestimmenden Punkt seiner Entwicklung - den man in Zusammenhang mit dem gesellschaftlichen Umbruch der sechziger Jahre bringen kann - sieht Lacan sich von etwas dazu genötigt, frühere Konzepte Punkt für Punkt um widerstreitende Begriffe zu ergänzen, die sich wie eigenartige Doppelgänger ausnehmen und die in der breiteren Rezeption meist nicht aufgenommen wurden. (Zu nennen wären etwa Begriffspaare wie Begehren/Trieb, Symptom/ Sinthom, Herrendiskurs/analytischer Diskurs und noch viele andere. ${ }^{5}$ ) In dieser aporetischen Erweiterung aber, so will es mir scheinen, rumort genau jene vielleicht unlösbare Problematik, die sich heute in neuer Form in der angesprochenen Diskussion niederschlägt.

Von besonderer Bedeutung ist in diesem Zusammenhang, dass Chétouanes Bühnenarbeit auch der szenischen Erkundung von Begehrensstrukturen gilt. Es scheint mir deswegen durchaus nahezuliegen, den „Quantensprung“ seiner neueren Bühnenarbeiten in Bezug auf Lacans Konterkarierung des Begriffs des Begehrens durch den des Triebs in den Blick zu nehmen, die zum ersten Mal in Lacans Seminar XI auftaucht. Aus der Perspektive späterer Seminare kann sie als wichtiges Moment einer Suche nach möglichen Alternativen zur „klassischen“ Theorie angesehen werden, in der das Begehren und überhaupt die Subjektivierung immer einer väterlichen Referenz unterliegen. Allerdings geht es nicht um einen absoluten Bruch, sondern eben um eine aporetische Erweiterung. Diese lässt sich nicht im Modell eines zeitlichen Verlaufs fassen, sondern zielt auf eine widersprüchliche Gleichzeitigkeit: Auch die letzten Seminare verabschieden die väterliche Referenz nicht vollständig und im Sinn

chen“ Lage wetteifern (vgl. Erich Hörl, „Die künstliche Intelligenz des Sinns. Sinngeschichte und Technik im Anschluss an Jean-Luc Nancy“, in: Zeitschrift für Medien- und Kulturforschung 2 (2010), S. 129-147). Die damit angesprochene Debatte prägt des Weiteren auch die neueren Diskussionen um den Begriff des Affekts (vgl. bes. Marie-Luise Angerer, Vom Begehren nach dem Affekt, Zürich, Berlin, 2007).

5 Lacan arbeitet diese Begriffe etwa in den Seminaren XI, XVII, XX und XXIII aus. Dabei gehe ich davon aus, dass Lacan die besagte Spannung nicht auflösen konnte, die sich darum gerade heute als offene Frage aus seinem und an sein Werk ergibt. 
einer Teleologie, sondern akzentuieren ihren Status als Version - als sogenannte „Pére-Version““. ${ }^{6}$ Und wie ich im Folgenden zeigen möchte, kann man eine ähnliche Figur in Chétouanes Umgang mit dem neuzeitlichen Bühnenkasten und seinen Traditionen entdecken.

\section{Publikumsbeschimpfung I: Zwischen Sprechen und Tanz}

Es soll um eine neuere Arbeit Chétouanes gehen, die sich meines Erachtens in besonderer Weise um die genannten Figuren dreht und die gewissermaßen den Quantensprung selbst auf der Bühne sichtbar werden lässt: eine Inszenierung von Peter Handkes Publikumsbeschimpfung, die im Herbst 2010 insgesamt nur wenige Male im Zürcher Theater am Neumarkt zu sehen war. Es handelt sich also nicht explizit um ein Tanzstück, wie Chétouane sie in einer unabgeschlossenen Serie seit 2007 entwickelt. Stattdessen kombiniert und verflicht Publikumsbeschimpfung Elemente des Sprechtheaters und des Tanzes, ähnlich wie es zuvor auch schon die Inszenierungen Empedokles/Fatzer, Dantons Tod oder Faust taten, in denen jedes Mal Tänzer zu den Schauspielern hinzugezogen wurden. Dabei generiert die Choreographie in „Publikumsbeschimpfung“ wiederum jene eigenartige Schönheit, die auch Tanzstück \#4: leben wollen (zusammen) und horizon(s) kennzeichnet. (Publikumsbeschimpfung ist zwischen diesen beiden Produktionen entstanden.) In diesem Fall wirkt sie sogar besonders befremdlich. Denn abgesehen von der Frage nach ihrem Status kontrastiert sie auch in auffallender Weise die „negative“ Stoßkraft von Handkes Text, der ja über weite Strecken eine Theatertradition nach der anderen verabschiedet. Jedenfalls scheint in dieser Spannung das wichtigste Skandalon für die (insgesamt recht verständnislosen) Tageskritiken der Inszenierung zu bestehen, die etwa erstaunt feststellen, dass hier trotz der grundsätzlichen Verweigerungshaltung der Publikumsbeschimpfung eine Fülle von „berückend schönen Bildern“" produziert werde. ${ }^{\text {" }}$

Die drei Schauspieler Romana Schröter, Franziska Wulf und Malte Sundermann bilden zusammen mit der israelischen Tänzerin Sigal Zouk das Ensemble der Inszenierung. Zouk hat eine besondere Position inne: Bis auf wenige, aber wichtige Ausnahmen bleibt sie stumm, während die anderen fast ununterbrochen Handkes Sätze sprechen. Mal hält Zouk sich abseits von den Dreien, tastet allein ihren Körper ab oder lässt sich ruckartig in die Knie fallen; dann wieder sucht sie die größtmögliche Nähe zu ihnen, setzt sich etwa direkt zu Wulf an den Biertisch (einer der wenigen Gegenstände auf der Bühne) und

6 Vgl. hierzu Lacans (bislang nicht auf Deutsch vorliegendes, aber auf Englisch im Internet zirkulierendes) Seminar XXI, „Les non-dupes-errent“ von 1973/1974.

7 Alexandra Kedves, „Handkes Bildersturm als Körpertheater“, in: Tagesanzeiger vom 09.10.2010. 
pickt zu deren Worten Trauben aus einem Obstglas, nascht eine, wirft andere in Richtung Zuschauerraum.

Die Konstellation der Inszenierung könnte man zunächst also als „, $3+1$ “ beschreiben. Andererseits aber bilden die vier Darsteller, wenn sie einander immer wieder umfassen, an den Händen nehmen, zögernd durch die Haare streichen oder sich ineinander verrenken, deutlich auch ein einziges Ensemble, das Formen und Rhythmen des gemeinsamen Erscheinens auf einer Bühne erprobt: Ein Geflecht von sich annähernden Körpern, wie es ähnlich bereits in Tanzstück \#4 zu sehen war. Manchmal scheinen die Vier sich sogar, passend zum Thema einer „Publikumsbeschimpfung“, zu einer einzigen, verschworenen Gruppe zusammenzufinden, die sich still über die Zuschauer amüsiert, wenn auch solche Momente der vollständigen Schließung nur verschwindend kurze Zeit dauern. Die Inszenierung oszilliert insofern beständig und fast ununterscheidbar zwischen zwei Strukturprinzipien: Zwischen einer „3 + 1“-Anordnung und einer einzigen, in sich differenzierten Menge. Dabei lässt sich gleich hinzufügen, dass ein solches permanentes Kippen zwischen einer differenzierten Gesamtheit und einer durch eine definierende Teilung charakterisierten Menge sich in Chétouanes Umgang mit dem Bühnenraum wiederholt und potenziert. Denn einerseits handelt es sich beim Bühnensaal des Zürcher Theaters am Neumarkt gerade nicht um eine klassische Guckkastenanlage mit ihrer krassen Zweiteilung zwischen Publikum und Darstellern, sondern um einen architektonisch ungeteilten Raum, der nicht als Theater entworfen wurde. Zuschauer und Spieler bilden hier deutlich eine einzige Versammlung, was noch dadurch unterstrichen wird, dass die Fenster auf der rechten Seitenwand des Saales sich im Bereich der Spielfläche fortsetzen - etwas, das einem Verständnis der Bühne als fensterlosem Innenraum, wie es sich im 17. Jahrhundert installiert hat, per definitionem widerspricht. Wie in anderen seiner Inszenierungen (beispielsweise Büchners Lenz) lässt Chétouane die Spieler von diesen Fenstern denn auch ausgiebig Gebrauch machen. Andererseits aber zitiert und reflektiert die konfrontative Anordnung von Publikum und Spielern in der Inszenierung geradezu überdeutlich die zentralperspektivische Anlage des Guckkastens mit Rampe und Zuschauerreihen. Das ist auch - aber nicht allein - mit Blick auf Handkes „Antitheatertext“ von Bedeutung, der mehrfach auf die ideologische Besetzbarkeit dieser Architektur abzielt, wobei die entsprechenden Stellen ihre besondere Schärfe vor dem Hintergrund der NS-Vergangenheit (die Uraufführung fand 1966 statt) bekommen: „Sie bilden ein Muster. Sie sitzen in einer gewissen Ordnung. Ihre Gesichter zeigen in eine gewisse Richtung. [...] Sie bilden eine Einheit.“8

Was bedeutet dieses Wechselspiel nun für die vier Darsteller? Aus der ersten, der „3 + 1“-Perspektive betrachtet, kann man Zouks Position als die eines überzähligen vierten Elements charakterisieren, das dennoch niemals

8 Peter Handke, Publikumsbeschimpfung, in: ders., Prosa Gedichte Theaterstücke Hörspiel Aufsätze, Frankfurt/M., 1969, S. 180-211: 183 f. 
von der Gruppe abgetrennt werden kann, deren Teil es ist. Diese eigentümliche Gleichzeitigkeit von Fremdheit und Zugehörigkeit wird durch andere Momente der Inszenierung bekräftigt. So spricht Zouk etwa die ersten Worte des Abends (und des Stücktextes): „Sie sind willkommen!“99 Aber sie spricht sie mit ihrem spezifischen Akzent, der auf deutschsprachige Hörer stark verzerrend wirkt und die Worte ins Unverständliche treibt. Publikumsbeschimpfung wird somit gleichsam von einem Schwellenpunkt her eröffnet, einem Ort der Fremdheit, der kein gemeinsames Zuhause voraussetzt, gerade dadurch aber zur zeitweiligen Gemeinsamkeit in einem (Theater-)Haus einlädt. Willkommen sind die Zuschauer hier offenbar als Fremde, vielleicht auch als „Fremdlinge im eigenen Hause“, um eine Wendung aus Hölderlins Hyperion aufzugreifen. Dabei kann man durchaus daran erinnern, dass ähnliche Einladungen, speziell im Zusammenhang mit Zouks Akzent in früheren Inszenierungen Chétouanes, oft genug Empörung auslösten: Bei Faust II in Weimar (2008) ließen einzelne Zuschauer sich ob der „Unverständlichkeit“ des Gehörten zu „Goethe hilf!“-Rufen hinreißen, und nach Dantons Tod in Köln (2010) wurde sogar darüber diskutiert, ob Zouk auf einer deutschen Bühne überhaupt „sprechen dürfe“. Solche Reaktionen haben vor dem Hintergrund der israelischen Herkunft Zouks sicherlich noch einmal eine besondere Färbung, die auch in Publikumsbeschimpfung mitschwingt - schließlich zielte Handke mit seinem Text durchaus explizit auf mutmaßliche NS-Verstrickungen des Uraufführungspublikums. Entscheidend ist aber, dass Zouk hier wie in den anderen Inszenierungen gerade nicht als Repräsentantin auftritt. Ihr Akzent steht in radikaler Weise für nichts, aber gerade dieses Nichts lässt sie auf der Bühne unverwechselbar, für manche anscheinend auch unerträglich werden.

Diese Zusammenhänge scheinen sich emblematisch in einem weiteren Requisit des Abends zu verdichten und verdoppeln: einem Totenkopf, der nicht nur an Hamlet denken lässt, das paradigmatische Stück der europäischen Theatertradition also, sondern auch an den anamorphotisch verzerrten Totenschädel auf Hans Holbeins Bild Die Gesandten. Und tatsächlich liegt es nahe, Zouks Stellung innerhalb des Ensembles mit einer solchen Anamorphose zu vergleichen: Auch diese ist ein überzähliges Objekt, das dennoch der Darstellung untrennbar zugehört; auch diese ist eine Schwellenfigur. Denn einerseits lässt die mit der anamorphotischen Verzerrung mögliche Verdoppelung oder sogar Vervielfältigung von Perspektivpunkten das Bild ins Räumliche kippen, andererseits jedoch kann sie als besonderes Faszinosum des Bildes dessen Ordnung auch nur vervollständigen oder supplementieren. Mit Blick auf Lacan lässt sich hingegen schon einmal festhalten, dass Seminar XI Holbeins anamorphotischen Totenschädel als direkte Manifestation des „Objekt a“ (in seiner Variante als „Blick“) deutet, jenes rätselhaften, überschüssigen Objekts

9 Ebd., S. 183. 
also, zu dessen Eigenschaften unter anderem gehört, das Begehren des Subjekts anzutreiben. ${ }^{10}$

All diese Aspekte treffen nun aber, wie gesagt, erst und ausschließlich die „3 + 1“-Komponente der Inszenierung. Die zweite mögliche Perspektive, die der ungeteilten, doch in sich differenzierten Gesamtheit, öffnet sich hingegen dort, wo die gemeinsame Choreographie das verwobene Geflecht der vier Körper akzentuiert und dabei eine berückende Intimität zwischen den Darstellern entstehen lässt. Mit dieser Ebene setzt die Inszenierung nun einen deutlichen Kontrapunkt gegenüber Handkes Textvorlage, der sie zugleich zu ihren spielerischsten, auch humorvollsten Momenten finden lässt. Heißt es bei Handke zum Beispiel: „Sie sehen nicht die Hintertür, durch die der, der nicht gesehen werden soll, hinausschlüpfen kann [...]. Es gibt keine Hintertür“11, dann schlüpft im nächsten Moment Malte Sundermann aus der von den anderen dreien überdeutlich fokussierten Hintertür der Bühne (die, ähnlich wie die Fensterfront, eine reale Gegebenheit des Raumes ist). Und wenn Handke schreibt: „Sie hören nicht das falsche Geräusch einer ins Schloss fallenden Tür“'12 - was auch als Negation der Türschlagkomödie verstanden werden kann - dann fällt in Chétouanes Inszenierung im nächsten Moment mit gewaltigem Knall die Tür ins Schloss. (Freilich stellt der Knall auch wieder einen Kontrapunkt im Kontrapunkt dar, schließlich handelt es sich beim Zufallen der Tür in der Tat nicht um ein „falsches“, das heißt einem illusionistischen Effekt dienendes Geräusch.)

Diese Ebene, die dem Text widerstreitet und bisweilen in sich noch einmal gefaltet ist, zieht sich durch die gesamte Inszenierung und bildet, neben Zouks besonderer Position, ihr zweites hervorstechendes Charakteristikum. Manchmal kristallisiert sich der Einspruch lediglich in kurzen, ironischen Pointen, zum Beispiel wenn Sundermann den Satz „Wir machen keine Kunstpausen“"13 mit betonter Kunstpause zwischen „Kunst“ und „Pausen“ spricht. Der eigentliche Motor des Widerstreits aber ist die Choreographie der vier Spieler: Sie generiert gewissermaßen eine autonome, bewegliche Körperskulptur, die Handkes Sätze permanent kommentiert, bricht oder bestätigt und damit letztlich überprüft - fast wie ein antiker Chor.

Nun ist, wie gesagt, die Choreographie zugleich auch die Quelle dessen, was in der Inszenierung als (durchaus irritierend) schön wahrgenommen wird: die körperliche Nähe, der Fluss der Bewegungen, die sanfte Ironie der Aktionen und überhaupt die träumerische Leichtigkeit des Abends, die noch durch kontemplativ wirkende, kurze Einspielungen von Scarlatti-Fragmenten verstärkt wirkt. Es stellt sich also zum einen die Frage, wie die Distanznahme ge-

\footnotetext{
10 Vgl. Jacques Lacan, Die vier Grundbegriffe der Psychoanalyse. Das Seminar Buch XI, Berlin, Weinheim, 1978, S. 94 f. Entscheidend ist, dass das Objekt a, je nach seinem Auftrittsort, sehr unterschiedliche Rollen übernimmt und die verschiedensten Funktionen innehat.

11 Handke (1969), Publikumsbeschimpfung, S. 189.

12 Ebd., S. 186.

13 Ebd., S. 191.
} 
genüber Handkes Text und die tänzerische Schönheit genauer zusammenhängen und wie beide Momente sich mit dem Thema der Bühne verknüpfen. Und zum anderen gilt es zu klären, wie sich die „3 + 1“-Organisation und die „Gesamtmenge“ genau zueinander verhalten. Und genau hier scheint es mir nun sinnvoll, einen Sprung zu Lacans begrifflicher Differenzierung zwischen Begehren und Trieb zu machen.

\section{Begehren und Trieb}

In seinen frühen Seminaren, insbesondere in den Seminaren IV bis VII ${ }^{14}$, entwickelt Lacan die Logik des Begehrens in striktem Bezug zum ödipalen Drama und zur (Un-)Möglichkeit einer genealogischen Abfolge. Doch es wäre ein Fehler, das Thema auf den Familialismus zu beschränken. Worum es bei näherem Hinsehen wirklich geht, ist die Frage nach Struktur und Einrichtung von Institutionen. Denn der Ursprung des Begehrens wird hier letztlich in der immer auch traumatischen Erfahrung eines Anderen verortet, der vielfach besetzbar ist und nicht zwingend mit dem Personal der ödipalen Matrix gefüllt werden muss (wo zunächst die Figur der Mutter den Ort dieses Anderen einnimmt).

Ob also Familie oder nicht - die Konfrontation mit diesem Anderen ist in sich bis zum Zerreißen gespannt: Zum einen erscheint er als Absolutum, als gleichermaßen faszinierendes wie erschreckendes „Ding“; zum anderen aber wohnt ihm ein rätselhaftes Begehren inne, dessen genauer Inhalt letztlich für beide Seiten ungreifbar bleibt: „Che voui?“, „Was willst du?“, lautet die unlösbare Frage an den Anderen, die sich in diesem Moment stellt. Vielleicht kann man die Konstellation mit der Situation Josef K.s aus Kafkas Process vergleichen: Von einer Instanz - in diesem Fall dem Gericht - ins Visier genommen zu sein, die einerseits als allmächtige und ubiquitäre Institution erscheint, andererseits jedoch den Gegenstand ihres Interesses an K., das heißt den Inhalt der Anklage, zu keinem Zeitpunkt artikuliert. ${ }^{15}$ Aber auch Handke zielt in Publikumsbeschimpfung darauf ab, die Zuschauer einem solchen Blick auszusetzen (und sie damit zugleich ihrer „voyeuristischen“ Sicherheit zu be-

14 Vgl. hierzu auch die von Lacan autorisierte Zusammenfassende Wiedergabe der Seminare IVVI durch Jean-Bertrand Pontalis. Aus dem Französischen v. Johanna Drobnig, unter Mitarb. v. Hans Naumann und Max Kleiner, mit einem Vorw. v. Hans-Dieter Gondek, hg. v. HansDieter Gondek und Peter Widmer, Wien, 2008.

15 Ein ähnliches, weniger drastisches Beispiel wäre das Unbehagen, das einen zuweilen überfallen kann, wenn man eine institutionelle Auszeichnung (z. B. einen Titel) erhält oder eine neue Stelle antritt: Was mag der Grund der Zuwendung, des Interesses sein, das die Institution an mir hegt? Kann ich ihm gerecht werden? Ist nicht alles ein Missverständnis? Der berühmte, für Lacan wie Deleuze/Guattari wichtige Fall Schreber hat denn auch genau mit einer solchen „paranoischen“ Situation zu tun: Schrebers Psychose brach aus, als er überraschend zum Gerichtspräsidenten ernannt wurde. (Zu einem möglichen Bezug zwischen Schreber und Kafka vgl.: Eric Santner, Zur Psychopathologie des Alltagslebens, Zürich, Berlin, 2010.) 
rauben). „Sie empfinden das Unbehagen derer, die angeschaut und angesprochen werden, wenn Sie von vorneherein bereit waren, selber im Dunkeln zu schauen und es sich behaglich zu machen “16, heißt es in seinem Stück. Und in Bezug auf Chétouane lässt sich festhalten, dass auch seine Choreographien ein ähnliches Moment kennen: Regelmäßig treten in ihnen Spieler hervor, um einzelne Zuschauer mit Blicken zu fixieren, die in ein und demselben Moment als durchbohrend und leer wahrgenommen werden, als zielten sie auf etwas, das sich zugleich innerhalb und jenseits der angeblickten Person befindet. Nicht in jeder Inszenierung haben die Blicke diese Funktion, in Publikumsbeschimpfung jedoch werden die - oder besser: einzelne - Zuschauer öfter solchen sphinxhaften und als durchaus unangenehm erfahrenen Momenten ausgesetzt.

Von einer Instanz angesprochen oder ,gemeint“ zu sein, die selbst nicht sagen kann, was der Grund ihrer Zuwendung ist, wird also in hohem Maße als krisenhaft empfunden. Für gewöhnlich bewegen sich die Reaktionen, bei allen möglichen Abstufungen, zwischen zwei Polen: der als unerträglich intensiv empfundenen Nähe des Anderen zu entfliehen (was den Versuch einschließt, diesen zu beseitigen), oder danach zu streben, sein rätselhaftes Begehren „korrekt“ zu beantworten. Aus psychoanalytischem Blickwinkel definieren diese beiden Pole darum das schwierige Verhältnis zwischen Mutter und Kind, insofern dieses zwischen Flucht/Aggression und „inzestuöser“ Einheitsphantasie changiert. Die „Alles oder nichts“-Spannung dieser Situation ist erst durch das Dazwischentreten einer dritten Instanz, einer - väterlich konnotierten - Sperre oder Barre, zu bewältigen. Dabei müssen die Klischees, Verkürzungen und auch Polemiken, die sich seit Entstehung der Psychoanalyse um diese Intervention ranken, hier nicht noch einmal aufgezählt werden; entscheidend ist der paradoxe Kern der Konstruktion: Die väterliche Grenzziehung verbietet etwas - den Versuch, eine dyadische Einheit, ein „totales Genießen“ herzustellen das ohnehin unmöglich wäre. Damit aber stellt sie die Dyade letzten Endes als möglich dar. Denn die „Barre“ lässt das, was sie absperrt, im selben Moment als grundsätzlich erreichbar erscheinen, gerade weil sie es unerreichbar macht. Und an diese Illusion kann sich nun ein Begehren knüpfen, das sich als fortwährender Drang zur Überschreitung darstellt und letztlich mit dem Aufschub synonym ist. Begehren ist in dieser Version eine niemals zu befriedigende Suche nach dem Absoluten, was es zugleich zentralperspektivisch ausgerichtet erscheinen lässt. Es handelt sich um ein melancholisches Begehren, denn alle Gegenstände, die es zu erfüllen versprechen, bleiben Trug- und Ersatzobjekte, die höchstens vorübergehende „Entladungen“ zulassen. Mit anderen Worten heißt das: Die paternale Geste des (zeitlichen) Aufschubs installiert letztlich einen illusorischen Ort, der niemals eingenommen werden kann - Freud verortet hier etwa die mythische Figur des Urvaters. Dieses Moment verleiht der gesamten Anordnung Züge der Kant'schen Transzendentalphilosophie, auch wenn es sich lediglich um einen „Quasi-Transzendentalismus“ handelt.

16 Handke (1969), Publikumsbeschimpfung, S. 190. 
Für das Thema der Bühne ist nun von Bedeutung, dass das Begehren von den beiden Größen des Bildes und der Zeit abhängt. Denn zum einen wird die rätselhafte „Anrufung“ durch den Anderen zunächst mit phantasmatischen oder auch fetischistischen Imaginationen beantwortet, die stabilisierende, aber notwendig falsche Antworten über deren konkrete Inhalte liefern - ähnlich wie Josef K. in Kafkas Process beständig über den Inhalt der Anklage phantasiert, um auf seine Verhaftung reagieren zu können. Oder vielleicht auch wie der Zuschauer, der von Chétouanes Tänzern qua Blick fixiert wird und unwillkürlich über die Motivation der Blicke zu rätseln beginnt („Was bedeutet dieser Blick?“, „Warum bin gerade ich aus der Menge der Zuschauer ausgewählt worden?"). Aber auch der Vater baut in dem Moment, in dem er die Anrufung durch die Verhängung der „Barre“ abmildert, ein Trugbild auf. Er unterbricht zwar die momentane Illusion, das heißt die Vorstellung, die Phantasie über das Begehren des Anderen sei dessen gültige Repräsentation, lässt aber die Illusion bestehen, dass es grundsätzlich eine vollständige Antwort/Repräsentation geben könne. Die beruhigende und zugleich aktivierende Funktion dieses Phantasmas besteht darin, dass sie den wahren Schrecken verbirgt, die Tatsache nämlich, dass der Andere sich selbst fremd ist, selbst nicht wissen kann, worauf sein Begehren in letzter Instanz zielt. Oder um noch einmal das Beispiel des Process heranzuziehen: Viel unheimlicher als einer zwar unbekannten, aber grundsätzlich konsistenten Anklage gegenüberzustehen wäre die Erkenntnis, dass das Gericht selbst nicht die geringste Ahnung hat, warum es einen anklagt.

Das Moment der Zeit wiederum kommt durch den Aufschub ins Spiel, der mit der Barre eingesetzt wird. Es handelt sich zwar nicht so sehr um eine teleologische als vielmehr um eine messianische Zeitlichkeit, die aber dennoch von einem illusorischen Zielpunkt, einem Absolutum abhängt: Von der Möglichkeit eines totalen Genießens, die freilich nur an einem vollständig unmöglichen Zeitpunkt, im Außerhalb jeder denkbaren Zeit lokalisiert und niemals realisiert werden kann. Gelingende Genealogie kann aus dieser Perspektive also nur „gelingendes Scheitern“ sein: Die Bedingung der Unmöglichkeit des Begehrens ist zugleich die Bedingung seiner Möglichkeit. Dabei neigt die illusorische Stelle des vollständigen Genießens (des totalen Bildes, der erfüllten Zeit) dazu, sich noch im aufgeklärtesten oder kritischsten Wissen um die Unvollständigkeit jeder Repräsentation zu erhalten. Sie stellt gewissermaßen die beharrlich wiederkehrende Rückseite, vielleicht sogar die unhintergehbare Voraussetzung eines solchen Wissens dar. Um etwa in einen Dialog mit einem Anderen zu treten, müssen wir uns einerseits permanent selbst unterbrechen und uns daran erinnern, dass wir ihn (noch) nicht verstanden haben; zugleich kommen wir aber nicht umhin, mit dem Moment einer grundsätzlichen Verstehbarkeit zu operieren, wie sehr wir auch um dessen illusorischen Status wissen oder es als absolut entzogen setzen. Vielleicht kann man in der Unhintergehbarkeit dieser Illusion, die sich gerade in ,antihermeneutischen“ Praktiken immer wieder einstellt, darum auch jene Seite der Dekonstruktion sehen, 
mit denen Chétouane in seiner eingangs zitierten Bemerkung hadert (und zwar bei aller gebotenen Vorsicht und allen Detailunterschieden zwischen den Konzepten des Anderen in Psychoanalyse und Dekonstruktion).

Entscheidend ist jedenfalls, dass im Modell des Vaters die Erfahrung der notwendigen Unvollständigkeit und der Unerreichbarkeit des Anderen (auch für diesen selbst) mit der phantasmatischen Bindung des Begehrens und dem zeitlichen Muster der genealogischen Abfolge verknüpft wird. Und vor diesem Hintergrund lässt sich nun genauer beschreiben, inwiefern dieses Modell solidarisch mit solchen Bühnenformen ist, die einerseits die Bildlichkeit in den Vordergrund stellen (und sei es in repräsentationskritischer Absicht) und die andererseits zeitliche Abläufe aus ihrer räumlichen Einbettung herausdifferenzieren.

Zunächst handelt es sich bei diesen beiden Merkmalen in der Tat um die wichtigsten Charakteristika des Übergangs zu den (früh-)neuzeitlichen Guckkästen nach 1600. Dabei gibt es vor allem eine barocke Bühnenanlage, die wie eine direkte architektonische Umsetzung des gesamten Zusammenhangs wirkt: Die Bühne von Andrea Pozzo, die man geradezu als Idealmodell einer „Bühne des Begehrens“ oder auch einer „Bühne der Genealogie“ bezeichnen könnte. ${ }^{17}$ Denn einerseits richtet Pozzo zum ersten Mal ein Theater vollständig unter dem Kriterium der konfrontativen Bildlichkeit ein, während der Zusammenhang von Zeit und Raum zerreißt, der speziell den mittelalterlichen Stationenbühnen als eschatologische Verklammerung eingesenkt war - der Guckkasten inszeniert zeitliche Abläufe als Nacheinander von Bühnenbildern, nicht als Nebeneinander von Stationen, die in einen einzigen Raum, eine einzige Landschaft eingebettet sind. Und andererseits installiert Pozzo den einzigen Betrachterstandpunkt, von dem aus man das Bühnenbild unverzerrt sehen könnte, als unmöglichen Platz in der Rückwand hinter den Zuschauern, so dass in seinem Theater streng genommen jeder auf dem falschen Platz sitzt, jeder ein unvollständiges Bild hat. Der ideale Ort des unmöglichen Betrachters entspricht damit exakt der uneinnehmbaren, quasi-transzendentalen Stelle des Freud'schen Urvaters, oder auch des totalen Genießens im Außerhalb jeder denkbaren Zeit. Zumindest potenziell ist mit ihm aber auch die kritische und sogar demokratische Funktion dieser Bühnenanlage verbunden: Niemand kann hier von sich behaupten, das richtige Bild zu haben, stattdessen muss die „Wahrheit“ des Gesehenen ausgehandelt werden, ohne dass sich jemand zum Statthalter der letztgültigen Repräsentation machen könnte. Der Un-Ort des unmöglichen Betrachters lässt sich darum auch als eine leere Referenz deuten, die weniger Gründungen als vielmehr „Verabgründungen“118 zulässt.

17 Vgl. zur Einrichtung von Andrea Pozzos Bühne: Ulrike Haß, Das Drama des Sehens, München, 2005, S. 366-380.

18 Vgl. zum Begriff der „Verabgründung“ Nikolaus Müller-Schöll, Das Theater des konstruktiven Defaitismus. Lektüren zur Theorie eines Theaters der A-Identität bei Walter Benjamin, Bertolt Brecht und Heiner Müller, Frankfurt/M., 2002. 
Speziell wegen dieses demokratischen Moments der Pozzo-Bühne ist zu betonen, dass es keinen Grund gibt, ihr Modell vorschnell und erst recht nicht im Sinn einer Fortschrittsgeschichte zu „verabschieden“. Dennoch gilt es, nach ihrem möglichen Jenseits zu fragen, was die Frage nach dem Jenseits des väterlichen Referenzmodells, des Begehrens und damit auch des genealogischen Prinzips einschließt. Und eben hier gewinnt nun Lacans Einführung des Triebs als einer Gegenfigur zum Begehren an Bedeutung. Zunächst ist dabei festzuhalten, dass der Trieb in einem Jenseits des Phantasmas (und damit des Bildes) lokalisiert ist, von dem das Begehren ja abhängt. Wenn Lacan die Analyse als einen Prozess fasst, in dem es darum gehe, das Phantasma zu „durchqueren“"19, dann kann man also folgern, dass die Zone des Triebs sich idealiter mit dem Ende einer Analyse öffnet - was allerdings sofort wieder alle Fragen nach teleologischem Verlauf, zeitlicher Folge und Grenzziehung ins Spiel bringt. Schon deswegen gilt es darauf zu beharren, dass Begehren und Trieb nicht absolut voneinander abgelöst werden können, wiewohl sie topologisch zwei getrennte Sphären markieren. Der Versuch einer realen Isolierung dürfte jedenfalls sehr schnell in Totalitarismus umschlagen.

Die Differenz lässt sich, entlang der Einführung des Triebs in Seminar $X I^{20}$, zunächst in einer Reihe von Entgegensetzungen fassen: Wo das Begehren in seinem Bezug auf das Absolute notwendig unerfüllt bleibt, da ist der Trieb immer schon erfüllt, sogar übererfüllt von Genießen. Wo das Begehren Produkt einer väterlichen „symbolischen Kastration“ ist und damit in eine Dialektik von Gesetz und Überschreitung verstrickt bleibt, da spielt der Trieb in einem Jenseits des Gesetzes (das freilich nicht ohne Bezug zum Gesetz ist). In ihren Extremformen lautet die Logik des Begehrens deswegen: „Ich möchte das Gesetz überschreiten, darum brauche ich es“, die Logik des Triebs hingegen: „Ob ich das Gesetz überschreite oder nicht, ist mir gleichgültig." Und wo schließlich der vertikale Fluchtpunkt des Begehrens im unerreichbaren Ding liegt, als dessen Substitut diverse Wunschobjekte auftreten, da beginnt das Reich des Triebs in dem Moment, wo die Totalität des Dings sich als Chimäre entpuppt und sich in eine horizontale, nicht mehr perspektivisch gebundene Vielzahl oder Mannigfaltigkeit zerstreut.

In Seminar XI gibt Lacan vom Trieb mehrere recht heterogene Bilder, was vermutlich den letztgenannten Aspekt der Vielzahl reflektiert. Im Kontext der choreographischen Arbeiten Chétouanes mit ihren topologischen Verflechtungen von Körpern (und Dingen) ist dabei das dritte Bild am aufschlussreichsten, das zusammen mit dem Aspekt der räumlichen Relationen auch ein Moment des Schönen ins Spiel bringt und zugleich in überraschender Nähe zu Deleuzes Begriff der Assemblage oder des Gefüges steht: „Ich möchte sagen“, heißt es bei Lacan,

19 Vgl. etwa Lacan (1978), Seminar XI, S. 288.

${ }^{20}$ Ebd., insbes. S. 127-210. 
wenn der Trieb irgendeiner Sache gleichsieht, dann einer Montage. Und zwar nicht einer Montage, die perspektivisch auf Zweckhaftigkeit bezogen wäre. [...] Die Montage beim Trieb präsentiert sich zuallererst ohne Schwanz und Kopf so wie man bei den Collagen der Surrealisten von Montage spricht. [...] Das Bild, das entsteht, [würde] eine in Gang befindliche Lichtmaschine darstellen, die an einen Gashahn angeschlossen ist, aus dem eine Pfauenfeder herausragt, die eine hübsche Frau am Bauch kitzelt, welche nur der Schönheit der Sache wegen da ist. ${ }^{21}$

Damit lässt sich noch ein letzter, entscheidender Unterschied zwischen Begehren und Trieb formulieren: Das Begehren bleibt letztlich beschränkt auf eine Dimension, die man die des Einzelwesens nennen könnte - deswegen ist seine Genese so deutlich verbunden mit dem, wenn auch struktural erweiterten oder in politische Souveränitätsstrukturen übersetzbaren familialen Rahmen. In diesen Kontext gehört aber auch die Fixierung des Begehrens auf die Figur eines herausgehobenen Anderen. (Noch einmal bei Chétouane: Der Blick auf einzelne, aus dem Publikum herausgerissene Zuschauer.) Mit dem Trieb hingegen öffnet sich die Sphäre der heterogenen und unabschließbaren Vielheit, die im Kontext des Theaters als Sphäre des Chorischen entziffert werden kann. Diese Sphäre ist es, die durch eine Überbetonung des Begehrens vernachlässigt wird und die, kein Zufall, in Pozzos Bühnenform vor allem als Störfaktor auftaucht. Insofern wird Lacans Frage nach dem Trieb auch als Teil einer Suche nach einer zweiten, „chorischen“ Dimension des Subjekts lesbar, die seiner Determinierung durch eine väterliche Genealogie unauflösbar widerstreitet. Allerdings ist die Asymmetrie dieses Widerstreits zu betonen. Begehren und Trieb spielen genauso wenig auf einer Ebene wie Einzelwesen und Chor. Sie sind daher auch nicht in Begriffen der Komplementarität oder des dialektischen Widerspruchs zu fassen. Am deutlichsten wird das, wenn man sich in Erinnerung ruft, dass die Sphäre des Begehrens mit dem Thema (und auch mit der Kritik) der Institutionen zusammenhängt, z. B. mit den Verfasstheiten von Familie, Gericht, politischer Souveränität oder eben der Bühne ab 1600. Mit der Sphäre des Triebs scheint sich hingegen die Frage eines weit weniger diskursiv artikulierbaren Jenseits jeder, zumindest jeder bekannten, Institution zu öffnen: weniger die Frage der Anti- als vielmehr die der Nicht-Institution. Der Unterschied lässt sich darum auch so formulieren, dass das Begehren untrennbar mit der Tatsache des Sprechens, des Signifikanten, verknüpft ist, während die unvermittelte Montage des Triebs ein Jenseits des Signifikanten eröffnet, das allerdings nicht ohne Bezug zum Signifikanten ist. ${ }^{22}$ Und vielleicht ist es

${ }^{21}$ Ebd., S. 178.

22 Neben der surrealistischen Montage ist darum Lacans zweites Bild für den Trieb in Seminar XI (S. 206-209) von Interesse: Der Mythos der „Lamelle“, eines untötbaren Lebens, das „keines Organs bedarf“ (S. 207), jede Gestalt annehmen kann und sich wie eine unmögliche Figuration der Lebenskraft unterhalb der sprachlichen Struktur ausnimmt. Lacan ist hier in großer Nähe zu Deleuze/Guattari, die mit ihrem „organlosen Körper“ den Akzent auf (zumindest scheinbar) nicht-sprachliche Vitalkräfte setzen. Dennoch bleibt die abgründige Frage nach 
genau diese Differenz, die mit Chétouanes Wechsel von Sprech- und Tanztheater auf dem Spiel steht.

Diese Bemerkungen führen zurück zu Publikumsbeschimpfung.

Publikumsbeschimpfung II: Wie man einen Quantensprung tanzt

Zunächst lässt sich nun deutlicher erkennen, was es mit den beiden verschiedenen Organisationsprinzipien von Chétouanes Inszenierung auf sich hat, mit der „3+ 1“-Struktur und der einen, in sich differenzierten Menge: Es handelt sich exakt um den Unterschied zwischen den Registern des Begehrens und des Triebs. Vor diesem Hintergrund erklärt sich, warum Zouks besondere Position innerhalb der „3 + 1“-Konstellation mit Lacans Begriff des Objekt a korreliert, das in der „Gesamtmenge“ keine Rolle mehr spielt. Denn in seiner Funktion als gleichermaßen faszinierendes wie irritierendes und auch störendes Etwas ist das Objekt a mit dem Begehren verknüpft und zudem in grundlegender Weise auf die Ordnung des Bildes (des Phantasmas) bezogen. Im Register des Triebs hingegen taucht es als solches nicht auf. Eher könnte man sagen, dass dort alles gleichermaßen Objekt a ist, und darum nichts mehr. Aus diesem anderen Status der Dinge und Objekte, die vom Trieb unaufhörlich neu montiert und gruppiert werden, erklärt sich darum auch ihre besondere affektive Kraft und es scheint mir letztlich genau diese Kraft zu sein, die in Chétouanes Tanzstücken den Effekt des Schönen hervorbringt.

Was bedeutet das nun für die Haltung der Inszenierung gegenüber Handkes Text? Schaut man sich Handkes „Antitheaterstück“ noch einmal genauer an, dann kann man zu dem Schluss kommen, dass es nach wie vor im Feld des Begehrens (und seiner Bühne) spielt. Es markiert gewissermaßen den äußersten Rand dieses Feldes, das gleichwohl seine grundlegende Referenz ist. Chétouane unternimmt demgegenüber den „Quantensprung“ ins Feld des Triebs, das aber dennoch in verschiedenen Aspekten unauflöslich mit dem Begehren verbunden bleibt.

Vor allem auf drei Ebenen der Inszenierung wird das deutlich. Zunächst zielt natürlich eine Publikumsbeschimpfung grundsätzlich auf eine konfrontative und damit bildliche Anlage, wobei hinzuzufügen ist, dass die eigentliche Beschimpfung erst am Ende von Handkes Stück steht: Auch Handke spielt bereits mit dem Entzug einer direkten Beschimpfung. Nichtsdestotrotz durchzieht seinen Text ein bestimmtes Bild (oder soll man sagen: ein notwendiges Phantasma?) von der Beschaffenheit des Uraufführungspublikums - eben die Tatsache, dass dieses sich zumindest zum Teil aus Zuschauern zusammensetzen musste, die in der ein oder anderen Weise in die NS-Geschichte verstrickt waren. Darauf zielen sowohl die zu Beginn bereits zitierten Assoziationen der

Vorgängigkeit und Nachträglichkeit des Signifikanten, auf die ich keine letztgültige Antwort habe. 
Theaterarchitektur mit einer totalitären Saalordnung als auch manche direkte Anreden: „Ihr KZ-Banditen“, „Ihr Genickschussspezialisten“, „Ihr Nazischweine“ ${ }^{23}$ Chétouanes Inszenierung hingegen nimmt dieses dialogische Moment, das ein Wissen um die mögliche Beschaffenheit des Publikums, und damit um seine wie auch immer aufgeschobene Darstellbarkeit, voraussetzt, entschlossen zurück, um im selben Moment von der Bildlichkeit zum Raum und zum tänzerischen Miteinander zu wechseln. Konfrontativ bleiben in seiner Publikumsbeschimpfung vor allem die bereits erwähnten Fixierungen einzelner Zuschauer, die an die Stelle der meist gestrichenen zeitgeschichtlichen Bezüge treten.

Wichtigstes Mittel für diese Rücknahme ist eine spezifische Art zu sprechen, die nicht zuletzt gegenüber Claus Peymanns Uraufführung vollkommen verändert scheint (wenn man Zeitzeugen glaubt). Denn die Sätze der Publikumsbeschimpfung von 2010 sind mit wenigen Ausnahmen auch dort, wo sie inhaltlich als Anrede geführt werden, niemals direkt gerichtet. Stattdessen lassen die drei Sprecher die Worte langsam und fast monoton aus ihren Mündern in den Raum fließen, wo sie sich zu einem eigenen, nicht dialogischen Gebilde verbinden, zu einer beweglichen Sprach- und Hörskulptur, die sich wie ein Drittes zwischen Zuschauerraum und Bühne ausbreitet. Der Tonfall ist dabei niemals aggressiv, auch nicht in der finalen Beschimpfung, im Gegenteil: Er bleibt während der gesamten Inszenierung gleichermaßen distanziert wie freundlich; eine Eigenart, die sich vielleicht auch als Brecht'sches Element beschreiben lässt. Es handelt sich weder um ein wertendes noch um ein urteilendes Sprechen, die Dinge bleiben buchstäblich in der Schwebe - analog zum Modus des Triebs, der nicht entscheidet, nicht bevorzugt, keine Grenzen zieht, sondern montiert.

Mit diesen Bemerkungen ist bereits die zweite Ebene berührt. Für Handkes Text ist eine grundsätzliche Negativität charakteristisch. Seine häufigsten Vokabeln sind „nicht“ und „kein“: „Wir sind keine Darsteller. Wir stellen nichts dar. Wir stellen nichts vor. “24 usw. In weiten Teilen liest Publikumsbeschimpfung sich darum als gigantischer Negativkatalog aller nur denkbaren Theatertraditionen, die eine nach der anderen ad acta gelegt werden. Aus dieser manchmal geradezu gebetsmühlenartig wirkenden Negation (es ist vermutlich nicht nur ironisch, wenn eine der vorangestellten „Regeln für Schauspieler“ empfiehlt: „Die Litaneien in den katholischen Kirchen anhören“(25) bezieht Handkes Stück eine Kraft, die deutlich der destruktiven Seite des Begehrens entspricht. Denn dieses kann auch die Gestalt einer seriellen Zurückweisung annehmen: Jedes erreichbare oder mögliche Objekt wird dann als Trugbild, als unzulängliche Repräsentation des Absoluten abgelehnt oder sogar zerschmettert. Man kann hier auch an die Anorexie denken, die Lacan zufolge ebenfalls

\footnotetext{
Handke (1969), Publikumsbeschimpfung, S. 209.

Ebd., S. 187.

25 Ebd., S. 180.
} 
eine Formation des Begehrens ist: Durch die Zurückweisung jeder möglichen Speise wird nicht nichts gegessen, sondern „das Nichts“. ${ }^{26}$ Und vielleicht ist es nicht übertrieben, wenn man Handkes Publikumsbeschimpfung einen anorektischen Zug bescheinigt. Wieder setzt Chétouanes Inszenierung genau an dieser Stelle an: Nicht nur der freundliche Tonfall widerstreitet der negativen Kraft des Textes. Wie eingangs bereits angedeutet, werden Handkes Negationen auch beständig durch die „positiven“ Aktionen auf der Bühne konterkariert, auch wenn diese häufig in sich noch einmal ironisch gebrochen sind: Beispielsweise wenn die angeblich nicht vorhandene Hintertür umso stärker bespielt wird, oder wenn auf den Satz „Ihnen wird kein Spiegel vorgehalten“27 hin ein Handspiegel an der angedeuteten Rampe entlanggetragen wird. (Der einen allerdings durch die Lichtreflexe der Scheinwerfer eher blendet als dass man darin etwas erkennen könnte.)

Drittens schließlich geht Handkes radikale Verneinung aller Traditionen mit einer Emphase der Gegenwart oder der Jetztzeit einher, die durchaus charakteristisch für eine avantgardistische Rhetorik des Bruchs ist. „Hier gibt es nur die Zeit, die wir, wir und Sie, am eigenen Leibe erfahren. Hier gibt es nur eine Zeit“, heißt es in Publikumsbeschimpfung ${ }^{28}$, oder: „Hier herrscht keine andere Zeit. Hier ist die Zeit Herrscherin, die nach Ihrem Atem gemessen wird.“29 Oder auch: „Hier gibt es nur ein Jetzt und ein Jetzt und ein Jetzt.“30 Diese Beschwörung des Momenthaften ist durchaus ambivalent. Sie kann einerseits als Feier der „Live-Situation“ verstanden werden, die letztlich eine Form des Versuchs darstellt, jenes reine Genießen „hier und jetzt“ zu verwirklichen, das durch das väterliche Gesetz untersagt bzw. als illusorisches Trugbild an einen unmöglichen Ort verschoben wird. Das wiederum ist typisch für einen 68erHedonismus, der genau dort problematisch wird, wo er als Ideologie direkter Bedürfnisbefriedigung eventuell nicht einnehmbare Stellen und Orte nicht anerkennen möchte. Hinzukommt, dass die Rückseite der Jetzt-Feier notwendig die alles andere als unschuldige tabula rasa-Haltung ist, die Handkes Text so eindrucksvoll zelebriert.

Andererseits kann man solche Stellen vielleicht auch als serielle Addierung von „Jetzt-Punkten“ lesen, die der Herrschaft der synthetisierten „einen Zeit“ widerstreitet. Problematisch bleibt die Serialität allerdings dann, wenn man sie als temporale Abfolge interpretiert. Denn als solche führt sie, gerade in Kombination mit einer avantgardistischen Rhetorik, in einen permanenten Innovationsdruck, der kaum von der Logik des Marktes mit seiner Gier nach Neuem, nach neuen „Jetzt-Punkten“, zu unterscheiden ist. Tatsächlich affirmiert Handke in frühen Essays und Reden, etwa in „Ich bin ein Bewohner des Elfenbein-

\footnotetext{
${ }^{26}$ Lacan (1978), Seminar XI, S. 110.

27 Handke (1969), Publikumsbeschimpfung, S. 185.

28 Ebd., S. 198. [Herv. S. K.]

29 Ebd., S. 193.

30 Ebd., S. 192.
} 
turms“'31, bei näherem Hinsehen diesen Innovationsdruck: Es gehe darum, ständig neue künstlerische „Methoden“ zu erfinden, weil jede Methode schon bei ihrer zweiten Anwendung zur „Schablone“ geworden sei, der sich dann die Werbung und die Trivialkunst bemächtigen könnten. In dieser Haltung liegt zwar ein wahres Moment, andererseits zwingt sie aber den Künstler dazu, in einen Wettlauf mit dem Markt oder auch dem „Spektakel“ einzusteigen, den er nicht gewinnen kann.

Auch diese beiden Aspekte konterkariert Chétouanes Inszenierung. Zunächst einmal problematisiert besonders eine Szene überdeutlich den Zusammenhang von Jetzt-Feier und tabula rasa: Die Spieler tragen Wischmobs, Eimer und Bürsten herein und beginnen buchstäblich, die Bühne zu säubern, was auch an die Thematik der „Säuberung“ im Nationalsozialismus (und darüber hinaus) denken lässt. Doch natürlich ließe sich die Bühne nur dann vollständig reinigen, wenn die Spieler sich selbst mit wegwischen würden oder auch die Bürsten sich selbst bürsten könnten. Wie man es also dreht und wendet - es bleibt immer ein Fleck übrig, ein Ort, der nicht eingenommen werden kann. An dieser Stelle wechselt die Inszenierung gerade nicht ins Feld des Triebs, sondern (re-)installiert gewissermaßen die väterliche „Barre“, deren Zerstörung die hedonistische Beschwörung des reinen Jetzt gilt.

Grundsätzlich allerdings widersetzen sich auch diesmal wieder der besondere Modus des Sprechens und das choreographische Element der Herrschaft sowohl der einen Zeit als auch der Abfolge der Jetzt-Punkte. Den spezifischen Gestus des Sprechens könnte man nämlich auch - was noch einmal die Brecht'sche Referenz hervorhebt - als den des Zitierens beschreiben. In und mit der „Sprachskulptur“, in der die Dinge nicht entschieden sind und in der Schwebe bleiben, öffnet sich ein Erinnerungs- und Gedächtnisraum, dessen spezifische Eigenschaften zusammen mit der Montage des Lacan'schen Triebs auch an Deleuzes/Guattaris Werdensbegriff erinnern. Denn die historischen Schichten und Momente erscheinen hier in ihrer Offenheit. Sie haben noch nicht ihre, vermeintlich, finale geschichtliche Gestalt angenommen und sind gerade deswegen in der Lage, neue und andere Zusammenstellungen und Konstellationen einzugehen. Genau dasselbe gilt für die tänzerischen Gesten und Bewegungen, die letztlich nichts anderes sind als sich beständig neu schreibende Relationen: eine Choreographie der „verzweigten Gegenwarten“32. Und wie das Sprechen erweckt auch diese Art des Tanzes den Eindruck, alle Zeiten in sich zu enthalten - mit der einen, entscheidenden Ausnahme der Jetztzeit. Das wiederum bedeutet eine direkte Umkehrung oder Umfaltung der Geste des „Hier und Jetzt“, die ja alle Zeiten zugunsten der einen Gegenwart suspendieren möchte.

31 Peter Handke, „Ich bin ein Bewohner des Elfenbeinturms“, in: ders. (1969), Prosa Gedichte Theaterstücke Hörspiel Aufsätze, S. 263-272.

32 Vgl. Ulrike Haß’ gleichnamigen Text über Chétouanes Tanzstücke \#3 und \#4, in: Martina Groß/Patrick Primavesi (Hg.), Lücken sehen .... Festschrift für Hans-Thies Lehmann zum 66. Geburtstag, unter Mitarbeit v. Katja Leber, Heidelberg, 2010, S. 291-302. 


\section{Von der Genealogie zur Nicht-Genealogie?}

Die Bühne des Triebs - die man auch als Bühne einer anderen Genealogie bezeichnen könnte - ist, zumindest bislang, vor allem als Einbruch in die Matrix der Bühne des Begehrens oder eben der väterlichen Genealogie, als deren Umfaltung formulierbar, nicht aber substanziell oder gar im Rahmen einer dauerhaften institutionellen Setzung zu fassen. Das liegt letztlich am Verhältnis von Trieb und Begehren, das dem eines Möbiusbandes gleicht: Der Trieb markiert zwar eine Sphäre im Jenseits des Gesetzes, steht aber dennoch in einem Bezug zu ihm. Allerdings heißt das nicht, dass diese Sphäre, wo sie im Theater hervortritt, die genealogische Bühne auch architektonisch voraussetzen würde; sie kann vielmehr auch und gerade in Räumen und an Orten inszeniert werden, die mit klassischen Theaterbauten wenig bis nichts zu tun haben. Nur wäre es eben ein Irrtum, dies als ein absolutes Jenseits oder ein zeitliches „Zurück“ vor den Einzug der Theater in die Innenräume um 1600 zu verstehen: Da diese Bewegung zum einen ein Produkt der barocken „Immanentisierung“ der Welt (Walter Benjamin) ${ }^{33}$ gewesen ist und sie zum anderen auch als grundsätzliche Markierung medialer Vermitteltheit begriffen werden kann, läuft der vorschnelle Auszug aus diesen Innenräumen immer Gefahr, präsenzmetaphysischen Wiederverschmelzungsphantasien nachzugeben. (Eine Gefahr, die beispielsweise die Ausgabe des Theaterfestivals Impulse von 2011 eindrücklich demonstrierte, deren Performances fast ausnahmslos unter dem Zeichen einer narzisstisch anmutenden Feier - oder eher Party - der Anwesenheit standen, die gerade nichts mit der Logik des Triebs zu tun hat.)

Nun scheint sich heute freilich die Bindekraft des genealogischen Prinzips, der einen der beiden Seiten also, auf einen Nullpunkt hinzubewegen, ohne dass auch nur annähernd deutlich wäre, was an ihre Stelle treten könnte - eine Situation, die schon deswegen ein Dilemma darstellt, weil diese Seite trotz all ihrer fragwürdigen Momente mit den Institutionen der repräsentativen bzw. parlamentarischen Demokratie verbunden ist. Umso stärker können sich daher in unbegriffener und sprachloser Form die Figuren des „nicht-genealogischen“ Pols mit den leerlaufenden institutionellen Logiken verbünden. Allerdings hat diese Melange kaum mehr das poetische Spiel mit ,verzweigten Gegenwarten " zur Folge, sondern eher das universelle Aufmerksamkeitsdefizitsyndrom einer „Hyper Attention“ (Bernard Stiegler) ${ }^{34}$. Ganz zu schweigen von neuen, nicht mehr zentralistisch lokalisierten Formen des Autoritarismus, die sie hervorbringt. Chétouanes choreographische Arbeit kann auch als Versuch begriffen werden, eine Sprache für diese Gemengelage zu finden, die vermutlich die

33 Vgl. Walter Benjamin, „Ursprung des deutschen Trauerspiels“, in: ders., Gesammelte Schriften, Band I.1, Frankfurt/M., 1974, S. 203-430.

34 Vgl. Bernard Stiegler, Die Logik der Sorge. Verlust der Aufklärung durch Technik und Medien, Frankfurt/M., 2008; und ders., Von der Biopolitik zur Psychomacht. Die Logik der Sorge I.2, Frankfurt/M., 2009. 
politische Signatur des 21. Jahrhunderts zunehmend prägen wird. Insofern ist der Hintergrund seiner Tanzstücke bei aller Schönheit alles andere als heiter.

\section{Literatur}

Angerer, Marie-Luise, Vom Begehren nach dem Affekt, Zürich, Berlin, 2007.

Benjamin, Walter, „Ursprung des deutschen Trauerspiels“, in: ders., Gesammelte Schriften, Band I.1, Frankfurt/M., 1974, S. 203-430.

de Man, Paul, Die Ideologie des Ästhetischen, Frankfurt/M., 1993.

Handke, Peter, „Ich bin ein Bewohner des Elfenbeinturms“, in: ders., Prosa Gedichte Theaterstücke Hörspiel Aufsätze, Frankfurt/M., 1969, S. 263-272.

Ders., Publikumsbeschimpfung, in: ders., Prosa Gedichte Theaterstücke Hörspiel Aufsätze, Frankfurt/M., 1969, S. 180-211.

Haß, Ulrike, Das Drama des Sehens, München, 2005.

Dies., „Verzweigte Gegenwarten. Zu den Tanzstücken \#3 und \#4 von Laurent Chétouane“, in: Martina Groß/Patrick Primavesi (Hg.), Lücken sehen .... Festschrift für Hans-Thies Lehmann zum 66. Geburtstag, unter Mitarbeit v. Katja Leber, Heidelberg, 2010, S. 291-302

Hörl, Erich, „Die künstliche Intelligenz des Sinns. Sinngeschichte und Technik im Anschluss an Jean-Luc Nancy“, in: Zeitschrift für Medien- und Kulturforschung 2 (2010), S. 129-147.

„Im Konzept-Schutzgebiet. Laurent Chétouanes Hommage an das Zaudern“, in: F.A.Z. vom 17.12.2011, S. 38.

Kedves, Alexandra, „Handkes Bildersturm als Körpertheater“, in: Tagesanzeiger vom 09.10.2010.

Lacan, Jacques, Die vier Grundbegriffe der Psychoanalyse. Das Seminar Buch XI, Berlin, Weinheim, 1978.

Müller-Schöll, Nikolaus, Das Theater des konstruktiven Defaitismus. Lektüren zur Theorie eines Theaters der A-Identität bei Walter Benjamin, Bertolt Brecht und Heiner Müller, Frankfurt/M., 2002.

Nancy, Jean-Luc, „Parallele Differenzen. Deleuze und Derrida“, in: ders./René Schérer, Ouvertüren. Texte zu Gilles Deleuze, Zürich, Berlin, 2008, S. 31-50.

Peterle, Astrid, „Die Zukunft des Tanzes? Laurent Chétouane mit ,Horizon(s)‘ im Tanzquartier Wien“, in: Corpus - Internetmagazin für Tanz Choreographie Performance vom 24.04.2011, online unter: http://www.corpusweb.net/die-zukunft-des-tanzes.html, zuletzt aufgerufen am 12.08.2013.

Pontalis, Jean-Bertrand, Zusammenfassende Wiedergabe der Seminare IV-VI. Aus dem Französischen v. Johanna Drobnig, unter Mitarb. v. Hans Naumann und Max Kleiner, mit einem Vorw. v. Hans-Dieter Gondek, hg. v. Hans-Dieter Gondek und Peter Widmer, Wien, 2008.

Santner, Eric, Zur Psychopathologie des Alltagslebens, Zürich, Berlin, 2010.

Stiegler, Bernard, Die Logik der Sorge. Verlust der Aufklärung durch Technik und Medien, Frankfurt/M., 2008.

Ders., Von der Biopolitik zur Psychomacht. Die Logik der Sorge I.2, Frankfurt/M., 2009. 



\section{RAUM-ZEITLICHE KIPPFIGUREN. ENDENDE RÄUME IN THEATER UND PERFORMANCE DER GEGENWART}

1. Kippfigur

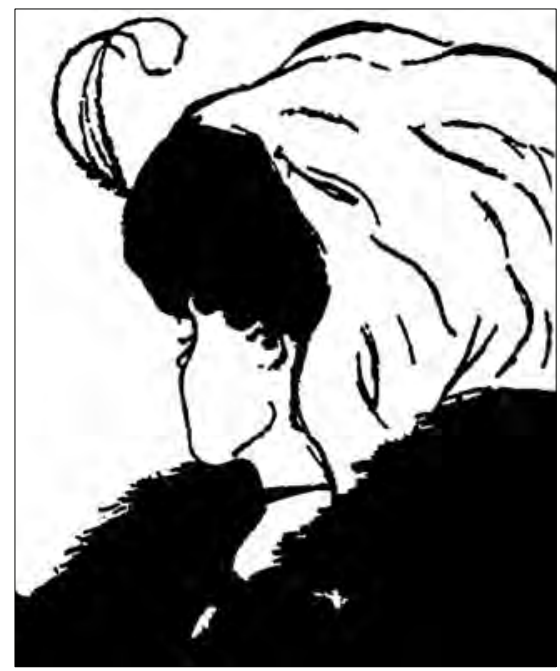

1 - Alte oder junge Frau? Klassisches Beispiel einer Kippfigur

Wie alt ist diese Frau? Mit dieser Frage wird im Allgemeinen dieses Bild vorgelegt. Je nachdem, ob wir darin eine junge Frau mit elegantem Turban, weitem Ausschnitt und lässig umgelegten Pelz oder aber eine alte Frau mit Augenringen, Hakennase und großem Wärmebedürfnis, das auf hohes Alter schließen lässt, zu sehen glauben und vermögen, werden wir zwischen Anfang 20 und Ende 70 schwanken. Vielleicht aber werden wir auch, sind wir einmal vom einen ins andere Bild verfallen, bei keinem mehr verweilen können, vielmehr oszillierend zwischen abgewandter junger und zugewandter alter Frau in eine Art von Doppelsicht verfallen, die uns im weiteren Verlauf dazu bringen wird, statt der zwei Bilder deren Zeichnung wahrzunehmen oder unsere Wahrnehmung selbst, im einen wie im anderen Fall also die Voraussetzung, eine unauflösbar ambivalente Linienführung oder eine immer schon auf vielfältige Weise vorgeprägte Vorstellung, die uns das eine wie das andere, beide oder 
aber überhaupt kein Bild mehr zu konstruieren erlaubt. Eine Kippfigur, so der gebräuchliche Name, lässt uns zwei Figuren sehen, deren eine irgendwann in die andere kippt, um schließlich, vermittelt über das Kippen, uns auf das Figurale der Figur selbst zu verweisen, deren Konstruktion oder Darstellung.

Kippfiguren sind nicht nur im Bereich des Bildes zu finden, sie tauchen in der dramatischen Literatur in Gestalt ambivalenter Helden auf, man denke nur an Shakespeares Richard III., an Goethes Iphigenie, Büchners Lucile oder Heiner Müllers „Lohndrücker“ Balke. Sie begegnen in der Philosophie, etwa im Denken Walter Benjamins, am prägnantesten in der Formulierung „Dialektik im Stillstand““1, die zugleich die Dialektik als Denken der Bewegung stillstehend vorstellt wie auch jene dialektische Bewegung, die noch im Stillstand am Werk ist und damit zwei einander entgegengesetzte Vorstellungen, die gleichzeitig zu denken sind, gleichwohl nicht zugleich gedacht werden können und insofern die Vorstellung, genauer: das mit ihr verbundene Darstellen und dessen Zeit und Raum, ausstellen. Nicht von ungefähr benutzt Benjamin diese Formulierung erstmals im Kontext seines Essays über Bertolt Brecht und entwickelt sie am Beispiel des raumbildenden Prozesses der Neher'schen Plakate für die Inszenierung von Aufstieg und Fall der Stadt Mahagonny. ${ }^{2}$

Unter dem Titel raum-zeitliche Kippfiguren möchte ich nachfolgend raumbildende Prozesse in Theater und Performance betrachten und analysieren, die uns den Prozess der Raumbildung selbst zu denken geben. Ausgehend von der Hypothese, dass die Bühne als Dispositiv (im Sinne Foucaults und Agambens) zu begreifen ist und im Kontext der verstärkten Aufmerksamkeit für die begrifflichen und konzeptuellen Grundlagen des Raumdenkens im Allgemeinen möchte ich speziell die Frage aufgreifen, wie die ebenso viel geschmähte wie sich beharrlich restituierende „Guckkastenbühne“ verlassen werden kann. Dieses Verlassen setzt, wie ich im Kontrast zu zwei Arbeiten aus dem Umfeld der freien Szene zeigen will, die Analyse des Dispositivs Bühne voraus und ist in den Beispielen, die ich bespreche, an die Konstruktion unterschiedlicher raumzeitlicher Kippfiguren gebunden. Konkret will ich dies an raumbildenden Prozessen bei Robert Wilson, Patrizia Talacko, Mark Lammert und Wanda Golonka nachverfolgen.

\section{Am Ende der Epoche des optischen Betrugs: Die Bühne als Dispositiv}

Wie also heute über die „Bühne“, wie über den Raum sprechen? Ulrike Haß entwickelt in ihrer Studie Das Drama des Sehens den Begriff der „Bühnen-

\footnotetext{
Vgl. Walter Benjamin, „Was ist das epische Theater? 1“, in: ders., Gesammelte Schriften, hg. v. Rolf Tiedemann/Hermann Schweppenhäuser, Band II, 2, Frankfurt/M., 1980, S. 519-531: 530.

2 Vgl. ebd., S. 525. Vgl. ausführlich zum hier angedeuteten Zusammenhang Nikolaus MüllerSchöll, Das Theater des „konstruktiven Defaitismus“. Lektüren zur Theorie eines Theaters der A-Identität bei Walter Benjamin, Bertolt Brecht und Heiner Müller, Frankfurt/M., Basel, 2002, S. 161-173.
} 
form“3 für die systematische Zusammenfügung von Sehen und Gesehenwerden in einer Ordnung, die sie als ein Paradigma gesellschaftlicher Gefüge begreift, das für die lange Epoche vom 15. Jahrhundert bis in die Gegenwart ${ }^{4}$ hinein Gültigkeit beanspruchen kann. Dieser Begriff ist in Analogie zum „weiten Theaterbegriff“ gebildet, den Rudolf Münz für das Leipziger Theatralitätsmodell vorgeschlagen hat. Werden dort neben der „Theater(kunst)“ auch Nicht-Theater, das Theater des Alltags und der Straße sowie Anti-Theater ${ }^{5}$ einbezogen, so hier neben den konkreten Bühnen des Theaters im engeren Sinne die Weltbühne, das „Theater“ der urbanen Bühnen und Feste sowie das „Nicht-Theater“ der abstrakten Bühnen z. B. der Politik. Wenn, wie Haß mit Welsch formuliert, die „Epoche des optischen Betrugs“ derzeit zu Ende geht und „von einem Modell der Intermedialität und Interaktivität zwischen Benutzern und Programmen überholt wird ${ }^{\text {“6 }}$, so stellt sich die Frage, wie ein diesem Modell angemessenes Verständnis zu gewinnen ist. Meine Hypothese lautet, dass Bühne in Verlängerung wie Absetzung von dem Modell, das Haß für die zu Ende gehende Epoche entwickelt hat, heute am ehesten als Dispositiv zu begreifen ist. Unter Rückgriff auf Foucault hat Giorgio Agamben jüngst eine Verwendung dieses häufig verwendeten Begriffs vorgeschlagen, die mir für den Zusammenhang des Nachdenkens über die Bühne hilfreich erscheint. ${ }^{7}$

Mit „diesem Begriff“, so Foucault, versuche er „eine heterogene Gesamtheit" zu bestimmen,

bestehend aus Diskursen, Institutionen, architektonischen Einrichtungen, reglementierenden Entscheidungen, Gesetzen, administrativen Maßnahmen, wissenschaftlichen Aussagen, philosophischen, moralischen und philanthropischen Lehrsätzen, kurz, Gesagtes ebenso wie Ungesagtes $[\ldots]^{8}{ }^{8}$

Foucault begreift ein Dispositiv als eine „bestimmte Manipulation von Kräfteverhältnissen“, die in ein Machtspiel eingeschrieben, doch auch an Wissensgrenzen gebunden seien. „Das eben ist das Dispositiv: Strategien von Kräfteverhältnissen, die Arten von Wissen unterstützen und von diesen unterstützt werden.“9 Wie Giorgio Agamben von hier aus entwickelt, lässt sich das „Dispositiv“ Foucaults mit seinen juristischen, technischen und militärischen Bedeutungen auf die theologische Oikonomia und vor allem auch auf Heideggers „Ge-stell“ beziehen, das heißt, so Agamben: „,[A]uf eine Gesamtheit von Praxen, Kenntnissen, Maßnahmen und Institutionen, deren Ziel es ist, das Verhalten, die Gesten und die Gedanken der Menschen zu verwalten, zu regieren, zu

\footnotetext{
Vgl. Ulrike Haß, Das Drama des Sehens. Auge, Blick und Bühnenform, München, 2005, S. 198200.

4 Vgl. zu dieser Formulierung ebd., S. 19.

5 Vgl. Rudolf Münz, Theatralität und Theater. Zur Historiographie von Theatralitätsgefügen, Berlin, 1998, S. 82-103.

6 Vgl. Haß (2005), Das Drama des Sehens, S. 19.

Giorgio Agamben, Was ist ein Dispositiv?, Zürich, Berlin, 2008.

Michel Foucault, Dits et Ecrits: Schriften, Bd. 3, Frankfurt/M., 2003, S. 392.

9 Ebd., S. 394 f.
} 
kontrollieren und in eine vorgeblich nützliche Richtung zu lenken. ${ }^{“ 10}$ In diesem Sinn begriffen, erscheint die Bühne als Teil jener Klasse des Vorhandenen, die, wie Agamben ausführt, den Lebewesen oder Substanzen gegenübersteht und mit diesen zusammen die Subjekte konstituiert. Sie lässt sich problemlos in die lange und unabgeschlossene Reihe einfügen, die Agamben in Erweiterung der von Foucault beschriebenen Dispositive der Gefängnisse, Irrenanstalten, Schulen und Fabriken, des Panoptikums, der Beichte, der Disziplinen und juristischen Maßnahmen aufführt, neben Federhalter, Schrift, Literatur, Philosophie, Landwirtschaft, Zigarette, Schifffahrt, Computer, Mobiltelefonen und der „Sprache selbst, die das vielleicht älteste Dispositiv ist“ ${ }^{11}$ Sie erscheint als der „Hominisierung“ gleichursprüngliche Abspaltung, mit deren Hilfe der Mensch das von sich abgesonderte tierische Verhalten leerzulaufen und das Offene als solches, das Ens als Ens zu genießen vermag. ${ }^{12}$ Die Transformation der Bühne in der jüngeren und jüngsten Zeit könnte entlang dieses Schemas als Ablösung eines Dispositivs durch ein anderes begriffen werden. Hier wie da erlangen Körper ihre Identität und ihre Freiheit mittels einer Reihe von Praktiken und Diskursen, Kenntnissen und Übungen. Hier wie da hat man es mit einer sich im Nahkampf mit den Dispositiven subjektivierenden und entsubjektivierenden Substanz zu tun.

Nun lässt sich allerdings Agambens Begriff des Dispositivs nicht übertragen, ohne sich mit einer Tendenz seiner Argumentation auseinanderzusetzen, die ebenso verführerisch wie - mit Blick auf den Erkenntniswert seiner Begrifflichkeit - verhängnisvoll erscheint. Agamben beschreibt die heutigen kapitalistischen Dispositive als insofern von den religiösen und den älteren Regierungsdispositiven unterschieden, als dort ein Subjektivierungsprozess in Gang gesetzt wurde, heute dagegen einer der Desubjektivierung - was ihm am auffälligsten am Benutzer von Mobiltelefonen und Fernsehzuschauern zutage zu treten scheint. In einem gleichermaßen alarmistischen wie von einer untergründigen Verfallsgeschichte geprägten Schluss seines Essays zeichnet er das Bild der heutigen Welt als von einem Leerlauf der Maschine gekennzeichnet, die in die Katastrophe führt. Diesem Leerlauf weiß er allerdings nicht mehr entgegenzusetzen als den nicht weiter spezifizierten Appell, die Dispositive, wie er es in seiner Terminologie formuliert, zu profanieren, das heißt, was in ihnen eingefangen und abgesondert wurde, dem allgemeinen Gebrauch zurückzugeben. Voraussetzung sei dabei, dass jene, die sich die Frage der Profanierung stellten, in der Lage seien, sowohl „in die Subjektivierungsprozesse als auch in die Dispositive einzugreifen, um jenes Unregierbare zum Vorschein zu bringen, das zugleich Anfang und Fluchtpunkt jeder Politik ist“ ${ }^{.13}$

\footnotetext{
${ }^{10}$ Vgl. Agamben (2008), Was ist ein Dispositiv?, S. 24.

11 Ebd., S. 26.

12 Vgl. ebd., S. 30.

13 Ebd., S. 41.
} 
Nachdem Agamben zuvor konstatiert hat, dass immer durchdringenderen Dispositiven der Desubjektivierung der „folgsamste[] und feigste[] Gesellschaftskörper“ der Menschheitsgeschichte gegenüberstehe, der harmlose Bürger der Demokratien, der gleichwohl „von der Macht als potentieller Terrorist" ${ }^{\text {"14 }}$ betrachtet werde, öffnet der wirkungsvoll platzierte Verweis auf das „Unregierbare“ in seinem Mangel an Spezifizierung Tür und Tor für jede erdenkliche Form der Mystifizierung wie auch des enthusiasmierten Missverständnisses. Insofern ist an diesem Punkt mit Blick auf die konkrete Frage nach den spezifischen Absonderungen und Subjektivierungsprozessen, die mit den unterschiedlichen Dispositiven der Bühne einhergehen, eine über Agamben hinausgehende Entmystifizierung, Ausnüchterung und letztlich Konkretion seiner Theorie notwendig - zumindest dann, wenn man sie im Zusammenhang einer Theaterforschung als kritischer Wissenschaft produktiv machen will.

\section{3. „Bühne“ im Kontext der Überprüfung der Herkunft von Raumkonzepten}

Die Entwicklung des Dispositivs der Bühne muss heute vor allem im Kontext jener „,begriffskritische[n] Überprüfung der Herkunft von Raumkonzepten“沼 diskutiert werden, die im Zuge der neuerlichen Aufmerksamkeit für die Bedingung von Räumlichkeit stattgefunden hat. Unter Verweis auf Edward Sojas Schrift Postmodern Geographies ${ }^{16}$ wurde sie als „spatial turn“, unter Verweis auf Sigrid Weigel als „topographical turn“ ${ }^{\text {“17 }}$ und von anderen schließlich als „topological turn“ etikettiert. Bernhard Waldenfels zeichnet zu Beginn eines Beitrags zu der Debatte um diesen „Turn“ drei große Etappen des westlichen Denkens von Ort und Raum nach: Während das klassische Denken der Antike um den „Kosmos“ kreise und im kosmischen Ortsgefüge wiederum jedem sein eigentümlicher Ort zugewiesen sei, trete mit der Reduktion des Kosmos auf die berechenbare Naturwelt an die Stelle des kosmischen und sozialen Topos das leere Raumschema des Spatium. Es entstehe ein homogener und isotroper Raum. Waldenfels verdeutlicht, dass an dieser vom euklidischen Raummodell beherrschten Raumkonstruktion „problematisch ist, ,dass wir für wahres Sein

14 Ebd., S. 40.

15 Vgl. Jörg Dünne/Stephan Günzel, Raumtheorie. Grundlagentexte aus Philosophie und Kulturwissenschaften, Frankfurt/M., 2006, S. 12; vgl. auch Stephan Günzel (Hg.), Topologie. Zur Raumbeschreibung in den Kultur- und Medienwissenschaften, Bielefeld, 2007; ders. (Hg.), Raumwissenschaften, Frankfurt/M., 2009.

16 Edward Soja, Postmodern Geographies. The Reassertion of Space in Critical Social Theory, London, New York, NY, 1989.

17 Sigrid Weigel, „Zum ,topographical turn“ - Kartographie, Topographie und Raumkonzepte in den Kulturwissenschaften“, in: KulturPoetik 2, 2 (2002), S. 151-165. 
nehmen, was eine Methode ist “ ${ }^{18}{ }^{18}$ Unschwer zu erkennen ist, dass hier, bezogen auf den Bereich des Theaters, jenes Dispositiv angelegt ist, das sich aufbauend auf den Entwürfen und Modellen der Frühen Neuzeit und unterstützt von den programmatischen und philosophischen Schriften des 18. Jahrhunderts in seiner Reinstform im 19. Jahrhundert herausbildet, um letzten Endes allerdings erst in Kino und Fernsehen zu sich selbst zu kommen: Die in der Vorstellungswelt der Spieler von einer Mauer, der vierten Wand, abgeschlossene, in der Bühnenarchitektur durch das Proszenium, das Bühnenportal und den Eisernen Vorhang ausgedrückte Scène à l'Italienne, die Guckkastenbühne. Der Eindruck der Realität, ja der Glaube, ihr unvermittelt auf der Bühne begegnen zu können, baut, entsprechend des Paradigmas des Spatiums, darauf auf, dass sich alles, was auf dieser Bühne erscheint, isoliert betrachten lässt, nichts einen eigenen Ort hat, an dem es sich wiederfindet, oder „einen gemeinsamen Ort, den es mit anderen teilt““. ${ }^{19}$

Wie Waldenfels in seiner Darstellung mit einer Vielzahl von Beispielen nachzeichnet, bahnt sich ein Umdenken des Raumes vor und nach der Wende vom 19. zum 20. Jahrhundert an: Beteiligt sind physikalische Feldlehre, mathematische Topologie, biologische Umweltlehre, Verhaltenstheorien der Human- und Sozialwissenschaften, Architektur und vor allem die Phänomenologie des Raumes, die in enger Verflechtung mit der Phänomenologie der Zeit zur Raum- und Zeiterfahrung zurückkehrt, ihren Ausgangspunkt von der Lebenswelt nimmt, in der jeder von uns ,,verankert ist und die sich uns durch unsere leiblichen Bewegungen hindurch erschließt"“. ${ }^{20}$ Von hier aus entwickelt sich jenes Denken des Raumes, das er, Husserls „Krisis der europäischen Wissenschaften“ aufgreifend, als gelebtes Paradox bezeichnet: Es besteht darin, dass der Ausgangspunkt eines leiblich in der Welt verankerten Betrachters impliziert, dieser Betrachter selbst könne dem Raum zwar angehören, den er betrachtet, gleichwohl nicht schlechterdings, denn sonst

wäre das Hier ein bloßer Teilort innerhalb des Gesamtortes; in Ermangelung der nötigen Distanz und einer bestimmenden Differenz wäre das Ganze nicht mehr als Ganzes fassbar und sagbar. Die Rede vom Ganzen wird totalitär, sobald sie sich als Rede vom Ganzen verleugnet. ${ }^{21}$

Wie er weiter ausführt, entspringen diese und viele weitere Paradoxien der Bestimmung des Raumes ,einer Selbstbezüglichkeit, die immer dann hervortritt, wenn die Annahme eines Ersten, eines Letzten oder eines Ganzen fragwürdig wird. ${ }^{\text {“22 }}$ Eine ausgedehntere Auseinandersetzung mit den Paradoxien des Rau-

18 Vgl. Bernhard Waldenfels, „Topographie der Lebenswelt“, in: Stephan Günzel (Hg.), Topologie. Zur Raumbeschreibung in den Kultur- und Medienwissenschaften, Bielefeld, 2007, S. 6984: 71. Waldenfels zitiert hier Husserl über Galilei.

19 Ebd., S. 70.

20 Ebd., S. 71.

21 Ebd., S. 75.

22 Ebd., S. 76. 
mes und den auf sie antwortenden Entwürfen seiner Vorstellung hätte zumindest auf die Tradition einer sozialen Raumbeschreibung einzugehen, die von Durkheim über Simmel, Lefebvre und Foucault - dem das 20. Jahrhundert als „Epoche des Raumes“'23 galt - bis zu den auf diesen Theoretikern aufbauenden, sie fortschreibenden oder revidierenden de Certeau, Augé und der gegenwärtigen Diskussion um den „spatial turn“ reicht.

Hier sei nur auf die für den Zusammenhang des Theaters besonders bedeutenden, weil hier wie generell schwer zu ertragenden Paradoxien der Raumerfahrung verwiesen. Von ihnen zeugen vielleicht am besten jene zwei von Waldenfels unter Berufung auf Eugène Minkowski angeführte Raumpathologien des Paralytikers, der auf die Frage „Wo bist du?“ auf die Stelle weist, an der er sich gerade befindet, während der Schizophrene andererseits erklärt: „Ich weiß, wo ich bin, fühle mich aber nicht dort. ${ }^{\text {“24 }}$ Dagegen ist zu denken, dass hier zu sein immer schon impliziert, nicht nur hier zu sein, sondern zugleich auch nicht anderswo zu sein, wobei sich aus dieser räumlichen zugleich eine zeitliche Differenz ableiten lässt. Man stößt hier, anders ausgedrückt, auf jene unauflösbare, zeiträumliche Differenz der Darstellung, die Derrida in seiner „differance ${ }^{\text {(25 } 25}$ zu fassen versucht hat. Keiner hat sie in jüngerer Zeit mit größerem Sinn für ihre zersetzenden Wirkungen und größerer Subtilität in ihren Auswirkungen beschrieben als Werner Hamacher in einer kurzen Sammlung von Notizen und Aphorismen unter dem Titel Amphora. Im Durchgang durch die unter dem Vorzeichen von Topos, Ort und Raum gedachten und zu denkenden Paradoxien der Selbstbezüglichkeit, kommt er an einer Stelle zu einer - für meine weiteren Überlegungen wichtigen - lapidaren Bestimmung: „Räume: Enden ${ }^{“ 26}$. Nicht nur, dass damit der raumbildende Prozess als ein eben deshalb immer unabgeschlossener beschrieben wird, weil Räume endend neue Räume eröffnen, es wird andererseits auch auf die Räume als Ende oder Grenze verwiesen, darauf, dass jedem Moment eine Verräumlichung und Verzeitlichung inhärent ist, eine ihn von sich wegstellende Dezentrierung. „Raum“ erscheint als Wort für eine ins Unendliche entgrenzte Begrenzung.

Die Epoche, die von Waldenfels als dritte vorgestellt wird und in den gegenwärtig unterm Vorzeichen des Raumes gedachten Paradoxien noch andauert, hat ihr Äquivalent in den im Theater um die Jahrhundertwende zum 20. Jahrhundert aufkommenden Bestrebungen, sich von der perspektivischen, ,auf Fluchtpunkte zulaufenden Bildkonstruktion“ zu lösen, die „die Bühnenform

${ }^{23}$ Vgl. Michel Foucault, „Andere Räume“, in: Karlheinz Barck/Peter Gente (Hg.), Aisthesis. Wahrnehmung heute oder Perspektiven einer anderen Ästhetik, Leipzig, 1990, S. 34-46: 34.

24 Vgl. Waldenfels (2007), Topographie der Lebenswelt, S. 80.

25 Vgl. Jacques Derrida, „Die différance“, in: ders., Randgänge der Philosophie, hg. v. Peter Engelmann, Wien, 1988, S. 29-52.

26 Werner Hamacher, „Amphora“, in: Wanda Golonka Tanz Ensemble Modell, Berlin, 2010, S. 2934: 34. 
des europäischen Theaters seit der Renaissance bestimmt hatte““ ${ }^{27} \mathrm{Zu}$ erinnern wäre hier an die Versuche der Auflösung des Dispositivs der Guckkastenbühne, den Kampf mit ihm und seine Ersetzung durch andere Dispositive in den konzipierten oder verwirklichten Bühnenentwürfen von Craig, Copeau, Reinhardt, Piscator, Meyerhold, Blok, Maeterlinck und vor allem in den Arbeiten Adolphe Appias, dessen Leistung und Erbe jüngst nicht von ungefähr in einem Sammelband unter dem Titel Theater ohne Fluchtpunkt neu gewürdigt wurde.

Doch dieser Titel, der die Auflösung des Dispositivs der Guckkastenbühne an die Lösung vom Fluchtpunkt bindet, sollte in seiner Herauslösung eines, wenngleich zentralen Elements, das sich im Verlauf der Bühnenreformen verändert, nicht als Nachhall einer Betrachtungsweise begriffen werden, mit der die Beiträge des Bandes brechen. Einer Betrachtungsweise, die in ihrer vollen Ausprägung in den verbreiteten Schemata des Bühnenraums von Carlson, Pfister, Kleberg und Pavis, um nur einige Beispiele zu nennen, in ihrer vollen Problematik erkennbar wird. Unterschieden werden hier in Varianten Typen der Bühne: von der die Zuschauer umgebenden, „environmental“ genannten Bühne der Performance, über die Arena und die frontale Bühne bis hin zur Kinobühne (vgl. Abb. 2 und 3). Gemeinsam ist den Modellen, dass sie, was als Dispositiv und insofern im Kontext des jeweils zugehörigen Raumdenkens, aber auch der Diskurse über Schauspielkunst, der institutionellen Entwicklungen, der Gesetze und Regeln, der philosophischen, moralischen und philanthropischen Lehrsätze etc. zu betrachten wäre, auf Bauformen reduzieren, die aus ihrem Funktionszusammenhang bzw. ihrer Struktur herausgelöst werden. Diese Bauformen werden ihrerseits dann zu Typen gebündelt, die ein historisches Verständnis suggerieren, tatsächlich aber nichts anderes sind als eine als solche unerkannte Projektion einer gegenwärtigen Theatervorstellung auf die Vergangenheit. Damit wird verhindert, dass in den Dispositiven der Vergangenheit deren je spezifische Geschichtlichkeit erkannt werden kann. Diese aber wäre eine in diesem Zusammenhang naheliegende andere Bezeichnung für das, was Agamben wohl unter dem „Unregierbaren“ zu fassen versucht, das Anfang und Fluchtpunkt jeder Politik sei. Nicht zuletzt vergessen solche Darstellungen die Historizität der Trennung des Raumes selbst mitzudenken, seine Problematisierung im Bereich der Philosophie seit Kant und, um es mit dem Architekten Daniel Libeskind zu sagen, seine Erhebung zu einem negativen Gott. ${ }^{28}$ Ihrer Darstellung unterliegt nolens volens eine selbst im Zuge der von Waldenfels als letzte Etappe charakterisierten Auflösung des leeren Raumschemas fraglich gewordenen Vorstellung des Raumes als Schachtel. Ein solch fehlgeleiteter Historizismus hat aber nicht zuletzt Folgen im Kontext

${ }^{27}$ Vgl. dazu Gabriele Brandstetter/Birgit Wiens (Hg.), Theater ohne Fluchtpunkt. Das Erbe Adolphe Appias: Szenographie und Choreographie im zeitgenössischen Theater, Berlin, 2010, S. 9.

28 Daniel Libeskind, „Das Ende vom Raum - ein Gespräch mit Gerhard Ahrens“, in: Hamburger Hefte, Nr. 4, raumgestalten, Hamburg, 2001, S. 42-51. 
der Versuche gehabt, den Kampf mit dem überkommenen, wenngleich immer noch dominanten Dispositiv der Guckkastenbühne aufzunehmen.

Tatsächlich scheint der Umbruch und die mit ihm einhergehende Neubestimmung des Raumes im Theater komplizierter als der Blick auf die Abfolge unterschiedlicher Bühnenentwürfe es nahelegt. Dies ergibt sich, befragt man konkret gegenwärtige Bühnenarbeiten, die in der Auseinandersetzung mit dem Dispositiv der Epoche des Spatiums weniger ein Neues entwerfen, als vielmehr auf jenen Moment des Unregierbaren abzielen, von dem Agamben am kryptischen Ende seines Essays spricht.

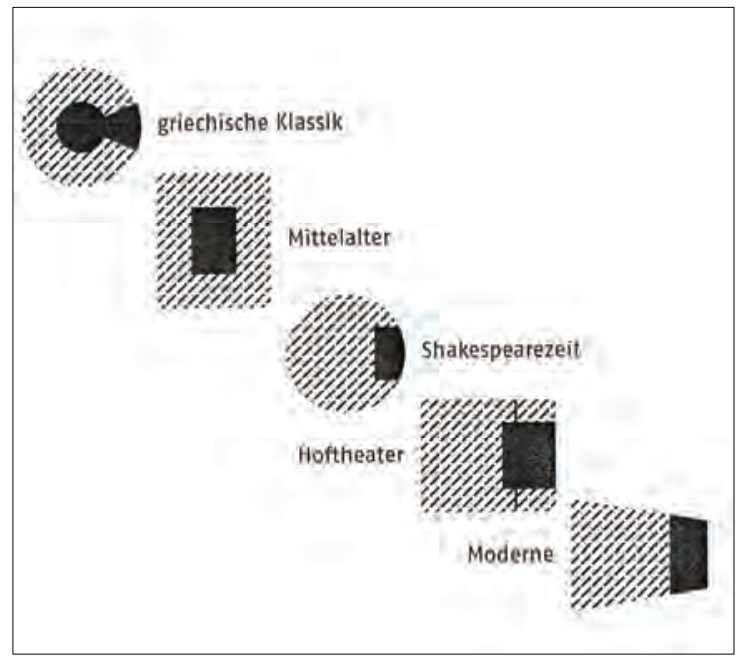

2 - Theaterräume nach Manfred Pfister

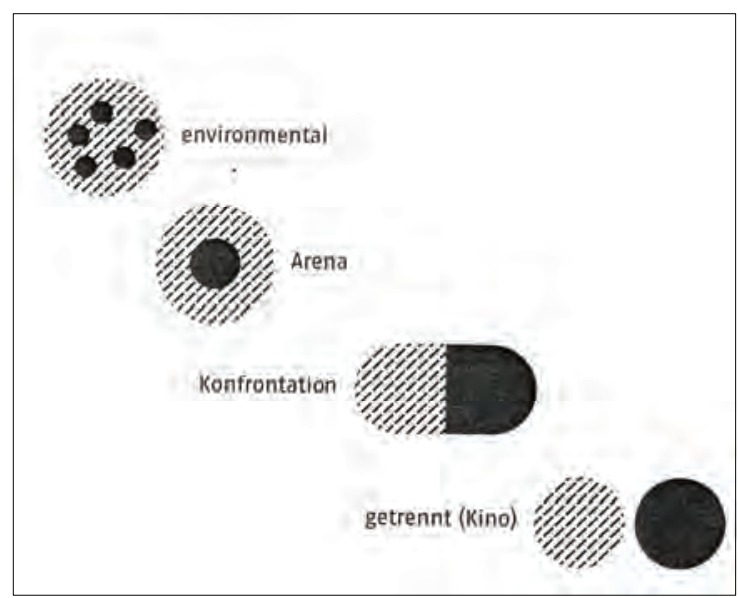

3 - Theaterräume nach Marvin Carlson 
4. Wie das Dispositiv der Guckkastenbühne (nicht) zu verlassen ist (Meyer \& Kowski, van Hove, Wilson)

Bis heute sind kritische theatrale Praktiken vom vorschnellen Schluss geprägt, man habe Guckkastenbühne und Vierte Wand bereits überwunden, wenn bloß die Rampe überschritten oder die Zuschauer zum Betreten des Spielraums animiert würden. Dass es nicht ausreicht, auf die Konstruktion einer Guckkastenbühne mit Fluchtpunkt zu verzichten, und andererseits auch eine vermeintlich vollkommen dem Dispositiv der Guckkastenbühne entsprechende Anordnung sich als Kampf mit diesem Dispositiv erweisen kann, lässt sich vielleicht am deutlichsten an drei Beispielen erläutern, die ich zum Teil nur in Kürze vorstellen und diskutieren will.

„Das Schauspielerpaar Jörg und Susanne laden in ihre Küche ein und sprechen über ihre Erfahrungen mit der Monogamie während sie für ihr Publikum japanische Köstlichkeiten zubereiten. ${ }^{\text {“29 }}$ So wird der Besucher per Mail auf einen Abend des Regieduos Meyer \& Kowski alias Susanne Reifenrath und Marc von Henning vorbereitet. Die Adresse, die in der Einladung steht, so stellt sich heraus, gehört zu einem alten Schuppen in einem trüben Hinterhof in Hamburg-Wilhelmsburg, in dem sich eine mit viel Geschmack eingerichtete Loftwohnung befindet. Die Besucher, etwas mehr als 20, sitzen an einem langen Holztisch, auf Sofas oder auf improvisiert herbeigetragenen Stühlen. Jörg und Susanne, die uns gerade noch begrüßt, unsere Mäntel abgenommen, uns mit Hausschlappen versorgt und fotografiert haben, stehen nun hinter dem in den Raum ragenden Kochtresen und fangen an zu kochen. Nachdem uns Einladung und Empfang für einen kurzen Augenblick im Zweifel gelassen haben, ob wir hier bei Jörg und Susanne und zur Erzählung von deren Erfahrungen oder aber in einem für zwei fiktive Personen Jörg und Susanne ausgesuchten Raum eingeladen sind, dauert es nur wenige Minuten, ja Sekunden, bis wir verstanden haben, dass hier zwei Schauspieler vor uns stehen, sobald diese, während sie kochen, zu sprechen beginnen. Mag man die geschulten Stimmen noch der Tatsache zuschreiben, dass es ja Schauspieler sind, die uns ihre Beziehungsgeschichten erzählen, so erscheinen die etwas zu geübten Versprecher, die Platzierung im Raum, das Timing der Gags und die bald erkennbare Dramaturgie doch nach kurzer Zeit als zu berechnet, um nicht Teil eines Schauspiels zu sein. Eben das, was die beiden für den Abend als Kunst und Schulung mitbringen, was sie zur Erfüllung ihrer Aufgabe als Schauspieler in diesem Rahmen befähigt, verwandelt im Gegenzug ihr Spiel im fremden Rahmen zurück in ein dem Dispositiv der Guckkastenbühne entsprechendes.

Nicht anders verhält es sich mit der einigermaßen spektakulären deutschsprachigen Erstaufführung eines Stücks unter dem Titel Faces nach dem gleichnamigen Film von John Cassavetes. Die Zuschauer wurden hier im Rah-

29 Vgl. die Ankündigung der Vorstellungen des Duos „Meyer\&Kowski“ alias Susanne Reifenrath und Marx von Henning für drei Vorstellungen am 21., 22. und 23. Januar 2011 in Hamburg. 
men des Stuttgarter Theaters der Welt in eine große Halle eingeladen, wo zahlreiche Doppelbetten standen, auf denen sie an diesem Abend zu zweit oder dritt ihren Sitz- oder Liegeplatz einnehmen. Zwischen den Zuschauern spielte das Ensemble des Hamburger Schauspielhauses unter der Regie von Ivo van Hove das Beziehungsdrama und spielte doch in jedem Moment so, als seien die Zuschauer nicht da oder so fern wie an jedem anderen Abend. Selbst wenn sich ein Zuschauer bemerkbar zu machen versuchte, begegnete er ihrem leeren, ihn nicht wahrnehmenden Blick.

Was beide Beispiele neben vielen anderen illustrieren, ist aber, dass eine Veränderung der Umgebung der Spielenden und Zuschauenden, ihre andere Platzierung im Raum oder ihre Ablösung von einer nach klassischen Regeln konstruierten Bühne allein das überkommene Dispositiv nicht zu erschüttern vermögen. Es wird reproduziert durch Institutionen, durch vermeintlich technische oder handwerkliche, tatsächlich aber zumindest auch gesellschaftliche und historische Regeln, durch Spieler und Zuschauer verbindende Codierungen, und nicht zuletzt durch die inkorporierten Haltungen der Spieler. Anders gesagt: Was in den Verhaltensweisen der Spieler sichtbar wird, ist ihre spezifische Subjektkonstitution im Zusammenspiel mit einem seine sichtbare Ausprägung überlebenden Dispositiv, ihr die Raumbildung eher bestimmender als von dieser bestimmter Habitus. Mit Blick auf das Theater hat vielleicht als erster Brecht im Zusammenhang mit seinen Ausführungen zum Lehrstück darauf verwiesen, dass die von der Not geprägten Haltungen dasjenige sind, was nach dem Wegfallen der Not diese überlebt und die Handlungen der Akteure prägt. In einer aus dem Zusammenhang der Überlegungen zur „großen Pädagogik“ stammenden Notiz zum Fatzer-Fragment liest man: „unsere haltung kommt von unseren handlungen, unsere handlungen kommen von der not. / wenn die not geordnet ist, woher kommen dann unsere handlungen? / wenn die not geordnet ist kommen unsere handlungen von unserer haltung. “30 Diese Beobachtung lässt sich aus dem engeren Kontext der Theorie des Lehrstücks in denjenigen der Frage, wie mit einem Dispositiv zu kämpfen sei, übertragen. Sie lässt begreifen, warum das gerade in Produktionen der freien Szene so beliebte Verlassen der Theaterbauten, das Aufsuchen von Fabriken, Steinbrüchen oder städtischen Räumen, allein nicht selten mit keinerlei Infragestellung des Dispositivs der Guckkastenbühne verbunden ist.

Eine andere Auseinandersetzung mit dem überkommenen Dispositiv reproduziert es auf den ersten Blick in einer so nur noch selten zu findenden Perfektionierung. In Robert Wilsons bereits legendärer Inszenierung von Heiner Müllers Hamletmaschine wird die Bühne ganz im Sinne des 18. Jahrhunderts als zwar räumliches, gleichwohl nach der Logik eines Tafelbildes gestaltetes Arrangement behandelt, als eine Art von Tableau vivant, das sich im Verlauf der Szene in langsamen, stilisierten Bewegungen aufbaut. Gemäß dem von

${ }^{30}$ Vgl. Bertolt Brecht, BBA 112/54 u. 62; zit. n. Reiner Steinweg, Brechts Modell der Lehrstücke,Zeugnisse, Diskussionen, Erfahrungen, Frankfurt/M., 1976, S. 47. 
Wilson einmal formulierten Motto, wonach Tonspur und Bild einer Inszenierung im Kontrast zueinander stehen sollten, um Vorstellungsräume jenseits der Grenzen dessen zu öffnen, was das Publikum sieht und hört ${ }^{31}$, illustriert die Bewegung den Text nicht, folgt vielmehr einer nicht weiter erklärbaren Eigenlogik. Wir sehen drei Frauen an einem Tisch, ihnen gegenüber eine auf einem rollbaren Stuhl postierte weitere Frau und im weiteren Verlauf eine ganze Reihe weiterer Akteure, die sich in bestimmte Posen hineinbegeben, um darin auf der Bühne bis zum Moment des Szenenendes, zum Teil mit wiederholten, festgelegten Bewegungen, zum Teil aufgrund der Anstrengung ein wenig zitternd zu beharren. Dann folgt eine in helles weißes Licht getauchte, stumme Umbauszene auf offener Bühne, in deren Verlauf die Spieler - nun nicht länger in stilisierter Bewegung, sondern vielmehr ungefähr so wie sonst die Bühnenarbeiter - die Anordnung der Requisiten um 90 Grad drehen, während ein regungslos ins Publikum blickender Spieler gleichsam die Begrenzung der hinter ihm stattfindenden Umbauszene markiert. Die 90-Grad-Drehung einer ansonsten nicht veränderten Anordnung wird unterstrichen durch eine jeweils - gleichsam als Hintergrund des vor ihr sich aufbauenden Bildes - freigelegte weiße Leinwand, die in der ersten, stummen Szene auf der rechten Seite die Bühne zur Seite hin begrenzt, um in der zweiten Szene, in der wir den Text von Müllers erster Szene hören, den Hintergrund der Bühne zu bilden. Die dann, nach erneuter Umbaupause, während der zweiten Szene des Stücks das immer gleiche Szenario auf der rechten Seite begrenzt, um später, nach zwei weiteren Drehungen der Bühne, wieder auf der rechten Seite ankommt.

Was Wilson dergestalt aber vor den Augen des Publikums ausbreitet, ist ein viermal zu beobachtender raumbildender Prozess, der, was etwa als Bühnenbild bezeichnet werden könnte, das Tableau im Sinne des 18. Jahrhunderts, als das Ende und den Anfang eines Bewegungsablaufes mit diesem zusammen vor Augen stellt. Statt eines Bühnenbildes sehen wir die Bühnenbildung, ja die Handlung auf der Szene ist nichts als der raumbildende Prozess. Wenn Heiner Müller an Wilsons Theater hervorhob, dass ihn der Moment zwischen Blick und Blick interessiere - „was und wie sieht man während des Blinzelns“'32 - so zeigt sich dieses Interesse in der Inszenierung der Hamletmaschine darin, dass Wilson uns in der vierfachen Drehung der Bühne um jeweils 90 Grad bei gleichbleibendem choreographischen Ablauf je anders sehen lässt, was wir in der zuvor entstandenen Raumbildung noch nicht gesehen haben. Er dekonstruiert dergestalt das vermeintliche Bild wie den vermeintlichen Raum der Szene von dem her, was im Prozess ihrer raumbildenden Erscheinung gleichursprünglich verschwinden muss. Wenn Müller Wilson weiter als bildenden Künstler „mit dem schrägen Blick“ bezeichnet (,die Kraft kommt nicht aus

31 Vgl. Robert Wilson, „Die Architektur des theatralischen Raumes“, in: Theaterschrift 2. The Written Space, S. 102-107: 104.

32 Vgl. Heiner Müller, „Robert Wilson/Freunde“, in: ders., Krieg ohne Schlacht, Köln, 1992, S. 327-336: 332. 
der Zentralperspektive, eher aus der versetzten Kausalität $\left.{ }^{\star(33}\right)$, so lässt sich mit Blick auf die Inszenierung der Hamletmaschine ergänzen, dass sie im vom Dispositiv der zentralperspektivischen Darstellung geprägten Raum an dessen Entkräftung arbeitet. Das Prinzip, dem diese Inszenierung folgt, lässt sich aber, wie mir scheint, entsprechend der eingangs entfalteten Definition als das einer raum-zeitlichen Kippfigur bezeichnen: Die viermal gekippte Bühne stellt uns die auf ihr aufgebaute Szenerie von vier Seiten und im Ganzen das unweigerlich partielle in jeder wie auch immer gearteten Begegnung mit einer Choreographie im Raum vor Augen; ein Fehlen, das weder ein bloßer Mangel noch überhaupt etwas Negatives ist. ${ }^{34}$ Es ist eine bühnentechnische Präzisierung dessen, was Agamben am Ende seines Essays als das in jedem Dispositiv „Unregierbare“ beschreibt. Das, was dem Dispositiv vorausgeht und es überlebt, der Rest, der ihm gleichursprünglich ist und von der Inkommensurabilität des Lebendigen mit jeder Form seiner Verwaltung zeugt.

\section{Ausgestellter Guckkasten - Patricia Talacko/Mark Lammert}

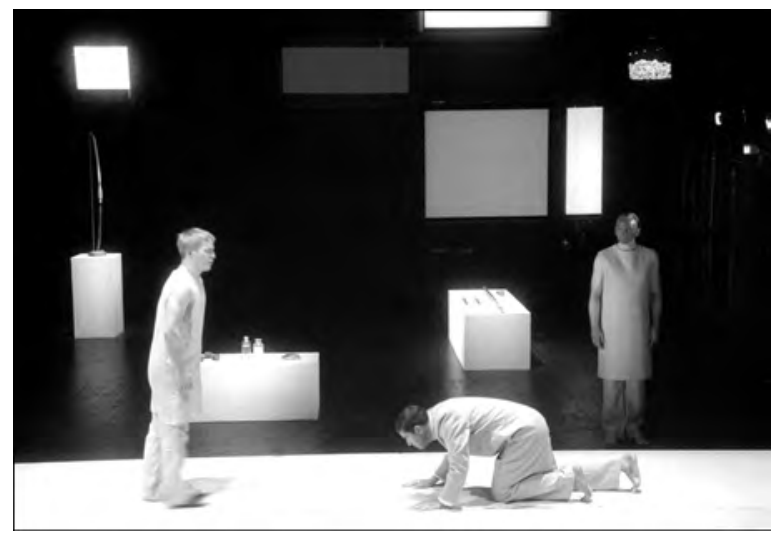

4 - Heiner Müller, Philoktet, Nationaltheater Mannheim, 2002.

Regie: Laurent Chétouane; Bühne: Patrizia Talacko

Weniger spektakulär als Wilson stellen auch Patricia Talacko und Mark Lammert in Inszenierungen, die auf einem Text von Heiner Müller aufbauen, den Rahmen der Inszenierung, den Guckkasten, aus. In Patricia Talackos Bühne zu Laurent Chétouanes Mannheimer Philoktet-Inszenierung ${ }^{35}$ ist die Bühne selbst

33 Vgl. ebd., S. 331

34 Vgl. zum Begriff des „Fehlens“, der hier nur angedeutet werden kann: Martin Heidegger, „Der Weg zur Sprache“, in: ders., Unterwegs zur Sprache, Pfullingen, 1959, S. 239-268.

35 Laurent Chétouane, Philoktet von Heiner Müller im Studio/Werkstatt des Nationaltheaters Mannheim. Premiere am 25.05.02. 
ein Ausstellungsraum, in dem Pfeil und Bogen wie in einem Museum auf der Bühne aufgebahrt sind (vgl. Abb. 4). Die drei Spieler des Stückes spielen miteinander nur insofern, als sie den Text des Stückes hörbar werden lassen - als Text, der gleichsam durch sie hindurch geht, als Text, der von anderswo kommt, nicht ihnen gehört und der zugleich, in der Ausgestaltung, die die drei Schauspieler ihm geben, einen im Spiel unauflösbaren Konflikt vor Augen führt - und dies zunächst einmal niemand anderem als den drei Spielern. Für die Zuschauer ist die Bühne so unmerklich, dass sie es beinahe vergessen könnten, für die Spieler aber unübersehbar, durch eine auf den Fotos kaum erkennbare Gaze vom Zuschauerraum getrennt, die, wenn die Bühne erleuchtet ist, die Zuschauer für die Spieler buchstäblich zum Verschwinden bringt. Müllers Stück wird dergestalt in der Tradition begriffen, in die es sich stellt: in derjenigen des Brecht'schen Lehrstücks. Als Stück nur für die Spielenden, ohne Zuschauer - wobei die Wendung, die Müller dem Lehrstück gibt, nicht zuletzt darin liegt, dass dessen uneingelöstes Potenzial dadurch vorgeführt wird, dass das Spielen ohne Publikum vor einem Publikum stattfindet, das gleichwohl gewissermaßen nicht gemeint ist. Es ist bloß anwesend, doch es hat hier so wenig zu sagen wie das Volk in der sich auf es berufenden angeblichen Demokratie außerhalb. Wie Chétouanes Inszenierung führt auch Talackos Bühne diesen Moment in der Entwicklung des Lehrstückes handgreiflich vor Augen: Das mit Blick auf die vermeintlich bald kommende erste Revolution und nachfolgende weitere permanente Revolutionierungen hin entworfene Lehrstück erscheint als Spielanordnung, welche die uneingelöste Utopie insofern modo negativo ausstellt, als sie hier im Stadium ihrer Musealisierung angekommen ist. Als Zuschauer sehen wir gleichsam in einer Vitrine die Konflikte einer vergangenen Zeit; umgekehrt wird der dergestalt ausgestellte Guckkasten für die Spieler buchstäblich zum Käfig, ihre Spielhaltung ihnen in jedem Moment durch die undurchdringliche Mauer vor Augen gestellt. Die vierte Wand erscheint, gerade weil sie nicht länger bloße Konvention ist, gleichwohl weiterhin willkürliche Setzung und Selbstbegrenzung, als Teil eines mit dem Spiel aufs Spiel gesetzten, der Verhandlung im Theater überantworteten Dispositivs. Dieses wird spätestens dann auch zum Thema, wenn am Ende des Stücks der sterbende Philoktet gegen die ihn vom Publikum trennende Gaze läuft. Die Logik des Stoffes wie auch des Stückes und seiner Spielweise kollidiert in diesem Moment mit der Logik des Theaters, die dem Spieler in jedem Moment, dem Zuschauer aber vermutlich erst dann handgreiflich vor Augen geführt wird, wenn er durch den Gang des Darstellers an die Grenze seines Spielfeldes erkennt, was er zuvor übersehen haben mag: dass ihn die ganze Zeit eine nicht lediglich immaterielle Wand vom Geschehen auf der Bühne getrennt hat. Wie im Falle Wilsons sorgt auch hier die Konstruktion einer Kippfigur dafür, dass die Aufmerksamkeit von der vorgestellten Handlung auf die Handlung der Vorstellung und dabei speziell auf dasjenige fällt, was das Vorstellen raumbildend ermöglicht. 


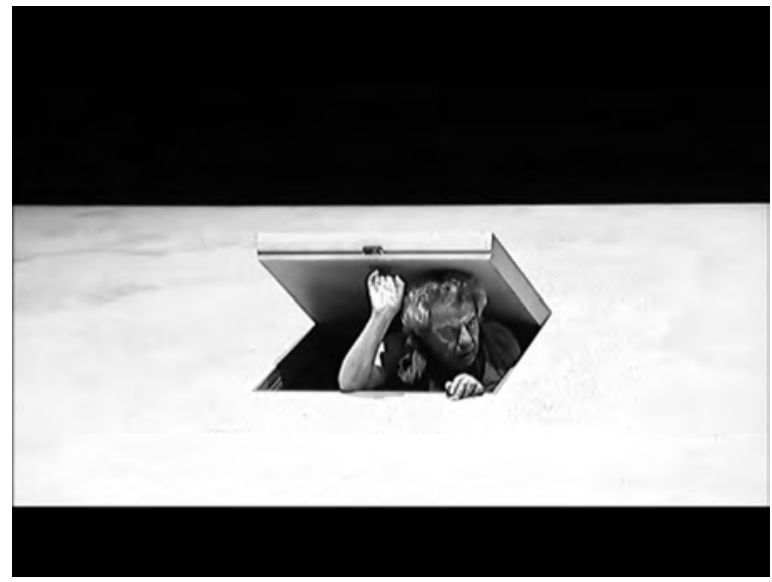

5 - Heiner Müller, Philoktet, Théâtre de la Ville, Paris. Regie: Jean Jourdheuil; Bühne: Mark Lammert

Auf seine Weise verdeutlicht dies auch Mark Lammert in seiner Raumgestaltung für eine andere Inszenierung des Philoktets, diejenige von Jean Jourdheuil in Paris und Straßburg. ${ }^{36}$ Auf einer ansonsten leeren und dunklen Bühne steht ein viereckiger, nach oben schräg ansteigender großer Kasten, in dessen Mitte eine geschlossene Klappe liegt. Er ist gehalten in der Farbe und trägt die Konturen eines Wolkenhimmels: bläulich und weiß. Er gibt zunächst gleichsam den Tisch ab, an dem Odysseus den Plan für die Operation entwirft, in deren Verlauf dem Philoktet der Bogen des Herakles abgeschwätzt und der ausgestoßene Held dann ins griechische Heer zurückgeholt werden soll. In die Bühne setzt er damit gleichsam eine zweite, perspektivisch verschobene Bühne ein. Eine Ebene, deren Schräge es uns erlaubt, statt frontal von vorn auch von oben auf die Szenerie zu schauen. Mit jeder Wendung der Handlung des Stückes verändert sich die Art des Einsatzes des Kastens. Er erlaubt, dass man auf ihm sitzt, über ihn geht. Wenn aus der Klappe in seiner Mitte Philoktet auftritt (vgl. Abb. 5), so wird er zu dessen Behausung, wenn Philoktet später auf ihm sitzt oder steht, erscheint er als die Insel, die zu bewohnen Philoktets Schicksal ist. Dreht er sich, so sehen wir ins Innere der Höhle Philoktets. In jedem Fall ist es dieser Kasten, der gleichsam die Einschnitte in der Inszenierung markiert. In jeder neuen Wendung des Stückes finden die Spieler eine neue Weise des Spielens mit ihm. Er wird so in seinen wechselnden Bedeutungen zunächst als eine vielfältig nutzbare raum-zeitliche Kippfigur erkennbar, im Spiel mit der sich die Handlung entfaltet. Zugleich erscheint er aber nach den wiederholten Wendungen auch als das, was die raum-zeitlichen Prozesse bedingend diesen

36 Vgl. Jean Jourdheuil, Philoctète, Premiere am 05.11.2009 im Théâtre de la Ville, Théâtre des Abesses, Paris. Meine Beschreibung bezieht sich auf die Vorstellung vom 31.03.2010 am TNS Strasbourg. 
äußerlich bleibt, in ihnen eine eigene, andere Ebene erkennbar macht, an ihnen den Raum und die Zeit des Spiels als eine vom Gespielten zu unterscheidende markiert. Jean Jourdheuils Inszenierung unterstreicht diesen Aspekt, wenn er den Darsteller des Philoktet in der Mitte des Stückes in dem zu diesem Zeitpunkt zum Zuschauerraum hin geöffneten Kasten liegend den Prolog vortragen lässt, der Müllers Stück vorangestellt ist: Wie dort der ans Publikum „aus der heutigen Zeit“ adressierte Text dem „Darsteller des Philoktet, in Clownmaske“ ${ }^{\star 37}$ zugeschrieben wird, so lenkt Jourdheuils Regie den Blick auf Lammerts Raumskulptur, die dergestalt als Mise en abyme erkennbar wird, als einer Maske vergleichbare Hinzufügung, die den Guckkasten vor uns in einem Zug als Totalität vorstellt und diese Totalität durch eben diese Hinzufügung auflöst, verändert, unterbricht. Wie in Talackos Ausstellungsraum wird so auch in Lammerts Mise en abyme das Dispositiv der Vorstellung vorgestellt, wobei die Vorstellung hier mit einer Entstellung einhergeht, zäsuriert wird.

\section{Raumskulpturen - Golonka}

Mit einer Konsequenz wie kaum ein anderer Regisseur und Choreograph der letzten Jahre hat Wanda Golonka in ihren Inszenierungen mit raum-zeitlichen Kippfiguren das Dispositiv der Bühne erkundet, ausgestellt und dabei jeweils auch verändernd neu bestimmt. So führte sie im Jahr 2010 die Zuschauer in Rrrungs! Eine Raumerkundung ${ }^{38}$ in kleinen Gruppen durch das Foyer über den Hof und die Treppen der Berliner Volksbühne von hinten auf die ungeheuer voluminöse Bühne und von dort in den noch nicht vollkommen enthüllten, renovierten Zuschauerraum, um in der weiteren Abfolge von Szenen aus Versatzstücken der Geschichte des vielleicht geschichtsträchtigsten deutschsprachigen Theaters die Choreographie des Abends zu entwickeln: Eines Abends, der mit der Vorstellung die Voraussetzungen dieses und jedes Abends in diesem Theater vor Augen führte. Entsprechend arbeitete sie in allen Performances, Theaterarbeiten und Tanzstücken, die sie in den Jahren zuvor im Schauspiel Frankfurt realisierte, mit jeder Inszenierung zugleich an der Ausstellung dessen, was da ist, bevor die Vorstellung beginnt, führte in For Sale und An Antigone die Zuschauer in alle Räume des Theaters, die ihnen sonst verschlossen bleiben, zu den Schnürböden, in die langen verwinkelten Gänge und Treppenhäuser, in den Malersaal und ins Magazin oder nutzte die Bühne des großen Hauses hinter dem Eisernen Vorhang auf so nicht vorgesehene Weise: In ihrer Inszenierung der Psychose 4.48 (vgl. Abb.6) von Sarah Kane diente sie der Aufhängung extrem langer Schaukeln, auf denen die Zuschauer so platziert wurden, dass sich das Sprechen der Darstellerin um sie herum,

\footnotetext{
37 Vgl. Heiner Müller, „Philoktet“, in: ders., Mauser, Berlin, 1988, S. 7-42: 7.

38 Rrrungs! Eine Raumerkundung, Regie, Choreographie, Bühne, Kostüme: Wanda Golonka. Volksbühne am Rosa-Luxemburg-Platz, Premiere: 28.04.2010.
} 
zwischen ihnen, abspielte und sie, durch die langen Drahtseile vermittelt, die Regungen aller mit ihnen die Schaukeln teilenden Mitbetrachter spürten. In Gier nach Sarah Kane nutzte sie die Drehbühne als eine Art von Amphi- oder Arenatheater im Theater, um dessen Rund die Zuschauer saßen.

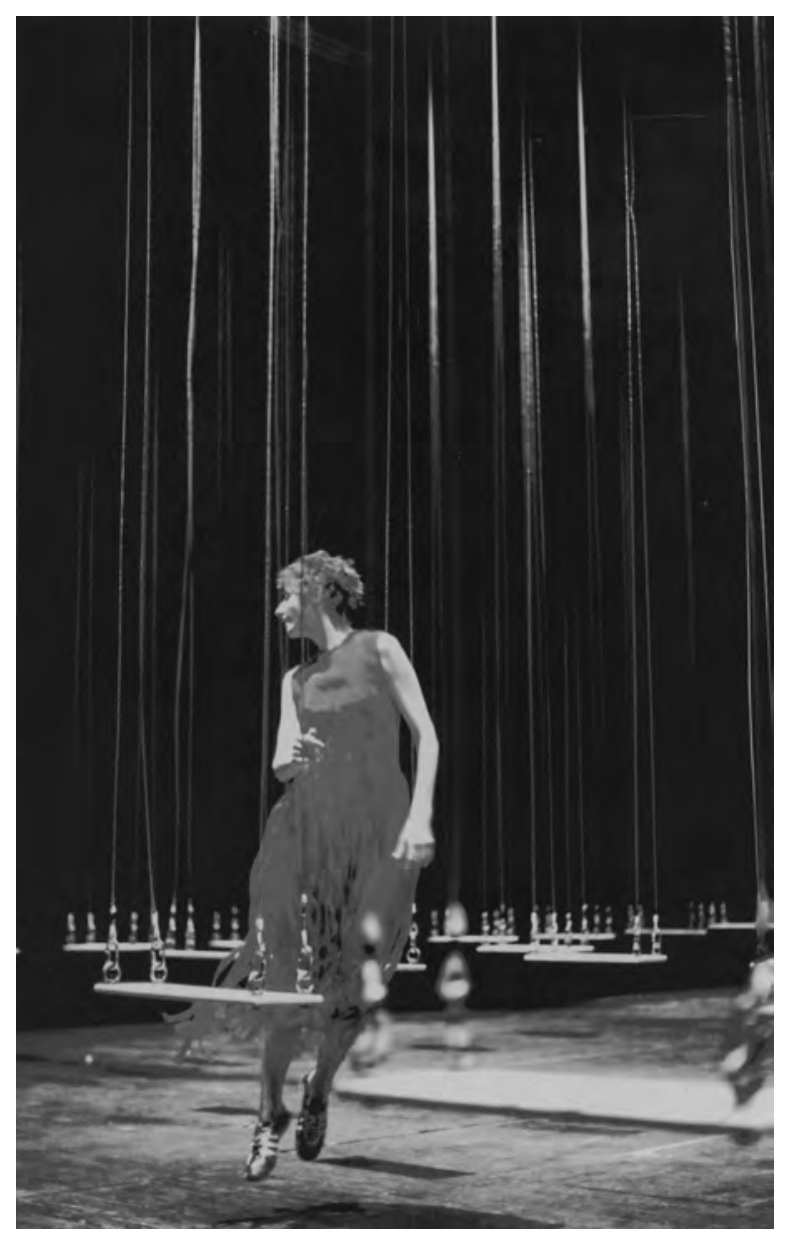

6 - Wanda Golonka, 4.48 Psychose, Schauspiel Frankfurt, 2002

Stellte in diesen Arbeiten die Kippfigur sich gleichsam durch den Bruch mit der konventionellen Nutzung des Raumes her, so entfaltete sich im zweiten Teil der Performancereihe An Antigone ${ }^{39}$ unter dem Titel Sticht es im Ohre, stichts im Innern dir? eine raum-zeitliche Kippfigur auf der als Blackbox angelegten, durch den Eisernen Vorhang abgetrennten Bühne des großen Hauses

39 Wanda Golonka, Antigone, Schauspiel Frankfurt, Premiere am 31.05.2003. 
des Schauspiels Frankfurt. Das Publikum ist in dieser Arbeit zunächst an den Seitenrändern der Bühne platziert, kann von dort eine Frau beobachten, die Zeitungspapier zerreißt, dann einen Mann (Oliver Kraushaar), der sich auf eine Liegefläche legt und dort herzzerreißend zu schreien beginnt und mehrere Minuten lang schreit. Nach einiger Zeit fahren langsam Lautsprecher herunter. In das leise bis unüberhörbare Murren einiger Zuschauer mischt sich ein immer lauter werdendes vielstimmiges Gemurmel, das, wie man irgendwann erkennt, aus den Lautsprechern dringt. Schließlich steht der Schauspieler auf und bittet Zuschauer, ihre Stühle in die Nähe der Lautsprecher zu stellen. Einige leisten Folge, setzen sich zögerlich in die Bildfläche, andere ziehen später nach. Irgendwann erlauben sich die ersten, von Lautsprecher zu Lautsprecher zu gehen, dann löst sich die Ordnung langsam auf, man flaniert durch den Raum, legt sich auf die Matratzen unter den am tiefsten gehängten Lautsprechern, steht unter den höchsten, setzt sich in einen Kreis anderer Hörer um die in der Mitte hängenden Lautsprecher, beginnt erste Gespräche über den Abend. Aus den Lautsprechern hört man Interviews mit Frankfurtern, die in den Wochen der Probenphase geführt worden sind.

Wie bereits in Golonkas Adaption von Sarah Kanes 4.48 Psychose $^{40}$ wird den Zuschauern auch hier der gemeinsame, geteilte Raum von Spielern und Betrachtern bewusst gemacht. Dabei verschiebt sich dieses Mal jedoch die Grenze zwischen Spielen und Zuschauen, wenn erst einer, dann mehrere, schließlich alle Zuschauer in den Spielraum gebeten und gesetzt werden: Mit einer gewissen Trägheit oder Zögerlichkeit vollzieht sich der Übergang jedes Einzelnen vom Betrachter zum Teil einer choreographierten, betrachteten Betrachteranordnung im Spielraum und dann wieder zu deren Auflösung in eine nicht länger geordnete, unbefangen hin- und herlaufende Menge der Zuhörer. Die Grenzziehung zwischen Spieler und Betrachter, Theater und Gesellschaft, die zu Anfang der Performance dem fremden Raum zum Trotz noch der Konvention des Guckkastentheaters entsprechend vorgenommen war, erscheint durch das Kippen der Theatervorstellung in eine Installation als eine je zu verhandelnde und nicht länger als eine, die als Teil des Dispositivs im Spielen und Betrachten außer Betracht bleibt, sie wird verhandelbar, erscheint historisch. Das Ende der Epoche des historischen Betrugs und ihr Übergang in eine andere Epoche werden im Verlauf der Performance in deren Bruch mit einem Dispositiv und im Übergang zu einem anderen erfahrbar. Nicht zuletzt versetzt Golonka mit diesem Bruch aber auf andere Weise als Wilson, Talacko und Lammert, nämlich in einem kurzen Moment der Verunsicherung, der von der Auflösung der ersten Schauordnung bis zur entspannten Nutzung der verschiedenen Höranordnungen reicht, alle Beteiligten an jenen Rand der bekannten Anordnungen, den Agamben vage als zum Vorschein bringen des „Unregierbaren“ bezeichnet. Für kurze Zeit stehen die Fragen: „Was tun? Wie richtig

40 Sarah Kane, Psychose 4.48, Choreographie: Wanda Golonka, Schauspiel Frankfurt, Premiere am 08.05.2002. 
handeln? Ja, soll ich überhaupt handeln?“ im Raum, Anfang und Fluchtpunkt jeder Politik auch der szenischen Anordnungen.

\section{Schlussbemerkung}

Nicht von ungefähr habe ich Beispiele von solchen Inszenierungen angeführt, die sich über die hier auf der Ebene der in ihrem Zusammenhang zu beobachtenden raum-zeitlichen Kippfigur hinaus auf vielen Ebenen mit dem ihnen vorausgehenden Dispositiv des Theaters auseinandersetzen, mit der konstitutiven Anordnung, die alle beteiligten Akteure subjektiviert und die Inszenierung als Ganzes prägt. Was die spezifische Form der Kippfigur - die ich hier nur exemplarisch bei Wilson, Talacko, Lammert und Golonka zeigen konnte auszeichnet, ist, dass sie nicht zuletzt Auseinandersetzung mit Formen der vermeintlichen Flucht aus den Zwängen der Institution ist, die tatsächlich nur ein Dispositiv durch ein anderes ersetzen.

Charakteristisch für die hier gewählten Beispiele raum-zeitlicher Kippfiguren ist dagegen, dass sie im Rekurs auf den Raumbildungsprozess das Enden der Räume und die Räume als endende erfahrbar machen, zu einer Grenze oder Schwelle gehen, an der - mit Agamben gesprochen - das in jedem Dispositiv Unregierbare zum Vorschein kommt. Mit gutem Grund könnte man diesen Moment in anderer Terminologie auch als Erfahrung der Medialität ${ }^{41}$ bezeichnen. Erfahren wird hier die Gleichursprünglichkeit jeder Regierbarkeit, wie sie durch die Dispositive erreicht wird. Mit einer konstitutiven Unregierbarkeit, die im Moment der Gründung des Dispositivs und von dort aus dieser Gründung entgegenstrebend an seiner Auflösung arbeitet. Jede der hier diskutierten Kippfiguren kann deshalb auch als das Aufsuchen der de-konstitutiven Zäsur des eigenen Mediums begriffen werden; das Wort Zäsur in dem von Hölderlin hergeleiteten Sinne als Begriff der Geschichtlichkeit verstanden. „Zäsur wäre, was in der Geschichte Geschichte unterbricht, und eine andere geschichtliche Möglichkeit eröffnet, oder aber jede Möglichkeit zur Geschichte schließt‘ ${ }^{\star 42}$, erläutert Philippe Lacoue-Labarthe luzide diesen Einschnitt. Es öffnet sich in solchen raumzeitlichen Kippfiguren - darin ist die ihnen inhärente radikale, ja revolutionäre Politik zu sehen - in der gegebenen Anordnung der Blick auf die Anordnung selbst und damit zugleich auf die mit ihr verbundene konstitutive Raumbildung und das, was mit ihr be- und entgrenzt wurde.

41 Vgl. zum Begriff von Medialität, wie er hier gebraucht wird: Müller-Schöll (2002), Das Theater des ,konstruktiven Defaitismus', S. 73-106, hier insbes. S. 93.

42 Vgl. Philippe Lacoue-Labarthe, Die Fiktion des Politischen. Heidegger, die Kunst und die Politik, Stuttgart, 1990, S. 72; ders., „Die Zäsur des Spekulativen“, in: ders., Die Nachahmung der Modernen, Typographien II, Basel, Weil am Rhein u. Wien, 2003, S. 37-70; vgl. auch Georg Christoph Tholen, Die Zäsur der Medien. Kulturphilosophische Konturen, Frankfurt/M., 2002. 
Es öffnet sich, anders gesagt, die Möglichkeit einer anderen Bühne, der Raum und die Zeit einer Bühne des Anderen.

\section{Literatur}

Agamben, Giorgio, Was ist ein Dispositiv?, Zürich, Berlin, 2008.

Benjamin, Walter, „Was ist das epische Theater? 1“, in: ders., Gesammelte Schriften, hg. v. Rolf Tiedemann/Hermann Schweppenhäuser, Band II, 2, Frankfurt/M., 1980, S. 519-531.

Brandstetter, Gabriele/Wiens, Birgit (Hg.), Theater ohne Fluchtpunkt. Das Erbe Adolphe Appias: Szenographie und Choreographie im zeitgenössischen Theater, Berlin, 2010.

Chétouane, Laurent, Philoktet von Heiner Müller im Studio/Werkstatt des Nationaltheaters Mannheim, Premiere am 25.05.02.

Derrida, Jacques, „Die différance“, in: ders., Randgänge der Philosophie, hg. v. Peter Engelmann, Wien, 1988, S. 29-52.

Dünne, Jörg/Günzel, Stephan (Hg.), Raumtheorie. Grundlagentexte aus Philosophie und Kulturwissenschaften, Frankfurt/M., 2006.

Foucault, Michel, Dits et Ecrits: Schriften, Bd. 3, Frankfurt/M., 2003.

Ders., „Andere Räume“, in: Karlheinz Barck/Peter Gente (Hg.), Aisthesis. Wahrnehmung heute oder Perspektiven einer anderen Ästhetik, Leipzig, 1990, S. 34-46.

Golonka, Wanda, Antigone, Schauspiel Frankfurt, Premiere am 31.05.2003.

Günzel, Stephan (Hg.), Topologie. Zur Raumbeschreibung in den Kultur- und Medienwissenschaften, Bielefeld, 2007.

Ders. (Hg.), Raumwissenschaften, Frankfurt/M., 2009.

Hamacher, Werner, „Amphora“, in: Wanda Golonka Tanz Ensemble Modell, Berlin, 2010, S. 29-34.

Haß, Ulrike, Das Drama des Sehens. Auge, Blick und Bühnenform, München, 2005.

Heidegger,Martin, „Der Weg zur Sprache“, in: ders., Unterwegs zur Sprache, Pfullingen, 1959, S. 239-268.

Jourdheuil, Jean, Philoctète, Premiere am 05.11.2009 im Théâtre de la Ville, Théâtre des Abesses, Paris.

Kane, Sarah, Psychose 4.48, Choreographie: Wanda Golonka, Schauspiel Frankfurt, Premiere am 08.05.2002.

Lacoue-Labarthe, Philippe, Die Fiktion des Politischen. Heidegger, die Kunst und die Politik, Stuttgart, 1990.

Ders., „Die Zäsur des Spekulativen“, in: ders., Die Nachahmung der Modernen, Typographien II, Basel, Weil am Rhein u. Wien, 2003, S. 37-70.

Libeskind, Daniel, „Das Ende vom Raum - ein Gespräch mit Gerhard Ahrens“, in: Hamburger Hefte, Nr. 4, raumgestalten, Hamburg, 2001, S. 42-51.

Müller, Heiner, „Philoktet“, in: ders., Mauser, Berlin, 1988, S. 7-42.

Ders., „,Robert Wilson/Freunde“, in: ders., Krieg ohne Schlacht, Köln, 1992, S. 327-336.

Müller-Schöll, Nikolaus, Das Theater des „,konstruktiven Defaitismus“. Lektüren zur Theorie eines Theaters der A-Identität bei Walter Benjamin, Bertolt Brecht und Heiner Müller, Frankfurt/M., Basel, 2002. 
Münz, Rudolf, Theatralität und Theater. Zur Historiographie von Theatralitätsgefügen, Berlin, 1998.

Rrrungs! Eine Raumerkundung, Regie, Choreographie, Bühne, Kostüme: Wanda Golonka. Volksbühne am Rosa-Luxemburg-Platz, Premiere: 28.04.2010.

Soja, Edward, Postmodern Geographies. The Reassertion of Space in Critical Social Theory, London, New York, NY, 1989.

Steinweg, Reiner, Brechts Modell der Lehrstücke,Zeugnisse, Diskussionen, Erfahrungen, Frankfurt/M., 1976.

Tholen, Georg Christoph, Die Zäsur der Medien. Kulturphilosophische Konturen, Frankfurt/M., 2002.

Waldenfels, Bernhard, „Topographie der Lebenswelt“, in: Stephan Günzel (Hg.), Topologie. Zur Raumbeschreibung in den Kultur- und Medienwissenschaften, Bielefeld, 2007, S. 69-84.

Weigel, Sigrid, „Zum ,topographical turn“ - Kartographie, Topographie und Raumkonzepte in den Kulturwissenschaften“, in: KulturPoetik 2, 2 (2002), S. 151-165.

Wilson, Robert, „Die Architektur des theatralischen Raumes“, in: Theaterschrift 2. The Written Space, S. 102-107. 



\section{EINE ANDERE GRAZIE. Zur AKTUALISIERUNG DER DiAgONALE IN LAURENT CHÉTOUANES TANZPERFORMANCE HORIZON(S)}

Sigal Zouk geht von links in die Mitte des Raums, bleibt stehen, sieht zu Boden und nimmt die erste Position ein. ${ }^{1}$ Eine knapp und präzise gesetzte Grundstellung der Füße reicht aus, um dasjenige Erbe des Tanzes wachzurufen, das der zeitgenössische Tanz in den letzten ein, zwei Jahrzehnten weitgehend unbeachtet gelassen hat - das Ballett. Zouks Eröffnungsszene ist allerdings nicht bloß ein Zitat des Ballett-Vokabulars, sondern vielmehr eine Auseinandersetzung mit der Frage, die am Anfang des Balletts steht: Die Frage von rechts und links, die Frage nach den beiden Körperhälften und ihrer Asymmetrie, die im Spiel mit symmetrischen Formen verhandelbar wird. Während Zouk die Beziehung ihrer Körperhälften erprobt, begeben sich die beiden anderen Tänzer, Anna MacRae und Matthieu Burner, in die linke obere Ecke des Raums, um ihren Platz für den Beginn der zweiten Szene von Laurent Chétouanes horizon(s) einzunehmen. Gleich werden sie den Raum aufmachen, der im Zentrum dieses Aufsatzes stehen soll: Vorsichtig und behutsam beginnen MacRae und Burner von links oben gemeinsam entlang einer ganz bestimmten, abstrakten Linie in den Raum zu gehen - der Diagonale. In diesem Gang liegt die größte Brisanz der Raumchoreographie von horizon(s), denn die Diagonale war vor allem im Kontext der freien Szene des zeitgenössischen Tanzes, in der Chétouane verortet ist, bis zur Aufführung von horizon(s) das vielleicht unausgesprochene Tabu jeder räumlichen Anordnung, sie war eine gewissermaßen unmögliche Linie. Umso erstaunlicher ist daher, auf welch simple Weise MacRae und Burner die Diagonale wieder hervorbringen: Sie gehen einfach die Linie entlang. Und doch steckt mehr dahinter, als nur ein paar Schritte zu machen: Wenn sie langsam Schritt für Schritt quer durch den Raum gehen, versuchen sie zwischen einander das zu etablieren und zu halten, was Chétouane in Probengesprächen immer wieder eine gewisse „Spannung“ nennt. Erst diese eigenartige körperliche Bezogenheit zwischen ihnen scheint die Diagonale entstehen zu lassen und umgekehrt scheint die Diagonale, die sich zwi-

1 Meinen Beobachtungen liegen Videoaufzeichnungen aus Essen (PACT Zollverein, 06. Mai 2011) und Berlin (Sophiensaele, 20. Mai 2011) und eine Aufführung im Rahmen der Tanzplattform 2012 in Dresden (An der Loge, 25. Februar 2012) zugrunde. Räumliche Ausrichtungen gebe ich jeweils aus der Sicht der Zuschauer an. 
schen ihnen aufspannt, die Linie zu sein, entlang der sie diese Spannung halten können.

Aber was hat es mit dieser Spannung auf sich und wozu diese Rückbesinnung auf die Diagonale? Wozu, so könnte der polemische Einwand lauten, wirft Chétouane in horizon(s) den Blick zurück auf eine Vergangenheit des Tanzes, die wir schon längst überwunden geglaubt hatten? Warum sollten wir uns heute noch mit dem Ballett und seiner Ordnung von Körper, Bewegung und Raum beschäftigen, die doch wegen ihrem Ideal des graziösen Subjekts der Transzendierung des Körpers hin zur schwerelosen Idee, die vertikal gen Himmel aufsteigt - vor allem deshalb verworfen wurde, weil es in der Praxis Disziplin, Quälerei und körperlichen Schmerz bedeutet? Warum sich wieder der Diagonale zuwenden, wenn sie doch genau jenes raumbildende Element ist, mit dem man dieses letztlich körperfeindliche Ideal zu verwirklichen glaubte, die längste Linie im Raum, die dem Körper sozusagen als Startbahn für den Sprung zur Grazie diente? Chétouane sieht im Ballett offensichtlich trotz all dieser möglichen Einwände noch Potenzial. horizon(s) zeugt von seiner Ansicht, dass es auch heute noch produktive Aspekte in dieser Tradition des Tanzes gibt, und zwar dann, wenn man dessen Ordnungen und Ideale wieder verhandelbar macht. Das bedeutet bei Chétouane, anders als im neoklassischen Ballett, von Anfang an weniger die Formsprache des Balletts in den Fokus zu nehmen, sondern die Problematiken von Körper und Subjekt, auf die diese reagiert, wie etwa in Zouks Eröffnungsszene. Eine Vergegenwärtigung des Balletts entspricht dann nicht der Tradierung der formalen Antworten des Balletts, sondern der Sichtbarmachung der Fragen, die in deren Ordnung und Form bearbeitet werden. Zu den Anliegen und Problemen des Balletts zurückzugehen heißt bei Chétouane, in dessen Erinnerung die Konzepte des Balletts einer Verschiebung oder Transformation zu unterwerfen, um wieder einen neuen Horizont für die Zukunft des Tanzes zu entwerfen.

Was Chétouane meiner Ansicht nach mit seiner Aktualisierung und gleichzeitigen Bearbeitung des Balletts sucht, ist nicht weniger als eine Erneuerung des Ideals der Grazie. Dabei knüpft Chétouane nicht an die Idee an, dass Grazie die Essenz des Balletts verwirklichen und dass dieser Essenz mit der Körperpraxis technischer Perfektion anhand geometrischer Linien und Formen zum Ausdruck verholfen werden könnte, sondern wendet sich stattdessen der Frage zu, die mit der Grazie ins Spiel gebracht wird, nämlich der nach dem Zusammenspiel der körperlichen und geistigen Vermögen des Subjekts. Denn was mit der Grazie zur Disposition steht, ist letztlich die Bestimmung des Verhältnisses zwischen Körper und Geist, zwischen Sinnlichkeit und Vernunft, Erfahrung und Bewusstsein in deren Differenz, wie auch die zwei prominentesten Theorien der Grazie nahelegen. Schiller auf der einen Seite konzipiert die Grazie beziehungsweise Anmut in seiner Figur der „schönen Seele“2 als

Friedrich Schiller, „Über Anmut und Würde“, in: ders., Sämtliche Werke. Bd. V, München, 1990, S. 231-285: 265. 
harmonische Vereinigung von Körper und Geist, die aber dem Primat des Geistes untersteht: „In einer schönen Seele ist es also, wo Sinnlichkeit und Vernunft, Pflicht und Neigung harmonisieren, und Grazie ist ihr Ausdruck in der Erscheinung““3; das harmonische Einssein muss aber stets von einer „Zulassung von Seiten des Geistes““4 ausgehen. Grazie ist demnach eine Zusammenfügung der Vermögen bis zu dem Punkt, an dem das Sinnliche scheinbar wie von selbst die Gebote des Geistes erfüllt und seine Differenz zu ihm weitestgehend aufgibt. Das Ballett folgt letztlich dieser Ansicht, solange der graziöse Tänzer durch die verstandesgeleitete Übung seinen Körper diszipliniert, um ihm den Schein der Schwerelosigkeit zu verleihen. Ungleich geheimnisvoller als Schillers sind auf der anderen Seite Kleists Gedanken zur Grazie in seinem kurzen Text Über das Marionettentheater. ${ }^{5}$ Mich interessiert an diesem so vielschichtigen und vieldiskutierten Text hier nur ein Aspekt, den Bernhard Greiner in seiner Lektüre besonders akzentuiert und der auf Chétouanes choreographischen Zugang zur Grazie hindeutet: „Mit Kleists Konzept von Grazie“, schreibt Greiner,

steht ein Einssein des Verschiedenen zur Debatte, das das Unterschiedene weder „verknüpft“ oder die Kluft in ihm „überbrückt“, noch das Entgegenstehende dialektisch „vermittelt“, sondern vielmehr ein Einssein, das im Raum der Differenz Kunde gibt von Nicht-Differenz. ${ }^{6}$

Grazie entsteht demnach durch eine ganz besondere Verbindung, in der die Vermögen zwar auf einen gemeinsamen Punkt bezogen sind, aber dennoch nicht ineinander aufgehen. Während Greiner diese Ankündigung von NichtDifferenz später mitunter als „geglücktes Einssein“ von Vernunft und Sinnlichkeit oder auch als „Raum jenseits der Differenz“7 bezeichnet, muss man, glaube ich, umgekehrt in Hinblick auf die immer paradoxe Definition der Grazie bei Kleist sagen, dass das einzige verbindende Moment der differenten Vermögen gerade die Differenz selbst ist, nämlich das, was man mit Gilles Deleuze die „Differenz an sich selbst“ oder „reine Differenz"8 ${ }^{\text {" }}$ nennen kann. Ein Ursprung, der wiederum immer schon in sich selbst differenziert ist und daher niemals einem indifferenten Einssein gleichkommt. Was die Vermögen damit bei Kleist einen würde, ihre Nicht-Differenz, ist, dass sie alle auf diese reine Differenz bezogen sind, die keinem Geist und keinem anderen Prinzip untersteht. „Inzwischen glaube er, dass auch der letzte Bruch von Geist, von dem er gesprochen, aus den Marionetten entfernt werden, daß ihr Tanz gänz-

Ebd.

Ebd., S. 256.

Vgl. Heinrich von Kleist, „Über das Marionettentheater“, Kleist-Archiv Sembdner, online unter: www.kleist.org/texte/UeberdasMarionettentheaterL.pdf, zuletzt aufgerufen am 28.06.2012.

6 Bernhard Greiner, Kleists Dramen und Erzählungen. Experimente zum ,Fall` der Kunst, Basel, Tübingen, 2000, S. 216.

Ebd.

8 Vgl. Gilles Deleuze, Differenz und Wiederholung, 3. Aufl., München, 2007. [Frz. OA Différence et répétition, Paris, 1968.] 
lich ins Reich mechanischer Kräfte hinübergespielt, und vermittelst einer Kurbel [...] hervorgebracht werden könne“ ${ }^{\text {} 9}$, lässt Kleist seinen Puppenspieler die Funktionsweise der Grazie resümieren. Die Kurbel, eine kleine unmenschliche Maschine, ist das differenzielle Element, das die Differenz entfaltet und damit die Marionette in Bewegung versetzt, ihre Glieder zum Leben erweckt und ihr Grazie verleiht.

In horizon(s), das ist meine Hypothese zu Chétouanes Raumchoreographie, übernimmt die Diagonale die differenzielle Funktion der Kurbel. Sie ist ebenso ein vollkommen unmenschliches Element, eine abstrakte Linie, die die zwei Tänzer MacRae und Burner und deren Vermögen in Bewegung bringt und zwischen ihnen jene merkwürdige Spannung entstehen lässt, die letztlich ihre Grazie ausmacht. Im Rückgriff auf Deleuzes Theorie der Subjektkonstitution, die er in seinem Hauptwerk Differenz und Wiederholung entwickelt, möchte ich nachvollziehbar machen, wie mit der Diagonale ein komplexes Zusammenspiel aller menschlicher Vermögen in Gang gebracht wird, in dem Wahrnehmung, Einbildungskraft, Verstand und Gedächtnis gleichermaßen, aber jeweils in ihrer Unterschiedlichkeit und ohne ineinander aufzugehen, zur Entstehung des graziösen Subjekts beitragen. So finden MacRae und Burner in der Erinnerung an das Ballett die Diagonale als ein Werkzeug wieder, mit dem sie ihre Wahrnehmung im Hier und Jetzt auf den Raum und aufeinander öffnen können und im Prozess der Öffnung eine körperliche Spannung zwischen einander generieren können. Diese Spannung lässt sich mit Deleuze als ein Zustand der Intensität begreifen, einer starken Empfindung zwischen den Körpern, in dem letztlich die reine Differenz als solche erfahrbar wird. Nach Deleuze ist nämlich die Intensität „die Form der Differenz als Grund des Sinnlichen. Jede Intensität ist differentiell, Differenz an sich selbst. ${ }^{\text {" }}{ }^{10}$ In diesem Kontakt mit der Intensität als Differenz an sich selbst erfährt das Subjekt seine Grazie.

Auch bei Chétouane ist das graziöse Subjekt ein wesentlich gemachtes, die Grazie seiner Tänzer ist wie im Ballett das Ergebnis langer Proben, in denen ihre Körper eine neue Haltung einüben. Allerdings setzt Chétouanes Technik der Grazie nicht wie das Ballett dabei an, den Körper zunächst durch disziplinäres Training in seiner inneren Funktionsweise zu beherrschen, um ihn dann in einen kontrollierten Außenbezug zum Raum zu stellen, der auf geometrische Linien beschränkt bleibt. Vielmehr umgekehrt geht Chétouane davon aus, dass der Körper in seiner Grazie zuerst durch das Außen, durch den Raum bedingt wird, und dass dessen Verhältnis zum Raum nicht auf abstrakte Linien

\footnotetext{
9 Kleist (o.J.), „Über das Marionettentheater“.

10 Deleuze (2007), Differenz und Wiederholung, S. 282.
} 
zu reduzieren ist. Sein Einsatz der Diagonale zeigt auf bezeichnende Weise, wie Chétouane deshalb ihre Funktion als abstrakte Linie gerade dahingehend wendet, dass sich der Körper entlang dieser Linie auf den konkreten Raum und die anderen Körper im Raum zu öffnen vermag. Die Diagonale wird gewissermaßen zum Vektor der Öffnung auf den Raum und auf den Kontakt zu den anderen Körpern im Raum. Sie initiiert das Moment der Grazie, indem sie die Körper in ihrer Außenwahrnehmung des Raums sensibilisiert. Jedoch sieht sich Chétouane bei seiner Arbeit mit dem Raum unmittelbar mit dem Dispositiv der Zentralperspektive konfrontiert, das eine wesentliche Einschränkung des Körpers mit sich bringt. Die Perspektive richtet den Körper nach vorne aus und erlaubt dem Tänzer keinen umfassenden Bezug zum Raum in dessen Tiefe und all dessen Richtungen. Wenn er gerade in der Relation des Körpers zum Raum und zum anderen Körper im Raum den Weg zur Grazie sieht, muss Chétouane deshalb zuallererst ihren wirkmächtigen Zugriff auf den Körper bearbeiten.

Im Tanz lässt sich die Ausrichtung des Körpers durch das Dispositiv der Zentralperspektive bis an die historischen Anfänge der Choreographie zurückverfolgen. In Raoul-Auger Feuillets Chorégraphie, ou l'art de d'écrire la danse bekommt man eine erste Ahnung vom Einsatz der zentralperspektivischen Anordnung des Körpers im Tanz, und zwar anhand einer besonders pointierten Darstellung des Körpers. ${ }^{11}$ Feuillet hat mit seiner Chorégraphie 1700 das erste systematische Notationssystem für die Bewegungen des Tänzerkörpers im Raum vorgelegt, gewissermaßen eine Semiotik des Tanzes, mit der sich die Raumchoreographie des Körpers auf Papier bringen lässt. Die Tanzfläche wird dabei von einem leeren Quadrat repräsentiert, in das anhand einer Grammatik arbiträrer Zeichen die Positionen und Schritte der Füße eingetragen werden können: Aus der Vogelperspektive zeichnet man die Linien und Wege des Körpers im Raum. Der Raum wird damit erstmals zum konstitutiven Bezugssystem des Körpers; nur in Relation zum Raum können fortan der Körper und seine Bewegungen gedacht und choreographiert werden.

Die doppelte Pointe von Feuillets Notation besteht in dem Zeichen, das der Körper in seiner Raumchoreographie erhält, und in der Art und Weise wie sich der Körper mit der Hilfe von Feuillets Buch als praktischer Tanzanleitung im Raum auszurichten hat. Zunächst zu Ersterem: In einem pikanterweise als „The Presence of the Body“ betitelten Punkt (ich zitiere nach John Weavers englischer Übersetzung) stellt Feuillet den Körper vor als einen halben Kreis, der an seiner Vorderseite durch einen Strich symbolisiert ist. ${ }^{12}$ Feuillet schreibt dazu: „The Posture of Presence of the Body, is to have respect to that part of the Room, to which the Face or Fore-Part of the Body is directed, which I de-

11 Vgl. zu Feuillet etwa André Lepecki, Exhausting Dance. Performance and the Politics of Movement, London, New York, NY, 2006.

12 Raoul-Auger Feuillet, Orchesography, or, The Art of Dancing, Gloucester, 2007, S. 3 [Herv. i. O.]. [Frz. OA Chorégraphie, ou l'art de d'écrire la danse, Paris, 1700.] 
scribe the Figure F G H I, of which F G shews the two Sides of the Body, $\mathrm{H}$ the Face or Fore-Part, and I the Back or Hinderpart." ${ }^{\text {"13 }}$

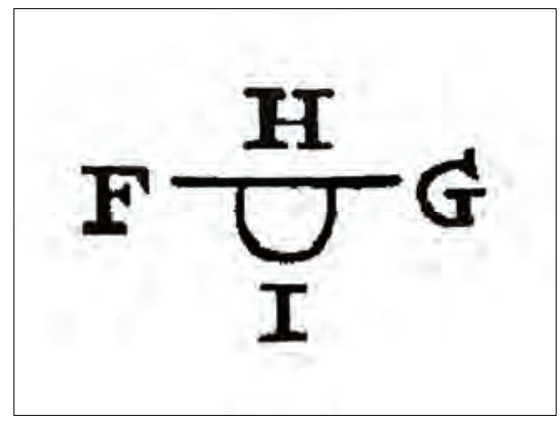

1 - Zeichen des Tänzerkörpers

Feuillets Zeichen des Körpers führt eine wesentliche Differenz in den Körper ein: Während seiner Rückseite, dem nach hinten ragenden Halbkreis, anschei-

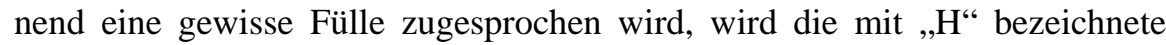
Vorderseite des Körpers als bloßer Strich angesehen. Ausgerechnet in dieser Flachheit des Körpers besteht nach Feuillet die Präsenz des Körpers: In der partiellen Auslöschung dessen, was den Körper in seiner ursprünglichen Verfasstheit auszeichnet, seinem Volumen und seiner Plastizität, wird er in der Zentralperspektive erst sichtbar. Zu diesem Körperzeichen als Einsetzung eines flachen Körpers gesellt sich Feuillets Beschreibung einer Szene von der Positionierung und Bewegung des Körpers im Raum mithilfe seines Buchs: Im Abschnitt „How to hold the Book or Paper, to decipher written Dances“"14 schreibt er, dass sich der Tänzer zur Einübung von neuen Choreographien mit dem Buch in der Hand auf die Tanzfläche stellen solle, zunächst nach vorne ausgerichtet, und dass er beachten solle, ,always to hold the upper end of the Book against the upper end of the Room; and whether the Dance have any Turning in it or not, you must carefully avoid removing the Book from the Situation above demonstrated. “15 Nachdem die Buchseiten den Raum repräsentieren, muss das obere Ende des Buchs immer nach der Front des Raums ausgerichtet sein, damit Buchseite und Raumrichtungen übereinstimmen. Solange der Tänzer ohnehin nach vorne positioniert ist, besteht ein direktes Abbildungsverhältnis von Seite und Raum - wenn er sich allerdings drehen muss, darf er nur seinen Körper in die jeweilige Richtung drehen, muss aber das Buch in die andere Richtung drehen, damit es weiterhin nach vorne ausgerichtet bleibt und die aufgezeichneten Wege weiter mit der Raumrichtung überein-

13 Ebd.

14 Ebd., S. 43.

15 Ebd., S. 44. [Herv. i. O.] 
stimmen. Feuillets Szene eines Tänzers, der mit seinem Buch Tänze einstudieren kann, legt also nahe, dass der Tänzer, selbst wenn er seinen Körper in einer Drehung von der Front abrichtet, die Bewegung im Raum mit dem Buch letztlich doch von der frontalen Ausrichtung aus zu denken hat. Wenn der Tänzer später das Buch zur Seite legt, ist diese Konstruktion in seinem Körperwissen derart internalisiert, dass er sich stets von vorne und gewissermaßen von außen zum und im Raum verhält.

Feuillets Körperzeichen und die Szene mit dem Buch weisen bereits auf die zweifache Funktion der Zentralperspektive hin: Zunächst fügt sie den Körper in das Bild der illusionistischen dreidimensionalen Darstellung ein. Wie Ulrike Haß in ihrer Habilitation zum Drama des Sehens etwa anhand von Pozzos Bühnenkonzept des quadro feststellt, das übrigens im gleichen Jahr wie Feuillets Chorégraphie anzusetzen ist, stellt sich die Wirkung der Perspektive in ihrem Extrem als totale Verbildlichung des Raums dar, die auch den Körper vollkommen vereinnahmt:

Das Bild legt sich als organisierte Ansicht über die Besonderheiten der Bühne und überzieht diese gleichsam mit einer symbolischen Leseanweisung: Dies alles hier ist ein und dasselbe, nämlich ,Bild‘. Das Bild ebnet die Differenzen zwischen Körpern, Bodenflächen und Vertikalen ein. ${ }^{16}$

Auch wenn diese Beschreibung noch nicht auf den Tanz um 1700 zutrifft, ist diese Verbildlichung des Körpers bei Feuillet dennoch schon angelegt, wenn die Körpervorderseite als flach zu verstehen ist und deren Ausrichtung stets über die Bühnenfront zu erfolgen hat. Die zweite Funktion des zentralperspektivischen Dispositivs hat eine symbolisch-repräsentative Dimension: Der Tänzer hat sich nach vorne hin auszurichten, um sich dem Blick des Publikums und, zu Feuillets Zeit, besonders dem des Königs zu unterwerfen. Er hat den Anwesenden sein Gesicht zu zeigen und darf ihnen nicht den Rücken zudrehen. Die Norm der Ausrichtung nach vorne dient der Subjektivierung und Anerkennung innerhalb einer symbolischen Ordnung, die nicht nur den symbolischen Vertrag der Aufführung bildet, sondern auch den der Gesellschaft repräsentiert. Darin offenbart sich die umfassendere Dimension von Feuillets Buchszene: Wenn sich der Tänzer aufgrund einer Drehung doch vom König und vom Zuschauer abwendet, dann bewegt er sich dennoch mit dem internalisierten, frontalen Blick des Königs oder der Zuschauer durch den Raum und bleibt diesem Blick unterworfen. Die Norm der Bildlichkeit und der Frontalität, deren Keim im Tanzkontext bei Feuillet zu finden ist, bedeuten für die Praxis des Tanzes letztlich, dass die Aufmerksamkeit des Körpers im Raum derart nach vorne gerichtet ist, dass dieser den Raum, in dem er sich bewegt, aber auch die anderen Körper im Raum nur teilweise wahrnehmen kann. Er kann sein körperliches Selbstverständnis nicht aus dem Bezug zu all dem beziehen, was ihn in der Tiefe des Raums umgibt.

16 Ulrike Haß, Das Drama des Sehens. Auge, Blick und Bühnenform, München, 2005, S. 373. 
Die Diagonale hat als abstraktes, raumbildendes Element des Balletts an dieser Einschränkung der körperlichen Wahrnehmung teil, solange auch für die Bewegung entlang ihrer Linie gilt, dass sich der Körper dabei stets über den inneren Bezug zur Front auszurichten hat. Eine besonders anschauliche Darstellung dieser Verbindung von Diagonale und Frontalität findet man in Doris Humphreys theoretischen Ausführungen zu ihrem Choreographiekonzept. Auch wenn sich ihr amerikanischer moderner Tanz zwar in vielen Punkten von den Kodizes und Idealen des Balletts wie etwa der Spitze und der vertikalen Transzendierung des Körpers abzusetzen versuchte, ist in Humphreys Buch The Art of Making Dances zu sehen, dass sie weiterhin der Überzeugung war, dass die Diagonale das zentrale Element der Raumchoreographie darstellt. Bei Humphrey beweist sich nicht nur, dass die Diagonale selbst über das Ballett hinaus eine bedeutende Wirkung auf die Choreographie des Raums im Tanz hatte, sondern auch, dass die flache, bildhafte Vorderseite des Körpers und die frontale Ausrichtung seiner Bewegung auch in ihrem gewissermaßen energetischen Modell des Tanzes unhinterfragt bleibt. In The Art of Making Dances zeugen mehrere Zeichnungen zur Diagonale davon, dass sie letztlich den gesamten Raum als von Diagonalen durchzogenes und erst durch diese erzeugtes Feld versteht, die den Körper energetisieren. An einer Stelle schreibt sie von den zwei horizontalen Raumdiagonalen als

the invisible diagonals which stream from the upper corners to the lower. These are certainly there, in spite of the fact that you cannot see them. Put the dancer to walking on one of these diagonals from the up right to down left, and he is moving in the most powerful path on the stage. ${ }^{17}$

Von den zwei am Boden verlaufenden Diagonalen bildet also eine das stärkste raumbildende Element des gesamten Bühnenraums: Die Linie, die, wie sie schreibt, von „up right to down left“ führt, oder, aus der Sicht der Zuschauer, nach der ich bisher räumliche Orientierungspunkte angegeben habe, von links oben nach rechts unten. In der Betonung dieser Diagonale stimmt Humphrey mit der räumlichen Syntax des Balletts überein, denn auch in der Balletttradition kommt dieser Diagonale das Privileg einer besonderen Bedeutung zu, und zwar vor allem deshalb, weil sie der rechtsläufigen Schreib- und Leserichtung der abendländischen Kultur entspricht: Die Raumchoreographie lässt sich wie die Seite eines Buchs von links oben nach rechts unten lesen. Auf dieser längsten Linie des Raums können die Tänzer die längsten Bewegungsphrasen und höchsten Sprünge tanzen und bewegen sich dabei vom hinteren Ende der Bühne auf die Zuschauer zu. Es ist auch diese Diagonale, die MacRae und Burner in horizon(s) entlang gehen werden.

Besonders interessant ist nun, dass der Körper auf zwei von Humphreys Zeichnungen zur Diagonale in Übereinstimmung mit der zentralperspektivischen Norm - einmal mehr, einmal weniger - offensichtlich nach vorne aus-

17 Doris Humphrey, The Art of Making Dances, 19. Aufl., New York, NY, 1980, S. 75. 
gerichtet ist. Humphreys Zeichnungen sind Ausdruck der Forderung, dass die Tänzer nicht nur über die Internalisierung des frontalen Blicks in Bezug zur Bühnenfront zu stehen haben, sondern auf real-körperliche Weise. Auf bezeichnende Art ist zu sehen, wie sich der Tänzer selbst im Abgang über die zweite Raumdiagonale nach rechts hinten noch einmal nach vorne umzuwenden hat. Durch die körperliche Umwendung bleiben der Blick und teilweise auch der Oberkörper nach vorne ausgerichtet, obwohl sich der restliche Körper mit seiner Bewegung von der Front abwendet. Zugleich weisen die Zeichnungen implizit auf die Paradoxie hin, die in der Konjunktion von Diagonale und real flachem, frontalem Körper besteht. Der Körper ist abgebildet, wie er den gesamten Raum abgeht, wie er also anhand der Diagonale die gesamte Tiefe der Bühne durchmisst, wie er aber zugleich jeweils von der gesamten Hälfte des Raums, von der er sich abzuwenden hat, und von allem, was er mit jedem Schritt vorwärts hinter sich lässt, keinen Eindruck bekommen kann. Genau an diesem Punkt hakt Chétouane ein. Er erkennt die abstrakte Linie der Diagonale als Vektor, mit dem sich der Körper auf den gesamten Raum in seiner Weite öffnen kann, wenn die Diagonale aus ihrer Verknüpfung mit der Norm der Frontalität gelöst werden kann. Von innen heraus versucht Chétouane das zentralperspektivische Dispositiv zu bearbeiten, indem er die Diagonale gegen die frontale Ausrichtung wendet, mit der sie bisher einherging, und ihr einen neuen Gebrauch zukommen lässt.
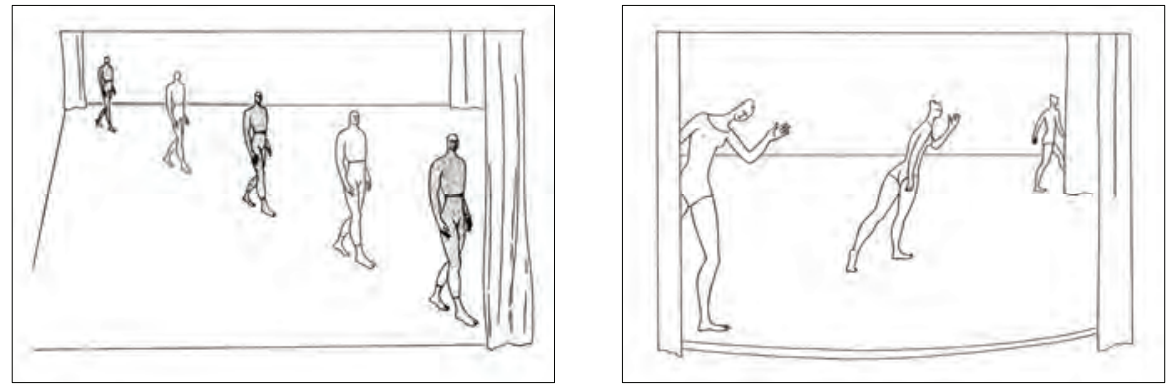

2 und 3 - Die horizontalen Raumdiagonalen

Wenn MacRae und Burner zu Beginn der zweiten Szene von horizon(s) in der linken oberen Ecke des Raums stehen, entfaltet sich vor ihnen entlang der Diagonale der ganze Raum. MacRaes und Burners erste Reaktion auf diese Situation ist bezeichnend: Sie machen - nichts. Sie stehen da und schauen. Sie nehmen den Raum nur wahr, schauen einander an, auch das Publikum und Zouk, dann wieder den Raum. Sie nutzen die Diagonale zwischen den beiden Ecken des Raums nicht sofort, um sich mit und auf ihr zu bewegen, sondern zualler- 
erst, um mit ihr eine umfassende Wahrnehmung des Raums zu erlangen. An ihrem Blick ist besonders auffällig, dass MacRae und Burner nicht unbedingt einen Punkt im Raum fokussieren, sondern vielmehr versuchen, den Raum auch in dessen Peripherie wahrzunehmen. Ihre Augen scheinen möglichst viele visuelle Eindrücke aufnehmen zu wollen, um eine möglichst weite Anschauung von der Räumlichkeit der Bühne zu bekommen. Sie schauen nicht nur frontal nach vorne, sondern auch in andere Richtungen. Die Diagonale fungiert dabei gewissermaßen als Trigger, um den Blick, aber auch den Körper zu weiten. Insbesondere der Oberkörper scheint geweitet, er ist weder starr vor Anspannung noch in sich gefallen, sondern im Gegenteil gelöst und dennoch nach außen hin in Richtung der Diagonale auf den Raum gerichtet. Wenn anschließend beide beginnen, konzentriert und bedächtig gemeinsam die ersten Schritte auf der Diagonale zu machen - ihre Gänge in ihrer Qualität eher alltäglich, die Beine aber hin und wieder stärker angehoben - ist bemerkenswert, wie leicht und sanft, aber auch unsicher und prekär ihre Bewegungen wirken. Jede Bewegung scheint im Moment verhandelt zu werden, sie wird nicht so sehr präzise gesetzt, sondern in ihrer Ausführung ihrerseits von den Tänzern wahrgenommen und auf ihre Effekte auf den eigenen und den anderen Körper befragt. Die Körper sind aufeinander ausgerichtet und nehmen einander wahr, während sie gemeinsam über die Diagonale gehen. Immer wieder drehen sich MacRae und Burner zueinander um, auch wenn sie sich dadurch vom Publikum abwenden. Der Bezugspunkt im Raum ist der andere Körper, nicht die Front. Mitunter strecken sie die Arme zueinander aus und berühren einander mit ihren Händen, umarmen sich auch zwei Mal. Die Berührung scheint eine intensive taktile Sinnlichkeit zu haben. Aber gerade, wenn sich die zwei Tänzer etwas voneinander wegbewegen und ein gewisser Abstand zwischen ihnen entsteht, gerade dann scheint sich eine besondere Spannung zwischen ihnen zu ereignen. Die Diagonale wird genau in diesen Momenten besonders erfahrbar. Sie ist die Linie zwischen ihnen, die den körperlichen Bezug auf der Ebene der Empfindung stützt, und zugleich wird durch diese empfindungsreiche Spannung zwischen den Körpern die Diagonale umso präsenter. Insgesamt scheinen ihre Körper im Gang auf und entlang der Diagonale mit dem konkreten Raum um sie herum verbunden und von der frontalen Ausrichtung gelöst, auch wenn MacRae und Burner das Publikum und die Tatsache, dass sie von ihm gesehen werden, nicht ignorieren, sondern auch immer wieder ins Publikum blicken.

Wie die Beschreibung der Szene nahelegt, eignet Chétouanes Choreographie der zwei Körper auch ein gewisses Pathos, mitunter eine besondere Bedeutungsschwere, wenn etwa die Umarmungen eine allzu symbolische Bedeutung annehmen und man vor sich beinahe zwei verliebte Turteltauben sieht, die vollkommen in ihrer gegenseitigen Bezogenheit aufgehen. Auch der Blick hat teils eine transparente Qualität, die meinen lässt, dass die beiden Tänzer beinahe auf mystische Weise eins werden mit dem, was sie sehen. Und dennoch bleibt der Zustand der Empfindung, die Spannung zwischen ihnen, meist 
konkret, ohne transzendiert zu werden, und in ihrem Bezug nach außen wahren sie immer eine gewisse Distanz, die sie von der gänzlichen Verschmelzung mit ihrer Umgebung abhält und auf die ich später noch zurück kommen werde. Zunächst aber möchte ich, trotz dieser Momente allzu großer Ergriffenheit, den enormen Einsatz nachzeichnen, der in der Öffnung nach außen und der Loslösung von der frontalen Körperausrichtung liegt. Dieses Verfahren der Öffnung ist nämlich eine gezielte Arbeit an der Subjektivität und den Vermögen der Tänzer, die man mit Deleuze als Ins-Spiel-Bringen der sogenannten „passiven Synthese ${ }^{\text {“18 }}$ des Subjekts fassen kann.

Die passive Synthese ist in Deleuzes Theorie der Subjektkonstitution die erste von drei Synthesen, die in ihrer Verbindung das Subjekt ausmachen. Die erste, passive Synthese benennt, in Anlehnung an Hume und in der Nähe zu Husserl, aber auch Leibniz stehend, die basale Verarbeitung der wahrgenommenen Perzeptionen durch die Einbildungskraft zu qualifizierten Eindrücken. Am Anfang des Subjekts steht demnach nicht das cogito, sondern die passive Wahrnehmung und präreflexive Synthetisierung des Außen. Die zweite, ,aktive Synthese ${ }^{\text {‘19 }}$, vor allem im Rückgriff auf Bergson definiert, macht die qualifizierten Eindrücke zum Objekt des Verstands und des Gedächtnisses, des Denkens und der Erinnerung. Und die dritte „Synthese der Zeit“20 schließlich benennt das wesentliche Eingebundensein des Subjekts in die abstrakte, leere Form der Zeit, wie Kant sie erstmals gedacht hat.

Im Rekurs auf Hume führt Deleuze die passive Synthese durch das Bild der photographischen Platte ein:

Die Einbildungskraft definiert sich hier als Kontraktionskraft: als photographische Platte hält sie das eine fest, wenn das andere erscheint. Sie zieht die Fälle, die Elemente, die Erschütterungen, die homogenen Augenblicke zusammen und verschmilzt sie zu einem qualitativen inneren Eindruck mit einem gewissen Gewicht. $^{21}$

In der Einbildungskraft findet die allererste Verarbeitung der Wahrnehmung statt, indem die einzelnen sinnlichen Perzeptionen aufgenommen und zu gesammelten Eindrücken verdichtet werden. Obwohl dieser Prozess bereits über die bloße Wahrnehmung der Dinge hinausgeht, da ihm das Verdienst einer ersten Synthetisierung zukommt, ist er nach Deleuze dennoch wesentlich passiv und präreflexiv: Die Synthese ist „zwar konstitutiv, aber darum noch nicht aktiv. Sie wird nicht im Geist hergestellt, erstellt sich aber im betrachtenden Geist, geht jedem Gedächtnis und jeder Reflexion voraus. ${ }^{\text {“22 }}$ Ihre konstitutive Leistung besteht vor allem darin, dass auf der Grundlage von inneren Eindrü-

\footnotetext{
18 Zum Konzept der passiven Synthese: Deleuze (2007), Differenz und Wiederholung, S. 99110.

19 Zur aktiven Synthese: ebd., S. 110-118.

20 Zur Synthese der Zeit: ebd., S. 118-125.

21 Ebd., S. 99.

22 Ebd., S. 100. [Herv. i. O.]
} 
cken sensomotorische Verhaltensmuster ausgeprägt werden, die prägend sind für das Handeln des Subjekts. Diese erste subjektive Einheit nennt Deleuze, wieder in Anlehnung an Hume, das „Problem der Gewohnheit““. ${ }^{23}$ In der Verarbeitung von Perzeptionen entwickeln wir - noch vor der Ausbildung verstandesgeleiteter Handlungen - Erwartungen und einen habitualisierten körperlichen Umgang mit unserer Umwelt und den anderen.

Diese tausend Gewohnheiten, aus denen wir bestehen [...] bilden also das Ausgangsgebiet der passiven Synthesen. Das passive Ich definiert sich nicht einfach durch Rezeptivität, d. h. durch die Fähigkeit, Empfindungen zu erfahren, sondern durch die kontrahierende Betrachtung, die den Organismus selbst noch vor der Ausbildung seiner Empfindungen bildet. [...] Die Ichs sind larvenhafte Subjekte. ${ }^{24}$

Genau an diesem Prozess der Ausbildung von Gewohnheiten, die das larvenhafte Stadium des Subjekts ausmachen, setzt Chétouane an, um den Körper zu öffnen, denn wie Miriam Engelhardt in ihrer Vertiefung des Deleuz'schen Subjektivitätskonzepts schreibt, muss man in der passiven Synthese den Anfang und „die Gleichzeitigkeit von Subjektivierungsprozessen und Normalitätsproduktion“ ${ }^{25}$ sehen. Die Art und Weise wie die Körper der Tänzer sich bewegen, wie Zouks, MacRaes und Burners Körper sich zum Raum und zueinander verhalten, ist durch die habituelle Einübung oder Internalisierung der zentralperspektivischen Norm der frontalen Ausrichtung bestimmt. Die Ausrichtung nach vorne und die Einschränkung der Körperlichkeit der Vorderseite sind in jahrelangem Tanztraining mit Ballettunterricht durch die Ausbildung eines präreflexives Körperwissens geprägt worden. Chétouane interveniert auf dieser Ebene der Gewohnheit, indem er die habituellen Reaktionen des Körpers durch die Erweiterung der Außenwahrnehmung gewissermaßen entsichert. Indem sich MacRae und Burner zunächst durch die Diagonale auf das Außen öffnen, indem sie den Raum möglichst genau wahrnehmen und nicht sofort beginnen, sich zu bewegen, versuchen sie ihre Einbildungskraft mit neuen Eindrücken anzureichen, so dass der Körper noch nicht mit einem etablierten sensomotorischen Muster auf die Bühnensituation zu antworten weiß. Zwischen Wahrnehmung und Aktion tut sich ein Raum auf, in dem die Umsetzung der sinnlichen Eindrücke in Bewegung, aber auch die Haltung und die Ausrichtung des Körpers veränderbar wird. Wir sehen zwei Tänzerkörper, die wieder in den Prozess ihrer Konstitution eintreten, zwei Körper, deren Verhältnis zum Raum und zum jeweils anderen wieder ins Spiel gebracht wird. Deshalb erscheinen etwa die Bewegungen von MacRae und Burner unsicher, deshalb können sie ihre Körper aber auch anders im Raum ausrichten und den gesamten Raum, der sie umgibt, auf andere Weise wahrnehmen. Durch den veränderten Raumbezug ist die Norm der bildlichen, frontalen Ausrichtung für

${ }^{23}$ Ebd., S. 103.

24 Ebd., S. 110.

25 Miriam Engelhardt, Deleuze als Methode. Ein Seismograph für theoretische Innovationen durchgeführt an Beispielen des feministischen Diskurses, München, 2008, S. 116. 
die Tänzer verhandelbar geworden. Die Körper können innerhalb oder unterhalb des repräsentativen Bezugs zum Publikum, der mit der Zentralperspektive installiert wird, dennoch eine andere Körperlichkeit ausbilden, indem sie nicht mehr die Front, sondern den anderen Körper zum ersten Bezugspunkt im Raum nehmen und auf der Diagonale als verbindender Linie eine gewissermaßen sub-repräsentative Empfindung zwischen einander etablieren, die mitunter auch von den Zuschauern erfahren werden kann, wenn sie sich ihrerseits auf das Geschehen im Raum einlassen können. Wie weiter oben bereits angedeutet, wird diese Spannung zwischen ihnen hergestellt, wenn sie einen gewissen Abstand zu einander haben, der nicht zu klein, aber auch nicht zu große sein darf. Ihre Körper werden dann zu zwei Punkten auf der diagonalen Linie, die die Spannung trägt.

Wie kann man diese Spannung genauer fassen? Wie der Wiener Philosoph Konrad Paul Liessmann in einem Versuch zu einer Theorie der Spannung schreibt, ist die Existenz zweier solcher Punkte, die durch eine gewisse Distanz in Kontakt gehalten werden, für Spannung konstitutiv: „Die Spannung braucht zumindest zwei Pole, zwischen denen sie sich aufbauen kann. Spannung existiert zwischen Gegensätzen, die auf einander bezogen sind [...]. “26 Spannung ist demnach immer ein relationales Phänomen, nur zwischen den zwei Körpern von MacRae und Burner kann sich eine Spannung aufbauen. Zwar nicht im Tanz, aber in der bildenden Kunst sieht Liessmann einen besonderen Einsatzort der Spannung, durch den er sich noch näher an deren Charakteristik anzunähern versucht. In der Kunst können wir Spannung

als eine spezifische Atmosphäre der Unruhe und Intensität wahrnehmen. So wie man die Spannung, die zwischen zwei Menschen herrschen mag, als geladene Atmosphäre empfindet, so können ästhetische Reize in einer Weise in Stellung zu einander gebracht werden, daß wir die dabei entstehende Spannung mitunter nahezu körperlich zu spüren scheinen. ${ }^{27}$

Ungleich eindeutiger lässt sich in Hinblick auf den Tanz sagen, dass sich dort, genau in der körperlichen Bezogenheit zweier Menschen aufeinander, innerhalb einer ästhetischen Rahmung diese Spannung ereignen kann. Entscheidend ist, dass Liessmann die Intensität als diejenige Empfindung nennt, die in der Spannung evoziert werden kann. Mit Intensität ist nämlich wiederum in Deleuzes Philosophie ein besonderes Konzept der Empfindung verbunden, das zum Kern der Grazie bei Chétouane führt. Intensität benennt bei Deleuze zu-

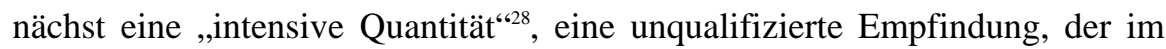
Gegensatz zu Gefühlen wie Liebe oder Wut keine klare Signifikanz zukommt. In der Intensität drückt sich aber nicht nur eine unklare, empirisch eindringliche Sinnlichkeit aus, sondern zugleich die transzendentale Dimension des Sinnlichen:

\footnotetext{
26 Konrad Paul Liessmann, Ästhetische Empfindungen, Wien, 2009, S. 136.

27 Ebd., S. 137. [Herv. G. D.]

28 Deleuze (2007), Differenz und Wiederholung, S. 294.
} 
Die Intensität, die Differenz in der Intensität ist es, die die eigentliche Grenze der Sinnlichkeit bildet. Daher besitzt sie den paradoxen Charakter dieser Grenze: Sie ist das Unsinnliche, das, was nicht empfunden werden kann, weil es stets von einer Qualität verdeckt wird, die sie entfremdet und ihr ,entgegenwirkt' [contrarie], weil sie in der Ausdehnung verteilt ist, die sie verkehrt und tilgt. Auf andere Weise aber ist sie das, was nur empfunden werden kann und den transzendentalen Gebrauch der Sinnlichkeit definiert, da sie empfinden macht und damit das Gedächtnis wachrüttelt und das Denken erzwingt. ${ }^{29}$

Die Intensität ist demnach keine minderwertige unbestimmte Empfindung, sondern im Gegenteil als unbestimmte Empfindung, die nicht und zugleich nur empfunden werden kann, der Ausdruck der Möglichkeitsbedingung jeder Empfindung und des Sinnlichen. In der Intensität wird die Differenz an sich selbst erfahrbar, denn Intensität ist, wie eingangs zitiert, „die Form der Differenz als Grund des Sinnlichen“. Mehr noch: Mit der Empfindung der reinen Differenz als in sich selbst differenziertem Ursprung offenbart sich dem empfindenden Subjekt zugleich die Quelle seiner Vermögen und derer Synthesen. Genau in ihrer paradoxen Verfasstheit als das, was nicht und nur empfunden werden kann, ermöglicht die Intensität also die beinahe unmögliche sinnliche Erfahrung der größten Differenz, die im Subjekt und seinen Vermögen wirkt.

Das ist die äußerste Grenze dessen, was bei Chétouane mit der Grazie im Spiel ist: Die Spannung zwischen MacRae und Burner etabliert sich auf der Diagonale als ein Zustand der Intensität, der die Tänzer nicht in eine bestimmte Gefühlslage versetzt, sondern ihnen und den Zuschauern vielmehr eine Ahnung von der Differenz als Möglichkeitsbedingung der Subjektivität und der Empfindung im Speziellen gibt. Interessanterweise knüpften Chétouane und seine Tänzer gerade mit dieser Verhandlung der Empfindung an das Ballett an; so schreibt Gerald Siegmund etwa in einer Analyse von William Forsythes Choreographien über die Praxis des Balletts: „Die Welt des Balletts besteht aus Schritten und deren Verbindung. Entgegen der populären romantischen Vorstellung arbeiten die Tänzer während der Proben nicht in erster Linie mit Gefühlen, sondern sie suchen nach Wegen, wie das Gefühl hergestellt werden kann. “30 In diesem Sinn offenbart Chétouane in seiner Arbeit an der Intensität letztlich die transzendentale Dimension des Umgangs mit Gefühlen im Ballett.

\section{IV}

Deleuze definiert die passive Synthese, deren Bearbeitung bei Chétouane zur Grazie hinführt, auch als die „gelebte“ oder „lebendige Gegenwart““. ${ }^{31}$ Tatsächlich kommt die Öffnung auf den Raum und die anderen Körper dem Einlassen

29 Ebd., S. 299 f.

30 Gerald Siegmund, „William Forsythe. Räume eröffnen, in denen sich das Denken ereignen kann“, in: ders. (Hg.), William Forsythe. Denken in Bewegung, Berlin, 2004, S. 9-72: 13.

31 Deleuze (2007), Differenz und Wiederholung, S. 100. 
auf die unmittelbare Gegenwart gleich, und dennoch gehen die Tänzer in horizon(s) weder in der Szene der Diagonale, noch in den darauffolgenden Szenen vollkommen im Hier und Jetzt auf. Die reine Differenz, deren Erfahrung am höchsten Punkt der Grazie in der Intensität möglich wird, weist in ihrer Transzendentalität immer schon über die unmittelbare Verfasstheit der Subjekte hinaus. Allerdings steht die Distanz zur Gegenwart nicht erst am Ende der prozessualen Hervorbringung der Grazie, sondern schon an deren Anfang. Erst dadurch, dass sich die Tänzer in gewisser Weise von der Gegenwart lösen und Zugang zu einer anderen Zeit finden, wird eine andere Grazie vorstellbar. Denn nur in der Vergangenheit des Tanzes, nur in Erinnerung an das Ballett finden sie mit der Diagonale das choreographische Mittel, um einen anderen Zugang zum Hier und Jetzt auszubilden. In gewisser Weise ist also in horizon(s) nicht die passive Synthese der Gegenwart die erste subjektbildende Einheit und Anstoß zur Grazie, sondern die aktive Synthese, mit der die Vergangenheit und das Vermögen der Erinnerung ins Spiel gebracht werden. Die zweite Synthese wird zur ersten, weil nur das Gedächtnis des Tanzes eine neue Perspektive für dessen Gegenwart bietet.

In seiner Lektüre von Bergson gelangt Deleuze zu der Ansicht, dass gerade die Vergangenheit die Zeit der Differenz bzw., Bergsons Terminologie folgend, des Virtuellen als Feld der Potenzialität ist. ${ }^{32}$ Bei Bergson selbst findet man die Vergangenheit definiert als das, „was nicht mehr wirkt, aber wirken könnte, was wirken wird, wenn es sich einer gegenwärtigen Empfindung einfügt und von ihr Vitalität entleiht.." ${ }^{* 33}$ Im Konjunktiv des Vergangenen liegt dessen Potenzialität: Es wirkt nicht unmittelbar, aber könnte wirken und die Gegenwart beeinflussen. Durch seine wesensmäßige Verschiedenheit von der Gegenwart kann die Vergangenheit, wie Engelhardt schreibt, als „das Zeitreservoir“ fungieren, „in dem sich die Virtualitäten erhalten“334 und von dem Veränderung ausgehen kann, wenn es in Erinnerung gerufen wird und sich dadurch aktualisiert. Der zweiten Synthese als Syntheseleistung des Verstands und des Gedächtnisses kommt also in horizon(s) gerade die Funktion zu, durch die Erinnerung einen anderen Blick auf die Gegenwart zu ermöglichen: In der Erinnerung an das Ballett greifen sie auf die Diagonale als abstrakte Linie zurück, die den Körpern im Hier und Jetzt neue Potenziale für einen anderen konkreten Bezug zum Raum und zueinander ermöglichen kann. Diese Erinnerungsarbeit beginnt natürlich nicht erst in der Aufführung, sondern schon in den Proben. Was später in der Aufführung zu sehen ist, hat seinen Anfang in den Anfängen der Proben, in denen Chétouane und die Tänzer im bewussten Rückblick auf den Tanz die Diagonale wieder entdecken und in Improvisa-

\footnotetext{
32 Vgl. Gilles Deleuze, Bergson zur Einführung, 4. Aufl., Hamburg, 2007, [frz. OA Le Bergsonisme, Paris, 1966]; und: Deleuze (2007), Differenz und Wiederholung, S. 110-112.

33 Henri Bergson, Materie und Gedächtnis. Eine Abhandlung über die Beziehung zwischen Körper und Geist, Mit einer Einleitung v. Erik Oger, Hamburg, 1991, S. 240 [Herv. G. D.]. [Frz. OA Matière et Mémoire, Paris, 1896.]

34 Engelhardt (2008), Deleuze als Methode, S. 125.
} 
tionen einsetzen, um ihr Potenzial im räumlichen Bezug auszutesten. Es ist also zunächst ein Akt der Erinnerung nötig, damit sich MacRae und Burner in der Gegenwart aufeinander öffnen können.

Die Vergangenheit findet darüber hinaus in Deleuzes Überlegungen auch eine räumliche Entsprechung, und zwar in der Tiefe.

Die Explikation der Ausdehnung beruht auf der ersten Synthese, der Synthese der Gewohnheit oder der Gegenwart; die Implikation der Tiefe aber beruht auf der zweiten Synthese, des Gedächtnisses und der Vergangenheit. [...] Die Tiefe entspricht der berühmten geologischen Linie von Nordost nach Südwest, jener Linie, die diagonal aus dem Innersten der Dinge stammt [... ${ }^{35}$

Auch wenn er nicht die Diagonale im Sinn hat, die in horizon(s) zu sehen ist, lässt sich in Anlehnung an Deleuze doch sagen, dass die Diagonale die Tiefe des Raums erfahrbar macht und damit zugleich einen Raum der Vergangenheit und Differenz aufmacht, der die Gegenwart bereichert.

Aber auch noch in einem letzten anderen Sinn scheinen die Tänzer in horizon(s) der unmittelbaren Gegenwart enthoben. In ihrem Blick kann man mitunter die Bewusstheit derjenigen Dimension der Subjektivität sehen, die nach Deleuze die dritte Synthese ausmacht. MacRae und Burner scheinen im Zustand der Intensität immerzu eine gewisse Distanz zu sich selbst zu wahren. Ihr Blick ist nicht nur nach außen auf die Umgebung gerichtet, sondern auch auf sich als Objekt ihrer selbst. Dieser Blick ist aber wesentlich unterschieden von dem internalisierten Blick von außen, weil er sie nicht an die Frontalität der Bühne bindet. Diese Dissoziation des Subjekts ist das konstitutive Moment der dritten Synthese, die Deleuze auf Kants transzendentale Einsetzung der Zeit zurückführt:

Die Form, in der die unbestimmte Existenz durch das Ich denke bestimmbar ist, ist die Form der Zeit ... Die Konsequenzen daraus sind unabsehbar: Meine unbestimmte Existenz kann nur in der Zeit bestimmt werden, als Existenz eines Phänomens, eines passiven oder rezeptiven phänomenalen Subjekts, das in der Zeit erscheint. [...] Ein Sprung oder ein Riß im Ego [Je], eine Passivität im Ich [moi] - dies ist die Bedeutung der Zeit ${ }^{36}$.

Zeit und Passivität haben hier eine andere Bedeutung als in der passiven und der aktiven Synthese: Die Zeit ist nicht die gelebte Gegenwart, auch nicht die Vergangenheit, sondern vielmehr ein abstrakter, leerer Container, der das Subjekt immer schon a priori umfasst. Engelhardt macht den Zusammenhang mit der Passivität verständlich, die dieser Subjektivität zukommt:

Hier läuft nichts mehr in der Zeit ab [...], sondern die Zeit selbst läuft (leer) ab. Vorher - Nachher, Vorher - Nachher. Das denkende Ego kann als einziges feststellen, dass Zeit vergeht und $u$. $U$. genau nichts passiert. Es muss gewisserma-

35 Deleuze (2007), Differenz und Wiederholung, S. 291.

36 Ebd., S. 119. [Herv. i. O.] 
ßen zusehen, wie sich seine passive Existenz permanent in der Zeit verändert, ganz ohne sein Zutun, ohne Intentionalität, ohne Reflexion oder Handlung. ${ }^{37}$

Passivität benennt in diesem Fall eine wesentliche Selbstbezüglichkeit des Subjekts: Das Ego nimmt sich selbst in seiner Veränderung durch das Wirken der Zeit wahr. Durch diese selbstbezügliche Wendung distanziert sich das Subjekt von sich selbst. Im Blick der Tänzer ist in horizon(s) eine Ahnung von dieser Prozessualität ihrer Subjektivität vorhanden, sie sehen nicht nur den anderen an und schauen nicht nur in den Raum, sondern blicken, gerade wenn sie über die Diagonale gehen, auch immer wieder sich selbst und ihre eigenen Bewegungen an, schauen sich selbst $\mathrm{zu}$, wie sie sich bewegen und bewegt werden. Wir sehen MacRae und Burner auf der Diagonale also gewissermaßen auch als Zuschauer ihrer selbst im Prozess der Öffnung hin zur Intensität.

In horizon(s) sind also letztlich alle drei Synthesen auf besondere Weise involviert und tragen in der Unterschiedlichkeit der Vermögen, die ihnen entsprechen, zur Konstitution des graziösen Subjekts bei. Nicht die Öffnung der Wahrnehmung allein, sondern nur deren Zusammenspiel mit der ihr vorausgehenden Erinnerung und die Bewusstheit von der zeitlich-prozessualen Verfasstheit der Subjektivität können zur Grazie führen. Im Zentrum dieses Zusammenspiels steht in horizon(s) die Diagonale als differenzielles Element und gewissermaßen Kleist'sche Kurbel: Durch die Erinnerung an die Diagonale können sich MacRae und Burner in der Sensibilisierung ihrer Wahrnehmung auf den Raum öffnen, den habituellen Bezug zur Front ablegen und sich auf den jeweils anderen Körper als neuen Bezugspunkt ausrichten. Entlang der abstrakten Linie zwischen ihnen kann sich schließlich jene Spannung ereignen, die einem Zustand der Intensität als paradoxer sinnlicher Erfahrung der reinen Differenz entspricht. Das Subjekt erfährt in diesem Zustand der Empfindung das transzendentale Moment, die Möglichkeitsbedingung seiner Vermögen und seiner eigenen Subjektivität - diese Erfahrung ist es, die ihm seine Grazie verleiht. $^{38}$

\section{Literatur}

Bergson, Henri, Materie und Gedächtnis. Eine Abhandlung über die Beziehung zwischen Körper und Geist. Mit einer Einleitung von Erik Oger, Hamburg, 1991. [Frz. OA Matière et Mémoire, Paris, 1896.]

37 Engelhardt (2008), Deleuze als Methode, S. 128.

38 Für ihre Kommentare und Anregungen zu diesem Text möchte ich Ulrike Haß, Nikolaus Müller-Schöll und Gerald Siegmund sehr herzlich danken. 
Deleuze, Gilles, Bergson zur Einführung, 4. Aufl., Hamburg, 2007. [Frz. OA Le Bergsonisme, Paris, 1966.]

Ders., Differenz und Wiederholung, 3. Aufl., München, 2007. [Frz. OA Différence et répétition, Paris, 1968.]

Engelhardt, Miriam, Deleuze als Methode. Ein Seismograph für theoretische Innovationen durchgeführt an Beispielen des feministischen Diskurses, München, 2008.

Feuillet, Raoul-Auger, Orchesography, or, The Art of Dancing, Gloucester, 2007. [Frz. OA Chorégraphie, ou l'art de d'écrire la danse, Paris, 1700.]

Greiner, Bernhard, Kleists Dramen und Erzählungen. Experimente zum ,Fall` der Kunst, Basel, Tübingen, 2000.

Haß, Ulrike, Das Drama des Sehens. Auge, Blick und Bühnenform, München, 2005.

Humphrey, Doris, The Art of Making Dances, 19. Aufl., New York, NY, 1980.

Kleist, Heinrich von, „Über das Marionettentheater“, Kleist-Archiv Sembdner, online unter: www.kleist.org/texte/UeberdasMarionettentheaterL.pdf, zuletzt aufgerufen am 28.06.2012.

Lepecki, André, Exhausting Dance. Performance and the Politics of Movement, London, New York, NY, 2006.

Liessmann, Konrad Paul, Ästhetische Empfindungen, Wien, 2009.

Schiller, Friedrich, „Über Anmut und Würde“, in: ders., Sämtliche Werke. Bd. V, München, 1990, S. 231-285.

Siegmund, Gerald, „William Forsythe. Räume eröffnen, in denen sich das Denken ereignen kann“, in: ders. (Hg.), William Forsythe. Denken in Bewegung, Berlin, 2004, S. 9-72. 


\section{(THEATER-)GRABEN: \\ DIE UNTERE BILDKANTE ALS GRENZWERTIGER SPIELRAUM DES BETRACHTERS}

Vielfältig haben Maler der Frühen Neuzeit daran gearbeitet, den Zwischenraum zwischen Bild und Betrachter einzunehmen und für die Fiktion des Bildes nutzbar zu machen. Diese „Übergriffigkeit“ der Kunst- in die Lebenswelt lässt sich besonders eindrücklich an religösen Historiengemälden ermitteln, deren prinzipielle Aufgabe es war, Betrachter zum Glauben an das Dargestellte zu bewegen. Hiermit kam der Illusion, dass das Bildwerk virtuell beide Realitäten - diejenige vor und diejenige im Bild - umgreifen könne, eine essenzielle Bedeutung zu.

Die notwendige Rahmung des Bildes als Abschluss seiner Fläche grenzt die Fiktion vom Umraum ab. Doch oft wird diese Einfassung schon durch die Einpassung des Werks in den liturgisch konditionierten Kontext des Kirchenbaus aufgehoben, wenn etwa der Vollzug kultischer Handlungen vor dem Bild die Differenz der aufeinandertreffenden Realitäten verstellt. Diese doppelte Rahmung sprengt also die Funktion der ersten, um in deren Öffnung ein Intervall für Interaktion zu gewinnen.

Die folgenden Bildbetrachtungen orientieren sich an der rezeptionsästhetischen Methode, wie sie in der Kunstgeschichte von Wolfgang Kemp und John Shearman dargestellt wird. Beide lehnen sich in der Konzeption des „impliziten Betrachters“ (Kemp) bzw. derjenigen des „more engaged spectator“ (Shearman) an den literaturwissenschaftlichen Ansatz der Konstanzer Schule an, der von einer im Werk strukturell verankerten Funktion des ,impliziten Leser[s]“ ausgeht. ${ }^{1}$ Kemp differenziert zwischen ,„äußeren) Zugangsbedingungen und (inneren) Rezeptionsvorgaben“. Während die erste Kategorie den architektonischen und soziokulturellen Kontext bedenkt, umfasst die zweite innerbildliche Motive, wie beispielsweise eine zwischen Betrachter und dargestellter Szene vermittelnde Figur, und bildkompositorische Strukturen wie die Perspektive, welche den Betrachter im Blick haben. ${ }^{2}$

Shearman entwickelte anhand einiger Beispiele aus Skulptur und Malerei die These, dass sich im Laufe des 15. Jahrhunderts ein Bewusstsein der Anwe-

1 Wolfgang Kemp, „Kunstwissenschaft und Rezeptionsästhetik“, in: ders. (Hg.), Der Betrachter ist im Bild. Kunstwissenschaft und Rezeptionsästhetik, Berlin, 1992, S. 7-27; John Shearman, Only Connect... Art and the Spectator in the Italian Renaissance, Princeton, NJ, 1992.

2 Wolfgang Kemp, „Kunstwerk und Betrachter: Der rezeptionsästhetische Ansatz“, in: Hans Belting et al. (Hg.), Kunstgeschichte. Eine Einführung, Berlin 2008, S. 247-265: 251-254. 
senheit der Betrachters herausbildete. Dieses Bewusstsein führte schließlich zu einer Konzeption von Werken, welche darauf abzielen, den Betrachter in das künstlerische Sujet eintreten zu lassen, um seinen „plot“ zu vollenden. ${ }^{3}$ Damit schreibt Shearman gleichsam eine Vorgeschichte zur barocken Kunst, welche ihrer kunsthistorischen Definition nach vornehmlich an der Aufhebung der Grenze zwischen Kunst und Wirklichkeit, u. a. mittels der „Verschmelzung aller Künste“ ${ }^{\text {‘ }}$, insbesondere durch die Verschleifung der Übergänge zwischen Skulptur und Architektur, arbeitet. Rudolf Wittkower, einem der wegweisendsten Barockforscher, zufolge befindet sich der Betrachter (in Anbetracht des Baldacchinos Lorenzo Berninis in St. Peter) ,in einer Welt, welche er mit den Heiligen und Engel teilt, und er fühlt sich magisch in die Umlaufbahn des Werks gezogen. Was ist Bild, was Realität? Die Grenze zwischen dem einen und dem anderen scheint aufgehoben. ${ }^{* 5}$

Doch wie, d. h. durch welche bildnerischen Mittel ist dieser Zusammenbruch der Grenze, der das Bildwerk zum Gegenstand einer Vision werden lässt, an eine „Grenzerfahrung“ gebunden?

\section{Die Einnahme des Betrachters}

Der Gestaltung der unteren Bildkante ist bisher weder eine strukturelle noch historische Untersuchung gewidmet worden. ${ }^{6}$ Das ist um so erstaunlicher, da schließlich Bildfeld und Außenraum hier unmittelbar aneinanderstoßen.

Altargemälde befinden sich in der Regel auf einem Altartisch und erhalten also einen schwerwiegenden Sockel: Auf der Altarmensa wird die Messfeier abgehalten und der Raum vor dem Gemälde ist zum rituellen Handlungsraum bestimmt. Die untere Bildkante bildet also einen empfindlichen Abschluss, da er auf die rituelle Sakralisierung des Orts vor dem Bild trifft.

Nicolas Régniers Gemälde Die Taufe Christi (vgl. Abb. 1) ist ein frappantes Beispiel hierfür. Christus steht nicht, wie üblich, im Wasser, sondern kniet auf einem Felsblock. Während er sich mit seiner Rechten an die Brust greift, stützt er sich mit seiner Linken auf einem höher gelegenen Erdwall ab. Der Oberkörper Christi ist nach vorn gebeugt, sein Kopf geneigt, um sich von Johannes

John Shearman (1992), Only Connect, S. 17.

4 „The creation of new species and the fusion of all arts enhance the beholder's emotional participation: when all the barriers are down, life and art, real existence and apparition, melt into one.“ Rudolf Wittkower, Bernini. The Sculptor of the Roman Baroque, London, 1997, S. 15.

5 „The beholder finds himself in a world which he shares with saints and angels, and he feels magically drawn into the orbit of the work. What is image, what is reality? The very borderline between the one and the other seems to be obliterated." Rudolf Wittkower, Art and Architecture in Italy 1600 to 1750 [1958], überarb. u. hg. v. Joseph Connors/Jennifer Montagu, New Haven, London, 1999, Bd. 2, S. 16. Vgl. von Wittkower aus- und weitergehend: Irving Lavin, Bernini and the Unity of the Visual Arts, New York, NY, 1980; Giovanni Careri, Envols d'amour: Le Bernin, montage des arts et dévotion baroque, Paris, 1990.

6 Der vorliegende Artikel ist eine erste Skizze dieses Projekts. 
taufen zu lassen. Die malerische Gestaltung des rosa gefärbten Tuchs, das, über seinen rechten Arm gelegt, seine Nackheit verbirgt, ist in seiner Plastizität greifbarer als das rote Tuch des Täufers. Christus hebt sich dadurch räumlich stärker ab. Die Körper beider Heiligen sind lebensgroß dargestellt, wodurch die Differenz zwischen Bild- und Betrachterrealität minimiert ist. Während der Blick des Täufers „himmelnd“ nach oben geschlagen ist, hat Christus die Augen gesenkt. Er scheint nach unten zu blicken.

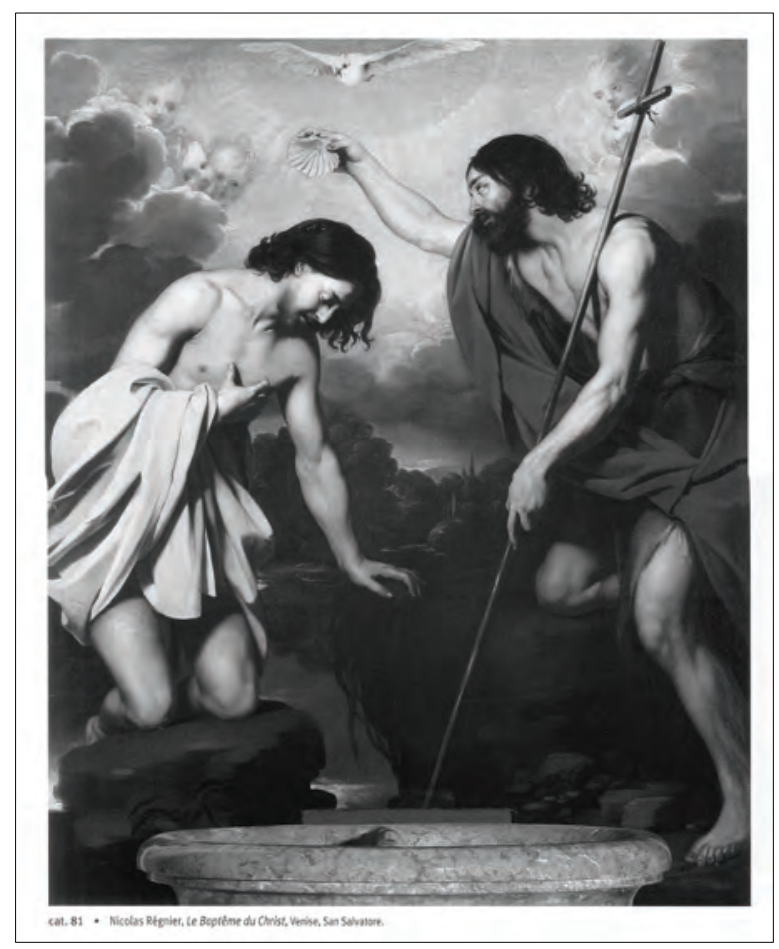

1 - Nicolas Régnier, Le Baptême du Christ, Venise, San Salvatore

Ein Weihwasserbecken, ohne welches das Gemälde nicht zu fotografieren ist, steht quasi im Bild. Eine Aussparung der Leinwand an der unteren Bildkante markiert seinen feststehenden Ort im Gefüge des Bildes. ${ }^{7}$ Die liturgische Funktion des Weihwasserbeckens besteht darin, die Schwelle, die Alltagswelt und sakralen Ort trennt, erfahrbar zu machen. Das Weihwasser dient dem

\footnotetext{
7 Vgl. Annick Lemoine, die einen derartigen Bezug andeutet: „Toutefois, la composition de l'œuvre, qui s'articule en fonction des fonts baptismaux placés devant la toile, prouve que le retable fut conçu pour son emplacement actuel.“ Dies., Nicolas Régnier (alias Niccolò Renieri) ca. 1588-1667, peintre, collectioneur et marchand de l'art, Paris, 2007, S. 81.
} 
Taufgedächtnis. ${ }^{8}$ Die enge kompositorische Bezogenheit des Bildwerks auf seinen Umraum ist folglich selbstredend. Interessanterweise lehnt sich nun der Körper Christi derart über die Schlucht, dass es erscheint, als ob Christus sich über das Weihwassergefäß beugen würde. In dieser szenischen Zusammenschau beider Realitätsebenen kollabieren historischer Moment und die Jetztzeit des Taufgedächtnisses - Bildraum und Betrachterraum.

Zugleich eröffnet der Blick Christi über die Bildgrenze hinaus eine noch ganz andere Reflexionsmöglichkeit: Régnier spielt sehr subtil mit dem Aspekt der Selbstbespiegelung, denn die Position Christi ähnelt auf frappante Weise derjenigen des Narziß, der über einen Brunnen gebeugt das eigene Spiegelbild als das Bild eines anderen erschaut. Die Mittelachse verläuft durch die Taube am oberen Rand, den Scheitel Christi, seine aufgestützte Rechte und trifft der Fiktion des Bildes nach, welche das Taufbecken einbezieht - auf die Wasseroberfläche. Bedenken wir, dass die Taufe in dreier Namen geschieht: „Im Namen des Vaters und des Sohns und des Heiligen Geistes“ (Mt. 28,19), dann evoziert die in Aussicht gestellte Spiegelung Christi Gott als Spiegelbild Christi. Die Gottesebenbildlichkeit Christi ${ }^{9}$ überträgt sich auf den Gläubigen, der, durch die Taufe von seinen Sünden reingewaschen, selbst ebenbildlich wird. ${ }^{10}$

Indem Régnier auf forcierte Weise den Umraum in seine Bildkonzeption einbezieht, um dem Betrachter eine ihn unmittelbar betreffende Sinndimension zu eröffnen, inszeniert er den Kirchenraum als Schauplatz. Wir können folglich das Weihwasserbecken im weiteren Sinne als „Rahmung“ begreifen, welche die Anschauung des Dargestellten konditioniert. Die Rahmung liefert uns den Schlüssel für die „verborgene“ tiefere Bedeutung, die sich jedoch erst im Zusammenspiel mit der Erwartung des Betrachters kommuniziert, d. h. sie ist ein sich im Zwischenraum aufbauender, gleichsam „überschüssiger“ Sinneffekt.

Gegen die hier vorgestellte Interpretation kann jedoch eingewendet werden, dass die konstatierte enge Bezugnahme Régniers auf den Ort zwar wahrscheinlich ist, das Zusammentreffen von Bild und Gefäß jedoch letztlich auch zufällig und nicht vom Künstler intendiert sein könnte. Eine abgesichertere Grundlage für unsere Argumentation bietet sich, wenn die Anhaltspunkte einer Eröffnung eines bedeutungsstiftenden Intervalls sich im Gemälde selbst befinden.

8 Siehe Artikel: „Wasser“, in: Lexikon für Theologie und Kirche, hg. v. Michael Buchberger, Bd. 10, Freiburg, 1965, Sp. 962-968: 966.

9 Siehe Paulus: „Er ist das Ebenbild des unsichtbaren Gottes“ (Kol 1,15).

10 So Paulus in seinen Korintherbriefen: 1 Kor 15,49; 2 Kor 3,18; und Kolosserbrief: Kol 3,10. Marilyn Aronberg Lavin kommt in ihrer Untersuchung zu Piero della Francescas Taufe Christi auf den Vergleich des Jordans mit einem Spiegel in einer Fussnote zu sprechen. Sie bezieht sich auf eine Festhymne des frühchristlichen Kirchenlehrers Ephräm der Syrer (um 303-373). Vgl. dies., Piero della Francescas's Baptism of Christ, New Haven, London, 1981, S. 125, Fn. 11. 
Zahlreiche Maler haben den Bildraum unmittelbar oberhalb der unteren Bildkante, der Schnittstelle zwischen dem Real- und dem Bildraum, dazu genutzt, einen Schwellenraum, welcher in die Fiktion des Bildes einführt, aufzubauen. Auf vielfältige Weise wurde dieser fiktive Zwischenraum in die Konzeption des illusionären Raums einbezogen, um den Betrachter ins dargestellte Geschehen zu involvieren. Wie wir gleich an exemplarischen Beispielen zeigen werden, wurde entweder damit dem Betrachter ein Einstieg geboten, oder ein Abgrund aufgerissen, über welchen sich fingierte Körper spektakulär herauslehnen, um sich dem Betrachter darzubieten. Der Raum unmittelbar vor dem Gemälde wird somit als ein potenzieller und de facto theatraler Handlungsraum bestimmt.

\section{„Außerästhetische Belastung“: Die untere Bildkante als Rampe}

In der Kunst der Frührenaissance weisen eine Vielzahl von Altarbildern an der unteren Bildkante die Einschneidung eines gemauerten Tiefenraums auf, der uns räumlich herabsetzt, vom Bildgeschehen absetzt und quasi in die Knie zwingt. ${ }^{11}$ Dieser Graben bietet der unteren Bildkante also einen doppelten Boden, um den Zwischenraum zwischen Bild und Betrachter in das Bild zu ziehen und von da aus beherrschbar zu machen. Eröffnet wird ein eingeschränkter und liturgisch konditionierter Handlungsspielraum.

Begibt sich der Betrachter/die Betrachterin im Geiste in den für ihn/für sie vorgesehenen Ort, so ist er/sie in das dargestellte Geschehen eingeschlossen und festgelegt auf die Zeugenrolle. Meist handelt es sich um eine Heilige Versammlung um die thronende oder auf einem Podest stehende Jungfrau Maria, die über die sie begleitenden, zwischen Betrachter und ihr vermittelnden Heiligen gestellt ist. In einigen Bildbeispielen ist der Zwischenraum schon besetzt durch die Figur des Auftraggebers, der sich fürbittend an einen der umstehenden Heiligen wendet ${ }^{12}$ (vgl. Abb. 2). Meist ist der Auftraggeber hier nicht nur

11 Zentral hierzu: André Chastel, „Le Donateur ,in abisso“ dans les ,pale““, in: ders., Fables, Formes, Figures, Bd. 2, Paris, 1978, S. 129-144.

12 Bezeichnenderweise wird genau dieser abgetrennte Bezirk auf der mittleren Predella-Tafel des San-Zeno-Altars von Andrea Mantegna zu einem Handlungsspielraum ausgeweitet. Wie Felix Thürlemann bereits in einem Aufsatz dargelegt hat, wird der Zwischenraum, der eigentlich für den Stifter reserviert ist, mit einer Nebenszene des Hauptgeschehens besetzt. Thürlemann identifiziert die Figur des Soldaten mit der Lanze in der Hand als Longinus, der dem toten Christus die Seitenwunde stach und daraufhin die Göttlichkeit des Menschensohns erkannte. Gezeigt sei die Weitergabe des Zeugnisses an einen Zweiten. Mit dieser Erkenntnis geht Thürlemann zufolge eine Handlungsaufforderung an den Betrachter einher, ein Glied in der Kette der Bezeugung der Gottessohnschaft zu werden. Thürlemann schließt mit der für uns relevanten Betrachtung: „Ebenso handelt es sich bei der narrativen Vermittlung zwischen den Bildfiguren und dem Rezipienten um ein Angebot an den jeweiligen Betrachter, das das mimetische Bild mit gestalterischen Mitteln aufbaut. In Mantegnas San Zeno-Altar öffnet sich die Malerei in einer zuvor unbekannten Weise auf den Betrachter hin, aber sie tut es so- 
räumlich abgesetzt, sondern auch deutlich kleiner. Mit dieser Unstimmigkeit ist nicht nur seine geringere Bedeutung angezeigt, sondern er ist auch als befremdendes, nicht wirklich zur Szene gehörendes Element markiert, das dem Bild der Heiligen Versammlung vorgesetzt ist. Es mag Bezugnahmen durch Blick und Geste geben, die Differenz der hier zusammentreffenden Realitäten ist jedoch bestimmend. Die untere Bildkante ist quasi zweigeteilt: Sie weist einen Graben auf, markiert einen Abstand, eine Kluft, und schafft auf der anderen Seite ein Raumkontinuum, das Zugang verspricht.

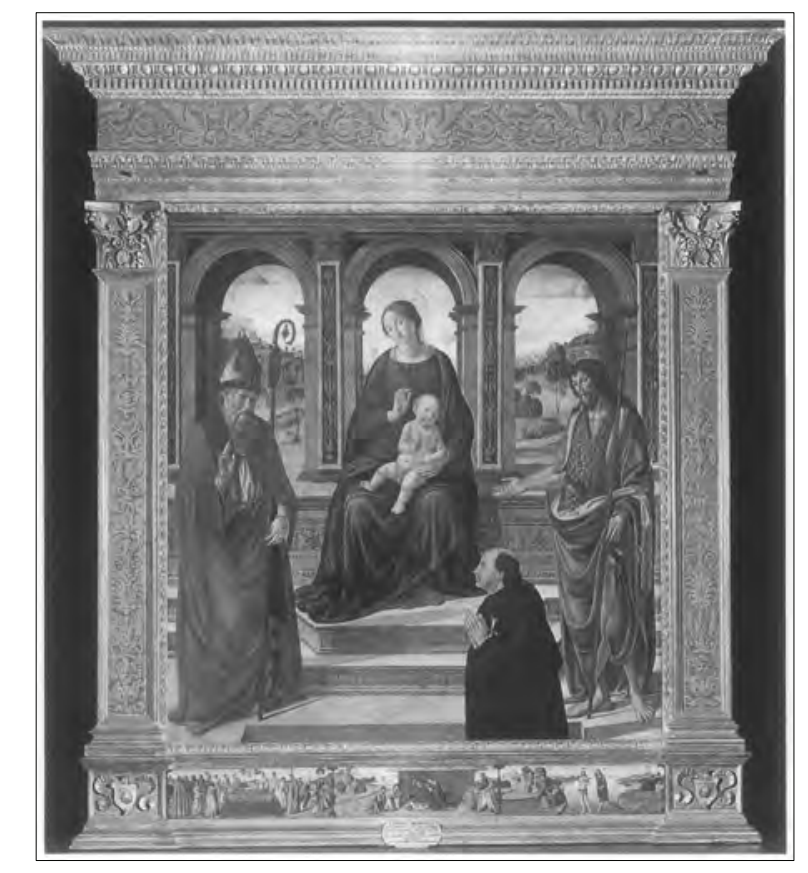

2 - Cosimo Rosselli, Pala Canigniani, Palazzo Strozzi, Florenz

Diese Konditionierung des Betrachterstandpunkts legt nahe, die stereotype Ausstattung der unteren Bildkante mit der Rampe im Theaterbau zu vergleichen. Die Rampe ist nur eingeschränkt Teil des Bühnenbildes, da sie dessen Illusionsauftrag nicht mitträgt. Doch stellt sie sich in der Frühen Neuzeit als bemalte Fläche, die meist ein Mauerwerk darstellt, dem Zuschauer entgegen und schafft einen Sockel für den Illusionsraum der Bühne. Die Rampe kann einen Schwellenraum ausbilden und damit die Aufmerksamkeit des Betrachters stimulieren. Sie kann Innen und Außen verbinden, wenn sie, wie oft, mit

zusagen auf selbstbewußte Weise.“ Felix Thürlemann, Vom Bild zum Raum. Beiträge zu einer semiotischen Kunstwissenschaft, Köln, 1990, S. 91-109. 
Treppen ausgestattet ist. ${ }^{13}$ Und es macht Sinn, sich diesen imaginären Zugang zur Szene genauer anzuschauen, auch wenn seine Ausgestaltung auf die Funktion der Vorspiegelung eines architektonischen Fundaments festgelegt ist.

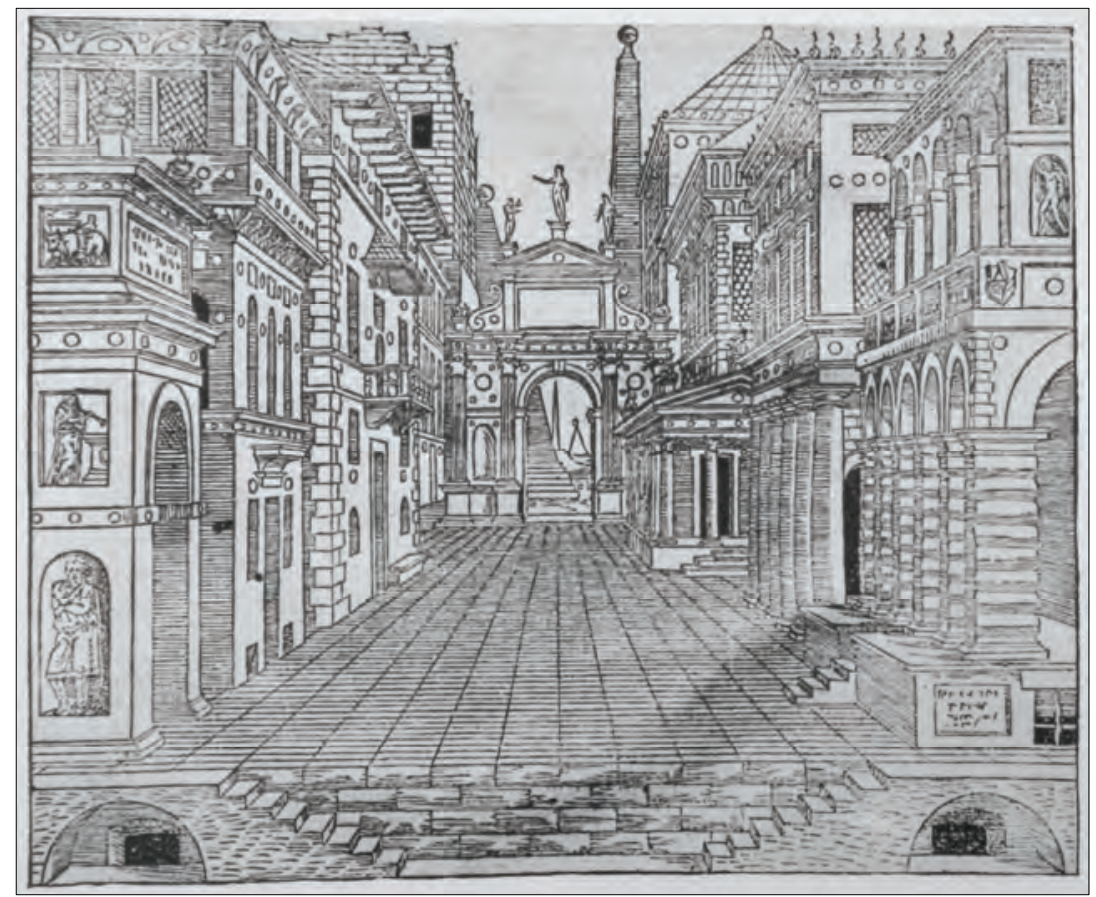

3 - Sebastiano Serlio, Entwurf für die tragische Bühne, 1545

13 Ernst Michalski bezieht sich auf Martin Hammitzschs Studie zum modernen Theaterbau aus dem Jahr 1906 (ders., Die Bedeutung der ästhetischen Grenze für die Methode der Kunstgeschichte, Mannheim, 1931, S. 192 f.). Ich zitiere Hammitzsch: „Besonders zu beobachten ist ferner, daß von der Bühne nach dem Zuschauerraum Stufen führten. Diese hatten den Zweck, den Darstellern der Ballette es zu ermöglichen, zu den im Parterre sitzenden Fürstlichkeiten herabzuschreiten und ihnen ihre Huldigung darzubringen. Es bildete sich jetzt zwischen Bühne und Parterre ein Verkehr aus, der zunächst die Ballettänzer von der Bühne nach der Parterre führte, bald aber auch die vornehmen Zuschauer aus dem Parterre auf die Bühne schreiten ließ, wo sie selbst tätigen Anteil am Ballett nahmen. Dieses geschah besonders in Frankreich unter Ludwig XIII. und XIV.“ (Martin Hammitzsch, Der moderne Theaterbau. Der höfische Theaterbau. Der Anfang der modernen Theaterbaukunst, ihre Entwicklung und Betätigung zur Zeit der Renaissance, des Barock und des Rokoko, Berlin, 1906, S. 23.) Cesare Molinari wird diese Vorstellung eines regen Verkehrs zwischen Bühne und Zuschauerraum zurückweisen („Les Rapports entre la Scène et les Spectateurs“, in: Jean Jacquot (Hg.), Le Lieu théatral a la Renaissance, Paris, 1964, S. 61-71). Weder sei es vorstellbar, dass der Zuschauer die Bühne besteigen könne, noch dass der Schauspieler in den Zuschauerraum hinunterschreitet. Er schließt eine solche Bewegung zwischen den beiden Räumen kategorisch aus mit dem Argument, dass viele dieser Treppen oft nur gemalt seien und also allein mit der Illusion der Möglichkeit gespielt würde, dass sich die Szene in die Realwelt fortführen könne. Vgl. hierzu: Ulrike Haß, Das Drama des Sehens. Auge, Blick und Bühnenform, München, 2005, S. 327. 
Ein minimaler Spielraum zeigt sich beispielsweise in Sebastiano Serlios Entwurf dreier Bühnenbilder, aus seinem zweiten Buch über die Architektur (Il secondo libro dell'architettura, 1545), den drei auf der Bühne aufgeführten literarischen Gattungen Tragödie, Komödie und Satyrspiel entsprechend. In der Tragödie wird der Betrachter quasi von der Mitte der Rampe zur Seite der Szene geführt (vgl. Abb. 3), bei der Komödie verhält es sich andersherum, während die Treppe des Satyrstücks nun nicht mehr architektonisch strukturiert ist, sondern aus Felsformationen besteht, die der Betrachter mühsam, aber geradewegs erklimmen kann. Wie bei dem Bühnenbild der Komödie landet er also quasi mitten im Geschehen.

Selbst wenn der Zugang zur Bühne nur vorgespiegelt ist, wenn also die Stufen nur gemalt sind, schafft die Rampe unterschwellig eine emotionale Involvierung des Zuschauers - unterschwellig deshalb, weil der Blick des Betrachters über die Rampe hinweggeht, er ist auf die Bühne gerichtet. Der Architekt und Ingenieur Nicola Sabbatini, der den Bühnenbau in seinem Lehrbuch Pratica di Fabricar Scene e Machine ne'Teatri aus dem Jahre 1638 ausführlich beschreibt, stellt fest, dass man sich an der Malerei des parapetto wenig ergötze, weil die Menschenmassen davorständen und sie damit verstelle. Zudem, und auf diesen Punkt hat bereits Ulrike Haß in ihrem Buch Das Drama des Sehens. Auge, Blick und Bühnenform aufmerksam gemacht, ,sind die Blicke und Gedanken der Zuschauer ganz auf das Betrachten der Szene gerichtet. “" ${ }^{\text {14 }}$

Der Kunsthistoriker Ernst Michalski kommt in seiner Untersuchung Die Bedeutung der ästhetischen Grenze für die Methode der Kunstgeschichte aus dem Jahre 1931 auf die Treppen des Theaterbaus zu sprechen, um die Heteronomie des Kunstwerks zu definieren. ${ }^{15}$ Als heteronom bestimmt Michalski ein Kunstwerk, das „außerästhetisch belastet“ sei, wo es zu einem „Übergreifen der Kunstformation in den Realraum “16 ${ }^{\text {, zu einer „Verschleifung “17 }}$ beider Räume komme. Die Suggestion der Möglichkeit, quasi die Bühne des Gesche-

14 „[D]evo però avvertire, che si gustano poco, si per la quantità delle genti, che vi si mettono innanzi, che non è possibile in quella occasione levarle, come anche perche quasi tutti gli Spettatori non ci attendono molto, havendo solo il pensiero, \& il guardo intendo a mirare la Scena.“ Nicola Sabbattini, Scene e Machine Teatrali, hg. v. Alberto Perrini, Rom, 1989, S. 52. Vgl. Haß (2005), Das Drama des Sehens, S. 327.

15 Michalski benutzt jedoch hier den Begriff der Rampe bezeichnenderweise nicht, sondern spricht am Rande seiner Argumentation nur von „Bühnen mit Treppen“ (Michalski (1931), Die Bedeutung der ästhetischen Grenze, S. 192). Der Begriff der Rampe ist hingegen reserviert für die Beschreibung der abriegelnden Funktion des parapetto, die er an Raffaels „Dresdner Madonna“ darlegt (ebd., S. 115). Für ihn stellt diese „Rampe“ eine „abgrundtiefe Trennung zwischen uns und der Madonna“ her. Mit der „Reserviertheit“ der Darstellung, der er „religiöse Gebundenheit“ abspricht, verbindet er die ästhetische Autonomie. Michalski sieht also nicht das Intervall, das diese Rampe schafft, als Zugang und Einräumung eines Standpunktes.

16 Ebd., S. 11.

17 Ebd., S. 48. 
hens zu erklimmen, verletzt nach Michalski die ästhetische Grenze, welche die Autonomie des Kunstwerks garantiert. ${ }^{18}$

Michalski, der den in der Kunstgeschichte fortan oft angewendeten Begriff der ästhetischen Grenze in seiner Schrift einführt, macht die Erfahrung der Distanz schaffenden Absetzung des fiktionalen Bildraums von demjenigen des Betrachters motivisch an der abriegelnden Funktion der Rampe fest. ${ }^{19}$ Sie schaffe eine „abgrundtiefe Trennung“ zwischen Betrachter und Dargestelltem. Mit der „Reserviertheit“ der Darstellung, der er „religiöse Gebundenheit“ abspricht, verbindet er ästhetische Autonomie. Michalski ignoriert, dass mit dem Abstand, den die Rampe schafft, der Standpunkt des Betrachters erst eingeräumt und damit ein potenzieller Zugang zur Szene eröffnet wird. Wir werden sehen, dass erst mit der Schaffung von Distanz - etwa durch die Einziehung eines Abgrundes zwischen Bild und Betrachter - deren Überwindung als spektakulär erlebbar wird.

Es lässt sich einiges einwenden gegen Michalskis Entwurf, die Kunst der Frühen Neuzeit durch die Kategorie der ästhetischen Grenze zu polarisieren. So thematisiert Michalski weder die verschiedenen medialen Bedingungen von Skulptur und Malerei noch differenziert er bezüglich der Funktion oder des Formats der Kunstwerke. Die „außerästhetische Belastung“, die sich kunsthistorisch als spezifischer situativer Kontext bestimmen ließe, kann, aber muss nicht in der Durchbrechung der ästhetischen Grenze zum Tragen kommen. Michalskis Blick ist vor allem auf die obere Bildgrenze fixiert, insbesondere auf das Motiv des Schleiers, und so lässt er die untere Bildkante außer Acht. ${ }^{20}$

\section{Stufen als Zugang:}

\section{Die in Aussicht gestellte Teilnahme des Betrachters am Geschehen}

In Tizians Dornenkrönung Christi aus dem Jahre 1540 (vgl. Abb. 4) sind es drei Stufen, die den Bildraum zum Betrachter hin öffnen und uns einladen, dem Geschehen näherzukommen.

Fünf Männer rücken verschiedenartig heftig dem gequälten Christus zu Leibe, dessen Anspruch, König der Juden zu sein, hier verspottet wird. Purpurmantel, Zepter und Krone, Insignien der Herrschaft, sind Werkzeuge

18 „Die Feststellung der Stabilisierung einerseits und der Überbrückung der ,ästhetischen Grenze‘ andererseits enthält die Antwort auf die methodische entscheidende Frage nach der ästhetischen Autonomie des Kunstwerks.“ Ebd., S. 10.

19 Beispielhaft ist ihm Raffaels Dresdner Madonna. Vgl. ebd., S. 115. Gleichbedeutend mit Rampe benutzt Michalski den Begriff des parapetto.

20 Wolfgang Kemp schließt mit seiner Untersuchungen zum Motiv des illusionistischen Vorhangs an Michalski an und erkennt darin eine „Kontextmarkierung“ des Bildes als Sammlungsstück. Siehe ders., Rembrandt - Die Heilige Familie mit dem Vorhang, Frankfurt/M., 1986 und ders. (1992), Kunstwissenschaft und Rezeptionsästhetik, S. 258-261. 
der Schmähung. Die dominante Treppe führt als Bewegungsachse die Koppelung von Erniedrigung und Erhöhung vor.

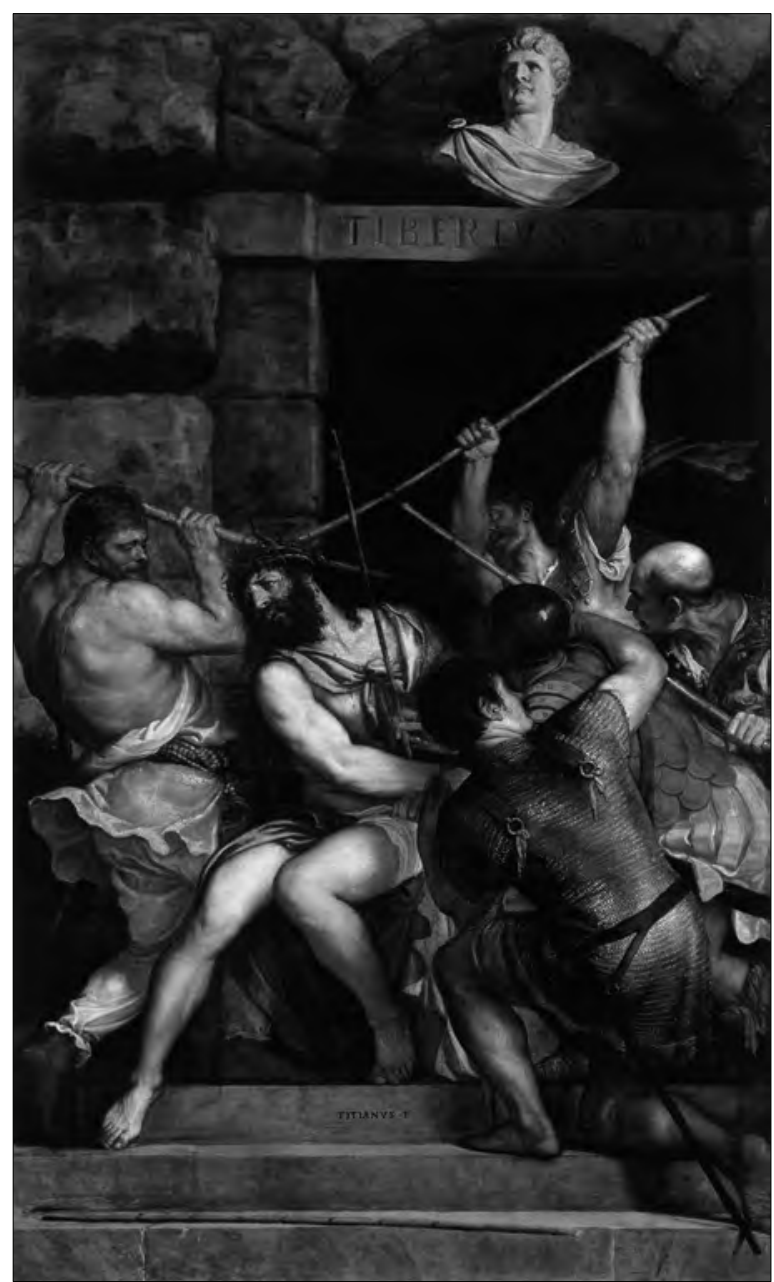

4 - Tizian, Dornenkrönung Christi, Louvre, Paris

Uns am nächsten knien zwei Soldaten vor Christus auf der Treppe, um Anbetung zu parodieren: Einer reicht Christus einen Stock als Spottzepter. Als Dritter im Bunde schaut ein Alter neugierig zum Geschehen hin. Die Haupthandlung, die Dornenkrönung, führen zwei Schergen mit ausladenden Gesten und langen Stöcken aus. Zwei Handlungsmomente, Dornenkrönung und Übergabe des Zepters durch eine vor Christus in die Knie gegangene männliche Figur, d. h. Peinigung und Verspottung, greifen Hand in Hand. Christus krümmt sich 
unter dem Druck von oben, sein Körper ist gestaut, seine Beine stark gegrätscht. Er steht auf Zehenspitzen. Da die Sitzfläche Christi motivisch nicht herausgestellt ist, vermittelt diese seltsame, beinahe schwebende Beinstellung Aufstand gegen die Erniedrigung. Die Labilität des Standmotivs - der eine Fuß scheint eine Stufe hinabgeglitten - erhöht die Dramatik der Szene.

Vielfach wurde schon darauf hingewiesen, dass Tizian wie auch andere Künstler seiner Zeit gern die Treppe als Bindeglied zwischen verschiedenen Ebenen und Räumen einsetzten. ${ }^{21}$ Dem Kunsthistoriker Michail Alpatov zufolge schafft die Treppe „die Voraussetzung für den Betrachter, im Geiste das Bild zu ,betreten'.“22 Wir treten also Christus entgegen. Damit werden wir quasi zum Protagonisten der Szene. Unsere Rolle ist jedoch prekär, denn beugen wir unser Knie vor Christus, dann rücken wir in gefährliche Nähe zu den Anbetung Parodierenden rechts von uns.

Auch wenn die Figur Christi uns nicht frontal begegnet, evozieren seine gebundenen Hände das Andachtsbild des Ecce-Homo. Die Erinnerung des Kultbildes in der Szene der Dornenkrönung ist äußerst zwiespältig: Der Betrachter ist unmissverständlich zur Andacht und Medition der Leiden Christi aufgefordert und zugleich realisiert er die Schändlichkeit der Huldigung des Königstums in dessen Parodie. Jacob Burckhardt zufolge vertat Tizian jedoch die Möglichkeit, die im Thema der Dornenkrönung liegt, ,durch die grausame Parodie des Königthums ein wahres Königthum hindurchleuchten zu lassen“ und zwar „schon wegen der gesteigerten Brutalität.“23

Günter Passavant bemerkt, dass die Dornenkrönung Christi ein in der italienischen Kunst selten angegangenes Thema ist. ${ }^{24}$ Der Auftrag der ersten Version der Dornenkrone wurde von einer dominikanischen Vereinigung erteilt, die sich nach der Dornenkrone Christi Istituto della Santa Corona benannt hat. Das vergleichsweise starke Interesse am Thema der Dornenkrönung nördlich der Alpen ist zweifellos vor der Folie der reformatorischen Kritik an der Idolatrie begreiflich zu machen: Die Dornenkrönung Christi, aufgefasst als Schändung eines lebendigen Kultbildes, ist zwiespältig. Das Heikle des Themas die Verspottung der Anbetung Christi - mag die Zurückhaltung in Italien er-

${ }^{21}$ Generell betrachtet dienen die Stufen der Erhöhung der Person über die sie Umstehenden und gehen quasi als begehbarer Sockel in den Aufbau eines herrschaftlichen Sitzes über. Auch aus seitlicher Sicht setzt Tizian die Treppe wiederholt ein: Prominent bestimmt sie den Raum in seinem früheren Werk Tempelgang Mariens wie auch in dem Wiener Gemälde Ecce homo. Das letztere stellt eine der Dornenkrönung vorausgehende Episode dar, die Schaustellung Christi. Auch in der Szene des Wiener Gemäldes finden sich Personen, die nicht vor der Treppe haltmachen, sondern im Begriff sind, sie zu erklimmen.

22 Michail V. Alpatov, „Tizians Dornenkrönung“, in: ders., Studien zur Geschichte der westeuropäischen Kunst, Köln, 1974, S. 65-94: 85.

23 Jacob Burckhardt, „Das Altarbild“ [1933], in: ders., Werke, Bd. 6, Beiträge der Kunstgeschichte von Italien, hg. v. Stella von Boch/Johannes Hartau/Kerstin Hengevoss-Dürkop/Martin Warnke, München, 2000, S, 15-138: 122.

24 Günter Passavant, „Tizians Darstellungen der Dornenkrönung Christi“, in: Neri Pozza (Hg.), Tiziano e Venezia, Vicenza, 1980, S. 343-349: 343. 
klären. Und es stellt sich die Frage, ob Tizian diese Doppelbödigkeit des Themas reflektierte und an den Betrachter kommunizierte. Dass Tizian uns die Position vor dem Bild zum Problem machen wollte, zeigt der Rohrstab, der auf der ersten Stufe griffbereit liegt und perspektivisch derart verkürzt ist, das er in den Betrachterraum zu ragen scheint und also das Intervall zwischen Bild- und Betrachterrealität einnimmt.

Auf effektive Weise öffnet sich der Bildraum zum Betrachter, wenn dessen physische Reaktionsfähigkeit herausgefordert wird. Die extreme Verkürzung und der Schattenwurf des Stabs provozieren den Impuls, ihn zu ergreifen und damit zum Protagonisten der Szene aufzusteigen. Der Betrachter/die Betrachterin kommt also der Fiktion eines sich ihm darbietenden, aus vom Dunkel abhebenden Körpers entgegen.

Fiktionen der Darbietung

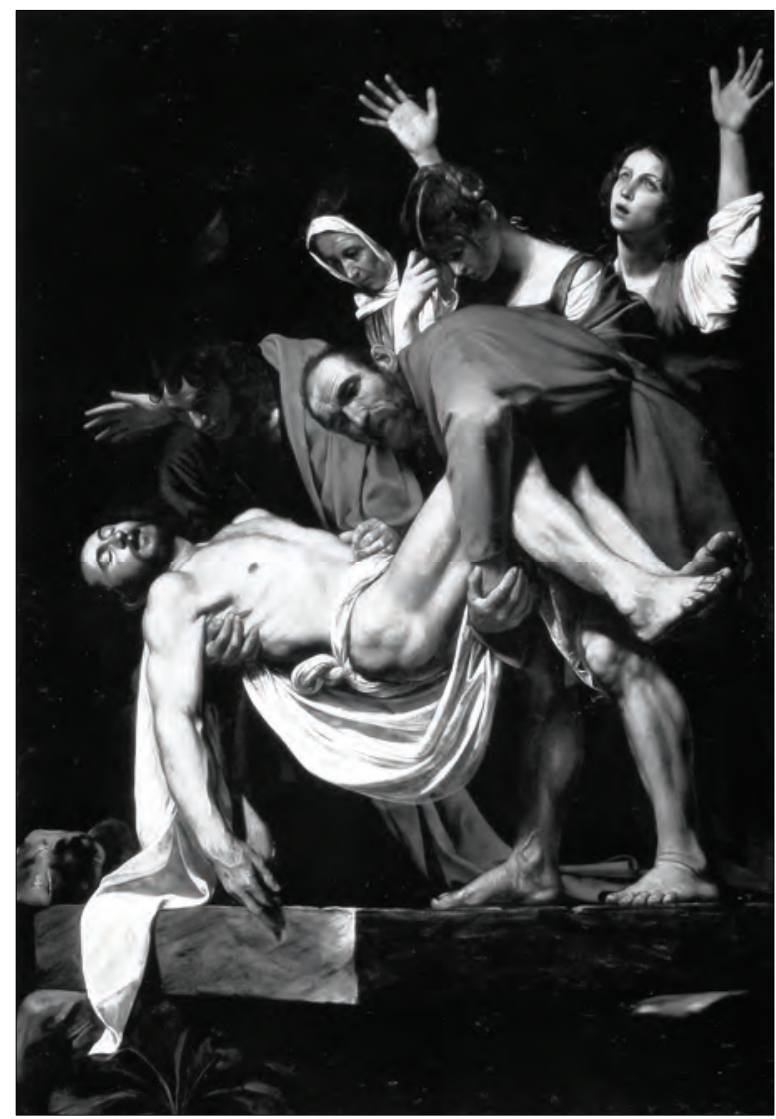

5 - Caravaggio, Grablegung, Vatikanisches Museum, Rom 
Gut 60 Jahre nach Tizian wird Caravaggio die Ausdehnung des Zwischenraums zum spannungsgeladenen Handlungsraum in seinem Gemälde Grablegung Christi (1603/4) zum zentralen Aspekt seiner Bildkonzeption machen (vgl. Abb. 5). Die Perspektive setzt uns als Betrachter/Betrachterin tief herab. Wir sehen quasi von unten auf die Figurengruppe, auf vorderster Ebene der Leichnam Christi, der von Johannes und Nikodemus getragen, und von den drei dahinter stehenden Marien betrauert wird. Unser Blick stößt auf die Ecke der Bodenplatte, auf der die Gruppe steht, wobei allein die Füße des Nikodemus motivisch herausgestellt sind. Unterhalb der Bodenkante ist alles in tiefen Schatten gesetzt, allein ein Stein und ein Gewächs treten links unten aus der Dunkelheit hervor. Wir befinden uns also schräg zum Geschehen. Marie-Ann Graeve weist darauf hin, dass wir an der Bodenplatte die Drehung der ganzen Komposition aus unserer Blickachse nachvollziehen können, die sich „von vorn“ besehen als das Andachtsbild der Pietà, der Beweinung Christi, herausstellen wird. Was uns hiermit vorgeführt wird, ist die skulpturale Dimension der geschlossenen Figurenkonstellation. ${ }^{25}$

Der dunkle Hintergrund, der den Ort unbestimmt lässt, dient als Folie ihrer plastischen Absetzung. Mit der Drehung der Figurengruppe geht eine entscheidende Wendung in der Konzeption des Bildes einher. Das Andachtsbild der Pietà wird in ein Historienbild transformiert. Die schräge Sicht auf die Gruppe deformiert also das Bildschema der Beweinung. Die mit ihren ausgestreckten Händen über Christus stehende Maria verliert an Bedeutung. Ihre über das Angesicht ihres Sohnen schützend ausgestreckte Hand erscheint in der Schrägsicht von ihrem Körper abgetrennt. Die Hand fügt sich als Element in den Spannungsbogen der Grablegung, der von den hell erleuchteten, klagend erhobenen Händen der Magdalena seinen Ausgang nimmt und in der Hand des Leichnams, die über die Grabplatte hängt, sie mit dem Mittelfinger berührt, ausläuft. ${ }^{26}$ Während die Köpfe der drei Marien zusammen mit dem des Johannes diese Bewegung auch durch ihre Senkung nachvollziehen, bricht die Kopfwendung des Nikodemus aus diesem Zusammenhang heraus. Seine Wendung hin zum Raum des Betrachtes weist diesem einen Standpunkt auf

25 „The six figures, massed solidly together on top of the stone, are turned away from the spectator at a five to ten degree angle, facing the diagonalized edge of their base. Their sculptural three-dimensionality makes it easy to imagine oneself walking a step or two to confront them straight-on. From this standpoint it is evident that the composition would assume the familiar pyramidal shape of the traditional type of the Pietà, the Virgin, as always, forming the central axis, her head making the apex.“ Marie-Ann Graeve, „The Stone of Unction in Caravaggio’s Painting for the Chiesa Nuova“, in: The Art Bulletin Magazine, Bd. 40, 1958, S. 223-238: 225.

26 Diese Bewegung, die sich allein aus der Zusammenschau der Figuren ergibt, und keine dargestellte Handlung ist, hat Georgia Wright eindrücklich beschrieben: „The woman with arms raised begins a carefully planned, open-ended descending movement through the bent figures of the Virgin and weeping woman, the doubled-over forms of Saint John and Nicodemus, the sagging body of Christ, and finally the stone that projects into the space over the altar." Georgia Wright, „Caravaggio’s Entombment Considered in Situ“, in: The Art Bulletin, Bd. 60, 1978, S. 35-42: 36. 
der rechten Seite vor dem Bild zu. Durch unsere Positionierung werden wir gleichsam Teil der Grablegung, wie bereits Georgia Wright herausgestellt hat, denn Nikodemus' Zuwendung appelliert an uns, „unsere Hände auszustrecken“, um den Körper Christi, der uns auf vorderster Ebene dargeboten wird, entgegenzunehmen. ${ }^{27}$ Der gedrängte Bildraum dringt hier quasi klaustrophobisch in den Betrachterraum, als ob es keine Tiefe gäbe, als würde die gesamte Handlung quasi auf dem Proszenium stattfinden.

Caravaggios radikales Bildkonzept hatte Folgen. Für einen der wichtigsten Förderer Caravaggios, Kardinal Maffeo Barberini, der spätere Papst Urban VIII., schuf Lodovico Carracci im Jahre 1612 die ungewöhnliche Darstellung des Martyriums des Heiligen Sebastians, dessen Leichnam in die Cloaca Maxima, den Abwasserkanal von Rom, geworfen wird. Bereits der Auftraggeber stieß sich daran, dass das brutale Sujet zur Devotion nicht inspiriere, wie er in einem Brief seinem Bruder mitteilte ${ }^{28}$ (vgl. Abb. 6).

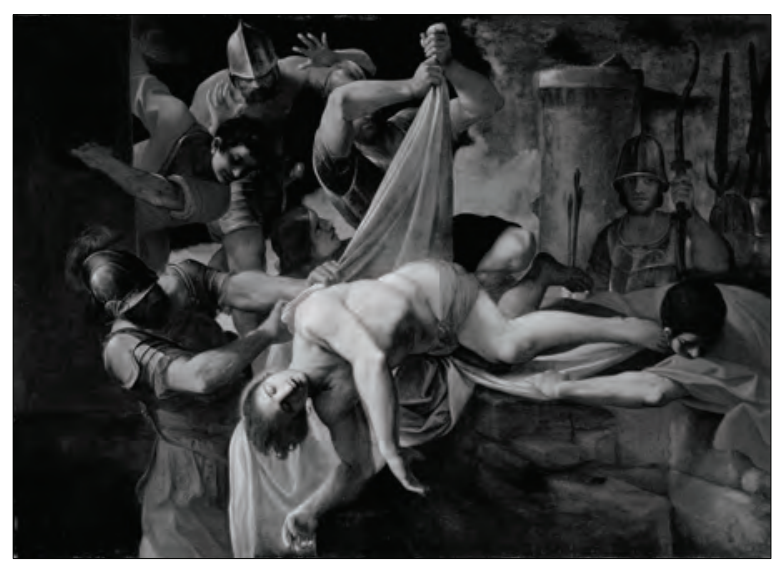

6 - Ludovico Carracci, Der Heilige Sebastian wird in die Cloaca Maxima geworfen, The J. Paul Getty Museum, Los Angeles

Mit roher Gewalt wird die Leiche des Heiligen in das Abwasser geworfen. Die Gesichter der Soldaten sind verschattet, ins Licht gesetzt hingegen die kräfti-

27 „The homely tears and supplications, the tender involuntary gesture of the Virgin, and the intense efforts of the bearers are calculated to move us to participate in the scene, to raise our hands to receive the body, and to renew the sense of mystery in the presence of the Host [...].“ Ebd., S. 38.

28 Brief vom 28. Nov. 1612 an seinen Bruder Carlo: „[I]l gettarvelo de soldati è ben rappresentazione di forza, ma non dà tanta devozione.“ Zit. aus: Gail Feigenbaum, „Kat. Nr. 70: Saint Sebastian Thrown into the Cloaca, c. 1612“, in: Andrea Emiliani (Hg.), Ludovico Carracci, Ausstellungskatalog, Kimbell Art Museum, Fort Worth, 1993, S. 152-154: 152; vgl. auch Charles Dempsey, „Kat. Nr. 30.: Saint Sebastian Thrown into the Cloaca Maxima“, in: The Age of Caravaggio, Austellungskatalog, The Metropolitan Museum of Art, New York, NY, 1985, S. 124. 
gen Arme. Der Leichnam ist in ein Dreieck agierender Kräfte eingespannt, die das Tuch, auf dem er liegt, nach oben und zu den Seiten ziehen. Zwischen dem linken und mittleren Schergen erblicken wir zwei Zeugen. Der Vordere blickt, hinter einem Verschlag sich vorbeugend, hämisch hinunter. Der andere scheint von hinten dazwischengehen zu wollen und zeigt in der Gestik der Hände Erschrockenheit. Unterhalb seiner befindet sich eine weitere Figur, die mit sprechend geöffnetem Mund zur zentralen Handlungsfigur aufschaut. Zwei weitere Soldaten halten sich rechts im Hintergrund im Schatten zurück und scheinen unbeteiligt. Doch hat der vorderste uns fest im Blick.

Der pietätlose Umgang mit der Leiche, das Skandalon des Bildes, wird jedoch durch die Inszenierung des Körpers des Heiligen konterkariert. Das Leichentuch erinnert an dasjenige Christi. Keiner der drei Soldaten berührt den Leichnam, sondern sie ziehen allein am Tuch, um den Körper aus ihm herausrollen zu lassen. Hierin formuliert sich Achtung gegenüber dem heiligen Körper. Zur Hälfte ist Sebastians feingliedriger Körper und sein schönes, beinahe entspannt wirkendes Gesicht beleuchtet: Er hebt sich effektvoll plastisch aus dem Dunkel heraus. Die starke Beleuchtung des heiligen Körpers stetzt diesen jedoch derart vom Umfeld ab, dass es erscheint, als ob der Leichnam aus dem Bildraum heraus in denjenigen des Betrachters gehoben würde. Der Fiktion des Bildes zufolge stehen wir hier also in der Kloake. Das unmissverständliche In-Aussicht-Stellen des Falls des Körpers provoziert auch hier eine physische Reaktion, die, da nicht ausführbar, emotional als Sorge erfahren wird. ${ }^{29}$ Wenn wir bedenken, dass Lodovico Carracci das Werk für die Ausstattung einer Kapelle schuf, die sich auf dem Auffindungsort der Leiche des Heiligen Sebastians gründete $e^{30}$, dann übernehmen wir quasi mit dem imaginären Empfang des Leichnams die Rolle der Römerin Lucina, die an dieser Stelle den Körper aus der Kloake barg.

So problematisch die Beschreibung der Rolle auch ist, die der Betrachter in der Ausweitung der Fiktion über den Rahmen des Bildes hinaus hat, so unmissverständlich ist jedoch der Appell, das Gegebene im emphatischen Sinne anzunehmen, und das heißt zugespitzt im theologischen Sinne das Opfer zu empfangen.

Wie bereits erwähnt, ist es nicht zur Aufstellung des Werkes an dem für ihn vorgesehenen Ort gekommen: Carraccis Gemälde wurde stattdessen Teil der Kunstsammlung des Kardinals. Diese Einverleibung eines Altarbildes in den

29 Ein eindrückliches frühes Beispiel hierfür ist die Londoner Version von Leonardos Felsgrottenmadonna. Hier wird das Jesuskind bedrohlich nah an den felsigen Abgrund gerückt, der den Betrachter von der dargestellten Szene trennt. Frank Zöllner bringt den Felsabgrund einerseits mit Leonardos geologischem Interesse und seiner Gesteinsschichtentheorie in Verbindung, andererseits mit der franziskanischen Auftraggeberschaft, die hier eine „franziskanische Topographie“ im Sinne einer Anspielung auf den Monte La Verna, den Stigmatisierungsort des Heiligen Franziskus, erkennen könne. (Frank Zöllner, Leonardo da Vinci. Sämtliche Gemälde, Köln, 2011, S. 67 u. S. 76.) Der Felsenabgrund hat jedoch ikonografisch eine längere Tradition und ist beispielsweise schon in der byzantinischen Kunst zu finden.

30 Vgl. Feigenbaum (1993), Kat. Nr. 70: Saint Sebastian Thrown into the Cloaca, c. 1612, S. 152. 
privaten Kontext einer Kunstsammlung ist kein Einzelfall. In allen diesen Fällen verliert das Werk seinen sinngebenden liturgischen Kontext und muss sich im „luftleeren“ Raum, d. h. auf der Ausstellungswand behaupten. Der Raum zwischen Bild und Betrachter wird unberechenbar und es stellt sich die Frage, ob die tiefe Verschattung der unteren Bildkante einem leichteren, da variablen Einstieg in die Szene dient. Denn sie invisibilisiert, indem sie die Aufmerksamkeit, d. h. die Gerichtetheit der Wahrnehmung schluckt, die reale Kluft, die zwischen Bild- und Betrachterraum sich insbesondere dann auftut, wenn die untere Kante auf nichts ruht. Der fiktionale Abgrund täuscht also über einen realen hinweg. Gelingt diese Täuschung, dann eröffnet sich oberhalb der unteren Bildkante, wenn nicht eine Welt, so zumindest ein theatraler Handlungsraum. Die Verlebendigung der dargestellten Szene scheint dann am wirkmächtigsten, wenn der Betrachter in die Gruft des Abgrunds gestellt ist.

Wir haben zwei Modelle der Involvierung des Betrachters anhand von Altarbildern von der Frührenaissance bis zum Barock dargestellt. Einerseits wurde ein Zugang vorgetäuscht, geschaffen durch die Perspektivkonstruktion einer baulichen Maßnahme im Bildvordergrund. Diese evozierte die Möglichkeit der Begehbarkeit eines illusionären Tiefenraums und also Augenzeugenschaft am Geschehen. Andererseits wurde der Betrachter affiziert und überwältigt durch die Gabe eines Körpers. Die gesteigerte Plastizität dieses Körpers ist nicht zuletzt durch das Zurücktreten der unteren Bildkante in den Schatten bewirkt. Der Betrachter kann also nicht die Szene betreten, denn er steht in der Fiktion des Bildes bereits in ihr.

Im Zeitalter der Aufklärung hatte man für eine derartige spektakuläre Involvierung des Betrachters keinen Sinn. Denis Diderot wird in seinen Pensées détachées schließlich eine derartige Bildvorstellung mit den Worten kritisieren:

Lairesse behauptet, dass es dem Künstler erlaubt sei, den Betrachter in die Szene seines Gemäldes eintreten zu lassen. Davon halte ich nichts [...]. Das erscheint mir von ähnlich schlechtem Geschmack wie das Spiel eines Schauspielers, der sich an die Parterre adressiert. Die Leinwand schließt den ganzen Raum ein und es gibt niemanden jenseits davon. ${ }^{31}$

Diese Abgeschlossenheit wird der Kunsthistoriker Michael Fried in seiner Untersuchung zum Kunstbegriff im Zeitalter Diderots schließlich auf den Begriff der „Absorption“ bringen. ${ }^{32}$ Die Paarung mit dem Begriff der „theatricality“, die eine Polarisierung bezweckt, erinnert stark an Michalskis Differenzierung zwischen „Autonomie“ und „Heteronomie“ des Kunstwerks. Bereits Micha-

31 „Layresse prétend qu'il est permis à l'artiste de faire entre le spectateur dans la scène de son tableau. Je n'en crois rien [...] Cela me semblerait d'aussi mauvais goût que le jeu d'un acteur qui s'adresserait au parterre. La toile renferme tout l'espace, et il n’y a personne au delà..“ Denis Diderot, „Pensée detachées sur la peinture, la sculpture, l’architecture et la poésie, pour servir de suite aux Salons“, in: ders., Salons IV. Héros et martyrs, hg. v. Gita May/Else Marie Bukdahl/Annette Lorenceau, Paris, 1995, S. 412 f.

32 Vgl. Michael Fried, Absorption and Theatricality. Painting \& Beholder in the Age of Diderot, London, 1980. 
elski berührt die Problematik einer solchen Polarisierung, wenn er feststellt: „Innerhalb unserer Betrachtungen wäre ja der Begriff ,Illusionsbühne‘ beinahe eine contradictio in adjectio, da ,Illusionismus' für uns eine Überschreitung, ,Bühne` jedoch eine strenge Wahrung der ästhetischen Grenze bedeutet.“33 Dieser Widerstreit wird unterschwellig getragen von der Konstruktion der Rampe, bzw. der Ausdehnung der unteren Bildkante zum Schwellenraum einer Grenzerfahrung.

\section{Literatur}

Alpatov, Michail V., „Tizians Dornenkrönung“, in: ders., Studien zur Geschichte der westeuropäischen Kunst, Köln, 1974, S. 65-94.

Buchberger, Michael (Hg.), Lexikon für Theologie und Kirche, Bd. 10, Freiburg, 1965.

Burckhardt, Jacob, „Das Altarbild“ [1933], in: ders., Werke, Bd. 6, Beiträge der Kunstgeschichte von Italien, hg. v. Stella von Boch/Johannes Hartau/Kerstin HengevossDürkop/Martin Warnke, München, 2000, S. 15-138.

Careri, Giovanni, Envols d'amour: Le Bernin, montage des arts et dévotion baroque, Paris, 1990.

Chastel, André, „Le Donateur ,in abisso“ dans les ,pale““, in: ders., Fables, Formes, Figures, Bd. 2, Paris, 1978, S. 129-144.

Dempsey, Charles, „Kat. Nr. 30: Saint Sebastian Thrown into the Cloaca Maxima“, in: The Age of Caravaggio, Austellungskatalog, The Metropolitan Museum of Art, New York, NY, 1985, S. 124.

Diderot, Denis, „Pensée detachées sur la peinture, la sculpture, l’architecture et la poésie, pour servir de suite aux Salons“, in: ders., Salons IV. Héros et martyrs, hg. v. Gita May/Else Marie Bukdahl/Annette Lorenceau, Paris, 1995.

Feigenbaum, Gail, „Kat. Nr. 70: Saint Sebastian Thrown into the Cloaca, c. 1612“, in: Andrea Emiliani (Hg.), Ludovico Carracci, Ausstellungskatalog, Kimbell Art Museum, Fort Worth, 1993, S. 152-154.

Fried, Michael, Absorption and Theatricality. Painting \& Beholder in the Age of Diderot, London, 1980.

Graeve, Marie-Ann, „The Stone of Unction in Caravaggio’s Painting for the Chiesa Nuova“, in: The Art Bulletin Magazine, Bd. 40, 1958, S. 223-238.

Hammitzsch, Martin, Der moderne Theaterbau. Der höfische Theaterbau. Der Anfang der modernen Theaterbaukunst, ihre Entwicklung und Betätigung zur Zeit der Renaissance, des Barock und des Rokoko, Berlin, 1906.

Haß, Ulrike, Das Drama des Sehens. Auge, Blick und Bühnenform, München, 2005.

Kemp, Wolfgang, Rembrandt - Die Heilige Familie mit dem Vorhang, Frankfurt/M., 1986.

Ders., „Kunstwissenschaft und Rezeptionsästhetik“, in: ders. (Hg.), Der Betrachter ist im Bild. Kunstwissenschaft und Rezeptionsästhetik, Berlin, 1992, S. 7-27.

33 Michalski (1931), Die Bedeutung der ästhetischen Grenze, S. 56. 
Ders., „Kunstwerk und Betrachter: Der rezeptionsästhetische Ansatz“, in: Hans Belting et al. (Hg.), Kunstgeschichte. Eine Einführung, Berlin, 2008, S. 247-265.

Lavin, Irving, Bernini and the Unity of the Visual Arts, New York, NY, 1980.

Lavin, Marilyn Aronberg, Piero della Francescas's Baptism of Christ, New Haven, London, 1981.

Lemoine, Annick, Nicolas Régnier (alias Niccolò Renieri) ca. 1588-1667, peintre, collectioneur et marchand de l'art, Paris, 2007.

Michalski, Ernst, Die Bedeutung der ästhetischen Grenze für die Methode der Kunstgeschichte, Mannheim, 1931.

Molinari, Cesare, „Les Rapports entre la Scène et les Spectateurs“, in: Jean Jacquot (Hg.), Le Lieu théatral a la Renaissance, Paris, 1964, S. 61-71.

Passavant, Günter, „Tizians Darstellungen der Dornenkrönung Christi“, in: Neri Pozza (Hg.), Tiziano e Venezia, Vicenza, 1980, S. 343-349.

Sabbattini, Nicola, Scene e Machine Teatrali, hg. v. Alberto Perrini, Rom, 1989.

Shearman, John, Only Connect ... Art and the Spectator in the Italian Renaissance, Princeton, NJ, 1992.

Thürlemann, Felix, Vom Bild zum Raum. Beiträge zu einer semiotischen Kunstwissenschaft, Köln, 1990.

Wittkower, Rudolf, Bernini. The Sculptor of the Roman Baroque, London, 1997.

Ders., Art and Architecture in Italy 1600 to 1750 [1958], überarb. u. hg. v. Joseph Connors/Jennifer Montagu, New Haven, London, 1999.

Wright, Georgia, „Caravaggio’s Entombment Considered in Situ“, in: The Art Bulletin, Bd. 60, 1978, S. 35-42.

Zöllner, Frank, Leonardo da Vinci. Sämtliche Gemälde, Köln, 2011. 


\title{
RAUM ALS DRAMATURGIEMASCHINE
}

\author{
„Mein Stück [...] spielt in Räumen, wo die \\ Moral ersetzt wird durch die Ästhetik der \\ Bühne.“
}

Jean Genet an Roger Blin ${ }^{1}$

\section{Handlungsmotoren und Dramaturgiemaschinen}

Wo eine Bewegung ist, bedarf es auch eines Antriebs. Hier ist davon zu reden, worin die Sprache ihren Raum findet, welchen Raum sie damit erzeugt und wie die Sprache räumlich bewegt wird. Solcherart Räume auf Bühnen, wie sie im Folgenden vorgestellt werden, sind als Skulptur sozial durch ihre Öffentlichkeit und beweglich durch ihre Benutzbarkeit. Sie stellen immer auch die

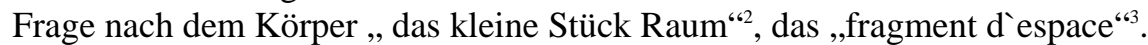

Er, der Körper, der der Akteur sein kann, ist mitzudenken. Als Antrieb und als derjenige, der die Folgen der Raumbewegung und die Um- und Übersetzung einer Raumveränderung zu tragen hat. Er ist immer mitzudenken, denn zwischen ihm und der Hülle, dem BÜHNENHAUS gibt es nur den Raum und Licht. Die Bewegung zwischen Haus, Körper, Licht und Raum kann als flexibles System bezeichnet werden. Das Statische in solchen Konstruktionen, kann Grundlage für Sprache sein. Erst die Bewegung macht Handlung.

Die menschliche Bewegung kann den GRUNDRISS ausschreiten und die Maschine Raum kann ihn überschreiten: den Grundriss verändern, den Grundriss aufreißen. Das macht Raum und seine Bewegung wichtig. Der Raum agiert und erweitert, auch sich selbst. Dabei determiniert die Farbe den Raum nicht nur, sondern trennt ihn auch von Hülle und Körper. Der Akteur aber bleibt der in den Räumen nicht sesshafte Nomade der Sprache.

Dem entsprechen die Parallelkonstruktionen sich bewegender Körper, die die Entfernung des Raums zum Publikum verändern ebenso wie die Entgegenständlichung der skulpturalen Setzungen im Raum, die nicht abstrakt sind, sondern in ihrer Reduzierung als Analogie zum Kern des dramatischen Textes

\footnotetext{
Jean Genet in einem Brief vom an Roger Blin. In: Jean Genet, Briefe an Roger Blin und andere Schriften zum Theater, Gifkendorf, 1996, S. 15.

2 Michel Foucault, Die Heterotopien. Der utopische Körper, mit einem Nachwort von Daniel Defert, Frankfurt/M., 2005, S. 25.

3 Jean Jourdheuil et al., „Michel Foucault, choses dites choses vues“, in: Jean Jourdheuil (Hg.), Travaux d'atelier. Foucault Mozart Müller. Théâtre/Public 176 (2005), S. 27-39: 36.
} 
verstanden werden können. Diese Räume sind deshalb das Gegenteil von ,Imitation of life ${ }^{4}$ und gleichermaßen bezeichnen sie auch eine Entfernung von den Sehweisen des Bewegungsmediums Film.

Die Isolierung des Augenblicks vom Kontext als Herangehensweise und die Verwandlung durch Bewegung aus der Bewegung selbst - das ist ein Kommentar und gleichermaßen Trennung zum Text. Aus dem Bedürfnis mitzuspielen entsteht eine Geometrie. Aus der Geometrie kann eine absichtsvoll ziellose Maschine entstehen, wiederum aus dieser eine sich selbst demolierende Maschine, eine auseinanderdriftende Dissonanz. Geometrie und Maschine kann in ihrer Entsprechung zum Plot die Bewegungsdramaturgie erzeugen. Wie aber funktioniert, wie bewegt sich eine absichtsvoll ziellose Maschine?

Eine zum Stillstand gekommene Maschine. „Duell-Traktor-Fatzer“, Heiner Müller/Bertolt Brecht, Regie: Heiner Müller, Berliner Ensemble, 1993

Müllers statischer Inszenierungsweise für „Duell-Traktor-Fatzer“ stand zunächst Matthias Langhoffs spielerische Brechung der Texte gegenüber, die auch in seinem Bühnenbildentwurf eine Entsprechung hatte. Heiner Müller kam damit nicht zurecht. ${ }^{5}$ Als ich hinzugezogen wurde, bestand die Herausforderung für mich im Bild einer zum Stillstand gekommenen Maschine, einer Gegenschräge der Zeit. Es begann insofern als Polemik. Die schräge Ebene, die durch einen überdimensionalen Tisch in einem zum Zuschauer hin abschüssigen Raum gestellt wurde, war zuallererst eine erzwingende Veränderung des gewohnten Bewegungsablaufs auf der Bühne und des Verhaltens der sich auf ihr bewegenden Körper zueinander. Die Polemik richtete sich gegen illusionistische und illustrative Abbildung von Vorgängen und Abläufen. Dem entsprach die Überlegung, die Geschichte rückwärts zu erzählen. Im Verhältnis von Tisch, schräger Ebene und Farbe (ein roter Streifen billigsten Fahnenstoffs verlief als schmaler roter Teppich parallel zum Tisch in der Bühnenmitte bis nach vorn zum Publikum) bezogen auf unterschiedliche Texte bzw. Textfragmente und -splitter und der Veränderung der Körperbewegung lag ein Moment von Raumdramaturgie in Sinne von Gilles Deleuze:

[D]ie Konstanten oder Invarianten eliminieren, nicht nur in der Sprache und den Gebärden, sondern auch in der theatralischen Repräsentation und in dem, was auf der Bühne repräsentiert wird; also alles eliminieren, was Macht ,ausübt‘, die

4 Filmtitel von Douglas Sirk.

Vgl. Stephan Suschke, Müller macht Theater, Theater der Zeit, Berlin, 2003, S. 162 f. 
Macht dessen, was das Theater repräsentiert [...], aber auch die Macht des Theaters selbst. ${ }^{6}$

Der Auflösung der Zeit im Text ist die Bewegungsdimension des Raums verbunden. In einer zeitgenössischen Rezension heißt es:

Mit dieser Anordnung setzte die Aufführung zwei verschiedene Orte, die zugleich eine Dissoziation in der Zeit bezeichneten. [...] Mit der Konzentration auf szenische Positionen wie Tisch und Stuhl [...] wurde die den Texten inhärente Statik noch verstärkt, Haltungen und Sätze determiniert. Erst in der Krise, dem Auf-stand, hätte die Sitzordnung in Bewegung geraten können. ${ }^{7}$

Die Inszenierung [...] markierte damit eine Grenze, in der Ausstellung eines Vakuums, das dem Publikum die eigene Totenstarre vorführte: „Es war ein Experiment an einem Kadaver. Die Leiche war das Publikum. Auf der Bühne die Gespenster, die Toten im Zuschauerraum.“ (Heiner Müller, 1995). ${ }^{8}$

„Duell-Traktor-Fatzer“ schreibt die nicht realisierte Inszenierung von Bertolt Brecht „Die Maßnahme“, 1930 fort. Sie ist insofern auch eine Erinnerung „,auf einem kleinen Podium, ich würde es den corpus-delicti-Tisch nennen, spielen die einzelnen Episoden der Handlung.“9 Im gemeinsam mit Heiner Müller konzipierten Arbeitsbuch zur Aufführung „Duell-Traktor-Fatzer“ ist daher bewusst eine Textpassage von Henri Michaux aufgenommen, die eine andere Bewegungsdimension des Tischs beschreibt:

Einmal auf ihn aufmerksam geworden, fuhr der Tisch fort, die Gedanken zu besetzen. Sozusagen bestand er sogar darauf, sich um seine eigenen Angelegenheiten zu kümmern. Es fiel auf, dass er weder einfach noch wirklich komplex, ursprünglich oder zweckdienlich komplex oder nach einem komplizierten Plan konstruiert war. Stattdessen war er im Verlauf der Zimmerei desimplifiziert worden. Wie er da stand, war es ein Tisch der Hinzufügungen, fast wie bestimmte als überfüllt beschriebene Zeichnungen von Schizophrenen, und wenn fertig, war er es nur insofern, als es keinen anderen Weg mehr gab, noch etwas hinzuzufügen: der Tisch war mehr und mehr eine Ansammlung geworden und weniger und weniger ein Tisch. Er war nicht für einen bestimmten Zweck geplant, für irgendetwas, das man von einem Tisch erwartet. Schwer und klobig, war er so gut wie unbeweglich. Man wusste nicht, wie ihn zu handhaben (verstandesmäßig oder materiell). Der nutzbare Teil des Tisches, seine Hauptoberfläche, nach und nach reduziert, war im Verlorengehen: mit sowenig Verständnis zu seinem plumpen Gerüst machte das Ding nicht mehr den Eindruck eines Tisches, son-

6 Gilles Deleuze, „Ein Manifest weniger“, in: Aisthesis. Wahrnehmung heute oder Perspektiven einer anderen Ästhetik. Essais, hg. v. Karlheinz Barck/Peter Gente/Heidi Paris/Stefan Richter, Leipzig, 1990, S. 379-405: 398.

7 Judith Wilke, Brechts „Fatzer“ Fragment. Lektüren zum Verhältnis von Dokument und Kommentar, Bielefeld, 1998, S. 243.

8 Ebd., S. 251. Ivan Nagel beschreibt die Abgrenzung vom gestischen Theater: „Das Abwesende der Worte und Gesten, die Starre jeden Ausdrucks wirkten als schnüre er seinen Nachlaß in wasserdichte Planen“. In: Ivan Nagel, Drama und Theater, München, Wien, 2006, S. 168.

9 Sergej Tretjakow, „Bert Brecht, 1934“, in: Erinnerungen an Brecht, zusammengestellt von Hubert Witt, Leipzig, 1964, S. 69-86: 78. 
dern den eines monströsen Möbelstückes, einer unbekannten Vorrichtung, für die es keinen Zweck gab. Ein entmenschlichter Tisch, nichts ,Mittelständiges‘ an ihm, nichts Rustikales, nicht Veränderliches, kein Küchentisch oder Arbeitstisch: ein Tisch, der sich zu keiner Funktion hergab, sich selbst schützend, sich selbst dem Dienst und der Kommunikation gleichermaßen verweigernd. Etwas Lähmendes umgab ihn, etwas Versteinertes. Vielleicht erinnerte er an eine zum Stillstand gekommene Maschine. ${ }^{10}$

Heiner Müller, November 1995: „Drama / Die Toten warten auf der Gegenschräge / Manchmal halten sie eine Hand ins Licht / Als lebten sie. Bis sie sich ganz zurückziehn / In ihr gewohntes Dunkel das uns blendet. “11

\section{Grundriss - Panoptikum.}

„Michel Foucault. Choses dites choses vues“. Regie: Jean Jourdheuil. Paris, Theatre de la Bastille, Festival d’Automne, 2004

Bei dieser Inszenierung ging es nicht nur um einen Bühnenraum, sondern um eine mit Jean Jourdheuil gemeinsam hergestellte Textfassung für die Aufführung, die aus fragmentarischen, assoziativ aneinandergereihten Zitaten bestand. Die Dramaturgiemaschine im Bühnenraum bewegt hier die Handlung durch die Errichtung des Modells, eines Panoptikums. Es wird sukzessive durch acht blaue Platten geschlossen - analog der Blickverweigerung zwischen Standort und Beobachter. Durch die Drehbewegung des Panoptikums als Objekt wird gleichermaßen Raum generiert. Grundriss und Objekt fallen zusammen. Das Objekt wird zum Zeichen des Objekts und dessen Grund. Es entsteht ein Raum, der sich aus Perspektiven zusammensetzt. Einen Auf- oder Abgang gibt es nicht. Die Bewegung, der Zusammenbau der acht Wände, ist die einzige sichtbare Handlung und Bewegung.

Nachdem Foucault den Raumbegriff benutzt hat in allen möglichen Facetten wie Splitter (Wer hat mehr von Raum gesprochen?) stößt er (zwangsläufig) auf den GRUNDRISS, der als Wesenheit, Eigentlichkeit erkannt wird. Etwas zu Foucault sagen, irgendetwas zu Foucault sagen, heißt zuallererst Foucault aus dem Zusammenhang reißen: Der panoptische Grundriss, der ein Subjekt zum beobachteten Objekt werden lässt und umgekehrt, den Beobachter zum Beobachten und umgekehrt ist das glatte Gegenteil eines sakralen Raumes. $^{12}$

In diesem Zusammenhang wurde an die bekannte Formulierung erinnert:

10 Henri Michaux, Le Grandes épreuves de l'esprit, Paris, 1966, S. 156 f. [Übersetzung Rolf Brauneis.]

11 Heiner Müller, „Drama“, in: Drucksache 20: Last Voyage/Krieg der Viren, aus einem Arbeitsbuch von Heiner Müller und Mark Lammert. Zu Germania 3 - Gespenster am Toten Mann (1995). Mit neun Photographien von Brigitte Maria Mayer, Berlin, 1996, S. 831.

12 Siehe ausführlich Mark Lammert, „Eclats de lettres et notices“, in: Jean Jourdheuil (Hg.), Travaux d'atelier. Foucault Mozart Müller. Théâtre/Public 176 (2005), S. 16-18. 
Ich bitte die Philosophiehistoriker um Verzeihung, aber ich glaube, das Bentham für unsere Gesellschaft wichtiger war als Kant oder Hegel. Wir sollten ihm in allen unseren Gesellschaften ein ehrenvolles Andenken bewahren. Denn er hat die Formen von Macht, in denen wir heute leben, äußerst präzise entworfen, definiert und beschrieben, und er hat uns diese Gesellschaft der generalisierten Orthopädie in einem wunderbaren kleinen Modell vorgestellt: seinem berühmten Panoptikum. Eine Architektur, die eine gewisse Macht des Geistes über den Geist ermöglicht; eine Form von Intuition, die sich für Schulen, Krankenhäuser, Gefängnisse, Besserungsanstalten, psychiatrische Anstalten und Fabriken eignet. Das Panoptikum ist ein ringförmiges Gebäude, das einen Hof mit einem Turm in der Mitte umschließt. Der Ring ist in kleine Zellen unterteilt, die sowohl auf den Innenhof als auch nach außen führen. In jeder dieser Zellen sitzt ein Kind, das Schreiben lernt, ein Arbeiter bei der Arbeit, ein Häftling auf dem Wege der Besserung oder ein Geisteskranker, der seinen Wahnsinn auslebt. In dem zentralen Turm sitzt ein Wärter. Da jede Zelle auf den Innenhof führt, kann der Wärter die gesamte Zelle einsehen; es gibt keine dunklen Winkel, so dass alles, was der Einzelne tut, dem Blick des Wärters ausgesetzt ist, der durch die halb geschlossenen Jalousien schaut und alles sehen kann, ohne selbst gesehen zu werden. In Benthams Augen ließ sich diese wunderbare kleine architektonische List in einer ganzen Reihe von Institutionen nutzen. Das Panoptikum ist die Utopie einer Gesellschaft und einer Form von Macht, die in unsere Gesellschaft Wirklichkeit geworden ist, eine realisierte Utopie. Diese Form von Macht kann man mit vollem Recht als panoptisch bezeichnen. Wir leben in einer Gesellschaft, in der der Panoptismus herrscht. ${ }^{13}$

Was aber geschieht, wenn dem Bewacher wie dem Bewachten der Blick verweigert wird, wenn der Ausgang verweigert wird? Das war eine wichtige Frage für den Foucault-Raum.

Gedankengänge als Staffellauf von Stichworten, die Assoziationen sind auch eine Assoziation von Stichworten. Mehr als Wahnsinn, besser, hinter dem Wahnsinn scheinen vier große Komplexe/Motoren beherrschend DER RAUM, DIE MASCHINE, DAS LABYRINTH, DAS PANOPTIKUM. Man könnte es auch anders sagen: ein hektischer Marathon als Möglichkeit. ${ }^{14}$ Panoptikum wie Textcollage schaffen Bewegungsmöglichkeiten und -zwänge für den FoucaultRaum.

Die „Ermittlung“ der Farbe ist „Zusammenempfinden“, also Synästhesie, was Hirnforscher beschreiben, wenn Menschen das, was sie hören, als Farbe wahrnehmen. Dem Panoptikum entspricht die Entstofflichung der Farbe Blau, die für die Wände des Objektes verwandt wurde und die Durchlässigkeit und Materialität von Grenze und Überwachung assoziiert.

\footnotetext{
13 Michel Foucault, „Die Wahrheit und die juristischen Formen“, in: ders., Dits et Ecrits. Schriften. Bd. II 1970-1975, hg. v. Daniel Defert, Frankfurt/M., 2002, S. 669-793: 734 f.

14 Lammert (2005), Eclats de lettres et notices, S. 16.
} 
Wand. Bewegung formulieren. Raum bewegen.

„Die Perser. Aischylos“, Regie: Dimiter Gotscheff, Deutsches Theater, Berlin, 2006

Auswahl des Stückes wie Festlegung auf die interlineare Übersetzung waren mitbestimmte Voraussetzungen für den Bühnenraum. Der Text sollte ohne illustrative Aktualisierungen den Raum organisieren. Raum und Bewegung sind durch eine Setzung bestimmt. Diese Setzung besteht aus einer Wand, die die Breite eines Fußballtores hat, und einer Farbe - der Farbe Gelb. Durch diese Setzung sind die Körper vom Hintergrund getrennt. „Gegen die Wand rennen“, „mit dem Rücken an der Wand stehen“, „etwas an die Wand fahren“. Eine Wand wird Mauer, die Bewegung ist eine Rotation, die das Bild der Wand nicht freilässt. Die Drehung treibt die Handlung bis zur gänzlichen Fortbewegung aus dem Drehpunkt der Geschichte. Das „in Bewegung setzen“ bzw. „in Bewegung bringen“ ist die Animation, nicht die Bewegung selbst. Der innere Zusammenhang, dessen Mechanik, wird nicht dem Blick entzogen, sondern ins Bild gesetzt. Eine Reaktion: „Eine dunkle Höhle, leer bis auf die gelbe Wand, die die Figuren nach vorne schieben, trennen, zum verschwinden [...] bringen kann. ${ }^{* 15}$

Mauer muss nicht Begrenzung von Raum sein, sondern kann auch Bezeichnung von verweigerter Perspektive sein. Michel Foucault:

Die einzigen Mauern sind die Mauern der verschwimmenden oder sich verfeinernden Transparenz. Allein der körperlose Abstand richtet seine Schranken auf. Das was unmittelbar bevorsteht kann von überall kommen, der Horizont ist ohne Tiefe und ohne Grund. In einem gewissen Sinne ist alles sichtbar, denn es gibt keinen Gesichtspunkt, keine verlorene Form, keine Perspektive, die in der Ferne versinkt, aber nichts ist wirklich sichtbar. ${ }^{16}$

Der Hintergrund rückt nach vorn, wird Vordergrund. Das ist die Voraussetzung dafür, dass Darstellung in den Hintergrund tritt, um der Wahrnehmung von Sprache und Licht Raum zu geben. Diese ostentative Flächigkeit gleicht Handlungsebenen an, die „Mauer führt hinters Licht“. Darstellungsmechanismen sind kurzgeschlossen mit einer Raummechanik, während das Gelb haften bleibt, nicht so sehr am Gegenstand Mauer als am Drehterritorium.

Nicht nur die Farbe als Ton, sondern auch die Materialität ihrer Konsistenz, macht die Bewegung anders sichtbar. Die Reflexion auf einer natürlichen Farbe ist eine andere, absolut intensivere, als auf einer synthetisch hergestellten Farbe. Der gelbe Bolusgrund setzt sich wie in antiken Zeiten aus folgenden Bestandteilen zusammen: „Ein halbes Pfund pontische Sinope-Erde, zehn Pfund helles Berggelb und zwei Pfund griechische Melos-Erde, gemischt und

15 Peter Laudenbach, „Nach dem Krieg ist vor dem Krieg“, in Süddeutsche Zeitung vom 13.10.2006, S. 17.

16 Michel Foucault, „Lauern auf den anbrechenden Tag“, in: ders., Dits et Ecrits. Schriften Bd. I 1954-1969, hg. v. Daniel Defert, Frankfurt/M., 2001, S. 357-365: 360. 
zwölf Tage miteinander gerieben, ergeben das. [...] (Poliment). Es ist das Bin-

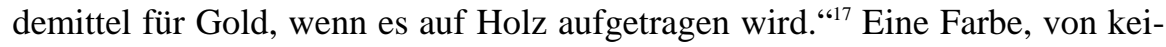
nem Scheinwerfer zu vernichten, eine Erdfarbe.

Löcher. Bewegen am Abgrund.

„Die Hamletmaschine“, Heiner Müller, Regie: Dimiter Gotscheff, Deutsches Theater, Berlin, 2007

„In die Bühne [...] sind zehn offene Gräber eingelassen. Die Untoten der Geschichte schlüpfen hier ungesehen ein und aus. Dimiter Gotscheff umschlurft den kleinen Weltfriedhof so, wie der Kuttenmensch aus Becketts Stück Quadrat das Loch im Bühnenboden umkreist, das ihn verschlingen wird.“"18

Es ist ein Raum aus weniger als nichts, ein Raum mit zehn Leeren, - der Versuch, analog dem Text zur „Hamletmaschine“, eine Entsprechung auf Beckett „Quad 1 und 2“ zu finden. Wie in Becketts „Quad 1 und 2“ der zentrale Punkt in den Gängen der Mitspieler bewusst freigelassen wird, werden in „Hamletmaschine“ die Löcher im Bühnenboden freigespielt und erhalten so in der Vertiefung des Raums nach unten eine besondere Intensität. Der Raum gefährdet bzw. schränkt die Bewegung ein und der einzige Akteur der Aufführung muss darauf achten, nicht in die Erweiterung des Raumes zu fallen, nicht von ihm aufgesogen zu werden. Die theatrale Nichtbenutzung der Löcher macht den Text zu einem Monolog, quasi mit negativen Monolithen. Der Leerraum wird als agierender Raum behauptet.

„Exhaustive Serien von Dingen bilden; [...] die Potentialitäten des Raumes ,entkräften' [...] in [...] der Sprache der Bilder und Räume. Sie bleibt in Verbindung mit der Sprache, aber richtet sich auf oder reckt sich in ihren Löchern,

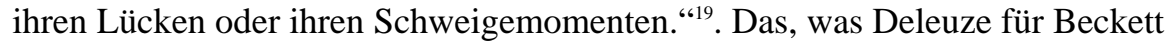
beschreibt: „[E]s ist die besondere Schwierigkeit, ,ein Loch nach dem anderen zu bohren` in die Sprachoberfläche“ ${ }^{\text {‘20 }}$, führt hier zu: zehn Gevierte im Geviert.

17 C. Plinius Secundus d. Ä., Naturheilkunde, hg. v. Roderich König, Düsseldorf, Zürich, 1997, S. 37.

18 Peter Kümmel, „Der kleine Weltfriedhof. Dimiter Gotscheff spielt in Berlin ,Hamletmaschine““, in: Die Zeit, vom 13.09.2007, S. 38.

19 Gilles Deleuze, „Erschöpft“, in: Samuel Beckett, Quadrat, Geister-Trio, ... nur noch Gewölk ..., Nacht und Träume. Stücke für das Fernsehen, aus dem Englischen von Erika und Elmar Tophoven, Frankfurt/M., 1996, S. 50-101: 73.

20 Ebd., S. 98. 
Vertikaler und horizontaler Raum. Bewegungsbilder. „Anatomie Titus/Fall of Rome“, ein Shakespearekommentar von Heiner Müller, Regie: Dimiter Gotscheff, Deutsches Theater, Berlin, 2007

Initiation ist eine Sequenz: „DER MANCHMAL AN DIE DECKE KLOPFT [...] ALS OB ER DIE BEWOHNER NECKEN WILL [...] KLOPFT ER AUS EINEM ANDERN ZIMMER SCHON“ aus Heiner Müllers Shakespearekommentar „Anatomie Titus/Fall of Rome“. Der Raum ist ein Versteckspiel oder fünf niemals gleichzeitig auftauchende identische Teile erscheinen als ob es ein Teil sei. Wie wandelt man eine vertikale in eine horizontale, eine horizontale in eine vertikale Bewegung um? Ein Wunsch war Immaterialität in einem vernetzten, verseilten Raum.

Der ganze Himmel ein großes, gelbes/goldenes Tuch ist der Anfang. Das Tuch wird der „rote Faden“, fordert einen Diskurs von Bildern, aus denen Figurationen entstehen. Das Tuch in seinem Auftauchen - das ein Herabfallen ist - ist auch adaptierte (Theater-)Geste. Die Bühne ist ein Ort der Horizontalen, die Rampe das Endspiel der Vertikalen. Letztendlich werden zwei Raumvorstellungen und zwei Raumsprachen durchsichtig überlagert: der gesamte Bühnenraum und der bewegliche, vom Stoff beherrschte Raum; determiniert durch ein schwer greifbar geformtes Objekt sozusagen. Es entsteht in diesen Momenten des Auftauchens eine Dynamik, die Bewegung selbst wird vom Blick fixiert. Die Bewegung des Tuches stellt sichtbare, flexible Form her, die Bewegung produziert die Form. Dagegen läuft eine Reihung von Szenen, keine Kettenreaktion, das heißt die Bewegung des Tuches ist nicht identisch mit dem durchfahrenden Raum der Maschine oder dem Durchlaufenen der Akteure. Buster Keaton war dabei gegenwärtig: „Keatons Traum: die größte Maschine der Welt nehmen und sie mit ganz kleinen Elementen laufen lassen, sie auf diese Weise dem Gebrauch eines jeden anzuverwandeln, aus ihr eine Sache aller zu machen. “21

Erst das Ende der Bewegung, die Abschaffung der Farbe zeigt die sterbende Maschine. Der taktile, der haptische Raum schafft sich selbst ab, in dem er sich der Hülle ergibt.

${ }^{21}$ Gilles Deleuze, Das Bewegungs-Bild, Frankfurt/M., 1989, S. 238. 


\section{Literatur}

Deleuze, Gilles, Das Bewegungs-Bild, Frankfurt/M., 1989.

Ders., „Ein Manifest weniger“, in: Aisthesis. Wahrnehmung heute oder Perspektiven einer anderen Ästhetik. Essais, hg. v. Karlheinz Barck/Peter Gente/Heidi Paris/Stefan Richter, Leipzig, 1990, S. 379-405.

Ders., „Erschöpft“, in: Samuel Beckett, Quadrat, Geister-Trio, ... nur noch Gewölk ..., Nacht und Träume. Stücke für das Fernsehen, aus dem Englischen von Erika und Elmar Tophoven, Frankfurt/M., 1996, S. 50-101.

Foucault, Michel, Die Heterotopien. Der utopische Körper, mit einem Nachwort von Daniel Defert, Frankfurt/M., 2005.

Ders., „Lauern auf den anbrechenden Tag“, in: ders., Dits et Ecrits. Schriften Bd. I 1954-1969, hg. v. Daniel Defert, Frankfurt/M., 2001, S. 357-365.

Ders., „Die Wahrheit und die juristischen Formen“, in: ders., Dits et Ecrits. Schriften. Bd. II 1970-1975, hg. v. Daniel Defert, Frankfurt/M., 2002, S. 669-793.

Genet, Jean, Briefe an Roger Blin und andere Schriften zum Theater, Gifkendorf, 1996.

Jourdheuil, Jean et al., „Michel Foucault, choses dites choses vues“, in: Jean Jourdheuil (Hg.), Travaux d'atelier. Foucault Mozart Müller. Théâtre/Public 176 (2005), S. 2739.

Kümmel, Peter, „Der kleine Weltfriedhof. Dimiter Gotscheff spielt in Berlin ,Hamletmaschine““, in: Die Zeit, vom 13.09.2007, S. 38.

Lammert, Mark, „Eclats de lettres et notices“, in: Jean Jourdheuil (Hg.), Travaux d'atelier. Foucault Mozart Müller. Théâtre/Public 176 (2005), S. 16-18.

Laudenbach, Peter, „Nach dem Krieg ist vor dem Krieg“, in: Süddeutsche Zeitung vom 13.10.2006, S. 17.

Michaux, Henri, Le Grandes épreuves de l'esprit, Paris, 1966, S. 156 f. [Übersetzung Rolf Brauneis.]

Müller, Heiner, „Drama“, in: Drucksache 20: Last Voyage/Krieg der Viren, aus einem Arbeitsbuch von Heiner Müller und Mark Lammert. Zu Germania 3 - Gespenster am Toten Mann (1995). Mit neun Photographien von Brigitte Maria Mayer, Berlin, 1996.

Nagel, Ivan, Drama und Theater, München, Wien, 2006.

Plinius Secundus d. Ä., C., Naturheilkunde, hg. v. Roderich König, Düsseldorf, Zürich, 1997.

Suschke, Stephan, Müller macht Theater, Theater der Zeit, Berlin, 2003.

Tretjakow, Sergej, „Bert Brecht, 1934“, in: Erinnerungen an Brecht, zusammengestellt von Hubert Witt, Leipzig, 1964, S. 69-86.

Wilke, Judith, Brechts „Fatzer“ Fragment. Lektüren zum Verhältnis von Dokument und Kommentar, Bielefeld, 1998. 


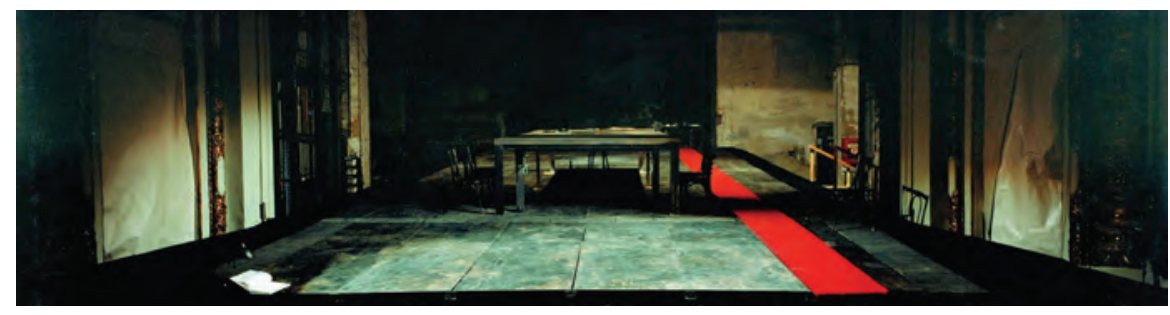




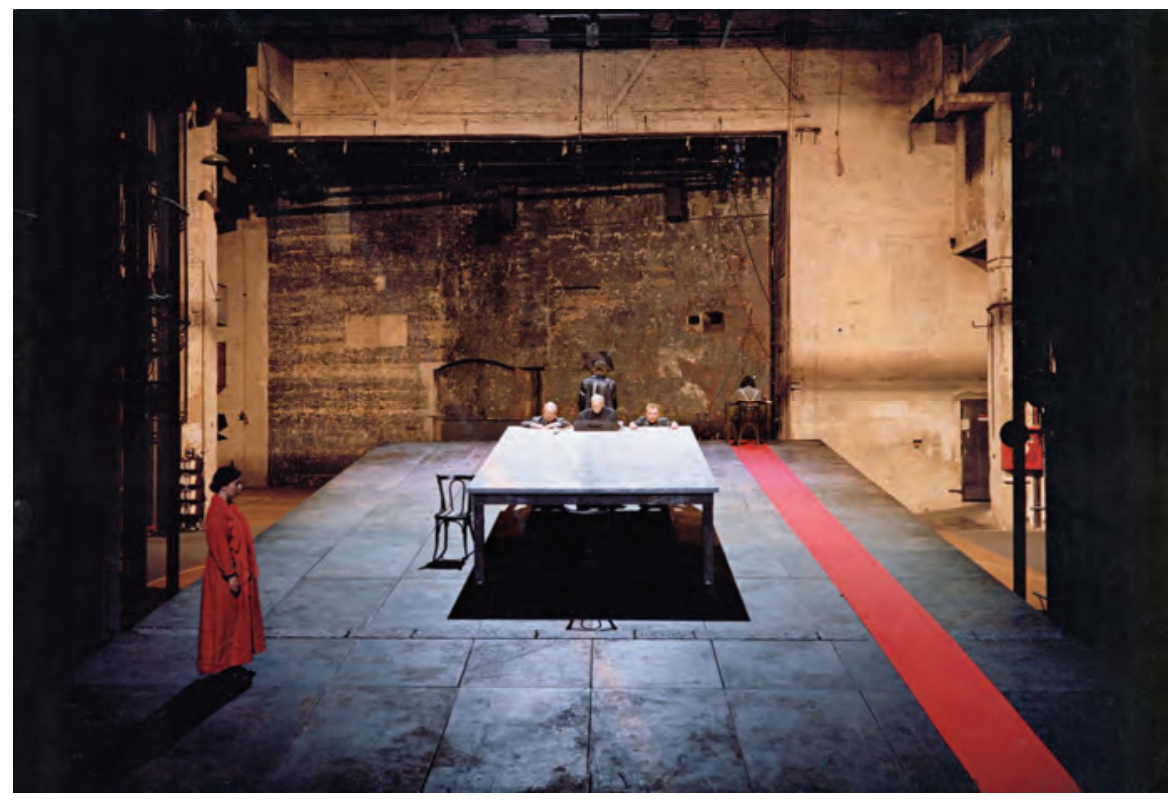




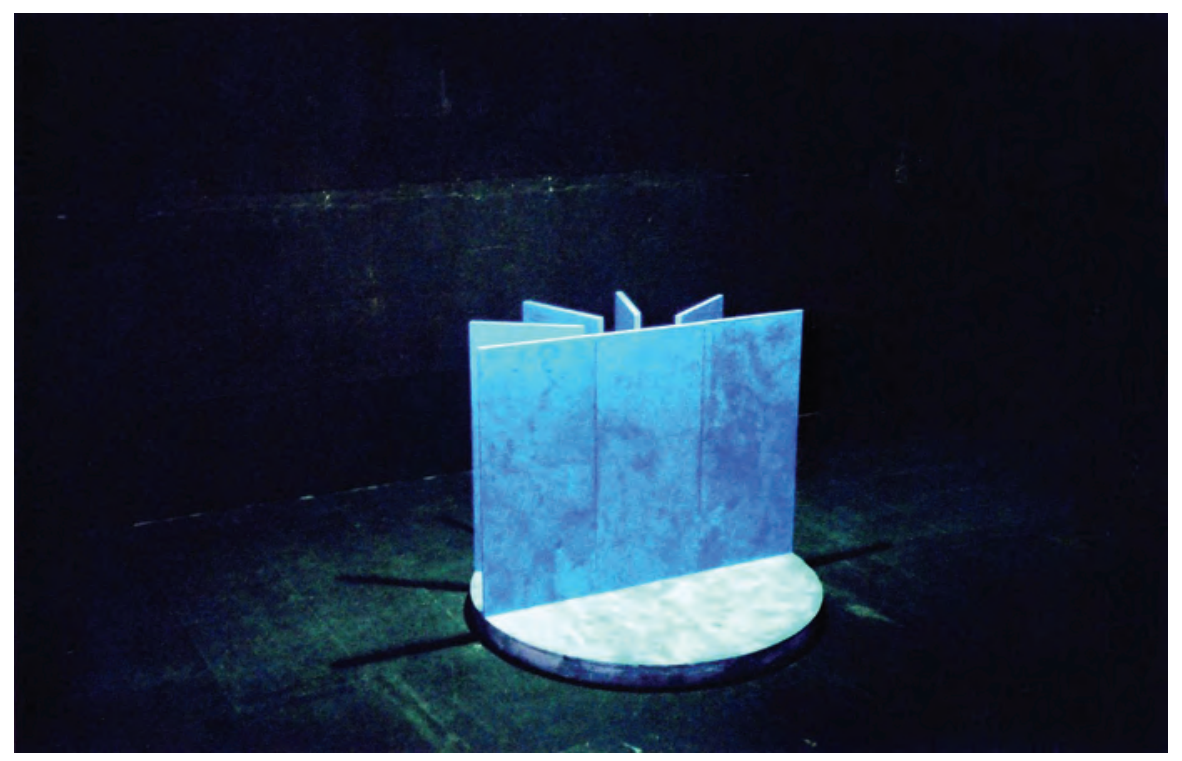




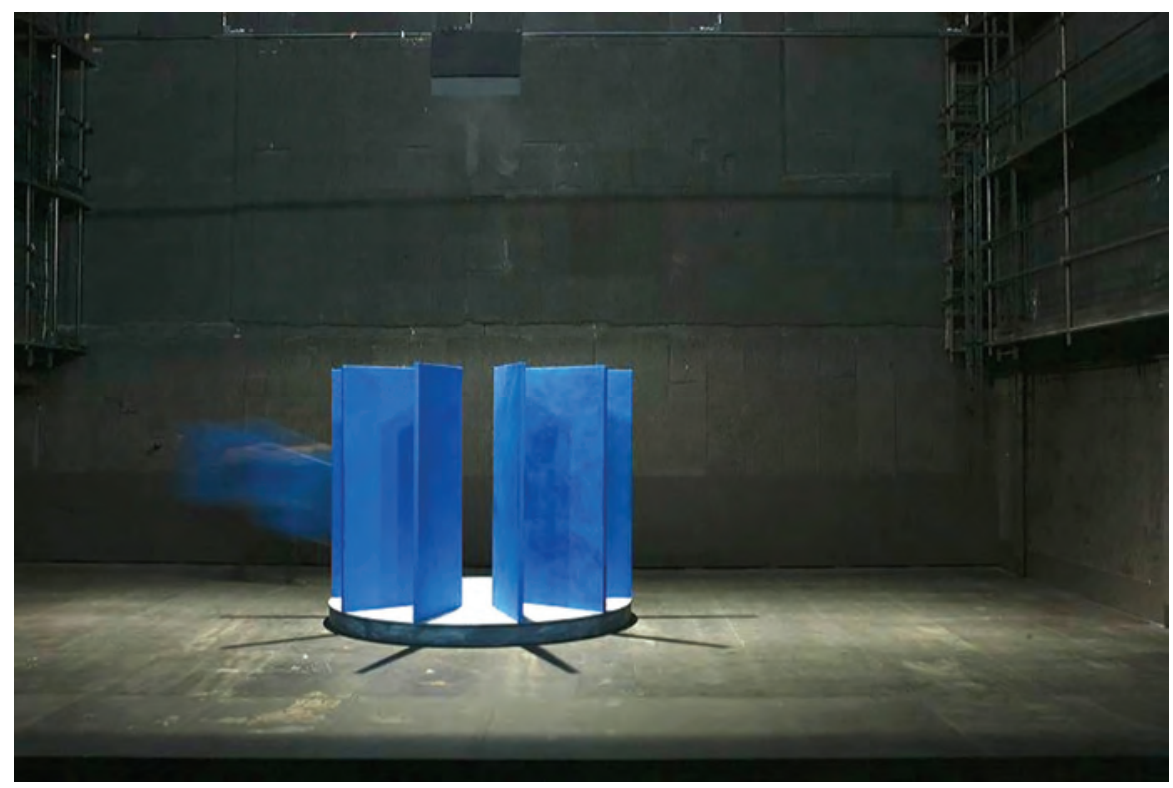




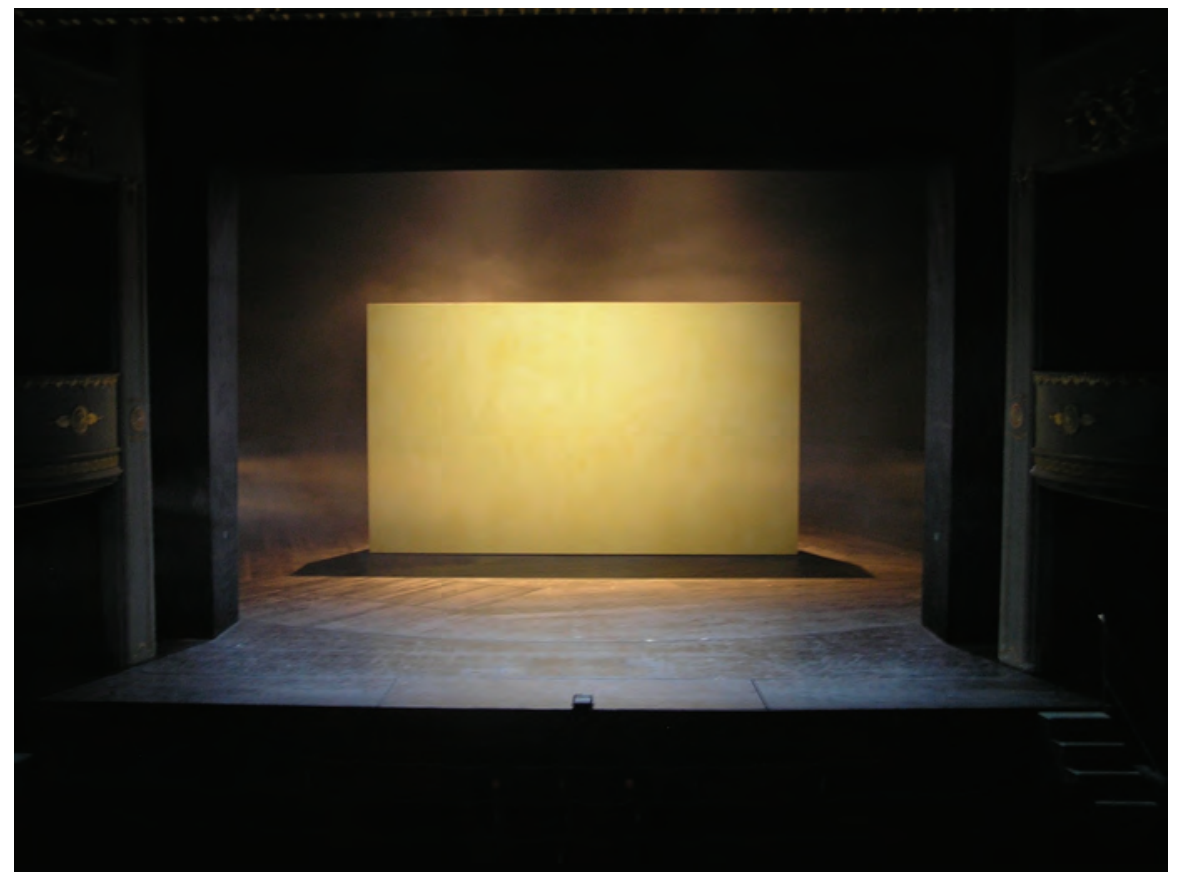



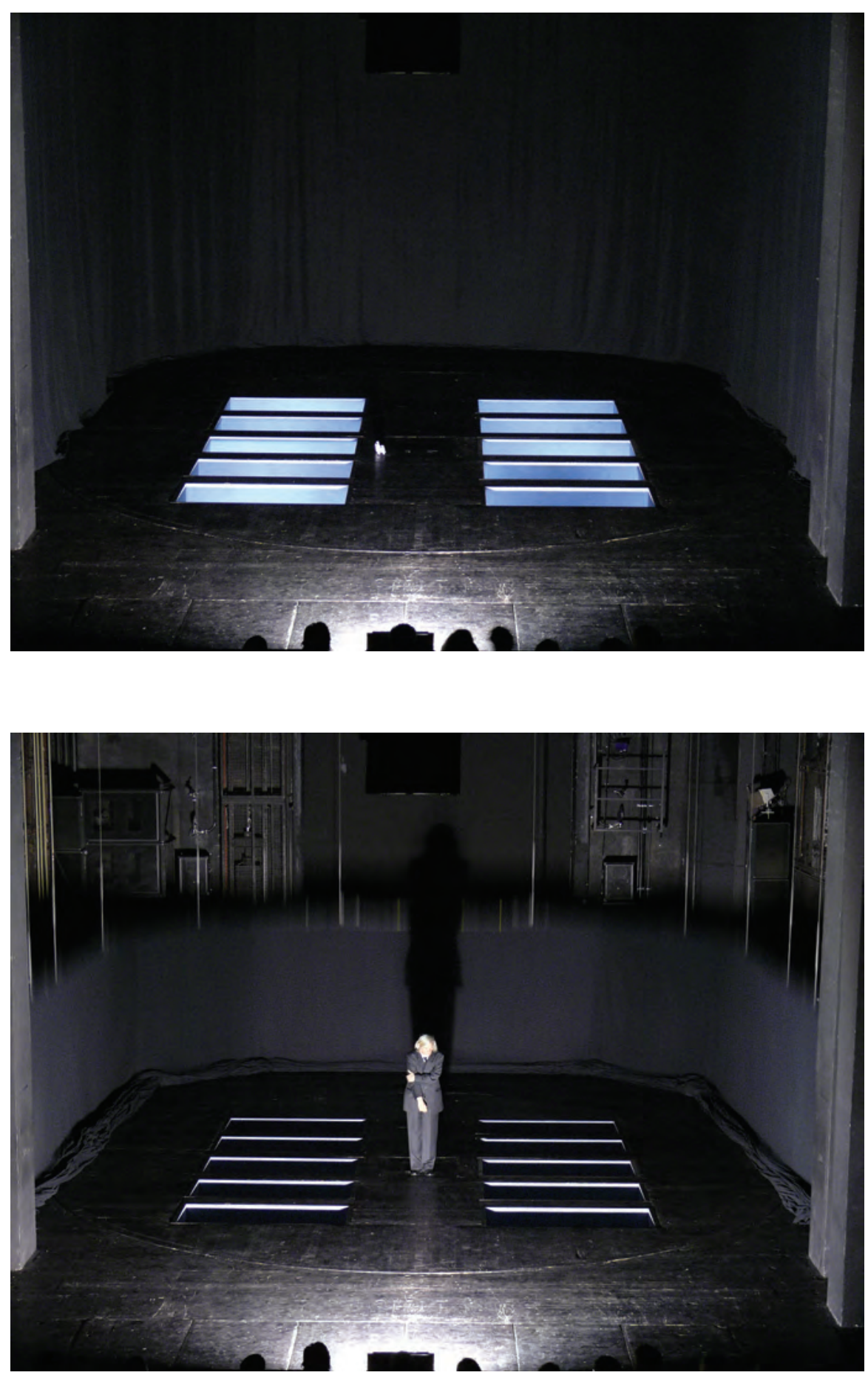


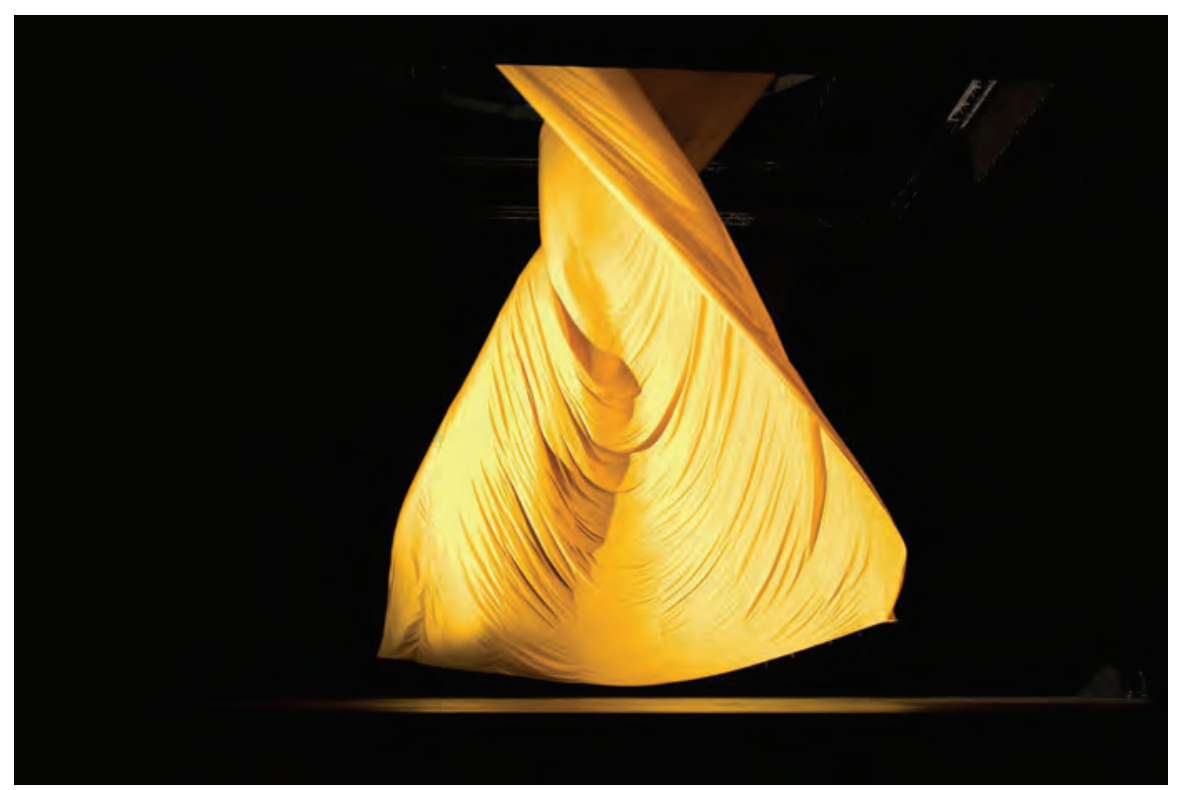




\section{Abbildungen}

S. 294/95 - „Duell-Traktor-Fatzer“. Heiner Müller/Bertolt Brecht, Regie: Heiner Müller, Berliner Ensemble, Berlin, 1993.

S. 296/97 - „Michel Foucault. Choses dites choses vues“, Regie: Jean Jourdheuil, Théâtre de la Bastille, Paris, 2004.

S. 298 - „Die Perser. Aischylos“, Regie: Dimiter Gotscheff, Deutsches Theater, Berlin, 2006.

S. 299 - „Die Hamletmaschine“. Heiner Müller, Regie: Dimiter Gotscheff, Deutsches Theater, Berlin, 2007.

S. 300 - „Anatomie Titus/Fall of Rome“, ein Shakespearekommentar von Heiner Müller, Regie: Dimiter Gotscheff, Deutsches Theater, Berlin, 2007. 

RÄUME ÖFFNEN 



\section{GEGEND OHNE KÖNIGE. DIE BÜHNE VON HÖLDERLINS EMPEDOKLES}

\section{Philosophie des Tragischen und Poetik der Tragödie}

„Seit Aristoteles gibt es eine Poetik der Tragödie, seit Schelling erst eine Philosophie des Tragischen. ${ }^{\text {“1 }}$ Mit diesem apodiktischen Satz beginnt bekanntlich Peter Szondi seinen Versuch über das Tragische. Denn Aristoteles - und die gesamte auf Aristoteles aufbauende Wiederbelebung der Tragödie in den romanischen Ländern seit der Renaissance - verstehe die Poetik einzig als „Unterweisung im Dichten“. ${ }^{2}$ Die einen historischen Abstand von mehreren Jahrtausenden überspannende, zutiefst deutsche philosophische Reflexion über „das Tragische“ aber, die Szondi von Schelling, Hölderlin und Hegel über Goethe, Schopenhauer und Vischer bis hin zu Kierkegaard (der der deutschen Tradition zugeschlagen wird), Nietzsche und Benjamin nachzeichnet, sieht er als Hegel'schen Flug der Eule der Minerva, welcher eben erst in der Dunkelheit beginnt ${ }^{3}$ : als eine abendliche, abendländische, weit nachträgliche Erforschung der „Idee“ ${ }^{\star 4}$ eines Gegenstands, von dem bislang, so scheint es, einzig das Phänomen vorlag.

Was indes die Philosophie des Tragischen von der Tragödie als Kunstform vor allem unterscheidet, ist sehr offensichtlich: Sie benötigt keine Bühne. Dort, wo sie eigentlich Philosophie des Tragischen wird, löst sie sich vom Bezug auf die tatsächliche Praxis des Schreibens und Aufführens von Tragödien und versucht im „Tragischen“ die Bestimmung des modernen Subjekts und/ oder des deutschen Volkes zu entschlüsseln. Für Szondi wird die Philosophie das „Tragische“, über die Unterschiede der Konzeptionen hinweg, letztlich als „eine bestimmte Weise drohender oder vollzogener Vernichtung“ fassen, „und zwar die dialektische“. ${ }^{5}$ Philippe Lacoue-Labarthe, der die These von der Geburt der Dialektik in den Theorien des Tragischen teilt, hat dennoch zweierlei nachzuweisen versucht: Dass sich zum einen die gesamte Philosophie des Tragischen, Szondis These zum Trotz, immer noch auf Aristoteles berufe, genauer: auf seine kryptisch knappe Lehre von der katharsis, der Reinigung, als „der

\footnotetext{
Peter Szondi, „Versuch über das Tragische“, in: ders., Schriften, Bd. I, Frankfurt/M., 2006, S. 149-260: 151.

Ebd.

Ebd., S. 152.

Ebd., S. 151.

Ebd., S. 209.
} 
tragischen Wirkung“66; dass sie aber, einer frühen Warnung von Schelling zum Trotz, zu oft vergesse, dass Aristoteles diesen Effekt unlösbar mit der mimesis verbunden habe, also eben mit der (ebenso theatralen wie sprachlichen, sprachtheatralischen) Darstellung. Die Philosophie des Tragischen, so ließen sich Lacoue-Labarthes skrupulöse Lektüren sicher etwas vereinfachend zusammenfassen, versucht die katharsis aus der mimesis zu lösen, wodurch sie zum Instrument politischer Macht werden kann. Auf diesen knappen Nenner kann ein sehr deutsches Problem gebracht werden.

Von den Autoren, an denen Szondi die Entwicklung der Philosophie des Tragischen aufweist, fallen zwei aus dem Rahmen: Es sind Goethe und Hölderlin. Denn im Vergleich zu den anderen haben jene eben nicht nur die „Idee“ des Tragischen reflektiert, sondern selbst für das Theater geschrieben. Im Falle Goethes scheint diese Verbindung weniger bedeutsam, denn sein Theater steht zur griechischen Tragödie sicher nur in einem losen Zusammenhang. Anders freilich verhält es sich mit Hölderlin. Kaum ein Zeitgenosse hat sich intensiver mit Form und Struktur der attischen Tragödie auseinandersetzt. In Hölderlins Übersetzungen von und Anmerkungen zu Sophokles kann wohl die erste dramaturgische Auseinandersetzung mit der Tragödie im deutschen Sprachraum gesehen werden. Zugleich fordert Hölderlin in den „Anmerkungen zum Oedipus“ eine „méchané“, also eine neue Poetik, nach der das Schreiben von Tragödien gelehrt werden könne: „Der modernen Poësie fehlt es aber besonders an der Schule und am Handwerksmäßigen, dass nemlich ihre Verfahrensart berechnet und gelehrt, und wenn sie gelernt ist, in der Ausübung immer zuverlässig wiederholt werden kann."7

Betrachtet man diese ganz offensichtliche Arbeit an der „Darstellung des Tragischen“8, wie Hölderlin ebenfalls in den „Anmerkungen zum Oedipus“ schreibt, und die vollkommen aus der Zeit fallende Forderung nach einem „Handwerk“ der Dichtung, dann überrascht es wiederum, dass Hölderlins eigener, den Übersetzungen vorausgehender Versuch, eine Tragödie zu schreiben, der Empedokles, immer wieder deswegen als gescheitert angesehen wird, weil er, so heißt es, keine theatralen Qualitäten habe, sondern einzig eine transzendentalphilosophische Abhandlung sei. Sogar Philippe Lacoue-Labarthe schließt sich dieser Meinung an: „Dennoch ist klar - und Hölderlin zeigt es selbst an: Was den Empedokles scheitern läßt, ist sein Mangel an Theatralität.“9 Denn: „Das Szenario des Empedokles ist nichts anderes als ein spekulatives Szenario in griechisch-platonischer Art. Das bedeutet: Der Held ist der Philosophen-König (basileus). “10 Empedokles verdanke sich einer profunden

\footnotetext{
Philippe Lacoue-Labarthe, Poetik der Geschichte, Berlin, 2004, S. 117. [Herv. i. O. ] Friedrich Hölderlin, „Anmerkungen zum Oedipus“, in: ders., Sophokles. Frankfurter Ausgabe, Bd. 16, Basel, Frankfurt/M., 1988, S. 247-258: 249.

8 Ebd., S. 257.

9 Philippe Lacoue-Labarthe, „Das Theater Hölderlins“, in: ders., Metaphrasis. Das Theater Hölderlins. Zwei Vorträge, Zürich, Berlin, o.J., S. 45-70: 50.

10 Ebd., S. 52.
} 
Unkenntnis der Poetik der Tragödie (vulgo: des Aristoteles) und wäre somit ein Stück Philosophie des Tragischen, das aufgrund eines kategorialen Irrtums die Form einer Tragödie angenommen habe, das also die Bühne keineswegs benötige, auf ihr fehl am Platze sei. Und so hat auch die philologische Forschung seit Emil Staiger immer wieder insistiert, dass dieses Stück auf einer Bühne nur schwerlich zur Aufführung kommen könne.

An Lacoue-Labarthes Auffassung wurde in den letzten Jahren vielfach Kritik geäußert. Martin Jörg Schäfer bemerkt, dass „mit den Mitteln des Theaters des 20. Jahrhunderts, die sich von einer Abbildästhetik unter Vorrang der Stimme gelöst haben“, Experimente mit dem Text des Empedokles möglich werden. ${ }^{11}$ Patrick Primavesi untersucht die genuin theatrale Gestik von Hölderlins Sprache ${ }^{12}$; nicht zuletzt widerlegen Inszenierungen wie jene von Klaus Michael Grüber oder (als Film) Jean-Marie Straub und Danièle Huillet sowie, aktueller, von Laurent Chétouane, das Verdikt, dass Empedokles auf einer Bühne nichts zu suchen habe. Um was für eine Bühne aber handelt es sich? Was geschieht in Hölderlins Empedokles mit der Bühne? In diesem Zusammenhang ist ein Aufsatz des in den USA lehrenden Literaturwissenschaftlers Rüdiger Campe von besonderem Interesse. Campe sieht im Empedokles eine Auseinandersetzung mit der Bühne selbst; und in dieser Auseinandersetzung wird eben das Verhältnis zwischen der Philosophie des Tragischen und der Poetik der Tragödie verhandelt. Auf der Bühne findet, so Campe, der „Umschlag ${ }^{\text {(13 }}$ von der Philosophie des Tragischen in die Tragödie als Theater statt: An den Auftritten und Abtritten der Figuren wird diese Funktion der Bühne sichtbar. So vertritt Campe die These,

dass Hölderlin, so sehr ihm bei der Konzeption des Empedokles jede praktische Rücksicht fremd gewesen sein mag, die Bühne in den Mittelpunkt stellt und dabei vom Bühnenraum als vorgestelltem Ort der Handlung - vom Bild der Bühne - übergeht zur tieferliegenden Frage der Örtlichkeit, die jedes Spiel von Anwesenheit und Abwesenheit und damit jedes Spiel überhaupt erst möglich macht. ${ }^{14}$

So ist Empedokles für Campe eben keine philosophische Abhandlung, die kaum auf je einer Bühne wirksam werden könnte, sondern In-Szene-Setzen dieser Bühne selbst - und zwar, so wäre zu präzisieren, als Guckkastenbühne. Durch das In-Szene-Setzen der Bühne aber stellt Hölderlin die Trennlinie zwischen der Philosophie des Tragischen und der Tragödie dar, den Umschlag der einen in die andere.

11 Martin Jörg Schäfer, Szenischer Materialismus. Dionysische Theatralität zwischen Hölderlin und Hegel, Wien, 2003, S. 76.

12 Vgl. Patrick Primavesi, ,,Seiner Hände Spiel‘. Gesten des Entzugs in Hölderlins Empedokles-Fragmenten“, in: Margret Egidi (Hg.), Gestik. Figuren des Körpers in Text und Bild, Tübingen, 2000, S. 259-268.

13 Rüdiger Campe, „Erscheinen und Verschwinden. Metaphysik der Bühne in Hölderlins ,Empedokles““, in: Bettine Menke/Christoph Menke (Hg.), Tragödie, Trauerspiel, Spektakel, Berlin, 2007, S. 53-71: 66.

14 Ebd., S. 55. 
Bevor ich Campes Argument nachzeichne, möchte ich den weiteren Verlauf der Untersuchung skizzieren. Denn wenn Campe im Empedokles ein Spiel von „Erscheinen und Verschwinden“ sieht, welches sich letztlich auf die Guckkastenbühne als Dispositiv des modernen Theaters beziehe, dann spricht er einzig vom ersten der drei Entwürfe (auch auf den zweiten Entwurf ließe sich sein Argument noch anwenden). Der dritte und letzte Entwurf aber, mit dem Hölderlin nach der grundlegenden philosophischen Vergewisserung über das Geschriebene im „Grund zum Empedokles“ noch einmal neu ansetzt, lässt sich, so scheint mir, kaum mehr als ein solches Spiel verstehen. Er scheint auch die Guckkastenbühnen nicht mehr vorauszusetzen oder als dasjenige zu inszenieren, was jenes Spiel ermöglicht. Versteht man mit Theresia Birkenhauer Hölderlins Arbeit am Empedokles nicht als Stufen in Richtung eines kategorial notwendigen Scheiterns (aufgrund des „Mangel[s] an Theatralität“), sondern vielmehr als einen „fortschreitende[n] Abbau einer klassizistischen Projektion“ ${ }^{15}$ auf die Tragödie, dann muss die Frage gestellt werden, welches Denken der Tragödie der dritte Entwurf nahelegt. Die Unterscheidung zwischen einer Philosophie des Tragischen und einer Poetik der Tragödie bzw. der theatralen Darstellung ist nicht mehr plausibel in Anbetracht eines rein sprachlichen Geschehens, das vor allem ein Innehalten ist: nach jeder dramatischen Intrige und vor dem Sprung in den Ätna. Die Philosophie des Tragischen ist vielmehr in einer Form der „Darstellung des Tragischen“ aufgegangen, welche sich weder, wie Szondi nahelegt, in der Dialektik aufzulösen im Stande ist, noch, wie Campe meint, die Guckkastenbühne des bürgerlichen Theaters manifestiert. Die Tragödie zeigt sich als eine eigene, von der Philosophie nicht restlos verrechenbare Form des Denkens und Sprechens; und zugleich scheint sich in Hölderlins Rückgang von der klassizistischen Projektion zur Tragödie ein anderer Raum zu öffnen. Mit einer Regieanweisung aus dem ersten Entwurf des Empedokles - und in Bezugnahme auf Heideggers Verwendung dieses Wortes - möchte ich diesen Raum als „Gegend“ bezeichnen. Der dritte Entwurf des Empedokles „spielt“ nicht allein in einer Gegend: Er überwindet die Guckkastenbühne hin zu einem Entwurf der Bühne selbst als Gegend.

\section{2. „Hinweg!“ Campes Lektüre des Empedokles}

Wenn Rüdiger Campe Empedokles, zumindest die ersten beiden Entwürfe und ihre theoretische Durcharbeitung im „Grund zum Empedokles“, als Inszenierung der (Guckkasten-)Bühne selbst bezeichnet, dann ist dies durchaus stichhaltig. Denn Empedokles, der als „Philosoph und Dichter“ eine „intellektuale Anschauung“ im Sinne Fichtes anstrebt, das Erfassen des All-Einen, wird

15 Theresia Birkenhauer, Legende und Dichtung. Der Tod des Philosophen und Hölderlins Empedokles, Berlin, 1996, S. 586. 
durch die Umstände seiner Zeit dazu gezwungen, aus seinem Garten herausund in eine Beziehung zur Mitwelt hineinzutreten, deren „besondere Verhältnisse“ ${ }^{\text {“16 }}$ ihm eigentlich verhasst sind: „So verhielt er sich“, heißt es im „Grund zum Empedokles“, „als religiöser Reformator, als politischer Mensch“ ${ }^{17}$ Durch den Austritt aus seinem Garten und der bloßen intellektuellen Anschauung und den Eintritt in die Sphäre der religiösen Reformation und Politik aber gerät Empedokles in den ersten beiden Entwürfen in Konflikt mit Hermokrates, dem Vertreter und Verwalter der positiven Religion und ihrer Politik, der deswegen seine Austreibung aus der Stadt betreibt. Der Dichter-Philosoph, der intellektuellen Anschauung fähig, tritt in die besonderen Verhältnisse und in die Religionspolitik ein - und leidet.

Doch dieser Austritt aus dem Garten in die Politik ist kein Schritt im Rahmen der Bühne, er ist, wie Campe nahelegt, der Auftritt auf die Bühne selbst. Wenn Empedokles aus seiner Selbstgenügsamkeit heraustritt, dann tritt er auf die Bühne. Im ersten und im viel kürzeren zweiten Entwurf handelt es sich, wie Campe feststellt, um eine Inszenierung von Auftritten und Abtritten, von Sichtbarkeit und Unsichtbarkeit, welche die Bühne als Bühne in Szene setzen: als jene Rahmung also, die ermöglich, dass etwas überhaupt abwesend oder anwesend sein kann. Die Handlung des ersten Entwurfs beginnt mit den Sätzen der Panthea, deren Name schon auf ihre Schwärmerei für Empedokles verweist: „Diß ist sein Garten! Dort im geheimen / Dunkel, da wo die Quelle springt, dort stand er / jüngst, als ich vorüberging“. ${ }^{18}$ Und enden soll sie, so zumindest der Frankfurter Plan, wie folgt:

Bald drauf stürzt sich Empedokles in den lodernden Aetna. Sein Liebling, der unruhig und bekümmert in der Gegend umherirrt, findet bald drauf die eisernen Schuhe des Meisters, die der Feuerauswurf aus dem Abgrund geschleudert hatte, erkennt sie, zeigt sie der Familie des Empedokles, seinen Anhängern im Volke, und versammelt sich mit diesen um den Vulkan, um laidzutragen, und den Tod des großen Mannes zu feiern. ${ }^{19}$

Jenseits der Bühne, im Unsichtbaren, liegt zum einen der Garten, in dem Empedokles seine Blumen pflegt; jenseits der Bühne liegt jedoch auch jener Ätna, in den er sich letztlich, in seiner Sehnsucht nach dem All-Einen, das nicht den besonderen Verhältnissen und dem Vergehen der Zeit unterliegt, stürzen soll auch wenn keiner der drei Entwürfe an jenen Punkt kommt. Zwischen diesen beiden unsichtbaren Orten, die das Geschehen räumlich wie zeitlich eingrenzen, spannt sich die szenische Handlung der ersten beiden Entwürfe auf: Die Bühne markiert dabei die Sphäre der politischen Sichtbarkeit, der tätigen Pra-

\footnotetext{
16 Friedrich Hölderlin, Empedokles. Frankfurter Ausgabe, Bd. 12 u. 13, Basel, Frankfurt/M., 1985, S. 544 („Frankfurter Plan“). Die Seitenzählung beider Bände ist durchgängig. Zitiert wird, wenn nicht anders vermerkt, der von Sattler konstituierte Text des 13. Bandes.

17 Ebd., S. 877 („,Grund zum Empedokles“).

18 Ebd., S. 697 („Erster Entwurf“).

19 Ebd., S. 546 („Frankfurter Plan“).
} 
xis. Und so kommt Auftritten und Abtritten in den ersten beiden Entwürfen eine besondere Bedeutsamkeit zu. Es geht um die Frage, was mit Empedokles geschieht, wenn er auf die Bühne tritt. Der in der Tragödie des Empedokles dargestellte Konflikt ist der Konflikt der Darstellung selbst.

Dieser Konflikt ist aber jener zwischen der Philosophie und dem Theater. Oder, um es mit der etwas eigentümlichen Terminologie Campes zu sagen (der auf Szondi verweist, aber zugleich Benjamin etwas unorthodox in Aristoteles rückprojiziert, indem er die Tragödie dann, wenn sie Theater ist, auch als „Trauerspiel“ bezeichnet): Es geht um den Konflikt zwischen der „Philosophie des Tragischen“ auf der einen und „dem Trauerspiel in der poetologischen Bestimmung seit Aristoteles“ auf der anderen Seite. ${ }^{20}$ Dem „Grund zum Empedokles“ zufolge wäre dieses „Tragische“ der Kampf des Subjekts, des „Organischen“, mit dem „Aorgischen“, der wilden Natur, in deren Angesicht jede Organisation aufgelöst wird: einer jener „tragischen“ Konflikte also, die ihre Aufhebung Szondi zufolge in der Dialektik finden werden. In Empedokles, in der Figur „Empedokles“ findet dieser Konflikt jedoch nur eine temporäre Lösung als Exzess der Innigkeit - Empedokles fühlt sich mit der Natur eins -; doch erscheinen aber kann diese Innigkeit nur veräußerlicht, in einer Darstellung, auf der Bühne. In einem poetologischen Fragment, das wahrscheinlich ab Sommer 1800 entstanden ist, definiert Hölderlin die Tragödie somit als „die Metapher einer intellectuellen Anschauung“'21 - also als Übertragung und Darstellung jenes Erfassens jenes All-Einen, das seiner Definition nach keiner Darstellung fähig ist. Weil der Auftritt des Absoluten auf der Bühne aber einen Konflikt erzeugt, ist das tragische Gedicht somit „heroisch“, dialogisch, auf Trennung aus. Die Manifestation des „Tragischen“ im Trauerspiel ist eben die Manifestation des Dichters und Philosophen Empedokles auf der Bühne der Politik: „Das Dramatisch- oder genauer: Theatralischwerden des Tragischen ist also zugleich auch die Wendung des Dichterischen in theologisch motivierte und reflektierte Politik. [...] Das Tragische ist seine Wendung ins Trauerspiel.“22 So wie das Tragische nur auf der Theaterbühne erscheinen kann, so kann Empedokles nur erscheinen, wenn er seinen Garten verlässt und sich auf der Bühne der Politik manifestiert. Um jene Bühne ist es also zu tun, da nur auf ihr und durch sie der „Umschlag“ vom Tragischen in das Trauerspiel oder das Theater stattfinden kann.

Campe zufolge ist das entscheidende Wort des Empedokles daher das „Verfahrenswort“ „Hinweg!“. Die gesamte Handlung des Stückes führt „hinweg“ in den Abgrund des Ätna, in den Empedokles sich werfen soll, obgleich keiner der drei Entwürfe an diese Stelle gelangt. Doch auch in den Dialogen kehrt dieses Wort immer wieder und regelt, wer auf der Bühne bleibt und wer von

20 Campe (2007), Erscheinen und Verschwinden, S. 55.

21 Friedrich Hölderlin, „Das lyrische dem Schein nach idealische Gedicht...“, in: ders., Entwürfe zur Poetik. Frankfurter Ausgabe, Bd. 14, Frankfurt/M., 1979, S. 343-372: 369.

22 Ebd., S. 62. 
ihr abtritt, es „organisiert die Auseinandersetzung um die Bühne, den Ort des Erscheinens ${ }^{{ }^{223}}$ und der Kopplung von Tragischem und Theater. Während sich die Handlung im ersten Akt des ersten Entwurfs aber noch auf stabile Orte in Agrigent bezieht, ist der Raum im zweiten Akt, angesiedelt in einer „Gegend am Aetna“"24, selbst nur mehr ein „Durchgangsraum, durch den sie [die Figuren] hindurchgehen, oder das Stück des Weges, auf dem man sie vorübergehen sieht. “25 So schiebt sich „die Durchgangsfunktion vor die Ortsfunktion“ ${ }^{26}$

In letzter Instanz aber ist dieses Spiel von Auftritten und Abtritten für Campe durch das Dispositiv der Guckkastenbühne determiniert, die er als Rahmen des modernen Theaters begreift:

Denn es ist die Bühne - und im Besonderen die moderne Guckkastenbühne -[,] in deren Apparatur des Auf- und Abtretens, des Daseins- und Nichtdaseins, das Erscheinen sichtbar und sinnlich wird, d. h. erscheint. In diesem Sinne handelt Empedokles davon, was bühnentechnisch modernes Theater ausmacht. ${ }^{27}$

Für den ersten Entwurf - und vor allem für dessen ersten Akt - ist diese Aussage sicher richtig. Und doch scheint sie nicht vollkommen befriedigend zu sein. Warum schließt Hölderlin den Entwurf nicht ab, wenn er derart ausgezeichnet die bühnentechnischen Bedingungen des bürgerlichen Theaters umzusetzen imstande ist; warum setzt er zweimal neu an, um im dritten und letzten Entwurf nur mehr zwei Dialoge zueinander zu gruppieren, die beide lange nach jeder politisch-theologischen Intrige stattfinden, zu einem Zeitpunkt, an dem eigentlich alles schon gesagt sein sollte, weit außerhalb der Stadt? Wäre es Hölderlin tatsächlich darum zu tun gewesen, die Guckkastenbühne zu inszenieren, dann ist es wenig einsichtig, warum er sich immer weiter von der Form des ersten Aktes des ersten Entwurfs entfernt, um letztlich die Arbeit nach dem dritten Entwurf einzustellen, in dem das Spiel mit Anwesenheit und Abwesenheit fast keine Rolle mehr spielt.

Wenn aber der erste Entwurf abbricht, an einen Punkt gelangt, an dem die ursprüngliche Konzeption sich offenbar nicht mehr als haltbar erweist, dann geschieht dies nicht in Agrigent, wo die Entwicklung der politisch-theologischen Intrige noch recht mühelos gelingt, sondern im zweiten Akt, in der „Gegend am Aetna“. Dort, in der Gegend, lehnt Empedokles die Krone der Agrigentiner mit den Worten ab: „Diß ist die Zeit der Könige nicht mehr. “28 (Eine Geste, die ganz offensichtlich Lacoues These widerspricht, nach der das Thema des Stückes das Philosophenkönigtum sei: Es ist vielmehr die Ermöglichung der radikalen Demokratie.) In der Gegend des Abschieds und der Abdankung aber scheint auch Hölderlins Plan für ein klassizistisches „Trauer-

\footnotetext{
Ebd., S. 59.

Hölderlin (1985), Empedokles, S. 731 („Erster Entwurf“).

Campe (2007), Erscheinen und Verschwinden, S. 61.

Ebd., S. 60.

Ebd., S. 67.

28 Hölderlin (1985), Empedokles, S. 742 („Erster Entwurf“).
} 
spiel in fünf Acten“ zu versanden; die Gegend macht eine neue Dramaturgie, eine neue Sprechweise, eine neuen Bühne notwendig. Worin besteht jene?

\section{Die Orte des Empedokles}

Um dieser Frage näherzukommen, soll im Folgenden noch einmal genau nachvollzogen werden, in welchen Räumen Hölderlins Empedokles stattfindet. Der erste Akt des ersten Entwurfs wird von keiner Ortsangabe begleitet, doch wird sie in den ersten, oben zitierten Worten der Panthea an die Tochter des Gastfreunds ihres Vaters, Rhea/Delia ${ }^{29}$ gegeben. Vom Bühnenraum aus wird auf den verborgenen Ort verwiesen, in dem Empedokles lebt, wenn er nicht „[h]eraus ins Volk“30 tritt. Nun, nach seinem nefas, hat er sich dort verborgen: „Da sizt / Er seelenlos im Dunkel. Denn es haben / Die Götter seine Kraft von ihm genommen, / Seit jenem Tage, da der trunkne Mann / Vor allem Volk sich einen Gott genannt.“31 Die folgenden Szenen des ersten Akts spielen alle an jener Grenze zwischen Empedokles` Garten und der Öffentlichkeit, der politischen Bühne der Stadt Agrigent: Zunächst treten Hermokrates und Pantheas Vater Kritias auf (,Wie sagtest Du? mein Vater? komm! hinweg!“322), welche dann Empedokles Platz machen, der in seinem Garten wandelt (,Laß uns gehen, Kritias! Daß er in seine Rede nicht uns zieht. ${ }^{\text {(33) }}$ ). Empedokles’ Schüler Pausanias tritt auf (Empedokles: „Hinweg! / Wer hat dich hergesandt?“34), und nach längerem Dialog, in dem Empedokles beklagt, dass die Götter ihn verlassen haben, erscheinen dann, wie Empedokles ausruft, „Hermokrates, der Priester, und mit ihm / Ein Hauffe Volks und Kritias, der Archon! ${ }^{\text {‘35 }}$ Empedokles, der aus dem Dunkel seines Gartens ausgetreten ist, ist nun vollkommen auf der politischen Bühne Agrigents exponiert und wird so auch von Hermokrates vorgeführt - und zwar, indem seine körperliche Präsenz dazu verwendet wird, eine mögliche Verklärung durch die Agrigentiner zu verhindern: „Hier ist der Mann, von dem ihr sagt, er sei / Lebendig zum Olymp empor gegangen. ${ }^{\star 36}$ Als ein Verfahren auf der öffentlichen politischen Bühne der Stadt betreibt Hermokrates nun auch die Verbannung des Empedokles, und sie ist eine Verbannung von dieser Bühne, ,offstage‘. Hermokrates, der Experte des PolitischTheologischen, kann Empedokles nicht verzeihen, dass „er des Unterschieds zu sehr vergaß ${ }^{\text {‘37 }}$ - des Unterschieds zwischen Menschen und Göttern näm-

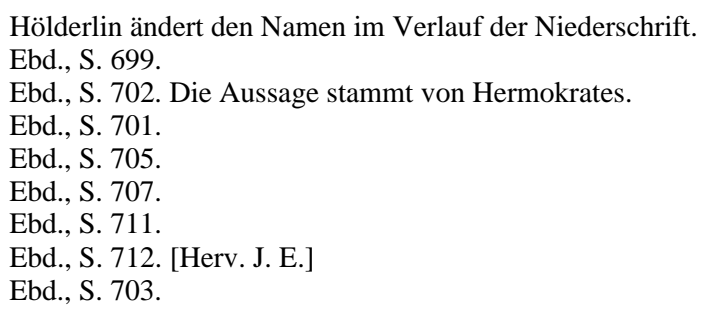


lich. Indem Hermokrates feststellt, dass Empedokles die Grenze zwischen ihnen verletzt habe, konfrontiert er auch jenen mit einer Grenze, er soll aus der Stadt und somit aus der politischen Öffentlichkeit verstoßen werden: „Dann aber muß der Frevler / Rüklings hinab ins bodenlose Dunkel.“38 Die Agrigentiner lassen sich von Hermokrates überzeugen: „Hinweg! wir hören nichts von allem was / Du sagst“ ${ }^{\star 39}$, entgegnet ein Bürger Empedokles.

Nachdem die Bürger abgegangen sind, neigt sich die Bühne vom öffentlichen Platz wieder mehr dem Garten zu: Empedokles und Kritias führen ein Gespräch im Abseits, im Vertrauen, und Empedokles entlässt, nun offenbar ganz in seinen eigenen häuslichen Bereich zurückgekehrt, seine Sklaven, ehe Panthea und Delia/Rhea den Akt beschließen. Bis zu diesem Punkt lässt sich Campes Beschreibung, dass Empedokles das technische Dispositiv der modernen Guckkastenbühne selbst in Szene setze, bestätigen. Der erste Akt spielt eben an der Grenze zwischen der Sphäre exponierter politischer Sichtbarkeit und dem dunklen Garten, in dem sich Empedokles mit der Natur eins fühlt. Es handelt sich um eine Form der „Szene vor dem Palast“, nur dass der Palast in diesem Fall der Garten ist, denn Empedokles ist kein politischer Herrscher, sondern eben Dichter und Philosoph der Natur.

Im zweiten Akt aber wird Agrigent verlassen. Im Gegensatz zu der in der Figurenrede gegebenen Ortsangabe im ersten Akt findet sich hier eine explizite Beschreibung, eben: „Gegend am Aetna. Bauernhütte“. Zuerst hatte Hölderlin geschrieben: „Abhang des Aetna“ und jene Ortsangabe dann präzisiert ${ }^{40}$. „Gegend“ erschien ihm offenbar treffender als „Abhang“. In dieser „Gegend“ werden Empedokles und Pausanias zunächst von einem feindseligen Bauern abgewiesen, der aus der in der Regieanweisung genannten Hütte tritt: „Hinweg! ${ }^{\text {‘41 }}$ Dann spricht Empedokles, von der Aussicht auf den nahen Tod erheitert, lächelnd zu seinem Schüler. Plötzlich aber tritt wieder das Volk auf, diesmal durch einen Ausruf des Pausanias angekündigt: „Ein Hauffe Volks! dort kommen sie / Herauf.“ Da das Volk ihm verzeihen und er genug gelitten habe, möchte Hermokrates Empedokles zur Rückkehr auffordern: „Genes’und kehre nun zurük; dich nimmt / Das gute Volk in seine Heimath wieder.“" ${ }^{\text {"42 }}$ Doch die Rückkehr aus der „Gegend“ in die „Heimath“ scheint unmöglich: Zurück gehen einzig die Agrigentiner, nachdem Empedokles die Krone abgelehnt und ihnen sein „Wort / Das ernste, langverhaltene ${ }^{\text {“43 }}$ als Gabe hinterlassen hat. In jenem „Wort“ wird ein bedeutsamer Satz Goethes wie in einem situationistischen détournement vollkommen umgekehrt: „So wagts! was ihr geerbt, was ihr erworben, / Was euch der Väter Mund erzählt, gelehrt, / Gesez und Bräuch, der alten Götter Nahmen, / Vergeßt es kühn, und hebt, wie Neugeborne, / Die

\footnotetext{
Ebd., S. 714.

39 Ebd., S. 718.

40 Vgl. das Faksimile in: Hölderlin (1985), Empedokles I, Bd. 12, S. 186

41 Ebd., S. 733.

42 Ebd., S. 738.

43 Ebd., S. 744.
} 
Augen auf zur göttlichen Natur [...].“44 Nachdem die Agrigentiner abgegangen sind, bleiben Empedokles und Pausanias in der Gegend zurück; und nach dessen Abgang finden sich abermals Panthea und Delia/Rhea, zu denen dann Pausanias tritt, auf der Suche nach seinem verschwundenen Meister.

Den zweiten Entwurf beginnt Hölderlin ohne Ortsangabe. In der - abgebrochenen -Reinschrift schreibt er indes: „Der Schausplatz ist theils in Agrigent, theils am Aetna“. ${ }^{45}$ Die erste Szene, der Dialog zwischen dem Priester Hermokrates und dem nun Mekades genannten Politiker, spielt offensichtlich in Agrigent. Empedokles tritt auf, Mekades und Hermokrates treten ab („Laß ihn! hinweg! ${ }^{\text {‘46 }}$ ). Empedokles wandelt in seinem Garten oder „Hain“ und betrauert seine Gottverlassenheit. Am Ende scheint Empedokles bereits verschwunden zu sein und Pausanias und die Mädchen bleiben am Ätna zurück.

Ganz anders aber stellt dies sich im dritten Entwurf dar, der nach der theoretischen Revision des „Grund zum Empedokles“ noch einmal neu ansetzt: Jener ist mit gar keiner Ortsangabe mehr versehen, und doch ist offensichtlich, dass er ausschließlich in der „Gegend am Aetna“ stattfindet. Im ersten der beiden einem einleitenden Monolog des Empedokles folgenden Dialoge, nach denen der Entwurf abbricht, verabschiedet Empedokles Pausanias. Jener hat eine Höhle zum Wohnen gefunden und möchte sich mit Empedokles dort niederlassen. Empedokles verwirft dieses Ansinnen; und hier fällt das einzige Mal in diesem letzten Entwurf das Campe“sche „Verfahrenswort“; Empedokles sagt: „Hinweg! ich hab es dir gesagt und sag / Es dir, es ist nicht gut, daß du dich / So ungefragt mir an die Seele dringest [...]. ${ }^{\star{ }^{* 47}}$ Doch anders als in den Dialogen des ersten Entwurfs hat dieses Wort hier keinerlei Wirkung auf das Bühnengeschehen; Pausanias bleibt trotz des Gebots noch eine Weile auf der Bühne. Aus seiner Erwiderung indes geht hervor, dass die Vertreibung aus Agrigent schon eine Weile her ist und er und Empedokles schon recht lange unterwegs sind; Pausanias spricht von „des Himmels Reegen“, dem „schattenlosen Sand“, auf dem Empedokles mittags seine Kleider trocknete und von der Spur des Blutes, „das auf / Den Felsenpfad von nakter Sohle rann.“48 Die Wanderung wird nur mehr erzählt; und das Spiel mit Sichtbarkeit und Unsichtbarkeit, mit Abgängen auf die und Aufgängen von der Bühne der Polis, das den gesamten ersten Akt des ersten Entwurfs beherrschte, spielt hier gar keine Rolle mehr. Das „Verfahrenswort“ ist unwirksam geworden, die Bühne ist nicht mehr die Szene von Auf- und Abtritten, sondern Ort eines fragilen Verweilens. Bereits zu Beginn der theatralen Handlung sind Empedokles und Pausanias in der „Gegend“ angekommen; und Empedokles hat auch seinen Entschluss zum Sprung in den Ätna bereits gefasst, von dem er sich durch Pausanias nicht abbringen lässt.

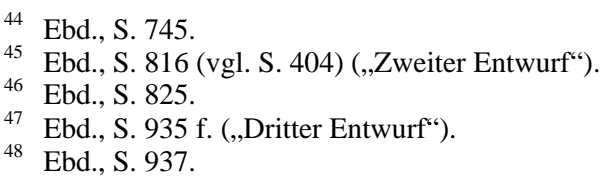


Nach dem Abgang des Pausanias tritt nun die Figur des Manes auf, welche in den Plänen, die dem „Grund des Empedokles“ folgten, noch als ein „Greis“ bezeichnet war und dort zwischen Empedokles und einer dort konzipierten, im dritten Entwurf letztlich nicht ausgeführten Figur vermitteln sollte: dem König von Agrigent und Bruder des Empedokles. Hier nun ist Manes Empedokles` ägyptischer Lehrer, der dessen Entschluss zum Selbstmord hinterfragt und von dem „Einen“ spricht, dem einzig der Selbstmord gestattet sei, weil er die Aussöhnung von Menschen und Göttern bewirke. ${ }^{49}$ Empedokles’ Entschluss wird hier also nicht durch eine dramatische Intrige begründet, sondern in einem Streitgespräch reflektiert. Nach diesem Gespräch bricht der Entwurf ab; ein „Neue Welt“ überschriebenes Blatt enthält wahrscheinlich Entwürfe für jenen „Chor“, der, nach einem letzten, auf der Rückseite des selben Blattes begonnenen und abermals auf fünf Akte angelegten Plans zur Fortsetzung, nun folgen soll. Auf diesem Plan - an dessen Rand bereits das Fragment „Das untergehende Vaterland“ notiert ist, das Hölderlins theoretische Reflexion über die Tragödie weitertreibt - ist neben „Chor“ noch geschrieben und mit einer gepunkteten Linie unterstrichen: „Zukunft“50; für Sattler lässt dies „den Schluß zu, daß dieses Motiv - nicht Neue Welt - Gegenstand des Chors sein sollte. “51 In diesem Chor zur „Zukunft“ heißt es: „,E]s / spottet unser, mit ihren Geschenken die Mutter / und alles ist Schein. - // O wann, wann öffnet sich / die Fluth über der Dürre. // Aber wo ist er? / Daß er beschwöre den lebendigen Geist. “52 An dieser Stelle bricht der Chor der Zukunft, der zukünftige Chor ab.

\section{Am Ende der Bahn: Empedokles und Ödipus auf Kolonos}

Es lässt sich also zunächst feststellen, dass die „Gegend am Aetna“, in die Empedokles und Pausanias im zweiten Akt des ersten Entwurfs ziehen, Schauplatz des gesamten dritten Entwurfs ist, der letzten und reifsten Fassung des Stückes; und aus jener „Gegend“ ist hier auch jenes letzte Zeichen menschlicher Bebauung verschwunden, das der erste Entwurf zur Motivierung eines dramatischen Dialogs noch für nötig hielt: die von dem feindseligen Bauern bewohnte „Bauernhütte“. In ihrer monumentalen Studie über das EmpedoklesProjekt hat Theresia Birkenhauer Hölderlins Arbeit als Weg von der klassizistischen Projektion hin zu einer zu seiner Zeit unerhörten Durchdringung der Tragödie verstanden, der auf die Forschung des 20. Jahrhunderts - sie nennt Lehmann, Vidal-Nacquet, Vernant - vorausweise: „Mit der Infragestellung des autonomen Charakters zerbricht auch das Subjekt des klassizistischen Dramas. Es ist die Verwerfung dieser Form des Dramas, die es Hölderlin ermög-

\footnotetext{
Zur Diskussion dieser Figur s. Birkenhauer (1996), Legende und Dichtung, S. 518-535.

Vorder- und Rückseite dieses Blattes faksimiliert: Hölderlin (1985), Empedokles, S. 520-523.

1 Ebd., S. 928.

52 Ebd., S. 946.
} 
licht, die griechische Tragödie neu zu lesen - und dann anders zu übersetzen. ${ }^{\text {"53 }}$ Denn bereits in den drei Entwürfen des Empedokles führt Hölderlin, so Birkenhauer, eine implizite Auseinandersetzung mit Sophokles, anhand seines letzten Stücks Ödipus auf Kolonos. Während gewisse inhaltliche Ähnlichkeiten bereits der älteren Forschung aufgefallen sind, betont Birkenhauer die formalen Ähnlichkeiten, welche im dritten Entwurf am weitesten entwickelt sind. Dabei wird sichtbar, dass die „Zuwendung zu Sophokles“54, die auch LacoueLabarthe als Rückkehr zur „Grundlage des Theatralischen“"55 versteht, nicht zwingend „auch eine Zuwendung zu Aristoteles" ${ }^{\text {"56 }}$ sein muss - zumindest nicht zur vermeintlich aristotelischen Form des Dramas. An anderer Stelle schreibt Birkenhauer:

Daß der tragische Held nicht Verkörperung einer sittlichen Idee, sondern Schnittpunkt extremer Gegensätze ist, die in ihm keinen Ausgleich finden, die Tragödie nicht die Kollision entgegengesetzter Mächte, sondern hyperbolische Steigerungen der Rede und des Bewußtseins zeigt, der tragische Dialog nicht Mitteilung, sondern Ausdruck ist, zu diesem Blick auf die griechische Tragödie findet $\mathrm{H}$ [ölderlin] durch den Versuch, mit Empedokles eine Figur widerstreitender Extreme und hybrider Überschreitungen sichtbar zu machen. ${ }^{57}$

Hölderlins Durcharbeitung von Sophokles‘ Ödipus auf Kolonos betrifft jedoch auch den Raum des Geschehens. Denn auch Sophokles‘ letztes Stück, von Hölderlin in den „Anmerkungen zur Antigonä“ als Modell einer „,vaterländischen“, also modernen Tragödie bezeichnet ${ }^{58}$, spielt, anders als die anderen thebanischen Tragödien, in einer Gegend. Zu Beginn treten Antigone und der blinde Ödipus in einen heiligen Hain ein - in Kolonos vor Athen, dem Geburtsort des Sophokles. Und Ödipus fragt seine Begleiterin - in Hölderlins eigener Übersetzung der Szene: „Was ists für eine Gegend? welchem Gott gehört sie?“659 Wenig später wird er vom Chorführer die Antwort bekommen: „Die ganze Gegend hier ist heilig.“60 In beiden Fällen übersetzt Hölderlin mit „Gegend“ das beziehungsreiche griechische Wort chôros, das Passows Handwörterbuch der griechischen Sprache wie folgt übersetzt: „ein bestimmter Jemanden einschliessender od[er] in sich bergender Platz, Stelle, Ort, Ortschaft“,

53 Birkenhauer (1996), Legende und Dichtung, S. 586.

54 Lacoue-Labarthe (o.J.), Das Theater Hölderlins, S. 57.

55 Ebd., S. 50.

56 Ebd., S. 57.

57 Theresia Birkenhauer, „Empedokles“, in: Johann Kreuzer (Hg.), Hölderlin-Handbuch. Leben - Werk - Wirkung, Stuttgart, Weimar, 2002, S. 198-223: 221.

58 Vgl. Friedrich Hölderlin, „Anmerkungen zur Antigonae“, in: ders. (1988), Sophokles, S. 409421: $418 \mathrm{f}$. „Eine vaterländische [Kunstform] mag, wie wohl beweislich ist, mehr tödtend factisches, als tödtlich factisches Wort seyn; nicht eigentlich mit Mord und Tod endigen, weil doch hieran das Tragische mußgefaßt werden, sondern mehr im Geschmake des Oedipus auf Kolonos, so daß das Wort aus begeistertem Munde schreklich ist, und tödtet“.

59 Hölderlin, „Zwei Proben aus Ödipus auf Kolonos“, in: ders., Sophokles. Frankfurter Ausgabe, Bd. 16, Basel, Frankfurt/M., 1988, S. 423-433: 431.

60 Ebd., S. 433. 
jedoch „insbesondere [...] das Ackerfeld [...] od[er] das einer Stadt gehörige Landgebiet. “61 Offensichtlich verwandt mit chôros ist das Wort chôra; Jacques Derrida hat es in Platos Lehrdialog Timaios untersucht, dessen Einfluss auf Hölderlins Empedokles allein durch die Namen ersichtlich ist: Hermokrates und Kritias, die Gegenspieler des Empedokles, sind auch Figuren dieses Dialogs. „Chôra“, so Derrida,

verzeichnet einen abseits gelegenen Platz, den Zwischenraum, der eine dissymmetrische Beziehung wahrt zu allem, was ,in ihr', ihr zur Seite oder ihr entgegen ein Paar mit ihr zu bilden scheint. In dem außerpaarlichen Paar können wir diese eigentümliche Mutter, die statt gibt, ohne zu erzeugen, nicht mehr als einen Ursprung ansehen. ${ }^{62}$

Chôra gibt Raum, aber sie erzeugt nicht, sie unterscheidet sich von allem, was sie besetzt und einnimmt. Bis heute umstritten scheint hingegen die Frage zu sein, ob chôros und chôra auch mit dem chorós verwandt sind, mit jenem zunächst ländlichem Tanzplatz, von dem der Tanz und dann der Chor seinen Namen nehmen. Bei Hölderlin zumindest geht die Gegend - chôros - in einen Chor - chorós - über; in einen Chor der Zukunft indes, der ausbleibt.

In Ödipus auf Kolonos erfährt Ödipus auf seine Frage nach dem chôros vom Chorführer, dass die heilige Gegend, in die er eingedrungen ist, den Eumeniden geweiht sei, den Rachegöttinnen. Und ihm wird auch der Name des heiligen Hains genannt: „bronzene Schwelle“. Der heilige Ort, den die Eumeniden bewachen, liegt an der Schwelle zur Stadt Athen, deren König Theseus Ödipus großmütig jede mögliche Gastfreundschaft beweist. Ödipus und Antigone betreten diese Stadt nicht: Sie bleiben das ganze Stück über auf der Schwelle, wie es Benjamin zufolge auch der Brecht'sche Keuner tut, der ,gar nicht von seiner Schwelle" ${ }^{\text {“63 }}$ kommt. Mehr noch: Ödipus wird auf der Schwelle sterben und ewig in ihr gebettet werden - als Fremder, dessen Leichnam, dem Orakelspruch zufolge, der Stadt, die ihn aufnimmt, Glück bringen wird. Nur Theseus darf ihn zu dem geheimen Ort seines Todes begleiten; und nur er darf diesen seinem Nachfolger verraten. Auf der Schwelle findet die gesamte Sprech-Handlung des Ödipus auf Kolonos statt, sie ist jener Ort, der den Tod des Ödipus zurückhält und auf dem er steht, um letzte, bittere Worte und Verfluchungen an Kreon und Polyneikes zu richten, die sich, nachdem auch sie den Orakelspruch vernommen haben, seines segensbringenden Leichnams bemächtigen wollen.

In Sophokles‘ letztem Stück tritt Ödipus also blind nicht in eine Stadt, sondern vielmehr in eine „Gegend“ ein, die zugleich eine Schwelle ist; und er verbleibt in dieser Gegend, auf dieser Schwelle, um dort zu sprechen und um

61 Franz Passow, Handwörterbuch der griechischen Sprache, Bd. 2, 2, Darmstadt, 1993 [1857], S. 2552.

62 Jacques Derrida, Chôra, Wien, 1990, S. 68.

63 Walter Benjamin, „Was ist das epische Theater? [1] Eine Studie zu Brecht“, in: ders., Gesammelte Schriften, Bd. II, Frankfurt/M., 1999, S. 519-531: 523. 
letztlich - an einem geheimen Ort hinter der Bühne - zu sterben. Für Samuel Weber ist der Ort, in den Ödipus eintritt, daher

a stage, ,platform', or podium - a place to set one's feet, a place to be seen, and yet not necessarily understood. A place that moves, but that is never simply a springboard for a change of place. In this sense, the khôra where Oedipus finds himself is both ,last place' and ,threshold', always gesturing somewhere else and yet at the same time a place beyond which one cannot go. ${ }^{64}$

Somit verweist Sophokles' Stück für Weber auf die Medialität des Theaters überhaupt. Was aber auf dieser Bühne als Gegend und als Schwelle stattfindet - die ebenso auf andere Orte verweist wie sie die letzte Grenze ist -, ist eine sprachliche Aushandlung, in der Leben und Tod sich von Beginn an vermischt haben. Nachdem er explizit die Hegel'sche Lektüre als „Dummheiten“65 verworfen hat, derzufolge sich in der Tragödie - bei Hegel: der Antigone - zwei gleichberechtigte Gesetze bekämpfen und aufheben, bemerkt Jacques Lacan, die Position der tragischen Figuren des Sophokles - ,ausgenommen König Ödipus“ - sei das „Am-Ende-der-Bahn. Sie sind in ein Extrem gebracht [...]. Es sind Personen, die von Anfang an in eine Grenzzone zwischen Leben und Tod gestellt sind.“66 In Bezug auf die Einmauerung der Antigone spricht Lacan im selben Text von einer ,detaillierte[n] Apophanie, die uns von der Bedeutung der Stellung, des Loses eines Lebens gegeben wird, das sich mit dem Tod, der gewiß ist, vermischen wird, einem Tod, der antizipiert, erlebt wird, einem Tod, der auf den Bereich des Lebens übergreift, Leben, das auf den Tod übergreift. “67 In „Ödipus auf Kolonos“ ist der Ort dieses Übergreifens des Lebens auf den Tod und des Todes auf das Leben der heilige Hain, die bronzene Schwelle, die Gegend. Hier beginnt Ödipus, wie einer zu sprechen, der den Lebenden nicht mehr angehört. Und auch Empedokles spricht in der Gegend am Ätna letzte Worte; und über dieses Sprechen selbst sagt er: „Es will zum sterblichen Gespräche fast / Und eitlem Wort die Zunge nimmer dienen.“68 Wenn Empedokles etwas mit den tragischen Figuren des Sophokles verbindet, dann weniger, dass er an einem Konflikt teilhat, der einer dialektischen Lösung zugänglich ist, sondern vielmehr, dass auch er am Ende seiner Bahn angelangt ist, und dass er am Ende dieser Bahn in ein Sprechen gerät, in dem Leben und Tod ineinandergreifen.

In Bezug auf die Raumkonzeption des Empedokles ist in diesem Zusammenhang bedeutsam, dass jener, wie Ödipus, die ganze Dauer des dritten Entwurfs über auf der Bühne bleibt - beide, Empedokles wie Ödipus, verharren in der Gegend, während das szenische Geschehen sich um sie gruppiert. Dies hat

64 Samuel Weber, „The Place of Death: Oedipus at Colonus“, in: ders., Theatricality as Medium, New York, NY, 2004, S. 141-159: 154.

65 Jacques Lacan, Die Ethik der Psychoanalyse. Das Seminar, Buch VII, Weinheim, Berlin, 1996, S. 306.

66 Ebd., S. 326.

67 Ebd., S. 299.

${ }^{68}$ Hölderlin (1985), Empedokles, S. 939 („Dritter Entwurf“). 
nichts damit zu tun, dass Hölderlin zu „subjectivisch“ und „überspannt“69 sei, um eine wirkliche, aus einem dramatischem Konflikt komponierte Tragödie zu schreiben. Denn die Bühne ist im Empedokles wie im Ödipus auf Kolonos kein Ort eines solchen, vielleicht auf eine dialektische Lösung ausgehenden Konflikts, sondern Schauplatz der Exponierung der tragischen Figuren im Zwischenbereich zwischen Leben und Tod. Oder, präziser noch: Sie ist der Hör-Platz, auf dem diese Exponierung sich ausspricht. Denn dass Hölderlins dritter Entwurf einzig aus einem Monolog und zwei Dialogen besteht, die von offensichtlich unbewegten Personen aufgesagt werden, kann nur dann als Mangel an theatraler Begabung gedeutet werden, wenn man übersieht, dass auch Sophokles' letztes Werk dem Auge fast gar nichts zu bieten hat. Dies freilich ist keineswegs überraschend in Anbetracht eines Stückes, dessen Hauptfigur blind ist: Jedes Wort, das an Ödipus gerichtet wird, kann nur an sein Ohr gerichtet werden; jedes visuelle Geschehen muss für Ödipus auf der Bühne beschrieben werden. ${ }^{70}$ Lacan hat sehr klar erkannt, dass der Zwischenbereich zwischen Leben und Tod in der Tragödie eben keine visuelle Darstellung findet: „Und in diesem Punkt kann ich mich nicht genug beglückwünschen, mit Aristoteles einer Meinung zu sein, für den die ganze Entwicklung der Theaterkünste auf der Ebene des Hörens geschieht, wobei das Schauspiel für ihn eine Einrichtung am Rande ist." ${ }^{\text {"71 } 1}$ Ist aber die Bühne als „Gegend“ vor allem ein Hör-Platz, dann ist sie auch nicht, wie noch im ersten Akt des ersten Entwurfs, durch jenes Spiel mit Auftritten und Abtritten gekennzeichnet, das Campe als Spiel der Manifestation der Philosophie des Tragischen auf der Theaterbühne des Trauerspiels entschlüsselt hat - und das er von der Guckkastenbühne als der Grundbedingung des modernen Theaters bestimmt sieht. Auf- und Abtritte, welche von einer klaren Rahmung ermöglicht werden, ergeben einzig einen visuellen Effekt. Ein Klang aber kann nicht scharf und eindeutig „gerahmt“ werden.

Auf die Bühne des dritten Entwurfs aber - nach dem von Campe analysierten „Grund zum Empedokles“ - wird kaum auf- und abgetreten, und ebenso ist hier die Unterscheidung zwischen einer „Philosophie des Tragischen“ und einer „Ästhetik des Trauerspiels“ nicht mehr zu treffen. Hölderlin revidiert die Trennung beider Termini: Das „Tragische“ ist hier nicht mehr Gegenstand der

69 So die Beschreibung, die Goethe von Hölderlin sowie von Siegfried Schmidt und Jean Paul in einem Brief an Schiller gibt. Vgl. Friedrich Hölderlin, Sämtliche Werke und Briefe, München, 1993, Bd. 3, S. 597 f.

70 Ödipus tritt in König Ödipus oder, bei Hölderlin, Oedipus der Tyrann, mit den Worten auf, er wolle „nicht von andern Boten, Kinder, / Vernehmen, selber komm ich hieher, ich, / Mit Ruhm von allen Ödipus genannt“ („,Oedipus der Tyrann“, in: Hölderlin (1988), Sophokles, S. 73-245: 81). Nun aber benötigt auch Ödipus wie der zuvor von ihm verspottete Tiresias jemanden, der ihn führt: Er ist von Antigone abhängig, die für ihn sieht. Als Blinder aber beginnt er beinahe prophetisch zu reden, so wie es zuvor Tiresias tat.

71 Lacan (1996), Die Ethik der Psychoanalyse, S. 304. Lacan spielt auf Aristoteles berühmten Hinweis an, die opsis sei „das Kunstloseste“ und habe „am wenigsten etwas mit der Dichtkunst zu tun“, Aristoteles, Poetik, Stuttgart, 1994, S. 25 (1450b). 
Philosophie, Ergebnis der Konfrontation eines Dichter-Philosophen mit dem Aorgischen der Natur im ,offstage seines Gartens - eines Philosophen also, der dann auf die öffentliche Szene der Politik treten muss, um sichtbar zu werden, und sich so in der Intrige seines Gegenspielers verstrickt. Das Tragische ist die „Darstellung des Tragischen“, es ist eine bestimmte Form des Sprechens, in dem Leben und Tod ineinandergreifen - es ist, wie Hölderlin in den „Anmerkungen zur Antigonä“ schreiben wird, ein Sprechen der „geheimarbeitenden Seele“, die „auf dem höchsten Bewußtseyn dem Bewußtseyn ausweicht“"72, so dass es diesem Sprechen zwischen Leben und Tod möglich wird, „des Menschen Verstand, als unter Undenkbarem wandelnd, zu objectiviren“. ${ }^{73}$

Dieses Sprechen benötigt jedoch keine Guckkastenbühne als Dispositiv, welches Auftritte und Abtritte ermöglich, die durch das „Verfahrenswort“ „Hinweg!“ gekennzeichnet sind. Wie bereits gesagt: Dieses Wort wird im dritten Entwurf nur einmal gesagt und bleibt szenisch folgenlos. Tragisch ist hier einzig das Sprechen des tragischen Charakters auf der Szene selbst. Die „Darstellung des Tragischen“ ist eine sprachliche Darstellung, welche die Sprache über sich hinaustreibt, bis sie jene Position zwischen dem Leben und dem Tod ausspricht.

\section{Heidegger: Gegend, Gegnet, Gelassenheit}

Und dieses Aussprechen findet nicht in einem Sterbezimmer statt, sondern, im Empedokles wie im Ödipus auf Kolonos, in einer Gegend. Also, noch einmal: Was ist eine Gegend, was hat sie mit demjenigen zu tun, der von der Position des „Am-Ende-der-Bahn“ aus spricht - und was für eine Bühne kann sie sein? Etymologisch ist „Gegend“ wahrscheinlich die deutsche Lehnübersetzung des mittellateinischen contrata, aus dem das französische contrée und das englische country abgeleitet sind: Die Gegend ist zunächst das, was gegenüberliegt. So definiert auch das Grimm 'sche Wörterbuch „Gegend“:

gegende, wie gegene und gegenôte, gegenheit, sind begriffliche bildungen zu gegen oder gagen, gagan: was mir vor augen steht oder liegt in gewisser weite (eig. schuszweite) mit gewissen beziehungen, eigentlich aber diese weite und diese beziehungen selber, also ursprünglich gleich gegenwart. ${ }^{74}$

Gegend ist also nicht allein eine räumliche, sondern eine raum-zeitliche Bestimmung; und sie ergibt sich durch Beziehungen. Sie ist nicht als objektiver, homogen messbarer Raum von vornherein da, sondern existiert nur durch Gegenüberstellung oder Entgegnung.

72 Hölderlin (1988), Anmerkungen zur Antigonae, S. 414.

73 Ebd., S. 413.

74 Jacob Grimm/Wilhelm Grimm, Deutsches Wörterbuch, Leipzig, 1897, vierten Bandes erste Abtheilung, zweiter Theil, Sp. 2228-2233: 2229. 
Diese Bedeutung von Gegend als das, was entgegnet, hat auf einzigartige Weise Martin Heidegger betont, bei dem der Begriff in einigen Texten aus der Zeit um 1945 eine herausgehobene Bedeutung zukommt. Heidegger gibt wichtige Hinweise auf das, was hier als „Gegend“ zu denken ist - auch wenn die „Gegend“, die bei Sophokles und Hölderlin begegnet, letztlich vielleicht eine andere ist. In der Vorlesung „Logik. Heraklits Lehre von Logos“ vom Sommersemester 1944 wird der Begriff der „Gegend“ zunächst als Übersetzung der griechischen chôra verstanden: „é chôra als die umgebende Umgegend ist dann ,die Gegend'. Wir verstehen darunter den offenen Bereich und die Weite, worin etwas seinen Aufenthalt nimmt, von woher es herkommt, entkommt und entgegnet. “75 Heidegger grenzt chôra als Gegend dann noch vom Ort, tópos, ab. In einem „Feldweggespräch über das Denken“, das Heidegger in den letzten Kriegsmonaten (und natürlich ohne jeden Kommentar zum aktuellen Geschehen) schreibt, lässt er dann einen „Forscher“, einen „Gelehrten“ und einen „Lehrer“ vor allem die „Gelassenheit“ erörtern, die dem viel bekannteren Vortrag vom Oktober 1955 den Titel geben wird. ${ }^{76}$ Der Lehrer bringt auch hier den Begriff der „Gegend“ ins Spiel und der Forscher fragt nach einer Weile noch einmal grundsätzlich nach: „Was bedeutet denn dieses Wort?“ Der Gelehrte antwortet: „In der älteren Form lautet es ,Gegnet“ und meint die freie Weite.“ Und der Lehrer ergänzt: „Gegend ist das versammelnde Zurückbergen zum weiten Beruhen in der Weile.“"77

In die Gegend oder „Gegnet“ aber muss sich, so geht aus dem weiteren Gespräch hervor, einlassen, wer das teleologische, von Subjekt- und Objektverhältnissen ausgehende und auf Vorstellungen abzielende abendländische, ,metaphysische“ Denken überwinden will. „Gegnet“ ist für Heidegger somit so etwas wie die raumzeitliche Entsprechung der „Gelassenheit“; „Gegnet“ kann als jene „Umwelt“ beschrieben werden, die der „Gelassenheit“ korrespondiert, auf die jene sich einlassen muss:

Die Gelassenheit kommt aus der Gegnet, weil sie darin besteht, daß der Mensch der Gegnet gelassen bleibt und zwar durch diese selbst. Er ist ihr in seinem Wesen gelassen, insofern er der Gegnet ursprünglich gehört. Er gehört ihr, insofern er der Gegnet anfänglich ge-eignet ist, und zwar durch die Gegnet selbst. ${ }^{78}$

Die „Gegnet“ ist nicht der Raum, den sich das Subjekt unterwirft, indem es ihn misst, berechnet und homogenisiert, indem es sich also, wie es an anderer

\footnotetext{
Martin Heidegger, „Logik. Heraklits Lehre vom Logos“, in: ders., Heraklit. Gesamtausgabe, Bd. 55, Frankfurt/M., 1994, S. 183-402: 335.

76 Martin Heidegger, „Gelassenheit“, in: ders., Reden und andere Zeugnisse. Gesamtausgabe, Bd. 16, Frankfurt/M., 2000, S. 517-529.

77 Martin Heidegger, „Zur Erörterung der Gelassenheit. Aus einem Feldweggespräch über das Denken“, in: ders., Aus der Erfahrung des Denkens. Gesamtausgabe, Bd. 13, Frankfurt/M., 1983, S. 37-74: 47.

78 Ebd., S. 55 f.
} 
Stelle heißt, „durchsetzt“ “79 In der „Gegnet“ soll vielmehr, so Heidegger, das Wollen aufhören: „Wenn wir uns auf die Gelassenheit zur Gegnet einlassen, wollen wir das Nicht-Wollen. “80 Die paradoxen, aus der Mystik des Meister Eckhard entnommenen Figuren lassen die „Gegnet“ somit als einen Zeitraum erkennbar werden, in dem sich das Subjekt seiner Allmachtsphantasien entledigt - und indem es die Künste des Wartens, des Sich-Einlassens, der Gelassenheit übt, hört es auch auf, Subjekt zu sein. Dadurch aber kann in der „Gegnet“ „geahnt“ werden, was das Wesen des Denkens jenseits von Homogenisierung, Rechnen, Durchsetzen ist: „Die Gelassenheit zur Gegnet ahnen wir als das gesuchte Wesen des Denkens. ${ }^{\text {“81 }}$ Es liegt, so lernen wir bei Heidegger, im Sagen. Und dieses Sagen ist durchaus das Sagen der Tragödie: Es sagt, dass der Mensch das ungeheuerste aller Wesen ist.

Und doch zeigt sich in Heideggers Denken der Gegend ein Zug, der Hölderlin ebenso fremd ist wie Sophokles. Für Heidegger ist das Sich-Einlassen auf die Gegend zugleich Rückkehr - wie immer paradox jene auch formuliert ist. Ebenso wie sich die drei Wanderer in Heideggers Lehrdialog zunächst von der „Behausung der Menschen“ entfernen, um am Ende zu ihr zurückzukehren, so ist auch die Gegend oder „Gegnet“ selbst Rückkehr; sie ist, trotz ihrer Fremdheit, vertraut. Schon in Sein und Zeit leitet Heidegger die „Gegend“ aus dem „zunächst Zuhandenen“ ab, dem „Zeug“, welches „als Zeug wesenhaft an- und untergebracht, aufgestellt, zurechtgelegt ist.“ Und er folgert: „Dieses im besorgenden Umgang umsichtig vorweg im Blick gehaltene Wohin des möglichen zeughaften Hingehörens nennen wir die Gegend. “82 Gegend bezieht sich also auf ein „Hingehören“. In dem späteren Lehrdialog wird über die Dinge, die in der „Gegnet erscheinen“ gesagt, dass sie „nicht mehr den Charakter von Gegenständen haben“683: „Sie ruhen in der Rückkehr zur Weile der Weite ihres Sichgehörens“ ${ }^{84}$ Lässt schon die Beschreibung der „plazierbaren Hingehörigkeit des Zeugganzen“ an eine wohlgeordnete schwäbische Küche denken, so wird die „Ruhe“ an dieser späteren Stelle mit dem Begriff des „Herdes“ benannt: In der Rückkehr, „die doch Bewegung ist“, kann „Ruhe sein“, „falls die Ruhe der Herd und das Walten aller Bewegung ist." ${ }^{\text {“85 }}$

Mit dem „Herd“ aber spricht Heidegger einen Begriff an, dem in seiner Vorlesung Hölderlins Hymnus „Der Ister" vom Sommersemester 1942 eine besondere Bedeutung zukommt, dort wo Heidegger eben versucht, das „Zwiegespräch“ zwischen Hölderlin und Sophokles - genauer: des Gesangs „Der Ister“ und des ersten Stasimon der Antigone - zu erläutern. Heidegger will dort

\footnotetext{
79 Martin Heidegger, „Wozu Dichter?“, in: ders., Holzwege. Gesamtausgabe, Bd. 5, Frankfurt/M., 1977, S. 269-320: 288.

80 Heidegger (1983), Zur Erörterung der Gelassenheit, S. 62.

81 Ebd.

82 Martin Heidegger, Sein und Zeit. Gesamtausgabe, Bd. 2, Frankfurt/M., 1977, S. 137.

83 Heidegger (1983), Zur Erörterung der Gelassenheit, S. 47.

${ }^{84}$ Ebd., S. 48.

85 Ebd.
} 
zeigen, das beide, wenn auch nicht das gleiche, so doch dasselbe dichten: das „Heimischwerden im Unheimischsein“"86, welches die beiden - und man darf ruhig ergänzen: die beiden einzigen - „historischen Menschentümer“, die Griechen und die Deutschen, zu bewältigen hätten. So versteht Heidegger den von Hölderlin besungenen Strom als „die Wanderschaft des geschichtlichen Heimischwerdens am Ort der Ortschaft. ${ }^{\text {“87 }}$ Und ebenso deutet er das erste Stasimon der Antigone: Nach einer bewundernswerten Untersuchung des deinón, des Unheimlichsten unter allem Unheimlichen, welches der Mensch sei, wendet sich Heidegger den letzten Versen des Chorlieds zu. Nachdem der Chor das Wirken dieses unheimlichsten Wesens beschrieben hat, das mit Schiffen ausfährt, sich die Tiere unterwirft, aber dem Tod nicht zu fliehen vermag, verstößt er schließlich jenen vom „Herd“, „der solches thut“ ${ }^{88}$ Heidegger folgert, dass es dem Chor in dieser schwierigen Stelle darum ginge, „zwischen dem eigentlichen Unheimischsein des Menschen und dem uneigentlichen zu scheiden und zu entscheiden. “69 Das eigentliche Unheimlichsein, so erfahren wir, ist das Heimischwerden im Unheimischen, das nur die geschichtlichen Menschentümer - Griechen und Deutsche - leisten können. Das uneigentliche Unheimlichsein aber sind der Amerikanismus und seine „Abart ${ }^{\star 90}$, der Bolschewismus.

Der Herd also kann deswegen für die Gegend stehen, weil auch jene zum Heimischwerden im Unheimlichen aufruft. Als die Sprechenden am Ende jenes Gesprächs wieder in die Nähe der menschlichen „Behausung“ zurückkehren, spricht der Lehrer die „Erfahrung unseres Gesprächs“ dahingehend aus, „daß wir in die Nähe der Gegnet kommen und ihr so zugleich fern bleiben, indes das Bleiben allerdings Rückkehr ist. ${ }^{“ 91}$

\section{Aufschub, Zögern und Halt}

Auch wenn also in Heideggers Rede von der „Gelassenheit“, vom Wollen des Nicht-Wollens und von der Sammlung vieles anklingt, was Empedokles in seinen Abschiedsworten ausspricht: Anders als die Heidegger“sche „Gegnet“ ist die Gegend am Ätna, in die Empedokles eingetreten ist, wie auch jene heilige Gegend, in die es Ödipus verschlagen hat, kein Ort der Rückkehr. Sie ist vielmehr der Ort, von dem aus jede Rückkehr unmöglich geworden ist. In den „Anmerkungen zum Oedipus“ spricht Hölderlin davon, dass der „Mensch“ in

\footnotetext{
${ }^{86}$ Martin Heidegger, Hölderlins Hymnus „Der Ister“. Gesamtausgabe, Bd. 53, Frankfurt/M., 1993, S. 151.

87 Ebd., S. 39.

88 So Hölderlins Übersetzung: „Antigonä“, in: ders. (1988), Sophokles, S. 261-407: 301: „Nicht sei am Heerde mit mir, / Noch gleichgesinnet, / Wer solches tut.“

89 Heidegger (1993), Hölderlins Hymnus „Der Ister“, S. 46.

90 Ebd., S. 86.

91 Heidegger (1983), Zur Erörterung der Gelassenheit, S. 69.
} 
der Tragödie „der kategorischen Umkehr folgen muß, hiermit im Folgenden schlechterdings nicht dem Anfänglichen gleichen kann. ${ }^{\text {“92 }}$ Kein Kreis schließt sich, kein Widerspruch hebt sich auf.

Die Gegend ist aber auch keine Heimat, in deren Kontext Heidegger nicht ohne Grund seinen Vortrag zur „Gelassenheit“ stellen wird ${ }^{93}$ : Ödipus ist ein Fremder in Athen; und nur ihm als Fremdem kann die Gastfreundschaft Theseus“ erwiesen werden. „Heimisch“ werden kann Ödipus in dieser heiligen Gegend, auf der Schwelle der Stadt, die er nicht betritt, nur als Toter. Und auch Empedokles irrt auf seinem Weg als Fremder durch eine als feindselig und gefährlich beschriebene Natur, wird - im ersten Entwurf - von einem Bauern nicht in den Herrgottswinkel eingeladen ${ }^{94}$, sondern verjagt, und er verweigert Pausanias“ Ansinnen, in der „neuen Heimath“泣 eine zumindest irgendwie an eine Behausung erinnernde Höhle zu beziehen: Auch er wird seine Aufnahme im Ätna, den er „,g]astfreundlich" ${ }^{\text {“96 }}$ nennt, einzig als Toter finden. Das Geschehen im dritten Entwurf von Hölderlins Tragödienfragment ist statisch, undramatisch; doch von dem unausweichlichen, wenngleich nicht ausgeführten Ende wird es in eine innere Bewegung versetzt. Von diesem Ende her ist alles zu verstehen, was sich auf der Bühne vollzieht, oder anders: Alles Geschehen auf der Bühne hält dieses Ende nur für eine Weile zurück. Ganz wie Barthes es für die Tragödien Racines festgestellt hat ${ }^{97}$, ist der Tod im Empedokles - und ganz besonders im dritten Entwurf, der nach jeder möglichen dramatischen Intrige spielt - solange noch nicht da, wie gesprochen wird: Er befindet sich aber unmittelbar jenseits der Bühne und jenseits der Worte. Die „Gegend am Aetna“ ist dem Tod vorgelagert, ist selbst raumzeitlicher Aufschub des Todes. Geografisch ist diese Gegend jener Raum, der den Krater, die flüssige Materie und die lebensvernichtende Hitze umschließt, ein Raum mit unklaren Grenzen, denn es liegt im Begriff der „Gegend“, dass jener „manigfach angewandt [wird], um von irgend einem räumlichen ganzen ein theilgebiet ungefähr zu bestimmen “. ${ }^{98}$ Definiert ist einzig die Mitte dieser Gegend, der Krater, eine dem Leben vollkommen unzugängliche Landschaft, Bruchstelle in der dünnen Kruste, auf der allein irdisches Leben möglich ist. Räumlich wie zeitlich, raumzeitlich, ist die „Gegend“ im Empedokles eine Hem-

92 Hölderlin (1988), Anmerkungen zum Oedipus, S. 258.

93 Heidegger hielt den Vortrag am 30.10.1955 in seiner Heimatstadt Meßkirch, dort heißt es auch: „Gehört nicht zu jedem Gedeihen des gediegenen Werkes die Verwurzelung im Boden einer Heimat?“, Heidegger (2000), Gelassenheit, S. 521.

94 „Wenn ich zur Zeit der Arbeitspause abends mit den Bauern auf der Ofenbank sitze oder am Tisch im Herrgottswinkel, dann reden wir meist gar nicht.“ Martin Heidegger, „Schöpferische Landschaft: Warum bleiben wir in der Provinz?“, in: ders., Aus der Erfahrung des Denkens. Gesamtausgabe, Bd. 13, Frankfurt/M., 1983, S. 9-13: 10.

95 Hölderlin (1985), Empedokles, S. 932 (,Dritter Entwurf“).

96 Ebd., S. 931.

97 Vgl. Roland Barthes, Sur Racine, Paris, 1963.

98 Grimm/Grimm (1897), Deutsches Wörterbuch, Sp. 2232. [Herv. i. O.] 
mung des Gangs zum Tode. Der „ewig menschenfeindliche[] Naturgang “999, wie Hölderlin es in den „Anmerkungen zur Antigonä“ formulieren wird, wird suspendiert, die auf den Tod zulaufende Sehnsucht nach dem All-Einen wird aufgehalten, indem sie sich aussprechen kann.

Denn, um es noch einmal ganz anders zu formulieren: Der Gegend entspricht die Sprache selbst, insofern sie nichts weiter ist als Aufschub, différance: Es ist die Sprache am Ende der Bahn, die keinen Weg zurück weist, aber einen Halt, ein Innehalten oder einen prekären Aufenthalt stiftet. ${ }^{100}$ Rainer Nägele hat vielfach auf die Verwandtschaft zwischen Hölderlins Poetologie und jenen spekulativen Überlegungen verwiesen, die der späte Freud in Jenseits des Lustprinzips über den Todestrieb angestellt hat: „[K]ein Wesen darf um des Lebens willen auf geradem Weg zum Ursprung zurück. Dieser Weg muss gehemmt und abgebogen werden, damit Leben sei. “101 Und in diesem Sinne versteht Nägele auch das eigentümliche Fließen des Ister (der Donau), von dem es in Hölderlins spätem Gesang heißt, er scheine „aber fast / Rükwärts zu gehen“"102, als eine solche Hemmung, als Umweg. Heidegger hatte dieses Fließen mit einem anderen Wort beschrieben: als Zögern. ${ }^{103}$ Letztlich, so scheint mir, ist die Zeit des dritten Entwurfs des Empedokles, aber auch die Zeit der Szenen aus dem zweiten Akt des ersten Entwurfs, die Zeit des Zögerns: und stattfinden kann das Zögern in der Gegend. Im ersten Entwurf bereits, kurz bevor jener abbricht, richtet Empedokles, nachdem er die Krone abgelehnt und das „Wort“ von Aufbruch und Vergessen als Gabe an die Agrigentiner verteilt hat, noch einmal ein Abschiedswort an jene:

Lebt wohl! Es war das Wort des Sterblichen,

Der diese Stunde liebend zwischen euch

Und seinen Göttern zögert, die ihn riefen.

99 Hölderlin (1988), Anmerkungen zur Antigonae, S. 418.

100 Als Sprache, die das Feuer aufhält, die es davon abhält, die Welt in Brand zu setzen, ähnelt Hölderlins Dichtung dem von Werner Hamacher untersuchten „Halt!“ des „Knaben Lenker“ aus der Mummenschanz-Szene des Faust II, die den Weltenbrand - hier als Verwandlung aller Phänomene in Kredit - aufhält. Siehe hierzu Werner Hamacher, „Faust, Geld“, in: Ernst Behler/Jochen Hörisch/Günter Oesterle (Hg.), Athenäum - Jahrbuch für Romantik, Nr. 4, München, 1994, S. 131-187: 180-187. „Die Schrift interveniert als Halt: als Unterbrechung der Maskenparade und ihrer allegorischen Illusion, als Aufhaltung und Verzögerung des Blicks in den Feuerquell, als Eindämmung und Zurückhaltung des Brands und als Behalten der Erinnerung an ihn" (S. 182).

${ }^{101}$ Rainer Nägele, Hölderlins Kritik der poetischen Vernunft, Basel, Weil am Rhein, Wien, 2005, S. 94.

${ }^{102}$ Friedrich Hölderlin, Gesänge. Frankfurter Ausgabe, Bd. 8, Frankfurt/M., Basel, 2000, S. 901.

103 „Aber der Ister geht nicht nur rückwärts. Inwiefern entsteht überhaupt der Schein, daß er fast rückwärts geht? Weil er zögernd fließt: dieses Zögern kann nur daraus kommen, daß dem ursprünglichen Entspringen eine geheime Gegenströmung entgegendrängt.“ Heidegger (1993), Hölderlins Hymnus „Der Ister“, S. 178. Diese Gegenströmung aus dem Osten wird freilich von Heidegger abermals auf die geschichtliche Aufgabe der historischen Menschentümer der Deutschen und Griechen hin gedeutet. 
Am Scheidetage weissagt unser Geist,

Und wahres reden, die nicht wiederkehren. ${ }^{104}$

Diese Stunde des Zögerns ist die Aufführung der Tragödie. Empedokles kehrt nicht wieder; aber auf der Bühne verweilt er zögernd eine Weile. Am Ende der Bahn angekommen, spricht er, obgleich seine Zunge „zum sterblichen Gespräche fast" nicht mehr dienen möchte.

In diesen letzten Worten ist sein Verschwinden bereits vorgezeichnet. Empedokles verweigert die Krone und überlässt es den Vielen, in Zukunft ihre Geschicke selbst zu bestimmen. Er steht in der Gegend der Bühne, um sie zu verlassen. Die Schwelle, auf der das Stück stattfindet, ist auch die Schwelle zu einer neuen Zeit. In einem Akt, der an Theaterexperimente des 20. Jahrhunderts erinnert, wird die Bühne letztlich als Ort der monarchischen Repräsentation dekonstituiert; in der Gegend, jenseits der Repräsentationsbühne, wird die souveräne Macht an die Vielen, den demos übergeben. Ob jene aber noch eine Bühne finden können, wird fortan fragwürdig sein. Der Chor der Agrigentiner, der auf die letzten Worte des Empedokles folgen soll, wird von Hölderlin nicht ausgearbeitet. „Viel hat von Morgen an / Seit ein Gespräch wir sind und hören voneinander, / Erfahren der Mensch; bald sind [wir] aber Gesang “ ${ }^{\star 105}$, lauten berühmte Verse aus Hölderlins „Friedensfeier“. Im Empedokles aber bleibt dieser kommende Gesang aus; der Chor, der die „Zukunft“ oder die „Neue Welt“ besingen soll, bricht ab. Die Feier, in der Rousseau und viele Nachfolger das Repräsentationstheater aufheben wollten, findet nicht statt. Einzig die Schwelle, die das Leben vom Tod, die alte Welt von der neuen, das Gespräch vom Gesang trennt, wird exponiert: als Gegend eines flüchtigen Verweilens, eines Zögerns und Sprechens.

\section{Literatur}

Aristoteles, Poetik, Stuttgart, 1994.

Barthes, Roland, Sur Racine, Paris, 1963.

Benjamin, Walter, „Was ist das epische Theater? [1] Eine Studie zu Brecht“, in: ders., Gesammelte Schriften, Bd. II, Frankfurt/M., 1999, S. 519-531.

Birkenhauer, Theresia, Legende und Dichtung. Der Tod des Philosophen und Hölderlins Empedokles, Berlin, 1996.

Dies., „Empedokles“, in: Johann Kreuzer (Hg.), Hölderlin-Handbuch. Leben - Werk Wirkung, Stuttgart, Weimar, 2002, S. 198-223.

\footnotetext{
${ }^{104}$ An dieser Stelle folge ich der von der Frankfurter Ausgabe abweichenden Textkonstitution der Münchner Ausgabe: Friedrich Hölderlin, Sämtliche Werke und Briefe, Bd. 1, München, 1993, S. 823.

${ }^{105}$ Hölderlin (2000), Gesänge, S. 643. [Einfügung vom Herausgeber.]
} 
Campe, Rüdiger, „Erscheinen und Verschwinden. Metaphysik der Bühne in Hölderlins ,Empedokles““, in: Bettine Menke/Christoph Menke (Hg.), Tragödie, Trauerspiel, Spektakel, Berlin, 2007, S. 53-71.

Derrida, Jacques, Chôra, Wien, 1990.

Grimm,Jacob/Grimm,Wilhelm, Deutsches Wörterbuch, Leipzig, 1897.

Hamacher, Werner, „Faust, Geld“, in: Ernst Behler/Jochen Hörisch/Günter Oesterle (Hg.), Athenäum - Jahrbuch für Romantik, Nr. 4, München, 1994, S. 131-187.

Heidegger, Martin, Sein und Zeit. Gesamtausgabe, Bd. 2, Frankfurt/M., 1977.

Ders., Hölderlins Hymnus „Der Ister“. Gesamtausgabe, Bd. 53, Frankfurt/M., 1993.

Ders., „Wozu Dichter?“, in: ders., Holzwege. Gesamtausgabe, Bd. 5, Frankfurt/M., 1977, S. 269-320.

Ders., „Schöpferische Landschaft: Warum bleiben wir in der Provinz?“, in: ders., Aus der Erfahrung des Denkens. Gesamtausgabe, Bd. 13, Frankfurt/M., 1983, S. 9-13.

Ders., „Zur Erörterung der Gelassenheit. Aus einem Feldweggespräch über das Denken“, in: ders., Aus der Erfahrung des Denkens. Gesamtausgabe, Bd. 13, Frankfurt/M., 1983, S. 37-74.

Ders., „Logik. Heraklits Lehre vom Logos“, in: ders., Heraklit. Gesamtausgabe, Bd. 55, Frankfurt/M., 1994, S. 183-402.

Ders., „Gelassenheit“, in: ders., Reden und andere Zeugnisse. Gesamtausgabe, Bd. 16, Frankfurt/M., 2000, S. 517-529.

Hölderlin, Friedrich, Sämtliche Werke und Briefe, München, 1993.

Ders., Gesänge. Frankfurter Ausgabe, Bd. 8, Frankfurt/M., Basel, 2000.

Ders., „Das lyrische dem Schein nach idealische Gedicht...“, in: ders., Entwürfe zur Poetik. Frankfurter Ausgabe, Bd. 14, Frankfurt/M., 1979, S. 343-372.

Ders., Empedokles. Frankfurter Ausgabe, Bd. 12 u. 13, Basel, Frankfurt/M., 1985.

Ders., „Oedipus der Tyrann“, in: ders., Sophokles. Frankfurter Ausgabe, Bd. 16, Basel, Frankfurt/M., 1988, S. 73-245.

Ders., „Anmerkungen zum Oedipus“, in: ders., Sophokles. Frankfurter Ausgabe, Bd. 16, Basel, Frankfurt/M., 1988, S. 247-258.

Ders., „Antigonä“, in: ders., Sophokles. Frankfurter Ausgabe, Bd. 16, Basel, Frankfurt/M., 1988, S. 261-407.

Ders., „Anmerkungen zur Antigonae“, in: ders., Sophokles. Frankfurter Ausgabe, Bd. 16, Basel, Frankfurt/M., 1988, S. 409-421.

Ders., „Zwei Proben aus Ödipus auf Kolonos“, in: ders., Sophokles. Frankfurter Ausgabe, Bd. 16, Basel, Frankfurt/M., 1988, S. 423-433.

Lacan, Jacques, Die Ethik der Psychoanalyse. Das Seminar, Buch VII, Weinheim, Berlin, 1996.

Lacoue-Labarthe, Philippe, Poetik der Geschichte, Berlin, 2004.

Ders., „Das Theater Hölderlins“, in: ders., Metaphrasis. Das Theater Hölderlins. Zwei Vorträge, Zürich, Berlin, o.J., S. 45-70.

Nägele, Rainer, Hölderlins Kritik der poetischen Vernunft, Basel, Weil am Rhein u. Wien, 2005.

Passow, Franz, Handwörterbuch der griechischen Sprache, Bd. 2, 2, Darmstadt, 1993. [1857]

Primavesi, Patrick, „,,Seiner Hände Spiel‘. Gesten des Entzugs in Hölderlins Empedokles-Fragmenten“", in: Margret Egidi (Hg.), Gestik. Figuren des Körpers in Text und Bild, Tübingen, 2000, S. 259-268.

Schäfer, Martin Jörg, Szenischer Materialismus. Dionysische Theatralität zwischen Hölderlin und Hegel, Wien, 2003. 
Szondi, Peter, „Versuch über das Tragische“, in: ders., Schriften, Bd. I, Frankfurt/M., 2006, S. 149-260.

Weber, Samuel, „The Place of Death: Oedipus at Colonus“, in: ders., Theatricality as Medium, New York, NY, 2004, S. 141-159. 


\title{
AUSSTREIGHUNG DER BÜHNE. ÜBERLEGUNGEN ZUM ORT DER BÜHNE IM ANSCHLUSS AN DERRIDAS CHŌRA
}

\begin{abstract}
Ein Schauplatz des Fremden ist das Theater eben nicht nur, weil es Fremdes zur Darstellung bringt, sondern weil es selbst aus der Fremde kommt.

Das Bühnengeschehen umkreist etwas, das sich der direkten Darstellung entzieht. Nicht erst der Traum findet, wie Freud zeigt, auf einem ,anderen Schauplatz' statt, sondern schon der Schauplatz des Theaters hat etwas Doppelbödiges. ${ }^{1}$
\end{abstract}

Das Theater, und mit ihm die Bühne, kommt aus der Fremde. Das Fremde, darauf verweist Bernhard Waldenfels immer wieder, ist zuallererst gekennzeichnet durch seinen topischen Charakter: Es ist nicht abzulösen von einer gewissen Örtlichkeit; es ist das, was nicht hier ist, das, was außerhalb des eigenen Bereiches liegt. Der Ort des Fremden lässt sich nicht kartographieren, nicht in ein „Ortsnetz einzeichnen, in dem wir uns frei bewegen, da er nur über eine Schwelle hinweg, also eigentlich gar nicht erreichbar ist“. ${ }^{2}$ Die Bühne, verstanden als Ort, der aus der Fremde kommt, als Fremdort, ist ein Topos mit atopischen Zügen - eine „topische Un-gestalt“. ${ }^{3}$ Und als diese „topische Ungestalt“, als Ort, der sich entzieht, gibt die Bühne einem Geschehen statt, das sich einer direkten Darstellung verweigert, einem Geschehen, das ihr fremd ist und sich nicht restlos aneignen lässt. Vor dem Hintergrund der Beobachtung dieser doppelten Fremdheit soll die Bühne im Folgenden als zwiefache Struktur eines Statthabens und eines Stattgebens in den Blick genommen werden: Wo hat die Bühne ihre Statt und wem oder was kann sie stattgeben - und vor allem: auf welche Weise?

\footnotetext{
Bernhard Waldenfels, Sinne und Künste im Wechselspiel. Modi ästhetischer Erfahrung, Berlin, 2010, S. 242.

2 Bernhard Waldenfels, Topographien des Fremden, Frankfurt/M., 1997, S. 24.

3 Ebd., S. 108. Ich entlehne den Begriff, den Bernhard Waldenfels zur Beschreibung des Paradoxes des Fremden gebraucht, hier zur Beschreibung der Bühne, gerade weil auch sie meines Erachtens unter diese paradoxe Struktur des Fremden fällt und als Fremdort oder Nicht-Ort, dessen Nicht keine einfache Negation bedeutet, beschrieben werden kann.
} 
Fragt man im geschlossenen Theaterraum mit klassischer Guckkastenbühne nach dem Ort der Bühne, scheint die Antwort zunächst einfach: Vorne, dem Zuschauerraum strikt gegenüber und klar begrenzt vom Proszeniumsbogen, befindet sich die Bühne, der Bühnenkasten, in und auf dem sich das Geschehen abspielt. In den Rahmen des Guckkastens eingefasst bzw. gebannt und scheinbar genau lokalisierbar, scheint die beschriebene doppelte Fremdheit der Bühne etwas von ihrer Beunruhigung verloren zu haben. In vielen zeitgenössischen Performances dagegen, gerade auch denjenigen, die den geschlossenen Theaterraum verlassen und im öffentlichen Raum arbeiten, taucht die Frage nach dem Ort der Bühne in verunsichernder Weise wieder auf, und zwar gerade deshalb, weil sie es ermöglichen, nach dem „Wo“ der Bühne zu fragen, ohne darauf eine eindeutige Antwort geben zu können. ${ }^{4}$ Ein Beispiel dafür wäre die 2008 in Regie von Ulrich Greb am Schlosstheater Moers entstandene Arbeit Hotel Europa. Mit ihr wagt sich das Theater in den Stadtraum, konkret in das ehemalige, im Zentrum von Moers gelegene Gefängnis, vor und setzt sich am historischen Ort mit dem Zeitraum auseinander, in dem das als Justizvollzugsanstalt errichtete Gebäude als Abschiebehaftgefängnis fungierte. Die Inszenierung wäre für die hier zu erörternde Fragestellung allerdings in zweierlei Hinsicht aufschlussreich: Denn einerseits lässt sie die Bühne in ihren atopischen Zügen aufscheinen und ermöglicht es so, die Frage nach dem Ort der Bühne, ihrem Statthaben, erneut zu stellen. Andererseits erliegt die Inszenierung aber immer wieder der Versuchung, das Fremde, um das es ihr geht, verkörpern, vergegenwärtigen, thematisieren zu wollen. Anstatt auf den Anspruch des Fremden zu antworten und es so in seiner Fremdheit zu belassen, missversteht sie das Moment des Stattgebens als eine Art „subjektiver“ Geste, versucht sie, das Fremde direkt darzustellen und macht es sich so immer wieder zu eigen. Da sich die Frage der doppelten Fremdheit der Bühne an dieser Inszenierung in besonderer Weise veranschaulichen lässt, möchte ich einen kurzen Seitenblick auf Hotel Europa werfen, bevor ich anschließend in enger Auseinandersetzung mit Derridas Essay chōra und Bernhard Waldenfels' Entwurf einer responsiven Ethik die Momente des Statthabens und des Stattgebens der Bühne theoretisch ausarbeite.

In der Inszenierung Hotel Europa werden die Zuschauer über einen Seiteneingang in die ehemalige Haftanstalt geführt. Lange Gänge mit jeweils zwan-

4 Genannt sei hier als ein Beispiel unter vielen anderen das vom Deutschlandradio Kultur entwickelte Projekt RADIOORTUNG - Hörspiele für Selbstläufer, für das unter anderem LIGNA (Verwisch die Spuren!, Berlin, 2010), Rimini Protokoll (50 Aktenkilometer, Berlin, 2011) und Hofmann \& Lindholm (Das Archiv der zukünftigen Ereignisse, Köln, 2011) Arbeiten entworfen haben. In allen drei Inszenierungen werden die Zuschauer bzw. -hörer mit GPS-fähigen Handys ausgestattet durch den Stadtraum geschickt. Öffentlicher Raum und „Bühnenraum“ schieben sich ineinander und überschreiben sich gegenseitig. Die Bühne scheint kaum mehr lokalisierbar. 
zig Zellen über vier Etagen. Nur eine Zelle ist als Musterzelle im Originalzustand verblieben; die anderen sind Installationsfläche. Zelle für Zelle arbeiten sich die Zuschauer, zunächst ohne Führung oder Kommentar, bis zur nächsten Etage vor. Erst dann beginnt die Inszenierung, die keine geschlossene Handlung hat. Während der kurzen Szenen, die sich hauptsächlich aus Gesprächen mit ehemaligen Wärtern, wenigen Briefen früherer Gefangener sowie Bruchstücken aus Kafkas Bau und Der Process zusammensetzen, befinden sich die Zuschauer auf unterschiedlichen Ebenen und an verschiedenen Enden der Gänge. Der Blick ist fragmentiert durch Treppenstufen, Geländer, Gitter. Die normative Architektur wird aufgesprengt. Die Bühne scheint kaum verortbar, ihr fehlt es an Rahmung und einer einheitlichen Perspektive: Befindet sich die Bühne dort, wo das szenische Spiel gerade auftaucht? Befindet sie sich dort, wo ich gerade bin oder soweit mein Blick reicht, bzw. an dem Ort, auf den ich meinen Blick gerade richte oder geht sie in meinem Rücken und an der Peripherie meines Blickfeldes weiter? Erstreckt sie sich über alle Räume der Haftanstalt oder darüber hinaus? Inwiefern kann überhaupt von „Bühne“ gesprochen werden?

Aber obwohl die Inszenierung auf die „topische Un-gestalt“ der Bühne, auf die Bühne als Fremdort aufmerksam macht, tilgt sie durch die Art ihrer Darstellung, das Fremde, dem sie eigentlich Platz einräumen möchte. Immer wieder versucht sie, die Häftlinge zu vergegenwärtigen und überspielt so ihr Nicht-(mehr-)anwesend-Sein. Immer wieder eignet sie sich deren Geschichten an und bringt so das Moment des Entzugs selbst zum Verschwinden. Der Versuch, die ehemaligen Häftlinge und ihre Erfahrungen zu verkörpern, führt letztlich dazu, dass diese keinen Platz mehr haben, nicht zu Wort kommen. Und dieses Nicht-zu-Wort-Kommen bringt Hotel Europa zum Schweigen, anstatt es zu markieren. Die Moerser Inszenierung verzichtet zwar auf eine Rahmung der Bühne, aber sie etabliert ein „durch den Rahmen [der Darstellung, M. H.] geschlossenes Vergessen“. 5

Die Frage, die sich im Anschluss an diese kurzen Überlegungen zu Hotel Europa stellt und die meine eingangs formulierte Frage nach der doppelten Struktur der Bühne aus der Perspektive einer konkreten Inszenierung wieder aufgreift, lautet: Wo befindet sich das zwar im Zentrum der Stadt gelegene, aber als Ort des Ausschlusses funktionierende ehemalige Abschiebehaftgefängnis, wo befindet sich im Rahmen der Inszenierung die Bühne an diesem Ort und in welchem Verhältnis steht sie zu dem „Wo“, auf das sie versucht zu antworten?

\footnotetext{
Jacques Derrida, Dissemination, in: ders., Dissemination, übers. v. Hans-Dieter Gondeck, hg.
} v. Peter Engelmann, Wien, 1995, S. 323-434: 334. 
Zunächst scheint die Frage nach dem „Wo“ unspektakulär. Tatsächlich birgt sie aber ein gewisses Potenzial, das ich für die hier zu erörternde Problematik fruchtbar machen möchte. In seiner Schrift Ortsverschiebungen Zeitverschiebungen verweist Bernhard Waldenfels auf das vierte Kapitel der aristotelischen Kategorienschrift, die

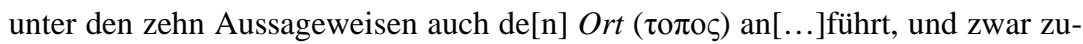
nächst nicht in der üblichen substantivischen Form, sondern in Form des unbestimmten Pronomens irgendwo ( $\pi \mathrm{ov})$. Das Pronomen erhält seine Bestimmung, wenn die zugehörige Wo-Frage beantwortet wird, etwa mit ,Sokrates ist im Lykeion` oder ,auf dem Markt‘. Es kommt Aristoteles in diesem Zusammenhang einzig darauf an zu zeigen, daß der Ortsangabe eine spezifische Aussageform entspricht. Mit ihrer Hilfe können wir sagen, wo etwas ist, nicht aber, was oder wie groß etwas ist. Mit diesem kargen Resultat endet die Kategorienlehre, nicht aber die Ortsanalyse. Denn als Philosophen wollen wir ja nicht bloß wissen, wie wir Ortsangaben machen, sondern, was es mit dem Ort selbst auf sich hat. So beginnt die Ortsabhandlung in Buch IV der Physik mit der gewohnten Frage: ,Was ist ein Ort?‘ Die anfängliche Wo-Frage tritt völlig hinter der Was-Frage zurück. Was zunächst als Prädikat behandelt wurde, wird nun als ein Seiendes besonderer Art angesetzt. ${ }^{6}$

Mit der Frage „Was ist der Ort?“ bewegt sich Aristoteles wieder im Modus der sokratischen Frage „Was ist x?“, die für das metaphysisch-philosophische Denken kennzeichnend ist und auf die Platon mit der Konzeption seiner Ideenlehre geantwortet hat. Die „Wo“-Frage scheint dagegen quer zur „Was“-Frage zu verlaufen, also zur Frage nach dem Wesen einer Sache. Sie spricht den Ort nicht direkt als Seiendes an, denkt ihn nicht in erster Linie als Vorhandenes. Ähnlich verhält es sich mit dem von Platon im Timaios-Dialog entwickelten und von Jacques Derrida aufgegriffenen Begriff $\chi \omega ́ \rho \alpha^{7}$, der jenseits oder - in einem nicht zeitlich gedachten Sinn - „vor“ der metaphysischen Urbild-Abbild-Struktur liegt. ${ }^{8}$

Im Ausgang von der Frage „Wo?“ und in enger Auseinandersetzung mit Jacques Derridas Aufsatz chōra möchte ich im Folgenden den von Derrida entwickelten Begriff chōra nachzeichnen, um ihn für das Denken der Bühne fruchtbar zu machen. Dabei versuche ich, das Moment des Statthabens der

6 Bernhard Waldenfels, Ortsverschiebungen Zeitverschiebungen, Frankfurt/M., 2009, S. 34 f. [Herv. i. O.]

7 Im Folgenden werde ich $\chi \omega \dot{\rho} \rho \alpha$ in der griechischen Schreibweise verwenden, wenn ich mich direkt auf den platonischen Dialog Timaios beziehe, die lateinische Umschrift chōra werde ich hingegen in der Auseinandersetzung mit Derridas Essay chōra gebrauchen. Ähnlich werde ich mit den anderen entscheidenden Begriffen verfahren, die Platon verwendet und auf die Derrida rekurriert. Wenn ich die griechische Schreibweise für die Kenntlichmachung eines Bezugs auf Platons verwende, werde ich allerdings bei der ersten Nennung die lateinische Umschrift in Klammern hinzufügen.

8 Vgl. Jacques Derrida, chōra, in: ders., Über den Namen. Drei Essays, übers. v. Hans-Dieter Gondeck/Markus Sedlaczek, hg. v. Peter Engelmann, Wien, 2000, S. 123-170: 164. 
Bühne im Anschluss an Derridas chōra als einen nicht zu verzeichnenden Ort und als Ausstreichung zu denken. Drei Aspekte von Derridas Relektüre des platonischen Timaios scheinen dabei besonders relevant: 1) Der Versuch, chō$r a$ als ein jenseits der metaphysischen Urbild-Abbild-Struktur Gelegenes zu denken, 2) der durch das Denken von chōra aufkommende Ruf nach einer dritten Diskursgattung beziehungsweise einer anderen Darstellung und 3) die Verschränkung von chōra mit einer Politik der Plätze und der damit einhergehende Versuch, Sokrates als chōra ähnlich und damit als Ausstreichung zu denken. Abschließend möchte ich dann das zweite Moment der Bühne, nämlich ihr Stattgeben, von Bernhard Waldenfels' Überlegungen zur Möglichkeit eines Antwortens auf den Anspruch des Fremden aus in den Blick nehmen.

\section{Statthaben der Bühne als Ausstreichung}

\section{a) chōra: diesseits/jenseits von Urbild und Abbild}

Der um 360 v. Chr. verfasste Dialog Timaios zählt zu Platons Spätwerk. Gemeinsam mit seinen drei Gesprächspartnern Timaios, Kritias und Hemokrates stellt Sokrates in diesem Dialog die Frage nach dem Anfang oder Ursprung des Kosmos. Er beschreibt dessen Erschaffung und Einrichtung aus naturphilosophischer, theologischer und metaphysischer Perspektive.

Die Kosmogenie des Timaios durchläuft den Zyklus des Wissens über alle Dinge. Deren enzyklopädisches Ziel muß die Endstellung eines logos markieren, der alles das, was ist, zum Sujet hat [...]. Dieser enzyklopädische logos ist eine allgemeine Ontologie, die alle Typen von Sein behandelt; sie beinhaltet eine Theologie, eine Kosmologie, eine Physiologie, eine Psychologie und eine Zoologie. Sterbliche oder Unsterbliche, Göttliche oder Menschliche, Sichtbare und Unsichtbare sind darin situiert. ${ }^{9}$

Im ersten Teil seiner Abhandlung über die Erschaffung und Einrichtung der Welt unterscheidet Timaios, der Hauptredner dieses Dialogs, das immer Seiende vom immer Werdenden. Das immer Seiende kennt kein Werden und ist nur durch das „an der Vernunft orientierte Denken“10 erfassbar. Das immer Werdende ist dagegen niemals und wird lediglich „durch auf vernunftlose Wahrnehmung bezogene Meinung erfahrbar". ${ }^{11}$ Der Demiurg gilt als Baumeister des Kosmos, der diesen nach dem Idealbild der platonischen Ideen, d. h. mit Blick auf das immer Seiende und mit sich selbst Identische, geordnet und gestaltet hat. Im Fortgang seiner Erläuterungen zeichnet Timaios die vollendete Konstruktion des Kosmos detailliert nach.

\footnotetext{
Ebd., S. 139.

Platon, Timaios, übers. u. hg. v. Rudolf Rehn/Thomas Paulsen, Stuttgart, 2003, S. 35.

1 Ebd.
} 
Erst in der Mitte der Abhandlung öffnet sich der ,weit aufgesperrte [...] Mund des quasi verbotenen Diskurses“12 über $\chi \omega ́ \rho \alpha$. Denn obwohl Timaios mit der Rede vom Demiurgen und der Erschaffung des Kosmos nach dem Urbild der Ideen den Anfang der Welt zu schildern vorgegeben hat, stellt Timaios in der Mitte der Untersuchung die Ursprünglichkeit dieses Anfangs infrage: „So müssen wir nun wieder zurückgehen und, indem wir für eben diese Dinge einen neuen passenden Anfang wählen, wie damals so auch jetzt mit dem neuen Gegenstand einen neuen Anlauf nehmen. ${ }^{\text {“13 }}$

Wurde bislang nur das durch die Vernunft Geschaffene aufgezeigt, muss jetzt, quasi nachträglich, auf einen Anfang vor dem Anfang zurückgegangen werden. Denn der Kosmos ist als eine Vermischung von Notwendigkeit und Vernunft zustande gekommen, bei der die Vernunft letztlich die Oberhand behalten hat. Der griechische Begriff $\alpha \nu \alpha ́ \gamma \kappa \eta$ (anankē), der hier mit Notwendigkeit übersetzt wird, bedeutet ursprünglich Zwang. Er meint eine allem Geschehen zugrunde liegende, teils schicksalhafte Notwendigkeit. Im Timaios ist

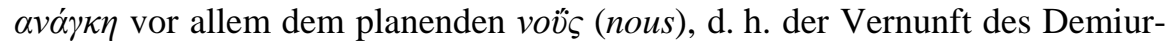
gen, entgegengestellt.

Um diesen vorausliegenden Anfang beschreiben zu können, muss - so Timaios - neben den bislang unterschiedenen Seinsgattungen des Urbilds beziehungsweise Musters und des Abbilds eine schwierige, dunkle und vage Form untersucht und durch Worte zum Ausdruck gebracht werden, die er $\chi \omega ́ \rho \alpha$ nennt. Metaphorisch tastend versucht sich Timaios diesem dritten $\gamma$ ćvoৎ (genos), also dieser dritten Gattung/diesem dritten Geschlecht, anzunähern. ${ }^{14}$ Sie stellt ein drittes Geschlecht hinsichtlich der ontologischen Seinsgattungen Idee und Ding dar und scheint sexuell konnotiert. Er beschreibt sie als Amme, die alles Werdende auf bzw. in Empfang nimmt ${ }^{15}$, als Mutter im Vergleich zum

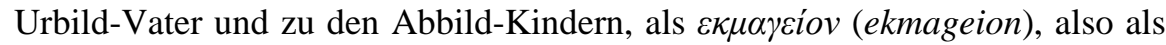
Abdruck- oder Spurenträger. Sie ist das, worin das Werdende als Abbild der Ideen wird und seinen Platz erhält. Sie ist beständig, hat aber keine eigene Beschaffenheit. Sie zeigt sich nur an dem, was sie aufnimmt, ist gestaltlos und unsichtbar. Doch obwohl sie nicht zur intelligiblen Gattung der Ideen gehört, hat sie am Intelligiblen - wenn auch in einer aporetischen Weise - Anteil und ist selbst „durch eine Art von unechtem Denken ohne Bewusstsein erfassbar". ${ }^{16}$

12 Derrida (2000), chōra, S. 140.

13 Platon (2003), Timaios, S. 85.

14 Vgl. ebd., S. 85-101.

15 Platon verwendet die Begriffe $v \pi \circ \delta о \chi \eta ் ~(h y p o d o c h \bar{e}$ (1. Aufnahme, a) gastliche Bewirtung, b) Empfang eines feindlichen Heeres, c) konkr. das zur Aufnahme Gehörige; Ort der Aufnahme, Bergungsort, Quartier) und $\delta \delta^{\prime} \chi o \mu \alpha l$ (dechomai) [I. von Dingen: 1. annehmen, hinnehmen, 2. erwarten; II. von Personen: 1. aufnehmen (freundlich), 2. standhalten, es mit jemandem aufnehmen (feindlich)]. Bei der Übersetzung habe ich das von Wilhelm Gemoll und Karl Vretska herausgegebene Wörterbuch Gemoll. Griechisch-deutsches Schul- und Handwörterbuch (10. Aufl., Oldenburg, 2006) gehalten.

16 Platon (2003), Timaios, S. 97. 
Derridas Relektüre des platonischen Timaios ist eigentlich eine Relektüre der Parerga dieses Dialogs. Den Hauptteil, die Entstehung und Einrichtung des Kosmos, die Kosmogenie und den Zyklus des Wissens lässt er außen vor. Derrida konzentriert sich in seinem Essay vor allem auf die Präambel, die ein Gespräch vom Vortag - vermutlich die Politeia - reflektiert und den dort entworfenen Idealstaat als Nachbildung des in der Vorzeit bereits existierenden Staates Ur-Athen erkennt, und auf die Passage in der Mitte der Abhandlung, die versucht, diese kaum fassbare dritte Seinsgattung der $\chi \omega ́ \rho \alpha$ zu beschreiben.

In seinem Text, in dem Derrida den Timaios mit Platon gegen Platon liest oder zumindest gegen eine bestimmte Lektüretradition Platons -, verwendet er weder die griechische Schreibweise $\chi \omega ́ \rho \alpha$ noch eine der möglichen Übersetzungen, wie beispielsweise „Ort“, „Zwischenraum“, „Land“, „Gegend“, „Gebiet“ „Platz“ oder „Stelle“. chōra wird nur in der lateinischen Umschrift gebraucht und verliert im Laufe des Aufsatzes ihren bestimmten Artikel „die“. Derrida will chōra „vor jeder Übersetzung geschützt belassen. Eine Übersetzung [aber] scheint gewiss stets am Werk zu sein, sowohl innerhalb der griechischen Sprache als auch von der griechischen Sprache zu einer anderen“. ${ }^{17}$ Derridas chōra ist nicht mehr der platonische Topos $\chi \omega ́ \rho \alpha-$ auch wenn sie mit ihm noch eine Beziehung unterhält. Und obwohl chōra ebenso einen Bezug zu den Übersetzungen „Ort“, „Land“ oder „Stelle“ hat, ist sie nicht „Ort“, „Land“ oder „Stelle“. Jede Übersetzung würde in den Interpretationsnetzen verfangen bleiben, die Derrida zu unterlaufen versucht - wiewohl er weiß, dass ihnen nicht zu entkommen ist. Denn sie geben chōra erst ihre Form und ihre Bedeutung, indem sie ,in ihr die schematische Markierung ihres Abdrucks hinterlassen und in ihr das Sediment ihres Beitrags ablegen“ ${ }^{18}$ Es gibt keine Möglichkeit, chōra richtig anzusprechen, sie angemessen zu nennen oder zu rufen.

Wir werden niemals Anspruch darauf erheben, das richtige Wort für chōra anbieten zu können, weder, sie endlich nennen/rufen zu können, sie selbst, jenseits aller Umwege der Rhetorik, noch endlich an sie herangehen zu können, an sie selbst, auf das hin, was sie außerhalb jeden Gesichtspunktes, außerhalb jeder anachronischen Perspektive, gewesen sein wird. Die Tropik und der Anachronismus sind unvermeidlich. ${ }^{19}$

Man kann an chōra also nicht jenseits aller Rhetorik herangehen und sie in ihrer Selbstheit beschreiben, weil Identität und Selbstheit keine Kategorien sind, in denen sie gedacht werden kann. Keine Übersetzung oder Interpretation kann sie erreichen oder ausschöpfen. So wird mit dem Denken von chōra der Ruf nach einer anderen Rede bzw. Darstellung laut.

17 Derrida (2000), chōra, S. 129.

18 Ebd., S. 131.

19 Ebd., S. 130. [Herv. i. O.] 


\section{b) Der Ruf nach einer anderen Rede/Darstellung}

Die Kühnheit des Denkens von chōra liegt in dem Zurücksteigen diesseits des Ursprungs hin zu einer „Notwendigkeit, die weder erzeugend ist noch erzeugt $^{\text {‘20 }}$ und die, obwohl sie einem vernunftgemäßen Denken des Wahren letztlich stattgibt, nicht selbst von diesem erfasst werden kann. chōra stellt also vor die Aufgabe, die Notwendigkeit dessen zu denken, das, obwohl es der Opposition intelligibel/sinnlich stattgibt, sich dem „Gesetz gerade des von ihr Situierten nicht zu unterwerfen scheint" ${ }^{21}$ Das Denken von chōra, das - so Derrida - aus dieser ,gekreuzten, bastardhaft unsauberen Gedankenführung“222 hervorgegangen ist, affiziert letztlich auch das Sprechen. Und zwar in zweifacher Hinsicht: das Sprechen über chōra ebenso wie das Sprechen nach ihr oder mit ihr als Aufgabe.

Die vorsichtig tastende, metaphorische Annäherung von Timaios an diese schwierige, dunkle und vage Form verweist auf die Problematik eines Sprechens über sie. Da chōra der kosmischen Ordnung vorausliegt, der auch der philosophische Diskurs angehört, kann sie nicht der Logik des Nicht-Widerspruchs der Philosophie unterworfen werden. Sie fordert diese viel eher heraus. Ihr Name bezeichnet keinen „durch den philosophischen Diskurs bekannten, anerkannten oder, wenn man das lieber möchte, genehmigten (recus) Typen von Seiendem“'²3: Vielmehr kann chōra überhaupt nicht als Seiendes angesprochen werden, weil chōra nicht ist. „Es gibt“'24 chōra, aber sie existiert nicht.

Dass sie sich nicht in die Logik des Nicht-Widerspruchs fügt, bedeutet nicht, dass eine mythische Rede angemessener wäre. So wie chōra jenseits von Urbild und Abbild liegt, liegt sie auch jenseits der philosophischen und der mythischen Rede. Denn aufgrund ihrer sprachlichen Verfasstheit sind beide durch die Dichotomie intelligibel/sinnlich strukturiert. Wie also wenn - um mit Derrida zu fragen, das Denken über chōra nach einer dritten Diskursgattung/einem dritten Diskursgeschlecht, $d$. h. vielleicht auch nach einem anderen Sprechen und einer anderen Darstellung, riefe? Und zwar nicht nur einem anderen Sprechen über sie, sondern einer anderen Darstellung mit ihr oder nach ihr? Wie kann auf diesen Ruf geantwortet werden bzw. kann überhaupt darauf geantwortet werden? Oder stellt die durch chōra aufgegebene Darstellung eine unmögliche Aufgabe dar?

In Außer dem Namen schreibt Derrida über die mögliche Unmöglichkeit der Sprache einer negativen Theologie:

20 Ebd., S. 164.

21 Ebd., S. 127.

22 Ebd., S. 126.

23 Ebd., S. 132.

24 Für eine genauere Analyse des „es gibt“ möchte ich hier u. a. auf Martin Heideggers späten Aufsatz „Zeit und Sein“ (in: ders., Gesamtausgabe, Bd. 14, hg. v. Friedrich-Wilhelm von Herrmann, Frankfurt/M., 1979, S. 3-30) und auf Jacques Derridas Schrift Falschgeld. Zeit geben I (München, 1993) verweisen. 
[S]ie gebietet: man muß (il faut) das Unmögliche tun, man muß dorthin gehen (,Geh*`), wohin man nicht gehen kann. Eine Leidenschaft für den Ort (passion du lieu), wiederum. Auf Französisch würde ich sagen: il y a lieu de, es besteht Anlaß [...], sich dorthin zu begeben, wohin man unmöglich gehen kann. Dorthin, auf den Namen zu, auf das Jenseits des Namens im Namen zu. Auf das (den oder die) zu, was (der oder die) bleibt - außer dem Namen. Gehen, wohin man gehen kann, das wäre keine Fortbewegung oder Entscheidung, das wäre das unwiderrufliche Abspulen eines Programms. Die einzig mögliche Entscheidung läuft über (passe par) die Verrücktheit des Unentscheidbaren und des Unmöglichen: dorthin gehen, wohin (wo*, Ort*, Wort*) man nicht gehen kann. ${ }^{25}$

$\mathrm{Zu}$ überlegen wäre, inwiefern der Ruf nach einem dritten Diskursgeschlecht auch die theatrale Darstellung betrifft, die ebenso wie die mythische und die logische Rede durch die Dichotomie von eidos und mimēta markiert ist. In welcher Form kann eine theatrale Ästhetik auf den Anspruch eines Denkens von chōra antworten? Welche Herausforderungen stellt dieses Denken an das Theater? Und in welchem Verhältnis steht die Bühne zu dieser anderen Darstellung? Gerade im Angesicht des Fremden muss der Versuch einer mimetischen Darstellung scheitern. Das Fremde als - wie Edmund Husserl schreibt „bewährbare Zugänglichkeit des original Unzugänglichen““26, also als Bezug, der sich nur im Entzug gibt, kann in einer nachahmenden, aneignenden Darstellung nicht eingeholt werden.

Im Timaios - so Derrida - eröffnet die Rede über chōra inmitten der Abhandlung einen leeren Raum, der nicht als die Leere, sondern vielmehr als Abgrund, Spaltung, Entfaltung oder Eröffnung zu begreifen ist. Und gegen Ende seines Essays schreibt Derrida: „Der Bezug der Unabhängigkeit, der NichtBezug ist in Hinblick auf das, was sich in ihm niederlässt, um darin aufgenommen zu werden, mehr dem des Intervalls oder des Zwischenraums ähnlich. “ ${ }^{27}$ Es wäre also zu überlegen, ob das Moment des Aufgenommenwerdens, wenn es nicht als subjektive Geste verstanden werden soll, aus einer responsiven Logik heraus gedacht werden kann. ${ }^{28}$

25 Jacques Derrida, Außer dem Namen, in: ders., Über den Namen. Drei Essays, übers. v. HansDieter Gondeck/Markus Sedlaczek, hg. v. Peter Engelmann, Wien, 2000, S. 63-121: 89. [Herv. i. O.]

26 Edmund Husserl, Cartesianische Meditationen, Hamburg, 1995, S. 117.

27 Derrida (2000), chōra, S. 162.

28 Ich möchte in diesem Zusammenhang auch auf Martin Heideggers Übersetzung des griechi-

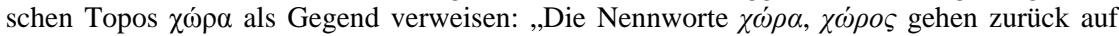
$\chi \alpha \dot{\omega} \omega$ (wovon $\chi \alpha o \varsigma$ ), gähnen, klaffen, sich auftun sich öffnen; $\eta \chi \omega ́ \rho \alpha$ als die umgebende Umgegend ist dann ,die Gegend'. [...] Wenn wir sagen ,in der Gegend des Feldbergs', so meinen wir weder nur ,in der Richtung dahin' noch gar den Ort, den der Feldberg einnimmt, sondern die umgebende, Orte und Richtungen gewährende, sich öffnende und entgegenkommende Weite. Diese offene Weite ist jedoch nicht die Leere eines Behältnisses, sondern das verhaltene, vieles aufbehaltende und eigentümlich aus sich sich eingrenzende Offene, dessen Grenzen selbst wieder Gegendhaft und das heißt weitend und weisend sind.“ (Martin Heidegger, Heraklits Lehre vom Logos, in: ders, Gesamtausgabe, Bd. 55, hg. v. Friedrich-Wilhelm von Herrmann, Frankfurt/M., 1979, S. 335.) Versucht man die Bühne im Ausgang der Heidegger'schen Gegend, verstanden als sich öffnende und entgegenkommende Weite, zu verstehen, 
Diese Fragen sollen im Folgenden noch einmal aus einer anderen Perspektive in den Blick genommen werden: Die in der Mitte der Abhandlung durch chōra „erzeugte Abgründigkeit ${ }^{\ltimes 29}$ soll zur Präambel des platonischen Dialogs in Beziehung gesetzt werden, um so die Verschränkung von chōra mit einer Politik der Plätze bzw. dem Platz der Politik zu fokussieren.

\section{c) Verschränkung von chōra mit einer Politik der Plätze}

Denn die durch chōra erzeugte Abgründigkeit affiziert „die Formen eines Diskurses über Plätze, namentlich die politischen Plätze [...] eine Politik der Plätze, die ganz und gar durch die Beachtung von Orten (Posten in der Gesellschaft, der Region, dem Territorium, dem Land) kommandiert wird, als Orte, die Diskurstypen oder Diskursformen zugewiesen werden. ${ }^{\text {“30 }}$

Der Dialog Timaios beginnt nämlich mit einer Rückblende. In der Präambel skizzieren die Dialogteilnehmer Sokrates, Timaios, Kritias und Hermokrates den platonischen Idealstaat. Sie berufen sich dabei auf ein fiktives, „gestriges“ Gespräch zu diesem Thema, vermutlich die Politeia. Das Gespräch umreißt die Forderung nach einer weitgehenden Gleichberechtigung von Männern und Frauen in der Erziehung, nach einer Auflösung der familialen Struktur und beschreibt den ständestaatlichen Aufbau der Gesellschaft. In der Präambel werden also der politische Raum des idealen Stadtstaates und die Plätze beschrieben, die den Einzelnen in ihm zugewiesen sind.

Darüber hinaus verknüpft die Präambel den eingenommenen Ort mit einer bestimmten Form der Rede. Wie Platon bereits hinsichtlich der verschiedenen Seinsgattungen von $\gamma \varepsilon ́ v o \varsigma$ gesprochen hat, klassifiziert er auch die Gruppierungen oder Gemeinschaften innerhalb der Gesellschaft als $\gamma$ ćvos. Die Zugehörigkeit zu einem bestimmten $\gamma \varepsilon ́ v o \varsigma$ bedingt jeweils die Möglichkeit eines Ortes, von dem aus in einer bestimmten Weise gesprochen werden kann.

Im Anschluss an die kurze Rekapitulation der ständischen Gesellschaftsordnung fordert Sokrates ein bewegtes Bild des bislang unbewegt und reglos erscheinenden idealen Stadtstaates. Er verlangt eine Schilderung der Kämpfe, „die die Stadt zu bestehen hat, wenn sie gegen andere Städte in den Krieg zieht, wie es ihr angemessen ist, und in der Kriegsführung eine ihrer Bildung und Erziehung würdige Probe ablegt, sowohl in der Ausführung der Taten als auch in Verhandlungen mit Worten. ${ }^{\text {“31 }}$ - Das ist an sich schon ein irritierender Wunsch, da das beschriebene Staatsmodell bislang ja der utopische Entwurf einer Stadt zu sein schien und nicht eine existierende Stadt, die bereits ihre

gibt sie sich neu zu denken als ein Raum, der sich nicht aneignen lässt, der vielleicht, wie Waldenfels schreibt, aus der Fremde kommt und das szenische Geschehen entgegenkommen, es begegnen lässt.

29 Derrida (2000), chōra, S. 140.

30 Ebd., S. 141.

31 Platon (2003), Timaios, S. 13. 
Kämpfe und Kriege zu bestehen hatte, von denen man erzählen könnte. Dazu aber später mehr. -

Sokrates beschreibt sich selbst als unfähig zu dieser Erzählung; er bezweifelt, die Stadt „gebührend preisen“32 zu können. Dieselben Zweifel äußert er hinsichtlich der Dichter und der Sophisten. Dem yévoৎ der Dichter, die er als Nachahmer bezeichnet, scheint es in Anbetracht ihrer Abstammung und ihrer Erziehung versagt, angemessen über die Stadt zu sprechen. Sie können nur das leicht und gut nachahmen, womit sie aufgewachsen sind, nicht aber das, was ihnen aufgrund ihrer Abstammung und mangelnder Erziehung fremd geblieben ist: die philosophische Rede ebenso wie die politische Tat. ${ }^{33}$ Die Gruppe der Sophisten hingegen verfügt zwar über eine Vielfalt an Reden, hat aber keinen eigenen Ort. Die Sophisten ziehen von Stadt zu Stadt, haben sich nirgends einen festen Wohnsitz eingerichtet, besitzen keine Oiko-nomie und sind grund dessen unfähig, die lebendige Geschichte der Stadt zu erzählen. ${ }^{34}$ Es bleibt also laut Sokrates „nur die Zunft eures Schlages übrig, die an beidem von Natur aus Anteil hat“. ${ }^{35}$ Mit diesem „euch“ bezieht er sich auf seine drei Gesprächsteilnehmer Timaios, Kritias und Hermokrates, die als Philosophen und Politiker einen Ort haben und zwar den einzigen, von dem aus man (wahr) sprechen (und handeln) kann. Allein die Zugehörigkeit zum Ort autorisiert also die Wahrheit des logos.

Sokrates hingegen - so Derrida - „operiert selbst aus einer Art von NichtOrt heraus““ ${ }^{36}$ Dadurch, dass er sich selbst für unfähig erklärt, eine Lobrede auf die Stadt zu halten, macht er sich den Dichtern und Sophisten ähnlich, die nicht statthaben, die keinen Ort haben, von dem aus sie sprechen können. Gleichzeitig nimmt er für sich in Anspruch, dass die Feststellung, dass er, ebenso wie die Dichter und Sophisten, keinen Ort habe, eine wahre sei:

Diese Wahrheit indes, daß nämlich sie und ich, sofern wir demselben genos anzugehören scheinen, ohne eigenen Ort sind, spreche ich, da es eine Wahrheit ist, von eurem Ort zu euch, die ihr auf der Seite des wahren logos, der Philosophie und der Politik steht. Ich adressiere mich von eurem Platz aus, um euch zu sagen, daß ich keinen Platz habe, da ich denen ähnlich bin, die die Ähnlichkeit zu ihrem Metier gemacht haben, die Dichter, die Nachahmer und die Sophisten, die Gattung derer, die keinen Platz haben. Ihr allein habt Ort/findet Statt und könnt zugleich den Ort und den Nicht-Ort in Wahrheit sagen, und deshalb werde ich mein Wort an Euch weitergeben. ${ }^{37}$

Mit diesem Spiel der doppelten Ausschließung sowohl vom Nicht-Ort der Dichter und Sophisten als auch vom Ort der Politiker und Philosophen situiert sich Sokrates als eine dritte Gattung von Ort. Sokrates geht von der Irre aus,

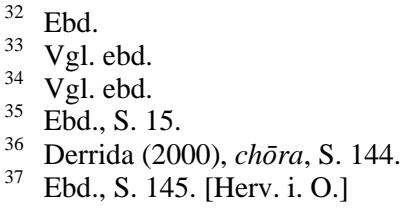


einem atopischen Ort, an dem alles verzeichnet wird, der jedoch selbst nicht verzeichnet werden kann. In der Präambel, am Anfang, macht er Platz für eine Behandlung des Platzes, „macht Platz dafür, den Gesprächspartnern ihre Plätze zuzuweisen, die damit dahin geführt werden, weiter davon zu handeln“ ${ }^{38} \mathrm{Er}$ bittet seine Gesprächspartner, ihm das Geschenk ihrer Reden abzustatten und gibt sich selbst „,von allen am meisten bereit, es in Empfang zu nehmen“.39 Dieses „in Empfang nehmen“ ist im griechischen Original durch das Wort $\delta \delta^{\prime} \chi 0 \mu \alpha \imath$ (dechomai) ausgedrückt, dieselbe Vokabel, die an späterer Stelle im Timaios zur Beschreibung von $\chi \omega ́ \rho \alpha$ verwendet wird und die Derrida zufolge mit chōra neu gedacht werden muss. chōra, so wurde gesagt, kann nicht als Seiendes angesprochen werden. Insofern ist chōra auch als Auf- oder In-Empfang-Nehmende nicht im Sinne von Behältnis, Substanz, Träger oder Subjekt zu denken. Ihr Stattgeben kann nicht als Geste eines Subjekts begriffen werden. Und das, was sie aufnimmt, darf sie nicht für sich oder um ihrer selbst willen aufnehmen, sie darf sich die Eigenschaften, die sie aufnimmt, nur darbieten lassen. Sie besitzt nichts als Eigentum und diese „Uneigenschaft/Untauglichkeit, die eben nicht ist, dies ist es, was chōra [...] bewahren muss (ce que chōra doit ... garder), dies ist es, was man ihr bewahren muss (ce qu'il faut lui garder)“. ${ }^{40}$

Sokrates, so schreibt Derrida, ist nicht chōra, weil chōra nicht als Seiendes gedacht werden kann. Wenn sie aber etwas wäre, wäre er ihr ähnlich. Er setzt sich

an ihren Platz - einen Platz, der kein Platz unter anderen ist - sondern vielleicht der Platz selbst, der unersetzliche (l'irremplacable). Ein unersetzlicher und nicht zu platzierender Platz, von dem aus er das Wort von denen aufnimmt, vor denen er sich ausstreicht, aber die es von ihm aufnehmen, denn er macht es so möglich, dass sie sprechen. ${ }^{41}$

Um den hier entwickelten Zusammenhang von Ort und Sprechen für die Frage nach der Bühne fruchtbar zu machen, möchte ich noch einmal kurz an Hotel Europa erinnern. Hat die Gruppe der ehemaligen Abschiebehäftlinge, die die oben skizzierte Inszenierung thematisiert, einen Ort, von dem aus sie sprechen kann? Gibt es einen Platz für sie an dem politischen Ort, wo man Fragen behandelt? Und wo hat demgegenüber die Bühne ihren Ort? Gehört sie eher zum

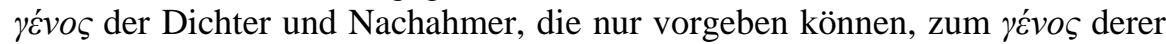
zu gehören, die einen eigenen Ort haben? Ist die Bühne in der Rahmung des Theaters als Institution zu verstehen, die inmitten der Stadt liegt und dort ihren festen Ort hat, von dem aus in der Logik eines philosophisch-politischen Diskurses gesprochen wird? Oder sollte man die Bühne vielleicht in Analogie zu Sokrates als chōra ähnlich denken? Nimmt die Bühne - ähnlich wie chōra und

\footnotetext{
38 Ebd., S. 147.

39 Platon (2003), Timaios, S. 15.

40 Derrida (2000), chōra, S. 134. [Herv. i. O.]

41 Ebd., S. 148. [Herv. i. O.]
} 
Sokrates es tun - ihren Ausgang in der Irre, kommt sie, wie Waldenfels schreibt, selbst aus der Fremde? Kann das Statthaben der Bühne als dieser unersetzliche und nicht zu platzierende Ort, als Ausstreichung gedacht werden? Und vor wem streicht sie sich aus?

Ich gebe an dieser Stelle zu bedenken, dass auch wenn chōra jenseits bzw. diesseits der kosmischen Ordnung liegt, sie dieser letztlich stattgibt. Ähnlich verhält es sich bei Sokrates. Er streicht sich aus und nimmt das Wort von denen auf, vor denen er sich ausstreicht. Das bleiben im Fall des Timaios seine drei Gesprächspartner: politisch und philosophisch gebildete Männer. Die Gruppe derer, die keinen Ort haben, von dem aus sie sprechen können, wird zwar genannt oder benannt, doch die Ausstreichung Sokrates' eröffnet keine andere Möglichkeit der Rede.

Umso zwingender ist es, noch einmal auf die oben aufgeworfene Frage einer angemessenen Rede/Darstellung nicht nur über/von chōra, sondern mit ihr oder nach ihr als Aufgabe zurückzukommen. Ich möchte daher abschließend Derridas Beschreibung der doppelten Alterierung des Gedächtnisses und Bernhard Waldenfels’ Überlegungen zur Möglichkeit eines Antwortens auf das Fremde skizzieren und dafür plädieren, das Moment des Stattgebens der Bühne aus einer responsiven Logik heraus als Antworten auf den Anspruch des Fremden zu denken.

\section{Stattgeben: Antworten auf den Anspruch des Fremden}

Nach der zuvor bereits beschriebenen Aufforderung Sokrates' an seine Gesprächsteilnehmer, ein bewegtes Bild des bislang unbewegt und reglos erscheinenden idealen Stadtstaates zu zeichnen, wiederholt Kritias eine Erzählung vom Krieg zwischen dem Idealstaat Ur-Athen und der Seemacht Atlantis, die er den beiden anderen Gesprächsteilnehmern bereits am Vortag geschildert hat. Die von Sokrates und seinen Gesprächspartnern entworfene Utopie eines idealen Staatsentwurfes scheint in einer von den Griechen vergessenen Vergangenheit bereits stattgehabt zu haben. In dieser Zeit führte der Inselstaat Atlantis einen Angriffskrieg gegen Ägypten und Griechenland, um beide zu versklaven. Lediglich der Stadtstaat Athen hielt der Invasion stand und befreite im Anschluss uneigennützig alle anderen Städte. Dann wurden sowohl Atlantis als auch ein Großteil der athenischen Bevölkerung durch ein Erdbeben und eine anschließende Überschwemmung vernichtet.

Der Grund für das Vergessen des eigenen Ursprungs bei den Griechen wird wieder in einen Bezug zum Ort gesetzt, ist durch ihre geografische Lage bedingt. Während die Ägypter durch den Nil einerseits vor Feuer, aufgrund des ebenen Landes aber auch vor Überschwemmungen durch Wassermassen aus den Bergen sicher waren, sind die griechischen Städte sowohl durch das eine als auch durch das andere vernichtet worden - und mit ihnen alle schriftlichen Überlieferungen. Nach jeder Zerstörung durch die Naturgewalten musste alles von Neuem mit Schrift und allem anderen, dessen eine Stadt bedarf, eingerich- 
tet werden, während die Inschriften in den ägyptischen Tempeln die Zeit überdauerten.

Die im Timaios niedergeschriebene Erzählung über den angeblichen Ursprung Athens ist eine mehrfach ineinander verschachtelte mündliche Überlieferung, die nur durch eine erste schriftliche Fixierung überhaupt tradiert werden konnte, die selbst wieder auf einen weiter zurückliegenden Anfang verweist. Kritias hat die Geschichte in sehr jungen Jahren von seinem Großvater gehört, der sie wiederum von dem griechischen Dichter Solon erfuhr, dem sie bei einer Reise nach Ägypten von einem ägyptischen Priester geschildert wurde, der sie den Schriften, die in den Tempeln aufbewahrt wurden, entnommen hatte. ${ }^{42}$

Die hier beschriebene verschachtelte Form der Überlieferung geht nicht, so Derrida, ohne formale Paradoxien ab:

Nicht nur stellt sich heraus, daß wie der Mythos ihres Ursprungs das Gedächtnis einer Stadt einer Schrift anvertraut wird, es wird gar noch der Schrift des anderen, dem Sekretariat einer anderen Stadt anvertraut. Es muss demnach zweifach alteriert werden, damit es gerettet wird, und es geht genau um seine Rettung, darum, ein Gedächtnis zu retten, wenn es auf die Wände des Tempels geschrieben wird. Das lebendige Gedächtnis muss in den graphischen Spuren/Überresten eines anderen Ortes, der auch eine andere Stadt und ein anderer politischer Raum ist, sein Exil nehmen. ${ }^{43}$

Was kann die hier beschriebene doppelte Alterierung für die Frage einer theatralen Darstellung bedeuten? Derrida verweist im Zusammenhang mit der Aufbewahrung des eigenen Gedächtnisses an einem anderen Ort nicht zu Unrecht auf die Geschichte der Kolonisierung. Gerade diese gilt es nicht fortzuschreiben. Genau diese Gefahr steht aber mit im Raum, wenn es um die Erzählung der Geschichte des Fremden geht. Es gilt in Hinblick auf das Fremde zu einem Sprechen zu gelangen, das nicht so sehr über das Fremde spricht, als dass es auf den Anspruch des Fremden antwortet.

Bernhard Waldenfels beschreibt in seinem Werk immer wieder diesen Ansatz einer responsiven Logik oder Ethik, der das im Rahmen der Phänomenologie entwickelte Konzept der Intentionalität nicht grundsätzlich aufkündigt, aber dessen Grenzen in Bezug auf die Auseinandersetzung mit einem Hyperphänomen wie dem Fremden aufzeigt. Intentionalität meint, vereinfacht gesagt, dass sich etwas als etwas zeigt, dass etwas in einem bestimmten Sinn

42 An dieser mehrfach ineinander verschachtelten Überlieferung sind verschiedene Aspekte interessant. Ich möchte aber vor allem darauf hinweisen, dass diese sich als wahr ausgegeben Erzählung des Urstaates Athen und seiner Kämpfe, die Sokrates zuvor gefordert hat und von der er bezweifelt hat, dass beispielsweise Dichter oder Sophisten sie angemessen wiedergeben können, jetzt über eine lange zurückliegende die Kindheitserinnerung Kritias', den Dichter Solon und einen ägyptischen Priester, der sie aus Tempelinschriften entnommen hat, zu Sokrates gelangen. Sowohl das Stadium der Kindheit als auch die Dichtung oder die Schrift gelten Platon in vielen anderen seiner Schriften, z. B. der Politeia oder dem Phaidon nicht als zuverlässige Quellen des Wissens.

43 Derrida (2000), chōra, S. 151. [Herv. i. O.] 
verstanden oder gemeint ist. Das Fremde, das sich nur zeigt, indem es sich entzieht, zeichnet sich aber gerade dadurch aus, dass es die Möglichkeit einer vom Subjekt ausgehenden Sinngebung unterbindet. Das Fremde widerfährt, es trifft, fordert heraus, stellt einen Anspruch, der etwas abverlangt und stellt so die eigenen Möglichkeiten immer wieder infrage. In dem Versuch, es nachträglich einzuholen, mit einem Sinn zu belegen oder anzueignen, entgeht das Fremde notwendigerweise, wird es zum Verschwinden gebracht.

Die Erfahrung des Fremden ist, laut Waldenfels, gekennzeichnet durch die Doppelstruktur von Pathos und Response:

Pathos bedeutet, daß wir von etwas getroffen sind, und zwar derart, daß dieses Wovon weder in einem vorgängigen Was noch in einem nachträglich erzielten Wozu aufgehoben ist. [...] So wie das Pathos diesseits der Intentionalität liegt, so ist unsere Response jenseits der Intentionalität anzusetzen. Die Responsivität geht über jede Intentionalität hinaus, da das Eingehen auf das, was uns zustößt, sich nicht in der Sinnhaftigkeit, Verständlichkeit oder Wahrheit dessen erschöpft, was wir zur Antwort geben. ${ }^{44}$

Diese doppelte Struktur von Pathos und Response, die in der Figur einer zeitlichen Diastase, der Vorgängigkeit des Pathos und der Nachträglichkeit der Response ineinander verschränkt ist, macht es möglich das Fremde als etwas zu denken, „,das sich niemals dingfest und sinnfest machen läßt“445 und das sich daher auch nachträglich nicht wieder in einen vom Subjekt ausgehenden Akt der Sinngebung überführen lässt.

Die Ausgangsfrage meiner Überlegungen war: Wo hat die Bühne ihre Statt und wem oder was kann sie stattgeben - und vor allem: in welcher Weise? Wenn wir das Statthaben der Bühne versuchen mit Derrida als Ausgang aus der Irre und als Ausstreichung der Bühne zu denken, wäre zu fragen, ob das Stattgeben gerade nicht - wie in Bezug auf Sokrates oben beschrieben - als Zuweisung eines Platzes, sondern vielmehr im Sinne eines Antwortens und zwar eines Antwortens auf den Anspruch des Fremden gedacht werden muss, ob die durch chōra eröffnete Notwendigkeit nicht als Unausweichlichkeit des Anspruchs des Fremden zu denken ist. Als etwas, das anspricht und im Ansprechen einen Anspruch erhebt, auf den nicht in Form eines Sprechens über oder einer Aneignung geantwortet werden kann, sondern nur indem man, wie Waldenfels schreibt, gibt, was man nicht hat. Denkt man das Stattgeben der Bühne vom Antworten auf den Anspruch des Fremden aus, entgeht man vielleicht auch der Versuchung, sich den Ort der Bühne nachträglich zu eigen zu machen, denn: „Der Ort, von dem aus wir auf das Fremde antworten, gehört uns nicht, er ist exterritorial, ein weißer Fleck auf der Landkarte und im Geschichtskalender.““46

\footnotetext{
44 Bernhard Waldenfels, Grundmotive einer Phänomenologie des Fremden, Frankfurt/M., 2006, S. 43-45.

45 Ebd., S. 54.

46 Waldenfels (1997), Topographien des Fremden, S. 143 f.
} 


\section{Literatur}

Derrida, Jacques, Falschgeld. Zeit geben I, München, 1993.

Ders., Dissemination, in: ders., Dissemination, übers. v. Hans-Dieter Gondeck, hg. v. Peter Engelmann, Wien, 1995, S. 323-434.

Ders., Außer dem Namen, in: ders., Über den Namen. Drei Essays, übers. v. Hans-Dieter Gondeck/Markus Sedlaczek, hg. v. Peter Engelmann, Wien, 2000, S. 63-121.

Ders., chōra, in: ders., Über den Namen. Drei Essays, übers. v. Hans-Dieter Gondeck/ Markus Sedlaczek, hg. v. Peter Engelmann, Wien, 2000, S. 123-170.

Gemoll, Wilhelm/Vretska, Karl (Hg.), Gemoll. Griechisch-deutsches Schul- und Handwörterbuch, 10. Aufl., Oldenburg, 2006.

Heidegger, Martin, Heraklits Lehre vom Logos, in: ders., Gesamtausgabe, Bd. 55, hg. v. Friedrich-Wilhelm von Herrmann, Frankfurt/M., 1979.

Ders., „Zeit und Sein“, in: ders., Gesamtausgabe, Bd. 14, hg. v. Friedrich-Wilhelm von Herrmann, Frankfurt/M., 1979, S. 3-30.

Husserl, Edmund, Cartesianische Meditationen, Hamburg, 1995.

Platon, Timaios, übers. u. hg. v. Rudolf Rehn u. Thomas Paulsen, Stuttgart, 2003.

Waldenfels, Bernhard, Topographien des Fremden, Frankfurt/M., 1997.

Ders., Grundmotive einer Phänomenologie des Fremden, Frankfurt/M., 2006.

Ders., Ortsverschiebungen Zeitverschiebungen, Frankfurt/M., 2009.

Ders., Sinne und Künste im Wechselspiel. Modi ästhetischer Erfahrung, Berlin, 2010. 


\section{VON DER SCHAU-BÜHNE ZUR ARCHITEKTUR UND ÜBER DAS THEATER HINAUS. RAUMBILDENDE PROZESSE BEI SABBATINI, TORELLI, POZZO UND APPIA}

Für die Entwicklung des modernen Theaterraums ist das 17. Jahrhundert entscheidend - jenes Jahrhundert, das Frankreich mit Ludwig dem XIV. als Sonnenkönig sein goldenes Zeitalter nennt oder mit Corneille, Molière, Pascal und Racine sein klassisches. Der Versailler Hof setzt Maßstäbe für die europäische Aristokratie, die überall Französisch lernt. 1648 veröffentlicht Descartes seine berühmte Formel für das Subjekt als denkendes Bewusstsein, res cogitans, und bestimmt ihm gegenüber den Raum als res extensa aller Körper. Descartes identifiziert damit Raum und Körperwelt unter dem Kriterium ihrer materialen Ausdehnung. Zeitgenossen und Nachfolger Descartes' überschlagen sich geradezu in dem Versuch, diese Synthese aufzubrechen, indem sie auf verschiedene Weise zwischen abstrakter räumlicher Ausdehnung und dynamischen, körperweltlichen Zusammenhängen differenzieren. Raumtheorie ist zu diesem Zeitpunkt noch keine naturphilosophische oder mathematische Spezialdisziplin. Raumfragen stehen, theoretisch oder nicht, im Zentrum von Reflexionen und experimentellen Praxen, in denen es um den Ort des Subjekts in einem Universum geht, aus dem sich Gott möglicherweise zurückzieht oder schon zurückgezogen hat. Philosophen, Empiriker, Kosmologen und Künstler greifen in diese Auseinandersetzung ein. Dabei forschen, formulieren und veröffentlichen sie stets in mehreren Bereichen gleichzeitig.

Mit Raumfragen gehen in Sonderheit auch die Szenographen des 17. Jahrhunderts um, die einerseits ausgedehnte Kosmologien zur räumlichen Darstellung bringen und diese andererseits für die Körperwelten eines vielköpfigen Publikums wahrnehmbar machen wollen. Die Problematik von optischer Organisation und Wahrnehmung überlagert das mit ihnen einhergehende oder ihnen zugrunde gelegte Raumdenken, das gleichwohl extrapoliert werden kann. Obwohl Szenographen im 17. Jahrhundert eher von der Einrichtung pikturaler Perspektiven handeln und ihre raumtheoretischen Positionen nicht gesondert dargelegt haben, lässt sich ihre Auseinandersetzung mit den beiden, im Barock auseinandertretenden Polen des Raumdenkens aufzeigen: Ausdehnung und Materie, die von Descartes in einem Raumkonzept zusammengeführt werden, streiten als metrische Modelle immer stärker mit dynamisierten Raumvorstel- 
lungen. Schließlich treten sie als zwei Pole unversöhnlich auseinander. ${ }^{1}$ Die Szenographen kombinieren, vermitteln und entscheiden sich in diesem Streit, indem sie ihn zur räumlichen Erscheinung bringen. Ihr Ausdruckssystem unterscheidet sich von dem der bildenden Künstler darin, dass es nicht um räumliche Darstellungen, sondern um Verräumlichung (spatialisation) als solche geht. Das heißt, szenographische Raum-Auffassungen, die sich als solche jeweils begrifflich beschreiben lassen, werden nicht einfach in Raumeinrichtungen niedergelegt, sondern in raumbildende Prozesse überführt. Szenographien, Theaterarchitekturen und optische Einrichtungen bespielen nicht vorexistente Räume, sondern stellen Erfahrung und Entfaltung von Räumlichkeit prozessual her. Dies gilt unabhängig davon, ob Szenographen von einem konkreten gebauten Raum mit bestimmten, klaren Abmessungen ausgehen oder nicht. Der szenographische Raum ist stets ein anderer als der blanke Baukörper.

Die Avantgarde der Szenographen im 17. Jahrhundert kommt aus Oberitalien, die stürmischen Entwicklungen der ausgehenden Renaissance, die ersten stabilen Theaterbauten, eine avancierte naturphilosophische Theoriebildung und zahllose szenische Experimente im Rücken. Oberitalienische Szenographen sind zwischen Rom und Versailles, zwischen Wien, Dresden und Furttembach kreuz und quer unterwegs. Studiert wird vor Ort, in Ansehung der Dinge und im Umgang mit ihnen. Gearbeitet wird da, wo ein genügend reicher Hof die flüssigen Mittel dafür aufbringen kann oder will. Es ist das Jahrhundert, in dem die Traktate der Theater-/Maler-/Architekten entstehen, nachgedruckt und relativ zügig in Umlauf gebracht werden. Es ist nicht mehr das Jahrhundert einer sich selbstgewiss feiernden Sichtbarkeit wie in Italien im 16. und noch nicht das von der Literatur eroberte und durchdrungene 18. Jahrhundert. Das 17. Jahrhundert bildet einen hochreflexiven, experimentellen und experimentierfreudigen Zeitraum, in dem es zum einen, anhand von tausenderlei optischen Geräten, um einen Begriff und die Folgen des Falls in die Sichtbarkeit geht, um den „Wahnsinn des Sehens“ (Buci-Glucksmann) in geschlossenen Räumen, zum anderen entfaltet sich in den physikalischen Wissenschaften eine zwischen Philosophen und Empirikern in europäischem Maßstab geführte Raumdebatte, die in Breite, Vielfalt und Leidenschaft ihresgleichen sucht.

In dieser Debatte kristallisieren sich nach und nach zwei völlig verschiedene Raumbegriffe heraus. Die eine Raum-Auffassung hält an der Voraussetzung einer abstrakten Raumhülle fest und lässt eine relative, veränderliche Räumlichkeit nur für partielle, lebensweltliche Zusammenhänge gelten. Sie ist mit dem Namen Newtons verknüpft und hat als Idee eines unanschaulichen, absoluten Raumkontinuums nicht nur in der Physik bis zum Ende des 19. Jahrhunderts, sondern auch vor allem mentalitätsgeschichtlich einen derartig nachhaltigen Erfolg erzielt, dass noch die Raumreflexionen in den Kulturwissenschaf-

Diese Polarisierung wird eindringlich dargestellt von: Karin Leonhard, „Was ist Raum im 17. Jahrhundert?“, in: Horst Bredekamp/Peter Schneider (Hg.), Visuelle Argumentationen. Die Mysterien der Repräsentation und die Berechenbarkeit der Welt, München, 2006, S. 11-34. 
ten jüngeren Datums dazu auffordern, die Vorstellung vom Container-Raum mit all seinen epistemischen Implikationen zu überwinden. Die andere RaumAuffassung schließt nahezu zeitgleich die Möglichkeit aus, sich den Raum als bergende Kapsel oder bewohnbare Schachtel vorzustellen. Sie ist mit den Namen Leibniz verknüpft, der die Relation mehrerer beweglicher Körper zueinander allein für ausschlaggebend hält. Der relationale Verbund bildet sowohl die Quelle für die Vorstellung räumlicher Einbettung in einem Zusammengesetzen (das unendlich variiert), als auch für die Körperwelt, in der die einzelnen points de vue bilden, Leibgesichtspunkte, wie sich mit Merleau-Ponty sagen ließe, die miteinander (direkt und indirekt) kommunizieren. Dem einzelnen kommt dabei kein Ort zu, sondern in Bezug auf das Relationsgefüge „Lagerung-Qualität“, wie Einstein formuliert, was dieser Raumauffassung wohl das (nicht ganz glückliche Kürzel) Lage-Raum eingebracht hat. Albert Einstein: „Man kann diese beiden begrifflichen Raum-Auffassungen einander gegenüberstellen als

a) Raum als ,Container‘ (Behälter) aller körperlichen Objekte

b) Lagerungs-Qualität der Körperwelt.“

Erscheint Raum im ersten Fall „als eine gewissermaßen der Körperwelt übergeordnete Realität“, so ist im zweiten Fall „der Raum ohne körperliche Objekte undenkbar". ${ }^{2}$

Zwischen-Zwei: Auch wenn Descartes die Identität von Körperwelt und ausgedehntem Universum für möglich hielt, bewegen barocke Raumtheorien stets ein Zwischen-Zwei, das polarisiert erscheinen kann (Newton) oder in unendlicher Vervielfältigung dynamisiert wird (Leibniz). Nicht anders als die große barocke Trias von Descartes zu Newton und Leibniz, variieren auch die barocken Szenographen ihre Entscheidungen stets Zwischen-Zwei und gehen zwischen Raum und Bild, zwischen Körpern, Sehwinkeln und Sichtbarkeit mit Fragen von Welträumlichkeit im Interieur um. Im Folgenden möchte ich daher der Trias wesentlicher Positionen des Raumdenkens im 17. Jahrhundert zunächst die nicht minder große Trias der barocken Szenographen zur Seite stellen - von Sabbatini zu Torelli und Pozzo - und wie angekündigt, mit einem Ausblick auf den Zeitgenossen der Einsteinschen Relativitätstheorie, Adolphe Appia, enden.

\section{Innen ohne Außen: Sabbatini mit Descartes}

Im 17. Jahrhundert werden die Innen- und Außengestalt der Gebäude unabhängig voneinander. Die Außengestalt ist nicht mehr Ausdruck eines Inneren, das sie umschließt, sondern tritt in Bezug zur städtischen Umgebung. Vor allem die Fassade erreicht eine neuartige Autonomie. Giebel ragen in die Höhe

\footnotetext{
Albert Einstein, „Vorwort“, in: Max Jammer, Das Problem des Raumes - Die Entwicklung der Raumtheorien, Darmstadt, 1980 [1954], S. XI-XV: XV.
} 
und korrespondieren mit keinem dahinter liegenden Baukörper mehr. Es gibt Scheinportale, durch die niemand hindurchgehen kann und fingierte Fensterfronten, die nur aus Stuck und Malerei bestehen. Umgekehrt gestalten neue architektonische Mittel den Innenraum: Kurven, Säulenstellungen, Aushöhlungen und Durchbrüche negieren die Wand als Abschluss oder Einschluss von Räumen. Die Wand fungiert nicht mehr als Raumgrenze, sondern wird selbst unbestimmt. ${ }^{3}$ Sie kann durch eine bemalte Kulisse ersetzt werden wie im Theater, vor die man bei Bedarf wieder eine weitere Kulisse schieben kann usw. Innen wird es, genau wie im Theater, unmöglich, die genaue Ausdehnung dieses Raums festzustellen, seine Grenzen zu bestimmen oder gar zu sagen, welches Außen ihm zugehört.

Die jeweilige Autonomie von Innen und Außen korreliert mit der strengen Zweiteilung der Welt im kartesischen Weltbild. Descartes unterscheidet zwischen einer äußeren Welt, die Ausdehnung besitzt und dem Geltungsbereich der Physik zugehört (res extensa) und einem Denkinnenraum, der selbst ohne jede Ausdehnung ist und als Sitz der denkenden Substanz bestimmt wird (res cogitans). Nach Art einer camera obscura empfängt das denkende Ich (cogito) Vorstellungen der äußeren Welt. ${ }^{4}$ Unter diesen Vorstellungen finden sich jedoch auch Ideen, die nicht der Beobachtung der äußeren Welt entnommen werden können (wie etwa die „größte Substanz“). An dieser Stelle bahnt Descartes gegenüber der Antike „die entscheidende Umkehrung an: Er holt Gott als die Ursache aller Naturvorgänge hinein in den Denkinnenraum“ “. ${ }^{5}$ Mit anderen Worten: Gott hat sich nicht in der äußeren Welt wie in einem Buch beschrieben, das man nur geduldig genug entziffern muss, um ihn zu finden, er bildet jetzt die Stütze des denkenden Ich.

Demgegenüber erscheint Descartes die Welt der körperlichen Volumina ausreichend beschrieben, wenn diese in Länge, Breite und Tiefe (Höhe) bestimmt sind. Die absolute Privilegierung des Ortes der Antike, dass körperliche Dinge einen Ort brauchen, um zu erscheinen, entfällt. Die physische

3 Zur Auflösung der Wand als Raumgrenze vgl. Hanspeter Landolt: Die Architektur „verzichtet auf jedes strukturelle Skelett, das den Raumschalen der Renaissance [...] Kompaktheit gegeben hat, verzichtet damit auf eine logische und konsequente Gliederung der Wand. Sie wird zur leichten Spinnwebe, die zu zerstören in unserer Vorstellung ein Windhauch genügt.“ Ders., „Der barocke Raum in der Architektur“, in: Rudolf Stamm (Hg.), Die Kunstformen des Barockzeitalters. Vierzehn Vorträge, Bern, 1956, S. 92-110: 101-103.

4 Die Verbindung von Descartes und der barocken Bühne sowie seines Cogito mit dem Video im zentralperspektivischen Apparat (Brunelleschi) bzw. dem ausgezeichneten Sichtpunkt im barocken Theater sind schon häufiger angemerkt worden. So z. B.: Viktoria Tkaczyk, „Cumulus ex machina. Wolkeninszenierungen in Theater und Wissenschaft", in: Helmar Schramm/ Ludger Schwarte/Jan Lazardzig (Hg.), Spektakuläre Experimente. Praktiken und Evidenzproduktion im 17. Jahrhundert, Berlin, New York, NY, 2006, S. 43-77; Angelika Horn, „Das Experiment mit der Zentralperspektive. Brunelleschi und Descartes“, in: dies./Wilhelm Friedrich Niebel/Herbert Schnädelbach (Hg.), Descartes im Diskurs der Neuzeit, Frankfurt/M., 2000, S. 9-32.

5 Stephan Günzel, „Physik und Metaphysik des Raumes. Einleitung“, in: Jörg Dünne/ders. (Hg.), Raumtheorie. Grundlagentexte aus Philosophie und Kulturwissenschaften, Frankfurt/M., 2006, S. 19-43: 22. 
Welt wird von Descartes als räumliches Kontinuum bestimmt, voller körperlicher Volumina, deren Substanz jeweils gleich bleibt, egal ob sie mit anderen Körpern mehr oder weniger vermischt sind. Die Substanzen greifen ineinander. Egal, ob Luft, Sand oder Gold einen Krug füllen, das von ihnen eingenommene und ausgefüllte Volumen bleibt stets dasselbe. Es ist kein leerer Raum denkbar. Die Welt ist „unbegrenzt ausgedehnt“, ein grenzenloses, ewig unveränderliches „Gefäß“. ${ }^{\circ}$

Wie Descartes für die Physik, entwickelt der Theaterarchitekt Nicola Sabbatini (um 1574-1654) für die Szenographen ein System strikter Zweiteilungen. Sein Lehrbuch ist das erste große Kompendium für Szenographen im 17. Jahrhundert. Es geht sofort von einem Innenraum aus. Kein Wort zum Äußeren des Gebäudes, seiner Lage, seinem Eingang oder Ähnlichem. Sabbatinis erstes Kriterium ist ein „genügend weiter Raum“ von entsprechender „Ausdehnung ${ }^{\text {“7 }}$, um eine scene darin zu errichten. Diese aber konstruiert Sabbatini ausgehend von einem idealen Sichtpunkt, der im Zuschauersaal liegt. Er übernimmt diese Praxis von seinem Lehrer, dem Mathematiker Guido Ubaldo Del Monte (1545-1607), der diesen Bezugspunkt im Saal zum ersten Mal in einem Büchlein von 1600 dargestellt und damit die Qualen der Szenographen des 16. Jahrhunderts beendet hat, die diesen Konstruktionspunkt auf die vordere Bühnenkante gelegt hatten und sich in der Folge mit perspektivischen Häuserfluchten abmühten, die schon in der Bühnenmitte den Darstellern nur noch bis zum Knie reichten. Von Del Monte übernimmt Sabbatini also diese Erfindung und macht sie mit seinem Lehrbuch zum Standard. Dabei handelte es sich nicht um einen bestimmten Ort im Saal, sondern um einen Punkt - in Augenhöhe eines erhöht platzierten Betrachters, dem Fluchtpunkt auf dem Abschlussprospekt genau gegenüber. An diesen Punkt wird der Fürst in der Loge später sein Gesicht bringen. Vorweg wird dieser Punkt als Projektionspunkt verwendet, von dem aus alle Visierlinien der Einrichtungen der scene festgelegt werden. Sabbatini beschreibt Schritt für Schritt die Einrichtung eines szenischen Bildraums, der üblicherweise eine Stadt (also einen Außenraum) zeigt. Die Einrichtung der Szene stützt sich auf die Dimensionen der Breite (mit den Richtungen rechts und links) und der Tiefe (mit den Richtungen vorne und hinten).

6 René Descartes, „Über die Prinzipien der materiellen Dinge“ [aus: Principia Philosophia (1644)], in: Jörg Dünne/Stephan Günzel (Hg.), Raumtheorie. Grundlagentexteaus Philosophie und Kulturwissenschaften, Frankfurt/M., 2006, S. 44-57: 55 u. 54.

7 Sabbatini, vgl. „Sabbattini: Analytik des Übergangs“, in: Ulrike Haß, Das Drama des Sehens, München, 2005, S. 322-347: 325. [Die Schreibweise des Namens Sabbattini geht offensichtlich zurück auf Willi Flemming, der die Schriften Sabbatinis erstmals ins Deutsche übertragen und herausgegeben hat (1926). Heute setzt sich indessen die Schreibweise Sabbatini durch, der ich mich hier anschließe.]

8 Eine Abbildung dieser Konstruktion der perspektivischen Szene, die vom vorausgesetzten Sichtpunkt [Augpunkt A] ausgeht, findet sich in: Hans-Christian von Herrmann, Das Archiv der Bühne. Eine Archäologie des Theaters und seiner Wissenschaft, München, 2005, S. 53. 
Der Bühnenboden dieser Stadt ist jedoch perforiert, voller Schlitze, Löcher und Klappen, weil sich unter ihm die machine befinden, genauso wie über ihr im Bühnenhimmel - mit Zugvorrichtungen, die hinter der Bühne oder von der Seite aus bedient werden. So sind plötzliche Verwandlungen möglich: Die Stadt brennt, die Hölle öffnet sich oder aus dem Bühnenhimmel fährt das Paradies herab. Die Bühne der machine stützte sich dabei auf die vernachlässigte Dimension der Höhe (mit den Richtungen oben und unten). Mit Sabbatini sind wir gänzlich in einer Welt der Volumen. Der szenische Bildraum wird von einem Maschinenraum umfasst und bildet mit ihm, „unbegrenzt ausgedehnt“, ein räumliches Kontinuum.

Die Merkmale dieser scene korrelieren auf frappierende Weise mit Descartes' Beschreibung der ausgedehnten äußeren Welt als res extensa. Der Projektionspunkt ihr gegenüber weist indessen alle Züge der res cogitans auf. Wie der Denkinnenraum ist dieser Punkt selbst ohne Ausdehnung, körperlos und gleichzeitig mit maximaler Einsehbarkeit verknüpft. An diesem Punkt der Selbstgewissheit wird „das, was sich meinem Geist so klar und deutlich zeigt“9 empfangen: Das Absolute, metaphysisch und naturwissenschaftlich, kann (ein)gesehen werden. Vielleicht bietet an dieser Stelle die Theaterlösung Sabbatinis eine mögliche Erklärung für das zugrunde liegende Raumdenken: Dieser Punkt, würde er - wie bei Descartes - als Sitz der denkenden Substanz bestimmt, befindet sich mit den Erscheinungen in einem Raum räumlicher Ausdehnung und körperlicher Fülle ohne Abstand. Der Punkt besitzt kein Volumen, er ist überhaupt keine räumliche Kategorie, aber er ist in diesen Raum eingeschlossen.

\section{Unendliche Ferne, unaufhörliche Alleen: Torelli mit Newton}

Sabbatini hatte ein dualistisches Konzept hinterlassen. Die Nachfolger haben sich mit diesem Dualismus nicht zufriedengegeben und waren bestrebt, die in machine und scene geteilte Bühne in einer einheitlichen Konzeption zu erfassen. Vor allem wollten sie das Raumbild aktivieren und den Bühnenraum als Ganzes dynamisieren. Der Name, der hier für eine fast zügellose Steigerung der Tiefenwirkung und eine ebenso hemmungslose Entfesselung von Dynamik steht, ist Giacomo Torelli (1608-1678) aus Fano.

Torelli perfektioniert die automatischen Operationen des Maschinentheaters, indem er die Bewegungsführung der Kulissen durch Schlitze im Bühnenboden in die Unterbühne verlegt und ihre Handhabung optimiert. Für seinen charakteristischen Bühnendekorationstypus führt er unterschiedliche Tradi-

9 „[C]e qui se presenteroit si clairement et si distinctement à mon esprit“. René Descartes, Discours de la méthode, hg. v. Jean-Robert Armogath/Michel Authier/Vincent Carraud, Paris, 1987 [frz. OA 1637], S. 21; vgl. auch René Descartes, Abhandlung über die Methode, dt. v. Kuno Fischer, Stuttgart, 1961, S. 19. 
tionslinien des 16. und frühen 17. Jahrhunderts ${ }^{10}$ in einem Schema zusammen, das bis zum Ende des 18. Jahrhunderts als Prototyp der Bühnen- und insbesondere Opernausstattung gilt. ${ }^{11}$ Sein Prototyp sieht gewaltige, streng axial angelegte Tiefenräume vor, die je nach Erfordernis Waldschneisen, Hafenanlagen, Grotten, Prunkstädte, Paläste oder Wolkensäle darstellen können. Torelli, dessen Arbeiten den Ruhm des venezianischen Maschinentheaters begründen, wird 1645 im Auftrag von Ludwig XIV. nach Paris gerufen und inszeniert 16 Jahre lang am Hof von Versailles. 1661 erzwingt ein Konkurrent Torellis Rückkehr nach Italien. Dort entwirft Torelli in den sechziger Jahren seines Jahrhunderts einige seiner radikalsten Dekorationstypen.

Torellis in die Ferne fliehende Alleen, die jede beliebige, illusionäre Wirkung und Tiefe artifiziell erzeugen und fingieren können, sind als Triumph über den Raum gedeutet worden. Möglich werden sie jedoch durch ein System von quasi relativen Räumen: Hinter der Tiefe der Vorderbühne wird die zweite Tiefe einer weiteren Hinterbühne eingerichtet, die sogar noch durch die Einrichtung einer dritten Hinterbühne gesteigert und im Abschlussprospekt mit der Darstellung einer weitere Tiefe kombiniert werden kann.

Torellis Alleen, gesäumt von regelmäßigen Dekorelementen, scheinen unaufhörlich. Als würde es sich bei diesen Alleen um Zeitpfeile handeln, die von den Dekorelementen in regelmäßigen Abständen skandiert oder rhythmisiert werden - wie die neue Zeit selbst, die auf einem Zeitpfeil mechanisch zerlegbar und berechenbar wird. Unaufhörliche Alleen erscheinen losgekoppelt vom körperlichen Schritt, der zu langsam erscheint, um sie zu durchmessen. Daher nehmen diese Alleen unter dem Aspekt ihrer Unaufhörlichkeit den Charakter von Sichtfluchten an. Ein Blick, der diese Alleen entlangfährt, wird ortlos. Martin Burckhardt spricht im Zusammenhang mit den Alleen der Versailler Parkanlagen vom „automobilisierten Blick“. ${ }^{12}$ Es wird eine Dynamik erfahrbar, die sich von eigenen körperlichen Rhythmen gelöst hat und das Gefühl erzeugt, den Boden unter den Füßen zu verlieren.

Torellis Fluchten erscheinen aber auch unendlich. Sie wollen die unendliche Ferne zeigen und diese Darstellung der Entfernung nicht in der Nähe, sondern in der Ferne selbst zur Erscheinung bringen. Ihr entspricht ein registrierendes, vielleicht lesendes Auge, wie es möglicherweise Schiffsreisende gegen

10 Bjurström nennt die Scenas atirica (Vitruv, Serlio, Ménestrier), mittelalterliche Himmel- und Höllendarstellungen, die Intermedientradition (Buontalenti, Parigi, Guitti), die Opernbühne. Vgl. Per Bjurström, Gioaccomo Torelli and Baroque Stage Design, Stockholm, 1962, S. 198211.

11 Das Schema des Prototyps tradiert zehn Dekorationen: Vier verschiedene Landschaften Garten, Wald, Wüste, Landschaft - ein Intérieur (gleich wo), eine ländliche Architektur mit Hafen und vier Architekturdekorationen - Palast, Salon, Tempel, reiches Gefängnis (Quelle: Encyclopédie ou dictionaire raisonné des scienes, 1772). Vgl. Bjurström (1962), Torelli and Baroque Stage Design, S. 211.

12 Martin Burckhardt, Metamorphosen von Raum und Zeit. Eine Geschichte der Wahrnehmung, Frankfurt/M., New York, NY, 1994, S. 192. Vgl. dort auch den Gedanken der Verzeitlichung der barocken Allee. 
den Horizont richten. Den Boden unter den Füßen verlieren oder lesen, registrieren: Zwei völlig verschiedene Wahrnehmungsmodi werden aktiviert, die einander ablösen. Unaufhörlich oder unendlich? In diesem doppelten, wechselnden Modus entsteht das Gefühl, als teilte sich die Welt.

In Torellis Entwürfen der letzten Jahre mehren sich die zweistöckigen Perspektiven. ${ }^{13}$ Eine große Himmelsdekoration, die sich in die Tiefe der Bühne öffnet, zeigt anstelle des axialen (leeren) Zentrums zwei ovale Wolkenkreise übereinander, in jedem einen Tempel. ${ }^{14}$ Diese doppelten Wolkenkreise können sich in anderen Dekorationen ihrerseits wieder verdoppeln. Torellis Spiel mit den Verdoppelungen in Tiefe und Höhe führen in ihrem Resultat zu einer immensen Verschärfung der Relativität des Raumes. Der Himmel ist nur einer unter mehreren. Im Umkehrschluss ist auch der vermeintlich reale Raum nur als relativer zu denken, dessen Einheit nicht mehr durch ein geometrales Raumschema gewährleistet werden kann. Kein Fluchtpunkt bietet hier mehr einen Halt.

An dieser Stelle sei auf Isaac Newtons Theorie des absoluten und relativen Raums hingewiesen, die mir auf das Engste mit den hier aufgeworfenen Fragen verknüpft zu sein scheint. Newton wendet sich gegen die cartesianische Zweiteilung der Welt, die aus einer Identifizierung von räumlichen Volumina und stofflicher Substanz resultierte. Newton macht theologische Gründe geltend, um einen absoluten Raum zu behaupten. Dieser absolute Raum sei gleichsam als „Sensorium Gottes“15 zu begreifen, durch das er überall unabänderlich währt, stets gegenwärtig, ewig. Gott ist dieser wie Raum und seine selbst unbewegliche Dauer. ${ }^{16}$ Dieser gedachte, absolute Raum ist der menschlichen Wahrnehmung nicht zugänglich, jedoch für Newtons Beschreibung objektiver Bewegung unerlässlich (die er mit seinem revolutionären Inertialsystem beschreibt). Der absolute Raum zeichnet sich durch absolute Bewegung aus, die dynamisch gedacht wird: verursacht durch die Wirkung von Kräften, die Körper mittels der Gravitationskraft aufeinander ausüben können (actio in distans). Voraussetzung für diese Bewegung durch Anziehung ist die Annahme eines leeren Raums, der von Descartes rigoros verworfen worden war. Auf diesen absoluten, von Gravitationskräften und ihrer Wirkung auf Massen durchquerten Raum geht bis heute die uns so geläufige Vorstellung vom Raum als einem Behälter zurück - ein Behälter, der unveränderlich bleibt, unabhängig davon, ob oder wie viele Dinge sich in ihm befinden, eben wie eine stabile

13 Bjurström (1962), Torelli and the Baroque Stage, S. 255.

14 Abbildung in: ebd., S. 257.

15 So der Streitpunkt in $\S 3$ des Briefwechsels zwischen Gottfried Wilhelm Leibniz und Samuel Clarke als Vertreter der Positionen Isaac Newtons 1715/1716, in: Dünne/Günzel (2006), Raumtheorie, S. 58-73: 58-60.

16 Newtons Theologie kommt nicht aus der abendländisch-christlichen Traditionslinie, sondern aus der jüdisch-kabbalistischen Tradition (Newton studierte in Cambridge u. a. bei dem Neuplatoniker Henry More) und ihren unterschiedlichen Modellen für das Mirko-/MakrokosmosDenken. Vgl. auch: Günzel (2006), Physik und Metaphysik des Raumes, S. 25. 
Kiste. Für Newton besaß dieser absolute Raum, neben seinen theologischen Implikationen, heuristische Funktion. Als absoluter Bezugsraum ermöglichte er alle endlichen, relativen, lokalen Raumordnungen im Plural: Ein universeller Container für alle relativen Räume, einem Ozean vergleichbar, auf dem das einzelne Schiff den relativen, begrenzten Raum darstellt.

Mir scheint nun, dass die Schauplätze, die sich in Torellis seriellen Räumen konkretisieren, sich zur Bühne genauso verhalten wie Newtons relative Räume zum absoluten Raum. Denn die Newton'schen Räume greifen in ähnlicher Weise ineinander, in der Torelli seine Dekorationen in den Bühnenraum schickt. Bei Torelli handelt es sich immer um dieselben Achsen, die zentral, symmetrisch in die Tiefe fluchten, nur das Dekor der Kulissen wechselt und gibt die unterschiedlichen, relativen Räume an: Waldschneise, Grotte, Hafen, Park etc. Während der relative Raum einen bestimmten Ort darstellt und endlich währt (je nach Erfordernis der Inszenierung), verhält sich die leere Bühne dazu wie der absolute Raum Newtons als ein gedachter Raum aller möglichen Standpunkte oder Perspektiven. Die szenographische Praxis Torellis behandelt oder begreift den Bühnenraum tatsächlich wie einen universellen Container für alle möglichen relativen Räume, der als solcher, stets gegenwärtig, der sinnlichen Anschauung entzogen bleibt.

Torellis leerer Bühnenraum ist nicht leer, möchte man in Anbetracht der grundständigen Einrichtungen der Bühne einwenden. Hier trifft eine Replik von Clarke auf Leibniz ins Schwarze, die Newtons Position mit folgenden Worten darstellt:

Denn unter einem leeren Raum verstehen wir durchaus keinen Raum, der von allem frei ist, sondern nur einen Raum, der von Körpern frei ist. In jedem leeren Raum ist selbstverständlich Gott gegenwärtig und möglicherweise sind auch noch viele andere Substanzen vorhanden, die keine Materie sind, da sie weder fühlbar noch Ziel eines unserer Sinne sind. ${ }^{17}$

Als „Substanzen, die nicht Ziel unserer Sinne sind“, können jedoch im leeren Bühnenraum Torellis exakt die Aufnahmevorrichtungen für die Dekorationen sowie die Maschinen zu ihrer Verwandlung gelten. Gehören sämtliche durch sie bewirkten Bewegungen des Dekors dem relativen Raum an, so sind diese Aufnahmevorrichtungen und Maschinen hinsichtlich ihrer kinetischen Möglichkeiten jedoch keinesfalls durch den relativen Raum (einer Aufführung) begrenzt, sondern tendenziell unendlich. So jedenfalls reflektieren Torellis unaufhörliche Fluchten die barocke Bühne und ihre operativen Eigenschaften selbst.

17 Briefwechsel zwischen Leibniz und Clarke, in: Dünne/Günzel (2006), Raumtheorie, S. 5873: 64. 


\section{Topologie: Andrea Pozzo mit Leibniz}

Das theoretische Hauptwerk von Andrea Pozzo (1642-1709) erscheint in zwei Bänden 1693 und 1700 in Rom. Wenig später die deutsche Erstausgabe Der Mahler und Baumeister Perspective Erster und Zweiter Theil in Augsburg. ${ }^{18}$ Zahlreiche weitere Auflagen machen es im 18. Jahrhundert rasch zu einem Standardwerk der Perspektivkunst. In diesem Werk gibt Pozzo den Plan seiner Bühne in schematischen Grundrissen und Längsschnitten wieder. ${ }^{19}$ Seine Pläne sind mathematisch exakte technische Zeichnungen, die keinen Gebäudegrundriss wiedergeben, sondern ein visuelles Schema, das sich in jeden beliebigen Raum eintragen lässt.

Diese Möglichkeit beruht auf einer ganz erstaunlichen Besonderheit. Pozzo situiert den idealen Sichtpunkt F nicht mehr im Zuschauerraum, sondern in der rückwärtigen Gebäudewand des Saales. Damit erlangt das perspektivische Schema bei Pozzo vollständige Autonomie, die jedoch auf einem seltsamen Paradox beruht. In Punkt F wird ein Zuschauer vorgesehen, der diese Stelle unmöglich einnehmen kann. Die vollständige optische Erschließung des Raums ist mithin abhängig von der Funktion eines unmöglichen Zuschauers, denn niemand kann in einer Gebäuderückwand sitzen.

Des Weiteren definiert Pozzo die Szene nicht als Raum, Volumen oder Dynamik, sondern als Bild, das auf der Grundlinie A spielt und in Distanz, Höhe und Breite dem Zuschauer gegenüber definiert ist. Wie eine Tafel, tabula heißt es bei Pozzo. Die Szene wird also als Zone der Bildherstellung und Bildwirkung bestimmt, die sich auf einen piktoralen Schnitt durch eine optische Architektur stützt. Sucht man nach einem Bildtypus, mit dem sich diese tabula vergleichen lässt, so wäre dies am ehesten das Fotonegativ als ein Bildträger, der ,von hinten' belichtet und ,von vorne“ gelesen werden kann und der sich durch seine Durchsichtigkeit auszeichnet. Es handelt sich um eine optische Fläche, entlang derer die räumliche Beziehung zwischen dem Zuschauerraum und der Bühne zerschnitten ist, und das was sie verbindet, ist dieser Schnitt.

Für die Erfassung des gesamten Raums im Schema der bildhaften, piktoralen Perspektive, ist es wesentlich, dass Pozzo, erstmals unter allen Bühnenarchitekten und Szenographen im 17. Jahrhundert, kein wirkliches Gebäude mehr zugrunde legt und von keinem Fürsten und keiner realen höfischen Versammlung mehr ausgeht. Pozzos Schema ohne räumliche oder gesellschaft-

18 Andrea Pozzo, Der Mahler und Baumeister Perspective Erster und Zweiter Theil. Erster Theil von Johann Boxbarth Kupfferstechern in Augspurg. Daselbst verlegt Jeremias Wolff Kunsthändler, 1708. Zweiter Theil von Georg Conrad Bodeneer Kupfferstechern in Augspurg. Verlegts allda Jeremias Wolff Kunsthändler, 1711. Sowie Andrea Pozzo, Rules and EXamples of Perspective Proper for Painters and Architects by ANDREA POZZO, London, 1707, reprint: New York City, NY, 1971. Die Bezeichnung der Figuren ist in den genannten Ausgaben identisch. Pozzo wird im Folgenden unter Angabe von Band/Figur zitiert.

19 Die schematischen Grundrisse und Längsschnitte der Bühne sind niedergelegt in Bd. I, Fig. 72 und in Bd. II, Fig. 24. 
liche Bezugsgröße gleicht einem weißen $\operatorname{Plan}^{20}$, der sich überall eintragen lässt. Mit dem Plan als erster Bezugsgröße ist ein Definitionswechsel des Publikums verknüpft. Aus dem Publikum werden Zuschauer, die selbst in einer piktoralen, also bildhaften, fiktiven Ordnung Platz nehmen, reduziert auf das Schauen. Keine Politik mehr, keine erotischen Vergnügungen am Rande. Der Rahmen des Theaters ist der Rahmen des Bildes, das sich zu sehen gibt.

Der Kunsthistoriker Felix Burda-Stengel beschreibt Pozzos Spiel mit den Rahmen am Beispiel der Kirche Sant‘Ignazio:

Der Rahmen ist die Grenze, die den Raum des Bildes vom Raum des Betrachters trennt, die den Kunstraum vom Realraum scheidet. Doch genau diese Grenze, an welcher der reale Raum der Architektur aufhört und der Raum der Malerei anfängt, hat Pozzo in Sant'Ignazio durch das Weglassen des Rahmens ignoriert bzw. dort wo sie trotzdem deutlich sichtbar wurde (Stichkappenzone) verwischt. Sein Ziel war es nämlich, die Trennung von Real- und Kunstraum aufzuheben und die Illusion eines Raumkontinuums zu schaffen. ${ }^{21}$

Ein Raumkontinuum, das im Fall dieser Kirche den Fußboden des Betrachters, die Säulenstellungen des Gewölbes, die lichthaften Öffnungen des Kirchenraums, die Öffnung der Kirchendecke in den Himmel und die dazwischen schwebenden Toten und Engel in einem Raum behauptet. In diesem virtuellen, unvorstellbaren Raum vollzieht sich nun das „Wunder der Raumverwandlung, die dem Betrachter die Vision vor Augen hält, in einer sich dem Himmel öffnenden Kirchenarchitektur dem Herabsinken des Himmels samt der Heiligen in den Kirchenraum beizuwohnen.“222

Die fast nahtlose Überlagerung von Realraum und fiktivem Raum erlaubt die Darstellung des Undarstellbaren. Vor allem das von Pozzo zur Meisterschaft getriebene Spiel mit den anamorphotisch verschobenen Koordinaten in Bezug auf den Betrachterstandpunkt, fiktionalisiert den Raum. Es lässt den Raum fast beliebig gedehnt, gewölbt, gestreckt oder zusammengezogen erscheinen. Diese Metamorphosen des Raums haben noch eine weitere Konsequenz: Sie mobilisieren den Betrachter. Der Betrachter kann richtige, falsche, annähernde oder verwirrende Standpunkte einnehmen. Er wird beweglich. Pozzos Kunst verschiebt den Betrachter. Es ist möglich, den Illusionsapparat von der Seite oder von außen zu betrachten und dadurch gleichsam ,auszuschalten“, während durch die Einnahme des richtigen Standpunktes der Illusionsapparat wieder „eingeschaltet“ wird. ${ }^{23}$ Man könnte jedoch auch zur Refle-

20 Zum Bedeutungswandel, den das Wort Plan von einem räumlichen Begriff (der Grundriss ,Plan', planter, planer, planer sur, plantieren, planieren) zu einem zeitlichen Projekt (das Zeitwort ,Plan‘, planen) zu Anfang des 18. Jahrhunderts durchläuft, vgl. Etymologisches Wörterbuch des Deutschen, erarb. v. einem Autorenkollektiv des Zentralinstituts für Sprachwissenschaft unter der Leitung v. Wolfgang Pfeifer, Berlin, 1989.

21 Felix Burda-Stengel, Andrea Pozzo und die Videokunst. Neue Überlegungen zum barocken Illusionismus, mit einem Vorwort v. Hans Belting, Berlin, 2001, S. 107.

22 Ebd., S. 106.

23 Burda-Stengel spricht hier von einer „Dekonstruktion der Perspektive“, ebd., S. 105. 
xion des Raums übergehen und hier die Alternative eines topologischen Verständnisses von Räumlichkeit geltend machen, wie es Pozzos Zeitgenosse Leibniz in seiner Auseinandersetzung mit der Substanzraum-Vorstellung getan hat.

Gottfried Wilhelm Leibniz bezweifelte die Notwendigkeit, für eine Raumbeschreibung vom Kräftespiel der Materie ausgehen zu müssen (wie dies Newton vertrat); vielmehr reiche die Bestimmung der Relationen von Körpern oder Beziehungspunkten aus. Leibniz begründete seinen Ansatz mit einem Argument gegen den Anthropomorphismus der zeitgenössischen Physik: Wenn man den körperlichen Vergleichsmaßstab verlässt (das Thema der unaufhörlichen, unendlichen Alleen Torellis) sind dessen Grundbegriffe (wie „Bewegung“) „letztlich bedeutungslos und deshalb aus mathematischer Sicht unbrauchbar. “24 Leibniz wendet sich gegen das Prinzip eines festen Vergleichsmaßstabs und damit gegen die Annahme einer geometral zu messenden Eigenschaft des Raums. Er entwendet der Geometrie gleichsam die „metrie“. Topologie bestimmt Raum als die Relation von Körpern oder Beziehungspunkten. In Bezug auf ihre Lagebeziehungen ist deren physikalische Beschaffenheit oder Materialität ohne Bedeutung. Topologie verabschiedet die Containerraum-Vorstellung Newtons zugunsten eines elastischen, relationalen Universums, in dem Beziehungen unablässig Raum hervorbringen, Raum zeitigen.

Inwiefern lässt sich jedoch die Figur eines mobilisierten Betrachters auf den Theaterraum übertragen, in dem doch alle Betrachter auf den ihnen zugewiesenen Plätzen sitzen und, je mehr sie zu Zuschauern werden, in möglichst regungsloser Passivität verharren?

Um den Status der Zuschauer in Pozzos Theaterraum zu verstehen, ist es sinnvoll, sich noch einmal die Wirkung der berühmten Scheinkuppeln Pozzos vor Augen zu halten. ${ }^{25}$ Diese entfalten ihr optimale illusionistische Wirkung nur von einem einzigen Punkt aus, der, wie im Fall der römischen Kirche Sant'Ignazio oder der Jesuitenkirche in Wien, durch eine Marmorplatte markiert ist. Der ideale Punkt, an dem sich das „Wunder“ der Raumverwandlung ereignet, wird symbolisch überhöht. An diesem Punkt steht der Betrachter unter einer Christusfigur oder auf der Schwelle zum Kircheninnenraum, was im übertragenen Sinn bedeutet, dass der Betrachter sich unter Christus oder unter die Obhut der Kirche stellen muss, um „richtig“ zu sehen und den Verwandlungseffekt in seiner Vollkommenheit zu erleben.

Pozzos Theaterraum geht von der Negation eines idealen Sichtpunktes aus. Die Achse ist hier nicht mehr vertikal, wie im Fall der Kuppel, sondern horizontal ausgerichtet und verläuft von einem idealen Sichtpunkt, der hinter dem Rücken der Zuschauer in der abschließenden Gebäuderückwand situiert wird,

24 Stephan Günzel, „Raum - Topographie - Topologie“, in: ders. (Hg.), Topologie. Zur Raumbeschreibung in den Kultur- und Medienwissenschaften, Bielefeld, 2007, S. 13-31: 22.

25 Vgl. Sebastian Kirsch, Das Reale der Perspektive. Der Barock, die Lacan'sche Psychoanalyse und das ,Untote' in der Kultur, Berlin, 2013, S. 315-341. 
durch den Zuschauer- und Bühnenraum bis zum hintersten Abschluss der Bühne. Der in die Gebäuderückwand verlegte, ideale Sichtpunkt hat zur Konsequenz, dass in Pozzos Theater jeder Zuschauer, ähnlich den im Kirchenraum frei beweglichen Betrachtern, nur über eine anamorphotische Teilansicht verfügt. Jeder mögliche Zuschauer verfügt nur über einen Gesichtspunkt (point de vue). Auch wenn es sich um ein und dieselbe Bühnenansicht handelt, von verschiedenen Seiten betrachtet, wird sie immer wieder anders und gleichsam perspektivisch vervielfältigt erscheinen. ${ }^{26}$ Pozzos optische Erschließung des Theaterraums ermöglicht, dass die Teilansichten sich nicht schroff brechen, sondern sich über die vorhandenen Zuschauerplätze hinweg, gleichsam wohltemperiert, ausbreiten. Die in diesem Theaterraum anerkannte Multiperspektivität entfaltet sich somit auf der Grundlage einer größtmöglichen Ordnung. Diese Ordnung kennt keinen einzelnen herausragenden Fixpunkt (sie hat ihn ausgeschlossen), sondern anerkennt in der relationalen Verwebung der je begrenzten, voneinander verschiedenen Gesichtspunkte das Ganze einer Ordnung, die als solche jedem Einzelnen unzugänglich bleibt. Erst in der Verbindung mit diesem Unzugänglichen entfaltet sich der barocke Perspektivismus, von dem Deleuze sagt, dass er „keine Variation der Wahrheit je nach Subjekt [ist], sondern die Bedingung, unter der dem Subjekt die Wahrheit einer Variation erscheint“. ${ }^{27}$

\section{Von der Schau-Bühne zur Relation beweglicher Körper}

In der Entwicklung von Theaterräumen im 17. Jahrhundert zeichnen sich nicht nur neuartige „Inszenierungen des Sehens“ ${ }^{\text {28 }}$ ab, die mit einer Logik der Bühne als Bild verknüpft sind und möglicherweise im weitesten Sinne zu einer Vorgeschichte des Kinos gezählt werden können, sondern auch ein Hadern mit den ungelösten Problemen eines Verhältnisses von Körperwelt und räumlicher Ausdehnung. Visibilität und Räumlichkeit überlagern einander. Sie treten zunächst, bei Descartes, nahezu verschmolzen miteinander auf. Im Verlauf der weiteren Entwicklung lassen sie jedoch immer deutlicher einen Abstand erkennbar werden, der zwischen Bildräumen der Bühne, den zugrunde liegenden mathematischen Raumentwürfen und der Vielzahl beweglicher Körper mit ihrer Vielzahl beweglicher Perspektiven immer stärker aufklafft. Schließlich tritt bei Pozzo im ausgehenden 17. Jahrhundert dieses Spannungsverhältnis in

26 Vgl. Gottfried Wilhelm Leibniz, Monadologie, Frz./Dt., hg. v. Hartmut Hecht, Stuttgart, 1998, Lehrsatz 57. Zur „größtmöglichen Ordnung“ und Relationalität vgl. auch Lehrsatz 58, 60 u. 61.

27 Gilles Deleuze, Die Falte. Leibniz und der Barock, Frankfurt/M., 2005, S. 37.

28 Kati Röttger/Alexander Jackob (Hg.), Theater und Bild. Inszenierungen des Sehens, Bielefeld, 2009, vgl. darin u. a. die Beiträge von Meike Wagner, Wolf-Dieter Ernst und Günther Heeg; ebenso die Akzentuierung der Bühne als Bild in meiner Pozzo-Darstellung in: „Pozzo: Architektur des Sehens“, in: Haß (2005), Drama des Sehens, S. 366-378. 
ein gleichzeitiges Einerseits und Andererseits auseinander. Einerseits wird dem cartesianischen „video“ ${ }^{\text {“29 }}$ zur größten Kunstentfaltung verholfen, andererseits wird die Vielzahl relativer Perspektiven als ein in sich selbst ungleichzeitiges, räumliches Geflecht begriffen. Dieses selbst unanschauliche Geflecht zeitigt Raum, der sich jedoch nicht selbst räumlich-horizontal konkretisiert, sondern in der Vertikale des Erlebens spielt.

Suchen wir nach einem Begriff der Bühne im engeren Sinn, so lässt sich einzig die Bühne Sabbatinis mit Descartes im wortwörtlichen Sinn als eine Schau-Bühne bezeichnen. Descartes’Außenwelt, die von ausgedehnten Körpern aller Art - ohne die Möglichkeit eines Vakuums - in unterschiedlicher und wechselnder Dichte ausgefüllt wurde, war körperlich erfahrbar. Im Unterschied zur Descartes' Theorie der visuellen Erfahrung, die auf einer Trennung von Außenwelt und einer inneren, ,blinden', bloß denkenden Verarbeitung von Sinnesdaten beharrte, sollte in der Raumfrage für Descartes ein universales Verhalten von Körpern unmittelbar einsehbar sein und wahrgenommen werden können.

In dieser Modellierung schwingt der Fetisch der „Einsehbarkeit“ im doppelten Wortsinne mit. Die Außenwelt strömt, wie das Sabbatinis Pratica Di Fabricar Scene e Machine Ne'Teatri [1637/38] zeigen, aus dem Bildraum der Bühne dem vorausgesetzten Betrachter entgegen. In seinem Auge bündeln sich die Perspektiven der Bildbühne, auf sein Auge hin sind sie berechnet, der Fluchtpunkt liegt ihm gegenüber. Das geometrale Schema wird in einer Welt angewendet, die zweigeteilt ist. In ihr stehen sich räumliche Spektakel und ein Cogito (video) gegenüber: Der Spektakelraum als substanzielles Kontinuum und das Cogito an einem unräumlichen Sichtpunkt. Die Außenwelt ist eine Bühne, auf der sich die Körper ereignen, d. h. bewegen, indem sie aus einem Ort in einen anderen übergehen und ihre relativen Eigenschaften wechseln. Dies geschieht unablässig, ohne Lücke, Mangel oder Hinterhalt. Weil Körper ihre Volumina nicht loswerden können und ein leerer Raum undenkbar ist, sind sie ihrer Wahrnehmbarkeit absolut ausgesetzt. Zugleich besagt dieses Modell jedoch auch, dass das Cogito am ausgezeichneten Sichtpunkt sich nur in der Hülle der Vor-Stellung und nicht als etwas Zugrundeliegendes hat. ${ }^{30} \mathrm{Da}-$ zwischen entfaltet sich das universale Spiel mit Hilfe jener machine, die vor keiner noch so entlegenen Darstellung zurückschreckt - nur denkbar muss sie

${ }^{29}$ Eine eindringliche Darlegung der engen Verbindung zwischen Video (Brunelleschi) und Cogito (Descartes) als Konsequenz eines Projektionsapparats auf der Basis einer ontologischen Entscheidung (die Welt als sichtbare zu definieren), findet sich bei: Jean-Louis Déotte, Video und Cogito. Die Epoche des perspektivischen Apparats, aus dem Frz. v. Heinz Jatho, Zürich, Berlin, 2006, vgl. bes. S. 21-23 u. S. 39-74.

30 Vgl. Jean-Luc Nancy, „Lavartus pro Deo“, in: Volker Bohn (Hg.), Bildlichkeit, Frankfurt/M., 1990, S. 468-501. 
sein. ${ }^{31}$ Was geschaut wird, gleicht insofern einer Selbst-Sicht, und die Bühne ist ein Trompe-l'Eil ohne Alternative.

Torellis Bühne ist viel abstrakter und spekulativer im Wortsinne. Sabbatini versucht zusammenzufassen und die Wissenschaft der Perspektive für die Bühne praktikabel zu machen. Torelli versucht in allem über die herkömmliche empirische oder praktische Erfahrung hinauszugehen, indem er sich auf jene operativen Einrichtungen der Bühne stützt, die als solche nicht das Ziel der sinnlichen Erfahrung sind. Ziehen wir noch einmal das Standardbeispiel vom relativen Raum eines Schiffes im absoluten Bezugsraum des Ozean heran: Torelli nimmt die machine als einen solchen Bezugsraum aller möglichen Perspektiven und ihrer Dekorationen an. Er entdeckt die Glätte, das Potenzielle, das Unaufhaltsame in der Wirkung von Kräften aufeinander, kurz: das Kinematische der Maschinen als einen gleichsam ozeanischen Container für alle nur denkbaren relativen Räume. Diese werden auf der Grundlage von Abmessungen, Punkten, Dimensionen, Kerbungen aller Art wie den zwei mal vier Schrägkulissen, den Fluchtlinien, ihren Schnittpunkten usw. auf der Bühne als arithmetischem Boden eingerichtet. Das Artifizielle der Bühnen Torellis beruht auf der Anerkennung der jeweiligen Eigenart dieser beiden Räume sowie in der Erkenntnis, dass sie nur als und wegen ihrer wechselseitig ineinandergreifenden Ordnungen vorkommen. Aus der maschinellen Perspektive ist der relative Raum eine (geo-)metrische Teileinheit, die unendlich variabel bestückt werden kann. Aus der Perspektive des relativen Raums ist der maschinelle Container pure Kinematik und Dynamik, ohne eine feststellbare Ursache der Kraft.

Torellis Bühnen reflektieren die raumbildende Dynamik dieser doppelräumlichen Anlage. Körperweltliche Relationen sind nur innerhalb dieser Anlage denkbar, die einerseits alle physikalischen Körper entortet und sie andererseits metrisch einbezieht. Die Bühnendynamik zeitigt ihre Wirkungen in einem, von der machine wie von einem Container umschlossenen Raum. Torelli, der anders als Sabbatini oder Pozzo kein Kompendium seiner Bühnenkunst und kein Architekturbuch hinterlassen hat, weist in seinen Dekorationstypen die Produktivität eines radikalen, räumlichen Subordinationskonzepts aus.

Demgegenüber setzt Pozzos Bühne wieder mit der Frage nach Sichtpunkten und Zuschauern ein, die er - anders als Sabbatini - im Plural voraussetzt. Aus dieser Drehung ergibt sich, dass für Pozzo der Theaterraum kein geometrales Gebilde oder Behältnis ist, sondern eine optisch erschlossene chose idéale (Leibniz). Der Raum beherbergt nicht mehr, sondern setzt sich aus einer Vielzahl von beweglichen Körpern und möglichen Orten bzw. Gesichtspunkten (points de vue) zusammen, wobei die Ausdehnung auf die Relation zwischen ihnen zurückgeführt wird. Die raumbildenden Prozesse werden in diesem rein relationalen Lageraum der Imaginationskraft überantwortet, die für sich ge-

31 Für Sabbatini zählen dazu: plötzliche Bewölkungen des Himmels, in Feuer aufgehende Städte oder Wälder, Hölle, himmlische Fahrzeuge, Erscheinung der Zwölfgötter, das Paradies etc. 
nommen keinen Fixpunkt kennt. Pozzos Bühne arbeitet am Ort der Imagination. Sie ist, so ließe sich hier Leibniz paraphrasieren, „kurzum das, was sich aus den Orten ergibt, wenn man sie zusammennimmt. ${ }^{\text {“32 }}$

Über Pozzos relationalen Raum und seine Bühne am Ort der Imagination geht das 18. Jahrhundert als die Epoche der Literatur und der Literalisierung des Theaters nicht hinaus, obwohl es natürlich Variationen und Verfeinerungen gibt, die vor allem im Bereich der malerischen und lichtgestalterischen Perfektionierungen liegen. Der nächste Schritt ist die Implementierung des Schauspielers auf den optisch erschlossenen Bühnen. Mit ihr setzt eine lange Periode des Haderns ein, das zwischen der physischen Realität des Schauspielers und einem fiktiven, imaginären Bühnenraumkonstrukt spielt.

Im 19. Jahrhundert vollzieht sich langsam ein Umschwung, der auf eigenartige Weise mit Veränderungen in der Auffassung vom Physisch-Realen in den Raumtheorien von Physikern korreliert. Einstein nennt die Erforschung des wellenförmigen Charakters des Lichts durch Thomas Young und Augustin Jean Fresnel und deren Annahme eines allgegenwärtigen Äthers als Trägermedium von Lichtwellen sowie die Entdeckung elektrischer und magnetischer Felder und die Entwicklung der Feldtheorie durch Michael Faraday und James Clerk Maxwell..$^{33}$ Naturwissenschaftliche Raumtheorie ist auch im 19. Jahrhundert nicht nur eine Angelegenheit der Physik. Vor allem ihre Modelle erhalten die Aufmerksamkeit in allen gesellschaftlichen und künstlerischen Bereichen, die soziologisch, politisch, kosmologisch oder ästhetisch mit Raumfragen umgehen. Zu den Modellen der Anschauung, des relationalen Raums und der Topologie gesellen sich im 19. Jahrhundert die Modelle der Wellenform und des Äthers (von zweifelhaften mechanischen Eigenschaften) sowie die des Feldes.

In den Weiterentwicklungen des Theaters im 19. Jahrhundert wird die Entdeckung des Musikalischen bedeutsam. Das Musikalische wird im gereimten Vers eingesetzt (Klassik), es wird als vergessene Komplementärform des Wortdramas entdeckt (Wagner) oder als Ursprung des Theaters „aus dem Geist der Musik“ (Nietzsche) behauptet. Das Musikalische hat, vom Modell her betrachtet, Ähnlichkeit mit einem von Lichtwellen durchsetzten Raum. Ähnlich wie das Licht stützt sich auch die Akustik auf eine gespenstische Allgegenwart von Wellen und ist selbst untastbar. Andererseits weisen akustische Wellen zahlreiche Interferenz- und Verstärkungsphänomene auf und bilden einen relationalen Raum mit den hörenden Körpern. Die Annahme eines Feldes liegt hier sehr nahe.

An dieser Stelle ist auf Appia einzugehen, der mit der Containerraum-Vorstellung denkbar konsequent aufräumt und an ihrer Stelle ein relatives, von der

32 Leibniz in seinem fünften und letzten Brief an Samuel Clarke [1716]: „Raum ist kurzum das, was sich aus den Orten ergibt, wenn man sie zusammennimmt.“ Zit. n. Dünne/Günzel (2006), Raumtheorie, S. 69.

33 Albert Einstein, „Raum, Äther und Feld in der Physik“ [1930], in: Dünne/Günzel (2006), Raumtheorie, S. 94-101: $96 \mathrm{f}$. 
Raumzeit eines Ereignisses abhängiges Raumverständnis entwickelt. Indem Appia sein Inszenierungsverständnis immer kompromissloser auf den Schauspieler als alleinigen Träger der Inszenierung stützt, dringt er zu einer eigenartigen, nicht-anthropozentrischen Ökologie der Bühne vor, in der Dinge, Licht und Farben zu den entscheidenden Mitspielern rhythmischer Räume werden.

\section{Appia: Rhythmische Räume}

Der Genfer Adolphe Appia (1862-1928), der in Zürich, Leipzig und Dresden Musik studiert hat, bewundert Wagner als Theoretiker des Wort-Ton-Dramas und als musikdramatischen Komponisten und ist zugleich extrem enttäuscht von Wagners szenischen Realisierungen in Bayreuth. Appia ist der Auffassung, dass die mise en scène bereits in der Partitur enthalten ist. Indem Wagner als Regisseur den visuellen Raum der Bühne einer besonderen Inszenierung unterziehe, habe er die Konsequenzen seiner eigenen musikdramatischen Revolution nicht begriffen. Um die grundlegenden Beziehungen zwischen Musik und Bühne zu studieren, widmet sich Appia intensiv dem Wort-TonDrama Wagners. Er analysiert die Partituren, die Libretti, ihre Dramaturgien und konkretisiert seine Ergebnisse in Bildentwürfen für einzelne Szenen. Dabei sucht Appia einen Weg der unbedingten dekorativen Zurücknahme, der Einfachheit, der Abstraktion und der dramaturgischen Konzentration auf wenige, tragende Elemente. Da ihm jeder Versuch einer praktischen Realisierung in dieser Zeit verwehrt wird, legt er seine Forschungsergebnisse notwendigerweise theoretisch und in zahlreichen Zeichnungen nieder. Seine Konzeption für „die Übertragung der Musik aus der bloßen Zeitlichkeit in die sichtbare Räumlichkeit“"34 fasst er 1899 in seiner Schrift La musique et la mise en scène zusammen, die noch im selben Jahr ins Deutsche übersetzt wird.

Musik verräumlicht, sie bringt selbst Räume hervor. ${ }^{35}$ Indem sich Appia den räumlichen Eigenschaften der Musik zuwendet, entfernt sich sein Denken von Wagner. „Dieses Buch ist also kein wagnerianisches im eigentlichen Sinne mehr“‘36, hält Appia fest. Die szenische Form gehe aus dem dichterisch-musi-

34 Adolphe Appia, Die Musik und die Inszenierung, aus dem Frz. v. F. Bruckmann, München, 1899, S. 11.

35 „Wenn wir sagen: die Musik übertrage sich ,auf die Bühne‘, so trifft dieser Ausdruck eigentlich auch nicht zu: Die Musik überträgt sich ,auf' nichts; sie wird vielmehr selbst zum Raum, dieser ist latent schon in ihr vorhanden.“ Ebd., S. 63. [Herv. i. O.]

36 Adolphe Appia, „Erfahrungen mit dem Theater und persönliche Überlegungen“ [1921]. In dieser Schrift reflektiert Appia die Entwicklung seiner Positionen und nimmt vielfach auf Die Musik und die Inszenierung Bezug. Auszüge aus diesem Text sind übersetzt und in zwei Teilen (im Kapitel „Texte zur Reform der Theaterinszenierung“ und im Kapitel „Visionäre und prophetische Texte") wiedergegeben in: Richard C. Beacham, Adolphe Appia. Künstler und Visionär des modernen Theaters, Berlin, 2006, S. 65-69 u. S. 368-374: 69. Vgl. Adolphe Appia, „Expériences de théâtre et recherches personelles“, in: ders., Oevres complètes I-IV, Edi- 
kalischen Text mit seinen Rhythmen, Tempi, Betonungen, Stimmungen und seinem gesamten gestischen Vokabular selbst hervor. Dass dieser Text „per definitionem die theatralische Form, das heißt seine Projektion in den Raum [enthalte] “37, sei eine Folge aus jener Struktur, die Appia als die „normale Hierarchie der Bühne“"38 bezeichnet, welche Wagner „nicht begriffen“ habe und „deshalb gescheitert ${ }^{\text {(39 }}$ sei.

Was macht Appia hier? Er bezieht sich, wie Wagner, auf das moderne Problem der Trennung von Oper und Drama im 17. Jahrhundert, jedoch nicht aus historischem Interesse, wie er betont, sondern weil das gesprochene Drama und die Oper den gleichen szenischen Konventionen unterliegen und sich von daher unausgesetzt beeinflussen würden. Die Möglichkeiten der Wort-TonDichtung seien von Wagner negiert worden, indem er eine zusätzliche, szenische Interpretation des dramatischen Textes durchführte und diese mithilfe beliebiger visueller Vorstellungen „ohne organischen Zusammenhang mit dem tondichterischen Text ${ }^{\star 40}$ inszenierte. Appia betont hingegen, dass für den poetisch-musikalischen Text weder das szenische Bild noch das dramatische Wort als Inszenierungsprinzip anerkannt werden können, sondern nur ein „ordnendes Prinzip, welche die Inscenierung ausdrücklich vorschreibt, ohne nochmals durch den Willen des Dichters hindurchzugehen“. ${ }^{41}$ Als dieses, dem Drama inhärente künstlerische Prinzip, das in die Verräumlichung der Inszenierung zu überführen vermag, gilt Appia die Musik im weitesten Sinne einer musikalischen Struktur. In ihr liegen Verhältnisse, Aufeinanderfolge und Bewegungen eines poetisch-musikalischen Textes fest, der somit als relationales, rhythmisches Gefüge aufgefasst wird. Das Wort-Ton-Drama ist zuallererst Kom-position, und die Inszenierung ist ihr raumzeitliches Ereignen. ${ }^{42}$ Musik wird nicht im engen Sinn, sondern als musikalische Relation im weitesten Sinn akzentuiert. Appia betont: „Aus der Musik (im weitesten Sinne des Wortes) entspringt die Conception des Dramas “43, also die gesamte rhythmische Struktur eines aus Wort und Ton gefügten Textes, den Appia gleichzeitig mit dem Begriff Drama und Partitur bezeichnet. Da uns die Ausdruckseite des Dramatikers als solche verschlossen bleibt (und dies auch bleiben soll) ${ }^{44}$, gewinnt die rhythmi-

tion élaborée et commentée par Marie L. Bablet-Hahn, Société suisse du théâtre, Montreux, 1983-1992, Bd. IV, S. 36-56.

37 Appia (1921), Erfahrungen mit dem Theater, zit. n. Beacham (2006), Adolphe Appia, S. 68.

38 Ebd., S. 65.

39 Ebd., S. 67 f.

40 Ebd., S. 68.

41 Appia (1899), Die Musik und die Inszenierung, S. 15.

42 Appia spricht von „Veränderungen, die die Musik in der Dauer bewirkt und durch die Dauer im Raum“. Vgl. ders. (1921), Erfahrungen mit dem Theater, zit. n. Beacham (2006), Adolphe Appia, S. 65.

43 Appia (1899), Die Musik und die Inszenierung, S. 23. Vgl. ebd. die schematische Darstellung der „Hierarchie“ szenischer Mittel, welche sich für Appia aus einer Analyse der technischen Beziehungen zwischen Drama (Wort/Ton) und Bühne (Darsteller, Aufstellung, Beleuchtung, Malerei) ergibt.

44 Appia (1921), Erfahrungen mit dem Theater, zit. n. Beacham (2006), Adolphe Appia, S. 67. 
sche Struktur des Materials überragende Bedeutung. Man muss ihnen als Regisseur nur zuhören, sagt Appia, gut zuhören und gehorchen. ${ }^{45}$

\section{Szenische Ökologie}

Doch es geht nicht nur um zeitliche Strukturen und deren Verräumlichung, sondern vor allem um eine „l'art vivant““46, eine Kunst des lebendigen Werdens, was zunächst eine Frage nach dem Darsteller aufwirft. Nach Appia entlasten die „formalen Befehle des in der Partitur verborgenen Lebens“447 die Darsteller von einer schauspielerischen Ausdrucksfunktion, denn Ausdruck liegt in der Musik schon vor und entfaltet sich als sinnlich und sinnhaft erfahrbare Qualität in der Verräumlichung. Im Wort-Ton-Drama ist der Darsteller kein Zentrum, kein höchster Vermittler, kein privilegiertes Medium, sondern lediglich „eines der Ausdrucksmittel“48 unter anderen. Appia fordert daher vom Darsteller (l'acteur) „den höchstmöglichen Grad von Entpersönlichung“ “ ${ }^{49}$ Nur wenn er von persönlichem Ausdruckwillen absieht, sei der Darsteller in der Lage, in die vielgliedrigen Beziehungen der Szene einzutreten, sich also szenisch als ,Mit'-Spieler zu verhalten. Der Darsteller sei jeglicher mimetischen Mission enthoben, damit er ,zu seinen darstellerischen Mitarbeitern: der Aufstellung, der Beleuchtung, der Malerei, in Beziehung treten und Anteil nehmen [kann] an ihrem gemeinschaftlichen Leben “. ${ }^{50}$

Paradoxerweise speist sich Appias szenische Ökologie aus der Konsequenz, mit der er den Körper des Darstellers in Betracht zieht. Im Zentrum seiner Kritik am Illusionismus der Perspektivbühne finden wir die Frage nach dem Körper des Darstellers und sein Hadern mit dem unauflöslichen Widerstreit zwischen gemalten Kulissen und Bühnenboden (was auch immer das sei, sagt Appia). Der Boden steht in Verbindung mit dem Körper des Darstellers. Er ist die Fläche, die ihn trägt und auf der er sich bewegt. Demgegenüber gehören die vertikalen Kulissen zu einer ganz anderen Ordnung. Nach dem Prinzip des Trompe-l'Eil bieten sie Bilder zur Szene auf dekorativen, vertikalen Prospekten, die keinerlei Verbindung mit dem Bühnenboden eingehen (einschließlich der ungelösten Übergänge der Kulissen an ihren unteren oder oberen Kanten). Appia verlangt die Abschaffung aller gemalten, vertikalen Kulissen, denn der „menschliche Körper ist nicht bestrebt, die Illusion der Wirklichkeit zu erzeu-

\footnotetext{
Ebd., S. 68.

Adolphe Appia, L'oevre d'art vivant, Genève, Paris, 1921. [1919] Appia unterscheidet darin: La durée vivante, l'espace vivant, la couleur vivante; siehe auch: ders. (1983-1992), Oevres complètes, Bd. III, S. 355-411.

47 Appia (1899), Die Musik und die Inszenierung, S. 13.

48 Ebd., S. 15.

49 Ebd., S. 41.
}

${ }^{50}$ Ebd. 
gen - er selbst ist die Wirklichkeit! Er verlangt vom Bühnenbild bloß, dass es diese Realität zur Geltung bringt““. ${ }^{1}$

Von der Wirklichkeit dieser Körper ausgehend, verbietet sich jeder symbolisch überhöhende, oder bloß bildhaft-dekorative Umgang mit den Körpern der Darsteller. Appia verlangt an dieser Stelle eine Umkehr der Denkbewegung. Der Raum der Bühne ist nicht als Ausdrucksträger gegeben, er ist kein Container, genauso wenig wie lebendige Körper zum Behälter von Ausdruck oder Vermittlung von Darstellung missbraucht werden dürfen. Lebendige Körper, welche Wirklichkeit sind, können nicht mit der Aufgabe betraut werden, Wirklichkeit, die ihnen in diesem Fall aberkannt oder als mangelnde unterstellt wird, erst zu erzeugen. Gefordert wird vielmehr ein Denken, das eine vorhandene Wirklichkeit sich ereignen, sich öffnen lässt und „zur Geltung bringt“ - denn ohne Entfaltung ist die Wirklichkeit dieser Körper etwas bloß Lebendiges, vielleicht Organisches am Rand seiner Umwelt. „Ein Gemälde, das in eine Kiste eingeschlossen ist, existiert nicht“"52, hält Appia zum Vorgang einer notwendigen Öffnung fest. Für die mögliche Entfaltung ist jedoch ein raumspendendes Denken erforderlich, ein Denken der Einräumung oder ein Denken des Raumgebens.

Im Sinn einer szenischen Ökologie schlägt Appia eine ganze Phalanx szenischer Mitspieler vor. Unbelebte Körper, Volumen, ansteigende oder abfallende Ebenen, Treppen, Corpi, die er Praktikabeln nennt, sollen in Kontakt mit dem Körper des Darstellers treten. Praktikabeln sind Mitspieler der Körper der Darsteller. Sie intensivieren die Positionierungen und Bewegungskombinationen der lebendigen Körper im Umgang, den diese mit jenen haben. Neben diesen Praktikabeln gilt Appia das Licht als das wichtigste Gestaltungsmittel des Szenographen. Raum entsteht mit dem Licht. Durch Licht können sich Räume ausdehnen oder zusammenziehen, können Orte der Bühne hinzugefügt oder weggenommen werden. Das Licht ermöglicht den mitspielenden Raum, den Raum als permanent wechselnde Form oder auch den Raum als Ko-Akteur. Mit der „flüssigen Lenksamkeit“ ${ }^{\text {53 }}$ des Lichts in seinen verschiedenen Brechungen geht wiederum die Farbe einher. Fließendes und dynamisch gestaltetes Licht ruft Farben hervor, verändert sie. Die Farbe wird damit als etwas begriffen, das jenseits der Information (,hier ist Blau“) zu einer erlebten Farbe wird („,dieses Blau“). Für das Material der Inszenierung lässt Appia insgesamt nur diese vier Komponenten zu, die sich untereinander und im stetigen Wechsel verflechten und so eine „wahrhaft unbegrenzte Zahl von Möglichkeiten““54 schaffen: die Darsteller, die Corpi (Praktikabeln), das Licht und die Farben.

51 Ebd., S. 47. [Herv. i. O.]

52 Appia (1921), Erfahrungen mit dem Theater, zit. n. Beacham (2006), Adolphe Appia, S. 370.

53 Appia (1899), Die Musik und die Inszenierung, S. 50.

54 Ebd., S. 94. 


\section{Chorische Räume}

Die gedankliche Bewegung von Appia ist außerordentlich. Indem ihm klar wurde, wie er rückblickend festhält, dass „der Schauspieler die Inszenierung war ${ }^{\text {(555 }}$, verwirft er das Theater, das seit dem Ausgang der Renaissance unter der Vorherrschaft des Visuellen stand und erklärt das Musikalische (Partitur) zur Grundlage der raumzeitlichen Entfaltung einer Komposition. Damit neigt sich Appia - wie auch Nietzsche mit der Geburt der Tragödie aus dem Geist der Musik - zu jener chorischen Ebene hin, die im Theater seit jeher mit Tanz und Gesang verknüpft ist. Diese Richtung konkretisiert sich in der Zusammenarbeit von Appia mit Émile Jaques-Dalcroze (1865-1950), den er 1906 kennenlernt. Jaques-Dalcroze lehrt seine Schüler, Musik durch körperliche Bewegungen zu verräumlichen und bezeichnet sein System, das er für eine bessere seelisch-körperliche Integration in reformpädagogischem Sinn entwickelt hatte, als Rhythmische Gymnastik. Appia reagiert enthusiastisch auf die Arbeit von Jaques-Dalcroze. Er begreift im Vorgang ihrer räumlichen Ausdehnung und Verkörperlichung sowohl die entgrenzenden als auch die organisierenden Aspekte des Musikalischen: „L'extériorisation de la musique [...] est l'idée dont je vis depuis de longues années. D'autre part, la vie du corps tend à l'anarchie, donc à la laideur; et c'est la musique qui doit le libérer en lui imposant sa discipline. “56

Appia suchte nach einer Übertragung dieser Erkenntnis für die Bühne, hatte aber jetzt keine konkrete Partitur, kein konkretes Drama und keinen anderen szenischen Anhaltspunkt mehr für seine Arbeit am Bühnenraum. Auf Bitten von Dalcroze, der regelmäßig öffentliche Demonstrationen seiner Arbeit mit den Schülern gibt, entwickelt Appia 1909 eine Serie von Espaces Rhythmiques. Seine Zeichnungen zeigen weder architektonische Ensembles, noch menschliche Figuren, sondern offene, gegliederte Räume, die mit Treppen, Schrägen, Kuben und Säulen ein Spiel von Licht und Schatten, Nähe und Ferne, Horizontale und Vertikale, Statik und Dynamik entfalten. Sie scheinen einerseits einer früheren Überzeugung Appias zu folgen: „Le mouvement du corps humain demande des obstacles pou s'exprimer; tous les artistes savent que la beauté des mouvements du corps dépend de la variété des points d'appui que lui offrent le sol et les objets. “57 Andererseits bieten sich die Espaces Rhythmiques als Öffnung für etwas dar, das als solches weder konzipiert noch inszeniert, wohl aber erwartet werden darf. Auch hier geht es um eine

\footnotetext{
Appia (1921), Erfahrungen mit dem Theater, zit. n. Beacham (2006), Adolphe Appia, S. 66.

Adolphe Appia, „Undatierter Brief an Jaques-Dalcroze“ [Mai 1906], in: ders., Oevres complètes I-IV, Edition élaborée et commentée par Marie L. Bablet-Hahn, Société suisse du théâtre, Montreux, 1983-1992, Bd. III, S. 3.

57 Adolphe Appia, „Comment réformer notre mise en scène“ [1902], in: ders., Oevres complètes I-IV, Edition élaborée et commentée par Marie L. Bablet-Hahn, Société suisse du théâtre, Montreux, 1983-1992, Bd. II, S. 348.
} 
Nuance. Die Espaces Rhythmiques erwarten nicht einfach „le corps humain““58, wie die Herausgeberin der Schriften Appias schreibt, sondern eine Bewegung, die in sie hineingetragen wird und die von irgendwoher kommen kann (Darsteller, Musik, Licht, Farbe) und sie verändern und zu Mitspielern machen wird. Ein lebendiger Körper ist nicht im Raum - der Raum ist in den Körpern. Unwillkürlich wechselt Appia in seiner (späteren) Beschreibung einer polyzentrischen, räumlichen Ausdehnung in den Plural: „,[L]'Espace est notre vie; notre vie créel'espace; notre corps l'exprime. [...] pour mesurer l'espace, notre corps a besoin du Temps! La durée de nos mouvements a donc mesuré leur étendue. Notre vie crée l'espace et le Temps, l'un par l'autre.“599

Szenische Kunst als l'espace vivant entsteht zwischen Lebenden, die sich mit solchen räumlichen Formen austauschen, die nicht diejenigen des Körpers sind und auf diese Weise permanent wechselnde Zwischenräume erzeugen, Raum hervorbringen. Appia verdeutlicht seinen Gedanken am Beispiel einer ko-agierenden Säule:

Prenons un exemple, et supposons un pilier vertical, carré, aux angles droits nettement accusés. Ce pilier repose, sans soubassement, sur des dalles horizontales. Il donne l'impression de stabilité et de résistance. Un corps s'en approche. Du contraste entre son mouvement et l'immobilité tranquille du plier naît déjà une sensation de vie expressive, que le corps sans plier et le pilier sans ce corps qui avance n'auraient pas atteinte. De plus, les lignes sinueuses et arrondies du corps diffèrent essentiellement des surfaces planes et des angles du pilier, et ce contraste est par lui-même expressif. Mais, le corps vient à toucher le pilier, l'opposition s'accentue davantage. Enfin le corps s'appui contre le pilier dont l'immobilité lui offre un point d'appui solide: le pilier résiste; Il agit! L’opposition a créé la vie de la forme inanimée: l’Espace est devenue vivant! ${ }^{60}$

Die Interkonnektion von unbelebten Formen und beweglichen Körpern erzeugt Raum, den Appia als espace vivant, als lebendigen Raum oder Raum des Lebendigen bezeichnet. In diesem interkonnektiven Raum mit diesen Körpern und wiederum unter ihnen (im Plural) entsteht das lebendige Kunstwerk, das Ouevre d'art vivant. Die Körper bewegen sich rhythmisch, das heißt als konfigurierte Körper. Die Rhythmik, sagt Appia, befreie uns davon, uns selbst darzustellen oder uns selbst zu verkörpern. Sie bringt uns „in lebendigen Kontakt mit unseren Mitmenschen“. ${ }^{61}$

1921 äußert sich Appia selbstkritisch zur seinen Zeichnungen der Espaces Rhythmiques. Sie seien noch zu sehr

auf eine Aufführung ausgerichtet, die sich den Augen der anderen darbietet. Folglich umfassen sie nur einen Teil des Saals. Heute bin ich für die Inszenie-

\footnotetext{
58 Marie L. Bablet-Hahn, „Kommentar“, in: Adolphe Appia, Oevres complètes I-IV, Edition élaborée et commentée par Marie L. Bablet-Hahn, Société suisse du théâtre, Montreux, 19831992, Bd. IV, S. 524-525: 524.

59 Appia, „L'oeuvre d'art vivant“ [1919], in: Appia(1983-1992), OC III, S. 387.

60 Ebd., S. 372 f. [Herv. i. O.]

61 Appia, (1921), Erfahrungen mit dem Theater, zit. n. Beacham (2006), Adolphe Appia, S. 370.
} 
rung bei den extremen Konsequenzen des hierarchischen Prinzips angelangt, wenn es aus dem Theater heraustritt und auf die lebendige Kunst angewandt werden will. Ich konzipiere einen Raum ${ }^{62}$

- und dann beschreibt Appia den Theaterraum von Hellerau ${ }^{63}$ : ein großer, hoher, leerer Raum mit Übungsboden (terrain d'étude) und beweglichen Elementen (Pratikabeln), die bei Bedarf herbeigeholt oder weggeräumt werde können. Der Saal hat Tageslicht, kann aber auch verdunkelt werden. Er hat eine vollständige Beleuchtungsanlage. Der Raum ist neutral, ganz mit hellem Stoff bespannt. Wenn mehrere etwas vorführen wollen, können nach Bedarf schnell Bänke aufgestellt werden. Doch gewöhnlich gehöre der Saal den Lernenden/Schülern. Keine frontale Anlage. Die Anwesenheit eines Publikums sei nicht unbedingt notwendig für die l'art vivant. Und wenn die Ausführenden ihre Arbeit und Anstrengungen einem Publikum schenkten, so tangiere das nicht wirklich das Leben der Kunst.

Der Weg, den Appia ausgeschritten hat, führt ihn über eine Kritik des modernen Theaterraums, in dem das exemplarische Element die einseitige Sichtbarkeit der szenischen Repräsentation ist, zur Entdeckung der raumbildenden Prozesse auf der Ebene der Musik, die er entlang der von ihm sogenannten „Hierarchie des Theaters“ als grundlegende raumzeitliche Struktion des Theaters erkennt (das, was am Theater schon immer und in Gänze Musik war). Bezogen auf die Topologie des Theaterraums geht er damit vom Ort der Bühne zum Raum der Architektur über, um sich in einem dritten Schritt von der „Aufführung ${ }^{* 64} \mathrm{zu}$ lösen und die Frage nach dem Geflecht des Lebendigen selbst zu stellen. Es ist die Frage danach, was Hannah Arendt die „gemeinsame Welt“65 nennt, welche unter dem Eindruck einer seriellen Isolation im Apparat der Perspektive lange Zeit für unerreichbar gehalten wurde oder als gänzlich verloren galt. Dennoch zeigt sich, dass gerade am chorischen Rand des Theaters und in den Arbeiten jener, die sich mit „extremer Konsequenz“ am weitesten vor- oder zurückbeugen, eine Vielheit von Theater-Körpern auftaucht, die allen Bühnen vorausgeht. Die Adressierung dieser Theater-Körper, ihr Lebendi-

62 Ebd., S. $370 \mathrm{f}$.

63 Hellerau bei Dresden. Das Festspielhaus mit dem großen Theatersaal im Zentrum wird als „Bildungsanstalt Hellerau“ für die Rhythmische Gymnastik Dalcroze’ nach den Entwürfen von Appia in Zusammenarbeit mit Wolf Dohrn (Werkbund, verantwortlich für das Projekt Hellerau), dem russischen Maler Alexander von Salzmann (Lichtanlage) und dem Architekten Heinz Tessenow ab 1910 gebaut und 1912 mit der Aufführung Orpheus und Euridike (Dalcroze, Appia), die zu einem europäischen Theatertriumpf gerät, eingeweiht. Mit dem Beginn des Ersten Weltkrieges gehen Dalcroze und Appia in die Schweiz zurück. Das Gebäude steht - nach seiner wechselvollen Geschichte und einer gründlichen Restauration - seit 2006 wieder der Kunst als „Europäisches Zentrum der Künste“ zur Verfügung, wird jedoch bis heute in einschlägigen Veröffentlichungen nicht unter die Theaterbauten in Deutschland gezählt. Vgl. ausführlich: Beachum (2006), Adolphe Appia, S. 108-194.

641921 macht Appia selbst auf diesen Schritt aufmerksam: „Früher drehten sich meine fortschrittlichsten Ideen immer ausschließlich um die Aufführung.“ Zit. n. ebd., S. 71, Fn. 5. [Herv. i. O.]

65 Hannah Arendt, Vita activa oder vom tätigen Leben, München, 1981, S. 72. 
ges, wie Appia sagt, ihre Dynamik, ihre umwelthaften und wechselseitigen Verflechtungen bringen die Szene hervor. Die Frage führt „aus dem Theater heraus“, aber sie hört deswegen nicht auf, etwas mit dem Theater zu tun zu haben. Es gibt vor oder jenseits des Theaters etwas „Theaterhaftes“, wie JeanLuc Nancy sagt, und dieses ,ist die Bedingung des Körpers, der selbst die Bedingung der Welt ist: der Raum der Miterscheinung der Körper“. ${ }^{66}$ In diesem Außen der Bezugnahmen pulsiert unser dunkelstes Nichtwissen. Aber es pulsiert. Es atmet, es eröffnet, es geht aus sich heraus. Es zeitigt Bezüge, es bildet Räume.

„Die Welt ist nicht verloren“, schreibt auch Jean-Louis Déotte in seiner Reflexion über den zentralperspektivischen Apparat: „aber sie hängt an einem Apparat, der theoretisch geschlossen ist, weil das Auge, das sich an seine Öffnung heftet, diese versperrt.“67 Es kommt alles darauf an, diese Liaison zwischen Apparat und diszipliniertem Auge zu lösen - und ebenso die Anordnung von Aufführung und Zuschauern, die aus ihr resultiert. Löst sich das Auge aus seiner immobilen Starre, werden auch das Gegenüber und die Seitenverteilung hinfällig und geben sich als Konfigurationen zu erkennen, als endlich geöffnete und sich eröffnende Räume von Intensitäten, Bezugnahmen, Rückzügen und Leere. Diese Räume unterschreiten ihre Abbildbarkeit, aber lösen womöglich einen Begriff der Bühne ein, der mit dem Begriff des Außen vollständig übereinkommt.

\section{Literatur}

Appia, Adolphe, Die Musik und die Inszenierung, aus dem Frz. v. F. Bruckmann, München, 1899.

Ders., L'oevre d'art vivant, Genève, Paris, 1921. [1919]

Ders., „Comment réformer notre mise en scène“ [1902], in: ders., Oevres complètes I$I V$, Edition élaborée et commentée par Marie L. Bablet-Hahn, Société suisse du théâtre, Montreux, 1983-1992, Bd. II, S. 348.

Ders., „Undatierter Brief an Jaques-Dalcroze“ [Mai 1906], in: ders., Oevres complètes $I-I V$, Edition élaborée et commentée par Marie L. Bablet-Hahn, Société suisse du théâtre, Montreux, 1983-1992, Bd. III, S. 3.

Ders., „Expériences de théâtre et recherches personelles“, in: ders., Oevres complètes $I-I V$, Edition élaborée et commentée par Marie L. Bablet-Hahn, Société suisse du théâtre, Montreux, 1983-1992, Bd. IV, S. 36-56.

66 Jean-Luc Nancy, „Theaterkörper“, aus dem Frz. v. Ulrich Müller-Schöll, in: Nikolaus MüllerSchöll/André Schallenberg/Mayte Zimmermann (Hg.), Performing Politics. Politisch Kunst machen nach dem 20. Jahrhundert, Berlin, 2012, 158-171: 171.

67 Déotte (2006), Video und Cogito, S. 61. 
Ders., „Erfahrungen mit dem Theater und persönliche Überlegungen“ [1921], [Auszüge] in: Richard C. Beacham, Adolphe Appia. Künstler und Visionär des modernen Theaters, Berlin, 2006, S. 65-69 u. S. 368-374.

Arendt, Hannah, Vita activa oder vom tätigen Leben, München, 1981.

Bablet-Hahn, Marie L., „Kommentar“, in: Adolphe Appia, Oevres complètes I-IV, Edition élaborée et commentée par Marie L. Bablet-Hahn, Société suisse du théâtre, Montreux, 1983-1992, Bd. IV, S. 524-525.

Beacham, Richard C., Adolphe Appia. Künstler und Visionär des modernen Theaters, Berlin, 2006.

Bjurström, Per, Gioaccomo Torelli and Baroque Stage Design, Stockholm, 1962.

Burckhardt, Martin, Metamorphosen von Raum und Zeit. Eine Geschichte der Wahrnehmung, Frankfurt/M., New York, NY, 1994.

Burda-Stengel, Felix, Andrea Pozzo und die Videokunst. Neue Überlegungen zum barocken Illusionismus, mit einem Vorwort v. Hans Belting, Berlin, 2001.

Deleuze, Gilles, Die Falte. Leibniz und der Barock, Frankfurt/M., 2005.

Déotte, Jean-Louis, Video und Cogito. Die Epoche des perspektivischen Apparats, aus dem Frz. v. Heinz Jatho, Zürich, Berlin, 2006.

Descartes, René, Abhandlung über die Methode, dt. v. Kuno Fischer, Stuttgart, 1961.

Ders., Discours de la méthode, hg. v. Jean-Robert Armogath/Michel Authier/Vincent Carraud, Paris, 1987. [Frz. OA 1637.]

Ders., „Über die Prinzipien der materiellen Dinge“ [aus: Principia Philosophia (1644)], in: Jörg Dünne/Stephan Günzel (Hg.), Raumtheorie. Grundlagentexteaus Philosophie und Kulturwissenschaften, Frankfurt/M., 2006, S. 44-57.

Dünne, Jörg/Günzel, Stephan (Hg.), Raumtheorie. Grundlagentexte aus Philosophie und Kulturwissenschaften, Frankfurt/M., 2006.

Einstein, Albert, „Raum, Äther und Feld in der Physik“ [1930], in: Jörg Dünne/Stephan Günzel (Hg.), Raumtheorie. Grundlagentexteaus Philosophie und Kulturwissenschaften, Frankfurt/M., 2006, S. 94-101.

Ders., „Vorwort“, in: Max Jammer, Das Problem des Raumes - Die Entwicklung der Raumtheorien, Darmstadt, 1980 [1954], S. XI-XV.

EtymologischesWörterbuch des Deutschen, erarb. v. einem Autorenkollektiv des Zentralinstituts für Sprachwissenschaft unter der Leitung v. Wolfgang Pfeifer, Berlin, 1989.

Günzel, Stephan, „Physik und Metaphysik des Raumes. Einleitung“, in: Jörg Dünne/ Stephan Günzel (Hg.), Raumtheorie. Grundlagentexte aus Philosophie und Kulturwissenschaften, Frankfurt/M., 2006, S. 19-43.

Ders., „Raum - Topographie - Topologie“, in: ders. (Hg.), Topologie. Zur Raumbeschreibung in den Kultur- und Medienwissenschaften, Bielefeld, 2007, S. 13-31.

Haß, Ulrike, Das Drama des Sehens, München, 2005.

Herrmann, Hans-Christian von, Das Archiv der Bühne. Eine Archäologie des Theaters und seiner Wissenschaft, München, 2005.

Horn, Angelika, „Das Experiment mit der Zentralperspektive. Brunelleschi und Descartes“, in: dies./Wilhelm Friedrich Niebel/Herbert Schnädelbach (Hg.), Descartes im Diskurs der Neuzeit, Frankfurt/M., 2000, S. 9-32.

Kirsch, Sebastian, Das Reale der Perspektive. Der Barock, die Lacan'sche Psychoanalyse und das ,Untote“ in der Kultur, Berlin, 2013.

Landolt, Hanspeter, „Der barocke Raum in der Architektur“, in: Rudolf Stamm (Hg.), Die Kunstformen des Barockzeitalters. Vierzehn Vorträge, Bern, 1956, S. 92-110.

Leibniz, Gottfried Wilhelm, Monadologie, Frz./Dt., hg. v. Hartmut Hecht, Stuttgart, 1998. 
Leonhard, Karin, „Was ist Raum im 17. Jahrhundert?“, in: Horst Bredekamp/Peter Schneider (Hg.), Visuelle Argumentationen. Die Mysterien der Repräsentation und die Berechenbarkeit der Welt, München, 2006, S. 11-34.

Nancy, Jean-Luc, „Lavartus pro Deo“, in: Volker Bohn (Hg.), Bildlichkeit, Frankfurt/ M., 1990, S. 468-501.

Ders., „Theaterkörper“, aus dem Frz. v. Ulrich Müller-Schöll, in: Nikolaus MüllerSchöll/André Schallenberg/Mayte Zimmermann (Hg.), Performing Politics. Politisch Kunst machen nach dem 20. Jahrhundert, Berlin, 2012, S. 158-171.

Pozzo, Andrea, Der Mahler und Baumeister Perspective Erster und Zweiter Theil. Erster Theil von Johann Boxbarth Kupfferstechern in Augspurg. Daselbst verlegt Jeremias Wolff Kunsthändler, 1708. Zweiter Theil von Georg Conrad Bodeneer Kupfferstechern in Augspurg. Verlegts all da Jeremias Wolff Kunsthändler, 1711.

Ders., Rules and Examples of Perspective Proper for Painters and Architects by ANDREA POZZO, London, 1707, reprint: New York, NY, 1971.

Röttger, Kati/Jackob, Alexander (Hg.), Theater und Bild. Inszenierungen des Sehens, Bielefeld, 2009.

Tkaczyk, Viktoria, „Cumulus ex machina. Wolkeninszenierungen in Theater und Wissenschaft“, in: Helmar Schramm/LudgerSchwarte/Jan Lazardzig (Hg.), Spektakuläre Experimente. Praktiken und Evidenzproduktion im 17. Jahrhundert, Berlin, New York, NY, 2006, S. 43-77. 


\section{FREMDENZIMMER}

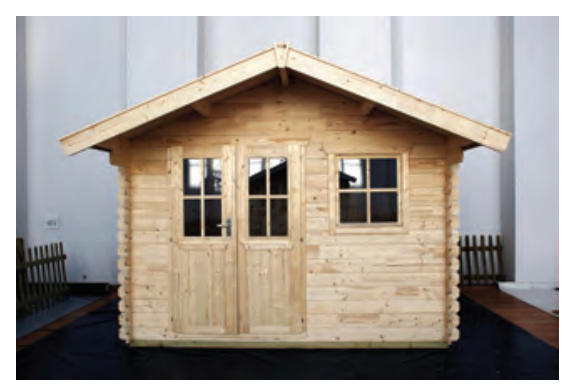

In der Zeit vom 7. bis zum 27. Mai 2007 erproben wir das Verhältnis zwischen öffentlichem und privatem Raum.

Wir tragen Stück für Stück einer Schrebergartenlaube ab, die wir zuvor im Festspielhaus Hellerau (Dresden) aufgebaut haben. Wir tauschen Bretter, Schrauben oder Beschläge der Laube gegen Holz- und Metallelemente aus, die wir im Dresdner Stadtgebiet vorfinden. Im Anschluss an die von uns durchgeführten Aktionen nehmen die jeweiligen Hüttendetails den Platz der entsprechenden Fundstücke im öffentlichen Raum ein, während die Objekte aus dem Stadtgebiet der Stabilität unserer Hütte dienen.

Das sich sukzessive verändernde Holzhaus ist Zeugnis einer diskreten Privatisierung.

Geschaffen wird ein Ort, der das Verhältnis zwischen Privatsphäre und Öffentlichkeit ebenso sichtbar wie durchlässig macht; zugunsten einer Transparenz, in der Zugehörigkeit in Produktion geht, konstruiert und hergestellt wird.

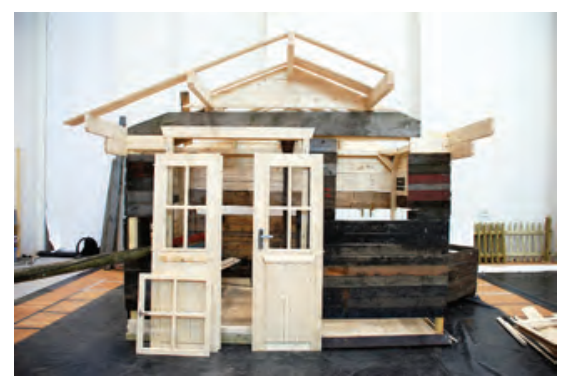

Eine Produktion im Rahmen des Festivals GRENZGEBIET HEIMAT, Festspielhaus Hellerau / Europäisches Zentrum der Künste Dresden, 2007. 

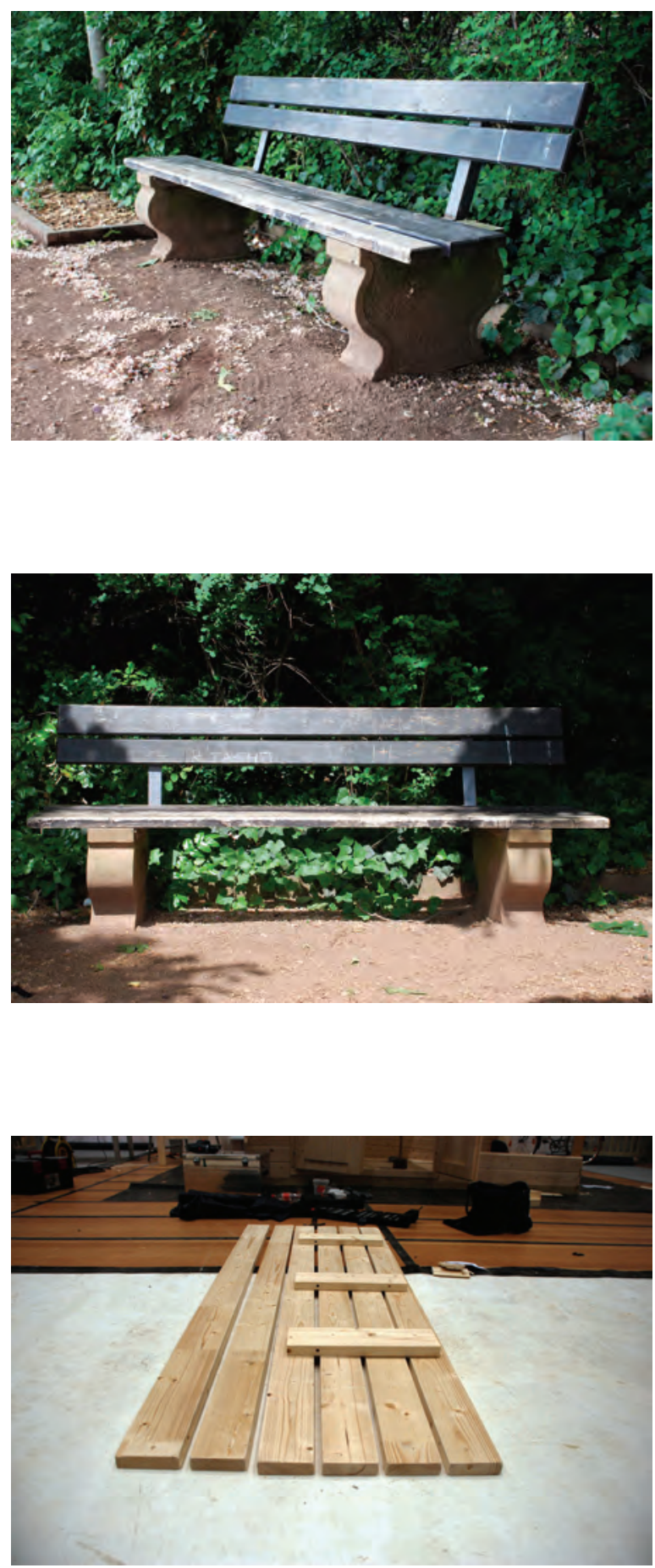

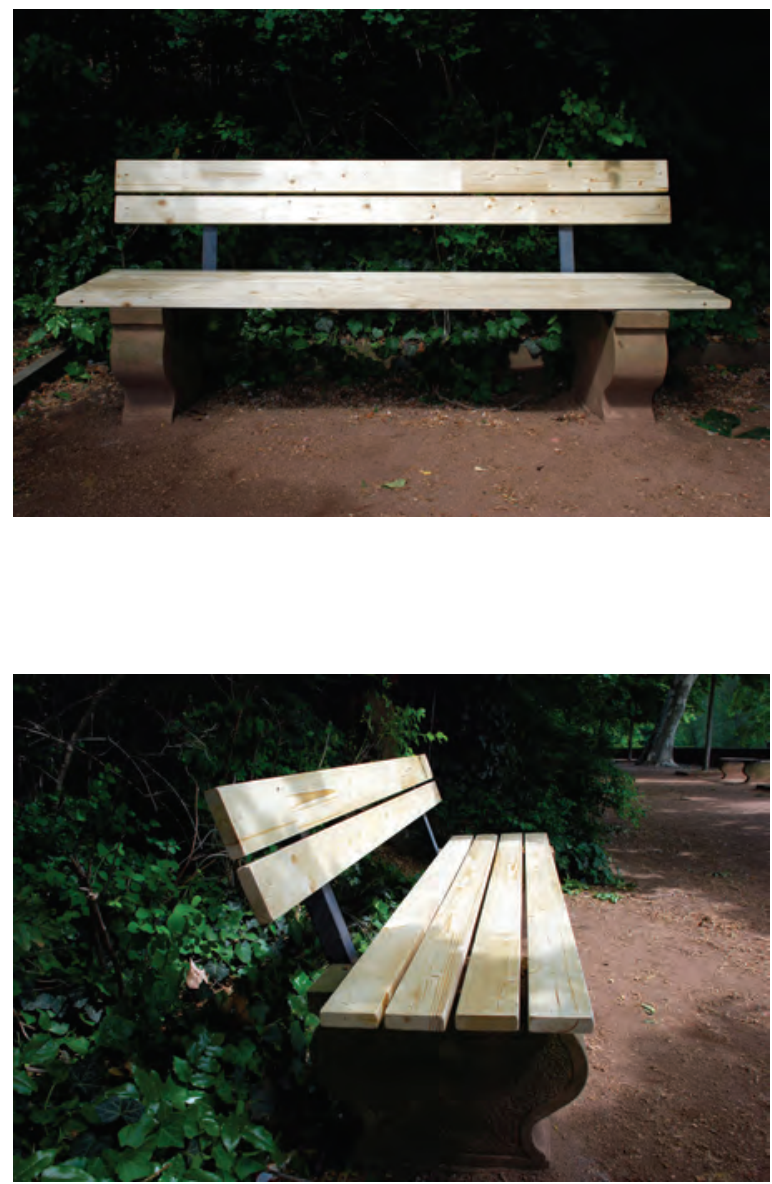

Dienstag, den 8. Mai,

Privatisierung einer Parkbank. 

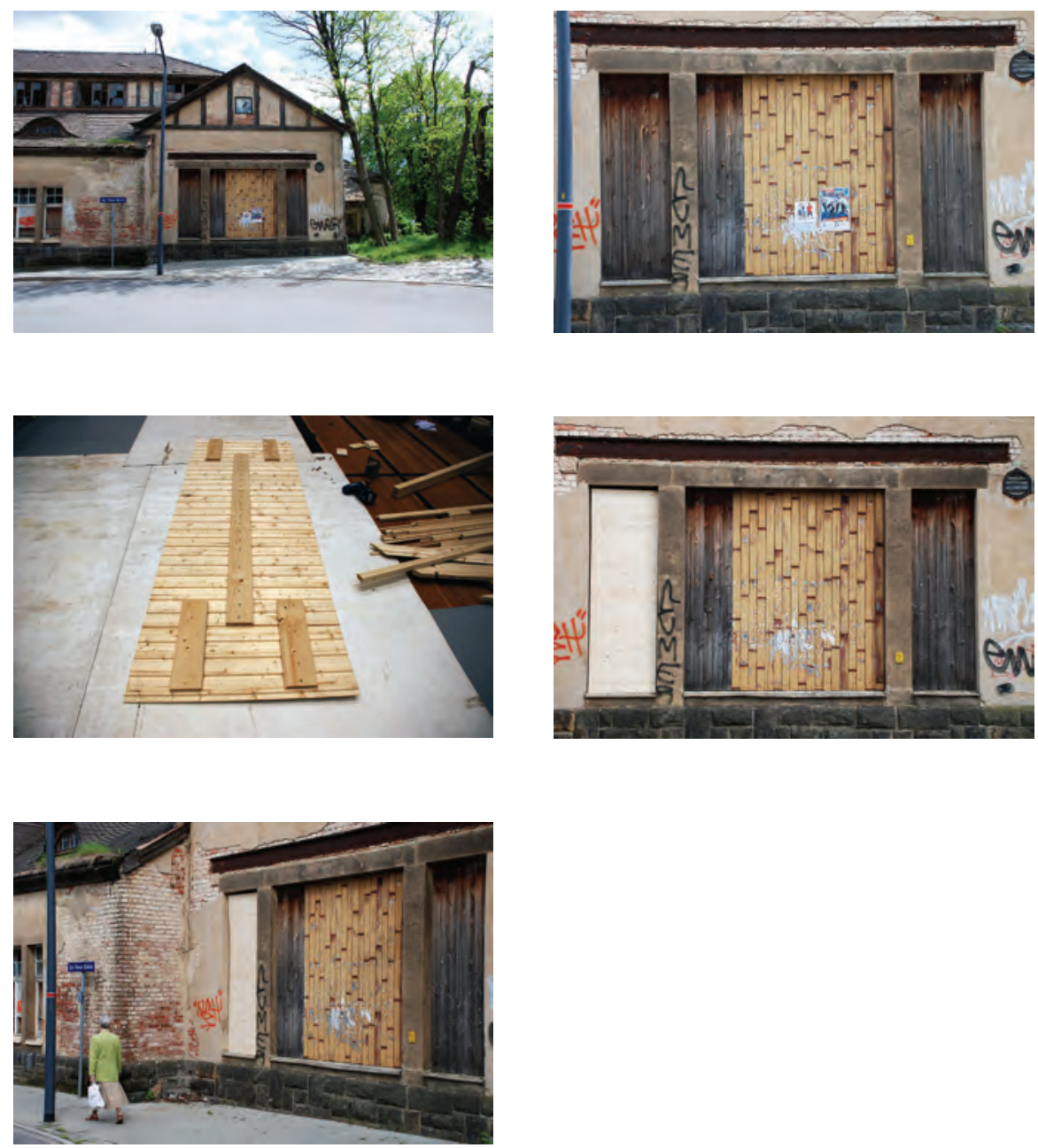

Donnerstag, den 10. Mai, Privatisierung einer Fensterverkleidung. 

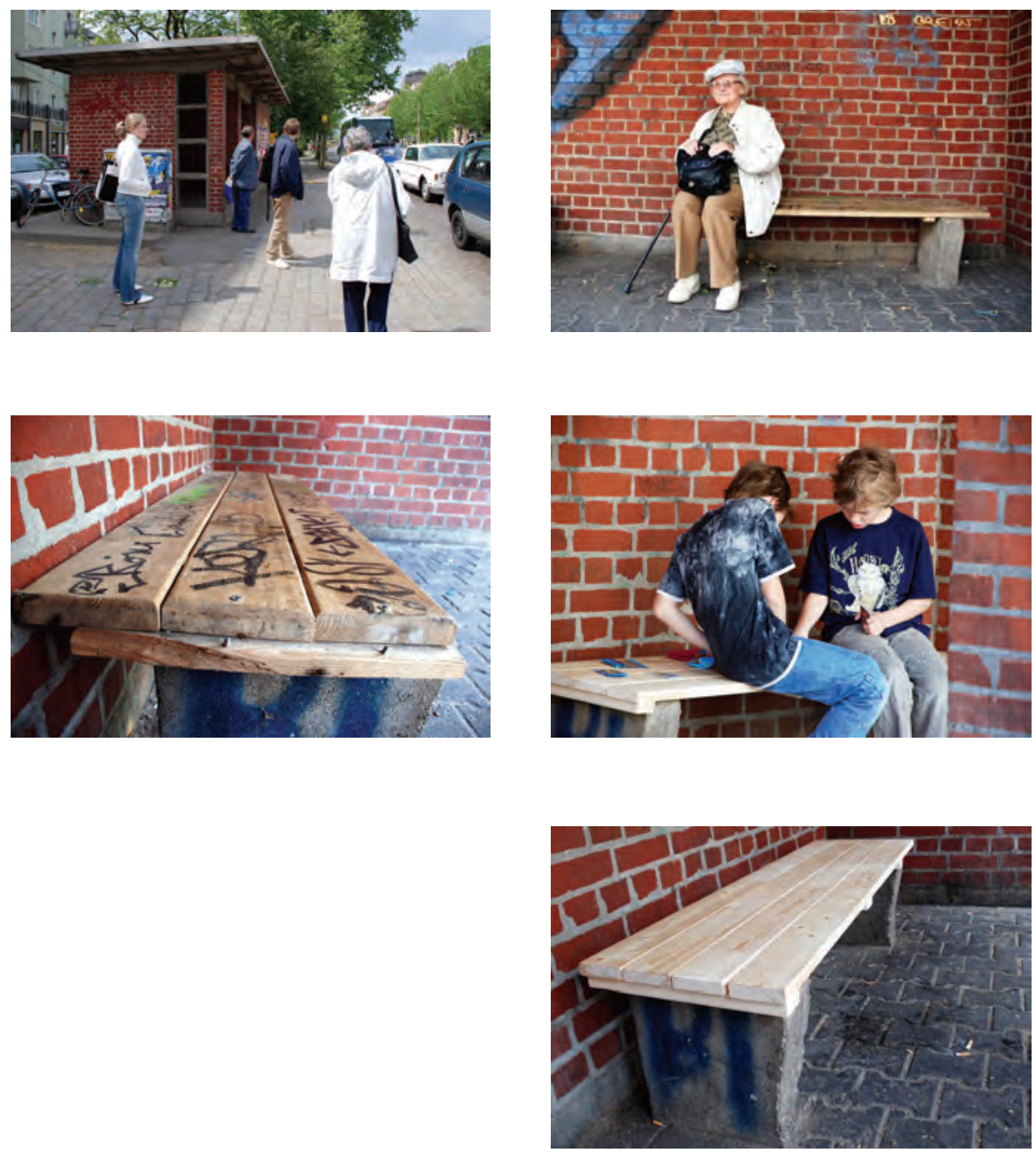

Samstag, den 12. Mai,

Privatisierung einer Bushaltestelle. 

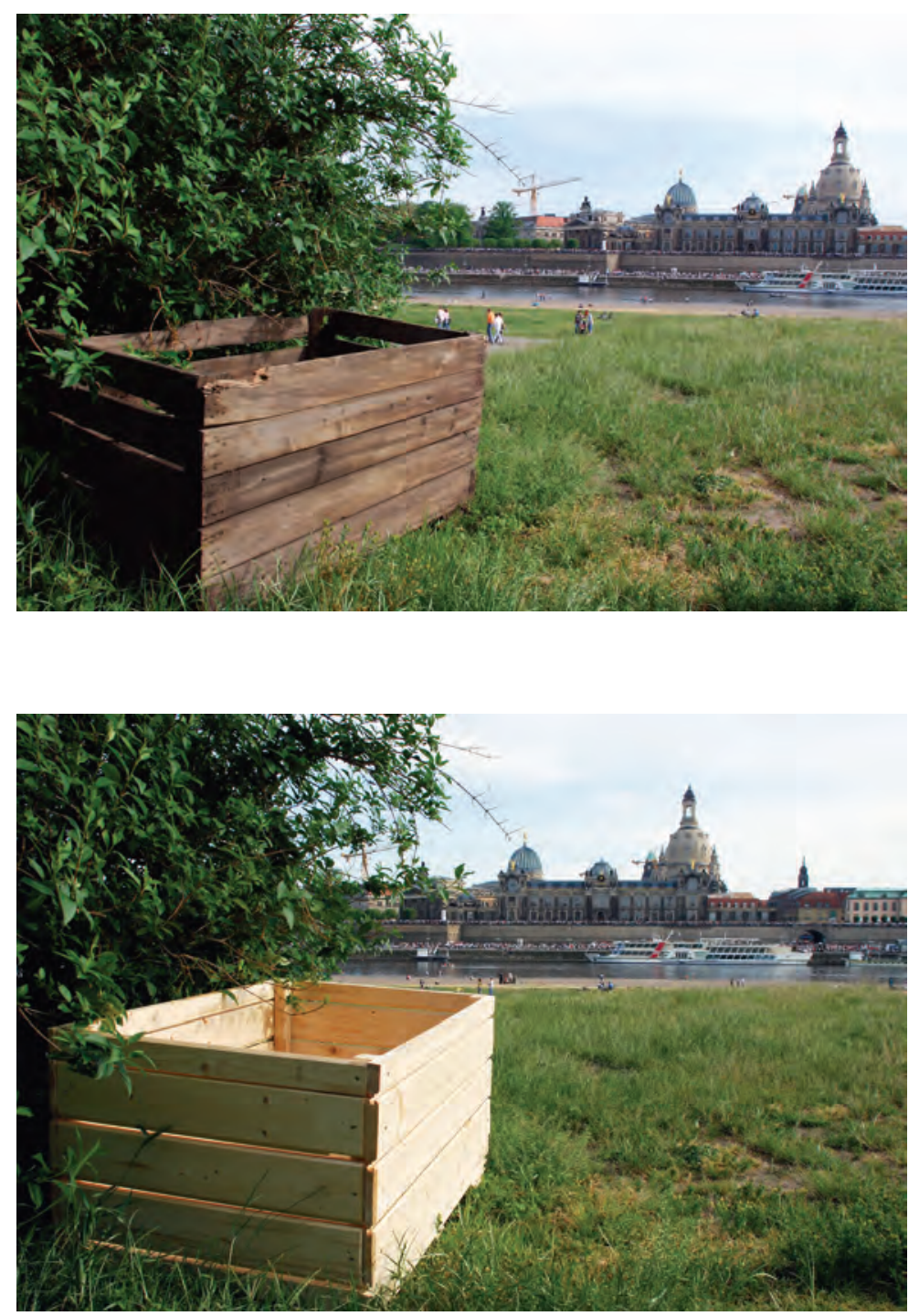

Montag, den 14. Mai, Privatisierung einer Streugutkiste. 

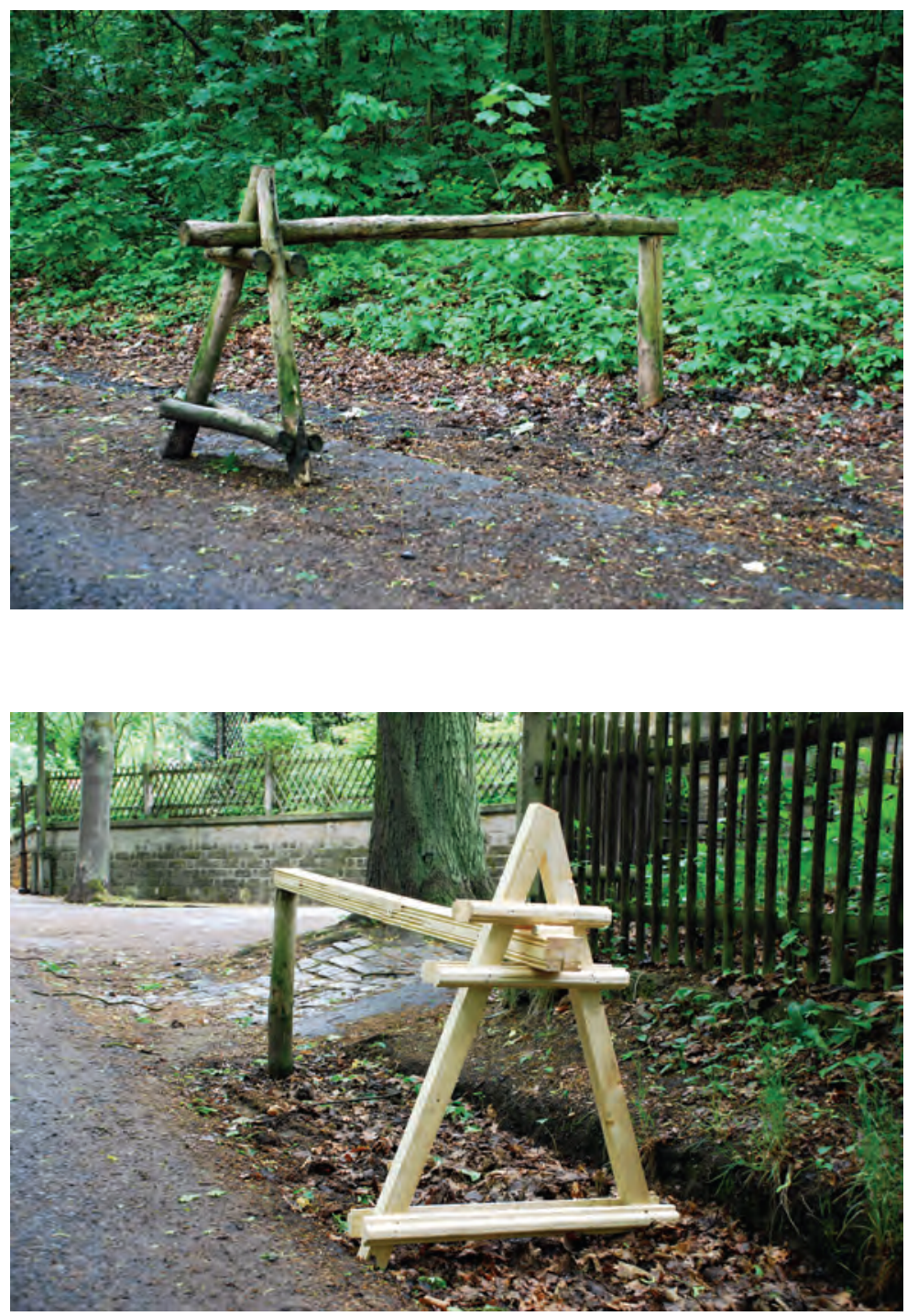

Dienstag, den 15. Mai,

Privatisierung einer Wegschranke. 

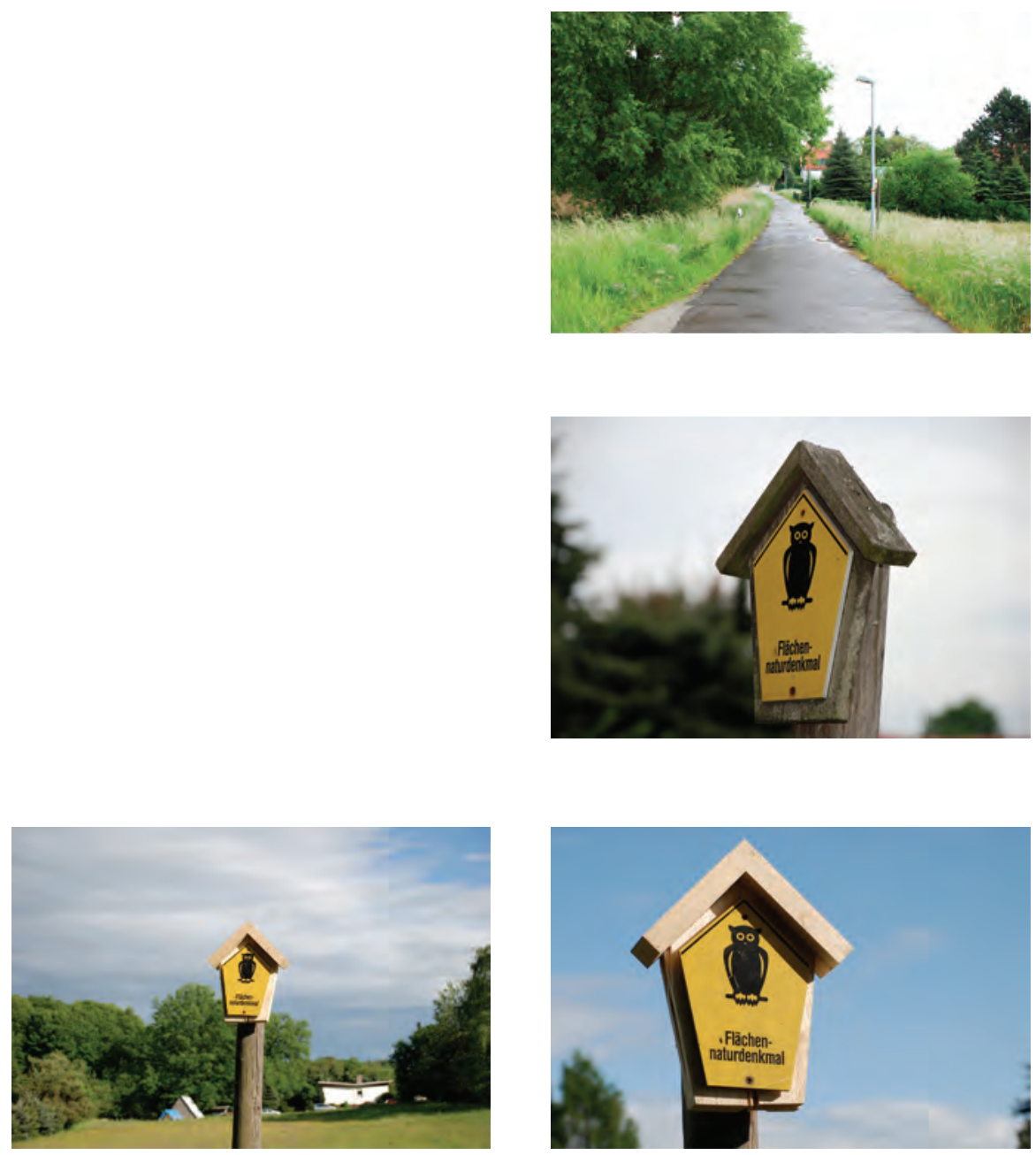

Mittwoch, den 16. Mai, Privatisierung einer Flächennaturdenkmalhinweisstütze. 

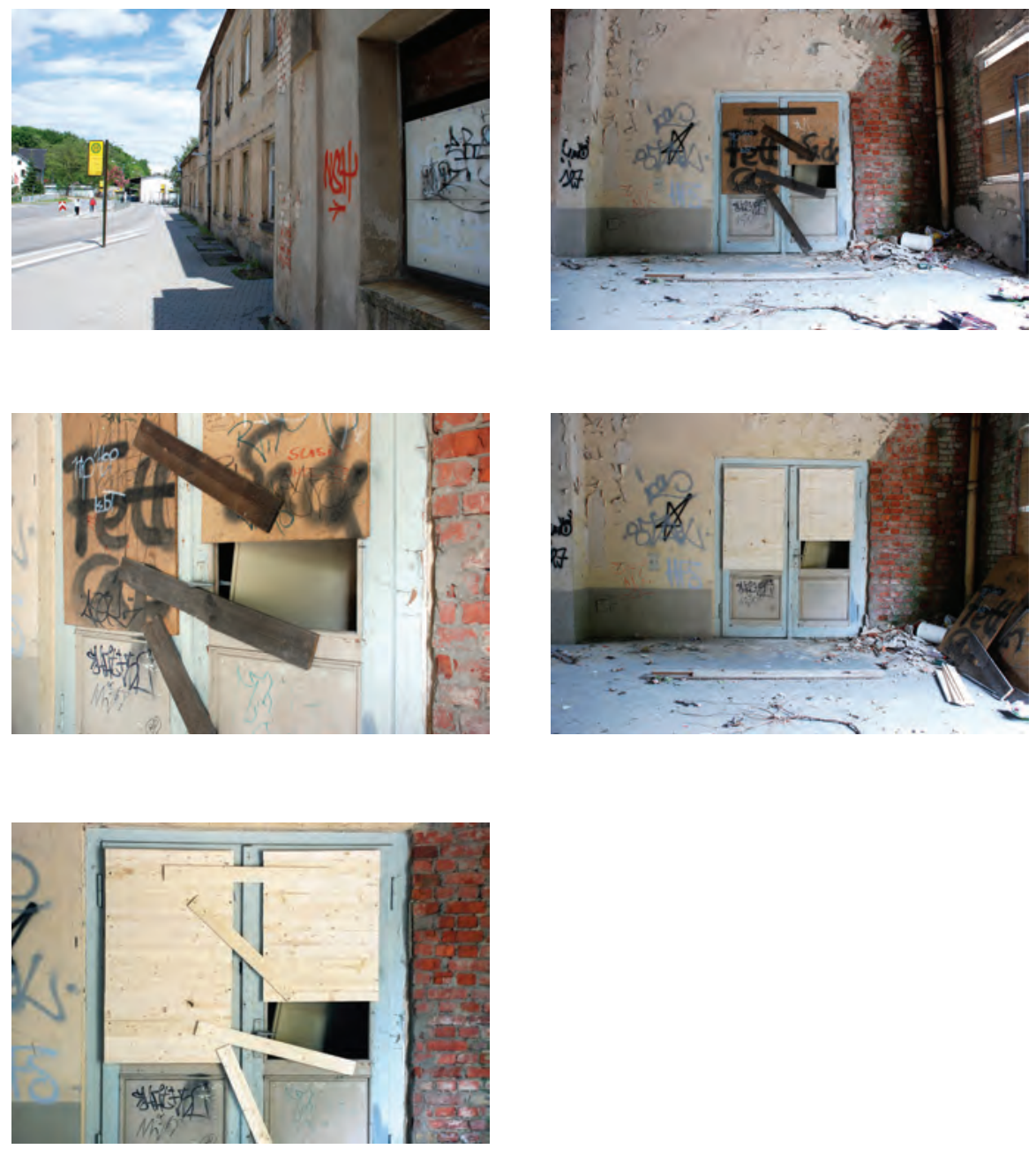

Sonntag, den 20. Mai,

Privatisierung eines Türverschlags. 

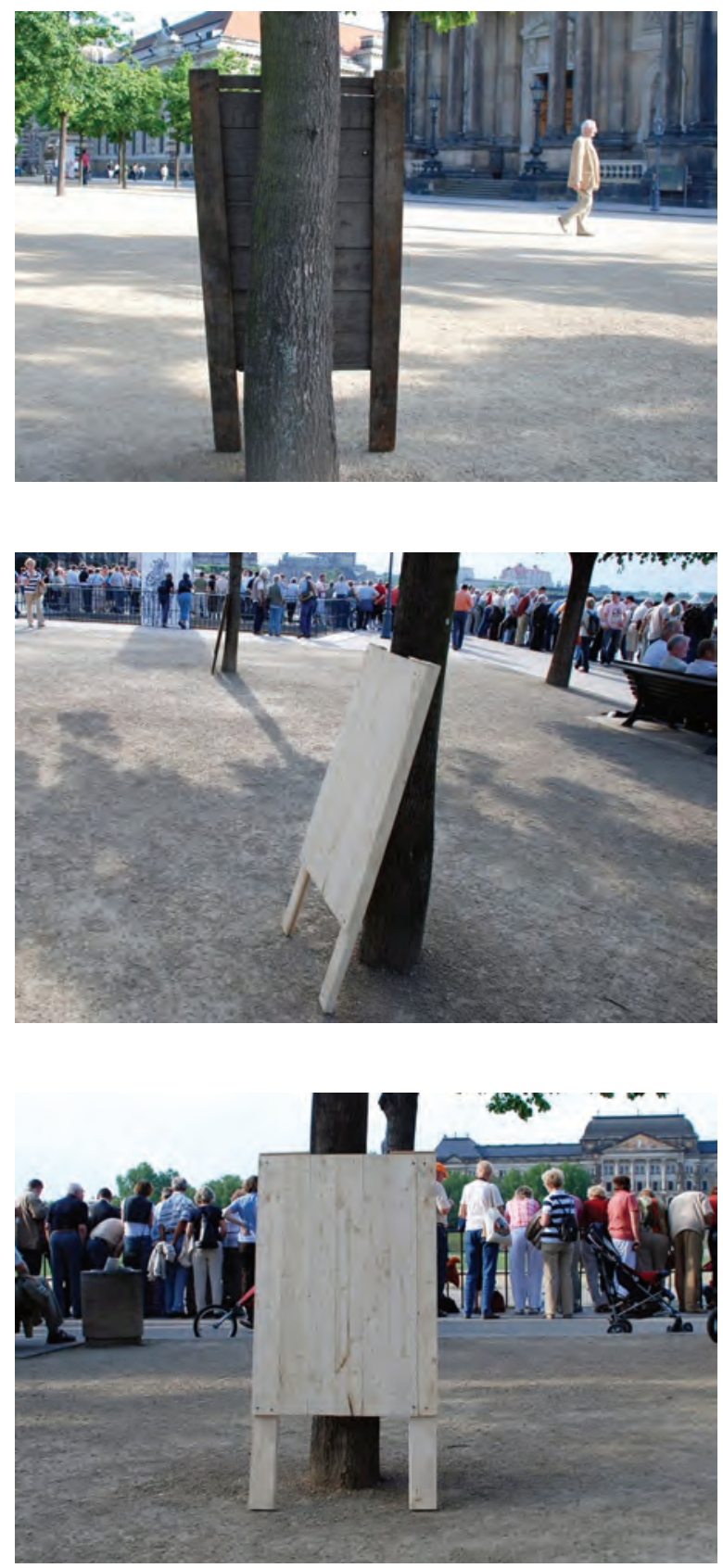

Dienstag, den 22. Mai, Privatisierung eines Werbeträgers. 

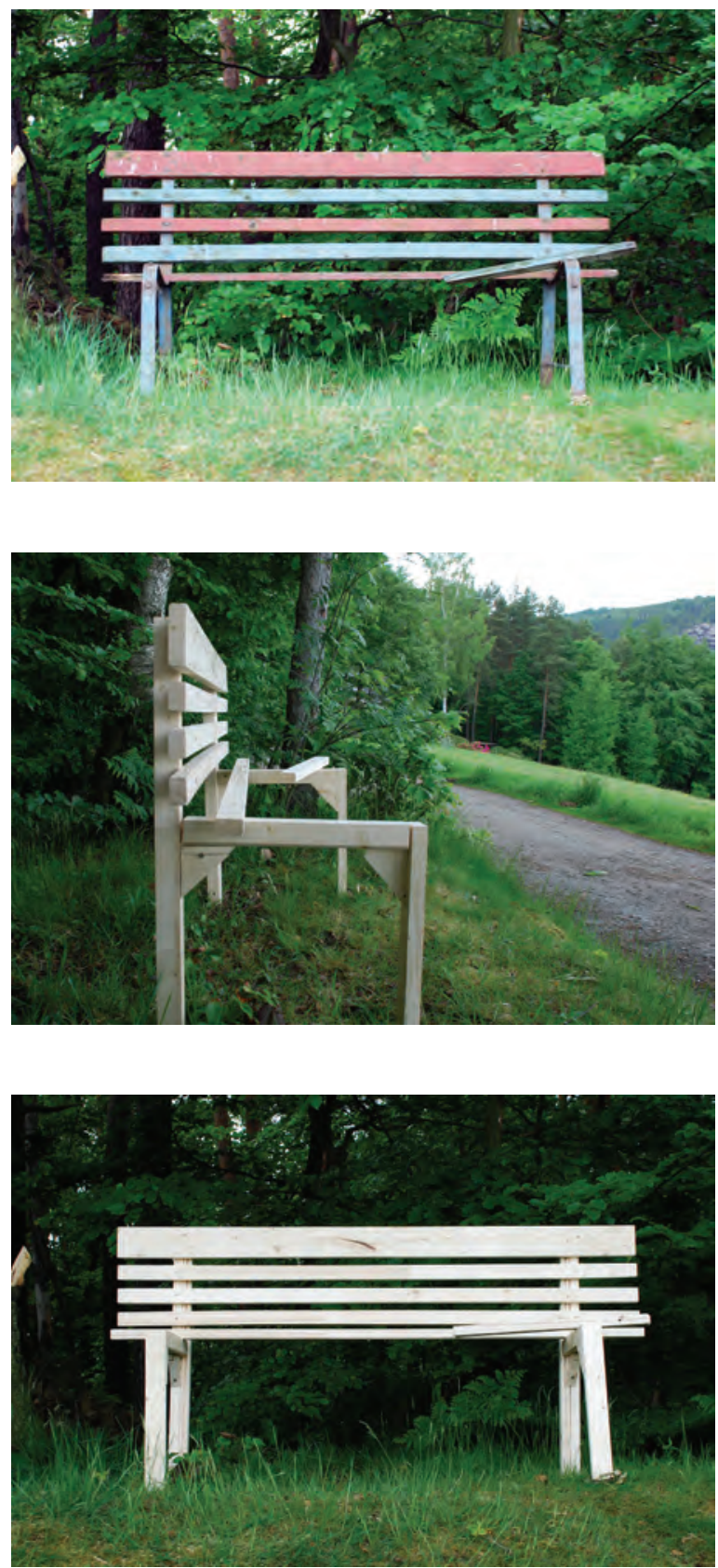

Mittwoch, den 23. Mai,

Privatisierung einer Panoramabank. 

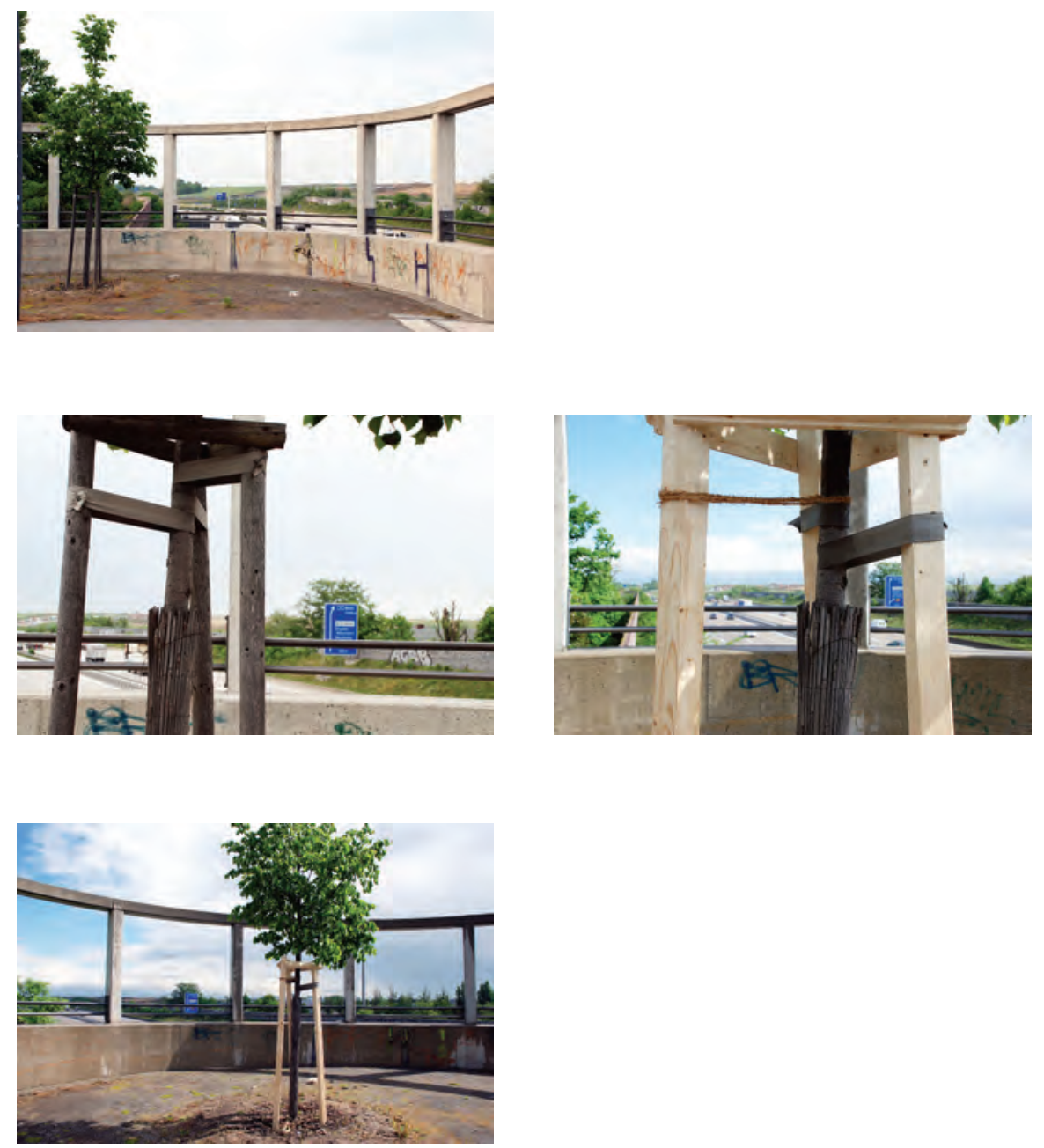

Freitag, den 25. Mai, Privatisierung einer Baumstütze. 

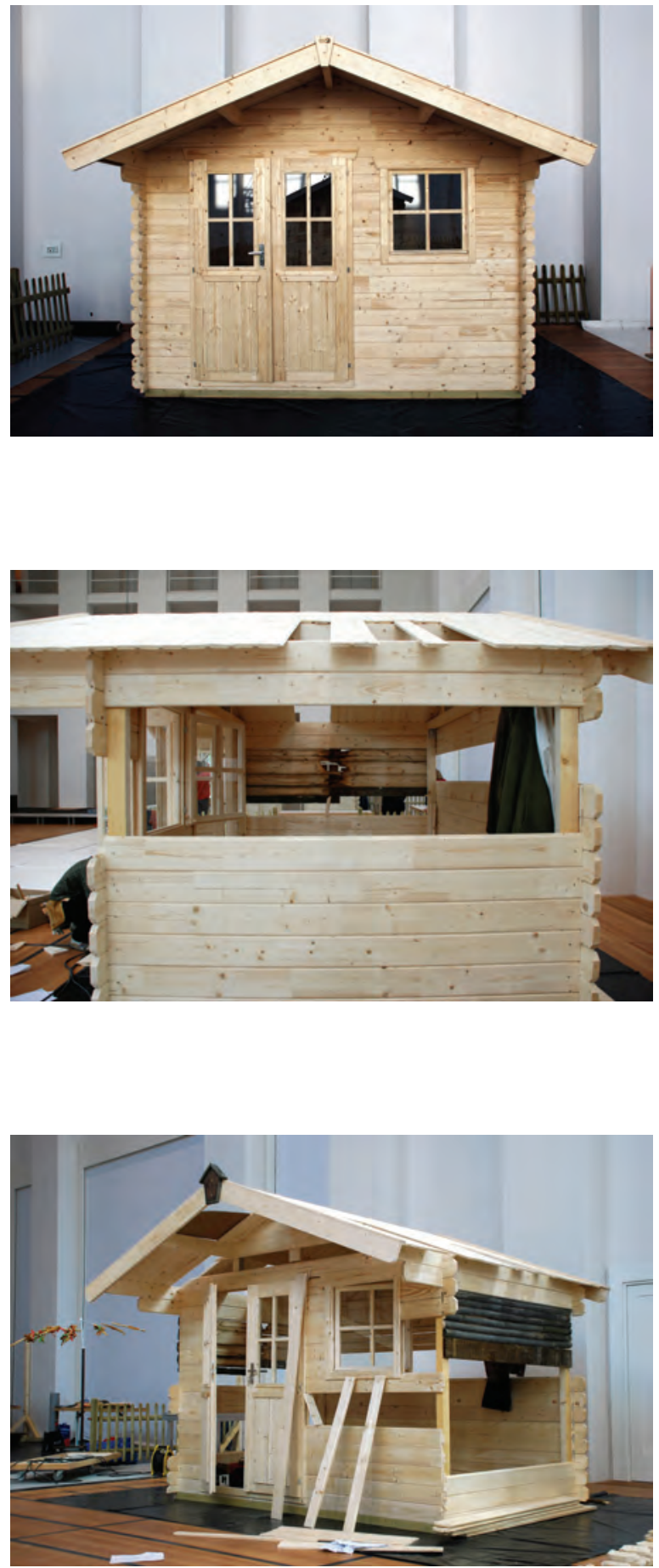

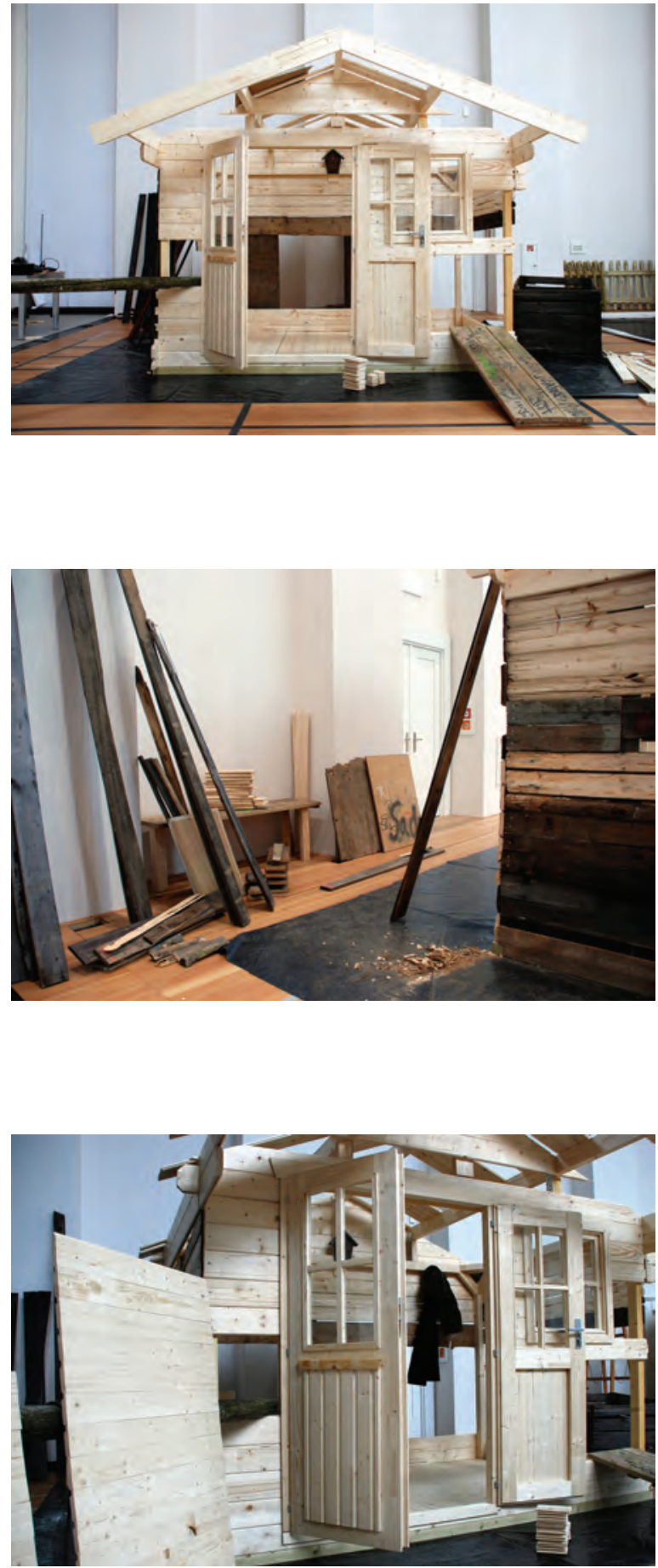

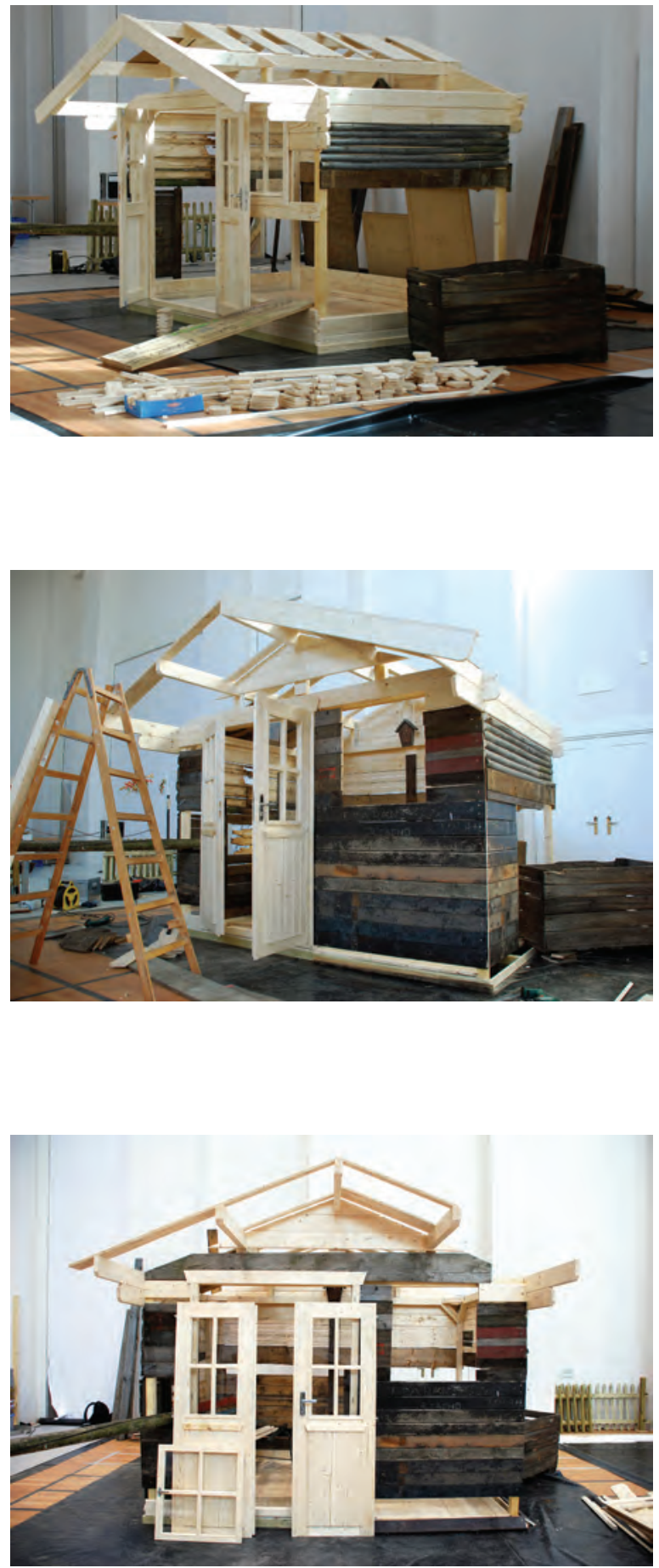

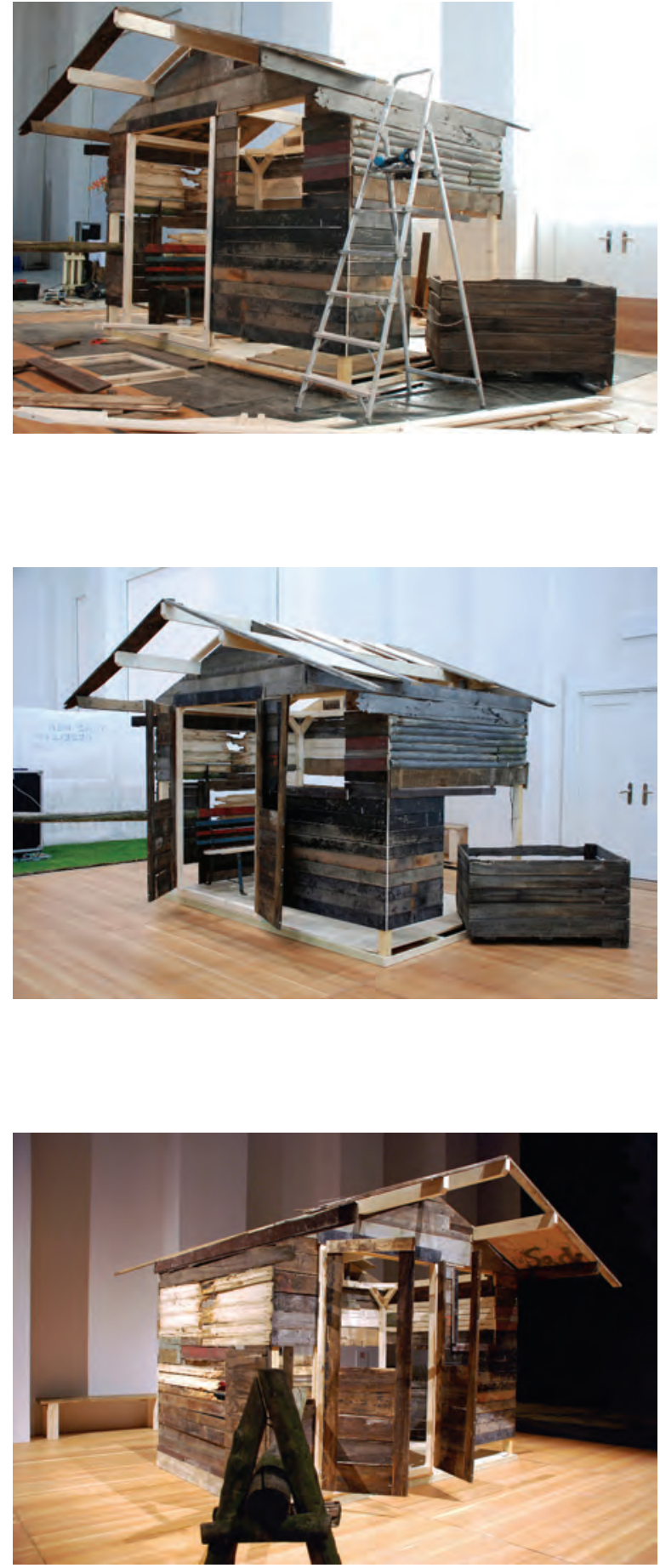


\section{ABBILDUNGSNACHWEISE}

Claudia Bosse

Abb. 1 bis 7: (C) Claudia Bosse.

Marita Tatari

Abb. 1: Arwed Messmer.

Martina Leeker

Abb. 1: Felix Noebauer; http://www.exile.at/dave/photos/deform1.jpg.

Abb. 2. http://www.exile.at/vivisector/photos/pixel.jpg.

Abb: 3: http://www.exile.at/apparition/photos/apparition_lines2.jpg.

Abb. 4: http://www.exile.at/sacre/sacre_photos/Sacre_arms.jpg.

Abb. 5: Foto: Pascal Maresch; http://www.exile.at/sacre/sacre_photos/sacre_ stage2Large.jpg.

Birgit Wiens

Abb. 1: Szene mit Hans Huebner. HAU 2, Berlin 2008. (C) Barbara Braun/ drama-berlin.de.

Abb. 2: „Breaking News - Ein Tagesschauspiel“, mit Carsten Hinz (vorne) und Ensemble. (c) Walter Bickmann.

Abb. 3: „, Breaking News - Ein Tagesschauspiel “, Probenszene, mit Simon Birgisson, Djengizkhan Hasso und Sushila Sharma-Haque. (C) Walter Bickmann.

Irina Kaldrack

Abb. 1: Étienne-Jules Marey, Die Chronophotographie (Kinematograph Nr. 2), aus dem Französischen übersetzt von A. von Heydebreck, Frankfurt/M., 1985. [Frz. OA 1893.]

Abb. 2: Frank B. Gilbreth/Lillian Moller Gilbreth, Angewandte Bewegungsstudien. Neun Vorträge aus der wissenschaftlichen Betriebsführung, Berlin, 1920, Tafel V.

Nikolaus Müller-Schöll

Abb. 1: dolmetscher-berlin.blogspot.com/2011_05_01_archive.html, letzter Zugriff: 11.07.2013.

Abb. 2: Andreas Kotte, Theaterwissenschaft, Köln, 2005, S. 73.

Abb. 3: Ebd., S. 72.

Abb. 4: Foto: Hans Jörg Michel. In: Anja Dürrschmidt/Barbara Engelhardt (Hg.), Werk-Stück. Regisseure im Porträt, Berlin, 2003, S. 36.

Abb. 5. Probenvideo. 
Abb. 6: Foto: Yvonne Kranz. In: Wanda Golonka, Tanz Ensemble Model, Berlin, 2010.

Georg Döcker

Abb. 1: Raoul-Auger Feuillet, Orchesography, or, The Art of Dancing, Gloucester, 2007 [frz. OA Chorégraphie, ou l'art de d'écrire la danse, Paris, 1700], S. 3.

Abb. 2 und 3: Doris Humphrey, The Art of Making Dances, 19. Aufl., New York, NY, 1980, S. 76 bzw. S. 77.

Nicola Suthor

Abb. 1 bis 3: Barnard Hewitt (Hg.), The Renaissance Stage. Documents of Serlio, Sabbation, and Furttenbach, Miami,FL, 1958.

Abb. 4: Digitale Diathek, Justus-Liebig-Universität Gießen, Institut für Kunstgeschichte, Justus-Liebig-Universität Gießen.

Abb. 5: Catherine Puglisi, Caravaggio, London, 1998.

Abb. 6: Imago, Humboldt-Universität Berlin, Kunstgeschichtliches Seminar, Humboldt-Universität Berlin.

Mark Lammert

Abb. 1 und 2: Brigitte Maria Mayer.

Abb. 3 bis 8: Archiv Mark Lammert.

Hofmann\&Lindholm

Für alle Abb.: (C) Hofmann\&Lindholm. 


\section{ÜBER DIE AUTORINNEN UND AUTOREN}

CLAUdia Bosse ist Künstlerin, Choreografin und künstlerische Leiterin von theatercombinat, einer transdisziplinären Companie. Nach dem Studium der Theaterregie an der Ernst Busch Hochschule für Schauspielkunst in Berlin arbeitet sie im Bereich des (experimentellen) Theaters zwischen Installation, (Raum-)Choreografie sowie urbaner Intervention und entwickelt „politische Hybride“ als mediale raumspezifische Settings für unterschiedliche Öffentlichkeiten. Ihre Installationen für Museen, Architekturen, Theater und Stadträume wurden u. a. in Wien, Zagreb, Tunis, Frankfurt, Prag, Brüssel und Genf gezeigt. Claudia Bosse kooperiert kontinuierlich mit KüstlerInnen und TheoretikerInnen verschiedener Genres, unterrichtet und initiiert Research-Projekte.

Arbeiten, Projekte und Kooperationen unter www.theatercombinat.com; http://claudiabosse.blogspot.co.at/

GEORG DÖCKER ist derzeit MA-Student und studentische Hilfskraft am Institut für Angewandte Theaterwissenschaft der Justus-Liebig-Universität Gießen, wo er zuletzt auch als Tutor tätig war. Neben dem Studium war er u. a. als künstlerischer Mitarbeiter und Produktionsassistent von Laurent Chétouane und Martin Nachbar tätig. Seine aktuellen Arbeitsschwerpunkte sind: Räumlichkeit, Zeitlichkeit und Subjektivität in Tanz und Theater der Gegenwart, Mimesis, Dramaturgie, Probenforschung und Produktionsästhetik.

DR. ANDRÉ EIERMANN. Arbeitsgebiet: Theaterwissenschaft. Neuere Veröffentlichungen u. a.: Postspektakuläres Theater - Die Alterität der Aufführung und die Entgrenzung der Künste, Bielefeld, 2009; „Vor-Schriften: Skizzen, Skripte und Scores im Tanz und in der bildenden Kunst“, in: Isa Wortelkamp (Hg.), Bewegung Lesen. BewegungSchreiben, Berlin, 2012, S. 156-179; „Other Performances - and the Otherness of Performance“, in: Saar Van Laere/ValérieWolters (Hg.), Margarita Production: Micro, Contact, Strings \& Things, Gent, 2013, S. 32-38.

DR. JÖRN ETZOLD arbeitet auf einer DFG-Forschungsstelle am Institut für Theaterwissenschaft der Ruhr-Universität Bochum an einem Habilitationsprojekt zu Hölderlins Denken des poetischen Rhythmus im Theater. Aktuelle Forschungsgebiete: das Verhältnis von Theater und Philosophie; Trauerspiel und Tragödie; Theater und Arbeit. Neuere Veröffentlichungen: Die melancholische Revolution des Guy-Ernest Debord, Zürich, 2009; Nicht-Arbeit. Poetiken, Konzepte, Ästhetiken (hg. mit Martin Jörg Schäfer), Weimar, 2011; Rhythmus der Vorstellungen (Hg., vorauss. 2014). 
PROF. DR. NORBERT OtTO EKE ist Professor für Neuere deutsche Literatur und Literaturtheorie an der Universität Paderborn. Arbeitsgebiete: Erinnerungskulturen und ästhetische Formungen mit Schwerpunkten in den Bereichen Dramen- und Theatergeschichte, deutsch-jüdische Literatur (Literatur und Shoah), Vormärzliteratur und Gegenwartsliteratur. Neuere Veröffentlichungen u. a.: „Nach der Mauer der Abgrund"? (Wieder-)Annäherungen an die DDR-Literatur (Hg.), Amsterdam, 2013; Deutschsprachige Literatur(en) seit 1989 (hg. mit Stefan Elit), Berlin, 2012; Poetologisch-poetische Interventionen: Gegenwartsliteratur schreiben (hg. mit Alo Allkemper/Hartmut Steinecke), Paderborn, 2012; Schemata und Praktiken (hg. mit Tobias Conradi/Gisela Ecker/ Florian Muhle), Paderborn, 2012; „Sprache, die so tröstlich zu mir kam “.Thomas Valentin in Briefen von und an Hermann Hesse (mit Dagmar Olasz-Eke), Bielefeld, 2011; New Readings - Neulektüren (hg. mit Gerhard P. Knapp), Amsterdam, New York, NY, 2009; Wort/Spiele. Drama - Film - Literatur, Berlin, 2007. Herausgeber der Zeitschrift für deutsche Philologie und der Amsterdamer Beiträge zur neueren Germanistik.

Prof. DR. UlRIKe HAß ist Professorin für Theaterwissenschaft an der RuhrUniversität Bochum. Arbeitsgebiete: Räume des Theaters, Topologie des Chores, Theater und Bildende Kunst, Mediengeschichte, Ästhetik des Gegenwartstheaters. Neuere Veröffentlichungen: Was ist eine Universität? (hg. mit Nikolaus Müller-Schöll), Bielefeld, 2009; Schauplatz Ruhr. Andere Räume (hg. mit Sebastian Kirsch), Berlin, 2011; Mark Lammert: Bühnen Räume Spaces, Berlin, 2013.

MEIKE HinNENBERG (M.A.), ist Lehrkraft für besondere Aufgaben am Institut für Theaterwissenschaft der Ruhr-Universität Bochum. Arbeitsgebiete: Antikes Theater, postkoloniales Theater, Phänomenologie. Publikationen: Schauplatz Ruhr. Geschichte im Spiel (hg. mit Guido Hiß/Robin Junicke), Berlin, 2013. Redaktionsmitglied bei brink - Magazin zwischen Kunst und Wissenschaft.

HofmanN\&LindHolm (HANNAH Hofmann, SVEn LindHOLM) sind ein Regie- und Autorenteam. Arbeitsgebiet: Realisation interdisziplinärer Projekte auf der Schwelle von szenischer, visueller und akustischer Kunst. Neuere Veröffentlichungen: Nebenschauplätze Nr. 1: Das 20. Jahrhundert, Künstlerhaus Mousonturm Frankfurt, 2013; Truce, Spring Festival Utrecht, 2013; Archiv der zukünftigen Ereignisse, Schauspiel Köln/Deutschlandradio Kultur, 2011; Basler Unruhen, Theater Basel, 2010.

DR. IRINA KALDRACK ist wissenschaftliche Mitarbeiterin am Digital Cultures Research Lab der Leuphana Universität Lüneburg. Nach dem Studium der Mathematik und Theaterwissenschaft in Mainz und Berlin promovierte sie in Kulturwissenschaft (HU Berlin). Sie war Postdoktorandin am Graduiertenkol- 
leg Automatismen und wissenschaftliche Mitarbeiterin (PostDoc) bei eikones NFS Bildkritik an der Universität Basel. Ihre Forschungsschwerpunkte umfassen Medialität technischer Medien, Mediengeschichte, Wissensgeschichte menschlicher Bewegung und Kulturgeschichte der Mathematik. Aktuelle Veröffentlichungen: Automatismen - Selbst-Technologien (hg. mit Hannelore Bublitz/Theo Röhle/Mirna Zeman), Paderborn, 2013; „Die Bauhaustänze Oskar Schlemmers. Bewegungs-Apparatur, dynamisierter Raum und mathematische Erkenntnisform“, in: Thomas Tode (Hg.), bauhaus \& film, Wien, 2012, S. 123-139; „Gehen in der Datenbank - Der BMLwalker“, in: Stefan Böhme/ Rolf F. Nohr/SerjoschaWiemer (Hg.), Sortieren, Sammeln, Suchen, Spielen. Die Datenbank als mediale Praxis, Münster, 2012, S. 269-293; Teilmengen. Mengen teilen. Taxonomien, Ordnungen und Massen im Facebook Open Graph (mit Theo Röhle), Beitrag zum 2. Medienwissenschaftlichen Symposium der DFG „Soziale Medien - Neue Massen“ (in Vorbereitung).

SEBASTIAN KIRSCH ist Theaterwissenschaftler und Redakteur der Theater der Zeit; 2008-2011 war er als Lehrkraft für besondere Aufgaben am Institut für Theaterwissenschaft an der Ruhr-Universität Bochum tätig und wurde 2011 am dortigen Institut promoviert. Als Lehrbeauftragter arbeitete er am Institut für Theater-, Film- und Medienwissenschaft der Universität Wien, wo er seit September 2013 eine Universitätsassistenz (Postdoc) ausübt. Arbeitsgebiete: Theater und Medien, 17. Jahrhundert, politische Philosophie, Psychoanalyse. Veröffentlichungen: Das Reale der Perspektive. Der Barock, die Lacan'sche Psychoanalyse und das ,Untote’ in der Kultur, Berlin, 2013; Schauplatz Ruhr. Andere Räume (hg. mit Ulrike Haß), Berlin, 2012.

MARK LAMMERT ist Maler, Grafiker und Bühnenbildner sowie Professor für Malerei und Zeichnung an der Universität der Künste Berlin. Veröffentlichungen: Kinne, Düsseldorf, 2003; Arbeitsbücher, Düsseldorf, 2005; Malerei, Düsseldorf, 2011; Mark Lammert: Bühnen Räume Spaces (von Ulrike Haß); Berlin, 2013. Texte: „Godard Maler“, in: Lettre International 91, (2010); „Rot/ Gelb/Blau“, in: Christian Hippe (Hg.), Bild und Bildkünste bei Brecht, Berlin, 2011,S. 156-175; „Heroische Störung“, in: Lettre International 99, (2012).

Prof. Dr. MARTINA LEEKER ist Professorin für Medienwissenschaft/Digitale Kulturen am Digital Cultures Research Lab (DCRL), Centre for Digtial Cultures (CDC) Leuphana Universität Lüneburg. Arbeitsgebiete: Theater und Medien, Gebrauchsgeschichte des Computers, Art and Technology, Mediengeschichte neoliberaler Gouvernementalität, Methoden zur Erforschung digitaler Kulturen. Neuere Veröffentlichungen u. a.: McLuhan neu lesen (hg. mit Derrick de Kerckhove/Kerstin Schmidt), Bielefeld, 2008; Entfesselte technische Objekte. Mensch - Kunst - Technik 2010 (hg. mit Alexander Firyn, Onlinepublikation: http://entfesselt.kaleidoskopien.de), „Just do it!: Mimesis in tech- 
nischem und künstlerischem Systems Engineering“, in: Archiv für Mediengeschichte 12 (2012).

PROF. DR. NiKOlaus MÜLleR-SChÖLl ist Professor für Theaterwissenschaft an der Goethe-Universität Frankfurt. Arbeitsgebiete: Fragestellungen an der Schnittstelle von Theater, Theorie und Politik, Gegenwartstheater, Theorien und Formen des Komischen, Benjamin, Brecht, Heiner Müller. Veröffentlichungen u. a.: Das Theater des konstruktiven Defaitismus. Benjamin, Brecht, Heiner Müller, Frankfurt/M., 2002; Ereignis (Hg.), Bielefeld, 2003; Performing Politics (Hg. mit André Schallenberg/Mayte Zimmermann), Berlin, 2012.

DR. CHRISTOPH RODATZ ist freischaffender Künstler und lebt in Dortmund. Er studierte Angewandte Theaterwissenschaft an der Justus-Liebig-Universität Gießen. Seine Promotion Der Schnitt durch den Raum wurde von Gernot Böhme und Gabriele Brandstetter betreut. Seit 2003 ist er Teil des Netzwerks New Guide to Opera. Er arbeitet an der Schnittstelle von Theorie und Praxis. Architektur-, Video- und Theater-Projekte verschränken sich dabei mit seiner Lehrtätigkeit an der ZHdK und der FH Dortmund.

PROF. DR. Nicola SuTHOR vertritt eine Professur für Kunstgeschichte an der Freien Universität Berlin. Arbeitsgebiete: Malerei und Kunsttheorie vom 16.18. Jahrhundert. Neuere Veröffentlichungen u. a.: Augenlust bei Tizian. Zur Konzeption sensueller Malerei in der Frühen Neuzeit, Paderborn, 2004; Ansteckung. Zur Körperlichkeit eines ästhetischen Prinzips (Hg. mit Mirjam Schaub), Paderborn, 2005; Verklärte Körper. Ästhetische Strategien der Transfiguration (Hg. mit Erika Fischer-Lichte), Paderborn, 2006; Bravura: Virtuosität und Mutwilligkeit in der Malerei der Frühen Neuzeit, Paderborn, 2010.

DR. MARITA TATARI ist wissenschaftliche Mitarbeiterin am Institut für Theaterwissenschaft der Ruhr-Universität Bochum (DFG-Projekt). Aktuelle Arbeitsgebiete: Epistemologie der Theaterwissenschaft, Theorie der szenischen Handlung im Drama und in gegenwärtigen Theaterformen, Theorie des Dramenbegriffs. Veröffentlichungen (u.a.): Öffnungen - Theater jenseits der Geschichtsteleologie (Hg.) (in Vorbereitung); Heidegger et Rilke - Interprétation et partage de la poésie, Paris, 2013.

Prof. DR. DR. h.c. Bernhard WALdenfels ist emeritierter Professor für Philosophie an der Ruhr-Universität Bochum. Arbeitsgebiete: responsive, leiblich verankerte Phänomenologie; phänomenologische Arbeit an bevorzugten Sachthemen wie Leiblichkeit, Lebenswelt, Ordnung, Fremdheit, Interkulturalität, Sinne und Künste, Ethos der Sinne, Aufmerksamkeit; Phänomenologie und Phänomenotechnik bzw. Biotechnik; Phänomenologie und Psychoanalyse; 
Fragen der Normalität und Normalisierung; Forschungen zur Tradition der Phänomenologie (bes. Husserl, Schütz) und zur neueren französischen Philosophie (bes. Derrida, Foucault, Levinas, Merleau-Ponty). Neuere Veröffentlichungen: Phänomenologie der Aufmerksamkeit, Berlin, 2004; Grundmotive einer Phänomenologie des Fremden, Berlin, 2006; Ortsverschiebungen, Zeitverschiebungen. Modi leibhaftiger Erfahrung, Berlin, 2009; Sinne und Künste im Wechselspiel. Modi ästhetischer Erfahrung, Berlin, 2010; Hyperphänomene. Modi hyperbolischer Erfahrung, Berlin, 2012.

PD DR. BIRGIT WIENS ist Privatdozentin am Institut für Theaterwissenschaft der LMU München. Aktuelle Arbeitsgebiete: Theater und Medien/Intermedialität, Szenographie (Geschichte und Gegenwart)/Theater als Raumkunst, Bildwissenschaft/Visual Studies, Dramaturgie im zeitgenössischen Theater. Neuere Veröffentlichungen u. a.: Theater ohne Fluchtpunkt. Das Erbe Adolphe Appias (hg. mit Gabriele Brandstetter), Berlin, 2010; Intermediale Szenographie. Raum-Ästhetiken des Theaters am Beginn des 21. Jahrhunderts (voraussichtlich Ende 2013). 
Der vorliegende Band fragt nach dem Begriff der "Bühne" als Übergangszone par excellence, ihrer experimentellen Entgrenzung, Umformulierung bzw. ihres möglichen Verschwindens in der Gegenwart medialer Figurationen.

Historisch betrachtet wird die Bühne des Theaters im 18. Jahrhundert zunächst als Bild/Tableau definiert und erst in den Avantgardebewegungen des frühen 20. Jahrhunderts als Raum entdeckt und begriffen. Zwar bilden Bild und Raum dabei ein Gegensatzpaar, die Vorstellung des Raums als Container allerdings bleibt davon unberührt. Die Bühne bleibt der Alternative von Nacheinander und Nebeneinander unterstellt und wird bis heute fast ausschließlich unter dem Aspekt der Zwei- oder Dreidimensionalität diskutiert. Demgegenüber beleuchtet der Band, welche Kategorien von Bühne zeitgenössische Theater- und Tanzperformances nahelegen. 